\title{
Contacts, conflits et créations linguistiques
}

Guylaine Brun-Trigaud (dir.) 


\section{Contacts, conflits et créations linguistiques}

\section{Guylaine Brun-Trigaud (dir.)}

DOI : $10.4000 /$ books.cths. 1185

Éditeur : Éditions du Comité des travaux historiques et scientifiques Lieu d'édition : Paris

Année d'édition : 2015

Date de mise en ligne : 13 novembre 2018

Collection : Actes des congrès nationaux des sociétés historiques et scientifiques

EAN électronique : 9782735508648

\section{Q OpenEdition}

Books

https://books.openedition.org

Édition imprimée

Nombre de pages : 270

Référence électronique

BRUN-TRIGAUD, Guylaine (dir.). Contacts, conflits et créations linguistiques. Nouvelle édition [en ligne]. Paris : Éditions du Comité des travaux historiques et scientifiques, 2015 (généré le 15 février 2023). Disponible sur Internet : <http://books.openedition.org/cths/1185>. ISBN : 9782735508648 . DOI : https://doi.org/10.4000/books.cths. 1185.

(C) Éditions du Comité des travaux historiques et scientifiques, 2015 Licence OpenEdition Books 


\section{RÉSUMÉS}

«Contacts, conflits et créations linguistiques » a été l'un des thèmes porteurs au sein du Congrès de Nîmes : plus de trente interventions ont été entendues, et vingt-trois auteurs nous ont confié leurs textes. Cet ensemble s'articule autour de deux sujets : d'une part les notions de diglossie et de bilinguisme qui figuraient dans l'appel à communication ont été particulièrement fécondes et d'autre part, la notion de création lexicale qui a apporté des contributions originales. Dans un premier temps, diglossie et bilinguisme ont été confondus avant d'être distingués en sociolinguistique par Ferguson et Fishman. La diglossie rendrait compte plus précisément de la situation de certaines langues ou variétés linguistiques d'une même langue sur un territoire donné, où, par suite d'événements politiques, historiques ou sociaux l'une des langues ou variétés a acquis un statut supérieur à l'autre. Tandis que le bilinguisme s'appliquerait à des situations où deux langues cohabitent sans qu'il y ait de rapport de force. La grande majorité des textes qui suivent nous montrent que quelles que soient les époques, il y a toujours des cohabitations plus ou moins consensuelles ou conflictuelles.

\section{NOTE DE L'ÉDITEUR}

Les articles de cet ouvrage ont été validés par le comité de lecture des Éditions du Comité des travaux historiques et scientifiques dans le cadre de la publication des actes du $139^{\mathrm{e}}$ Congrès national des sociétés historiques et scientifiques tenu à Nîmes en 2015. 
COMITÉ DES TRAVAUX HISTORIQUES ET SCIENTIFIQUES

Contacts, conflits et créations linguistiques

Sous la direction de

Guylaine BRUN-TRIGAUD

ÉDITIONS DU CTHS

2015 
Ministère de l'Éducation nationale,

de l'Enseignement supérieur et de la Recherche

Congrès national des sociétés historiques et scientifiques

139e, Nîmes, 2014

Collection Actes des congrès des sociétés historiques et scientifiques,

Version électronique

ISSN 1773-0899 
Ana Isabel BLASCO TORRES

Les ostraca de Narmouthis dans le contexte

du bilinguisme gréco-égyptien de l'époque romaine

p. 11

Christel FREU

Communiquer l'accord.

Réflexions juridiques romaines et pratiques provinciales concernant l'établissement des contrats et accords commerciaux dans un Empire plurilingue

Michel CHRISTOL

Les mutations de l'identité dans la cité de Nîmes

à l'époque romaine ( ${ }^{e r}$ s. av. J.-C.-III s. ap. J.-C.)

Michel BANNIARD

L'oralité de Césaire d'Arles.

Jean-Loup LEMAITRE

Bernard Itier et la diglossie

à Saint-Martial de Limoges (1195-1225)

Marie Rose BONNET

Provençal et français : la communication au service de la politique

Gabriel AUDISIO

Entre latin, français et langue d'oc: le notaire et son client (Provence, $X V^{e}-X V I^{e}$ siècles)

\section{Bernard THOMAS}

Latin ou français : la tenue des actes paroissiaux dans les États pontificaux d'Avignon et du Comtat Venaissin, entre usage canonique, pratique administrative et choix de souveraineté (1768-1792) 
Régis BERTRAND

Aller jusqu'à user du patois ?

Remarques sur les emplois des dialectes occitans

pendant la Révolution

p. 100

Hervé TERRAL

Antonin Perbosc à Comberouger :

une expérience originale de défense de la langue d'oc

p. 112

Marie-Jeanne VERNY

Une littérature en situation de diglossie:

la littérature occitane vue par ceux qui l'écrivent

p. 119

Marie-Noële Denis

Les politiques linguistiques en Alsace

et la régression du dialecte

p. 129

Houssine SOUSSI

Diglossie au Maroc : Inter-culturalité

et Aménagement Linguistique

p. 142

Claire TORREILLES

Un dictionnaire savant de la langue occitane

au XVIII siècle

p. 153

Jean-Roger WATTEZ

Quelques aspects $d u$ vocabulaire en usage dans une région se situant sur les confins

de l'Artois et de la Picardie

p. 167

Serge LUSIGNAN

Langues $d u$ roi et langues des sujets en France

et en Angleterre : identité et communication

p. 173

Camille DesEnClos

Assurer la communication politique

à l'étranger : enjeux et stratégies

linguistiques au début du XVII siècle 
Annie LAGARDE FouQueT

Récits de voyages: Barrières et passerelles linguistiques

L'exemple de l'Autrichienne Ida Pfeiffer (1797-1858)

Annette NOGARÈDE

Les écrivains allemands et autrichiens

dans l'exil (1933-1945)

p. 214

Regina POZZI

Tocqueville et le problème de la "langue démocratique "

Le cas de l'anglais américain

p. 226

Isabelle-Rachel CASTA

Horlor gorom!

p. 235

Pascal SEMONSUT

L'homme préhistorique, Janus linguistique

La représentation du langage préhistorique

dans la seconde moitié $d u X^{e}$ siècle français

p. 248

Michel A. RATEAU

Extension de l'emploi de quelques lexèmes français

à l'étranger : le cas des créations onomastiques commerciales porteuses de prestige linguistique et culturel 


\title{
Introduction
}

\author{
Guylaine BRUN-TRIGAUD \\ Membre de la section Anthropologie sociale, \\ ethnologie et langues régionales (CTHS) \\ Ingénieur CNRS \\ (UMR 7320, Laboratoire Bases-Corpus-Langage)
}

\begin{abstract}
Extrait de : Guylaine BRUN-TRIGAUD (dir.), Contacts, conflits et créations linguistiques, Paris, Édition électronique du CTHS (Actes des congrès des sociétés historiques et scientifiques), 2015.

Cet article a été validé par le comité de lecture des Éditions du CTHS dans le cadre de la publication des actes du $139^{\mathrm{e}}$ Congrès national des sociétés historiques et scientifiques tenu à Nîmes en 2014.
\end{abstract}

\begin{abstract}
«Contacts, conflits et créations linguistiques » a été l'un des thèmes porteurs au sein du Congrès de Nîmes : plus de trente interventions ont été entendues, et vingt-trois auteurs nous ont confié leurs textes qui sont réunis ici.
\end{abstract}

Cet ensemble s'articule autour de deux sujets qui ont fédéré de manière plus ou moins importante les intervenants: d'une part les notions de diglossie et de bilinguisme qui figuraient dans l'appel à communication ont été particulièrement fécondes et d'autre part, la notion de création lexicale qui a apporté des contributions originales.

Quelques mots sur ces notions : dans un premier temps, diglossie et bilinguisme ont été confondus avant d'être distingués en sociolinguistique par Ferguson ${ }^{1}$ et Fishman ${ }^{2}$ (pour plus de détails, cf. ici même Soussi). La diglossie rendrait compte plus précisément de la situation de certaines langues ou variétés linguistiques d'une même langue sur un territoire donné, où, par suite d'événements politiques, historiques ou sociaux l'une des langues ou variétés a acquis un statut supérieur à l'autre (ex. en France: français standard vs parlers d'oc ou d'oïl). Tandis que le bilinguisme s'appliquerait à des situations où deux langues cohabitent sans qu'il y ait de rapport de force (ex. la Suisse). Voilà pour la théorie. Dans la pratique, il semble que les choses soient plus nuancées que cela. D'ailleurs, la grande majorité des textes qui suivent nous montrent que quelles que soient les époques, il y a toujours des cohabitations plus ou moins consensuelles ou plus ou moins conflictuelles. Évidemment à époques anciennes, il s'agit de traces écrites qui ne nous disent pas tout des pratiques orales, ces dernières étant bien sûr plus documentées aujourd'hui.

Ainsi l'intervention de Ana Isabel Blasco-Torres portant sur les inscriptions relevées sur les Ostraca découvertes à Narmouthis en Égypte (II ${ }^{\mathrm{e}}$ siècle après J.-C.) et celle de Christel Freu sur la langue des contrats et accords commerciaux dans l'Empire romain, rendent compte que, très tôt, les échanges commerciaux et culturels ont impliqué le bilinguisme dans le vaste espace dominé par les Romains autour de la Méditerranée. À la même époque, au cœur de la région où s'est déroulé le congrès, Michel Christol montre qu'à Nîmes les dénominations de personnes se caractérisent par une latinisation précoce, élément essentiel de l'identité vers une intégration, tandis qu'un peu plus tard à Arles, Michel Banniard prouve qu'au travers des fluctuations du latin de Césaire (évêque, $\mathrm{VI}^{\mathrm{e}}$ siècle), les compromis linguistiques peuvent être illustrés dans une communauté de locuteurs encore latinophones, et non déjà romanophones.

\footnotetext{
${ }^{1}$. Charles A. Ferguson « Diglossia », Word, 15, 1959, p. 325-340.

2. Joshua A. Fishman, Sociolinguistique, Bruxelles-Paris, Nathan et Labor, 1971.
} 
Jean-Loup Lemaître nous fait faire un bond dans le temps et nous transporte dans le Limousin du XIII ${ }^{\mathrm{e}}$ siècle à la rencontre de Bernard Itier, bibliothécaire de l'abbaye de Saint-Martial de Limoges qui, par le biais de sa chronique, montre l'utilisation de la langue limousine, en concurrence avec le latin, aussi bien pour les noms de personnes et de lieux que pour les termes techniques et les propos qu'il rapporte.

Avec l'intervention de Marie-Rose Bonnet, on retourne à Arles aux $\mathrm{XV}^{\mathrm{e}}$ et $\mathrm{XVI}^{\mathrm{e}}$ siècles lorsque les documents puisés dans les riches archives communales révèlent à la fois une attestation tardive du provençal, mais aussi une apparition précoce du français, instrument de la lutte pour le pouvoir par l'appropriation d'un système linguistique considéré comme plus favorable. À la même époque, en élargissant l'aire géographique à l'ensemble de la Provence, Gabriel Audisio montre que, dans les actes notariés, trois langues sont utilisées: le latin, le provençal et le français devenu obligatoire depuis l'ordonnance de Villers-Cotterêts en 1539. La traduction est indispensable entre les clients qui ne pratiquaient le plus souvent que la langue vernaculaire et les notaires chargés de la mise en forme des actes, entraînant parfois des problèmes d'identification.

Bernard Thomas évoque le cas particulier des États pontificaux d'Avignon qui présentent une exception dans la tenue des registres paroissiaux entre 1768 et 1792, puisque contrairement au reste du royaume, c'est principalement en latin, au lieu du français, qu'ils ont été tenus dans une grande majorité des cas, au gré des fluctuations politiques, jusqu'à l'imposition définitive du français à la Révolution. C'est précisément sur cette époque de la Révolution, que porte l'intervention de Régis Bertrand qui a recherché les attestations de la langue vernaculaire dans les écrits recueillis sur un axe ToulouseMarseille lesquels montrent une situation diglossique et une francisation très avancées. Plus près de nous, Hervé Terral nous décrit l'expérience originale menée par Antonin Perbosc (1861-1944) pour la défense de la langue d'oc alors qu'il est instituteur dans le Tarn-et-Garonne, en créant avec ses élèves " une société traditionniste » pour la collecte de contes, chansons, etc. qui donnera lieu à une publication.

Deux éclairages proposent un aperçu de la situation diglossique d'aujourd'hui dans le domaine français. D'une part, Marie-Jeanne Verny a mené une enquête auprès des écrivains occitans contemporains pour connaître leur itinéraire biographique et leurs motivations dans notre société actuelle où la pratique des langues vernaculaires ne cesse de baisser. D'autre part, Marie-Noële Denis décrit pour l'Alsace les nombreux changements de langue qui ont été imposés du fait des fluctuations politiques qu'a connu cette région et nous fait part des résultats d'enquêtes menés auprès d'adolescents alsaciens pour connaître leur pratique actuelle, qui est en fort déclin. Nous élargissons notre champ d'investigation avec l'intervention de Houssine Soussi qui décrit la situation complexe contemporaine au Maroc où langues nationales et langues étrangères se côtoient.

Les dictionnaires bilingues ont donné lieu à deux interventions. La première, de Claire Torreilles, porte sur un important ouvrage anonyme, datant du $\mathrm{XVIII}^{\mathrm{e}}$ siècle qui vient d'être retrouvé à Nîmes, et dont l'abondante documentation littéraire constitue sans doute un des premiers monuments de la langue moderne. La seconde, de Jean-Roger Wattez, nous donne un aperçu du vocabulaire utilisé encore aujourd'hui dans le Montreuillois en Picardie.

Les interventions suivantes élargissent notre champ d'investigation dans le temps et dans l'espace : nous retrouvons la conférence plénière de Serge Lusignan sur les langues de communication du pouvoir royal utilisées en France et en Angleterre du XIII ${ }^{\mathrm{e}}$ au XV $\mathrm{XV}^{\mathrm{e}}$ siècle, période où le français a joué un rôle important dans les deux royaumes. Camille Desenclos montre, de son côté, les multiples difficultés rencontrées dans les relations diplomatiques au XVII ${ }^{\mathrm{e}}$ siècle du fait de la multiplicité des langues utilisées dans les cours européennes. 
Annie Lagarde Fouquet évoque de son côté l'expérience singulière de l'Autrichienne Ida Pfeiffer (1797-1858) qui effectua cinq voyages dont deux tours du monde, souvent seule. Ses aventures firent l'objet de récits publiés et montrent l'importance du choix de la langue de communication dans l'approche des peuples rencontrés. Anne Nogarède nous entraîne dans l'exil des écrivains allemands et autrichiens pendant la Seconde Guerre mondiale: elle analyse les conséquences de la perte de la langue maternelle et de l'adaptation à la langue et à la culture des pays d'accueil. Enfin la communication de Regina Pozzi analyse un passage de la Démocratie en Amérique de Tocqueville où il décrit «comment la société américaine a modifié la langue anglaise ».

En dernier lieu, trois interventions se rapportent au thème de la création lexicale. Les deux premières s'attachent à décrire des langues fictives: Isabelle-Rachel Casta s'intéresse aux langages cryptiques utilisés dans la fantasy française, tandis que Pascal Semonsut nous rend compte de la représentation du langage préhistorique dans la fiction contemporaine (littérature, bande dessinée, cinéma).

Enfin, Michel Rateau nous donne un aperçu du processus de création des noms commerciaux, notamment en Afrique du Sud et de l'usage du français dans ce processus. 


\title{
Les ostraca de Narmouthis dans le contexte du bilinguisme gréco-égyptien de l'époque romaine
}

Ana Isabel BLASCO TORRES ${ }^{1}$

Doctorante à l’Université catholique de Louvain

\begin{abstract}
Extrait de : Guylaine BRUN-TRIGAUD (dir.), Contacts, conflits et créations linguistiques, Paris, Édition électronique du CTHS (Actes des congrès des sociétés historiques et scientifiques), 2015.

Cet article a été validé par le comité de lecture des Éditions du CTHS dans le cadre de la publication des actes du $139^{\mathrm{e}}$ Congrès national des sociétés historiques et scientifiques tenu à Nîmes en 2014.
\end{abstract}

Les archives du complexe de temples de Narmouthis furent retrouvées sur le site de Médinet Madi pendant la quatrième campagne de fouilles dirigées par Achille Vogliano. Cette campagne de fouilles eut lieu du début avril au 30 juin 1938 et fut notamment effectuée dans les parties nord et intérieure du téménos du temple et dans la partie sud de la voie sacrée méridionale. A. Vogliano nous dit :

«Pendant que l'on achevait l'exploration d'un édifice au bord est du téménos, à la hauteur du vestibule précédant les constructions ptolémaïques du temple, on a mis la main sur les archives d'un haut personnage religieux. On y a trouvé 1555 ostraca, dont beaucoup de grandes dimensions, qui vont de l'époque d'Hadrien à celle de Commode ; une partie est écrite en grec, une autre en grec et démotique, et une troisième en démotique. Il s'agit de documents qui se rapportent au culte du temple, aux fonctions des prêtres, à des querelles judiciaires où quelque personnage du temple est impliqué, à des comptes des biens du temple. $\mathrm{D}^{\prime}$ un document de ces archives il résulterait que le personnage en question avait aussi la juridiction sur les temples de moindre importance de la région et devait en assurer le fonctionnement. S'il est permis d'en tirer quelque conclusion, il faudrait dire qu'à Narmouthis - l'ancienne Madīnet Mādī grecque (on peut l'affirmer maintenant) ${ }^{2}$ - et à l'île de Soknopaios existaient deux centres religieux importants de l'Arsinoïte (...) $»^{3}$

Bien que nous ne disposions que de peu de détails concernant l'endroit exact de la découverte, il y eut des tentatives pour situer cet endroit en suivant les indications du fouilleur ${ }^{4}$. D'après celles données par A. Vogliano, la strate dans laquelle les ostraca furent retrouvés, à l'intérieur de deux récipients d'argile, était composée de sable, et sur cette strate, il y en avait une autre plus récente ${ }^{5}$. Les derniers occupants avaient rempli le sol de

1. Cet article a été réalisé dans le cadre d'une bourse de Formation de Professorat Universitaire du Ministère de l'Éducation espagnol. Son auteur est attachée au Projet de Recherche FFI2010-21125, subventionné par le Ministère de la Science et de l'Innovation d'Espagne.

2. L'existence d'une ancienne ville grecque appelée Narmouthis était déjà connue depuis longtemps grâce à quelques papyrus (cf., par exemple, P. Lund. II 5, P. Ryl. II 226, P. Ryl. II 236, P. Tebt. II 393, P. Tebt. II 400, P. Tebt. IV 1099 ou P. Wisc. II 87) et à la Notitia Dignitatum (XXVIII, 46), datée du règne de Valentinien III (ca. 425-455). B. P. Grenfell et A. S. Hunt identifiaient Médinet Madi avec la ville connue comme 'I $\beta$ t⿳亠丷

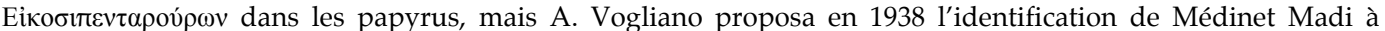
Narmouthis. Il détermina aussi qu'il s'agissait de la ville qui était nommée $D_{3}$ à l'époque pharaonique. Malgré l'identification définitive de Médinet Madi à Narmouthis grâce aux ostraca trouvés lors des fouilles italiennes, il reste encore à élucider la question de l'identification d'autres toponymes du Fayoum et, notamment, de la ville

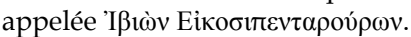

3. A. Vogliano, « Madinet Madi. Fouilles de l'Université Royale de Milan », p. 88 (communiqué du Service des Antiquités).

4. Pour plus de détails sur l'analyse des indications d'A. Vogliano, cf. P. Gallo, Ostraka demotici e ieratici dall'archivio bilingue di Narmouthis II (34-99), p. XXXII-XXXVI.

5. A. Vogliano, « Rapporto preliminare della IV campagna di scavo a Madînet Mâdi (R. Università di Milano) », p. 543 . 
la chambre de sable afin de pouvoir utiliser la pièce sans éliminer le sol précédent, ainsi la superposition d'une couche de sable sur celle dans laquelle se trouvaient les ostraca a conservé les documents presque intacts. Même si beaucoup d'ostraca avaient été numérotés et placés d'une manière précise, leur ordre ne fut pas enregistrét. De plus, les ostraca qui furent découverts dans les deux récipients d'argile furent mélangés avec d'autres ostraca qui furent trouvés dans la même pièce mais éparpillés par terre?

Les fouilles de Narmouthis furent interrompues par la Seconde Guerre mondiale. A. Vogliano, inquiet pour la conservation du matériel trouvé auparavant et conservé jusqu'à ce moment dans l'entrepôt des fouilles, fit deux voyages en Égypte en 1939 et 1940. Pendant ces deux séjours, les objets les plus importants, y compris les ostraca trouvés dans les fouilles et placés dans dix boîtes de bois, furent transportés dans les réserves du Musée du Caire. En mai 1994, pour pouvoir étudier les textes sur les ostraca originaux, P. Gallo retrouva au Musée égyptien du Caire les boîtes en bois qui contenaient les textes. Pendant le premier décompte, réalisé en août 1994, on dénombra 1471 ostraca $^{8}$, parmi lesquels approximativement $40 \%$ étaient rédigés en égyptien démotique, $40 \%$ en grec et $20 \%$ en démotique et en grec $^{9}$.

La plupart des ostraca de Narmouthis sont écrits sur une céramique à pâte calcaire, de couleur claire ; les scribes préféraient ce type d'ostraca, puisque l'encre ressortait mieux sur une surface claire ou même blanche. Les ostraca de céramique à pâte rouge nilotique sont moins fréquents dans les archives ${ }^{10}$. La plupart des ostraca ont été écrits avec de l'encre noire, dont le principal composant est le carbone, mais quelques-uns ont la numérotation ancienne, ou l'une des numérotations anciennes, écrite avec de l'encre rouge. La composition de l'encre noire n'a pas encore été analysée, mais P. Gallo ${ }^{11}$ distingue deux qualités d'encre, dont l'une contient plus de carbone ${ }^{12}$. En général, les textes ont été rédigés sur la surface convexe de la céramique, et parfois l'écriture a été effectuée sur toute la surface disponible et les textes ont été écrits sur plusieurs ostraca successifs. Dans quelques cas seulement, la surface disponible n'a pas été utilisée entièrement. Les textes écrits suivent, par conséquent, la forme du support d'écriture ${ }^{13}$.

Tous les ostraca de Narmouthis ont été écrits avec le calame grec en roseau réalisé à partir de la plante de Phragmites Communis L. et non pas avec le pinceau égyptien en jonc réalisé à partir de Juncus Acutus L., quelle que soit la langue dans laquelle les textes ont été rédigés ${ }^{14}$. En effet, à la fin de l'époque ptolémaïque on adopta le calame grec pour la

6. Il n'est pas possible actuellement de reconstruire les archives grâce à la numérotation ancienne parce qu'elle se répète souvent. En plus, la numérotation récente établie pour les textes est complètement fortuite, sans relation avec la numérotation ancienne.

7. Cf. P. Gallo, Ostraka demotici e ieratici dall'archivio bilingue di Narmouthis II (34-99), p. XXXVII.

8. Cf. Ibid., p. XL. Conformément à ce décompte, 84 textes furent perdus.

9. D'après E. Bresciani, S. Pernigotti, M. C. Betrò, Ostraka demotici da Narmuti I (nn. 1-33), p. 2, plus de 600 ostraca sont écrits complètement en démotique, presque 500 en grec, approximativement 350 sont démotico-grecs et 70 gréco-démotiques, et une dizaine contient des signes en écriture hiéroglyphique, hiératique et démotique, avec des tentatives de transcription de la langue égyptienne avec des caractères grecs, constituant des gloses en copte ancien.

10. P. Gallo, Ostraka demotici e ieratici dall'archivio bilingue di Narmouthis II (34-99), p. LIII.

11. Ibid., p. LIII.

12. L'existence de deux types différents d'encre utilisés sur les papyrus, un basé sur le carbone et l'autre sur des éléments métalliques, a été vérifiée grâce à l'utilisation de la technique PIXE (" Particle-Induced X Ray Emission ») sur quelques papyrus de la collection de 1'Institut Papyrologique « G. Vitelli » de Florence. Cf. I. Andorlini, F. Lucarelli, P. A. Mandò, «Particle-Induced X Ray-Emission for the Analysis of Writing and Painting Materials on Papyri and Textiles from Graeco-Roman Egypt », p. 51-64. On avait constaté aussi que pendant la période ptolémaïque principalement les textes démotiques étaient écrits avec une encre dont le principal composant était le carbone et les textes grecs étaient écrits avec une encre réalisée à base d'éléments métalliques. Cf. E. Delange, G. Grange, B. Kusko, E. Menei, « Apparition de l'encre métallo-gallique à partir de la collection de papyrus du Louvre », p. 213-217.

13. Cf. R. Pintaudi, P. J. Sijpesteijn, Ostraka greci da Narmuthis (OGN I), p. 17.

14. Nous ne sommes pas d'accord avec P. Gallo, Ostraka demotici e ieratici dall'archivio bilingue di Narmouthis II (34-99), p. LIII, qui affirme que la plupart des textes grecs, démotiques ou démotico-grecs des archives de Narmouthis ont été écrits avec le « calamo egiziano », fait qui montrerait que les scribes de Narmouthis étaient de formation et de langue indigène égyptienne, et que les textes démotiques écrits avec le « stilo greco » sont encore peu fréquents à Narmouthis. L'utilisation de l'expression «calame égyptien » est, d'autre part, une 
notation de la langue égyptienne, et vers la fin de cette période, celui-ci remplaça complètement le pinceau égyptien. Cette adoption du calame grec pour écrire les documents égyptiens peut être liée à l'hellénisation de l'administration égyptienne. Par conséquent, dans les ostraca de Narmouthis, la paléographie ne permet pas de distinguer l'origine grecque ou égyptienne du scribe ${ }^{15}$.

Les scribes des textes démotiques de Narmouthis évitent les groupes plurilittères de signes, montrant une préférence pour les signes "alphabétiques » ${ }^{16}$. Ce phénomène est caractéristique de l'écriture démotique de l'époque romaine, probablement à cause de l'influence croissante de l'écriture alphabétique grecque et de la difficulté pour les scribes de comprendre et d'utiliser les graphies démotiques traditionnelles. Cependant, étant donné que d'autres documents démotiques provenant de Narmouthis ne sont pas connus pour le moment, il n'est pas possible de suivre l'évolution paléographique des scribes ${ }^{17}$. Dans les textes grecs l'écriture est bien lisible, majuscule à caractère documentaire, réalisée par des mains assez expérimentées. Par contre, la difficulté la plus importante pour comprendre les textes réside dans l'absence de références aux contextes connus des scribes mais que nous ignorons. Parfois, même si nous pouvons lire et traduire les textes, nous ne pouvons pas vraiment les comprendre à cause des allusions à des toponymes, documents, personnes et situations qui nous sont par ailleurs inconnus ${ }^{18}$.

Même si, dans plusieurs cas, les faits auxquels les textes font allusion nous échappent, le contexte de réalisation de quelques ostraca peut être déterminé. Quelques textes des archives de Narmouthis, rédigés en grec et dans les différentes écritures égyptiennes, sont, en effet, de caractère clairement scolaire ${ }^{19}$. Il s'agit, notamment, des textes démotiques $\mathrm{ODN}^{20}$ I 25-26, ODN II 44, OMM 70 ${ }^{21}$, et probablement ODN II 80, OMM 804 et OMM 933, qui contiennent des règles de comportement. Les textes grecs OGN I 125126 et OGN I 128-131 semblent être également de caractère scolaire ${ }^{22}$. $\mathrm{D}^{\prime}$ autre part, les ostraca scolaires ODN II 34-41, écrits en écriture hiéroglyphique, hiératique et démotique, comportent des gloses en alphabet grec avec quelques signes en démotique notant les phonèmes inexistants en grec. Avec ce type d'exercices, les élèves apprenaient les écritures hiéroglyphique et hiératique, en se servant des gloses en grec avec quelques signes démotiques pour pouvoir bien prononcer les expressions écrites.

L'existence de ce type de textes dans les archives prouve que, dans le complexe de temples de Narmouthis, il y avait un «lieu d'enseignement». En effet, l'éducation et l'apprentissage des écritures de la langue égyptienne avaient lieu traditionnellement, en grande partie, dans les temples ${ }^{23}$. La «Maison de vie», $p r-{ }^{`} n h$, jouait un rôle important

contraditio in terminis, étant donné que l'outil d'écriture égyptien était le pinceau de jonc (Juncus Acutus L.), et l'outil caractéristique grec était le calame de roseau (Phragmites Communis L.).

15. Cf. W. Clarysse, «Egyptian Scribes Writing Greek», p. 188-201; W. J. Tait, «Rush and Reed : the Pens of the Egyptian and Greek Scribes », p. 477-481.

16. Cf. W. J. Tait, «Uniconsonantal Signs and Patterns of Change : Exploring the Orthography of the Demotic Script », p. 127-143.

17. P. Gallo, Ostraka demotici e ieratici dall'archivio bilingue di Narmouthis II (34-99), p. LIV.

18. Ibid., p. XLI.

19. Nous ne sommes pas d'accord avec E. Bresciani, S. Pernigotti, M. C. Betrò, Ostraka demotici da Narmuti I (nn. 1-33), p. 2-3 ; E. Bresciani, R. Pintaudi, « Textes démotico-grecs et greco-démotiques des ostraca de Medinet Madi : Un problème de bilinguisme », p. 123, qui considèrent que la plupart des ostraca de Narmouthis sont de caractère scolaire et que les archives sont « fictives ».

20. Dans cet article, les ostraca de Narmouthis ont été cités en suivant la façon traditionnelle de citation : ODN (ostracon démotique de Narmouthis), OGN (ostracon grec de Narmouthis) et OMM (ostracon de Médinet Madi). 21. Les textes démotiques ODN I 25-26 contiennent des maximes de sagesse; OMM 70 a un exercice mathématique et dans ODN II 44, l'expression $t_{3}{ }^{\prime} n$-s $s b_{3}$ « le lieu d'enseignement » est attestée. Cf. P. Gallo, Ostraka demotici e ieratici dall'archivio bilingue di Narmouthis II (34-99), p. 22.

22. Ils contiennent notamment des noms de divinités, des lettres de l'alphabet grec, des maximes morales et des trimètres iambiques. Cf. aussi l'ostracon sans numéro d'inventaire contenant un exercice d'écriture dans G. Nachtergael, « Ostraca de la 'Maison des ostraca' », p. 76-77.

23. Le rôle des prêtres en ce qui concerne l'enseignement des écritures de la langue égyptienne et l'astrologie est mentionné par Diodore de Sicile (I, 81). D'autre part, l'importance de l'astrologie dans le complexe de temples de Narmouthis est attestée par le grand nombre de textes de caractère astrologique, rédigés en grec et en démotique, présents dans les archives. 
dans la transmission de la culture égyptienne. Même si cette institution ne peut pas être considérée comme une école ou une université, il s'agissait, d'après les sources égyptiennes, d'un endroit en relation avec les livres relatifs à la religion et avec les scribes, c'est-à-dire d'un scriptorium ${ }^{24}$, comme le montre le titre "scribe de la Maison de vie », š̌ pr- 'nh, dans les textes égyptiens ; ces scribes apparaissent nommés en démotique

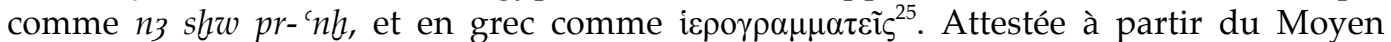
Empire $^{26}$, l'expression égyptienne qui désignait l'endroit spécifique d'apprentissage était 't $s b_{3}$, littéralement « chambre d'apprentissage ${ }^{27}$. Ce terme, présent dans ODN II 44, a été conservé en démotique et en copte pour désigner l' "école ». Même si ce mot indique qu'il y avait des lieux spécifiques où l'éducation était donnée, il reste difficile d'identifier ces endroits. L'éducation démotique avait lieu, en effet, dans les temples ${ }^{28}$, mais l'endroit exact est difficile à déterminer ${ }^{29}$.

Pendant la période romaine, l'utilisation de l'écriture égyptienne hiéroglyphique et hiératique était limitée, semble-t-il, à la copie des anciens textes religieux. La plupart des papyrus en hiéroglyphique et en hiératique qui datent de cette époque sont des fragments de rituels religieux, magiques ou funéraires. Il s'agit, en général, des textes écrits auparavant, qui étaient recopiés par les scribes des temples; ce ne sont pas des créations de l'époque, mais des tentatives de compilation des connaissances d'une culture millénaire qui était menacée ${ }^{30}$. La méconnaissance progressive des systèmes d'écriture hiéroglyphique et hiératique et l'utilisation de la langue grecque d'une manière croissante s'observent dans l'emploi de l'alphabet grec dans les gloses des textes de Narmouthis pour assurer la prononciation correcte des mots écrits en égyptien et, par conséquent, l'efficacité des formules magiques ${ }^{31}$; il s'agit, effectivement, de la naissance du copte ancien.

La situation de l'écriture démotique à l'époque romaine s'avère plus complexe que celle du hiéroglyphique et du hiératique. Déjà avant l'arrivée des Romains en Égypte, l'administration préférait le grec pour les témoignages dans les actes juridiques et pour la

24. Cf. A. H. Gardiner, "The House of Life», p. 175 ; R. J. Williams, "Scribal Training in Ancient Egypt», p. 220-221. L'institution de la «Maison de vie" comme une sorte de scriptorium plutôt que comme une école ou une université apparaît dans l'inscription qui se trouve sur le dos de la statue d'Oudjahorresne (statuette naophore du Vatican 158 ; cf. G. Posener, La première domination perse en Égypte. Recueil d'inscriptions

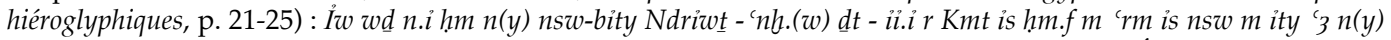
$h 3 s t n b(t) h k_{3}{ }^{\prime} 3 n(y) K m t r s m n h_{3} n(y) p r$ - $n h$, « La Majesté du roi de la Haute et de la Basse Égypte Darius, qu'il vive éternellement, m'ordonna de retourner en Égypte, - tandis que Sa Majesté se trouvait en Elam, alors qu'elle était grand roi de tous les pays étrangers et grand souverain de l'Égypte -, pour remettre en état l'établissement du $p r$ - ' $n h$ » (traduction de G. Posener). Le mot $h_{3}$, « bureau », est aussi en relation avec un centre d'études dans d'autres attestations (cf. Ibid., p. 23).

25. Cf. A. H. Gardiner, «The House of Life », p. 170. Le grec ignore la présence de l'expression $p r-' n h$ en

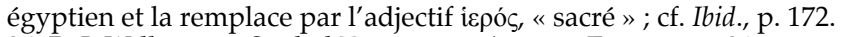

26. R. J. Williams, « Scribal Training in Ancient Egypt», p. 215.

27. L'éducation des personnes proches du roi avait lieu, semble-t-il, dans les palais royaux, comme on peut déduire à partir de la stèle d'Ikhernofret (Berlin 1204), du Moyen Empire. Cf. Ibid., p. 216.

28. Les documents trouvés dans d'autres villes du Fayoum, comme Soknopaiou Nesos et Tebtynis, montrent aussi l'existence d'écoles démotiques associées au temple local. Cf. R. Cribiore, Gymnastics of the Mind. Greek Education in Hellenistic and Roman Egypt, p. 22-23.

29. Il est difficile de déterminer si, dans le complexe de temples de Narmouthis, la pièce où l'éducation était donnée est la même que celle où les ostraca furent retrouvés. D'après A. Vogliano, « Rapporto preliminare della

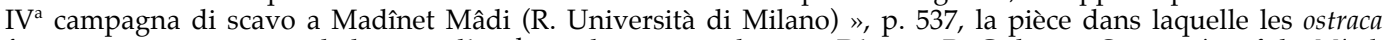
furent trouvés aurait été le bureau d'un haut dignitaire religieux. D'après R. Cribiore, Gymnastics of the Mind. Greek Education in Hellenistic and Roman Egypt, p. 22, le vestibule du temple d'Hathor à Dendera, par exemple, semble avoir été un endroit où l'apprentissage avait lieu. Cf. aussi F. Daumas, Dendara et le temple d'Hathor. Notice sommaire, p. 34 ; C. Leblanc, «L'école du temple (ât-sebaït) et le per-ânkh (maison de vie). A propos de récentes découvertes effectuées dans le contexte du Ramesseum », p. 93-101; et C. Leblanc, "L'éducation, la formation des scribes et les institutions d'enseignement dans l'Égypte ancienne », p. 28-30.

30. P. Gallo, Ostraka demotici e ieratici dall'archivio bilingue di Narmouthis II (34-99), p. XXVI.

31. Selon la conception égyptienne, les textes magiques n'étaient efficaces que s'ils étaient prononcés conformément à la manière dont les ancêtres les prononçaient. Dans la plupart des cas, les formules magiques devaient être utilisées dans leur langue originale pour conserver intact le principe magique ; on considérait que la traduction de cette sorte de textes pouvait éliminer l'effet magique des formules. Les conséquences des traductions et des modifications des textes magiques sont abordées par Jamblique (VII, 4-5). Cf. C. Préaux, « De la Grèce classique à l'Égypte hellénistique : traduire ou ne pas traduire », p. 372-376. 
rédaction des contrats, mais les documents rédigés en démotique pouvaient être aussi valables. À l'époque de Ptolémée $\mathrm{I}^{\mathrm{er}}$ Sôter (ca. 305-285 av. J.-C.) et de Ptolémée II Philadelphe (ca. 385-246 av. J.-C.), les contrats privés rédigés en démotique pouvaient être enregistrés dans les archives officielles. À l'époque romaine, en revanche, seuls les documents rédigés en grec pouvaient être enregistrés dans le bureau appelé $\beta 1 \beta \lambda$ เo $\theta \dot{\kappa}\rceil$ $\dot{\varepsilon} \gamma \kappa \tau \eta ́ \sigma \varepsilon \omega v^{32}$. De la même manière, à la période ptolémaïque, il existait en Égypte deux tribunaux différents pour les procès grecs et égyptiens, mais, pendant l'époque romaine, cette organisation juridique bipartite fut éliminée et dans les tribunaux, comme dans $d^{\prime}$ autres organes de gouvernement, seul le grec pouvait être employé ${ }^{33}$. Pour ces raisons, dans le cas des documents légaux et notariaux, le démotique est rarement utilisé à l'époque romaine ${ }^{34}$.

En revanche, les textes littéraires et religieux en écriture démotique sont relativement abondants pendant les deux premiers siècles de la période romaine. À cette époque, l'activité littéraire et scientifique dans les temples égyptiens est attestée par une grande quantité de textes religieux, magiques, médicaux, mathématiques et scolaires, et le démotique fut utilisé aussi dans les documents privés rédigés par les prêtres pour un usage limité aux temples ${ }^{35}$. Cependant, à partir de la fin du $\mathrm{II}^{\mathrm{e}}$ siècle, l'utilisation de l'égyptien démotique, limitée au milieu religieux et littéraire, se réduisit progressivement, même si le clergé continua à s'en servir pour la rédaction de quelques documents. Les ostraca des archives de Narmouthis, dont au moins la moitié a été rédigée en démotique ${ }^{36}$, montrent que, de l'époque d'Hadrien à la période de Commode ${ }^{37}$, le démotique était non seulement enseigné, mais aussi largement utilisé pour la rédaction de textes dans un milieu religieux.

Les ostraca de Narmouthis constituent le reflet de la situation linguistique, culturelle, religieuse et sociale des habitants de ce village pendant la deuxième moitié du II $^{\mathrm{e}}$ siècle après J.-C. Cette communauté pratiquait à cette époque les cultes religieux conformément aux croyances égyptiennes traditionnelles, dans lesquelles l'astrologie jouait un rôle important. Dans l'école qui se trouvait dans le complexe de temples, les élèves apprenaient les écritures démotique, hiéroglyphique, hiératique et grecque, ainsi que des règles de comportement en grec et en démotique. Les gloses en grec dans les textes écrits en hiéroglyphique et hiératique montrent, en effet, que les écritures démotique et grecque étaient apprises en premier et que l'égyptien hiéroglyphique et le hiératique étaient enseignés seulement ensuite. Les gloses en alphabet grec, grâce auxquelles la prononciation correcte des textes hiéroglyphiques et hiératiques et, par conséquent, des formules magiques, était assurée, sont les premiers témoignages du "copte ancien ». L'utilisation de l'alphabet grec pour ces gloses, ainsi que l'emploi du calame grec en roseau réalisé à partir de la plante de Phragmites Communis L. au lieu du pinceau égyptien en jonc réalisé à partir de Juncus Acutus L. pour la rédaction des textes en égyptien, témoignent d'une situation linguistique de diglossie dans laquelle la langue grecque prédominait clairement sur la langue égyptienne au moment de la formation des archives de Narmouthis.

32. N. Lewis, «The Demise of the Demotic Document : When and Why », p. 279.

33. Ibid., p. 279-280.

34. On a constaté, en effet, l'existence de traductions grecques de documents légaux démotiques pendant cette période, comme dans le cas du papyrus P. Oxy. XLVI 3285. Cf. Ibid., p. 280-281.

35. Cf. P. Gallo, Ostraka demotici e ieratici dall'archivio bilingue di Narmouthis II (34-99), p. XXVIII.

36. Cf. note 9 .

37. A. Vogliano, « Madinet Madi. Fouilles de l’Université Royale de Milan », p. 88 (communiqué du Service des Antiquités). 


\begin{abstract}
Résumé
Les archives de Narmouthis, découvertes pendant la campagne de fouilles dirigées par A. Vogliano à Médinet Madi (Égypte) en 1938, contiennent à peu près 1500 ostraca rédigés en égyptien et en grec. Malgré l'existence d'autres archives bilingues en Égypte, les ostraca de Narmouthis sont exceptionnels en raison du grand nombre de textes conservés, de la diversité des types de textes qu'ils contiennent (documents juridiques et administratifs, ordres, exercices scolaires et règles de comportement, comptes et enregistrements, notes cadastrales, notes adressées à une ou à plusieurs personnes, textes astrologiques,... ) et de la variété des langues et des écritures présentes dans les ostraca (grec, égyptien hiéroglyphique, égyptien hiératique, égyptien démotique et « copte ancien »). Dans ce travail, nous abordons la problématique de ces documents dans le contexte du bilinguisme gréco-égyptien de l'époque romaine.
\end{abstract}

\title{
Bibliographie
}

ANDORLINI Isabella, LuCARELLI Franco, MANDÒ Pier Andrea, « Particle-Induced X RayEmission for the Analysis of Writing and Painting Materials on Papyri and Textiles from Graeco-Roman Egypt», dans ANDORLINI Isabella, BASTIANINI Guido, MANFREDI Manfredo, Menci Giovanna (éds.), Atti del XXII congresso internazionale di papirologia, Firenze, 23-29 agosto 1998, Firenze, Istituto Papirologico « G. Vitelli », 2001, p. 51-64.

Bresciani Edda, Pernigotti Sergio, Betrò Maria C., Ostraka demotici da Narmuti I (nn. 133), Pisa, Quaderni di Medinet Madi (1), 1983.

BRESCIANI Edda, PINTAUDI Rosario, "Textes démotico-grecs et greco-démotiques des ostraca de Medinet Madi : Un problème de bilinguisme», dans VleEMING Sven P. (éd.), Aspects of Demotic lexicography. Acts of the Second International Conference for Demotic Studies, Leiden, 19-21 September 1984, Leuven, Peeters, 1987, p. 123-126.

ClARYSSE Willy, "Egyptian Scribes Writing Greek», Chronique d'Égypte, vol. LXVIII, $\mathrm{n}^{\circ} 135,1993$, p. $186-201$.

CRIBIORE Raffaella, Gymnastics of the Mind. Greek Education in Hellenistic and Roman Egypt, Princeton, Princeton University Press, 2001.

DAUMAS François, Dendara et le temple d'Hathor. Notice sommaire, Le Caire, Institut français d'archéologie orientale, 1969.

Delange E., GRANGe G., KusKo B., MeneI E., « Apparition de l'encre métallo-gallique à partir de la collection de papyrus du Louvre", Révue d'Égyptologie, vol. XLI, 1990, p. 213217.

GaLlo Paolo, Ostraka demotici e ieratici dall'archivio bilingue di Narmouthis II (34-99), Pisa, Edizioni ETS, 1997.

GARDINER Alan H., «The House of Life », Journal of Egyptian Archaeology, vol. XXIV, n ${ }^{\circ}$, 1938 , p. 157-179.

LEBLANC Christian, «L'école du temple (ât-sebaït) et le per-ânkh (maison de vie). À propos de récentes découvertes effectuées dans le contexte du Ramesseum », Memnonia, vol. XV, 2004, p. 93-101.

LEBLANC Christian, "L'éducation, la formation des scribes et les institutions d'enseignement dans l'Égypte ancienne", Senouy. Bulletin de l'Association dauphinoise d'égyptologie, vol. VI, 2007, p. 28-30. 
LEWIS Naphtali, "The Demise of the Demotic Document: When and Why ", Journal of Egyptian Archaeology, vol. LXXIX, 1993, p. 276-281.

NACHTERGAel Georges, "Ostraca de la 'Maison des ostraca'», dans BRESCIANI Edda, Delattre Alain, HeILPORn Paul, Martin Alain, Menchetti Angiolo, NACHTERGAEL Georges, PINTAUd Rosario, SiLvano Flora (éds.), Narmouthis 2006. Documents et objets découverts à Médinet Madi en 2006, Pisa, Plus-Pisa university press, 2010, p. 74-81.

PINTAUDI Rosario, SIJPESTEIJN Pieter J., Ostraka greci da Narmuthis (OGN I), Pisa, Quaderni di Medinet Madi (2), 1993.

POSENER Georges, La première domination perse en Égypte. Recueil d'inscriptions hiéroglyphiques, Le Caire, Institut français d'archéologie orientale, 1936.

PrÉAux Claire, «De la Grèce classique à l'Égypte hellénistique: traduire ou ne pas traduire », Chronique d'Égypte, vol. XLII, no 84, 1967, p. 369-383.

TAIT William John, «Rush and Reed : the Pens of the Egyptian and Greek Scribes », dans MANDILARAs Basil G. (éd.), Proceedings of the XVIII International Congress of Papyrology, Athens 25-31 May 1986, Athens, Athens Greek Papyrological Society, 1988, p. 477-481.

TAIT William John, "Uniconsonantal Signs and Patterns of Change: Exploring the Orthography of the Demotic Script », dans VlEEMING Sven P. (éd.), Aspects of Demotic Orthography. Acts of an International Colloquium Held in Trier, 8 November 2010, Leuven, Peeters, 2013, p. 127-143.

VogLiAno Achille, «Madinet Madi. Fouilles de l'Université Royale de Milan », Chronique d'Égypte, vol. XIV, nº 27-28, 1939, p. 87-89.

VOGLIANO Achille, « Rapporto preliminare della IV campagna di scavo a Madînet Mâdi (R. Università di Milano)», Annales du Service des Antiquités de l'Égypte, vol. XXXVIII, 1938 , p. 533-549.

WiLliams Ronald J., "Scribal Training in Ancient Egypt», Journal of the American Oriental Society, vol. XCII, n 2, p. 214-221. 


\section{Illustrations}

OMM 1504 : Ostracon bilingue écrit en démotique et en grec à parts égales, avec un nom propre en hiératique sur la partie supérieure.

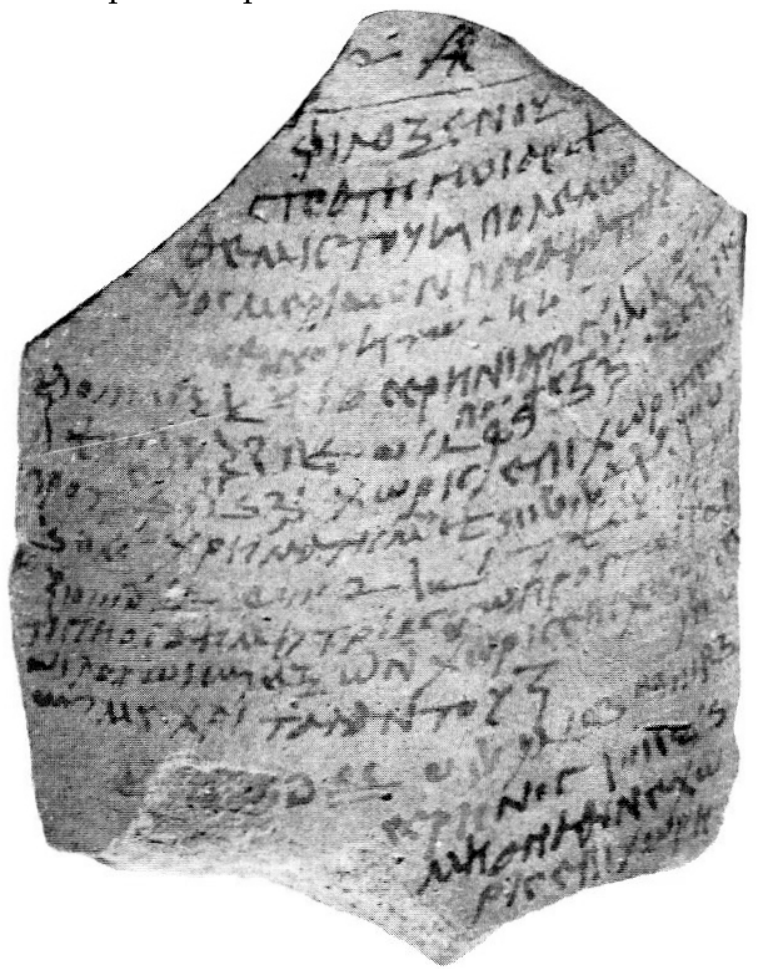

ODN II 95 : Fac-similé d'un ostracon des archives de Narmouthis rédigé principalement en démotique, avec la numérotation et deux noms propres écrits en grec.

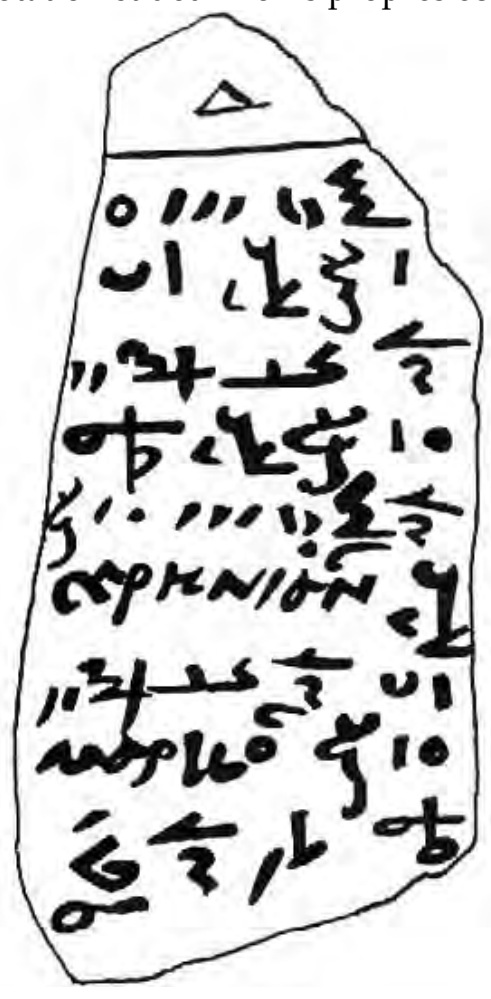




\title{
Communiquer l'accord. Réflexions juridiques romaines et pratiques provinciales concernant l'établissement des contrats et accords commerciaux dans un Empire plurilingue
}

\author{
Christel FREU \\ Professeure d'histoire romaine, \\ Université Laval, Québec.
}

\author{
Extrait de : Guylaine BRUN-TRIGAUD (dir.), Contacts, conflits et créations linguistiques, Paris, \\ Édition électronique du CTHS (Actes des congrès des sociétés historiques et scientifiques), 2015. \\ Cet article a été validé par le comité de lecture des Éditions du CTHS dans le cadre de la publication des actes du \\ $139^{e}$ Congrès national des sociétés historiques et scientifiques tenu à Nîmes en 2014.
}

En 1946, dans un important article sur les «Conflits de lois dans le monde grec et romain », le juriste Hans Lewald remarquait déjà qu' «en droit international privé, il n’y a guère de matière plus controversée que celle des contrats », soulignant «la multiplicité et la diversité des rapports contractuels dans le monde hellénistique et romain $»^{1}$. La diversité des langues et des formulaires juridiques des transactions commerciales privées d'époque impériale en témoigne en effet. Face aux possibles « conflits de lois » nés de la confrontation, dans le droit des affaires, de citoyens de langue et de droit divers, seront ici examinées les solutions impériales romaines, bien distinctes de celles qui ont été trouvées à l'époque hellénistique.

Ces solutions seront abordées dans leurs différents aspects :

- on rappellera d'abord la création d'un espace de droit commun à tous les peuples, le fameux ius gentium. Cette création avait notamment pour but d'offrir un cadre juridique aux affaires commerciales entre citoyens relevant de droits différents et de faciliter ainsi les communications entre commerçants, dans des langues parfois diverses.

- ensuite, nous aborderons les actes de la pratique, pour confronter le droit aux faits et voir à travers la question de la langue des contrats si les principes du ius gentium se sont appliqués dès le Haut Empire. J'ai pris en compte différents types d'archives privées, commerciales ou familiales, qui toutes conservaient trace de diverses transactions : les archives italiennes des négociants Sulpicii, les archives du désert de Judée, les papiers de l'Euphrate et quelques dossiers égyptiens significatifs.

Cette question de la langue des accords commerciaux et privés était à l'époque hellénistique intimement liée à la question du droit. Ainsi, dans l'Égypte ptolémaïque, on avait instauré le principe selon lequel la langue de rédaction était « l'élément juridique de rattachement. Les contrats conçus en langue égyptienne [étaient] soumis à la juridiction et au droit indigènes ; les contrats conçus en langue grecque [étaient] soumis à la juridiction et au droit grecs. »

1. H. Lewald «Conflits de lois dans le monde grec et romain », p. 439.

2. H. Lewald «Conflits de lois dans le monde grec et romain », p. 439. 
Nous nous intéresserons ici aux solutions romaines : l'instauration d'abord de deux langues véhiculaires officielles pour l'Empire - le latin en Occident, le grec en Orient - ; l'autorisation ensuite d'usages variés de bilinguisme dans les contrats.

- enfin, on s'intéressera à l'évolution des formulaires des contrats " grecs » et à l'adaptation de la langue et des formules grecques aux principes fondamentaux du droit romain. La question des transcriptions et surtout des traductions des formules romaines montre que même si les contrats, selon le principe du ius gentium, n'avaient pas de forme très précise, ils devaient néanmoins s'accorder avec les principes romains du consensus s'ils voulaient être jugés par les cours romaines selon les principes du droit romain.

\section{Le cadre juridique : les contrats consensuels selon le ius gentium}

Pour régler les conflits de droit impliquant deux personnes de citoyenneté différente, la Rome républicaine avait, dans la tradition hellénistique, sauvegardé les juridictions locales et pensé une casuistique de règlement des conflits selon le droit du défendeur ${ }^{3}$; par ailleurs un préteur pérégrin avait été créé pour juger à Rome les conflits opposant Romains et pérégrins. C'est peut-être d'ailleurs au sein de cette juridiction romaine que se développa le concept de ius gentium, mentionné explicitement pour la première fois au II $^{\mathrm{e}}$ siècle av. J.-C. Cicéron (Des devoirs III, 17, 69-70), rapproche ce "droit des gens» du concept grec de droit naturel, commun à tous les hommes et donc ouvert à tous ${ }^{4}$. Un des champs d'application du ius gentium fut le droit des affaires, afin que tous pussent commercer selon des règles unifiées. La distinction entre le ius ciuile, droit propre aux citoyens de chaque cité, et le ius gentium fut donc jugée si essentielle que c'est par elle que le juriste Gaius ouvrit son célèbre manuel au milieu du II siècle ap. J.-C. :

«Tout peuple géré par le droit écrit et par la coutume suit en partie un droit qui lui est propre, en partie un droit qui lui est commun avec l'ensemble du genre humain »

(Inst. I, 1 ; trad. J. Reinach).

Ce «droit des gens» n'a été jugé que théorique, voire fictif, par certains savants, au motif qu'il n'était pas un élément évoqué dans les cours de justice ${ }^{5}$. Mais, comme l'a bien montré Max Kaser, les magistrats n'avaient à se prononcer que sur l'action concernée par la plainte et non sur le type de droit à laquelle elle appartenait: le ius gentium est concerné par les obligationes ex contractu et par les actions ex bona fide ${ }^{6}$. Quand la cause est entendue par le magistrat, c'est l'action qui compte, non le type de droit ; ainsi dans les cours, la distinction n'était-elle pas visible; mais dans les faits, les réflexions des juristes concernant le droit des affaires sont tout à fait concrètes et cohérentes et montrent bien l'élaboration de cette catégorie de droit pour résoudre les « conflits de lois » dans la pratique.

3. J. Fournier, Entre tutelle romaine et autonomie civique. L'administration judiciaire dans les provinces hellénophones de l'Empire romain (129 av. J.-C.-235 ap. J.-C.), p. 263-276. L'examen des cas sicilien, achaïen, asiate et lycien à l'époque républicaine montre toutefois des solutions provinciales diverses. Cf. aussi J. Fournier, "L'essor de la multicitoyenneté en Orient : problèmes juridiques et judiciaires », p. 79-98.

4. M. Kaser, Ius gentium, p. 4-5. Sans doute, la notion commence-t-elle à s'élaborer plus tôt, au contact entre Romains et Italiens, mais elle se développe dans de nouvelles directions, notamment pour le droit des affaires, à la fin de la République.

5. H. Cotton, «Private international law or Conflict of Laws : Reflections on Roman Provincial Jurisdiction», p. 236, suivant H.J. Wolff, Das Problem der Konkurrenz von Rechtsordnungen in der Antike, p. 66-68, qui juge la notion de ius gentium peu claire; voir aussi C. Ando, Law, Language, and Empire in the Roman Tradition, p. 29, qui estime que le ius gentium ne s'est vraiment appliqué qu'après 212: "Reflections on the content of ius gentium before the Antonine Constitution are empty shells ».

6. M. Kaser, Ius gentium, p. 125-127. 
Dans ce ius gentium romain, des contractants de citoyennetés et de droits divers pouvaient ainsi passer des contrats ensemble selon une forme souple de pactum ou contractus. La pensée juridique reconnaissait en effet que, pour les besoins des affaires, bien des contrats ne devaient pas suivre un formalisme dépassé7. La seule chose qu'exigeait le droit romain de ces contrats était qu'ils soient de nature consensuelle, c'est-à-dire que les deux parties aient communiqué leur accord. Ainsi, les contrats de société, de prêt, de mandat, de location ou de vente, qui répondaient aux critères du ius gentium, étaient dits simplement établis "par consensus » puisqu'aucune forme fixe, orale ou écrite, n'était exigée d'eux. Gaius, sans doute le plus attentif des juristes aux différents droits de l'Empire ${ }^{8}$, distingue ainsi les quatre manières de créer l'obligation par contrat: chez les Grecs, le document écrit, chez les Romains, les paroles échangées ou les choses consignées, et enfin, relevant du ius gentium, le seul consensus des parties ${ }^{9}$. Les juristes du Digeste ne disent pas autre chose. Paul affirme dans son commentaire sur l'édit du préteur: Locatio et conductio cum naturalis sit et omnium gentium, non uerbis, sed consensu contrahitur, sicut emptio et uenditio "comme la location et la conduction sont choses naturelles appartenant à tous les peuples, elles ne sont pas engagées par des paroles mais par le consensus, de même que l'achat et la vente » (Paul 34 ad ed. Dig. $19,2,1)$.

Aux yeux des juristes romains, l'obligation de l'acte ne résidait donc pas dans une forme précise, mais dans la seule bona fides des parties qui s'accordaient entre elles sur un objectif commun. Le consensus était marqué par l'échange oral du consentement des parties - la sollemnitas uerborum, l'obligatio uerborum ${ }^{10}$-, seul à même d'engager l'action en justice, l'écrit n'ayant valeur que de preuve ${ }^{11}$. L'accord prenait donc essentiellement forme au travers d'une interrogation des deux parties, le créancier ou le vendeur posant une question stipulatus est ou interrogatus est et le débiteur ou l'acheteur répondant ... spopondi. Dans les archives des Sulpicii de Pouzzoles, on trouve cette formule dans les contrats de mandat ${ }^{12}$, de prêt ${ }^{13}$, de caution en cas de citation à comparaître (uadimonium) ${ }^{14}$; en revanche, les contrats de location ne sont pas concernés. La même formule se lit aussi dans les tablettes de Dacie pour les contrats d'achat-vente ${ }^{15}$ ou de société, mais toujours pas pour les contrats de location du

7. Pour cela, voir S. Riccobono, Stipulation and the theory of contract, p. 109-122.

8. H. Lewald «Conflits de lois dans le monde grec et romain», p. 617 ; voir aussi les commentaires de M. Kaser, Ius gentium, p. 115-118 sur le droit des obligations chez Gaius.

9. Gaius Inst. III, 89, CUF, éd et trad. J. Reinach : Et prius uideamus de his [obligationibus], quae ex contractu nascuntur. Harum autem quattuor genera sunt; aut enim re contrahitur obligatio, aut uerbis aut litteris aut consensu. "Et voyons d'abord ce qui a trait à ces obligations qui naissent d'un contrat. Elles sont de quatre genres : l'obligation se contracte par prestation, verbalement, par écrit ou par consensus».

10. Sur la solemnitas uerborum, on a plusieurs textes qui le rappellent: Paul, Sent. V, 7, 1 ; Inst. III, 15 (où l'on admet tout de même l'assouplissement des formules); CI IV, 64, 3 (stipulatio subiecta ex uerborum obligatione). Pour d'autres références, voir encore S. Riccobono, Stipulation and the theory of contract, p. 43-44. Pour le maintien - non pérennedes principes du droit privé romain par Dioclétien, voir M. Kaser, Das römische Privatrecht, II, (Munich, 1959), p. 3 et p. 274 (pour l'obligation de solemnitas uerborum dans la stipulatio).

11. S. Riccobono, Stipulation and the theory of contract, p.41-42, a dressé la liste des passages des Prudents qui le rappellent. Cf. Dig. 44, 7, 38 Paul 3 ad edictum : non figura litterarum sed oratione, quam exprimunt litterae, obligamur ; Dig. 46, 2, 2.

12. TPSulp. 48-49.

13. TPSulp. 50-59. Par exemple, en TPSulp. 51 (contrat de prêt de 37 ap. J.-C.), p. 2 et 3 : et ea sesterta (sic) decem millia $<q(u a e)>s($ upra $)$ s(cripta) s(unt), p(roba) r(ecte) d(ari) stipulatus [[ets]] est Hessychus Eueni Ti(berii) Cessaris Augusti l(iberti) Primiani ser(uus), spepodi (sic) ego C(aius) Nouius Eunus «Et les dix mille sesterces mentionnés ci-dessus, Hésychus esclave d'Evenus Primianus, affranchi de Tibère César Auguste, a stipulé qu'ils lui soient donnés de bon aloi selon le droit, et moi C. Novius Eunus j'ai promis ».

14. TPSulp. 1-21.

15. CIL III, p. 937 (TC VI : contrat, daté de 139 ap. J.-C., d'achat d'une petite esclave) ; CIL III, p. $940=$ FIRA III' ${ }^{2}$, n. 88 (TC VII ; contrat, daté de 142, d'achat d'un enfant) ; CIL III, p. 944 (TC VIII ; contrat, daté de 159, d'achat d'une moitié de maison); CIL III, p. 959 (TC XXV : contrat, daté de 160, d'achat d'une esclave). Voir à leur sujet l'étude de G. Ciulei, Les triptyques de Transylvanie (Études juridiques). 
travail, pourtant placés dans la même catégorie des contrats consensuels par les juristes du III siècle $^{16}$.

En dehors du problème précis de la locatio-conductio, on voit que la réflexion jurisprudentielle a adapté la vieille formule des contrats oraux de prêt, la fameuse stipulation, à tout type d'interrogation contractuelle et a ainsi affaibli considérablement le formalisme des anciens contrats oraux, en concédant que les pérégrins pouvaient même "stipuler ", c'est-à-dire passer une interrogation dans un contrat, en utilisant une autre langue que le latin. Gaius affirme ainsi qu'un Latin peut répondre à une question en grec ; et un Grec répondre à une question posée en latin, du moment bien entendu - et c'est le principe du consensus qui joue là - que les contractants se comprennent ${ }^{17}$; Ulpien ne dit pas autre chose :

«Il n'importe pas que la réponse se fasse dans la même langue ou dans une autre. Ainsi, si un homme a posé l'interrogation en latin et qu'on lui réponde en grec, l'obligation est constituée du moment que la réponse est congruente. ${ }^{18}$

Notons que les seules langues données en exemple sont le grec et le latin. Cela ne peut surprendre, puisque ce sont les deux langues officielles du Haut Empire, pour les deux parties de l'Empire. Et l'on va voir tout de suite que les actes de pratique n'en connaissent en effet pratiquement aucune autre à partir de l'époque flavienne, après un siècle d'élimination progressive des langues vernaculaires dans les contrats.

Ces principes posés, nous pouvons maintenant interroger les actes de la pratique pour voir s'ils se sont adaptés à ce nouveau droit des contrats qui permettait une communication internationale.

\section{La langue des contrats, entrave ou accès à la communication?}

De façon liminaire, il faut reconnaître que nous manquons, hélas - à une exception près, que l'on regardera plus loin en détail - d'archives commerciales provenant des grandes zones romaines d'échange, notamment portuaires, où une population cosmopolite était précisément amenée à employer des langues diverses: on n'a gardé aucune trace des transactions des ports d'Alexandrie, de Cyzique ou d'Ostie. Dans la grande majorité des cas connus, les contrats sont conclus dans des régions où les échanges sont locaux ${ }^{19}$; ils sont donc souvent écrits dans une seule langue, laquelle n'est pas toujours, en réalité, la langue

16. U. Yiftach-Firanko, «Law in Graeco-Roman Egypt: Hellenization, Fusion, Romanization », p. 554, estime que la locatio-conductio et l'achat-vente sont des contrats consensuels en eux-mêmes et n'ont donc pas besoin de la clause stipulatoire. Pourtant, les misthoseis grecques ne sont pas des contrats consensuels (voir notamment H. J. Wolff, « Die Grundlagen des griechischen Vertragsrechts», p. 26-72). Et d'autre part, on a bien trace de contrats d'achat-vente pérégrins en Dacie - mais pas de location, il est vrai - qui contiennent la clause stipulatoire avant 212. Je ne crois donc pas à l'argument de l'auteur qui voudrait que la clause stipulatoire en Égypte ait été apposée aux contrats de location et d'achat-vente de façon irrégulière.

17. Gaius Inst. III, 92-93 : « les autres [formules] au contraire relèvent du droit des gens et par la suite créent des obligations valables entre tous les hommes, qu'ils soient citoyens romains ou étrangers; et même si elles sont

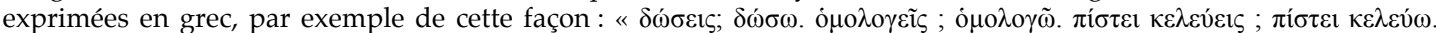

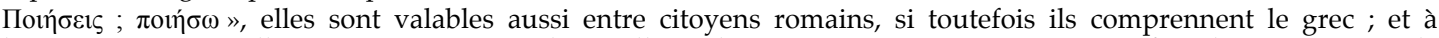
l'inverse, même si elles sont exprimées en latin, elles valent aussi entre étrangers, si toutefois ils comprennent le latin » (trad. J. Reinach).

18. Dig. 45, 1, 1, 6: Eadem an alia lingua respondeatur, nihil interest. Proinde si quis latine interrogauerit, respondeatur ei graece, dummodo congruenter respondeatur, obligatio constituta est.

19. L'article de G. Camodeca, "Il credito negli archivi campani : il caso di Puteoli e di Herculanum ", p. 69-98 (notamment p. 71), souligne bien la différence entre les archives provenant de marchés locaux, où dominent les transactions de vente et de location, et dont les tablettes d'Herculanum sont pour lui un bon exemple, et les archives venant de grandes zones cosmopolites, dont les tablettes des Sulpicii de Pouzzoles sont pour nous la trace unique. 
vernaculaire des contractants. Ainsi dans l'Orient sémitique et égyptien, surtout à partir des époques flavienne et antonine, l'écrasante majorité des contrats était écrite en grec, quand les langues d'usage restaient l'araméen, l'hébreu, l'égyptien. S'il existait encore au I $\mathrm{I}^{\mathrm{er}}$ siècle des

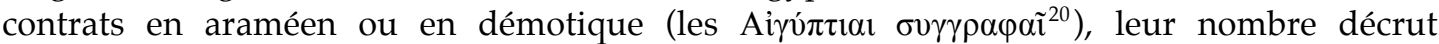
rapidement, suivant en cela d'ailleurs une évolution déjà entamée à la fin des royaumes hellénistiques: le contrat démotique le plus tardif retrouvé en Égypte date de 71 ap. J.-C ${ }^{21}$. Quant aux contrats retrouvés dans le désert de Judée, qui appartenaient à des Juifs d'Arabie réfugiés dans des grottes lors de la révolte de Bar Kochba, ils montrent que ces Juifs entrés tard dans l'empire, en 106, adoptèrent le grec immédiatement après la constitution de la province pour leurs transactions importantes (achats et locations, pétitions, affaires familiales). Avant la provincialisation, les contrats étaient rédigés dans la langue administrative mise en place par les Perses, l'araméen, l'hébreu n'étant qu'une langue utilisée de façon idéologique lors des sursauts du nationalisme juif, durant les grandes révoltes de 66 et de $132^{22}$.

En réalité, la situation est encore plus complexe, car les Romains ont aussi autorisé que les actes en grec soient souscrits en langue vernaculaire ou, à l'inverse, ont imposé, dès le début de la provincialisation, que les documents qui survivaient en langue locale aient obligatoirement une souscription originale en grec : Mark Depauw l'a bien démontré pour les contrats démotiques. On constate le même phénomène pour les contrats grecs d'Arabie, qui portent une souscription en araméen ou en nabatéen ou encore pour les documents grecs de $l^{\prime} E u p h r a t e$, datés du III $^{\mathrm{e}}$ siècle, qui ont une souscription en syriaque ${ }^{23}$. Ces contrats étaient en ce cas bilingues, pour les besoins de l'administration: quand l'acte était en langue vernaculaire, il était en effet enregistré avec une souscription en grec résumant les termes de l'accord et donnant valeur légale à l'acte. Cette souscription prit une forme de plus en plus élaborée, ce qui entraîna la réduction du document en langue vernaculaire, jusqu'à sa disparition. La question du moment de la disparition des langues vernaculaires dans l'écriture des contrats fait encore débat. Naphtali Lewis estimait que la fin du démotique et celle de l'araméen étaient concomitantes et s'expliquaient par les exigences romaines; Hannah Cotton a récemment souligné pour sa part l'importance des lacunes documentaires et plaidé pour la continuité des droits et usages locaux, au moins oraux, rappelant qu'en Syrie, à la frontière parthe, l'usage du syriaque documentaire était encore attesté au début du III siècle. Toutefois l'exemple des papyrus et parchemins de Doura et du Moyen Euphrate n'est peut-être pas très significatif, la région étant occupée depuis peu par Rome. Si une partie des coutumes et droits locaux a peut-être survécu jusque dans l'Antiquité tardive à la romanisation du droit provincial, notamment en matière de droit des personnes et des familles, les langues supports de ces contrats se sont, elles, bien éteintes, ne survivant peutêtre que le temps que les générations de scribes locaux passent aux usages nouveaux ${ }^{24}$. Les souscriptions en langue vernaculaire ont toutes été poursuivies, en revanche, jusqu'au début du III $^{\mathrm{e}}$ siècle.

20. Voir ainsi la souscription en grec du P. Mich. V347 (contrat alimentaire démotique provenant de Tebtynis et datant de 21 ap. J.-C.).

21. Voir M. Depauw, "Autograph confirmation in Demotic private contracts ", notamment p. 89-97 ; M. Depauw, "Language use, literacy, and bilinguism », p. 494, qui insiste aussi sur le déclin du démotique comme langue unique des contrats dès le $\mathrm{I}^{\mathrm{er}}$ siècle av. J.-C. et sur la croissance parallèle des contrats bilingues.

22. Voir les importantes remarques de H. Cotton, « The Languages of the Legal and Administrative Documents from the Judaean Desert », p. 219-231 ; S. Schwartz, «Language, power and identity in Ancient Palestine », p. 3-47.

23. Voir surtout les P. Euphrat. provenant du moyen Euphrate et édités par J. Gascou et D. Feissel.

24. N. Lewis, «The demise of the Demotic document: when and why », p. 276-281 et N. Lewis, "The demise of the Aramaic Document in the Dead Sea Region", p. 179-181; contra H. Cotton, "Continuity of Nabataean law in the Petra papyri : a methodological exercise », p. 154-174, qui apporte les preuves de la perpétuation de documents en langue araméenne ou syriaque pendant des siècles : P. Dura 28 (243 ap. J.-C., contrat d'achat d'une esclave en syriaque avec quelques signatures de témoins en grec); mais à ce propos, voir nos remarques ci-dessus. 
Les Romains ont donc bien imposé en Orient le grec comme langue véhiculaire et poussé à l'adoption des formes contractuelles grecques, malgré la survivance de quelques coutumes locales en matière de succession ou de mariage ${ }^{25}$. Deux raisons à cela : d'une part, on l'a dit, l'obligation imposée par l'administration à faire traduire une partie de l'accord, ce qui a poussé à l'abandon de deux rédactions distinctes sans doute plus coûteuses pour les contractants ; d'autre part, le désir des provinciaux eux-mêmes de voir leurs documents bien reçus dans les cours de justice ${ }^{26}$. On verra que l'adoption de formulaires romains s'explique de la même façon.

L'imposition de ces langues véhiculaires a entraîné paradoxalement une augmentation de l'«illettrisme» des contractants; comme Herbert Youtie l'a bien montré, les formules agrammatos ou mè eidôs grammata écrites dans les souscriptions des actes égyptiens rappelaient en fait, dans la plupart des cas, l'absence de maîtrise de l'écriture de la langue véhiculaire, certains contractants étant tout à fait capables, comme ils le rappellent euxmêmes, d'écrire en démotique ${ }^{27}$. Dans le $P$. Gen. 30 , où est enregistrée la vente d'un âne en 140 ap. J.-C., la personne qui écrit rappelle :

"J'ai écrit pour lui car il ne sait pas les lettres, sinon les égyptiennes »

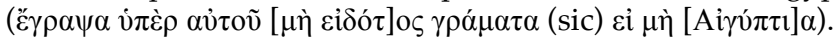

Le « bi-lettrisme » était en effet beaucoup moins répandu que le bilinguisme oral. Quant à la compréhension orale du grec, elle s'est répandue du fait de la disparition de la langue vernaculaire écrite et des besoins professionnels des contractants, tout en restant globalement assez médiocre ${ }^{28}$. À l'oral, les contractants pouvaient donc s'entendre dans la langue vernaculaire, mais ils devaient confier aux notaires ou aux scribes la traduction de leur accord; la souscription elle-même, si elle était en grec, était prise en charge par un souscripteur parfois distinct du scribe (l'hypographeus) et toujours homme de confiance. Herbert Youtie a d'ailleurs rassemblé un petit dossier de disputes autour des problèmes de rédaction : contractant profitant de l'«illettrisme » de l'autre partie pour falsifier les pièces d'un dépôt $t^{29}$; réclamation de prêt auprès de débiteurs contestant l'acte et sa souscription ; instructions orales mal enregistrées par écrit, dont témoigne aussi la novelle 44 de Justinien.

En somme, en imposant peu à peu les langues véhiculaires pour les actes de la vie des affaires, les Romains ont parfois entravé la communication entre contractants, qui devaient recourir à des tiers lettrés de confiance pour s'assurer que la traduction de l'accord suivît bien leur pensée. Dans ces zones d'échanges d'échelle régionale ou locale, le problème qui se posait à l'administration romaine n'était pas vraiment la communication entre parties contractantes, qui se faisait bien à l'oral, mais plutôt la communication de l'accord aux bureaux compétents et son archivage. Loin de l'insistance romaine sur l'importance du consensus des parties, ces contrats locaux demeuraient seulement des preuves écrites et des reconnaissances unilatérales de la transaction ${ }^{30}$; beaucoup d'entre eux, d'ailleurs, relevaient

25. H. Cotton, "Continuity of Nabataean law in the Petra papyri : a methodological exercise », p. 154-174, a sans doute raison de chercher des pratiques nabatéennes dans les affaires de succession dévoilées par les $P$. Petra ( $\mathrm{VI}^{\mathrm{e}}$ siècle). Mais ici, $\mathrm{c}^{\prime}$ est le droit des obligations et des contrats qui nous intéresse, et en cette matière, $\mathrm{c}^{\prime}$ est bien le droit gréco-romain et la langue grecque qui l'ont emporté.

26. H. Cotton, « The Languages of the Legal and Administrative Documents from the Judaean Desert », p. 230.

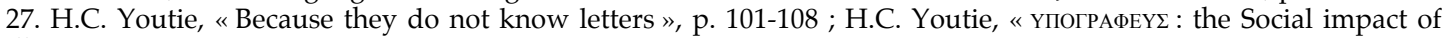
illiteracy in Graeco-Roman Egypt », p. 201-221.

28. M. Depauw, "Language use, literacy, and bilinguism », p. 494-499, est un tableau récent de la littérature sur la question. Tous les spécialistes estiment que, dans leur majorité, les Égyptiens ne maîtrisaient le grec que pour un usage purement professionnel. L'apparition du copte marque bien la résurgence de la langue parlée dans la littérature.

29. Voir par exemple P. Oxy. I 71, col. 1, 1. 10-11, datant du début du IV siècle ap. J.-C.

30. Toute une littérature allemande a démontré, de façon convaincante, que les contrats grecs en général, et ceux conservés en Égypte en particulier, n'étaient pas des contrats consensuels : voir notamment H. J. Wolff, «Consensual 
encore du droit local, grec ou égyptien, et non du ius gentium, ne s'étant pas adaptés aux formulaires romains essentiels. En tout cas, en permettant, pendant des périodes de longue transition, la pratique de contrats bilingues, Rome a de fait rompu avec le principe hellénistique d'adéquation stricte entre le droit et la langue du contrat.

Les cas de bilinguisme que nous venons d'évoquer ne relèvent donc pas de la casuistique établie par les prudents; en revanche, on devait bien trouver dans les grandes zones commerciales de l'Empire des contrats où les négociants communiquaient dans leurs deux langues ou tout au moins dans les langues véhiculaires qu'ils maîtrisaient. Un seul acte se rapproche de ces cas et il provient précisément des archives des financiers Sulpicii établis dans le grand port romain de Pouzzoles. Il s'agit de la tablette 78, dans l'édition de Guisepe Camodeca, acte bilingue composé de deux chirographes, l'un grec, l'autre latin. Le document date de 38 ap. J.-C. ; il est bilingue au sens où il est rédigé dans les langues des deux participants de l'accord, mais il ne témoigne pas en réalité de leur bilinguisme; il renseigne au contraire sur le fait que chacun a voulu écrire ou faire écrire dans sa langue.

Le texte du contrat ne relève donc pas des cas de bilinguismes mentionnés par les juristes Gaius ou Paul; il ne s'agit d'ailleurs pas à proprement d'un accord commercial, mais simplement d'une quittance accompagnant une naulotikè grecque, contrat de transport ou assurance maritime en forme de prêt fictif $-c^{\prime}$ est encore disputési. Le naviculaire grec Ménélas originaire de Keramos de Carie, y reconnaît avoir reçu 1000 deniers de l'esclave d'un négociant romain en huile dans le cadre d'un contrat grec. Ménélas écrit alors un chirographe de forme assez romaine, traduisant dans un Grec typique de la koinè les contrats

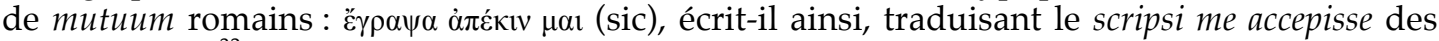
contrats latins ${ }^{32}$. Son fideiussor pouzzolan, quant à lui, signe sa garantie en latin, en la faisant écrire d'ailleurs par un de ses amis car il ne sait pas les lettres. Comme l'a souligné Giuseppe Camodeca, le texte est d'un type juridique mixte ne correspondant ni aux contrats grecs, ni aux contrats romains traditionnels : il adopte en partie la forme du chirographe latin des contrats de prêt en en traduisant certains termes, mais en en laissant d'autres de côté ${ }^{33}$ et surtout en négligeant d'écrire la formule consensuelle fondamentale pour la validité d'un contrat romain ; il n'y a pas interrogation des deux parties mais reconnaissance unilatérale du débiteur accompagné de son garant.

Le bilinguisme de ce contrat témoigne là de la mixité du droit, au sens d'une " coexistence » et d'une «combinaison» des droits ${ }^{34}$ dans une grande zone portuaire antique où les commerçants étaient d'origine extrêmement diverse. Ce document unique informe donc sur les processus d'adaptation des Romains et pérégrins à la diversité des droits, sans que pour autant les solutions trouvées cadrent parfaitement avec les données jurisprudentielles plus tardives.

Un dernier cas tout à fait particulier et propre au contexte italien se trouve dans les archives du banquier Caecilius Jucundus de Pompéi. Il s'agit de deux chirographes écrits en latin mais

contracts in the Papyri?», p. 55-79 ; H. J. Wolff, «Die Grundlagen des griechischen Vertragsrechts », p. 26-72 ; H.

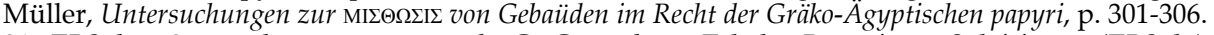

31. TPSulp. 78 avec le commentaire de G. Camodeca, Tabulae Pompeianae Sulpiciorum (TPSulp), edizione critica del archivio puteolano dei Sulpicii, p. 178-179; G. Camodeca, «Il credito negli archivi campani: il caso di Puteoli e di Herculanum », p. 88-90 ; A. Tchernia, Les Romains et le commerce, p. 340-345.

32. Formule que l'on trouve notamment dans les documents de la même archive : les contrats de prêt avec formule stipulatoire TPSulp. 50-59.

33. Voir G. Camodeca, «Il credito negli archivi campani : il caso di Puteoli e di Herculanum », p. 88-89 : et debere est ainsi absent après me accepisse, ce qui peut s'expliquer en cas d'assurance maritime ou de prêt fictif ; ensuite il manque à cette reconnaissance la formule stipulatoire typique des contrats de prêt.

34. Je reprends là les termes de Tinziana Chiusi dans son article sur les aspects légaux des archives de Babatha: T. Chiusi «Babatha vs. the guardians of her son : a struggle for guardianship - legal and pratical aspects of $P$. Yadin 12$15 ; 27 »$, p. $105-132$. 
dont l'une des pages, la page 5, est en lettres grecques. Ces deux tablettes, les Tab. 32 et $136^{35}$, toutes deux d'époque néronienne, sont sans doute écrites de la même main. Si l'usage de la transcription est souvent le signe de la marginalité et du déclin pour la langue ainsi transcrite dans une langue dominante et internationale, cet usage proprement italien des transcriptions du latin en grec, dans deux langues dominantes de l'époque, s'explique de différentes façons selon les $\operatorname{cas}^{36}$. Dans ces tablettes, on ne saurait voir l'étalage d'une revendication culturelle comme on l'a soutenu pour les inscriptions funéraires, mais plutôt le cas d'un homme alphabétisé en grec et dont le latin est devenu la langue d'usage.

Ce phénomène de transcription extrême est tout à fait singulier et nous ne devons guère nous $\mathrm{y}$ attarder face à un phénomène beaucoup plus massif dans les contrats pérégrins orientaux, celui de la transcription ou de la traduction des termes ou formules du droit romain dans les contrats grecs.

\section{Adaptations diplomatiques : la clause consensuelle des contrats grecs}

L'introduction d'un formulaire romain dans les accords de type grec se voit par différents aspects: transcription de mots administratifs latins, et surtout traduction des formules romaines essentielles à l'adéquation avec les principes du droit romain.

On a vu que les contrats consensuels romains mettaient comme seule condition à la validité de l'accord le fait qu'il soit conclu par une formule d'interrogation mutuelle, dite stipulatoire, formée sur le modèle des vieux contrats de prêt romains, mais désormais appliquée à tous types de contrats ${ }^{37}$.

Or, les syngraphai ou chirographes grecs, contrats où l'écrit seul était source d'obligation et élément de preuve, n'avaient jamais été de vrais contrats consensuels et ne le devinrent pas plus sous l'Empire, on l'a vu ${ }^{38}$. Quand ils ne s'adaptèrent pas au système juridique romain, ces documents demeurèrent donc sans doute en dehors des règles du ius gentium. En revanche, les contrats que leurs auteurs voulaient intégrer au système romain pour qu'ils puissent être produits dans les tribunaux des gouverneurs de province, subirent une légère modification des formules finales. Les premiers contrats désormais connus sont les papyrus du désert de Judée datés de 128-131 ${ }^{39}$. La formule grecque, avec de légères variantes, est la

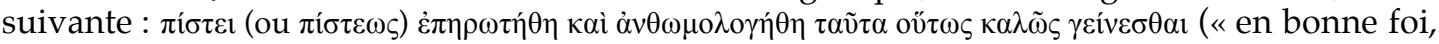
la question formelle a été posée et il a été répondu que tout était bien ainsi »). La pistis grecque traduit ici le concept essentiel de la bona fide; on en trouve d'ailleurs la traduction

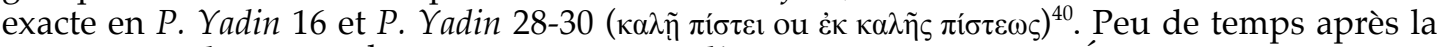
constitution de cette archive, on a aussi trace d'un contrat retrouvé en Égypte mais provenant de Sidè en Pamphylie et concernant la vente d'une petite esclave en 142 ap. J.-C. (P. Turner

35. CIL IV, Suppl. I, éd. K. Zangemeister, tab. 32 (datée de 57 ap. J.-C.), pag. 5, p. 322; tab. 136, pag. 5, p. 381.

36. Voir l'article important de J.J. Price et S. Naeh, «On the margins of culture : the practice of transcription in the ancient world», p. 257-288, notamment p. 272-274 (pour les inscriptions latines transcrites en grec). Les auteurs rappellent que ce phénomène se limite à l'Italie et se retrouve dans quelques dizaines d'épitaphes et dans quelques papyrus et contrats.

37. Pour la clause stipulatoire, voir S. Riccobono, Stipulation and the theory of contract, notamment p. 18-20 ; D. Simon, Studien zur Praxis der Stipulationsklausel, pour sa signification et son évolution ; M. Kaser, Das römische Privatrecht, II,

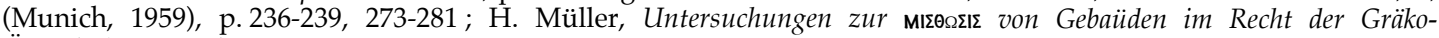
Ägyptischen papyri, p. 44-46.

38. Gaius Inst. III, 134, CUF, éd et trad. J. Reinach : Praeterea litterarum obligatio fieri uidetur chirographis et syngraphis, id est si quis debere se aut daturum se scribat... Quod genus obligationis proprium peregrinorum est. "Une obligation naît aussi, semble-t-il, par écrit, du fait de chirographes et de syngraphai, c'est-à-dire d'écrits par quoi on reconnaît une dette actuelle ou future ; ce genre d'obligations est propre aux pérégrins ".

39. P. Yadin 17-18, 20-22, 37. Voir à leur propos E. Meyer, «Diplomatics, Law and Romanisation in the Documents from the Judaean Desert », p. 53-82.

40. P. Yadin, papyrus grecs, introduction de N. Lewis, p. 17-18. 
22). Les contractants sont un dénommé Pamphilos, fils d'Aegyptos, un Alexandrin sans

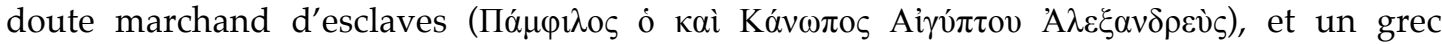
Artémidore fils d'Aristoklès. Le contrat ressemble beaucoup aux contrats d'achats d'enfants esclaves en Dacie. Dans les papyrus d'Égypte, en revanche, cette clause devint systématique seulement après 212 ; il ne semble pas qu'elle ait été introduite avant: une recherche de la clause stipulatoire dans les bases de données recensant tous les papyrus égyptiens édités montre que, sur quelque 1280 cas répertoriés pour l'époque tardive, seuls quatre cas seraient à placer avant 212 ; toutefois, dans ces quatre cas, la formule est restituée dans une lacune : aussi cette restitution a-t-elle été contestée récemment pour les quatre papyrus ${ }^{41}$. Ainsi, l'apparition de cette clause est bien une rupture majeure en Orient, à mettre en lien avec la concession de la citoyenneté. Comme en Égypte, les actes syriens de l'Euphrate, provenant de Doura Europos ou du Moyen Euphrate ${ }^{42}$, contiennent d'ailleurs aussi systématiquement cette formule au $\mathrm{III}^{\mathrm{e}}$ siècle. Ainsi, peu après 212 , et malgré des variantes régionales assez nettes $^{43}$, la formule est utilisée universellement dans les contrats grecs.

Ce changement formulaire a paru à certains savants comme étant uniquement de façade ${ }^{44}$; il est cependant très net : la généralisation de la stipulation a fait entrer, sans discussion, tous les contrats grecs et indigènes dans la forme des contrats consensuels. La clause sert assurément à légaliser les contrats - elle accompagne en effet la formule kuria è homologia ou kurion to sunallagma ${ }^{45}$ - et ce, jusqu'à la période arabe. Elle se retrouve en effet dans des contrats coptes très tardifs jusqu'au VIII ${ }^{\mathrm{e}}$ siècle, la formule classique ne disparaissant que vers $710 / 720$ au profit d'une autre, au moment précis où les chefs de village gréco-égyptiens viennent à être remplacés comme arbitres par des administrateurs arabes ${ }^{46}$.

41. P. Michael 9 ; P. Eirene I 4 ; P. Harr. I 66 ; P. Princ. III 177. Voir, pour la contestation des restitutions : D. Simon, Studien zur Praxis der Stipulationsklausel, p. 3 (jugeant impossible la restitution de P. Princ. III 177) ; C. Armoni et Th. Kruse, "Papyri editae in memorian W. Brashear, II », p. 169-170, rejetant la restitution pour les quatre papyrus. Pour le P. Harr. I, 66, la restitution avait déjà été rejetée dans BL VII, 67. Cf. N. Gonis, « Notes on Miscellaneous Documents II », p. 205-207.

42. Voir par ex P. Dura 26 et 29 (227 et 251 ap. J.-C.) et P. Euphrat. 6-10.

43. Tous les contrats grecs tardifs d'Égypte se concluent par la formule : $\dot{\varepsilon} \pi \varepsilon \rho(\omega \tau \eta \theta \varepsilon \grave{\varsigma}) \dot{\omega} \mu(\mathrm{o} \lambda \hat{\gamma} \gamma \eta \sigma \alpha)$ «ayant été interrogé, je m'y suis engagé ». La formule diffère un peu des variantes d'Arabie, de l'Euphrate ou d'Asie Mineure ; notamment, elle ne rappelle presque jamais, sauf en quelques contrats de l'Oxyrhynchite au III siècle, l'identité des interlocuteurs, mais use, de façon stéréotypée, du seul aoriste passif pour l'interrogation. Voir D. Simon, Studien zur Praxis der Stipulationsklausel, p. 15-16 et pour les exceptions en Oxyrhynchite : P. Oxy. VII 1040 ; contrat de prêt de 225

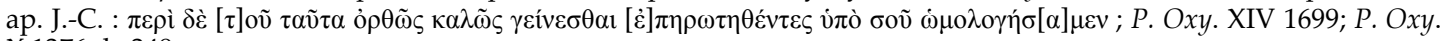
X 1276 de 249.

44. A. Jördens, Vertragliche Regelungen von Arbeiten im späten griechischsprachigen Ägypten (=P. Heid. V), 373-374, ne croit pas du tout à une romanisation des contrats grecs à l'époque tardive.

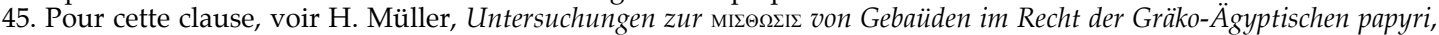
p. 41-44 (elle sert, jusqu'à l'époque byzantine, à authentifier les actes).

46. W. Till, « Die koptische Stipulationsklausel », p. 81-87. 
Il est assez difficile de comprendre pourquoi des pérégrins comme la juive Babatha ou les contractants alexandrins et pamphyliens de Sidè ont ressenti le besoin d'utiliser la clause stipulatoire, au moment où tous les commerçants et habitants d'Égypte n'y recouraient pas. Était-ce dû aux édits des gouverneurs édictant des règles du droit différentes pour chaque province ? C'est possible, tant il est difficile de comprendre que des Juifs d'Arabie tout juste provincialisés recourent si vite à des formules si romaines.

Ces adaptations furent donc, on le voit, irrégulières géographiquement et chronologiquement. La plupart des Égyptiens s'accommodèrent fort bien de leur droit propre jusqu'à ce qu'ils devinssent citoyens romains, quoique l'administration, en marginalisant peu à peu les langues vernaculaires, n'ait guère favorisé, contrairement aux principes affirmés, la communication aisée entre contractants.

Mais l'on peut penser que dans les grandes zones d'échanges, le besoin de communication poussa plus rapidement à adopter des formulaires romains, qui permettaient en une petite phrase l'échange des consentements et leur validation auprès de l'administration.

\section{Résumé}

La réflexion romaine sur les contrats d'affaires (prêts, mandats, louage, achat-vente) montre combien les juristes d'époque impériale étaient soucieux d'offrir aux Romains et aux provinciaux un cadre légal large et souple favorisant des accords commerciaux : les contractants pouvaient en effet ne pas parler les mêmes langues, ne pas dépendre des mêmes droits, mais cela ne les empêchait pas de souhaiter entrer en accord pour régler des affaires communes.

En créant la catégorie du ius gentium, les juristes romains firent entrer ces contrats dans le genre des contrats dits "consensuels », dont la forme n'était précisément pas déterminée : les juristes estimaient même, à l'encontre du formalisme romain traditionnel, que ces contrats pouvaient être bilingues (latin/grec) pour favoriser la communication entre contractants.

En interrogeant les actes de la pratique, ces contrats grecs et latins sur papyrus et tablettes qui nous sont parvenus d'Italie et des provinces grecques et latines de l'Empire, nous confrontons ici les principes jurisprudentiels aux usages courants. Cette recherche sur les actes de la pratique montre que jusqu'à la concession de la citoyenneté romaine à tous, en 212 ap. J.-C., bien des contrats locaux, qui n'étaient pas de grands accords commerciaux mais de petites transactions foncières ou mobilières, sont restés, surtout en Égypte, hors du cadre du ius gentium et des contrats consensuels. Quelques pérégrins orientaux adoptèrent néanmoins les principes romains pour les besoins de leurs affaires, en intégrant des formules romaines à leurs contrats grecs. Ces actes orientaux étaient en effet écrits essentiellement en grec, les Romains imposant cette langue comme langue véhiculaire au détriment des langues locales qui disparurent en quelques générations de tous les contrats, en Égypte, en Judée ou ailleurs. En revanche, dans la grande zone portuaire et cosmopolite de Pouzzoles, une quittance de prêt rappelle davantage les textes des juristes romains, par son bilinguisme latin/grec et par une certaine adéquation au droit romain. On voit donc que l'adaptation aux principes romains des contrats a été très irrégulière géographiquement et chronologiquement, jusqu'à ce que l'édit de Caracalla romanise définitivement les contrats de tous les provinciaux. 


\section{Bibliographie}

ANDO ClifFORD, Law, language, and empire in the Roman tradition, Philadeplhia, 2011.

ARMONI Charikleia et KRUSE Thomas, "Papyri editae in memorian W. Brashear, II », ZPE 140, 2002, p. 165-176.

CAMODECA Giuseppe, Tabulae Pompeianae Sulpiciorum (TPSulp), edizione critica del archivio puteolano dei Sulpicii, Rome, 1999.

CAMODECA Giuseppe, «Il credito negli archivi campani : il caso di Puteoli e di Herculanum », dans LO CASCIO Elio (dir.), Credito e moneta nel mondo romano, Bari, 2003, p. 69-98.

CHIUSI Tiziana, «Babatha vs. The guardians of her son : a struggle for guardianship - legal and pratical aspects of P. Yadin 12-15; 27 », dans KATZOFF Ranon and SCHAPS David (dir.), Law in the Documents of the Judaean Desert, Leiden-Boston, 2005, p. 105-132.

CiUleI Georghe, Les triptyques de Transylvanie (Études juridiques), Zurphen, 1983.

COTTON Hannah, «Private International Law or Conflict of Laws : Reflections on Roman Provincial Jurisdiction », dans HAENSCH Rudolf et HEINRICHS Johannes (dir.), Herrschen und Verwalten. Der Alltag der römischen Administration in der Hohen Kaiserzeit, Köln, 2007, p. 234255.

COTTON Hannah, "The Languages of the Legal and Administrative Documents from the Judaean Desert », ZPE 125, 1999, p. 219-231.

COTTON Hannah, "Continuity of Nabataean law in the Petra papyri : a methodological exercise » dans COTTON Hannah (dir.), From Hellenism to Islam. Cultural and Linguistic Change in the Roman Near East, Cambridge, 2009, p. 257-288.

DEPAUW Mark, "Autograph confirmation in Demotic private contracts », CdE 155, 2003, p. 66-111.

DEPAUW Mark, "Language use, literacy, and bilinguism», dans RIGGS Cristina (dir.), The Oxford Handbook of Roman Egypt, Oxford, 2012, p. 493-506.

FOURNIER Julien, Entre tutelle romaine et autonomie civique. L'administration judiciaire dans les provinces hellénophones de l'Empire romain (129 av. J.-C.- 235 ap. J.-C.), Athènes, 2010.

FOURNIER Julien, «L'essor de la multi-citoyenneté en Orient: problèmes juridiques et judiciaires", dans HELlER Anna et PONT Anne-Valérie (dir.), Patrie d'origine et patries électives : les citoyennetés multiples dans le monde grec d'époque romaine, Bordeaux, 2012, p. 79-98.

GONIS Nikolas, « Notes on Miscellaneous Documents II », ZPE 154, 2005, p. 205-207.

JÖRDENS Andreas, Vertragliche Regelungen von Arbeiten im späten griechischsprachigen Ägypten (=P. Heid. V), Heidelberg, 1990.

KASER Max, Das römische Privatrecht, II, Munich, 1959.

KASER Max, Ius gentium, Köln, 1993. 
LEWALD Hans, "Conflits de lois dans le monde grec et romain", Revue critique de droit

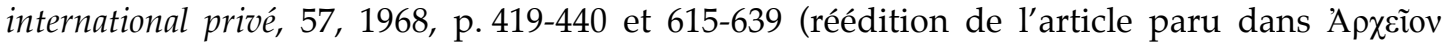

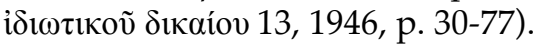

LEWIS Naphtali, "The demise of the Demotic document: when and why », JEA 79, 1993, p. 276-281 (repris dans LeWIS Naphtali, On Government and Law in Roman Egypt: collected papers on Naphtali Lewis, Amsterdam-Toronto, 1995, p. 351-356).

LEWIS Naphtali, "The demise of the Aramaic Document in the Dead Sea Region », SCI 20, 2001, p. 179-181.

MeYer Elisabeth, «Diplomatics, Law and Romanisation in the Documents from the Judaean Desert ", dans CAIRNS John and Du PLESSIS Paul, Beyond Dogmatics. Law and Society in the Roman World, Édimbourg, 2007, p. 53-82.

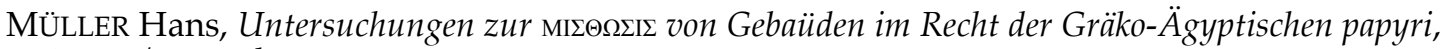
Cologne/Munich, 1985.

NAEH Schlomo et PRICE Jonathan, "On the margins of culture : the practice of transcription in the ancient world", dans COTTON Hannah (dir.), From Hellenism to Islam. Cultural and Linguistic Change in the Roman Near East, Cambridge, 2009, p. 257-288.

RicCOBONO Salvatore et alii, Stipulation and the theory of contract, Amsterdam-Cape Town, 1957, (engl. trans. with further notes and introduction of RicCOBONO Salvatore, 'Stipulatio ed instrumentum nel Diritto giustinianeo', ZSS RA 35 (1914), 214-305 et 47 (1922), 262-397).

SCHWARTZ Seth, «Language, power and identity in Ancient Palestine », Past and Present 148, 1995, p. 3-47.

SIMON Dieter, Studien zur Praxis der Stipulationsklausel, Munich, 1964.

TCHERNIA André, Les Romains et le commerce, Rome-Naples, 2011.

TILL Walter, « Die koptische Stipulationsklausel », Orientalia, 19, 1950, p. 81-87.

WolfF Hans Julius, Das Problem der Konkurrenz von Rechtsordnungen in der Antike, Heidelberg, 1979.

WOLFF Hans Julius, « Consensual contracts in the Papyri ? », JJP 1 (1946), p. 55-79.

WOLFF Hans Julius, « Die Grundlagen des griechischen Vertragsrechts », ZSS 74 (1957), 26-72.

YIFTACH-FIRANKO Uri, "Law in Graeco-Roman Egypt: Hellenization, Fusion, Romanization », dans BAGNALl Roger (dir.), The Oxford Handbook of Papyrology, Oxford, 2009, p. 541-560.

YOUTIE Herbert, « Because they do not know letters », ZPE 19, 1975, p. 101-108.

YOUTIE Herbert, « ҮПОГРАФЕҮ : the Social impact of illiteracy in Graeco-Roman Egypt », ZPE 17, 1975, p. 201-221. 


\section{Les mutations de l'identité dans la cité de Nîmes à l'époque romaine (I ${ }^{\text {er }}$ siècle av. J.-C. - III siècle ap. J.-C.)}

Michel CHRISTOL

Professeur émérite à l'Université de Paris-I École antique de Nîmes

\footnotetext{
Extrait de : Guylaine BRUN-TRIGAUD (dir.), Contacts, conflits et créations linguistiques, Paris, Édition électronique du CTHS (Actes des congrès des sociétés historiques et scientifiques), 2015.

Cet article a été validé par le comité de lecture des Éditions du CTHS dans le cadre de la publication des actes du $139^{\circ}$ Congrès national des sociétés historiques et scientifiques tenu à Nîmes en 2014.
}

L'intégration de la région dans l'Empire romain, qui s'accentue à partir de la fin du $\mathrm{II}^{\mathrm{e}}$ siècle av. J.-C., met en contact la langue du monde indigène, une variante du celtique, et le latin, la langue de l'État qui imposait sa présence et sa prépondérance. C'est alors que le peuple des Volques Arécomiques, défini comme une « confédération ${ }^{1}$, réunissant une variété de communautés ayant conscience d'une unité qui s'exprimait au moins par le rôle de «métropole » attribué à Nîmes, passa peu à peu de l'influence marseillaise, qui s'estompait progressivement vers l'Ouest lorsqu' on dépassait la région d'Agde, sous l'autorité de la puissance romaine. L'effacement de Marseille est brutal à partir de la guerre civile et de l'échec de cette cité face à César en 49 av. J.-C. Mais dès la fin du II siècle, peut-être même avant, la puissance romaine (dans le domaine politique) et la puissance italienne (dans le domaine de l'économie et des rapports sociaux) étaient devenues plus marquantes. Le peuple des Volques Arécomiques et Nîmes, grande ville indigène qui jouait un rôle politique et religieux ${ }^{2}$, était entraîné dans un horizon plus large. Et dans ce nouvel horizon, la langue latine tenait un rôle essentiel.

Antérieurement s'était diffusée, en incluant la zone arécomique, la pratique de l'épigraphie gallo-grecque, apportant des documents dans lesquels on notait en caractères grecs des mots celtiques, qui avaient un sens dans cette langue, telle qu'elle était parlée localement ${ }^{3}$. On dispose ainsi des noms de divinités, mais aussi des noms de personnes, car définir l'identité de personnages marquants paraît la raison d'être de ce passage à l'écriture, qui se diffuse progressivement et que l'on peut bien circonscrire spatialement à son apogée. Mais le passage sous la domination de Rome, dans le cadre provincial, qui est un cadre de regroupement, apporte un changement d'échelle à la vie de la communauté. Il favorise l'usage du latin et il produit une documentation latine à divers niveaux de l'organisation sociale. La documentation latine, qui s'ajoute et qui bien vite l'emporte, apparaît dans la perspective d'une continuité 4 .

L'intégration du peuple et de ses élites, par l'effet des clientèles et par celui, dérivé, de la participation militaire au développement de la puissance romaine ${ }^{5}$, favorisa le recours au latin, langue du pouvoir dominant et aussi langue de tous les principaux médiateurs, en

1. C. Jullian, Histoire de la Gaule, II, p. 3-36 ; G. Barruol, Les peuples préromains, p. 185-391 ; P. Thollard, La Gaule selon Strabon, p. 76-90, p. 142-144, p. 147-189.

2. On peut ainsi envisager d'expliquer le terme de «métropole» qu'apporte Strabon: B. Puech, « Des citésmères aux métropoles », p. 388-389. On ajoutera l'observation de P. Thollard, La Gaule selon Strabon, p.172-173 : le mot renvoie à une situation pré-romaine.

3. M. Lejeune, Recueil des inscriptions gauloises, I, p. 1-5 ; P.-Y. Lambert, La langue gauloise, p. 14-19 ; M. Bats, « La logique de l'écriture », p. 142-147. Sur l'inclusion de la zone arécomique, carte de M. Lejeune, ibid., I, p. 2, améliorée par M. Bats, ibid., p. 146.

4. On peut envisager qu'il n'y a pas succession des deux formes épigraphiques, mais que l'épigraphie gallogrecque se prolonge quelque peu au delà du début du $\mathrm{I}^{\mathrm{er}}$ siècle av. J.-C. D'autre part, la continuité implique des chevauchements d'usages: M. Bats, «La logique de l'écriture », p. 146-147.

5. Chr. Goudineau, Regard sur la Gaule, p. 53-63. 
plus des «autorités » provinciales et de leurs descendants, les grands aristocrates de la dernière période de la république romaine. Il faut tenir compte aussi des manieurs d'argent, des commerçants, des exploitants des biens de l'État. La province est «pleine » de ces gens venus d'ailleurs, comme le souligne Cicéron avant même l'horizon du Pro Fonteio, qui correspond à la décennie 70, lorsqu'il défend Quinctius pour des affaires qui l'avaient entraîné en Transalpine ${ }^{6}$. D'autres mots sont utilisés, avec une autre langue. Et peu à peu aussi, une partie de l'élite provinciale joue à son tour le rôle de médiateur, au service des plus puissants. César avait à ses côtés, dans la campagne contre Arioviste, qui ouvre le récit de la Guerre des Gaules, des interprètes helviens, dont le père avait reçu le droit de cité romaine du proconsul C. Valerius Flaccus7. Puis il eut dans son proche entourage, le représentant de l'élite du peuple des Voconces, dont le père et l'oncle avaient gagné par leur bravoure le droit de cité dans les guerres qu'entreprit Pompée contre Sertorius en péninsule ibérique et contre Mithridate en Asie ${ }^{8}$.

Les signes de cette transformation marquent les individus, dans la tenue vestimentaire qui leur permet d'établir leur qualité de citoyen romain, lorsqu'ils l'ont gagnée", mais aussi dans la dénomination. Ce sont des changements qui s'appuient sur la force des institutions organisant la vie collective. Une loi municipale avait certainement accompagné la création d'une colonie latine par la volonté de César : il est nécessaire de postuler son existence. Elle accompagne l'octroi du droit latin aux communautés provinciales, à l'initiative du même proconsul ${ }^{10}$. Les effets en sont décisifs, tant pour la communauté qui vivait autour de la grande ville, qui émergeait au cœur de la confédération, que pour les autres communautés, car partout la possibilité de gagner la citoyenneté romaine existait pour les familles de notables, par l'exercice des magistratures. C'était depuis la fin de la guerre sociale (91-89 av. J.-C.) l'un des traits caractéristiques du droit latin, dont le contenu avait été transformé pour devenir un cadre de romanisation des populations en Gaule Cisalpine. Or, l'acquisition de la cité romaine per magistratum est le trait le plus marquant que rappellent les sources antiques à ce propos $^{11}$. Il faut ajouter que dans le cas des Volques Arécomiques, l'application se réalise dans le contexte d'un émiettement de la vie politique, à l'intérieur de la confédération, car, pour des raisons qui tiennent au développement même de la vie politique dans la période antérieure, la pluralité des cellules qui vivaient d'une manière propre leur destin était une des caractéristiques qui furent préservées, et celle-ci se maintint même pour quelques-uns de ces centres de moindre importance après que la plupart furent rattachés à Nîmes pour former une grande cité ${ }^{12}$. On peut apprécier le nombre de ces « républiques villageoises » à partir de la mention des vingt-quatre oppida ignobilia chez Pline ou par celle des vingt-quatre «bourgs » ou kômai chez Strabon ${ }^{13}$. Le rattachement de ces vingtquatre petites communautés à la colonie latine se produisit peut-être entre 16 et 13 , mais on peut aussi mettre l'accent sur la date de 22 av. J.-C., qui fut celle du retour de la province des mains d'Auguste dans celles du peuple romain ${ }^{14}$. Ainsi pendant plus de vingt ans les élites politiques du peuple des Arécomiques avaient pu recevoir sur une large base le droit de cité romaine, l'émiettement des "républiques » villageoises ayant eu un effet démultiplicateur en ce domaine ${ }^{15}$. Or, devenir citoyen romain impliquait de

6. M. Christol, Une histoire provinciale, p. 41-86

7. Cés., Bell. Gall., I, 47 et I, 53, cf. VII, 65 ; Chr. Goudineau, Regard sur la Gaule, p. 139-140.

8. Just. Epit. 48, 5, 11. E. Badian, Foreign clientelae, p. 305 ; P.-M. Duval, La Gaule jusqu'au milieu du V'e siècle, I, p. 310-313.

9. Selon l'interprétation des représentations statuaires du mausolée de Glanum : voir note 21.

10. M. Christol, Chr. Goudineau, " Nîmes et les Volques Arécomiques », p. 92.

11. D. Kremer, Ius Latinum, p. 121-127, à propos du commentaire d'Asconius (in Pis. 3 C), ce qui est confirmé à une date ultérieure par Strabon (Géogr., IV, 1, 12) puis par la loi d'Irni : ibid., p. 146-148.

12. M. Christol, Chr. Goudineau, "Nîmes et les Volques Arécomiques », p. 97-98 ; M. Christol, "La formation d'une élite municipale », p. 78-80.

13. Strab., Géogr., IV , 1, 12 ; Plin., NH, 37. Etat de la question : P. Thollard, La Gaule selon Strabon, p. 172-185. On ne doit pas occulter la réflexion sur les réalités territoriales, surtout vers l'Ouest : ibid., p. 155-156 et p. 172.

14. M. Christol, Chr. Goudineau, "Nîmes et les Volques Arécomiques », p. 99 et 102 ; nuances par M. Christol, «La formation d'une élite municipale », p. 77-78.

15. On pourrait même évaluer à près de 500 le nombre de bénéficiaires de ce privilège juridique : M. Christol, "La formation d'une élite municipale », p. 81. 
renoncer à la dénomination « bi-membre » (l'idionyme complété par le patronyme $)^{16}$ pour adopter une dénomination civique spécifique, avec un gentilice se transmettant de génération en génération, un praenomen, voire un cognomen, sur le modèle qui s'était généralisé en Italie ${ }^{17}$. Les premières inscriptions latines enregistrent ce phénomène, en visualisant fortement le statut du personnage : la dénomination constitue l'essentiel du texte.

Antérieurement, la diffusion du droit de cité romaine avait été marquée, mais quantitativement dans des proportions moindres selon toute vraisemblance, par la diffusion des gentilices des grands personnages représentant la puissance romaine, depuis Marius jusqu'aux Iulii (César, puis Octavien/Auguste) ${ }^{18}$. Ces noms, liés à la grande histoire de Rome, se retrouvent dans la dénomination des grands personnages de la cité de l'époque du Principat. Ce sont les descendants des aristocrates de la fin de la période proto-historique. Cnaeus Domitius Ahenobarbus avait été un des premiers organisateurs de la province, lors du passage sous la domination romaine : on retrouve son gentilice tant chez le quattuorvir L(ucius) Domitius Axiounus (dont le cognomen conserve une trace d'anthroponymie celtique), que chez Cn. Domitius Afer, consul en 39 ap. J.-C., qui porte pour sa part un cognomen latin ${ }^{19}$. Il en va de même pour Pompeia Plotina, l'épouse de Trajan: son gentilice renvoie au grand Pompée, dont les clientèles $\mathrm{s}^{\prime}$ étendirent dans toutes les parties de $\mathrm{l}^{\prime}$ Occident ${ }^{20}$. On peut ainsi détecter dans l'épigraphie des élites la succession des clientèles avec leurs effets, jusqu'à l'époque augustéenne: les sénateurs nîmois qui sont connus se rattachent tous à ce contexte onomastique qui met en évidence l'engagement, notamment militaire, des grands personnages dominant le peuple provincial ${ }^{21}$.

En revanche les nouveaux citoyens, dont le statut dérivait de l'application du droit latin, ne se référaient pas nécessairement à un grand personnage, membre d'une grande lignée romaine. L'acquisition du droit de cité romaine ne se réalisait pas dans le contexte militaire qui mettait en évidence la bravoure du personnage (ob virtutem) et ce n'était plus la volonté d'un général vainqueur qui décidait de cette transformation du statut juridique. La médiation ne renvoyait pas à un grand personnage mais à un processus abstrait. C'était d'habitude le nom individuel qui servait de fondement pour créer un gentilice, par la suffixation en - ius. Cette pratique ne s'écartait pas trop des usages linguistiques du monde indigène, car souvent on adoptait pour donner la filiation, en second élément de la dénomination, au lieu du nom patronymique au génitif, un adjectif tiré de ce dernier, en le suffixant en - akos/acos, en - ikos/icos, en - iknos/icnos, en - ios. Et dans ce dernier cas on se rapprochait du gentilice latin ${ }^{22}$. On peut d'ailleurs se demander si à Nîmes une des plus anciennes inscriptions religieuses, sur un autel dédié à Nemausus, ne serait pas à expliquer de cette manière ${ }^{23}$ : C(aius) Andolatius devant être interprété comme $C$ (aius) fils d'Andolate. Andolatius ne serait pas le gentilice d'un citoyen romain, mais l'adjectif patronymique tiré du nom Andolate, qui est attesté par ailleurs, en sorte que le personnage devrait être considéré comme un pérégrin ${ }^{24}$.

16. M. Lejeune, Recueil des inscriptions gauloises, I, p. 453 ; A. Chastagnol, «L'onomastique de type pérégrin », p. 573-593 (= La Gaule romaine et le droit latin, p. 51-71).

17. D. van Berchem, Les routes et l'histoire, p. 155-164; A. Chastagnol, «Considérations sur les gentilices des pérégrins ", p. 169-181 (= La Gaule romaine et le droit latin, p. 157-162).

18. M. Christol, Une histoire provinciale, p. 87-99.

19. Sur le magistrat : CIL, XII, 3215. Y. Burnand, Domitii Aquenses, p. 29-40, p. 223-225.

20. PIR2 P 679; M.-Th. Raepsaet-Charlier, Prosopographie des femmes, I, p. 511-512, notice 631 ; Y. Burnand, Primores Galliarum, II, p. 314-315. Il faut insister aussi sur les travaux de R. Syme : The Provincial at Rome, p. 32124 passim ; Tacitus, I, p. 327-328.

21. C'est ce qu'éclaire à Glanum le monument des Iulii avec son décor : P. Gros, « Le mausolée des Julii », p. 6869 , p. 70-72, p. 75-80.

22. M. Lejeune, Recueil d'inscriptions gauloises, I, p. 453-454 ; P.-Y. Lambert, La langue gauloise, p. 30-31.

23. CIL, XII, 3093.

24. On connaît ainsi, mais depuis peu le nom féminin Andolata Ateponis f(ilia) : M. Christol, Inscriptions antiques, p. 21-26, n ${ }^{\circ} 4$ (sur ce nom, p. 25). Il s'agirait donc d'épigraphie gallo-latine : M. Lejeune, Recueil des inscriptions gauloises, II, 1, p. 57-59 ; P.-Y. Lambert, La langue gauloise, p. 91-92. Sur la chronologie précoce qu'il faut adopter pour cette sorte d'inscription, M. Bats, « La logique de l'écriture », p. 145-146. 
Quoi qu'il en soit, est alors créé un stock de gentilices qui conservent dans leur composition la marque des noms indigènes, mais qui en transforment l'usage, et qui, de plus, en font perdurer la trace puisque le gentilice se transmet de génération en génération. Il en va ainsi pour le chevalier romain de l'époque flavienne Sex(tus) Adgennius Macrinus. Adgennius dérive d'Adgennus, également connu dans l'anthroponymie de la cité de Nîmes que livrent les inscriptions latines. Mais il était déjà présent dans l'épigraphie gallo-grecque (Adgennos à Nîmes, Adgennorix à L'Isle-surSorgue $)^{25}$. On pourrait multiplier les exemples en analysant les gentilices de l'élite municipale à l'époque impériale, avec des gentilices tels que Indelvius, Indamius, Indedius ${ }^{26}$, etc.

Mais il faut tenir compte que la dérivation du gentilice peut se produire soit à partir d'une dénomination bi-membre dont tous les éléments appartiennent au fonds linguistique local ou bien d'une dénomination plus ou moins contaminée par la substitution de noms latins à des noms celtiques. C'est ce qui explique l'apparition dans le groupe des notables municipaux, et plus généralement dans l'ensemble de la population de gentilices tels que Severius (issu de Severus), Frontonius (issu de Fronto), Secundius (issu de Secundus), etc. Ils apparaissent un peu plus tard, car il faut admettre que leur apparition présuppose un début de latinisation de l'anthroponymie. Mais à peine plus tard ${ }^{27}$.

On aborde ainsi un des chapitres les plus vastes du sujet, car il s'agit de la latinisation de l'anthroponymie locale. Le phénomène peut être étudié de diverses manières, car on découvre une situation très complexe dans l'univers linguistique nîmois, tel qu'il est révélé par les inscriptions et par les indications onomastiques qu'elles livrent. On peut s'intéresser à des groupes bien circonscrits, mais on s'oriente alors vers des perspectives marquées par la stratification sociale, notamment la distinction entre les groupes essentiels de l'élite, les notables municipaux et les sévirs augustaux. Un angle d'attaque significatif peut prendre appui sur les inventaires que permet l'isolement des documents contenant des "dénominations pérégrines", autrement dit les dénominations bimembres : elles révèlent une population de personnes de condition libre, mais qui n'ont pas encore franchi le seuil du droit de cité. Elles sont enracinées dans une situation juridique qui représente le passé. Il pourrait être éventuellement complété par l'étude, suivie selon les mêmes critères, des personnes qui indiquent la possession du droit de cité romaine, celles qui ont de leur temps, ou dont la famille a dans un passé plus ou moins lointain franchi le cap de la romanisation juridique. Il s'agit aussi d'inscriptions funéraires qui sont à l'écart des processus institutionnels de la vie municipale.

Un mot d'éclaircissement est nécessaire pour clarifier le problème. Le droit latin est conçu à cette époque comme une voie de transition afin de transformer le statut juridique d'une communauté $^{28}$. On l'engage dans une voie de manière inéluctable, comme Rome l'avait fait en Cisalpine au lendemain de la guerre sociale. Il y a donc, tendanciellement, un basculement de la population dans la cité romaine, ce qui sera même accéléré un peu plus tard par des décisions prises par Hadrien ${ }^{29}$. En même temps ont été mis en place des aménagements juridiques destinés à ne pas bouleverser les structures sociales et les

25. CIL, XII, 3175 ; Y. Burnand, Primores Galliarum, II, p. 259-261; sur les noms qui se rapprochent dans l'épigraphie gallo-grecque, M. Lejeune, Recueil des inscriptions gauloises, I, p. 181-187 (G- 147) et p. $289-291$ (G208); sur l'ensemble de la documentation épigraphique nîmoise: M. Christol, «La formation d'une élite municipale ", p. 81-82; à Lattes, dans la partie occidentale du territoire de la cité on trouve Illuana Adgonneti $(A E, 1972,331)$.

26. Ensemble de références à propos de la publication d'une inscription Q(uintus) Caranto, Endami f(ilius) : M. Christol, Inscriptions antiques, p. 24-25. Panorama de l'ensemble du monde des notables par M. Christol, « Du peuple celtique à la colonie latine », p. 78-83.

27. L'ensemble épigraphique provenant de la nécropole de Lattes permet de prendre la mesure à haute époque des débuts de la latinisation de l'anthroponymie dans toute sa complexité : E. Demougeot, "Stèles funéraires ", p. 110-116 ; M. Christol, « Epigraphie et onomastique », p. 29-32.

28. M. Humbert, « Le droit latin impérial », p. 217-226 ; D. Kremer, Ius Latinum, p. 180-189.

29. A. Chastagnol, «L'empereur Hadrien et la destinée du droit latin provincial au II ${ }^{\mathrm{e}}$ siècle », p. 220-225. 
structures patrimoniales (notamment le conubium, qui maintient la légitimité des droits paternels, face à la parenté naturelle de la mère $)^{30}$.

Par le choix de ce groupe, à l'exclusion des autres pour le moment, on touche une partie de la population que l'on peut considérer comme représentative de la population provinciale qui n'a pas été détachée de sa condition initiale. Les personnages qui constituent le groupe étudié n'ont pas encore profité de la mutation juridique qui fait entrer dans la cité romaine. La définition de l'identité ne résulte pas d'un effet direct des bienfaits de l'appartenance à une cité de droit latin.

L'abondance du corpus épigraphique nîmois permet un classement chronologique, et des distinctions entre la ville et la campagne. On est ainsi progressivement conduit de la fin du $\mathrm{I}^{\text {er }}$ siècle av. J.-C. au $\mathrm{III}^{\mathrm{e}}$ siècle ap. J.-C. En s'appuyant sur les caractéristiques de l'épigraphie locale on peut répartir les inscriptions en quatre sous-ensembles : 1 - du milieu du $\mathrm{I}^{\mathrm{er}}$ siècle av. J.-C. à la fin de l'époque augustéenne (soit: -50/20, pour simplifier) ; 2 - de la fin de l'époque augustéenne au début de l'époque flavienne (soit: +20/70) ; 3 - du début de l'époque flavienne à l'époque de Marc Aurèle (soit : + 70 / + 160) ; 4 - du début du règne de Marc Aurèle au cœur du III $^{\mathrm{e}}$ siècle (soit : +160/250). En même temps, chacune de ces inscriptions s'inscrit dans une chronologie propre, qui relève de l'association d'un nom appartenant au passé, celui du père, et d'un nom appartenant au présent, celui de l'enfant : c'est une des particularités qu'apporte l'étude des dénominations bi-membres.

Le tableau succinct qui est présenté ci-dessous montre la rapidité de la latinisation de l'anthroponymie. Même si le fonds celtique n'a pas été éliminé, il subit une rétraction considérable que l'on peut placer durant la première moitié du I ${ }^{\mathrm{er}}$ siècle ap. J.-C.

\begin{tabular}{|c|c|c|}
\hline $\begin{array}{c}\text { Evolution de la forme de la } \\
\text { dénomination }\end{array}$ & $\begin{array}{c}\text { Période } 1 \\
-50 / 20\end{array}$ & $\begin{array}{c}\text { Période } 2 \\
+20 / 70\end{array}$ \\
\hline celtique $>$ celtique & 19 & 5 \\
\hline celtique $>$ latin & 20 & 22 \\
\hline latin $>$ latin & 10 & 34 \\
\hline latin $>$ celtique & 3 & 4 \\
\hline
\end{tabular}

On peut aussi tenter d'autres approches à partir du même stock d'information. Si l'on répartit d'une manière plus simple les éléments d'anthroponymie collectés, selon la répartition entre élément indigène et élément latin, et si l'on ajoute la distinction entre la ville et le territoire en fonction de la provenance des inscriptions, on parvient aux résultats suivants, qui viennent concorder avec la mesure précédente.

\begin{tabular}{|c|c|c|c|c|c|}
\hline & Période 1 & Période 2 & Période 3 & Période 4 \\
\hline Ville & $\begin{array}{c}\text { total des } \\
\text { occurrences }\end{array}$ & 45 & 74 & 134 & 54 \\
\hline $\begin{array}{c}\text { éléments } \\
\text { indigènes }\end{array}$ & $32(71,1 \%)$ & $18(24,3 \%)$ & $15(11,1 \%)$ & $2(3,7 \%)$ \\
\hline $\begin{array}{c}\text { éléments } \\
\text { latins }\end{array}$ & $13(28,9 \%)$ & $56(75,7 \%)$ & $119(88,8 \%)$ & $52(96,3 \%)$ \\
\hline Territoire & $\begin{array}{c}\text { total des } \\
\text { occurrences }\end{array}$ & 83 & 88 & 125 & 36 \\
\hline $\begin{array}{c}\text { éléments } \\
\text { indigènes }\end{array}$ & $35(42,3 \%)$ & $22(25 \%)$ & $11(8,8 \%)$ & $6(15,1 \%)$ \\
\hline & $\begin{array}{c}\text { éléments } \\
\text { latins }\end{array}$ & $48(57,7 \%)$ & $66(75 \%)$ & $96(91,2 \%)$ & $30(84,9 \%)$ \\
\hline
\end{tabular}


En somme, avec des données quantitativement suffisantes, il est possible d'apprécier comment dans un contexte social qui était marqué par l'orientation vers l'acquisition du droit de cité romaine, la latinisation de l'anthroponymie est un phénomène qui s'est déroulé au terme du premier siècle d'existence de la colonie latine. Avant même d'avoir la possibilité d'affirmer l'identité de citoyen romain, le monde indigène a adopté les caractéristiques de l'anthroponymie latine.

Il est certes possible aussi d'observer que les choix ne signalent pas toujours une grande recherche lexicale. À Lattes par exemple, où le stock documentaire est de haute époque (périodes 1 et 2), on peut constater que dans la population pérégrine les noms latins choisis sont d'une grande banalité (Quartus, Quintio, Secundus, Sextus), alors que chez ceux qui par leur dénomination signalent qu'ils détiennent le droit de cité romaine on relève une plus grande recherche (Rufinus, Marinus, Piperclus, Fortunatus, Moderatus). Mais il est vrai que la série documentaire est plutôt restreinte. Quand on s'élève à l'ensemble de la cité, on constate, dans le groupe de personnes sur lequel se fonde la présente étude, une assez grande diversité des choix, car sur 198 occurrences dans 58 cas le nom n'est attesté qu'une fois.

En revanche, à l'autre extrémité de la statistique, quelques noms ou groupes de noms se caractérisent par la fréquence des attestations : 139 attestations correspondent ainsi à 29 noms ou noms dérivés. Au-dessus de 4 attestations on trouve Avitus (4), Carus et Carinus (6), Mansuetus (4), Marcellus associé à Marcellinus, à Marcinus et à Marculus (12), Maternus (5), Maximus associé à Maximinus et Maximillus (10), Montanus (4), Paternus (5), Primus associé à Primulus (18), Quartus associé à Quartinus, Quartio et Quartulus (11), Sabinus (7), Secundus associé à Secundinus et Secundilla (28), Servatus (5), Severus associé à Severinus (14), Verus associé à Verinus (6).

En somme, c'est la rapidité de la latinisation de l'anthroponymie qui doit être soulignée : elle est acquise à l'entrée de l'époque flavienne lorsque Pline le Naturaliste émet son jugement élogieux sur la province. L'exemple de la cité de Nîmes, cité de droit latin, montre la profondeur du phénomène au-delà du monde des notables, et au-delà du seul cadre urbain. C'est l'ensemble de la cité, ville et territoire, qui avancent à peu près à même allure à partir du milieu du $\mathrm{I}^{\mathrm{er}}$ siècle ap. J.-C. Et, d'autre part, l'épigraphie permet $\mathrm{d}$ 'aborder la diffusion du phénomène dans les niveaux moyens de la population, tant urbaine que rurale. On peut même envisager que l'expression épigraphique, qui est réductrice, conduirait parfois, lorsque l'anthroponymie révèle une situation de continuité linguistique, à en surévaluer la signification. Il ne s'agit en réalité que d'une persistance dans la dénomination de personnes. Si on a la chance de disposer d'un texte un peu plus expressif, notamment par les références au testament ou au droit de la tombe, on constate que ce sont les usages romains, ceux d'Italie, qui apparaissent ${ }^{31}$. En somme, le phénomène de latinisation n'effaça pas brutalement tout le fonds anthroponymique local, puisque l'on en décèle même des traces dans la dénomination des notables, surtout aux premières périodes, mais à terme, en s'imposant de plus en plus, il en menaçait la survie.

31. Comme le montre la mention du testamentum: témoignage précoce publié par J. Charmasson, M. Christol, M. Janon, dans M. Christol, «Inscriptions antiques de la cité de Nîmes », p. 79-95. Une inscription récemment publiée (et non encore reprise par l'Année épigraphique) est analysée par M. Christol, " Une histoire provinciale ", p. 199-206. La datation proposée (vers la fin du I ${ }^{\text {er }}$ siècle ap. J.-C.), pourrait être rehaussée jusqu'au milieu de cette période : Sex(to) Smeri f(ilio) / exs testamento / h(eredes) rogati / f(ecerunt). 


\begin{abstract}
Résumé
La richesse de l'épigraphie locale, tant dans la ville de Nîmes que dans le territoire dépendant, permet d'engager avec des données suffisantes des enquêtes sur la dénomination des personnes. Dans cette cité de droit latin, remodelée par Auguste, la partie de la population qui ne dispose pas encore du droit de cité romaine se caractérise par une latinisation précoce de l'anthroponymie, élément essentiel de l'identité.
\end{abstract}

\title{
Bibliographie
}

BADIAN Ernst, Foreign clientelae (264-70 BC), Oxford, University Press, 1971.

BARRUOL Guy, Les peuples préromains du sud-est de la Gaule. Essai de géographie historique, Paris, 1969 (Revue archéologique de Narbonnaise, Supplément 1) (réimpr. 1975).

BATS Michel, «La logique de l'écriture d'une société à l'autre en Gaule méridionale protohistorique », RAN, 21, 1988, p. 121-148.

BURNAND Yves, Domitii Aquenses. Une famille de chevaliers romains de la région d'Aix-enProvence. Mausolée et domaine, Paris, Ed. de Boccard, 1975 (Revue archéologique de Narbonnaise, Supplément 5).

Burnand Yves, Primores Galliarum, II. Prosopographie, Bruxelles, Editions Latomus, 2006 (Collection Latomus, 330).

ChastagnOL André, «L'onomastique de type pérégrin dans les cités de Gaule Narbonnaise », MEFRA, 102, 1990, p. 573-593.

CHAStagnOL André, «Considérations sur les gentilices des pérégrins naturalisés romains dans les Gaules et les Germanies », BSNAF, 1993, p. 167-183.

CHAStAgnOL André, «L'empereur Hadrien et la destinée du droit latin provincial au II siècle ap. J.-C. », RH, 592, 1994, p. 217-227.

Chastagnol André, La Gaule romaine et le droit latin, Paris-Lyon, Ed. de Boccard, 1995.

CHRISTOL Michel, « Le droit latin en Narbonnaise : l'apport de l'épigraphie (en particulier celui de la cité de Nîmes)", dans CASTILlo Carmen (éd.), Epigrafia jurídica romana. Actas del coloquio internacional A.I.E.G.L. (Pamplona, 9-11 de abril de 1987), Pamplona, Universidad de Navarra, 1989, p. 65-76.

CHRISTOL Michel (avec la collaboration de CHARMASSON Jean, COGITORE Isabelle, DAGUET Anne, JANON Michel, LEFEBVRE Sabine, TARPIN Michel), Inscriptions antiques de la cité de Nîmes, IACN 1-21, Nîmes, Musée archéologique, 1992 (Cahiers des Musées et Monuments de Nîmes, 11).

CHRISTOL Michel, «Épigraphie et onomastique dans la cité de Nîmes du milieu du $\mathrm{I}^{\mathrm{er}}$ siècle av. J.-C. à la seconde moitié du I ${ }^{\mathrm{er}}$ siècle ap. J.-C. : analyse d'un échantillon », dans Dondin-PAYRE Monique et RAEPSAET-CHARLIER Marie-Thérèse (éd.), Noms, Identités culturelles et Romanisation sous le Haut-Empire, Bruxelles, Le Livre Timperman, 2001, p. 1738. 
CHRISTOL Michel, Une histoire provinciale. La Gaule narbonnaise de la fin du II siècle av. J.-C. au III siècle ap. J.-C., Paris, Publications de la Sorbonne, 2010.

CHRISTOL Michel, «La formation d'une élite municipale: l'originalité de la cité de Nîmes ", dans C. DEROUX (éd.), Corolla Epigraphica. Hommages au professeur Yves Burnand, Bruxelles, Éditions Latomus, 2011 (Collection Latomus, 331), 2 vol., I, p. 76-87.

CHRISTOL Michel, «Du peuple celtique à la colonie latine : les élites de la cité de Nîmes à l'époque romaine », Mémoires de l'Académie de Nîmes, IX série, LXXXVI, 2012 [paru en 2013], p. 69-84.

CHRISTOL Michel et GOUdineAu Christian, «Nîmes et les Volques Arécomiques au $\mathrm{I}^{\mathrm{er}}$ siècle avant J.-C. », Gallia, 45, 1987-1988, p. 87-103.

DEMOUGEOT Émilienne, «Stèles funéraires d'une nécropole de Lattes », RAN, 5, 1972, p. 49-116.

Duval Paul-Marie, La Gaule jusqu'au milieu du V'e siècle, Paris, A et J. Picard, 1971, 2 vol. (Les sources de l'histoire de France des origines à la fin du XV siècle).

GROS Pierre, «Le mausolée des Julii et le statut de Glanum », RA, ns., 1986, p. 65-80.

GOUdinEAu Christian, Regard sur la Gaule, Paris, Ed. Errance, 1998.

HUMBERT Michel, «Le droit latin impérial : cités latines ou citoyenneté latine », Ktèma, 6, 1981, p. 207-226.

Jullian Camille, Histoire de la Gaule, II (4 éd.). Paris, Hachette, 1921.

LAMBERT Pierre-Yves, La langue gauloise, Description linguistique, commentaire d'inscriptions choisies, Paris, Ed. Errance, 1994.

LEJEUNE Michel, Recueil des inscriptions gauloises (R.I.G.), I. Textes gallo-grecs, Paris, Ed. du CNRS, 1985 (XLV $V^{e}$ supplément à « Gallia»); II, 1. Textes gallo-étrusques. Textes gallo-latins sur pierre, Paris, Ed. du CNRS, 1988 (XLV supplément à « Gallia »).

PUECH Bernadette, «Des cités-mères aux métropoles », dans FollET Simone (éd.), L'hellénisme d'époque romaine. Nouveaux documents, nouvelles approches (I siècle a. C. III siècle ap. J.-C.) (Actes du Colloque international à la mémoire de Louis Robert, Paris, 78 juillet 2000), Paris, De Boccard, 2004, p. 357-404.

RAEPSAET-CHARLIER Marie-Thérèse, Prosopographie des femmes de l'ordre sénatorial ( ${ }^{e r}$ II siècles), Louvain, Peeters, 1987, 2 vol. (Académie royale de Belgique, classe des lettres, IV).

SYME Ronald, Tacitus, Oxford, Clarendon Press, 1958, 2 vol.

SYME Ronald, The Provincial at Rome and Rome and the Balkans, 80 BC - AD 14, ed. by A. Birley, Exeter, University of Exeter Press, 1999.

THOLlARD Patrick, La Gaule selon Strabon. Du texte à l'archéologie. Géographie, livre IV: traduction et études, Paris, Ed. Errance/Centre Camille-Jullian, 2009.

VAN BERCHEM Denis, Les routes et l'histoire. Études sur les Helvètes et leurs voisins dans l'empire romain, Genève, Droz, 1982. 


\title{
L'oralité de Césaire d'Arles. Latinophonie et communication en Provence au $\mathrm{VI}^{e}$ siècle
}

\author{
Michel BANNIARD \\ Professeur à l'Université de Toulouse-II, Jean-Jaurès \\ Directeur d'études à l'EPHE, Paris-Sorbonne
}

\begin{abstract}
Extrait de : Guylaine BRUN-TRIGAUD (dir.), Contacts, conflits et créations linguistiques, Paris, Édition électronique du CTHS (Actes des congrès des sociétés historiques et scientifiques), 2015.

Cet article a été validé par le comité de lecture des Éditions du CTHS dans le cadre de la publication des actes du $139^{\text {e }}$ Congrès national des sociétés historiques et scientifiques tenu à Nîmes en 2014.
\end{abstract}

\section{Latin parlé ou roman parlé au VI siècle : révision des paramètres}

En philologie romane synchronique, la langue parlée indigène sur un territoire qui s'étend vers l'Est à partir de Nîmes a été jusqu'au XIX ${ }^{\mathrm{e}}$ siècle le provençal, dialecte qui borde jusqu'aux Alpes l'ensemble occitano-roman, dont le pendant occidental est le languedocien [Bec, 1971]. En philologie romane diachronique, la question de la date à laquelle on a commencé de parler provençal sur ce même espace a fait l'objet de nombreux débats, qui s'intègrent aux travaux de la linguistique diachronique romane, puisqu'aussi bien la question est valable pour tout l'espace romanophone, lui-même issu du premier espace latinophone installé par et sous l'Empire romain [Ernst \& alii, 2003 ; Glessgen, 2007]. Cette question, fort débattue, a reçu depuis trente ans des réponses innovantes fondées sur les méthodes de la sociolinguistique diachronique, base de la contribution présente, et champ auquel elle s'intègre en s'efforçant de l'enrichir [Banniard, 1992 ; Lüdtke, 2009 ; Wright, 1982]. Il s'agit de montrer ici rapidement que l'oralité de Césaire, évêque d'Arles dans la première moitié $\mathrm{du} \mathrm{VI}^{\mathrm{e}}$ siècle était latine, qu'elle s'adressait à une communauté de locuteurs majoritairement illitterati, que ces locuteurs comprenaient son latin, et que par conséquent, la langue parlée quotidienne de son diocèse était encore de type latin (et non pas roman, a fortiori provençal). Autrement dit, dans la vieille Provincia romana, on parlait encore au temps des Goths, le latin tardif.

Cette affirmation entre évidemment en contradiction forte avec les habitudes mentales que nous a léguées une partie des philologues romanistes. Pour eux en effet, la masse des locuteurs des territoires de l'Empire a certes été plus ou moins romanisée (là aussi, les débats continuent), mais pas vraiment latinisés, ou du moins ils l'ont été sous une forme démonétisée. En effet, selon ce modèle, ils n'ont jamais parlé qu'une forme de "mauvais latin, de sabir, de lingua franca » ou, dans le meilleur des cas de " latin vulgaire » devenu très vite, au III ${ }^{\mathrm{e}}$ ou IV $\mathrm{e}^{\mathrm{e}}$ siècle un gallo-roman fourre-tout, qui sur le territoire de l'ancienne Gaule, s'est dégradé en langue d'oïl au Nord, en langue d'oc au Sud. C'est ainsi que le "français prélittéraire » ou le "gascon » reçoivent leur certificat de baptême dès le $\mathrm{VI}^{\mathrm{e}}$ siècle, en restant condamnés à l'exclusion de l'écrit sous la férule d'une Église peu soucieuse de démocratie langagière. Ce discours pseudo scientifique repose sur 4 piliers [Banniard, 1993, 2013a] :

1) Des préjugés lourds hérités directement du XIX $X^{\mathrm{e}}$ siècle, sur le fait notamment qu'il n'est de vrai langage que savant;

2) Sur le deuil obligé d'une civilisation romaine en perdition au temps de la si souvent invoquée décadence ; 
3) Sur la conviction que le monde laïc et le monde ecclésial formaient des univers clos et séparés ;

4) Sur la certitude que la philologie romane triomphante était capable, à partir des données des parlers romans réels du XIX ${ }^{\mathrm{e}}$ siècle, de reconstruire la parole non moins réelle pratiquée deux mille ans plus tôt.

La recherche récente, disons depuis les années 1960, a quand même permis des progrès au prix évidemment de changements radicaux [Banniard, 2013b ; Lüdtke, 2009 ; Wright, 2003]:

1 -Tout langage est complexe, indépendamment de son apprêt culturel sous l'effet de la stratification sociale ;

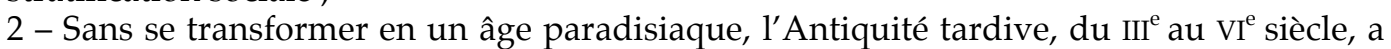
conquis un statut de dignité historique objectivée [Brown, 2012 ; Hen, 1995] ;

3 - Le monde laïc et le monde clérical ont été en rapport de plus en plus intriqués, à mesure qu'a progressé la christianisation de l'Occident Latin [Dumézil, 2005 ; Graus, 1965].

4 - Les contemporains nous ont légué une masse d'écrits, de témoignages et de documents sur leur propre langage qui ne saurait être écartée d'un revers de main positiviste.

Pour le dire plus crûment, il est tout de même extravagant de ne tenir aucun compte des testimonia que nous ont laissés en abondance les acteurs de cette époque. Bien entendu, tout travail d'historien consiste à interpréter les documents, à les tamiser et ensuite à construire la réalité proposée. Mais au moins, on demande leur avis aux contemporains. Or, le $\mathrm{VI}^{\mathrm{e}}$ siècle a été particulièrement bavard, et il a notamment beaucoup parlé de la culture et du langage, de son langage qui s'entendait dans les rues de Nîmes ou d'Arles. Il nous en a même laissé des échantillons. Tout ceci, je vous prie de me croire, a été écarté comme "hors champ» par les philologues romanistes. C'est en réaction contre cet a priori pseudo-scientifique que s'est bâtie la sociolinguistique diachronique romane.

\section{Un évêque latinophone et son public}

C'est dans ce cadre heuristique que se placent les questions adressées à l'œuvre écrite de l'évêque d'Arles (502-542) [Delage, 2010]. Prélat d'un siège prestigieux, héritier d'une éducation religieuse de haut niveau, ancien membre de la communauté monastique désormais célèbre de Lérins, Césaire aurait pu être classé parmi les grands détachés des réalités du monde. Mais il a aussi été mêlé, souvent contre son gré, aux vicissitudes de l'histoire tourmentée d'un diocèse où se sont affrontés les pouvoirs antagonistes des différents peuples germaniques plus ou moins en conflit [De Vic \& Vaissette, 1730; Wolfram, 1990]. Le récit de sa vie, bien établi par l'excellente spécialiste qui a édité une partie importante de ses Euvres, nous convainc facilement que l'évêque a été plongé dans les tourbillons de l'époque et confronté directement aux foules et aux individus de son temps. Ce fait ne devrait pas être négligé au moment de l'interroger sur la manière dont il instruisait ses fidèles.

Je ne ferai pas ici une démonstration pas à pas. Voici donc les conclusions principales du dossier, lui copieux [Beck, 1950 ; Delage, 1971, 2010 ; Delaplace, 1986 ; Riché, 1962]

1 - Césaire a beaucoup prêché en personne. Ne tergiversons pas : les testimonia sont irréfutables.

2 - Les catégories sociales auxquelles il s'est adressé ont été variées, depuis l'élite des moines ou des moniales jusqu'aux commerçants, artisans, paysans.

3 - La version écrite de ses sermons nous est parvenue sous la forme de dizaines de textes longs de deux à dix pages, correspondant à un temps de parole effectif de 5 à 20 minutes. 4 - Contrairement à une interprétation présomptueuse qui a délégitimé ces testimonia comme moyens d'accès à l'oralité, il est absolument certains que ces pages étaient 
réellement lues à haute voix par Césaire ou par d'autres évêques, voire par des prêtres [Banniard, 1996 ; Riché, 1962].

5 - Tous ces sermons sont entièrement en latin.

La conclusion logique est que la masse de la population de la Provence gothique comprenait toujours ce latin, ce qui implique qu'elle était toujours à cette époque spontanément latinophone.

C'est le moment d'introduire des précisions et des nuances.

1 - D'abord, sous le terme "latin», d'un point de vue proprement linguistique est désigné un état de langue qui n'est pas celui du trop fameux latin dit "classique », mais celui du latin parlé tardif, évolué considérablement depuis ses origines, mais encore loin d'être du provençal. Les caractères de cette langue parlée sont en cours de reconstitution [Banniard, 2005b].

2 - La masse des auditeurs est illettrée: cette situation est clairement discernée et présentée fréquemment par Césaire, pasteur bien au contact des realia de son temps.

3 - Césaire les prend fréquemment à partie : pour leurs mœurs, leurs superstitions, leurs soucis, voire pour leur conduite pendant la messe. Les sermons incluent les réactions de ces fidèles, voire leur indiscipline ou leur agressivité. Cela exclut que la parole de l'évêque n'ait été qu'un rituel mimétique sans emprise réelle : il doit être compris et si possible obéi (cf. infra, Annexe 2).

4 - À l'intérieur d'un cadre langagier latin, Césaire, à l'exemple de son modèle, Augustin [Banniard, 1998a, b], fait fluctuer sa langue en niveaux divers, jusqu' au plus simple (sermo rusticus, sermo humilis), quitte à encourir l'agacement culturel de la minorité lettrée. Ces fluctuations offrent une base pour paramétrer la parole quotidienne.

5 - Il est régulièrement demandé aux fidèles d'apprendre les grandes prières par cœur, voire de se faire lire à haute voix des pages de l'Évangile, tout ceci sans qu'il y ait d'allusion à un obstacle langagier. Et il n'y a pas l'ombre d'une trace de demande de traduction en « roman ». Or, il est exclu qu'une communauté déjà romanophone ait pu comprendre là aussi une lecture à haute voix du texte sacré (cf. infra, Annexe 2).

Il appartient donc aux traditionalistes de déconstruire cet ensemble : à eux de faire la preuve que cette masse de témoignages est inopérante sur la question si passionnante de la chronologie du passage du latin au roman.

\section{Latin quotidien et immigrés}

Quelques-uns de la masse des testimonia sont donnés en annexe. Je voudrais à présent ouvrir un instant nos oreilles à un savoureux épisode de la Vita Caerarii Arelatensis, écrite et publiée peu de temps après sa mort. Le style et la langue en offrent des pépites linguistiques variées, mais un passage a déjà retenu l'attention des philologues, malheureusement avec des lectures construites sur le moule de l'ancien clivage.

Peu de temps après la mort de Césaire, lorsque donc Arles était passée depuis une dizaine d'années sous le pouvoir des Francs, dont quelques-uns étaient cantonnés dans la cité, le diacre Étienne, un des narrateurs principaux de la Vita narre l'anecdote édifiante suivante :

Vita Caesarii, II, 42 [Delage, 2010] :

Alias uero eunte me per plateam, Francus quidam, iam totus frigore quartanae febris incuruus aeque tremebundus ante me ambulabat. Et cum uelociter ire disponerem ego quo citaueram, post me coepit clamare: "Benedicte, si habes, da mihi de drapo sancti Caesarii ; propter frigoras, quia multis ualet, uolo bibere ». Ego, qui uelociter properare uolebam quo coeperam, dixi: "Si me expectas, crastino do tibi quod quaeris». Ille uero ait: "Ego hodie habeo diem, et iam totus tremo; quando te expectare habeo? ». Tunc ego non otiose mihi illum in platea totiens ante positum cogitans, dixi ad eum: "Veni, inquio, iuuenis; ego tibi dono quod quaeris". Statim ambo rediuimus; et cum in cella mea ingressi manus uterque lauassemus, protuli linteum, ex quo sanctum corpus dulcis domni tersum fuerat. Tuli ergo paruulam partem, ut darem ei. Et ille Francus cum suo grandi furore ait ad me: 
"Tolle, homo, quid mentiris? Ego audiui quod ille benedictus non linteum sed pannos in usum habuerit, quod ego lauare uolo, et cum aqua bibere». Tunc ego cum lacrimis dixi: "Bene dicis, uerum audisti. Sed hinc corpus ipsius sancti, quando transiit, detersum est». Et ille: "Da, inquit, ergo si sanus sim ». Acceptum itaque, statim in eadem hora a Domino sanitatem sensit.

Autre cas : tandis que je passais par la place, un Franc, recroquevillé sous l'effet du froid d'une fièvre quarte, allait en tremblotant devant moi. Alors que je comptais filer à mon rendez-vous, il se mit à crier derrière moi :

«Homme béni, si tu en as, donne-moi de l'étoffe de saint Césaire. Je veux en boire contre le froid, parce qu'elle vaut contre beaucoup de maux ».

Moi, qui voulais filer vers mon but, $j$ 'ai dit :

«Si tu m'attends, je te donne demain ce que tu demandes».

Mais lui déclare:

«Pour moi, c'est le jour d'aujourd'hui, et je tremble de la tête aux pieds. Quand est-ce que je dois $t^{\prime}$ attendre? ».

Moi, alors, songeant que lui ne s'était pas trouvé si souvent pour rien devant moi sur la place, je lui ai dit, à lui :

«Viens, jeune homme ; je te donne, moi, ce que tu réclames ».

Nous fîmes aussitôt demi-tour ensemble. Et après être entré dans ma cellule et nous être l'un et l'autre lavé les mains, j'ai apporté un linge avec lequel avait été frotté le corps sacré de mon doux maître. J'en ai prélevé un bout pour le lui donner, lorsque ce Franc me dit à moi dans une violente colère :

«Enlève, mon gars! Pourquoi mens-tu ? Moi, j'ai appris que ce saint se servait non pas de linge, mais de chiffons. C'est ça que je veux faire tremper et boire avec son eau ».

Alors, moi, j'ai dit, les larmes aux yeux :

«Tu dis bien; tu as entendu le vrai ; mais c'est avec ceci que le corps du saint en personne a été frotté après son décès ».

Alors lui :

« Donne-le, ainsi que je guérisse ».

(Traduction établie par mes soins, ainsi que celles de l'Annexe 2).

Que ce genre de recette "magique » soit connu comme le loup blanc, et la guérison miraculeuse, après tout possible - surtout avec une fièvre à épisodes !-, ne doit pas nous empêcher de prendre en compte l'authenticité langagière du récit. Là aussi, je vais à l'essentiel :

1 - Le niveau et les caractères du latin employé par le narrateur, tant pour raconter les circonstances que pour reproduire ses propres énoncés est identique à celui des parties correspondantes du livre 2 : un latin en sermo rusticus correspondant bien au type LPT2 ${ }^{1}$. 2 - Le face à face avec le Franc est instructif : contrairement à ce qu'affirment des lecteurs peu avisés, il n'y a aucun rapport de force établi entre lui et le diacre : il fait partie du paysage, n'est pas menaçant, est appelé affectueusement par le narrateur «jeune homme", et respecte le rituel immémorial du lavage des mains (comme dans l'Odyssée et les Chansons de geste).

3 - La discussion est conduite entièrement en latin. Le diacre et le Franc se comprennent sans difficulté. Or ce Franc, certainement nouveau venu en Provence, a appris son latin ailleurs, au Nord, ce qui confirme la thèse que les Francs étaient bilingues dès le $V^{\mathrm{e}}$ siècle (Francique/ LPT2) [Hägermann \& alii, 2004; Banniard, 2004]. D'autre part, le partage langagier qui séparera le Nord et le Sud, s'il est sans doute amorcé, est loin d'être accompli [Banniard, 1991, 2003].

4 - Contrairement aux remarques pincées de certains philologues, son latin n'est pas si approximatif, ni hésitant que cela. La phrase souvent citée par les philologues (qui n'ont pas lu le reste), da mihi de drapo Sancti Caesaris est un excellent échantillon de LPT2. Le syntagmème de drapo annonce certes les tournures romanes à venir, mais il se trouve depuis longtemps en LPC sous forme sporadique. On remarquera en revanche qu'il n'y a pas de ille ou tout autre prototype de l'article défini (il n'existe pas encore) et que le génitif déterminatif perdurera en AFC et en AOC sous la forme d'un CRIP-.

5 - Certains traits particuliers propres au LPT2 $n^{\prime}$ ont pas été relevés ou compris. Ainsi le quando te expectare habeo ? est traduit de façon approximative par l'éditrice : "comment

1. Voir en Annexe 1, la terminologie et les abréviations. 
t'attendre ? ». Mais le syntagmème expectare habeo appartient à l'oralité commune du $\mathrm{VI}^{\mathrm{e}}$ siècle : il est le prototype du nouveau futur I, \{espettarai\}, cf. dicere habeo \{dirai\}, en voie de grammaticalisation. L'ordre des mots lui-même est fidèle au substrat oral réel. Cette forme signe l'authenticité de la langue (le narrateur n'a pas pu l'inventer, pas plus que toutes les autres spécificités de cette latinophonie tardive). De même le syntagmème si sanus sim porte la trace d'une oralité réelle. Mais il faut comprendre le si comme la transcription d'un descendant du sic, désormais prononcé sans c implosif, étymon du si de l'AFC et de l'AOC, abondamment employé : si m'aït Dieus ! si nos secort li reis ! : "Que Dieu nous aide! Que le roi nous secourre». Le Franc ne pouvait pas prononcer un sic depuis longtemps prononcé « à la moderne », et le narrateur a respecté ce qu'il a entendu.

La langue du narrateur, tant dans le récit que dans ses propres interventions au style direct, est justiciable d'analyses convergentes qui trouveront ailleurs leur développement. Certes, sa mise par écrit implique un filtrage et un toilettage. Mais ces deux opérations n'établissent pas un clivage entre une oralité qui serait inaccessible et une scripturalité qui serait artificielle (c'est la thèse d'une partie des romanistes). Le rapport écrit/oral est certainement plus tendu qu'au temps du LPC, ou qu'en français du XIX siècle, mais il n'est ni brisé, ni artificiel. La preuve en est que ce récit porte de nombreux traits de l'oralité tardive, qui caractérise le latin parlé du VI siècle [Stotz, t.1, 2004] dont par ailleurs les puristes déplorent la «barbarie », inventant ainsi un " mauvais latin », selon des critères qui ont peu à voir avec la linguistique, ce qui est d'autant plus dommageable, puisque ces documents se trouvent ainsi doublement rejetés, et comme " continuateurs latins » (axe esthétique) et comme «authentifiables pour la parole réelle » (axe linguistique).

\section{Du latin de Provence}

Comme vous le voyez, en conclusion, les méthodes modernes de la linguistique diachronique répondent à trois innovations: elles respectent bien mieux les savoirs de ceux qui ont vécu les événements décrits [Van Uytfanghe, 2013] ; elles appliquent des grilles de lecture à la fois plus complexes, mais aussi plus souples que les paramétrages anciens [Mostert, 2013] ; elles ne refusent pas d'affronter la réalité langagière dans sa spécificité et sa dynamique réelle [Richter, 2013]. Si l'on compare les caractères du latin consigné dans la page précédente aux fluctuations de niveau de langue attestées dans le reste de la Vita, mais aussi dans les sermones et les autres Euvres de Césaire, notamment des règles monastiques [Courreau, De Voguë, 1988, 1994], on peut conclure à la cohérence linguistique de ces matériaux. Ils ouvrent des chemins d'accès vers la réalité du diasystème du latin tardif parlé en Provence à cette époque. L'oralité de Césaire d'Arles nous est ainsi rendue et à travers elle, la réalité d'une région encore latinophone [Norberg, 1999]. Pour être complet, il faudrait aussi tenter une reconstitution de la prononciation de cette langue écrite : nul doute $\mathrm{qu}^{\prime} \mathrm{au} \mathrm{VI}^{\mathrm{e}}$ siècle, elle avait fort évolué, avec quelques traits locaux annonçant la couleur des parlers du VIII siècle, tout en étant encore loin du clivage qui interrompra avant l'an mil la communication horizontale entre occitanophones et oïlophones [Banniard, 2004]. Ce sera peut-être pour une autre fois. 


\section{Résumé}

Cette communication traite de la problématique de la mémoire de la langue parlée, en suivant les principes et les méthodes de la recherche moderne sur ce domaine effectivement complexe. L'auteur anonyme de la Vita Caesarii défend la modestie de son latin en se plaçant sous l'égide de Césaire d'Arles qui, affirme-t-il, hoc et ipse domnus communi habuerit in sermone, quia quod erudite diceretur, intellegentiam doctis tantummodo ministraret, quod uero simpliciter, et doctos simul et simplices competenter instrueret. On montrera qu'à cette date les mots communis sermo, simpliciter, simplices désignent un niveau de langue à l'intérieur du diasystème du latin tardif parlé par une communauté de locuteurs (y compris la masse des rustici) encore latinophones, et non déjà romanophones. Les compromis langagiers que cela implique peuvent être illustrés par des fluctuations du latin de Césaire, attestées dans ses sermons, à la manière de son maître en communication, Augustin. La Provence " gothique » s'inscrit ainsi en périodisation longue du côté de l'Antiquité tardive finissant.

\section{Références}

\section{Caesarii Arelatensis opera :}

Ed. Morin G., Opera omnia, 1932, t. 1, Sermones, Maredsous ; t. 2, 1942, Opera varia, ib.

Ed. M.J. Delage, 1971-1986, Sermons au peuple, t. 1-3, Paris (SC).

Ed. M.J. Delage, 2010, Vie de Césaire d'Arles, Paris (SC).

Ed. Courreau J., De Voguë A., CEuvres monastiques, t. 1, 1988, CEuvres pour les moniales, Paris (SC) ; t. 2, 1994, CEuvres pour les moines, Paris (SC). 


\section{Bibliographie}

BANNIARD M., 1992, Viva voce. Communication écrite et communication orale du IV au IX siècle en Occident Latin, Paris.

BANNIARD M., 1993, Latin tardif et français prélittéraire: observations de méthode et de chronologie, in BSL, t. 88, p. 139-162.

BANNIARD M., 1991, Naissance et conscience de la langue d'oc (VIII / IXe siècle), in Zimmermann M. (éd.), La Catalogne et la France méridionale autour de l'an mil, Barcelone, p. 351-361.

BANNIARD M., 1998a, Variations langagières et communication dans la prédication d'Augustin, in Madec G.(éd.), Augustin prédicateur (395-411), Paris, p. 73-93.

BANNIARD M., 1998b, Niveaux de langue et communication latinophone d'après et chez Ambroise, in Pizzolato L.F. (éd.), Nec timeo mori, Atti del cong. int. di studi ambrosiani, Milan, p. 513-536.

BANNIARD M., 1996, Latin tardif et langue d'oc: de quelques témoignages sociolinguistiques, in Faucon J.C. (éd.), Actes du colloque Languedoc et langue d'oc, Supplément à Perspectives médiévales, t. 22, Paris, p. 33-46.

BANNIARD M., 2003, Structures accentuelles en latinophonie du Sud (III / VII siècle). Remarques sur les origines du partage entre langue d'oc et langue d'oül, in G. Hasenohr (éd.), Langues du Sud entre érosion et émergence, Paris, p. 14-31.

BANNiARD M., 2004, Parler en l'an Mil. La communication entre insularisme et flexibilité langagiers, in Bonnassie P., Toubert P. (éd.), Hommes et sociétés dans l'Europe de l'an Mil, Toulouse, p. 333-350.

BanNiard M., 2005a, Prérequis de réceptibilité du latin tardif en période de transition, in S. Kiss (éd.), Mélanges J. Herman, Tübingen, p. 105-113.

BANNIARD M., 2005b, Niveaux de langue et communication latinophone, in Settimana LII : Communicare e significare nell'alto medioevo, Spolète, p. 155-208.

BANNIARD M., 2006, Langue des Vies, langue des chartes aux VI ${ }^{e}$-VIII siècles : questions sur la réceptibilité de l'Écriture en Occident Latin, Bremer \& alii, p. 191-204.

BANNIARD M., 2013a, Migrations et mutations en latin parlé: faux dualisme et vraies discontinuités en Gaule ( $V^{e}-X^{e}$ siècle), in Molinelli P., Lo Monaco F. (éd.), Plurilinguismo e diglossia fra Tarda Antichità e Medio Evo Bergamo, Florence, SISMEL, p. 89-117.

BANNIARD M., 2013b, The Transition from Latin to the Romance Languages, in Maiden M., Smith J. Ch. (dir.), The Cambridge History of Romance Languages, Cambridge, p. 57-106.

BEC P., 1971, Manuel pratique de philologie romane, t. 1, L'occitano-roman, p. 395-555.

BECK H.J., The Pastoral Care of Souls in South East France, during the Sixth Century, Rome, 1950.

BREMER E., JARNUT J., RICHTER M. (éd.), 2006, Language of religion - language of the people. Medieval Judaism, Christianity and Islam, Munich.

BROWN P., 2012, Through the Eye of a Needle. Wealth, the Fall of Rome, and the making of Christianity, Princeton. 
De Vic Dom, VAissetTe Dom, 1730, Histoire générale de Languedoc, t. 1, Paris.

DelaPlace C., 1986, Le sermo rusticus : la conquête spirituelle, in Paganus, Images du paysan et de la société rurale en Occident à la fin de l'Antiquité (IV $-V I^{e}$ siècle), Thèse de doctorat NR, (dir.) Ch. PIÉTRI, Université de Paris-IV, exemplaire dact., t. 2, p. 369-404.

DumÉZIL B., 2005, Les racines chrétiennes de l'Europe. Conversion et liberté dans les royaumes barbares ( $V^{e}-$ VIII $^{e}$ siècle), Paris.

ERNST G., GLESSGEN MD, SCHMITT Ch., SCHWEICKARD W., 2003 sqq., Romanische Sprachgeschichhte. Eine internationale Handbuch zur Geschichte der romanischen Sprachen, t. 1, Berlin-New-York. (8 vol.).

GARrison M., OrbAN A., MOSTERT M. (éd.), 2013, Spoken and written Language. Relations between Latin and Vernacular languages in the Earlier Middle Ages, Turnhout.

GLESSGEN MD, 2007, Linguistique romane. Domaine et méthodes en linguistique française et romane, Paris.

GRAUS F., 1965, Volk, Herrscher und Heiliger im Reich der Merowinger, Prague.

HÄGERMANN D., HAUBRICHS W., JARNUT J., 2004, Akkulturation. Probleme einer germanisch-romanischen Kultursynthese in Spätantike und frühen Mittelalter, (Ergängzungsbände zum Reallexikon des Germanischen Altertumskunde, t. 41), Berlin.

HEN Y., 1995, Culture and Religion in Merovingian Gaul, A.D. 481-751, Leyde.

LÜDTKE H., 2009, Der Ursprung der romanischen Sprachen. Eine Geschichte der sprachlichen Kommunikation, Zweite vermehrte und verbesserte Auflage, in Dialectologia pluridimensionalis romanica, Kiel.

Mostert M., 2013, Préface, in Garrison \& alii, p. VII-IX.

NorberG Dag, 1999, Cristianesimo e paganesimo in Gallia: un sermone di san Cesario d'Arles, in Norberg Dag, Manuale di Latino Medievale (A cura di Massimo Oldoni), Salerne, p. 125137.

RICHÉ P., 1962, Éducation et culture en Occident barbare, VI ${ }^{e}-V I I I^{e}$ siècle, Paris.

RICHTER M., 2013, Traces of Obliterated Vernacular Languages in Latin Texts, in Garrison \& alii, p. 1-9.

Rose E., 2013, Liturgical Latin in Early Medieval Gaul, in Garrison \& alii, p. 303-313.

STOTZ P., 1996-2004, Handbuch zur lateinischen Sprache des Mittelalters, 5 vol., Munich.

VAN UYTFANGHE M., 2013, L'ancien français archaïque et le fonctionnement de la communication vericale en Gaule (VII -VIII siècle), in Garrison \& alii, p. 149-162.

Wolfram H., 1990, Histoire des Goths, Albin Michel, Paris, 1990.

WRIGHT R., 1982, Late Latin and Early Romance in Spain and Carolingian France, Liverpool.

Wright R., 2003, A sociophilolgical Study of Late Latin, Turnhout. 


\section{Annexe 1 : Terminologie / Chronologie}

LPC : Latin Parlé d'époque Classique [-200 / + 200]

LPT : Latin Parlé Tardif [III ${ }^{\mathrm{e}}-\mathrm{VII}{ }^{\mathrm{e}}$ siècle]

LPT1 : LPT de phase $1\left[\mathrm{III}^{\mathrm{e}}-\mathrm{V}^{\mathrm{e}}\right.$ siècle] (LPT « impérial »)

LPT2 : LPT de phase 2 [VI ${ }^{e}-\mathrm{VII}^{\mathrm{e}}$ siècle] (LPT «mérovingien » en Gaule ; « wisigothique » en Espagne ; « lombard » en Italie).

PF : Protofrançais ( $\mathrm{VIII}^{\mathrm{e}}$ siècle).

AFC : Ancien Français Classique (IX $\mathrm{X}^{\mathrm{e}} \mathrm{XIII}{ }^{\mathrm{e}}$ siècle)

PO : Protooccitan (VIII ${ }^{\text {e siècle) }}$

AOC : Ancien Occitan Classique ( $\mathrm{X}^{\mathrm{e}}$-XIII ${ }^{\mathrm{e}}$ siècle)

CRIP- : Cas Régime Indirect non Prépositionnel («fonction » ablatif/ datif/ génitif»).

CRIP+ : Même statut, mais avec préposition.

PPP : Participe Passé Passif.

\section{Annexe 2 : Convergences autour de la Provence latinophone}

\section{Savoir requis : écoute directe du latin biblique par les illettrés :}

Sermo 6 (SC, t. 175) :

1.Quando aliquid de utilitate animae proferimus, fr. car., nemo se excusare conetur, ut dicat: "Non mihi uacat legere et ideo non possum Dei praecepta uel agnoscere uel implere». Nec dicat aliquis uestrum: "Non noui litteras, ideo mihi non imputabitur quidquid minus de Dei praeceptis impleuero ». Inanis est et inutilis excusatio ista, fr. car. Primum est, quod lectionem diuinam, etiamsi aliquis nesciens litteras non potest legere, potest tamen libenter audire. Qui uero litteras nouit, numquid potest fieri, quod non inueniat libros, in quibus possit scripturam diuinam relegere?

Lorsque nous énonçons quelque précepte qui bénéficie à l'âme, que personne ne tente de s'excuser en déclarant: "Je n'ai pas le temps de lire et c'est pourquoi je ne peux ni connaître ni accomplir les préceptes de Dieu ». Et que l'un d'entre vous n'aille pas dire : "Je ne sais pas lire, c'est pourquoi il ne me sera pas imputé d'avoir manqué de respect à tel ou tel précepte de Dieu». Vanité et inutilité de cette excuse. D'abord parce que la lecture divine, même si quelqu'un ne sachant pas lire ne peut pas la lire, il peut tout de même s'appliquer à l'écouter. Quant à celui qui sait lire, est-il possible qu'il ne trouve pas de livres dans lesquels il puisse relire l'écriture sacrée?

Sermo 6

2. Adtendite, rogo uos, fratres, hoc dico, quod non ignoratis. Nouimus enim aliquos negotiatores, qui cum litteras non nouerint, requirunt sibi mercennarios litteratos; et cum ipsi litteras nesciant, aliis scribentibus rationes suas ingentia lucra conquirunt. Et si illi, qui litteras nesciunt, conducunt sibi mercennarios litteratos, ut adquirant terrenam pecuniam, tu, quicumque es, qui litteras non nosti, quare etiam non cum pretio et mercede rogas, qui tibi debeat scripturas diuinas relegere, ut ex illis possis praemia aeterna conquirere?

Attention, je vous le demande, je le dis, ceci que vous n'ignorez pas. En effet, nous connaissons des commerçants qui, du fait qu'ils ne savent pas lire, vont chercher pour eux-mêmes des salariés qui savent lire et écrire. Et, alors que, quant à eux, ils ne savent pas lire, ils font des bénéfices considérables grâce à d'autres qui tiennent leur comptabilité par écrit. Alors, si ceux qui ne savent pas lire louent des salariés qui savent lire et écrire, pour acquérir des valeurs terrestres, toi, qui que tu sois, qui ne sais pas lire, pourquoi n'en requiers-tu pas un, contre argent et récompense, pour qu'il te relise l'écriture sacrée afin d'acquérir à partir d'elle les récompenses éternelles ?

Commentaire : Il s'agit bien de la communauté des locuteurs sans distinction culturelle. Césaire se heurte directement à leur mauvaise volonté, l'intérêt sociolinguistique étant que l'argument langagier (ils n'affirment à aucun moment ne pas comprendre le latin biblique) n'est jamais évoqué : cette ligne de défense aurait pourtant été autrement efficace [Banniard, 2006 ; Rose, 2013]. 


\section{Savoirs exclus, la voix des illettrés :}

3. Sed dicit aliquis: "Ego homo rusticus sum et terrenis operibus iugiter occupatus sum. Lectionem diuinam nec audire possum nec legere ». Quam multi rustici et quam multae mulieres rusticanae cantica diabolica amatoria et turpia memoriter retinent et ore decantant! Ista possunt tenere atque parare, quae diabolus docet, et non possint tenere, quod Chistus ostendit? Quanto celerius et melius quicumque rusticus uel quaecumque mulier rusticana, quanto utilius poterat et symbolum discere et orationem dominicam, et psalmos uel quiquagesimum uel nonagesimum parare et tenere et frequentius dicere, unde animam suam et Deo coniungere et a diabolo liberare! Nam quomodo cantica turpia in tenebras diaboli mittunt, sic cantica sancta Christi lumen ostendunt. Nemo ergo dicat: "Non possum aliquid de id, quod in ecclesia legitur, retinere. Sine dubio enim, si uelis, et poteris. Incipe uelle et statim intelleges ».

Mais quelqu'un dit: "Moi je suis un paysan et pris sans cesse par les travaux de la terre, je ne peux ni écouter, ni lire la lecture sacrée ». Mais combien de paysans et combien de paysannes retiennent de mémoire et chantent en entier de leur bouche de honteux cantiques érotiques soufflés par le diable! Ces horreurs que le diable leur enseigne, ils peuvent les retenir et les assimiler et ils ne pourraient pas retenir ce que le Christ leur montre? Avec combien plus de vitesse ou d'application n'importe quel paysan ou n'importe quelle paysanne, et avec combien plus d'utilité pourraient-ils apprendre le Credo et le Notre Père, et assimiler, retenir et réciter le plus souvent les psaumes 50 et 90 , d'où unir leur âme à Dieu et la séparer du Diable! Car tout comme les cantiques honteux mènent aux ténèbres du Diable, les cantiques purs montrent la lumière du Christ. Que nul donc ne dise : "Je ne peux retenir rien de ce qui est lu à l'église ». Assurément en effet, pour peu que tu le veuilles, tu le pourras. Commence par vouloir et tu comprendras sur-le-champ ».

Commentaire : Cette situation complète et enrichit la précédente. Elle prouve que la distinction ville/ campagne ne recouvre pas d'opposition langagière marquée. La variation diatopique est modérée. De plus, la voix de ces paysans et paysannes illettrées a bien été entendue par l'évêque qui s'offusque de leur côté «immoral », mais ne trouve rien à redire sur leur langage, que lui-même comprend manifestement sans difficulté. La variation diastratique, sûrement présente, ne révèle aucun clivage langagier, différence marquée avec la situation au temps d'Alcuin, qui déplorera l'état lamentable du latin parlé par les illettrés (rustica romana lingua) deux siècles et demi plus tard.

\section{Discipline requise, contre l'esquive :}

\section{Sermo 74}

1.Si uelitis agnoscere et diligenter adtendere, fratres carissimi, quantus dolor et quanta amaritudo sit in animo meo, quando uos uideo missas ad integrum perexpectare non uelle, et in uobis et in me poteratis habere misericordiam. Qui enim intellegit, quid in ecclesia agatur, quando diuina mysteria celebrantur, agnoscit quantum male faciunt illi, qui de ecclesia non expletis missis sine aliqua grandi necessitate discedunt...

Si vous vouliez bien reconnaître et accorder une attention ferme à la grandeur de la douleur et à la grandeur de l'amertume qui occupent mon cœur lorsque je vous vois ne pas vouloir assister intégralement jusqu'au bout à la messe, vous pourriez éprouver de la miséricorde et envers vous et envers moi. Celui en effet qui comprend ce qui se joue à l'église, quand les mystères divins sont célébrés, reconnaît combien agissent mal ceux qui s'en vont de l'église en dehors de quelque contrainte majeure sans que la messe soit terminée...

\section{Discipline adoucie, pour les handicapés :}

Sermo 77

1.Supplico, fr. car., et paterna pietate commoneo, ut quotienscumque oratio indicitur, qui forte pro aliqua infirmitate non potest genua flectere, uel dorsum curvare et ceruicem humiliare non differat... 
Je supplie et enjoins avec une pitié paternelle que, chaque fois que commence la récitation du Notre Père, celui que quelque maladie empêche de s'agenouiller, n'hésite pas à au moins se pencher et à baisser la tête...

Sermo 78

1.Ante aliquot dies, propter eos, qui aut pedes dolent, aut aliqua corporis inaequalitate laborant, paterna pietate consilium dedi, et quodam modo supplicaui, ut, quando aut passiones prolixae aut certe aliquae lectiones longiores leguntur, qui stare non possunt, humiliter et cum silentio sedentes, adtentis auribus audiant, quae leguntur.

Il y a quelques jours, à cause de ceux ou qui ont mal aux pieds ou qui souffrent d'un défaut physique, j'ai conseillé avec une pitié paternelle et j'ai en quelque sorte supplié que, lorsque sont lues des passions détaillées, voire des lectures longuettes, ceux qui ne peuvent pas rester debout, écoutent assis avec humilité et en silence d'une écoute attentive ce qui est lu...

Commentaire $(C, D)$ : Ces injonctions essentielles pour l'accès aux réalités les plus concrètes de la vie quotidienne confirment la valeur opératoire de la parole latinophone. L'évêque a du fil à retordre avec certains, prend d'autres en pitié, veille à la réalité de la participation sans aucun médiateur (interprète); en outre, la lecture à haute voix des textes écrits n'est pas non plus médiatisée, sauf à accepter une prononciation non hiératique et à mettre en place un pilotage intonationel.

\section{Indiscipline des dames :}

\section{Sermo 78}

Nunc uero aliquae de filiabus nostris putant, quod hoc aut omnes aut certe plures, quae sanae sunt corpore, frequenter debeant facere. Nam ubi uerbum Dei coeperit recitari, quasi in lectulis suis iacere uolunt. Atque utinam uel iacerent tantummodo, et tacentes uerbum Dei sitienti corde susciperent, non etiam se ita otiosis fabulis occuparent, ut quod praedicatur nec ipsae audiant nec alios audire permittant !.. Vnde rogo uos, uenerabiles filiae, et sollicitudine paterna commoneo ut, quando lectiones leguntur, aut uerbum Dei praedicatur, nulla se in terram proiciat, nisi forte quam nimium grauis infirmitas cogit, sic tamen ut non iaceat, sed magis sedeat et adtentis auribus quae praedicatur auido corde suscipiat.

Ah oui, mais certaines de nos filles pensent que ça, soit toutes, soit assurément la majorité, qui sont en excellente santé, elles ont à le faire assidûment, car lorsque la parole de Dieu vient de commencer à être lue à haute voix, elles veulent s'étendre comme si elles étaient sur leurs banquettes. Et si seulement elles se contentaient de s'étendre et si elles recevaient la parole de Dieu en silence d'un cœur assoiffé, sans en plus s'absorber dans des commérages qui les empêchent d'écouter la parole de Dieu sans permettre aux autres de le faire !... C'est pourquoi, mes vénérables filles, je vous demande et je vous enjoins avec une affection paternelle qu'aucune d'entre vous, lorsque sont lues les lectures ou qu'est proclamée la parole de Dieu, ne se laisse tomber à terre, sauf si quelque handicap sérieux l'y contraint, et encore sans s'allonger, mais plutôt en se tenant assise pour recevoir ce qui est dit à haute voix d'un cœur avide et de toutes ses oreilles.

Commentaire: Il s'agit probablement des femmes de l'élite, des «patriciennes» (uenerabiles filiae), tout aussi indisciplinées que les paysannes! S'allongeaient-elles vraiment par terre ? On peut en douter, sans doute disposaient-elles de couvertures ou de quelques éléments de confort, semblables à ceux dont elles usaient chez elles, in lectulis renvoyant sûrement à l'usage antique toujours vivant du «banquet couché ». Une fois de plus ces textes confirment la fiabilité "archéologique» de ces testimonia, avec toutes les conséquences qui en découlent pour des interactions à l'intérieur d'une communauté encore latinophone [Banniard 2005a]. 


\title{
Bernard Itier et la diglossie à Saint-Martial de Limoges (1195-1225)
}

Jean-Loup LEMAITRE

École pratique des hautes études

\begin{abstract}
Extrait de : Guylaine BRUN-TRIGAUD (dir.), Contacts, conflits et créations linguistiques, Paris, Édition électronique du CTHS (Actes des congrès des sociétés historiques et scientifiques), 2015.

Cet article a été validé par le comité de lecture des Éditions du CTHS dans le cadre de la publication des actes du $139^{\text {e }}$ Congrès national des sociétés historiques et scientifiques tenu à Nîmes en 2014.
\end{abstract}

Bernard Itier est un de ces «oubliés de l'histoire", pour reprendre le titre d'une chronique de Pierre Miquel donnée à France-Inter dans les années $1970^{1}$. Il est en effet absent de ce qui reste la référence en matière de littérature médiévale française, le Dictionnaire des lettres françaises, dans sa dernière édition revue par Geneviève Hasenhor et Michel Zink ${ }^{2}$, tout comme il l'est de la monumentale histoire de la littérature latine du Moyen Âge de Max Manitius ${ }^{3}$. Il faut se tourner vers des auteurs plus anciens et des ouvrages plus spécialisés pour en trouver mention comme Louis-Georges Oudart Feudrix de Bréquigny, au premier tome des Notices et extraits des manuscrits de la Bibliothèque du Roi, en 17874, Alfred Leroux dans ses Sources de l'histoire du Limousin, en $1895^{5}$, Auguste Molinier, dans ses Sources de l'Histoire de France, en $1902^{6}$, qui note au passage «la langue est un mélange de langue vulgaire et de latin peu correct»! L'encyclopédie en ligne Wikipédia lui consacre modestement cinq lignes... en allemand.

Et pourtant, son œuvre « historique » à fait l'objet de trois éditions, une par siècle, dont deux autonomes :

- Chroniques de Saint-Martial de Limoges, publ. d'après les manuscrits originaux, par Henri Duplès-Agier, Paris, 1874 (Société de l'Histoire de France, 167), p. 28-129 Chronicon Bernardi Iterii armarii monasterii S. Marcialis. [Cité Duplès-Agier].

- Bernard Itier, Chronique. Texte établi, traduit et commenté par Jean-Loup Lemaitre, Paris, 1998 (Les classiques de l'histoire de France au Moyen Âge, 39). [cité Lemaitre].

- The Chronicle and Historical Notes of Bernard Itier, Edited end Translated by Andrew W. Lewis, Oxford, 2012 (Oxford Medieval Texts). [cité Lewis].

C'est que son œuvre de «chroniqueur » n'est pas anodine, sans toucher à la "grande histoire » comme celle d'Adémar de Chabannes par exemple ou d'Hugues de Flavigny. $C^{\prime}$ est un chroniqueur au sens moderne du terme, journalistique même, et nous avons d'ailleurs qualifié dans notre édition son principal manuscrit de «bloc-notes ». C'est aussi un des rares auteurs médiévaux dont la production conservée est exclusivement autographe et n'a pas fait l'objet de copies, sinon quelques extraits pris par dom Claude Estiennot en 1675, mais il s'agit là de copies d'érudit?

1. Pierre Miquel, Les oubliés de l'histoire.

2. Dictionnaire des lettres françaises, Le Moyen Âge.

3. Max Manitius, Geschichte der lateinischen Literatur des Mittelalters. III. Vom Ausbruch des Kirchenstreites bis zum Ende des 12. Jahrhunderts. Il est vrai toutefois que l'activité principale de Bernard Itier se situe au début du XIII ${ }^{\mathrm{e}}$ siècle.

4. Louis-Georges Oudart Feudrix de Bréquigny, « Note d'une chronique autographe de Bernardus Iterius, bibliothécaire de l'abbaye de Saint-Martial de Limoges dans le treizième siècle, contenue dans le manuscrit du Roi coté 1338».

5. Alfred Leroux, Les sources de l'histoire du Limousin, p. 56, qui n'en dit d'ailleurs pas grand chose.

6. Auguste Molinier, Les sources de l'histoire de France, II. Époque féodale. Les Capétiens jusqu'en 1180, p. 109$110, \mathrm{n}^{\mathrm{O}} 1477$.

7. Lemaitre, p. XCI-XCII. 


\section{L'homme}

Nous renvoyons pour le détail de la vie de notre homme, relativement longue pour l'époque, soixante-deux ans, à l'introduction de notre édition ${ }^{8}$. Bernard Itier a été en effet prolixe dans ses notes sur sa famille et sur lui-même. Retenons seulement ici quelques dates pour le situer: il naît à Limoges en 1163 de Pierre Itier et de Marie, son père mourant en 1188. Il est écolier et moine à Saint-Martial en 1177, diacre en 1185, à 22 ans, prêtre en 1189, à 26 ans, trésorier de l'abbaye et sous-bibliothécaire en 1195, sous-chantre en 1198, bibliothécaire (armarius) en 1204 il occupe cette charge jusqu'à sa mort le 23 janvier 1225. Il est également troisième prieur entre 1204 et 1209.

C'est son activité de bibliothécaire de Saint-Martial, charge généralement confondue avec celle de chantre, qui lui a d'abord permis de passer à la postérité ${ }^{9}$. Il est intervenu sur une centaine de manuscrits, faisant des tables de leur contenu, les faisant relier, rédigeant l'inventaire de la bibliothèque (111 items), mais aussi de la sienne (10 items) et celui des livres de médecine conservés dans l'infirmerie ${ }^{10}$, achetant aussi des livres, copiant des textes... Ayant donc la haute main sur les livres de la bibliothèque, il a pu également en abuser il a ainsi couvert les marges de quantité de manuscrits de notes qui n'ont rien à voir avec son métier de bibliothécaire et a entrepris de rédiger une "chronique », c'est ainsi qu'il désigne l'actuel ms. BNF lat. 1338 dans son inventaire [147] Himni cum cronica. Il a réuni deux volumes de même format, dix cahiers d'un séquentiaire et d'un prosaire $\mathrm{du} \mathrm{XI} \mathrm{e}^{\mathrm{e}}$ siècle (ff. 1-142) et la traduction par Boèce des Topiques d'Aristote, du XII siècle (ff. 143-253), qui offraient l'un et l'autre de très belles marges, dépourvus l'un et l'autre de foliotation ancienne. Il a réparti ses notes en suivant un ingénieux système à partir de l'an mil, elles sont placées sur le folio recto correspondant à la dizaine qui termine le millésime », par exemple le fol. 77 correspond à 1077... C'est un peu plus compliqué pour le XIII ${ }^{\mathrm{e}}$ siècle, du fol. 202 au fol. 225r, " elles ont été placées sur des feuillets dont les deux premiers chiffres sont en rapport avec le $2^{\mathrm{e}}$ et le $3^{\mathrm{e}} \mathrm{du}$ millésime et dont le dernier chiffre se rapproche le plus possible du dernier chiffre énoncé dans la date ${ }^{11}$.

Bernard Itier n'a pas agi autrement que ses devanciers, il les recopie, les abrège, ce qui fait que toute une partie de sa chronique n'offre que peu d'intérêt. Les choses changent progressivement à partir de la seconde moitié du XII ${ }^{\mathrm{e}}$ siècle. Il continue à exploiter les autres, comme Geoffroy de Vigeois, dont le manuscrit est dans la bibliothèque de l'abbaye, sous sa garde, mais il va aussi s'appuyer sur la mémoire collective puis devient un témoin oculaire des faits rapportés. À partir des années 1180, les notes prennent de l'importance, touchant certes quelques grands évènements, vus de Limoges, mais surtout les évènements marquants de la vie de l'abbaye, de la ville, de la région. Les marges de sa «chronique » ne suffisent plus et il utilise celles de nombreux autres manuscrits, notant parfois le même fait en plusieurs endroits. C'est de la micro-histoire, frisant parfois les ragots, mais une histoire que l'on ne trouve pas ailleurs et qui fait pour nous tout son intérêt pour l'histoire de la vie d'une communauté monastique et de la vie quotidienne tout court.

8. Lemaitre, p. I XXXIII. Voir aussi Lewis, p. 251-257.

9. Lemaitre, p. XXXIV-LV. Voir aussi Jean-Loup Lemaitre, «Un bibliothécaire modèle? Bernard Itier, bibliothécaire de Saint-Martial de Limoges (1195-1225)».

10. Voir Jean-Loup Lemaitre, «Les livres de médecine dans les monastères clunisiens au Moyen Âge d'après les inventaires et les livres conservés ».

11. Bréquigny, voir Lemaitre, p. LXXXIII. 


\section{La diglossie de Bernard Itier}

En 1177 Bernard Itier est reçu à Saint-Martial, à l'école monastique (monachus receptus, puer scolaris), il va donc apprendre à parler latin, la langue vernaculaire en usage a Limoges étant l'occitan (lemozi), qui tend depuis les années 1120 à supplanter le latin dans les actes de la pratique ${ }^{12}$.

Si l'on considère ses sources écrites, on remarque que l'occitan est absent de la chronique d'Adémar de Chabannes ${ }^{13}$, mais qu'il fait quelques timides apparitions dans la Commemoratio abbatum basilice S. Marcialis, à travers des additions des continuateurs d'Adémar. Il en va différemment avec la chronique de Geoffroi de Breuil, prieur de Vigeois, lui aussi moine de Saint-Martial et que Bernard Itier a sans doute connu puisqu'il meurt peu après 1183 , sans doute en $1184^{14}$. Nous aurions pu traiter ici pareillement de la diglossie de Geoffroi : nous sommes dans le même lieu, dans le même monde, l'abbaye de Saint-Martial de Limoges, avec deux moines appartenant à des familles locales, aisée pour Bernard, noble pour Geoffroy, né vers 1140 et mort vers 1184, peut-être à la suite de l'effondrement d'un pan de mur le 17 octobre 1183 à Arnac, où il fut blessé à la tête ? L'emploi de l'occitan dans leurs textes est proche, mais plus accentué chez Bernard, son cadet d'une vingtaine d'années. Alors que le texte de la chronique de Geoffroi n'est connu, à quelques passages près ${ }^{15}$, qu'à travers des copies des XVII ${ }^{\mathrm{e}}$ et XVIII siècles, celui de Bernard l'est uniquement par des notes autographes, à travers lesquelles on peut d'ailleurs suivre l'évolution de sa presbytie, comme l'a fait naguère MarieThérèse d'Alverny ${ }^{16}$. On est en présence de son parler, tel qu'il l'a transcrit, sans la contamination possible de copistes ou de réviseurs.

Andrew W. Lewis, qui s'est intéressé à la latinité de Bernard ${ }^{17}$, est réservé (p. L) à l'égard d'une des hypothèses que nous avions avancée en 1998, à propos des notes contemporaines, à savoir que Bernard écrivait en latin mais pensait sans doute d'abord en langue vernaculaire, qu'il nuance en estimant que le latin de Bernard était fortement influencé par le langage oral, que c'était en quelque sorte le latin parlé à Saint-Martial. Sur le fond, le résultat est le même.

Sur les 149 paragraphes que compte notre édition de la chronique, 51 présentent des formes occitanes, allant d'une seule, comme dans le $\S 17$, «Abbo abbas, qui Sancto Marciali dedit Sanctum Valericum et Sancto Stephano Salanac ", à plus d'une centaine comme dans les derniers paragraphes correspondant aux années 1220-1223. Il est présent dans les $\S \S 106-148$, sauf dans les $\S \S 109-110,112-113,116-117,122,134$ et 130, soit pour les années 1182 à 1224.

Comme chez Geoffroy de Vigeois, l'occitan est employé majoritairement pour les noms de personne et les noms de lieu, mais aussi pour des noms de matières, avec un nombre d'occurrences beaucoup moindre, qui permet de les passer systématiquement en revue.

12. Voir par exemple les cartulaires en rouleau de l'aumônerie de Saint-Martial, arch. dép. de la Haute-Vienne, H Supp. Limoges, B 1, A 2-A 3, éd. Alfred Leroux, « Premier / second cartulaire de l'aumônerie de S. Martial », et Clovis Brunel, Les plus anciennes chartes en langue provençale, Supplément, $\mathrm{n}^{\text {os }} 350-354,357-358$.

13. Ademari Cabannensis Chronicon.

14. La seule édition complète disponible de la chronique de Geoffroy de Vigeois reste celle donnée par Philippe Labbe dans sa Nova Bibliotheca manuscriptorum librorum, t. II, p. 279-342. Le livre I a été publié par Pierre Botineau, Geoffroi de Breuil, prieur de Vigeois, Chronique (Première partie), thèse inédite de l'École des chartes, 1964. Une nouvelle édition est en préparation pour la société de l'Histoire de France, reprenant pour la première partie le texte procuré par Pierre Botineau, accompagné d'une traduction préparée par Bernadette Barrière et ses anciens étudiants de l'université de Limoges.

15. Voir Jean-Loup Lemaitre, «Les emprunts à la chronique de Geoffroy de Vigeois dans le Majus chronicon Lemovicense (BNF lat. 5452)».

16. Marie-Thérèse d'Alverny, «L'écriture de Bernard Itier et son évolution ».

17. Lewis, p. XLIII-LIV. 


\section{Les termes techniques}

Des mots techniques isolés d'abord, concernant la liturgie, les vêtements et vases sacrés, les fêtes et les offices :

- «Henricus Anglie rex junior ...pallium de baudequin obtulit» (§ 106,1 : 1182) ${ }^{18}$. - Un ornement en drap de soie, mais on notera que le mot, vernaculaire certes, n'est pas occitan; c'est même le seul mot d'ancien français présent dans les notes de Bernard Itier.

- «Iste [Henricus junior] de thesauro nostro habuit... l-orzol d-argent ... » (§ 107, 2 : 1183). - L'aiguière en argent, cf. Levy ${ }^{19}$ S.v. orjol, orzol, «cruche, pot, burette ». Ce dernier sens, les burettes, pourrait également être retenu.

- « casula de samiz vert cum stola et manipulo a Petro Cofolent» (§ 139, 2 : 1217). - Levy, samit, «étoffe de soie ».

- «Octavas Pasche in r (esponsis) dobles cepimus celebrare» (§ 133, 2 : 1211). - Il s'agit des répons doubles, pour lesquels l'expression duplex est largement employée dans la liturgie.

- «Nativitas sancti J (ohannis) Babtiste cum primclas et processione sollemni... octaba Omnium Sanctorum en respo dobles... » (§ 146, 9 : 1223). - Princlas, primclas est absent du dictionnaire de Levy, le mot est fait de la réunion de l'adjectif prim «premier» et du substantif clas, "sonnerie de cloche, glas", correspondant à une grande sonnerie, une sonnerie solennelle. On le retrouve en particulier dans la liturgie des défunts, avec le sens de « glas ».

- la vie à l'abbaye :

- «Vitrea magna, que est super archam de la obra, similiter corruit $(\S 137,8: 1215)$ ». La grande verrière, qui est au-dessus du coffre de l'œuvre, s'effondra pareillement ». Levy, s.v., donne parmi les divers sens, celui de l'administration des bâtiments. L'operarius, ou magister operis, était un des officiers de l'abbaye et est présent dans les listes de Bernard Itier $^{20}$.

- «Duo candelabra d-esmaus empta sunt IIII lb.»(§ 129,4: 1209), Levy, s.v. esmaut, «émail ».

- «... vacabant in abbatia la chabechasaria...»(§ 142, 6: 1220), "Étaient vacants dans l'abbaye la chèvecerie... ». Chabechasaria, absent de Levy, traduit capiceria.

- Li dozil de la font noviter fiunt» (§ 133, 1 : 1211). - Les trous de fausset (ou les faussets) de la fontaine sont refaits, cf. Levy, dozil, dozilh, «fausset ou trou du fausset ».

- «[Isembertus abbas] dedit quinque solidos de giomes in bona pellicia de agnis, et hoc anno dedi XXX solidos de barbaris » (§ 133, 21 : 1211). - Des sous de Gien (Loiret), cf. Du Cange, s.v. Moneta Giemensis ${ }^{21}$, les barbarins étant la monnaie de Saint-Martial de Limoges ${ }^{22}$.

- «XLIII solidi dantur en la lesda de Lemovicis, et L solidi en la lesda de Chaluz» (§ 134, 16, 1214). - Levy, sur la forme leuda, leid, leusda, traduit simplement par «leude », il vaudrait mieux « leyde », s'agissant des droits perçus sur les transactions faites sur les marchés, ici au bénéfice de l'abbaye.

- «Stephanus abbas fecit la morena »(§ 148, [920]). Morena est absent de Levy, mais est cité par Du Cange, à partir des sources limousines, avec un double sens, celui de « charpente » et avec celui de reliquaire, d'après Geoffroy de Vigeois (Labbe, II, 312), ... ferentes morenam, id est imaginem protomartyris... Une première occurrence, latine, figure au § 30, l'année 920 (902 corrigée), Stephanus fecit morenam et turrem de Cortina. Nous n'avons pas traduit ce mot, qui revient à plusieurs reprises chez Geoffroy pour désigner un reliquaire, mais dans sa Commemoration abbatum, Adémar de Chabannes dit aussi que l'abbé Etienne fit faire et placer sur l'autel une église d'or et d'argent appelée Munera... Hic composuit super altare Salvatoris ecclesiam ex auro et gemmis et argento, quam vocavit

18. Lorsque les citations vont au-delà d'un seul nom + surnom, nous donnons la référence à notre édition à la suite ( $\mathrm{n}^{\circ}$ de $\S, \mathrm{n}^{\circ} \mathrm{d}^{\prime}$ alinéa : date).

19. Emil Levy, Petit dictionnaire provençal-français.

20. Voir Lemaitre, p. 88.

21. A. Dieudonné, Manuel de numismatique française. T. IV, p. 320-321 ; Lemaitre, p. 183.

22. A. Dieudonné, Manuel de numismatique française. T. IV, p. 248-249. 
Muneram ${ }^{23}$. Bernard Itier a certes condensé sa source. Faut-il voir une métathèse entre le Munera d'Adémar et de Geoffoy et le Morena de Bernard C'est le sens qu'a retenu Lewis dans sa traduction ${ }^{24}$.

- «La croz commendatur a Malmiro» (§ 146, 6, 1223). - Levy, s. v., crotz, la croix est ici donnée à un Limougeaud partant en Terre sainte. Malmiro figure sur une liste de moines de l'abbaye copiée en 1224 par Bernard Itier (BNF, lat. 10400, f 133).

- Quelques événements de la vie limougeaude et marchoise, comme l'arrivée des franciscains à Limoges :

- «Li Menudet ante ecclesiam Sancti Pauli adunantur (§ 146, 6: 1223); - Ordo deu Menudet a S(an) Paul recipitur» (§ 146, 9-10 1223). Levy, s. v. menudet, (adj.), " tout petit», (s. m.), « petit enfant » mais aussi «frère mineur », ce qui est le cas ici ${ }^{25}$.

- «Lo portals de Mairabou consummatur...»(§ 134, 2 : 1212) ... «Lo portal de Bocharia (§ 134, 13 : 1212). - Levy précise pour Portal, « portail ; porte d'une ville ». Il s'agit ici des deux portes de l'enceinte de Limoges, les portes Mirebeuf et Boucherie.

- «Populus Lemovicensis erexit X peireiras metu Philippi regis (§ 136, 2 :1214). Levy, s.v., Peirieira, au second sens, " pierrier, machine à lancer des pierres », qui est l'emploi ici.

- "Comes Ugo de Marchia novam monetam instituit apud Belac faciendam marques (§ 133, 5 :1211). - « Cenobium istud debet circiter XL.M. solidorum de marches » $(\S 138,9$ : 1216). Nous avons gardé l'expression «marques» dans notre traduction, la traduction donnée par Levy pour ce mot étant uniquement «marquis ». L'emploi de "marc » est ambigü pour cette monnaie féodale du comte de la Marche, effectivement appelée "marques, marquis", marchiones en latin, qui a été en usage jusqu'au début du XIV siècle ${ }^{26}$. - « capicerius [dedit] X marcs » $(\S 142,5: 1220)$.

- «Turris de Du, que erat de talucs, vehemencia ventorum cecidit» $(\$ 128,1: 1207)$, «la tour de Dun, qui était sur une motte, s'écroula sous la violence des vents... », cf. Levy, s.v. talus, «talus »; il faut comprendre ici une tour sur une motte.

- «Lodoicus filius Philipi, duxit uxorem la nepsa Johannis regis » (§121, 2 : 1200). - Levy, s.v., donne la même forme, nepsa, mais aussi nepta, netsa, « la nièce ».

On retiendra quelques expressions ou membres de phrases :

- «Anno gracie $\mathrm{M}^{\circ} \mathrm{C}^{\mathrm{o}} \mathrm{IX}$, incipit regnare lo reis gros, qui appellabatur Ludovicus 71, 1 : 1109). On renverra sur cette appellation à Suger et à sa vie de Louis VI, dont le titre donné par les manuscrits est Vita Ludovici grossi regis, gesta Ludovici regis cognomento grossi $i^{27}$.

- «J (ohannes) de Cusansa, burgensis de Marteu, cepit $\mathrm{R}$ (aymundum) vicecomitem de Torena, lo costeu a la gola, cunctis videntibus 102, 2 : 1178). L'acte de ce bourgeois de Martel (Lot) n'a pas besoin de traduction; Levy, s. v., donne la forme coltel, et gola, comme ici.

- «Li dozil de la font noviter fiunt...»(§ 133, 1 : 1211), voir supra.

- "Ecclesia S. Michaelis de Lemotges et de Rialac eran en tenso. Annunciationem beate Marie ab prim clas e ab processio festal per nosmetipsos devote fecimus ${ }^{28}(137,8: 1215)$. Le sens de tenso est bien sûr ici le premier, celui de «querelle ». Levi, s.v., donne procesion, et festal. - «Nous avons célébré dévotement l'Annonciation de la bienheureuse Marie avec sonnerie solennelle et procession festive ».

Anno $\mathrm{M}^{\circ}$ CCXXII, Fesc, DCCC et XIII cornudas sobre coisa las Cumbas CC (§ 144, $\left.9: 1222\right)$, «À Feytiat 813 cornues, sur la fournée des Combes 200. Il faut prendre ici le dernier sens de cornuda donné par Levy, s.v., " pâtisserie à trois cornes », très répandue en Limousin au Moyen Âge, souvent mentionnée dans les obituaires de Saint-Étienne et Saint-Martial de Limoges et de Solignac, et coisa comme dérivé de coire, cozer, « cuire ».

23. Duplès-Agier, p. 3

24. Lewis, p. 22.

25. Sur l'implantation des frères mineurs à Limoges, voir Lemaitre, p. 253.

26. Voir Adolphe Dieudonné, Manuel de numismatique française. T. IV, p. 292-293.

27. Suger, Vie de Louis VI le Gros, p. 2, et chap. XXIX, p. 236, XXXIII, p. 270.

28. BNF lat. 5064, f. 1. 


\section{Les noms de lieu}

Ils sont omniprésents dans les notes de Bernard Itier. L'abondance même des noms de lieu peut surprendre, car ce ne sont pas seulement des microtoponymes. La pratique de garder la forme vernaculaire de certains villages ou mas s'est d'ailleurs perpétuée jusqu'au XVIII ${ }^{e}$ siècle et on en trouve la trace dans les actes notariés mais aussi dans les documents plus officiels, comme les états des fonds confectionnés en Limousin dans les années 1740-1750.

Un bon nombre de ces noms de lieu bénéficie d'une forme latine bien attestée, et pourtant ils sont donnés en occitan. Ainsi cette mention d'un voyage de Bernard : "Fui a Clarmont, au Poi Sancta Maria, a la Chesa Deu» $(\S 129,1$ : 1208). Il ne peut ignorer les noms latins de Clermont, du Puy ou de la Chaise Dieu, ni ceux de Ventadour ou de Tulle, «Bernardus de Ventedor e Galart de Cardalac, electi de Tuela, in discordia perseverantes, destruunt monasterium » $(\S 132,6: 1210)$, et pour le règlement de cette querelle, "papa ... posuit finem negocio de Tuela, mandans ut Rocamador Bernardo abbati redderetur » (§ 134, 6 : 1212).

Lorsqu'il évoque les créations d'ordres nouveaux, l'occitan se mélange au latin, «... Cabilonis Cistercienses, a Masco Cluniacenses, [...], a Granoble Cartusienses » (§ 132, 1 : 1210). Les noms d'abbayes du diocèse de Limoges ou de diocèses voisins sont fréquemment en occitan, alors que les formes latines sont connues de lui, puisqu'il les utilise également :

- «monasteria Borguol e Malazes » (§ 40, 5 : 1000), Bourgueil et Maillezais.

- «prior de Grantmont. » (§86, 1 : 1152), Grandmont.

- « abbas de S. Michael la Clusa» (§92, 2 : 1161), La Chiusa S. Michele.

- «Miraculum de imagine lapidea de Duls» (§ 11, 3 : 1187), Déols [Bourgdieu].

- «abbas $d$-Usercha » (\$133, $7: 121)$, Uzerche.

- « abbates de Charros e d-Uzercha » (§ 144, 3 : 1222), Charroux et Uzerche.

- «Hugone, abbate de Solomnac », «Hugo abbas de Solonnac » (§ 135, 5, 12 : 1213).

- «Geraldus, abbas de Moleime» (§ 137, $1: 1215)$, Molesmes.

- «adjunctis sibi abbatibus de Beana et de Vusias (§ 144, 5 : 1222), " abbates d-Uzercha, de Beana, deu Daurat (§ 146, 12 1223), Baignes et Vigeois, Uzerche, Baignes et Le Dorat.

- «Sanctimoniales de Zurac (§ 126, 4 1205), Usurat, à Limoges.

- « abbas deu Palai » (§133, 12 : 1211), Le Palais.

- «W (illelmus) Gaufredi abbas de Tostoirac » (§ 138, $5: 1216)$, Tourtoirac.

- «W (illelmus) de Jaunac, prior de Monmorlo 139, 11 1217), Montmorillon.

Parfois en mélangeant les deux langues

- "prior Sancti Benedicti de Sauz » (§ 119, 1 : 1198), Saint-Benoît-du-Sault.

- «Alienor, sepulta est ad Font Ebraldi. » (§ 125, 2 : 1204), Fontevrault.

- «veni ad Sanctum Martinum de Tors » (§ 132, 3 : 1210), Saint-Martin de Tours.

- «P. d-Analac, capicerius, apud Sanctum Eutropium de Sanctas morabatur» $(\S 137,8$ : 1215), Saint-Eutrope de Saintes.

- «per episcopum [Sancti] Georgii de Ramas 99, 2 :1174), Saint-Georges de Ramla, au royaume latin de Jérusalem (act. Israël), «episcopum Sancti Georgii de Rama» dans Geoffroy de Vigeois, I, 69.

Les deux formes peuvent aussi voisiner, ainsi :

- «Gui de Blaom, abbas Dauratensis » (§ 127, 1: 1208), et «Hugo lo Brus, tunc comes de Marchia, destruxit muros de Subterranea e deu Daurat » (§ 128, 1: 1207), pour Le Dorat.

«Caercis, prior de Grandmont », et «Caercis prior Grandis Montis » $(\S 138,2,3: 1216)$, pour Grandmont.

On remarque la même chose pour les noms de seigneuries ou de principautés territoriales :

- «Boso, comes de Marchia (§ 91, 2 1160), la Marche. 
- «Audebertus, comes de la Marcha 102, 4 : 1178).

- «Nafilat, bonus senescalcus de Marchia 131, 8, 1212).

- «Hugoni lo Brus, qui comitatum d-Engoleime post mortem supradicti Ademari possessurus erat » $(\S 121,3: 1200)$, Angoulême.

- « comes del Perche » (§ 139,5 : 1217), le Perche.

- «Vicecomitissa de Ventedor Maria » (§ 141, 6: 1219), Ventadour, un des quatre vicomtés du Limousin.

- «Ludovicus rex ... habuit secum comitem d-Engoleime e de la Marcha et vicecomitem Lemovicensem $e$ de Torena » (§ 147,5 : 1224), les comtes d'Angoulême et de la Marche, les vicomtes de Limoges et de Turenne...

- «Apud Acram, obiit Hugo de Surgeiras, vicecomes de Chastel airau » (§ 134, 6: 1212).

On notera que le vicomte de Limoges (ou la vicomtesse) est toujours désigné par la forme latine, vicecomes Lemovicensis, Sarra vicecomitissa...

Où l'occitan est quasiment de règle, c'est pour toutes les dépendances de l'abbaye SaintMartial, prévôtés et prieurés, dont Bernard Itier a dressé notamment la liste, conservée dans le ms. Vossius Oct. 15 de Leyde ${ }^{29}$, où la quasi-totalité des noms des soixante-dix-huit dépendances répertoriées sont en occitan. On les retrouve, parfois groupées, au fil des notes:

- "Prioratus de Vusias, de Chambo, d-Arnac, de Monleu, de Riupeiros, de Rofiaco, de Monmorlo vacabant, de Du, de Malveira, de Pairac, d-Ichiduol, de Cirac, de Sancta Valeria... »(§ 144, 5 : 1222).

Si l'on fait exception des anciennes abbayes réduites au rang de prieuré (Vigeois, Arnac et Paunat), des prévôtés (Chambon-Sainte-Valérie et La Souterraine), il s'agit de petites maisons comptant le plus souvent un ou deux moines ${ }^{30}$, désignées d'abord par leur nom occitan, Montandre, S. Sauri, Monleu, Peiraficha, lo Doat, Roffiec... Montendre, Saint-Sour [de Terrasson], Montlieu, Pierrefitte, Le Duhet, Ruffec... et l'on peut comprendre que ce soient ces formes vernaculaires qui reviennent d'abord sous la plume de Bernard Itier?

\section{Les noms de personne}

Ce sont de loin les plus nombreux dans les notes de Bernard Itier, plusieurs centaines, et l'on retrouve le même système que pour les noms de lieu :

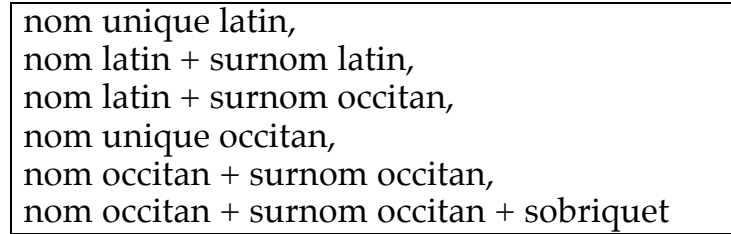

Avec parfois une difficulté d'interprétation, Bernard Itier usant largement d'abréviations, il n'est pas toujours évident de savoir si l'initiale seule correspond à la forme latine ou occitane, en raison de la mixité des systèmes, "J. de Cusansa, burgensis de Marteu », "J. de Colonjas, quondam abbas deu Palai ${ }^{31}$..

On passera rapidement sur le nom unique latin, qui correspond aux périodes anciennes et concerne surtout des noms de rois et de princes, d'évêques de Limoges ou d'abbés de Saint-Martial, voire de simples religieux, Ludovicus rex, Amalricus rex Jherusalem, Alienor regina Anglorum, Willelmus dux Aquitanie, Abbo abbas, Eustorgius episcopus..., mais certains

29. Leiden, bibl. univ., Vossius, oct. 15, f. 190, éd. Lemaitre, n 159,p. 89-92.

30. Voir Charles de Lasteyrie, L'abbaye Saint-Martial de Limoges..., p. 350-407; Jean-Paul Avisseau, « Les prieurés de l'abbaye Saint-Martial de Limoges ", dans Positions des thèses de l'École nationale des chartes, 1963, Paris, ENC, 1963, p. 9-14.

31. Voir Louis Pérouas (dir.), Léonard, Marie, Jean et les autres. Les prénoms en Limousin depuis un millénaire ; - Bernadette Barrière, «L'anthroponymie en Limousin aux XI et XII siècles ». - Ead., " La dénomination chez les vicomtes limousins : le lignage des Comborn ». 
de ces noms peuvent être suivi d'un qualicatif, "Gaufredus presbiter, prior de Laureira" (§ 91,2: 1160), « Helias capellanus de Tarn » (§ 120, 1: 1199)...

Le deuxième type, nom latin + surnom latin, est peu fréquent. Donnons quelques rares exemples: «quidam burgensis, qui appellabatur Petrus Vitalis (§ 126, 3:1205), Petrus Auderii, Petrus Pictavinus, Iterius Bernardi, Gaufredus de Niolio, "Audierius Iterii, frater armarii » (§144,3:122), B (ernardus) Raim (undi)...

Avec le troisième type, nom latin + surnom occitan, on touche une grande majorité des noms, avec la réserve faite ci-dessus lorsque le nom est réduit à une initiale Jordanus de Cabanes, Petrus de Bordeus, Petrus deu Barri, Hugo Bausart, W (illelmus) de Manauc, Hugo de Barbais, "Hugo de Clermont abbas Cluniacensis (§ 120, 1: 1199), "unus sacerdos, qui vocabatur Helias Guitbert»(§ 121, 1: 120), A. Marteu capicerius, Helias la Mosnaria, «Petrus Girau, notarius domini pape Innocencii III » (§ 127, 1 1206), « obierunt $A$. de Sant Remei, Gaufredus Lacela, prior de Rofiaco, Boso de Mathaz, abbas Stirpensis, Helias Berquet, Petrus Chavalers, sacerdos » (§ 129, 3 1208), « obiit Petrus de Chasteunou, lancea percussus inter hereticos ( $\S 129,6: 1208)$, le légat Pierre de Castelnau, assassiné le 15 janvier 1208 à Trinquetaille.

Le quatrième type, nom unique occitan, est rare : «Chatart, clarissimus aurifex » (§ 133, 13 : 1211), Merchaders, Caercis, Mainart, Joscineu...

Le cinquième type, nom occitan + surnom occitan, est lui aussi assez largement répandu, un peu moins toutefois que le précédent : «Gaufre de Bruil, tunc prior Vosiensis 108, 1: 1184), «Gui de Blaom, abbas Dauratensis » (§ 127, 1 : 1206), "Galart de Cardalac, electi de Tuela 132, 6 : 1210), Marti Alcair, Folcau de Laia, Aimar la Ribeiria, magister Arnau Espero, magister Aiceli de Barmont, Gaubert Palmut, Aimar deu Perer, Gaufre Lancles, Bertran de Longa, Gaucelm de Cossac, Nicolau Faure, Gaucelm de Peirabufeira, Bertrans Relier, Gui Gaucelm, Gui Folcau, Humbert Gui, Audoi de Perrussa, Gaucelm de Meiras, Perrio d-Espana, Perrio Bonabocha...

Il faut aussi prendre en compte l'ambivalence de certains prénoms, au nominatif ou au cas sujet comme Helias, Helias de Lopsaut, He (lias) Chalboi, Helias Cofolent...

Le sixième et dernier type, nom occitan + surnom occitan + sobriquet, est quant à lui, très rare et l'on n'en relève qu'un seul exemple : "Johan deu Peirat lo jauvi », "J. deu Peirat lo Jauvi » (§ 126, 3: 1205). Il en va de même pour l'équivalent en latin, où l'on relèvera seulement « Helias Iterii junior » $(\S 143,6: 1221)$.

Il serait vain de multiplier les exemples, que l'on retrouvera plus ou moins facilement dans les éditions de la chronique (A. W. Lewis n'a pas distingué les mots en langue vernaculaire). L'intérêt majeur de ce texte, outre l'ampleur des mentions qu'il donne, est qu'il est autographe et daté et qu'il montre la place prise par la langue occitane à Limoges dans les premières décennies du XIII ${ }^{\mathrm{e}}$ siècle, une place qui va aller croissant au fil du temps. Bernard Itier est un moine certes cultivé - il est bibliothécaire de la principale abbaye de la ville -, mais ce n'est pas un grand érudit. C'est un bon témoin du niveau moyen des élites locales, il parle et il écrit latin, mais il est aussi familier de la langue occitane, qui est la langue commune dans cette région du Limousin.

Le cartulaire du consulat du Château, commencé dans les années 1230, quand meurt Bernard Itier, et continué jusqu'aux premières années du $\mathrm{XVI}^{\mathrm{e}}$ siècle, est intégralement rédigé en occitan ${ }^{32}$, langue qui va être utilisée pour la rédaction d'un certain nombre de registres, de «cartulaires » et de «lièves » dans les milieux de la bourgeoisie pieuse limougeaude, jusqu'au début $\mathrm{du} \mathrm{XVI}^{\mathrm{e}}$ siècle. Il suffit de parcourir la liève de la confrérie

32. Camille Chabaneau, Cartulaire du consulat de Limoges. Voir aussi la thèse d'École des chartes d'Aubin Leroy, Le cartulaire du consulat de Limoges. Un livre juratoire de l'occitan limousin, XIII $^{\mathrm{e}}-\mathrm{XVIII}^{\mathrm{e}}$ siècles, 2005 . = École nationale des chartes. Positions des thèses soutenues par les élèves de la promotion de 2005..., Paris, ENC, 2005, p. 118-123. 
des premières chandelles, rédigée en 1388 pour en avoir un bon aperçu ${ }^{33}$. Alfred Leroux a montré qu'il y avait, dès le commencement du XIV ${ }^{\mathrm{e}}$ siècle, des bourgeois de Limoges qui comprenaient le français, mais ce n'est qu'à l'extrême fin $d u X V^{e}$ siècle que le français se substitue à l'occitan et au latin ${ }^{34}$. Pourtant, jusqu'au XVIII ${ }^{\mathrm{e}}$ siècle, on continue à utiliser en Limousin l'occitan pour désigner de nombreux noms de lieu, des noms de personne et des termes dont on ne connaît pas la traduction en français, comme le faisait Bernard Itier dans les deux premières décennies du XIII ${ }^{\mathrm{e}}$ siècle.

\section{Résumé}

L'abbaye de Saint-Martial de Limoges est un des hauts lieux de la culture limousine, célèbre pour l'importance et la qualité des productions de ses auteurs comme de son scriptorium. $C^{\prime}$ est aussi un des berceau de la langue limousine (nord occitan). Si la langue de la liturgie et des chroniqueurs reste avant tout le latin, celle de la vie quotidienne est aussi le limousin et Bernard Itier nous offre un excellent exemple de diglossie. Bibliothécaire de l'abbaye de 1198 à sa mort en 1255, il rédige une chronique, accumulation de notes classées chronologiquement sur les marges de deux manuscrits qu'il réunit en un seul volume (auj. BNF, lat. 1338 : éd. J.-L. Lemaitre, Paris, 1998 ; A. W. Lewis, Oxford, 2012) et sur celle d'une trentaine d'autres volumes. Il écrit en latin, mais très souvent, il utilise l'occitan pour des noms de personne ou de lieu certes, qu'il pourrait facilement traduire, pour des termes techniques, ou la forme occitane vient spontanément sous sa plume, mais aussi pour des propos qu'il rapporte.

Sources: mss. BNF lat. 1338 et marginalia de 32 autres mss. de la BNF, Bibl. apost. Vaticane, bibl. de L'université de Leyde.

\section{Bibliographie}

Ademari CABAnNensis Chronicon, éd. Pascale Bourgain, avec la collab. de Richard LANDES et Georges PON, Turnhout, 1999 (Corpus christianorum Continuatio mediaeualis, CXXIX).

BARRIÈRE Bernadette, "L'anthroponymie en Limousin aux XI ${ }^{\mathrm{e}}$ et XII ${ }^{\mathrm{e}}$ siècles ", dans Genèse médiévale de l'anthroponymie moderne, Tours, publ. de l'université de Tours, s.d. (I ${ }^{\text {re }}$ et $\mathrm{II}^{\mathrm{e}}$ rencontres d'Azay-le-Ferron), p. 23-34.

BARRIÈRE Bernadette, «La dénomination chez les vicomtes limousins le lignage des Comborn, dans Genèse médiévale de l'anthroponymie moderne, t. III, Enquêtes généalogiques et données prosopographiques, Tours, publ. de l'université de Tours, s.d. (I ${ }^{\text {re }}$ et $\mathrm{II}^{\mathrm{e}}$ rencontres d'Anzay-le-Ferron), p. 65-80.

BERnARD ITIER, Chronique. Texte établi, traduit et commenté par Jean-Loup LEMAITRE, Paris, 1998 (Les classiques de l'histoire de France au Moyen Âge, 39). [cité : Lemaitre].

BRUNEL Clovis, Les plus anciennes chartes en langue provençale, Supplément, Paris, 1952.

ChabaneAu Camille, Cartulaire du consulat de Limoges, Montpellier, Société des langues romanes, 1895.

33. Jean-Loup Lemaitre et Françoise Vielliard, «La liève de la confrérie des Premières Chandelles à Limoges (1388)».

34. Voir aussi Alfred Leroux, « De la substitution du français au latin et au provençal à Limoges ». 
Chronicle (The) and Historical Notes of Bernard Itier, Edited end Translated by Andrew W. LEWIS, Oxford, 2012. (Oxford Medieval Texts). [cité : Lewis].

Chroniques de Saint-Martial de Limoges, publ. d'après les manuscrits originaux, par Henri DUPLÈS-AGIER, Paris, 1874 (Société de l'Histoire de France, 167). [Cité : Duplès-Agier].

Dictionnaire des lettres françaises, publ. sous la dir. du cardinal Georges GRENTE. Le Moyen Âge, ouvrage préparé par Robert BOSSUAT, Louis PICHARD et Guy RAYNAUD DE LAGE, éd. revue [...] sous la dir. de Geneviève HASENOHR et Michel ZINK, Paris, Fayard, 1992.

DIEUDONNÉ Adolphe, Manuel de numismatique française. T. IV. Monnaies féodales françaises, Paris, Picard, 1936.

DUBOIS Jacques, «Bernard Itier, bibliothécaire de Saint-Martial de Limoges », École pratique des Hautes Études, IV Section, Livret I, 1978-1981, p. 153-154.

LABBE Philippe, Nova Bibliotheca manuscriptorum librorum..., 2 vol. in fol., Paris, S. et G. Cramoisy, 1657.

LASTEYRIE Charles de, L'abbaye Saint-Martial de Limoges..., Paris, A. Picard, 1901.

LEMAITRE Jean-Loup, « Les emprunts à la chronique de Geoffroy de Vigeois dans le Majus chronicon Lemovicense (BNF lat. 5452)", dans Amicorum societas. Mélanges offerts à François Dolbeau pour son $65^{e}$ anniversaire, études réunies par Jacques ELFFASSI, Cécile LANERY et Anne-Marie TURCAN-VERKERKE, Florence, SISMEL, 2013, p. 417-433.

LEMAITRE Jean-Loup, «Les livres de médecine dans les monastères clunisiens au Moyen Âge d'après les inventaires et les livres conservés », dans Monachisme et technologie dans la société médiévale du $X^{e}$ au XIII siècle. Actes du colloque, scientifique international, Cluny, 4, 5 et 6 septembre 1991, publ. par Ch. HETZLEN et R. DE VOS, Cluny, 1994, p. 267-319.

LEMAITRE Jean-Loup, «Un bibliothécaire modèle Bernard Itier, bibliothécaire de SaintMartial de Limoges (1195-1225) », dans Histoire des bibliothécaires. Actes du colloque de Lyon, 27-29 novembre 2003 [Enssib, en ligne].

LEMAITRE Jean-Loup et Françoise VIELLIARD, «La liève de la confrérie des Premières Chandelles à Limoges (1388)», dans Bulletin de la société archéologique et historique du Limousin, t. 129 (2001), p. 45-113.

LEROUX Alfred, «De la substitution du français au latin et au provençal à Limoges », dans Bulletin philologique et historique, 1900, p. 478-490.

LEROUX Alfred, « Premier / second cartulaire de l'aumônerie de S. Martial », dans Alfred LEROUX, Émile MOLINIER et Antoine THOMAS, Documents historiques bas-latins, provençaux et français concernant principalement la Marche et le Limousin, t. II, Limoges, 1885, p. 1-25.

LEROUX Alfred, Les sources de l'histoire du Limousin, Limoges, Vve H. Ducourtieux, 1895, p. 56.

LEVY Emil, Petit dictionnaire provençal-français, 5e éd, Heidelberg, Winter, 1973.

LEWIS Andrew W., "The Beginning of the Year un the Limousin. The Evidence from the Chronicle and Notes of Bernard Itier », dans Medieval Studies, t. 74 (2912), p. 197-218.

MANITIUS Max, Geschichte der lateinischen Literatur des Mittelalters. T. III. Vom Ausbruch des Kirchenstreites bis zum Ende des 12. Jahrhunderts, C.H. Beck'sche Verlag, München, 1931 [Réimpr. 1973]. 
MIQUEL Pierre, Les oubliés de l'histoire, 2 vol., Paris, Nathan, 1978.

MOLINIER Auguste, Les sources de l'histoire de France, des origines aux guerres d'Italie (1494), II. Époque féodale. Les capétiens jusqu'en 1180, Paris, A. Picard, 1902, p. 109-110, nº 1477.

OUdART FEUDRIX DE BRÉQUIGNY Louis-Georges, « Note d'une chronique autographe de Bernardus Iterius, bibliothécaire de l'abbaye de Saint-Martial de Limoges dans le treizième siècle, contenue dans le manuscrit du Roi coté 1338 », dans Notices et extraits des manuscrits de la Bibliothèque du Roi lus au Comité établi par Sa Majesté dans l'Académie royale des inscriptions et belles-lettres, t. I, Paris, Impr. Royale, 1787, p. 579-596.

PÉrouAs Louis (dir.), Léonard, Marie, Jean et les autres. Les prénoms en Limousin depuis un millénaire, Paris, CNRS, 1984.

Suger, Vie de Louis VI le Gros, éd. Henri WaQuet, Paris, 1964 (Les classiques de l'histoire de France au Moyen Âge, 11). 


\title{
Provençal et français : la communication au service de la politique
}

\author{
Marie Rose BONNET \\ Professeur de lettres modernes, \\ chargée de cours de langue et littérature d'oc médiévales \\ à la faculté des lettres d'Aix, en retraite
}

\footnotetext{
Extrait de : Guylaine BRUN-TRIGAUD (dir.), Contacts, conflits et créations linguistiques, Paris, Édition électronique du CTHS (Actes des congrès des sociétés historiques et scientifiques), 2015

Cet article a été validé par le comité de lecture des Éditions du CTHS dans le cadre de la publication des actes du $139^{\mathrm{e}}$ Congrès national des sociétés historiques et scientifiques tenu à Nîmes en 2014
}

Les Archives Communales d'Arles conservent des documents rédigés en latin et en provençal d'abord, en français par la suite. Les deux premiers systèmes linguistiques se pratiquent essentiellement jusqu'au $\mathrm{XV}^{\mathrm{e}}$ siècle, puis apparaît le français, surtout à partir $\mathrm{du} \mathrm{XVI}^{\mathrm{e}}$ siècle, le latin disparaissant alors de plus en plus; un bilinguisme provençal/ français remplace ainsi le latin/ provençal, le trilinguisme étant aussi présent. En fait, les Arlésiens, à cause de leurs rapports (parfois conflictuels) avec l'archevêque, le comte, puis le roi, mais aussi pour d'autres raisons, ont toujours recopié leurs actes, ont beaucoup écrit.

Au XIII e siècle, la famille d'Anjou s'installe en Provence ; Charles, frère de saint Louis, épouse Béatrice, fille du comte Bérenger IV. La dynastie barcelonaise est remplacée par une dynastie française. Mais Charles se tournant plutôt du côté de l'Italie pour constituer le royaume angevin d'Italie, les Provençaux en général, et les Arlésiens en particulier, ne subirent pas de conséquences langagières. Malgré tout, ainsi que le remarque A. Brun :

«Pour mettre de l'ordre dans les finances de son nouvel État, sans doute aussi pour dérouter les faussaires italiens, et qui sait, pour accentuer le caractère français de son établissement napolitain, il publia une ordonnance (27 octobre 1277), qui introduisait le français dans les services de la trésorerie, 'Et feres ferre deus quaternes, et en l'un feres escrivre en françois, et en l'autre en latin ; ... lequel commandement soit fait par nos lettres ouvertes et les lettres soient faites en ceste menière : Premièrement, les lettres soient escrites en françois ...; mes pour nulles autre lettres qui vous viegnent, qui ne seront escrites en françois et en la forme qui est desus devisée, ... monoie ne pou ne grant vous n'envoieres ne bailleres ne ne despandres' Il fut obéi, mais sous ses successeurs on revint vite au latin. »

Or à Arles, des textes en français de cette époque ne sont pas conservés : parce qu'ils n'ont pas existé ? parce qu'ils ont été perdus? Les documents fiscaux et financiers du $\mathrm{XV}^{\mathrm{e}}$ siècle ont une grande importance, certains (la plupart) étant en langue vernaculaire. Par contre, les registres de notaires, malgré leur nombre, sont beaucoup plus décevants quant à l'emploi du provençal. Pour la période suivante,

«Les archives municipales ont conservé l'intégralité des registres de délibérations du conseil, toutes les pièces comptables, des cadastres, des registres de capitation (à partir de 1750 seulement), une belle série de registres paroissiaux, quantité de registres et liasses correspondant aux divers aspects de la gestion des consuls. Les archives départementales possèdent, outre les fonds de la sénéchaussée et de l'amirauté, l'ensemble des minutiers des notaires d'Arles [...]. Les visites pastorales des archevêques sont pour l'essentiel conservées et figurent parmi les plus précises et les plus détaillées du Sud-Est. Les archives des établissements conventuels renferment les fonds exceptionnels de l'Ordre de Malte et de Montmajour ... $»^{2}$

1. A. Brun, Recherches historiques sur l'introduction du français dans les provinces du Midi, p. 45.

2. R. Bertrand, «Introduction», Arles, histoire, territoires et cultures, p. 461. 
Par contre, beaucoup, à partir du $\mathrm{XVI}^{\mathrm{e}}$ siècle, sont rédigés en français, langue du roi désormais souverain de Provence et terres adjacentes. Mais cette remarque doit être modulée en ce qui concerne les délibérations communales. Cette présentation ne concernera que quelques documents de la fin $\mathrm{du} \mathrm{XV}^{\mathrm{e}}-\mathrm{XVI}^{\mathrm{e}}$ siècle, même si tous sont tout aussi intéressants pour étudier les enjeux de pouvoir qui se révèlent derrière l'emploi du langage choisi.

La ville d'Arles, dont l'histoire s'associe à celle de la Provence, possède des vestiges et des monuments appartenant à diverses époques. Grâce à sa situation géographique (elle est à un carrefour de voies fluviales et routières), elle a entretenu des liens avec d'autres régions et d'autres États. Elle a connu la colonisation romaine, vu différentes invasions, subi les influences des divers pouvoirs qui l'ont régie. Beaucoup d'éléments portent témoignage de tout cela, dont le texte écrit, en latin parfois, parfois dans la langue vernaculaire utilisée par les habitants de la région : le provençal rhodanien. Nombreux sont les textes concernant Arles rédigés en latin pour la période antérieure au XIV ${ }^{\mathrm{e}}$ siècle surtout. Le provençal n'apparaît vraiment que dans la seconde partie du XIV $\mathrm{XV}^{\mathrm{e}}$ siècle, et tend à se généraliser (dans les textes administratifs) pendant le $\mathrm{XV}^{\mathrm{e}}$. Bien sûr, il y a les Statuts de l'Ordre de Saint Jean de Jérusalem ${ }^{3}$, en langue d'oc, datant de 1384, la Chronique de Bertran Boysset et son Traité d'arpentage. Mais les deux derniers empiètent aussi sur le $\mathrm{XV}^{\mathrm{e}}$ siècle. La production en langue vernaculaire est minoritaire pendant le $\mathrm{XIV}^{\mathrm{e}}$ siècle à Arles, le $\mathrm{XV}^{\mathrm{e}}$ siècle connaissant une situation inverse. La langue devient progressivement dominée, mais l'histoire des dialectes utilisés par la communauté sociohumaine arlésienne ne peut être séparée de la politique, ou des politiques, en action dans cette ville, la communication qu'elle sous-tend étant au centre de ces activités. Les choix entre l'utilité d'un système renvoyant à l'inutilité d'un autre sont idéologiques mais aussi pragmatiques. Néanmoins, la stabilité supposée des $\mathrm{XIV}^{\mathrm{e}}-\mathrm{XV}^{\mathrm{e}}$ siècles n'est qu'apparente, et surtout pas définitive, et se déroule alors sous nos yeux une lente maturation. L'étude d'une langue permet d'appréhender une réalité multiple et multiforme, car se rattachant aussi bien à la structure même du langage qu'à l'histoire, événementielle, politique, économique, au droit, à la religion, à l'ethnographie, aux coutumes, aux modes de vie, à la personnalité, à la psychologie, aux mentalités collectives. La langue est un creuset dans lequel viennent se fondre toutes ces entités, dont elle est aussi un reflet, et un témoin. La vie sociale et le langage sont dépendants dans la mesure où l'activité langagière ne peut s'exercer qu'à partir du moment où l'homme qui la pratique a besoin de communiquer à, et avec autrui, la fonction du langage étant d'établir un échange culturel, certes, mais aussi commercial, technique, entre deux ou plusieurs individus. Mais la communication, à Arles comme dans d'autres villes ou régions, est-elle au service de la politique, et cette dernière, infléchie par les dirigeants, en dispose-t-elle comme d'une arme véritable ? Les membres de la communauté sociale et linguistique dialoguent entre eux, comme avec d'autres groupes ; se posent alors des questions d'inter-compréhension. Mais les langues d'une même famille - comme les langues romanes - ont entre elles des liens de parenté ayant créé tout un réseau de traits structuraux permettant de passer assez aisément de l'une à l'autre. Néanmoins, des facteurs externes se greffent à elles, qui provoquent des divergences: substrat local, époque de la romanisation, permanence du groupe colonisateur - la romanisation n'a pas été uniforme dans le temps ni dans l'espace; Arles, carrefour, a vu depuis longtemps des passages, et des brassages, de populations différentes.

Les $\mathrm{XIV}^{\mathrm{e}}, \mathrm{XV}^{\mathrm{e}}$ et $\mathrm{XVI}^{\mathrm{e}}$ siècles permettent de mieux percevoir les transformations et les réactions de ces organismes vivants et, comme tels, susceptibles de modifications; la langue est élaborée et structurée, voire normalisée, et la période charnière qu'est la fin du $\mathrm{XV}^{\mathrm{e}}$ - début $\mathrm{du} \mathrm{XVI}{ }^{\mathrm{e}}$ siècle présente l'évolution-révolution d'un système encore bien ancré dans le dispositif social. La parole médiévale, désormais "incompréhensible " ${ }^{4}$, ne peut être retrouvée que dans des textes dont la littéralité est moins évidente que celle des

3. M.R. Bonnet, R. Cierbide (eds.), Les Statuts de l'Ordre de Saint-Jean de Jérusalem. Édition critique des manuscrits en langue d'oc (XIV siècle).

4. cf. G. Gröber, Grundiss der romanischen Philologie, I. 
œuvres des troubadours, et parfois plus proche du discours quotidien. L'écrit médiéval propose cette ambiguité : sclérose d'un système plus ou moins figé, plus ou moins imprégné de la syntaxe latine, ouverture vers des formes plus novatrices d'une oralité en activité. Cependant, ces deux siècles et les suivants permettent d'enregistrer une évolution régulière et sûre. Le changement linguistique s'inscrit donc dans la continuité de l'écrit. Ce nonobstant, si le latin représente bien le domaine de l'écrit, le provençal est celui de l'oral - et de l'écrit. Ce dernier constitue déjà un système linguistique jouissant d'une certaine autonomie, correspondant au sentiment des locuteurs d'appartenir à un même pays, "aquest present pais ", expression fréquemment employée dans des lettres envoyées aux consuls notamment. Et les comtes d'Anjou, jusqu'en 1481, ne cherchant à franciser ni la Provence, ni Arles, ne tentent pas de modifier la provençalité des gens et de les priver d'une certaine indépendance vis-à-vis d'un pouvoir français, même si les comtes de Provence par la suite, dont le roi René, sont attirés par la littérature et la culture françaises.

Le 28 décembre 1490, Charles VIII promulgue l'édit de Moulins, prévoyant le remplacement du latin par le « langage françoys ou maternel » dans les interrogatoires et les procès-verbaux en Languedoc. La langue d'oc n'étant pas concernée, les textes continueront à être rédigés en vernaculaire pendant encore quelques décennies. Elle reflète alors l'écrit aussi bien que l'oral. En septembre 1535, l'édit de Joinville, puis l'ordonnance d'Is-sur-Tille en octobre, présentent la prescription suivante: "les enquêtes, en quelque matière que ce soit, seront faites en français ou à tout le moins en vulgaire du pays ${ }^{5} »$. Les deux langues sont, à peu près, mises sur un pied d'égalité, même si le «à tout le moins" apporte une importante restriction. L'ordonnance de VillersCotterêts, concernant essentiellement les notaires et les secrétaires de l'administration bien souvent les mêmes - promulguée le 15 août 1539, entérine un fait constaté dans les A.C.A. L'usage $d u$ «langage maternel françoys » dans les documents administratifs est flagrant. Il supplée alors le provençal, non le latin, qui n'avait plus l'exclusivité de l'emploi. Tous les Arlésiens ne parlent pas français, loin de là ! Des preuves attestent du contraire $!^{6}$ Mais l'administration mise en place est de plus en plus française. Or, selon A. Brun $^{7}$ :

"L'établissement du français comme langue écrite, dans nos provinces, a été, avant tout, une affaire administrative, sa diffusion, comme langue parlée, est une question de sociologie ».

Les deux systèmes, le provençal et le français, découlent donc de choix politiques autant que d'une obligation de facilité, notamment dans les délibérations communales. La langue dominante à Arles devient progressivement langue dominée, conformément à ce qui se passe ailleurs. Cette politique expansionniste correspond pratiquement à une " francophonie», puisque s'appliquant dans des régions certes désormais françaises, mais depuis peu, même si, auparavant, les contacts étaient nombreux avec la France. Or, aucun écho n'est parvenu de cette installation progressive de la langue du roi, qui n'était pas celle des Arlésiens. Tout au long de ces siècles, comment la langue a-t-elle pu suivre/refléter les tendances politiques des Arlésiens? Comment passe-t-on d'un bilinguisme latin - provençal à un bilinguisme provençal - français, puis à un monolinguisme administratif parfois entaché de dialectalisme?

Plusieurs séries des A.C.A. présentent des documents en latin, puis en provençal, enfin en français. Certains textes sont très brefs (quelques lignes), d'autres assez longs (300 folios ou plus). Ils concernent presque deux siècles, puisqu'ils débutent dans la seconde moitié du XIV ${ }^{\mathrm{e}}$, et terminent au début du XVI ${ }^{\mathrm{e}}$ siècle. Le $\mathrm{XV}^{\mathrm{e}}$ siècle est particulièrement riche en production vernaculaire, peut-être parce que la période amenant peu à peu la ville à devenir française (au moment où la Provence le devient, 1489) est une charnière

5. Cité par A. Brun, Recherches historiques..., p. 335.

6. A. Brun cite l'exemple des "pièces du procès qui, au début du XVII ${ }^{\mathrm{e}}$ siècle, fut intenté à l'abbé Gaufridi, et à Madeleine de Demandolx; bien que le dossier soit en français, les conversations relatées sont en provençal : Madeleine et sa mère n'emploient jamais le français dans leurs entretiens », p. 10

7. A. Brun, La langue française en Provence de Louis XIV au Félibrige, p. 5. 
pour la langue aussi, et voit alors une volonté affirmée, peut-être par réaction, d'utiliser le système linguistique qui lui est propre dans la vie de tous les jours. Les pièces contenues dans ce fonds ne sont pas toutes, cependant, en provençal. Mais ce dernier est malgré tout très présent.

Série $A A$ : Elle comprend des recueils de privilèges, des correspondances, ainsi que des cartulaires contenant des copies des statuts municipaux. La plupart sont en latin, certains sont en français. Quelques passages sont en provençal. Parmi eux, le AA 14, dit Livre Noir, 1251 à 1395, en latin. Mais les premiers folios, parfois difficilement lisibles car $l^{\prime}$ encre est assez effacée, sont en provençal, $\mathrm{f}^{\circ} 1 \mathrm{r}^{\circ}$ à $6 \mathrm{r}^{\circ}$. Le AA 16 contient une copie de ce même texte, ne présentant que quelques variantes orthographiques. Il présente d'abord des droits de péages, puis des cens, enfin des coutumes successorales ou de vente.

Série $D D$ : Elle concerne les propriétés communales, les eaux et forêts, les édifices, les travaux publics, les ponts et chaussées, la voirie. Le provençal est beaucoup moins présent dans cette série, pour ne pas dire absent.

Série EE : Elle se rapporte aux affaires militaires et maritimes, et est surtout en latin, ou en français.

Série FF : Justice, procédure, police. Elle aussi est en latin, ou en français, qui apparaît,

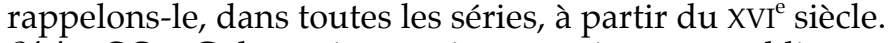

Série GG: Cultes; instructions, assistance publique. Latin ou français. Parmi ces documents, il y a le GG 76 (fin XIV ${ }^{e}$ siècle), qui contient les statuts de l'Ordre de SaintJean-de-Jérusalem, en langue d'oc (d'autres textes en provençal, concernant cet ordre, sont conservés aux A.D. des B.-du-R., cf. par exemple le manuscrit 56 H 78, du XIV ${ }^{\mathrm{e}}$ siècle).

Série HH : Agriculture ; industrie ; commerce. Latin ou français.

Série des Archives Hospitalières: Elle représente les titres de propriétés, les donations, les échanges, les acquisitions. Elle contient aussi des registres concernant les baux, les droits utiles de l'établissement. Certains sont en provençal. Le I E 3, par exemple, contient les cens de l'Hôpital de Saint Esprit de la Cité de l'Arc Admirable (cet arc, romain, est un vestige du Castrum de Portaldosa) pour 1478. Le II B 12 (pour l'Hôpital de Saint Esprit du Bourg) propose ceux des années 1372 à 1517. Le II E 36 et le II E 37 représentent les comptes (recettes et dépenses). Le II E 36 rend compte des années 1439-1506 pour l'Hôpital de Saint Esprit du Bourg. Le II E 37 porte sur les années 1440-1475, toujours pour le même Hôpital. Des centaines de pages sont ainsi rédigées en provençal. Ces textes concernent presque deux siècles, puisqu'ils débutent dans la seconde moitié du $\mathrm{XIV}^{\mathrm{e}}$, et terminent au début du XVI $\mathrm{X}^{\mathrm{e}}$ siècle.

Série CC : Dans la série CC, nombreux sont les documents écrits en langue dite vulgaire.

Les compoix, les comptes de la taille, ainsi que les comptes trésoraires, sont souvent rédigés ainsi, malgré quelques passages en latin (quelquefois moitié-moitié). Ils « couvrent » pratiquement tout le $\mathrm{XV}^{\mathrm{e}}$ siècle. Parfois très répétitifs, ils n'en donnent pas moins une vision assez nette et précise de ce qu'était la ville à cette époque, participant alors de cette approche textuelle qui étaie la recherche archéologique en lui apportant le témoignage de l'écrit. Cette série présente aussi de nombreuses lettres écrites en langue dite vulgaire, quelques-unes en français, envoyées aux consuls. Elles émanent soit des autorités d'autres villes ou villages voisins soit d'ambassadeurs envoyés par Arles, qui rendent compte de leur mission, soit de simples particuliers ayant une réclamation à présenter. Souvent très brèves, parfois de quelques feuillets, elles datent du dernier quart du XV $V^{\mathrm{e}}$ siècle - début du XVI. . Des différences existent entre ce provençal et celui utilisé dans les délibérations. Des changements sont patents : -a final féminin> -o, ou -e ; introduction de quelques formes françaises; formes italianisantes, bien souvent dans le même document. Dès la fin du XV ${ }^{\mathrm{e}}$ siècle, une évolution s'est donc déjà amorcée. Et si le français qui pénètre au $\mathrm{XVI}^{\mathrm{e}}$ siècle est usité en fonction des circonstances, la langue locale subit des influences extérieures. En effet, ces lettres témoignent de transformations d'abord orales. Or, elles sont toutes envoyées au pouvoir local, qui use encore de cet idiome qui le distingue de celui du pouvoir central. De plus, toutes les classes sociales sont affectées, prouvant que l'évolution est bien réelle pour tous, et non pas seulement 
pour une catégorie de personnes. En outre, un compte trésoraire présente une particularité, le CC 161, celui de l'année 1442. Cette année-là, un péril familier menace Arles et toute la côte provençale. Ce n'est pas la première fois qu'il surgit. Des galères catalanes sont annoncées dans les eaux de la région, et Arles va devoir prendre des précautions afin de se défendre. Tout son territoire est touché. Cependant, les syndics ne pouvaient pas négliger, malgré la menace des Catalans, les autres problèmes posés par la cité. Tailles et gabelles sont présentes. Tout en fait est mêlé, aussi bien les dépenses causées par les réparations des murailles que celles du service funèbre célébré pour le décès de Yolande d'Aragon, femme de Louis II, comte de Provence. Dans ce CC, les consuls témoignent du soin qu'ils prennent à protéger la ville. Or, pour la même époque, des textes émanant de la chancellerie comtale, traitant du même sujet, mais insistant sur l'incurie de ces mêmes consuls, sont rédigés en latin. Lequel, du provençal ou du latin, est « langue de bois »?

\section{Les délibérations communales, série $B B$.}

À travers cette série se révèlent des enjeux de pouvoirs : commune / pouvoir central, comtal d'abord puis royal. L'emploi de la langue renvoie alors aux conflits qui peuvent survenir entre eux. Cela apparaît très nettement au $\mathrm{XVI}^{\mathrm{e}}$ siècle, époque importante pour Arles en proie, comme le reste du royaume, aux luttes de la Ligue, même si, ainsi que le note B. Bourjac ${ }^{8}$,

«La Ligue n'a pas à Arles connu une évolution linéaire. Il n'y a pas eu, pour le moins d'emblée, d'adhésion franche et massive au parti ligueur [...] les catholiques zélés qui prennent le parti de l’Union en 1588 sont loin d'être les plus forts dans la ville. »

Les années qui ont précédé ont aussi été agitées. Lorsque la Provence et la ville d'Arles sont rattachées à la France, les Arlésiens acceptent apparemment facilement le fait. Déjà, le ralliement de l'archevêque d'Arles au Comte de Provence avait créé pour Arles le statut de terre adjacente au comté de Provence. Cela fait de la cité un milieu un peu à part dans le droit, comtal d'abord, puis national. Selon R. Bertrand et St. Durand ${ }^{9}$ :

«Terre adjacente, la ville ne ressortit pas aux États de Provence et se trouve directement soumise à l'autorité des agents du roi, aux gouverneurs d'abord puis aux intendants lorsque ceux-ci ont été installés par la monarchie française dans la province. »

De nombreux écrits prouvent que les deux langues cohabitent tout au long du XVI ${ }^{\mathrm{e}}$ siècle, et le bilinguisme peut caractériser nombre d'Arlésiens - aristocrates essentiellement, mais - et de plus en plus - bourgeois. D'après A. Brun ${ }^{10}$ :

«En 1646, Monseigneur Fr. de Grignan, archevêque d'Arles, se rendant compte que l'instruction religieuse faite en français n'était pas toujours bien comprise, ordonne que, le dimanche, on prêchera en provençal. En 1675, à Arles, on prêche encore en provençal, et, en 1688 , le Père Allègre imprime des Instructions morales, 'per la commoditat et l'utilitat deis paures gens que non entendon ni comprenon pas lou français'. À cette époque, les Oratoriens semblent disposer à réagir, et en 1685 , le conseil délibère. »"11

Ce sont bien souvent les remarques du clergé qui alertent sur la langue parlée par le peuple ! Cependant les deux pouvoirs, communal et royal, s'opposent tout en composant ensemble dans une mise en place d'une politique de plus en plus restrictive pour les instances locales. L'implantation du français, au $\mathrm{XVI}^{\mathrm{e}}$ siècle $\mathrm{d}^{\prime}$ abord puis aux siècles

8. B. Bourjac, « La Ligue arlésienne », Arles, histoire, ..., p. 485.

9. R. Bertrand et St. Durand, «Un rayonnement administratif et un pouvoir judiciaire local », Arles, histoire, ..., p. 467.

10. A. Brun, La langue ..., p. 13.

11. A. Brun cite alors le passage: «sur ce qui a esté aussi représenté que le prédicateur de notre église de Marseille prechoît en provençal, à quoi il y auroit beaucoup d'inconvénients, il a esté arreté que l'on y prescheroit désormais en françois, mais que l'on feroit en provençal de forts catéchismes et des instructions familières pour le peuple. » Nous pouvons supposer que ce qui est valable pour Marseille l'est aussi pour Arles. 
suivants, découle de causes multiples: politiques, commerciales, culturelles, sociales. $C^{\prime}$ est bien le constat qui découle des registres de délibérations. Une certaine conscience linguistique se déploie dans ce passage d'un système à un autre ; malheureusement, nous ne connaissons pas les véritables raisons qui amènent le scribe à user de l'un ou l'autre. Veut-il satisfaire un pouvoir? S'agit-il d'un usage local qui oscille entre deux, ou plusieurs, systèmes, sans choisir vraiment pour l'un d'entre eux ? Ces langues en conflit sont écrites et reflètent, peut-être, une confusion quant à l'oral. D'après J.-M. Woehrling ${ }^{12}$ :

«De l'Ancien Régime, l'histoire n'a retenu que la réglementation linguistique des actes publics. Celle-ci n'a cependant pas eu pour objectif de remettre en cause la diversité linguistique du royaume. La réglementation linguistique durant l'Ancien Régime n'est pas un but en soi, mais un aspect de la construction d'un appareil unitaire de justice et d'administration appuyé sur une élite socialement et culturellement homogène. »

Le français tente d'occuper l'espace dévolu autrefois au latin, qui perdure cependant de manière très intermittente ; cela ne témoigne-t-il pas d'un autre conflit : pouvoir laïque contre pouvoir religieux? Dans les lettres, le scripteur surveille moins sa syntaxe et son vocabulaire; dans les délibérations, officielles, le scribe fait attention. Ces documents révèlent en outre que provençal et français ne se contentent pas de se côtoyer, mais s'imbriquent assez fortement. Sont-ils en concurrence ? Certains estiment que la langue est liée à un territoire. Les secrétaires ont recopié ce qui a été dit lors des séances. Emploient-ils leur langue maternelle, ou retranscrivent-ils textuellement ce qu'ils ont entendu? Quelle était donc la langue d'usage dans ce groupe d'aristocrates et de bourgeois réunis pour délibérer au sujet des affaires publiques?

Le BB1, en latin, concerne les années 1426-1432. Les BB 2, 3 et $4(\rightarrow 1467)$ sont aussi en latin, ainsi que le début du BB 5 (1468-1486). Mais la seconde partie, de 1469 à 1470, est en provençal, comme le BB6, 1487-1513, qui offre toutes les décisions prises par le conseil tant à propos de l'entretien de la ville que des problèmes posés et montre l'importance des consuls et du viguier. Le consulat d'Arles est l'un des plus anciens: 1131. L'archevêque a accordé une charte de consulat vers 1150 . Cependant, au XII siècle déjà, les consuls ne sont pas véritablement indépendants dans les faits, et un viguier représente le roi. Ce système fonctionne encore à la fin $d u X V^{e}$ siècle, et le $B B$, en plus des noms des consuls et des syndics élus (syndics représentant les nobles et les non nobles, appelés "borges " plutôt que "prohome ", terme qui apparaît quelquefois dans d'autres documents) montre l'élection du viguier pour un an, qui n'est plus un Arlésien, et au pouvoir assez large. Le comte de Provence nomme aussi, chaque année, deux juges, celui du Tribunal du Lion en appel, et pour les nobles celui de la Porte. Ces trois personnages seront parfois renvoyés par les Arlésiens. Sur la page de garde est écrit :

«Consilia civitatis Arelatis Bernardinus Blandrata notarius ».

Cependant, en 1499, si les Arlésiens acceptent de prêter serment de fidélité à Louis XII, ils n'en demandent pas moins la confirmation des privilèges auxquels ils sont très attachés. Par exemple, au $\mathrm{f}^{\circ} 14 \mathrm{v}^{\circ}$, une délibération porte sur la peinture des armes du roi et de la ville à quatre points stratégiques :

«Escus de Rey XVI pagadors a mestre Johan lo pintre.

Item car messenhors los consols de l'an present ham baylat a presfach a mestre Juhan lo pintre de penher d'or et d'asur las armas del rey nostre souverain senhor en quatre pars so es davant la court real, al pont de Crau, als portals de la Cavalarie et del port, et oussi de penher en la present mayson las armas de la present cieutat, e aquo tout per lo pres de sege escus de rey sensa soleil, per so es estat ordenat al present conseil que losdichs XVI escus ly sien pagatz e admesses al compte deldich tresourier. »

12. J.-M. Woehrling, « Histoire du droit des langues en France », Ibid., p. 72. 
Ce paragraphe est rédigé en rhodanien, ainsi que les suivants. Mais, au folio $297 \mathrm{v}^{\circ}$, daté du 4 juin 1503, apparaît la mention :

« Election de notaire de la villa maistre Andrieu Biguini notaire.

Et premierement, mesdits seigneurs les consulz, attendu la mort de maistre GilletCandelarii a qui Dieu pardonne, de leur bonne grace comme sindigue $\mathrm{m}^{\prime}$ ont esleu pour notaire de ce noble conseil d'Arle avecques les gaiges acoustumes pour ung an tant seullement. Et le present conseil approuve ladite election. »

Ce bref paragraphe est en français. Le suivant est à nouveau en idiome local, mais bien entaché de français :

«Sarrada dels blatz. Item plus a estada legida en ce present conseil una letro missivo clauso de mess $^{\text {rs }}$ de parlament faisant mention de faire sarrar la traicta dels bladz. Est estat ordennat en lo present conseil que per aucunes causes samprans en la presenta citat que la traicta dels blads se sarre et que on requiere mons ${ }^{\mathrm{r}}$ lo viguier ou son lieutenant que en face faire la crida en exeqution de l'ordonnance faicte per lo present conseil. Et aquo subre penna de cent marcs d'argent fin et confiscation delsdits blads jusques a tant que autrament aye estat ordonnat per lo present conseil. $»^{13}$

Quelle est la langue maternelle du secrétaire : le français ou le provençal, langue de la cité, des habitants comme des consuls, nobles ou bourgeois ? En fait, ainsi que le raconte Fassin ${ }^{14}$, l'ancien secrétaire était le notaire Gilles Candelarii, tué à coups de couteau par son collègue Matthieu Bompar le 27 mai 1503. André Béguin lui succéda dans cette charge. Or, cette année-là, les présidents de Forbin, de Mélat et d'Audibert sont accueillis à Arles. Leur but : faire reconnaître le nouveau parlement établi le 10 juillet 1501 à Aix par Louis XII grâce à l'édit de Lyon. Les consuls arlésiens prennent soin de leur faire jurer le 22 avril sur les Évangiles de conserver tels quels les «statuts, privilèges, franchises et libertés ». Le choix de la langue ressort-il alors d'une revendication linguistique et/ou politique? Dans la suite du registre, le même Béguin rédige, apparemment indifféremment, dans l'un ou l'autre idiome, quand il n'y a pas mélange au sein même du paragraphe. Le rédacteur, ou plutôt le copiste, des délibérations ne cherche pas, comme le feront les écrivains, à transgresser des codes au profit d'une idéologie particulière et contestatrice. Le copiste ne peut se permettre, en tant que représentant d'un organe officiel, de faire preuve de liberté émancipatrice. Il faut que tous puissent comprendre ce qui s'est dit lors de ces séances, qu'elles entérinent la politique royale, ou celle de la communauté si cette dernière s'en éloigne, voire s'oppose à la première. Choisir de rédiger dans l'un ou l'autre système, c'est affirmer, pour l'élite arlésienne, son appartenance politique, c'est se placer du côté de la royauté française, ou de la fidélité à un passé encore très présent.

Le français semble être apparu assez tôt, confirmant les études menées par ailleurs sur la ville. Mais cela n'est peut-être pas aussi simple qu'il y paraît. En effet, le registre suivant, coté BB7, allant de 1508 à 1513, présente des passages en français au milieu d'autres en provençal :

«Et premierament venez une lettres mandees a la presente cite par monseigneur le lieutenant en Prouvence touchant la paix faicte et passee entre le roy nostre souverain seigneur et le roy $\mathrm{d}$ 'Angleterre pertant( ?) obtemperant en mandement dudit seigneur ha ordonne le present conseilh estre faict feu de joye en la meilheure sorte que fere ce poura. »

$\mathrm{f}^{\circ} 52 \mathrm{r}^{\circ}, 18-01-1514:$

«Et premierement attendu la mort du feu roy Loys nostre souverain seigneur que Dieu par sa grace absolve pour aller fere la reverance et homage au roy nostre souverain seigneur ainsi comme sommes tenuz de fere et luy supplier son bon plaisir soit jurer de observer, agrder et maintenir et fere garder immutes, us et coustumes de la presente cite ha esleu le 
present conseilh nobles et honnetes Honorat de Brunet, Jehan Bernard deux des consulz de la presente cite, Anthoine Quiqueran barron de Beaujeu et Pierre d'Arle seigneur de Beaumont». Juste avant que ne commencent les délibérations, sont cités les consuls, en latin : «Consilium Anno Incarnatione ....»

Le BB8, 1514-1521, est en français, avec les noms des consuls toujours en latin. Le BB10, 1521-1531, présente la liste des noms en latin, des passages en provençal, quelques-uns en français. Le BB18, qui couvre la période 1589-1596, correspondant aux troubles de la Ligue, est intégralement en français, qui s'impose donc, certes, mais très lentement, avec des revirements ; les secrétaires emploient les deux idiomes sans raison bien définie.

Les dépôts arlésiens présentent peu de textes médiévaux en français, contrairement à $\mathrm{d}^{\prime}$ autres villes de la région, ainsi que le montre A. Brun ${ }^{15}$. Mais les deux langues cohabitent tout au long $\mathrm{du} \mathrm{XVI}^{\mathrm{e}}$ siècle, et le bilinguisme (voire le trilinguisme) peut caractériser nombre d'Arlésiens - aristocrates essentiellement, mais - et de plus en plus bourgeois. Or, ainsi que l'explique G. Kremnitz ${ }^{16}$ :

«La pratique d'une langue sert deux buts à la fois, d'une part la communication, de l'autre la démarcation. »

Une certaine conscience linguistique se déploie dans ce passage d'un système à un autre ; malheureusement, nous ne connaissons pas les véritables raisons qui amènent le scribe à user de l'un ou l'autre système. Pour satisfaire un pouvoir? Est-ce un usage simplement local qui oscille entre deux, ou plusieurs systèmes, sans choisir vraiment pour l'un d'entre eux ? Ces langues en mutation, écrites, reflètent peut-être une confusion quant à l'oral. A. Brun cite plusieurs documents ${ }^{17}$ :

«En 1521, la légende des Saintes Maries est translatée 'de latin en mon gros langage et escript par moy Vincens Philippon, d'Avignon, habitant d'Arles'. [...] Après 1540, le français s'emploie dans les écrits de toute nature: Annales d'Arles (1553-1554), Chronique de la peste (1579-1580), livre de comptes de la confrérie des Pénitents, livres de raison. »

Plusieurs influences se mêlent pour amener cette langue à devenir officielle, et à remplacer dans l'usage, notamment des lettrés, un idiome vernaculaire qui perdure cependant dans certaines couches de la population. En effet, lorsque nous consultons les livres de raison conservés dans le Fonds Ancien de la Médiathèque d'Arles, nous constatons qu'ils sont bien rédigés en français. Ainsi que le dit A. Brun ${ }^{18}$ :

« La plume et l'encrier appellent le français. »

Or, Arles est une ville qui attire. D'après R. Bertrand ${ }^{19}$ :

«Autre élément du prestige d'Arles, preuve des grandes qualités du site et de la vie que l'on peut y mener, la ville est le séjour de gens ' du bel air'. Le célèbre Voyage de François Le Coigneux de Bachaumont et Claude-Emmanuel Lhuillier, dit Chapelle (1663) ne retient

15. A. Brun, Recherches historiques ..., p. 328 : «Le latin cesse, à vrai dire, d'être la langue fondamentale : on le trouve dans les Privilèges des Baux (1435) ; mais le français est assez usuel ; une lettre de 1455 adressée en son nom aux baille, capitaire, syndic et conseil de Sisteron est en français; il y en a de pareilles à Brignoles (1472), à Toulon (1466). Parmi les fonctionnaires administratifs, les trésoriers généraux rédigent leur comptabilité en français dès 1419, tandis que les recettes et dépenses des clavaires de la Chambre des comptes d'Aix sont en latin. Les claveries secondaires, Moustiers, Sisteron, Tarascon, Brignoles, Forcalquier, Grasse, Hyères, Barjols, Colmars, Draguignan, etc. préfèrent le latin : les comptes de la claverie de Fréjus sont en provençal depuis 1472 ; ceux que tient le capitaine de Châteaurenard sont en français ; font de même, le trésorier de la maison du roi et son argentier (1451-1454). Ainsi la langue vulgaire est rare chez les agents de finances. Mais les officiers attachés à la personne du roi ou à sa cour emploient de préférence le français. »

16. G. Kremnitz, «Introduction générale », Histoire ..., p. 27.

17. A. Brun, Recherches historiques ..., p. 336.

18. A. Brun, La langue ..., p. 9.

19. R. Bertrand, "Introduction », Arles, histoire, ..., p. 265. 
guère que ce trait : 'La situation admirable de ce lieu y a presque attiré toute la noblesse du pays'. »

Le français devient de plus en plus l'apanage de la bourgeoisie, qui veut rivaliser avec l'aristocratie. Cette tentative reflète les tensions entre ces deux états, qui revendiquent au sein de la ville la même importance et veulent conserver le pouvoir, voire le maîtriser. Parler une langue, c'est alors se placer d'un côté ou l'autre de ce même pouvoir. Ce phénomène se retrouve bien sûr ailleurs. À Arles, la pratique très pragmatique du français renvoie à des enjeux politiques, à des luttes, à des choix stratégiques. L'écart se creuse de plus en plus entre trois groupes sociaux, et le provençal se cantonnera progressivement dans les campagnes et les couches de la population les plus défavorisées socialement. J.-M. Woehrling ${ }^{20} \mathrm{l}^{\prime}$ explique bien :

«Si le français se développe vigoureusement durant l'Ancien Régime et s'affirme de plus en plus dans la plupart des activités sociales, ce n'est pas en vertu d'un appareil juridique, mais en raison de son prestige culturel et de l'adhésion des classes sociales montantes et des élites. »

Il n'y a alors plus de troubadours pour relever le gant, et porter haut une langue désormais en déliquescence, ou presque! De plus, différentes écoles prennent en charge l'enseignement. Selon A. Brun ${ }^{21}$,

«Les Oratoriens, si appréciés en Provence, y avaient introduit le français, et aussi les Doctrinaires, puis, avec plus de réserve, les Jésuites. »

Et plus loin, il ajoute encore ${ }^{22}$ :

«Au milieu du XVI siècle, l'état linguistique de la Provence s'exprime par une formule grossière, mais simple: le français langue écrite, le provençal langue parlée; à la fin de l'Ancien régime, une seconde formule [...] résume la situation: le français, langue du bourgeois, le provençal, langue du peuple. »

Ce qui est valable pour la Provence en général l'est aussi pour Arles en particulier! L'opinion politique de chacun, correspondant plus, parfois, à un état social qu'à une position par rapport au pouvoir royal, utilise en fait le canal de la langue pour se révéler. Si le choix des aristocrates, à partir du XVII ${ }^{\mathrm{e}}$ siècle, puis $\mathrm{du} X \mathrm{XVII} \mathrm{e}^{\mathrm{e}}$, se porte plutôt sur le français, comme le feront les bourgeois au XVIII ${ }^{\mathrm{e}}$ siècle, nous assistons à un retour aux sources littéraires et à une volonté chez certains de préserver les documents anciens en langue d'oc, celui du peuple reste fidèle à un passé et à des coutumes langagières qui les ancrent un peu plus dans leur terroir.

Et la naissance, en 1666, de l'Académie royale d'Arles, "fille aînée » de l'Académie française dont la création en 1635 par Louis XIII résulte d'une tentative du pouvoir monarchique central pour favoriser l'usage du «bon» français renforce cet état. Les lettres patentes par lesquelles le roi autorise son établissement comportent une allusion très nette à un paragraphe de l'Académie française. C'est une véritable "machine de guerre " dont le but est de veiller "à la pureté de la langue françoyse, une Académie royale à bien parler », ainsi que la définit le parlement d'Aix en 1668. Quelques décennies plus tard, elle périclite. Mais ses membres n'ont pas de stratégie de combat contre l'idiome local. Au contraire, lorsqu'au XVIII ${ }^{\mathrm{e}}$ siècle, ils disparaîtront peu à peu (guerre, peste, etc.), il y aura peu de monde pour reprendre le flambeau, et les érudits arlésiens, fort intéressés par le provençal, n'entreront pas dans cette Académie. De plus, la plupart des académiciens appartiennent à la noblesse, ce qui est d'ailleurs inscrit dans les premiers statuts :

20. J.-M. Woehrling, p. 73.

21. A. Brun, La langue ..., p. 63.

22. A. Brun, La langue ..., p. 92. 
«L'académie ne sera composée que de personnes d'eslite, et veritables amis, originaires de la ville d'Arles et gentilshommes. »

Le pouvoir royal tendant à se déliter, il y a alors un retour aux sources, une revendication politique qui passent par la langue. Le système linguistique paraît bien étroitement lié à la politique. Or, le français devient de plus en plus l'apanage de la bourgeoisie, qui veut rivaliser avec l'aristocratie. Cette tentative reflète les tensions entre ces deux états, qui revendiquent au sein de la ville la même importance et veulent maîtriser le pouvoir, voire le conserver. Parler une langue, c'est alors se placer d'un côté ou l'autre de ce même pouvoir. Ce phénomène se retrouve bien sûr ailleurs.

À partir du début du XVII siècle, les documents proposés par les A.C.A. seront rédigés en français. La langue employée obéit à des impératifs politiques ou utilitaires plutôt qu'à une idéologie locale. Lorsque J. Sibille évoque ${ }^{23}$ « L'expansion du français à partir de la fin $d u X^{e}$ siècle », il explique qu'elle :

«Ne s'est pas faite par grignotage territorial, mais par la francisation d'abord des élites sociales, puis de franges de plus en plus larges de la population, avec une phase de bilinguisme (ou de diglossie) qui a duré plusieurs siècles. En pays d'oc par exemple, cette francisation des élites (qui restaient néanmoins très largement bilingues) était un fait acquis au XVII ${ }^{\mathrm{e}}$ siècle. »

Cela peut s'appliquer, bien sûr, à la ville d'Arles, à cette "terre adjacente» dont l'aristocratie est très proche du pouvoir, mais dont les habitants sont si jaloux de leur liberté ! C'est d'ailleurs plus ou moins le reproche que va faire Mistral, à la fin du XIX siècle, dans une lettre insérée par l'abbé Rance dans son livre L'Académie d'Arles au XVII siècle d'après les documents originaux! Mistral exprime la réalité linguistique et les habitudes langagières des Arlésiens tout au long de ces trois siècles pendant lesquels deux systèmes ont coexisté, et se sont confrontés.

Ces documents ne sont pas uniquement à usage interne. Certains émanent d'une correspondance entre divers protagonistes qui ne sont pas tous provençalophones; or les correspondants doivent obligatoirement se comprendre. Les langues sont donc en contact constant. La communication écrite englobe divers éléments mettant en œuvre différentes ressources, de codification entre autres, qui vont permettre l'échange et la compréhension mutuelle. Arles n'est pas une cité isolée. De nombreux échanges ont lieu ; c'est un lieu de passage: routes et fleuve ont généré depuis longtemps un trafic commercial et de pèlerinage. La proximité d'Avignon, la présence des papes au Moyen Âge, ont favorisé la venue de populations étrangères, italiennes notamment. Or, si à l'époque médiévale, Arles est un gros bourg plutôt somnolent, ses activités la poussent à l'échange verbal, et scripturaire. L'histoire de la langue parlée à Arles ne peut donc s'écrire sans considérer l'histoire de la cité elle-même, les deux étant étroitement liées. La place tenue par l'aristocratie, la volonté de la bourgeoisie d'en tenir une tout aussi importante s'inscrivant dans la lutte pour le pouvoir se reflètent dans l'appropriation du système linguistique le plus apte à favoriser leurs desseins. Il est ainsi un révélateur de la hiérarchie des classes qui s'est établie tout au long d'une période allant du Moyen Âge jusqu'à la Révolution, et il n'est pas anodin de constater que l'usage $\mathrm{du}$ provençal et du français recoupe tous ces éléments. Depuis longtemps, la relation langue/littérature est faite. Celle entre la langue et la politique est tout aussi importante, l'une déterminant l'autre. Or, la littérature, passée la grande époque des troubadours, n'est plus qu'une survivance, et le français l'a supplantée y compris dans le Midi. Le lettré, Arlésien ou non, jusqu'au XVII ${ }^{\mathrm{e}}$ siècle, apprécie plutôt le français, même si, par la suite, certaines œuvres sont toujours écrites en langue d'oc. Enfin, n'oublions pas qu'ainsi que l'a dit Frédéric Mistral, « quau tèn la lengo tèn la clau ${ }^{24}$ ».

23. J. Sibille, « La notion de langues de France, son contenu et ses limites », Histoire ... , p. 54.

24. Fr. Mistral, Lis Isclo d'Or, Les Îles d'Or ; qui possède la langue possède la clé. 


\begin{abstract}
Résumé
Les Archives communales d'Arles conservent un nombre très important de documents dont les premiers datent $\mathrm{du} \mathrm{XI}^{\mathrm{e}}$ siècle. D'abord rédigés en latin, ils offrent dès le milieu du $\mathrm{XIV}^{\mathrm{e}}$ siècle des textes en provençal. Mais pourquoi cette langue apparaît-elle plus tard que dans d'autres lieux du Midi? Au XVII siècle, l'Académie d'Arles reproduit dans ses statuts celui proposé par l'Académie française concernant le français et devient alors un outil du pouvoir royal, et, peut-être, une "arme » contre un dialecte employé par ceux qui sont susceptibles de s'opposer au roi. Quelles influences ce même pouvoir a-t-il donc eues sur la cité arlésienne ? Cette dernière est-elle plus « française » que d'autres ? Telles sont quelquesunes des questions posées par la lecture des documents arlésiens.
\end{abstract}

\title{
Bibliographie
}

BERTRAND R., «Introduction», Arles, histoire, territoires et cultures, Paris, Imprimerie Nationale Édition, 2008.

BERTRAND R., DURAND St., «Un rayonnement administratif et un pouvoir judiciaire local », Arles, histoire, territoires et cultures, Paris, Imprimerie Nationale Edition, 2008.

BONNET M. R., CIERBIDE R. (eds.), Les Statuts de l'Ordre de Saint-Jean de Jérusalem. Édition critique des manuscrits en langue d'oc (XIV siècle), Université du Pays Basque, 2006.

BOURJAC B., «La ligue arlésienne », Arles, histoire, territoires et cultures, Paris, Imprimerie Nationale Édition, 2008.

BRUN A., La langue française en Provence de Louis XIV au Félibrige, Marseille, Bibliothèque de l'Institut Historique de Provence, 1927.

BRUN A., Recherches historiques sur l'introduction du français dans les provinces du Midi, Slatkines Reprints, Genève, 1973.

FAssin É., Bulletin Archéologique d'Arles, 1891 nº 6.

GRÔBER G., Grundiss der romanischen Philologie, I, Strasbourg, K. J. Trûbner, 1997.

KREMNITZ G., «Introduction générale», Histoire sociale des langues de France, Presses Universitaires de Rennes, 2013.

MistRal Fr., Lis Isclo d'Or, Les Îles d'Or.

SIBILLE J., "La notion de langues de France, son contenu et ses limites », Histoire sociale des langues de France, Presses Universitaires de Rennes, 2013.

WOEHRLIN J.-M., " Histoire du droit des langues en France », Histoire sociale des langues de France, Presses Universitaires de Rennes, 2013. 


\section{Pièces justificatives}

CC 522, 1493-1497, lettre 8, A.C.A.

Messenhors, tant e de cy tres bon cor que fayre pode me recomande a vous. Jeu ay entendut comment aves rescript au mestre reverent frayre Peyre Salvany que veguesses venyr dimenche prochan en Arle per cause de cauques conclusions que deu metre mestre Robert de las Arenes per que messenhors vous avysse que lodich mestre reverent non y hyra point per plusors rasons come plus a plen voys dyra mon compayre mys. Simon Griglo alcal lodich mestre reverent rescriore ansy: «mess. vous deves ben entendre e considerar que non es cause convenyente que ung mestre en teologie ce vague metre a disputar enbe ung semblant home come lodich mestre Robert car el a fahc plusors que son sos diciblos que lo mendre saumaix en dorment que aquest non fa en vedglant come vegies ce plas a Dieux per effet, car despueix que jeu ly fesy la resposte de que me dones charge per vous autres, messenhors, lodich mestre reverent a mandat queryr tres bacheliers loscalx ce plas a Dieux seran aisy a Toux sans per lo plus luen. E alore ce lodich mestre Robert vol disputar ne autre enbe el trobara ases que ly fara aplaser. E ce Dieux vol que entre cy e la lo temps contunye de estre ben come a present, ay esperance en Dieux que tout lo monde repayrara e vendre myelx a point que mantenent. E pueix messenhors me merevedgle de vous autres que dones auredgle a ren que vous digue lodich mestre Robert atendut la charge que my donnes d'asegurar lodich mestre reverent de las escoles lacal cause ay fahc per vostre bon voler. Per que cant a my non entende que me fases dyre une cause e que pueix en deliberes autrament, lacal cause non cuide que vueglas fayre car san vostres reverencies lo mon serye ny ben fahc ne honestament ne de rason non o podes fayre perque, messenhors, jeu vos pregue que ajas honor de la ville e la vostre per recomandade come aves agut toutjourt fins aysy e que per ung quidan que non es suficient ne convenient per tenyr la plassa que cant a lasdiches escoles metas las causes asegurades en diferent. / v / Et ce en nengune cause, messenhors, pode servyr la ville e vous autres toux. Mandas lo my e de bon cor lo faray a l'ajude de Nostre Senhor que vous tengue toux en sa sancte garde e vous done so que plus desiras. »

Escript a la bastide de Trebons aquest divendres XVIIeme jourt d'outobre.

Votre humble frayre Gauthier.

A mos honorables senhors e [s]yres messenhors los consolx de la cioutat d'Arle.

CC 522, 1493-1497, lettre 12, A.C.A.

Mons. lo conso a la vostro bonno gracio humbloment my recomande. Ay entendut coment vos autres, messeniors, aves fach apellar mossen lo conresier et Johan dou Borc, loqual m'a inormement cargat a l'ostal de la villo a causo d'oucuno sitassion facho contro ly. Et que per la part de Joham dou Borc vos autres, messeniors, o prenes fort contro certans particulars que n'es siam ou monestier. Messeniors, je vous avise qu'il n'y a home ou monestier que se melle dou plach de Johan dou Borc ne de mossen Perre Bertran. Il sont tous dos de la maison, il faront ansins que bon leur semblera. Du regard de my yeu vous vorrie requerir si ansins es que la villo lo prengo contro nous commo l'on dit qu'il vous plagues ousir partido car yeu vous baile Joham dou Borc oussi voutif que home que visses X ans ya. Mossen Frances me disit a Monmaior que mossen Peyre Bertran l'avie requist faire qualque plaser senso my ren declarar ne dire. Yeu ly disi que mossen Peire Bertran ero home de bien et bon jantilhome et que el ly fasie nul service, el ero home per lo ly rendre. Et quant lodit mossen Frances l'ac citat yeu entendy aqui mesmes per mossen Thomas, curat de Sant Joham, le dit que lo rey avie fach et d'aquel horo et moment, ly disi que non fisso nullo exsequssion et que anullo la citassion commo fit. Lo prior de Castillion my portit lendeman uno lettro de mossen Peyre Bertran que yeu ly fisso mandar las lettros a Tharascon ont el ero arrestat et a la requesto de ly, yeu las fi bailar ou capellan de mossen Peyre Bertran per lo faire relaxar. Pertant considerat toutos causos vous supplie et requere qu'il soit de vostre bon plaisir et grace si ren entendes m'apellar en l'ostal de la villo acr yeu edificaray mielx que Joham dou Borc visto veritat. Autro causo non per lo present fors que Dieu vous conserve commo la vostro seniorie desiro.

Lo tout vostre plusque sien Johannon sosprior. 
v/ A mon tres cher et honore senier et amic mons. lo consol Guillem Bochon en Arle humbloment sie d.

Abbé Rance, L'Académie d'Arles au XVII' siècle d'après les documents originaux, lettre de Fr. MISTRAL.

«Maillane, 22 janvier 1886.

Vous voulez bien, Monsieur l'abbé, prendre mon avis sur cette honnête Académie d'Arles que vos intéressantes recherches viennent d'exhumer. Le voici tout sincère. Je ne professe qu'une considération très modérée pour les beaux esprits de province, qui, sous Louis XIV, contribuèrent peu ou prou à implanter le culte du soleil de Versailles, et tout ce qui s'en est suivi, dans le libre domaine du soleil provençal. Je sais bien qu'il n'est pas juste de juger les idées d'un siècle avec celles d'un autre siècle, mais vous permettrez, je crois, à un poète provençal, profondément épris de son pays et de sa langue, de regretter cet entraînement, composé d'adulation plus encore que d'admiration, qui, sous le roisoleil, poussa toutes nos provinces à faire litière de leurs droits et de leur personnalité devant l'absolutisme et le nordisme triomphants. Or, les académiciens d'Arles, prenant pour tâche de répandre dans leur cité romaine le beau langage de la cour, ou de chasser, en d'autres termes, la langue provençale de l'usage habituel "des gens de qualité ", faisaient à leur manière ce que firent, au même temps, les consuls arlésiens qui portèrent au roi leur admirable Vénus pour recevoir en échange une croix de Saint- Louis. La Vénus d'Arles est aujourd'hui au Louvre, et le plâtre est à Arles; c'est bien gagné. Et de l'Académie qui rêva de tailler les peupliers blancs du Rhône comme les ormes de Le Nôtre reste-t-il autre chose que le madrigal de Roubin ? Que faire de mon île'? Il n'y croît que des saules Et tu n'aimes que le laurier, Que les mânes des vingt illustres me pardonnent l'injure! Vers 1740, au grand scandale de quelques demeurants de l'Académie défunte, un fils de paysan, C'est appelé J.B.Coye, se remit naïvement à écrire en provençal des épîtres, un poème et une comédie ; et il se trouve qu'Arles, oublieuse des poètes de son académie royale, a voulu voir dans Coye son poète typique, et les œuvres de Coye ont des rééditions.

Quoi qu'il en soit. Monsieur l'abbé, recevez, avec l'assurance que j'ai pris plaisir quand même à lire votre étude sur une phase curieuse de notre passé local, l'expression de mes sentiments les plus distingués.

F. MISTRAL. » 


\title{
Entre latin, français et langue d'oc: le notaire et son client (Provence, $X V^{e}-X V I^{e}$ siècles)
}

\author{
Gabriel AUDISIO \\ Professeur d'histoire émérite, \\ Aix-Marseille Université
}

\author{
Extrait de : Guylaine BRUN-TRIGAUD (dir.), Contacts, conflits et créations linguistiques, Paris, \\ Édition électronique du CTHS (Actes des congrès des sociétés historiques et scientifiques), 2015. \\ Cet article a été validé par le comité de lecture des Éditions du CTHS dans le cadre de la publication \\ des actes du $139^{\text {e }}$ Congrès national des sociétés historiques et scientifiques tenu à Nîmes en 2014.
}

Toute transmission comporte un risque d'erreur : que la communication s'opère par oral, par écrit, ou bien de l'oral à l'écrit ou de l'écrit à l'oral. Dans le cas de figure envisagé ici, la question prend une importance particulière puisque l'acte notarié est réputé " authentique », c'est-à-dire ayant valeur de preuve en justice. Le tribunal jadis, comme le chercheur aujourd'hui, prend pour argent comptant l'acte notarié, base de remarquables études historiques ou juridiques portant sur nombre de domaines: économique, financier, démographique, anthropologique, culturel, religieux, ainsi que l'ont montré nombre d'historiens depuis la mise en valeur de ce type de sources notamment par le colloque de Strasbourg en 1978. Or ces actes sont-ils réellement et totalement exempts d'erreur? Vu les conséquences, il importe de poser la question et de tenter d'y répondre. C'est à cette démarche que j'invite le lecteur. À cette fin, dans le cadre chronologique et géographique retenu, il convient auparavant d'établir le contexte administratif, social et culturel.

\section{La pratique linguistique}

\section{Un pays d'oc}

Que savons-nous de la pratique de la langue d'oc à cette époque ? Le fait est établi depuis longtemps car bien des documents en témoignent. Tentons de préciser. De grands bourgeois ont laissé leurs mémoires rédigés dans cette langue, tel Honoré de Valbelle à Marseille qui a tenu les siens de 1498 à 1539, date probable de sa mort; tel encore Jacques de La Roque, marchand d'Aix-en-Provence, fondateur de l'hôpital de la ville, une des cent plus grosses fortunes de la cité : il rédigea son «livre de raison » entre 1528 et $1540^{1}$. Un entrepreneur de transhumance, Noé de Barras, tint au jour le jour son livre de compte en 1480 pour l'estivage de quelque 34000 moutons depuis Aix jusque dans les Alpes, entièrement rédigé en provençal et bien d'autres firent de même pour leur livre de raison ${ }^{2}$. La langue d'oc se pratiquait donc ordinairement chez les lettrés, tant à l'oral qu'à l'écrit. À plus forte raison chez les autres. Le dossier des « révélations » (déclarations spontanées) reçues par l'inquisiteur d'Apt entre mai et juillet 1532 s'avère particulièrement intéressant par l'utilisation des diverses langues, fidèlement reproduites par un greffier, qui est un notaire, d'évidence polyglotte ${ }^{3} .34$ témoins, soit 3 femmes et 31 hommes, se présentèrent au tribunal. Le latin est omniprésent, notamment pour ce qui

1. H. de Valbelle, Histoire journalière (1498-1539), par V.L. Bourrilly, R. Duchêne, L. Gaillard, Ch. Rostaing, Aixen-Provence, Publications de 1'Université de Provence, 1985, 2 vol. Journal de Jacques de la Roque: A.D. Bouches-du-Rhône, désormais 13, Aix, 1 B 165.

2. J.-Y. Royer, Le journal de Noé de Barras..., Les Alpes de Lumière, n 98, 1988. M. R. Bonnet, Livres de raison et de comptes en Provence, fin du XIV siècle - début du XVI siècle, Aix-en-Provence, PUP, 1995.

3. Musée Arbaud, Aix-en-Provence, Ms MQ 755. 
relève du formulaire. Il est plus intéressant pour nous de voir en quelle langue se sont exprimés les "révélants", soit quand ils parlent eux-mêmes, soit quand ils rapportent des propos entendus. Cinq s'exprimèrent en latin, dont un juriste, un chanoine et un moine franciscain. Vingt et un, dont neuf artisans, usèrent du français seul mais fortement provençalisé, enfin six, soit quatre paysans, une femme et un maître artisan, ont parlé provençal. Pour deux nous ne savons pas, car le greffier a seulement mentionné en latin "a déclaré comme dessus». Il ressort de cet échantillon, sans doute non représentatif mais malgré tout indicatif, que le latin est un marqueur socio-culturel de supériorité, que le français est déjà bien implanté dans la population et que le provençal est pratiqué à tous les échelons de la société.

Les archives judiciaires des institutions royales attestent pareillement de cette pratique courante du provençal. Certes elles sont rédigées en français mais quand il s'agit de restituer précisément les paroles de l'accusé, notamment dans les cas d'injure ou de blasphème, c'est bien la langue populaire qui surgit alors, comme dans le simple récit des événements. Suite au pillage de Cabrières d'Avignon, Valentine Rambert déposant en janvier 1537, au capitaine qui lui demande :

Que vous on fach aquelos gendarmes? (Que vous ont fait ces gendarmes?),

elle répond en pleurant :

Ellos me an fort batude et aussi ma paure mayre et me an emportas tous mes abilhemans et tout nostre pan et tout quau que nous avian ${ }^{4} .$. (Ils $\mathrm{m}^{\prime}$ ont fort battue et aussi ma pauvre mère et m'ont emporté tous mes vêtements et tout notre pain et tout ce que nous avions...)

Quand le parlement de Provence émet un arrêt, toujours en français, il le fait traduire pour être sûr d'être compris. En 1509, il fait proclamer pour la énième fois l'interdiction de blasphémer. Le début et la conclusion de l'arrêt sont en français mais pas les dispositions :

Que deguna persona, home ny fema, de queqz estat ho condicion que sia, non ause ny presumisca jurar ny balsphemar ho reneguar lo nom de Dieu, Nostre Dama ny delz sancts ho sanctas en deguna faysson surs la pena per premiera veguada de demorar 5 horas al collar ambe ung grand papier surs la testa en lo qual sera escrich: regnegador de Dieu; et per la segonda veguada surs la pena d'estre foytat et corregat tout lo lonc de la villa; et per la tercia fes surs la pena d'aver pertusada la lengua ambe ung ferre cault. Et aquo sensa deguna remission. Et aysso sera per avisar los payres et las mayres que seran tengutz pers leurs enfans que faran las causas subredichas... (Que personne, homme ni femme, de quelque état et condition qu'il soit, n'ose ni se permette de jurer ni de blasphémer ou renier le nom de Dieu, Notre Dame ni des saints ou saintes en aucune façon sous peine pour la première fois de rester cinq heures au carcan avec un grand papier sur la tête sur lequel sera écrit: négateur de Dieu; et pour la deuxième fois sous peine d'être fouetté et corrigé tout le long de la ville; et pour la troisième fois sous peine d'avoir la langue percée avec un fer chaud. Et cela sans aucune rémission. Et aussi sera pour prévenir les pères et les mères qu'ils seront tenus [responsables] pour leurs enfants qui feront les choses susdites...)

Il en va de même, au niveau plus modeste de la communauté d'habitants. Les registres paroissiaux, bien moins nombreux à cette époque qu'aux siècles suivants, montrent que le provençal est largement pratiqué par les curés, en concurrence avec le latin, même après l'obligation de les rédiger en français de 1539, ainsi à Allauch, Aubagne, Auriol, La Ciotat, Roquevaire, toutes localités de l'actuel département des Bouches-du-Rhône ${ }^{6} . .$. À Orange, en 1460, le trésorier de la ville paya 18 florins au notaire Claude de Coreas pour

4. A. D. Vaucluse, désormais 84, E Caderousse, 331.

5. A.D. 13, Aix, B 3319 bis, f ${ }^{\circ} 83,25$ mars 1509.

6. Ibid., Marseille, 201 E 1458 (Allauch, 1549-1564) ; 201 E 1526 bis (Aubagne, 1543-1547) et 1527 (Aubagne, 15561563) ; 201 E 2176 (Auriol, 1571-1587) ; 201 E 1943 (La Ciotat, 1539-1549) et 1944 (La Ciotat, 1557-1607) ; 201 E 2286 bis (Roquevaire, 1558-1575). 
traduire les libertés et statuts de la cité en romans ${ }^{7}$. Il en va ainsi également pour convoquer l'assemblée des habitants, comme à Cucuron (84) en 1541 :

Parlament cridat per Peyre Peytavy, servent public et juraty de la court del present luoc de Cucuron: que tout cap de hostal si ajo a trobar al cymenteri de la gleysa de Nostro Dama de Bel Luoc al parlament, sus la pena de ung florin per tous aquellos que y manquara ${ }^{8}$ (Assemblée criée par Pierre Peytavy, serviteur public et juré de la cour du présent lieu de Cucuron : que tout chef de maison ait à se trouver au cimetière de l'église Notre Dame de Beaulieu à l'assemblée, sous peine d'un florin à tous ceux qui y manqueront).

La justice seigneuriale agit de même pour procéder à ses criées, généralement annuelles, comme à La Roque d'Anthéron (13) tous les 25 mars ou, dans les Alpes de Haute Provence, à Jarjayes, Valbelle, Saint-Symphorien, Nible, Venterol tout au long du XVI siècle ou encore à Puyricard (13) en 1544 :

Que deguno personne de quelque stat, grad ou conditioun que sie non ause jura Dieu, la glorioso V.M. ny lous sainctz et sainctes de paradis sur la peno soies la premiero fes de 5 sous $^{9}$... (Que personne de quelque état, grade ou condition qu'il soit n'ose jurer Dieu, la glorieuse Vierge Marie ni les saints et saintes de paradis sous peine soit la première fois de 5 sous...).

Voici encore un cas particulièrement probant. Ange de Pontevès, coseigneur de Buoux (84), passait en 1512 un acte d'habitation avec six colons, créant ainsi une communauté d'habitants pour cultiver à nouveau son terroir abandonné. Le notaire d'Apt s'apprête à rédiger l'acte en latin, selon l'usage. Mais, à la demande expresse des habitants, comme il est précisé, ceux-ci voulant absolument comprendre toutes les clauses qui allaient désormais gérer leur vie, la minute est établie in lingua vulgari. Mais qu'est-ce à dire, quand toute autre langue que le latin était alors qualifiée de vulgaire ? Il suffit de lire la suite pour être fixé :

Et primo que ung chascun sie tengut de pagar au seignor chascun an per lur meyson et habitation una emina d'anona bona et bella a la Madaleno... (Et primo que chacun soit tenu de payer au seigneur chaque année pour leur maison et habitation une émine d'annone bonne et belle à la Madeleine...), soit le 22 juillet.

De fait, les vingt articles que compte le contrat sont en provençal. Les paysans ne comprenaient évidemment pas le latin mais, apparemment, pas beaucoup mieux le français. Aussi ne doutons pas que l'acte passé en janvier de la même année par le même seigneur pour un arrentement et un contrat de bétail à mi-croît a également été traduit en provençal, le notaire ayant porté cette mention marginale sur le document latin Facta copia in vulgari pro parte renderiorum ${ }^{10}$ (Copie faite en langue vulgaire pour la partie des preneurs).

L'examen des registres des communautés est également utile ici. Dans son tableau portant sur vingt villes de Provence, Michel Hébert relève que, au milieu du XVI ${ }^{\mathrm{e}}$ siècle, dix secrétaires rédigeaient en latin, neuf en provençal et le dernier, celui des Baux, usant des deux ${ }^{11}$. Mais dans les communautés rurales, le provençal règne en maître comme dans la région de La Roquebrussane (83) où, jusque vers 1560, il est utilisé de façon exclusive et ininterrompue $\mathrm{e}^{12}$.

C'est encore dans cette langue qu'en 1517 un malheureux a dicté son testament au curé du lieu, vu l'urgence en ce cas de peste et l'absence du notaire de Cucuron (84) :

7. W. F. Leemans, La principauté d'Orange de 1470 à 1580. Une société en mutation, Hilversum Verloren, 1986,2 vol., t. 1 , p. 47.

8. A. D. 84, 3 E 36, 191, fo après 595, 10 mars 1541.

9. A. D. Alpes de Haute Provence, E DEP 027, CC1 et A.D. B-du-R., B 66, 20 avril 1544.

10. A. D. 84,3 E $4,438, f^{\circ} 9 \mathrm{v}^{\circ}, 18$ octobre 1512.

11. M. Hébert, «Latin et vernaculaire : quelles langues écrit-on en Provence à la fin du Moyen Âge ? ", Provence Historique, t. XLVII, fasc. 188, 1997, p. 281-299.

12. E. Aguillon, « Dins lo present pais de Provenso... », Cahiers Critiques du Patrimoine, n 4, 1989, p. 99-100. 
Et yeu, Audet Bosso, cappellan de Lauris, et per lo present curat de Cucuron, ay pres lo present testament per causo de la pestilensi regnant adonc au present luoc de Cucuron et a defaut de notari $^{13}$ » (Moi, Audet Bosse, prêtre de Lauris et, pour le présent, curé de Cucuron, ai pris le présent testament à cause de la pestilence régnant pour lors au présent lieu et à défaut de notaire...)

Le curé n'a pas pu ou su mettre en forme ces dernières dispositions comme l'aurait fait sans doute le notaire qui, après les avoir reçues, les a conservées telles quelles. Retenons que la pratique du provençal est générale, indépendamment de l'appartenance socioprofessionnelle.

\section{La pratique linguistique des notaires}

La plupart des actes notariés s'établissaient en latin. Non pas grâce à une formation universitaire mais suite à un apprentissage de deux ou trois ans chez un membre de la profession. N'empêche que, comme tous, les notaires participaient d'un monde provençalisant. Dans un certain nombre de cas, ils ont rédigé dans la langue populaire. Ainsi à Aix en 1532, pour une convention entre un chanoine et un maître maçon, le notaire commence comme de coutume en latin, précisant sub pactibus et condicionibus in gallico descriptis de voluntate dictarum partibus in modo qui sequitur (avec les accords et conventions écrites en français de la volonté desdites parties comme suit). Suivent en effet les clauses de la convention que nous pensons trouver logiquement en français. C'est le cas pour les tout premiers mots : Et premièrement, mais il continue aussitôt

fundera lo dict mestre Alizandre a suis propriis despens lo carage de la dicta mayson despuyes la codiera del premier solier fins a la taulissa ${ }^{14}$... (Ledit maître Alexandre fera à ses propres dépens la façade de ladite maison depuis l'appui de fenêtre du premier étage jusqu'au toit).

Ici l'intérêt est triple : d'abord le notaire indique que c'est à la demande des parties qu'il rédige l'acte non pas en latin mais en français (in gallico) pourtant ensuite ce n'est pas au français qu'il passe mais au provençal avec enfin, quelques mots latins. Et tout l'acte est d'oc.

Nous voyons aussi surgir la langue commune, par exemple, dans les inventaires après décès : dans la maison du défunt, passant d'une pièce l'autre, le notaire note absolument tout, y compris les objets les plus communs, les désignant sous le nom qui lui vient spontanément à l'esprit. L'inventaire tout entier est parfois rédigé d'oc: Et primerament l'inventari dels bens movables ${ }^{15} \ldots$ Mais, même plus tard, quand l'acte est entièrement rédigé en français, de temps à autre jaillissent les mots les plus usités, sans que le notaire éprouve le besoin de les traduire. Il note ainsi deux cadières (chaises), un calen (lampe à huile), trois fedes (brebis), une padelle de peu de valeur (poëlle), un payrol (chaudron), etc.

Enfin, pour situer un bien immobilier ou pour décrire les confins d'une parcelle de terre, lors d'une vente, un échange, une location, c'est une fois encore la langue d'oc qui surgit. Telle terre se trouve, dans le terroir de Castelmagno en Piémont, au lieu-dit « Al Clot » et une autre «A la font del Clot ». Inutile de multiplier de tels exemples qui sont légion ${ }^{16}$.

Puis l'ordonnance de Villers-Cotterêts obligea les notaires à écrire en français. Du jour au lendemain exactement, le latin est abandonné pour le français. Certains s'en expliquent dans leur registre même. Voici comment, par exemple, l'exprime l'un d'entre eux :

S'ensuyvent les actes prins et receuz par moy Jehan-Loys Fulconis, tabellion royal du lieu de Cucuron depueys la publication des ordonnances royalles faicte à Aix mercredi cinquiesme

13. A.D. Vaucluse, E 36113 , $\mathrm{f}^{\circ} 6$ (8 août 1517).

14. A.D. 13306 E 498 (?), $\mathrm{f}^{\circ} 89 \mathrm{v}^{\circ}, 16$ février 1532.

15. A. D. 84,3 E $36,14, \mathrm{f}^{\circ} 76 \mathrm{v}^{\circ}, 18$ janvier 1467.

16. Ibid., $3 \mathrm{E} 36,22, \mathrm{f}^{\circ} 46 \mathrm{v}^{\circ}, 2$ janvier 1483 , ratification de vente. 
de ce présent moys de novembre l'an mil cinq cens trente neuf par devant la court de monsieur le lieutenant de séneschal publiées, lesquelles contienent que le roy nostre sire - à qui Dieu doint bonne vie - veult et entend que doresenavant tous contraictz se seront en françois et plusieurs aultres caps contenus en icelles ${ }^{17}$.

Et, de fait, alors qu'il a jusqu'ici rédigé tous ses actes en latin, il passe immédiatement et définitivement au français, de même que son confrère Jacques Escuyer, notaire d'Apt, expliquant également le changement ${ }^{18}$. Ce qu'appliquent tous les notaires provençaux, preuve qu'ils pratiquaient déjà largement la langue du roi, mais le plus souvent sans donner d'explication. Pour autant ils n'abandonnent totalement ni le latin ni le provençal. Voilà un personnel qui était en fait trilingue, parfaitement adapté aux conditions de sa profession. Notons au passage que la réunion du comté de Provence au royaume de France, opérée en 1481 et qui causa par ailleurs de notables changements, n'eut aucune incidence linguistique décelable pas plus chez les notaires que chez les autres lettrés.

\section{L'acte notarié}

Tentons à présent une approche de l'activité notariale. La variété des actes notariés a de quoi nous étonner. C'est que l'appel au notaire était alors bien plus commun qu'aujourd'hui. J'ai eu la possibilité de diriger pendant quatre ans une équipe de recherche composée à la fois d'historiens et de juristes d'Aix-en-Provence pour établir une sorte de panorama de l'activité notariale $d u X^{e}$ au XVIII ${ }^{\mathrm{e}}$ siècle. Nous avons abouti à un résultat impressionnant : au total plus de 36000 actes ont été examinés sur 14 sites par 11 chercheurs, qui ont révélé finalement 441 types d'acte. Cette diversité ne manque pas de surprendre. Même si, pour permettre la comparaison avec notre société actuelle, nous soustrayons les actes relatifs à la féodalité (27) aux affaires ecclésiastiques (28) et aux affaires religieuses musulmanes en Égypte (5), soit 80, il en reste tout de même encore 361.

Les résultats principaux ne surprendront pas ceux qui connaissent les fonds notariés des archives : $37 \%$ de quittances et dettes ; $9 \%$ d'achats/ventes ; $4 \%$ d'actes matrimoniaux ; $4 \%$ d'actes successoraux. Ces quatre types d'actes à eux seuls représentent $54 \%$ de l'activité notariale. Tous les autres actes, soit moins de la moitié, se répartissent donc en 357 types. Là se révèle l'originalité de cette société comparée à la nôtre car nous y trouvons des actes qui, pour nous, ne relèvent pas du notariat mais, pour une bonne part, de la justice: émancipations, adoptions, commissions, sommations, protestations, intimations, réquisitions, nominations d'experts ou d'arbitres, arbitrages, inventaires après décès. Mais nous découvrons aussi des actes surprenants : achat d'un seul olivier, contractions de dettes pour des sommes qui nous semblent minimes... Voici quelques exemples trouvés en dépouillant systématiquement tous les actes notariés de la ville d'Aix conservés pour l'année 1532 (plus de 7 000) : don d'une fillette de dix-huit mois ou encore deux promesses de ne plus jouer ${ }^{19}$. Mais j'ai trouvé par ailleurs la vente d'un enfant de deux ans en avril 1545 et Marc Venard a signalé un acte par lequel un acteur, inquiet de son salut éternel tandis qu'il jouait alors dans le mystère de sainte Barbe à Avignon en 1470 et dont le rôle nécessitait des invocations au diable, s'en alla trouver un notaire de la ville déclarant solennellement qu'il n'y figure que par manière de jeu, qu'il ne croit pas vraiment ce qu'il proclame sur scène et qu'il n'entend pas que le diable, ennemi de la nature humaine, ait de ce fait quelque droit sur son âme $e^{20}$. Au total, dans le Midi, les archives notariées constituent, malgré les déperditions, des fonds considérables : $3,8 \mathrm{~km}$ de rayonnages aux archives départementales de Vaucluse; 7,5 $\mathrm{km}$ pour celles des

17. Ibid., 3 E 36,189 , fo 902

18. Ibid., 3 E 4, 483, $\mathrm{f}^{\circ} 559,22$ novembre 1539.

19. G. Audisio (dir.), "De la masse à l'unique (Aix-en-Provence, 1532)", L'historien et l'activité notariale..., Toulouse, PUM, 2005, p. 105.

20. Respectivement: A. D. 84, 3 E 38, 961, f ${ }^{\circ}$ 157, 24 avril 1545; M. Venard, Réforme protestante, Réforme catholique..., Paris, Cerf, 1993, p. 231, note 27. 
Bouches-du-Rhône. De sorte que s'y engager c'est, pour plagier V. Hugo (Oceano nox), risquer d'être enfouis « dans une mer sans fond par une nuit sans lune».

Il faut admettre qu'une marge de manœuvre bien plus grande qu'aujourd'hui était alors laissée aux notaires, qui leur permettaient de répondre à la demande plus variée de leur clientèle. Par ailleurs, bien des accords et contrats étaient passés seulement par oral et en restaient à ce stade. Nous en avons la preuve par exemple quand un différend surgit pour cause de rupture de l'accord par l'une des parties et que l'affaire se retrouve en justice. Alors les parties et les témoins décrivent comment le contrat avait été passé en « toquant et chopant ». En 1553, suite à un différend, un marchand d'Ansouis (84), déclare que la vente de diverses céréales avait bien été conclue, puisqu'il y avait eu "touchement des mains ${ }^{21}$. Les actes notariés, si nombreux soient-ils, ne constituent donc en fait qu'une partie émergente des conventions établies.

Ainsi une personne, le plus souvent analphabète, allait trouver un notaire, lui adressant une requête précise pour qu'une preuve matérielle soit établie. Pourquoi donc vouloir un acte écrit? Jusqu'alors l'oralité dominait et suffisait dans le fonctionnement de cette société, y compris en justice : au $\mathrm{XVI}^{\mathrm{e}}$ siècle courait encore l'adage "Témoins passent lettres ». Nous avons un témoignage de cette pratique dans les testaments qui, sous leur forme la plus courante, étaient dictés (nuncupatifs), toujours en présence d'au moins sept témoins. Pourquoi donc, puisque la signature du notaire et, à la limite, l'attestation de deux témoins suffisaient à authentifier l'acte ? C'est le vestige d'une époque où l'acte écrit n'existait pas ou peu et donc, par précaution, le testateur faisait appel à sept témoins (nombre symbolique) pour qu'ils puissent, du moins les survivants, attester de ses dernières volontés si, des années plus tard, les successeurs en avaient besoin.

\section{Notaire et client}

Comment s'opérait concrètement l'établissement d'un acte ? Nous avons donc d'une part une clientèle globalement analphabète, surtout à la campagne, parlant d'oc, entendant plus ou moins le français et frottée de latin par la fréquentation de l'église et, de l'autre, une mince couche sociale plus ou moins fortunée, plus ou moins puissante, composée de lisants-écrivants trilingues, ce qui leur conférait un statut à part socialement et culturellement.

L'acte pouvait passer par trois étapes. Le «brouillard» était un véritable brouillon - il reste quelques-uns de ces petits carnets - le notaire n'écrivant que les éléments principaux ; c'était une étape possible mais non obligatoire. La «minute » ou brève constituait, contrairement au brouillard, l'acte authentique ; leurs registres sont les plus nombreux. Enfin, à la demande de l'une des parties, le notaire pouvait être appelé à rédiger une étendue ou "extensoir» où toutes les formules juridiques se trouvent développées alors que dans la minute elles sont abrégées; tous les actes n'ont donc pas atteint cette ultime forme.

Il est évidemment fondamental que le client se fasse comprendre pour que le notaire établisse avec précision l'acte souhaité. Si la personne était totalement étrangère à la langue du pays, il fallait faire appel à un interprète (trucheman ou trocman). Ainsi quand l'archevêque arménien Oscan Valtablier, se trouvant à Marseille en 1674, décide de tester, le notaire eut recours à Estienne Guirard, « marchand de cette ville et interprète ordinaire des Arméniens » pour établir l'acte en français ${ }^{22}$. Mais si le client baragouinait un peu la langue locale, on pouvait tenter de s'en passer, avec tout de même le risque de quelques surprises. Sinon, jusque dans un $\mathrm{XVIII}^{\mathrm{e}}$ siècle avancé, notaire et client parlaient

21. A. D. 13, B 221, $\mathrm{f}^{\circ} 458$, novembre 1553. La tradition s'est d'ailleurs maintenue longtemps.

22. A. D. 13, 391 E 403, $\mathrm{f}^{\circ}$ 63, 13 février 1674, «Testament de illustre seigneur messire Hosquan Valtabier archevesque ». Information due à l'obligeance d'Olivier Raveux (Telemme, Aix). 
habituellement d'oc, provençal ou une de ses variantes : ils se comprenaient. Du moins on peut le supposer.

Mais le notaire ne pouvait éviter la traduction puisque parlant d'oc avec son client il devait ensuite établir l'acte le plus souvent en latin ou, plus tard, en français. Si, pour les clauses principales ils finissaient toujours par s'entendre, deux types d'indications posaient un problème particulier pour une population immigrée, qui fut massive en Provence aux $X V^{e}-X V I^{e}$ siècles. Des milliers d'immigrés s'y installèrent, répondant à un fort appel $d$ 'offres après un siècle tourmenté et dévastateur. Dans les villes arrivèrent nombre d'étrangers originaires surtout de pays méditerranéens et principalement d'Italie. Dans les campagnes, l'immigration fut différente. J'ai montré ailleurs qu'une grande vague migratoire, composée de plusieurs milliers d'Alpins est venue alors s'établir dans un Luberon ravagé et dépeuplér ${ }^{23}$. Ces populations parlaient également $\mathrm{d}^{\prime} \mathrm{oc}$, venues surtout des diocèses de Turin et d'Embrun. Ces gens, comme les autochtones, ne tardèrent pas à faire appel eux aussi aux notaires. Ceux-ci durent faire face à une clientèle inconnue. Le problème principal auquel ils se heurtèrent fut celui des noms propres, personnes et lieux. Cette difficulté s'avère parfois cruciale pour leur identification.

Ainsi d'abord les prénoms sont écrits de temps à autre comme ils se prononçaient et non sous leur forme classique, latine ou française : Bernabeu et non Barnabé, Antoni ou même Toni pour Antoine; Margarido au lieu de Marguerite, Jaumeto pour Jacqueline, etc. D'ailleurs cette langue offre parfois des nuances difficiles à rendre en français. Ainsi le prénom Jaume, peut devenir Jacques, mais aussi Jacas (le gros Jacques), ou Jacquet aussi bien que Jaumet (le petit Jacques). Hormis le cas de traduction, le nom lui-même peut laisser perplexe. Ainsi, dans la période "française ", un même homme peut être nommé Jean, Jeannon, Jeannet. Mais cette variation peut aussi indiquer des personnes différentes, par exemple quand le père et deux enfants portent le même prénom, ou encore le père, le fils et le petit-fils. Dans ce cas, seuls d'autres éléments peuvent permettre de les différencier. Faute desquels nous restons dans l'incertitude.

Quant aux patronymes, l'immigration contribua fortement au renouvellement onomastique de la population de la région. Il est peu probable que, si erreur il y a, elle puisse provenir de l'intéressé. Mais prenons garde au fait que quelquefois ce que nous prenons pour une erreur n'en est pas une. Ainsi quand dans un acte une personne, apparemment la même, est affectée tantôt d'un patronyme et tantôt d'un autre, il arrive que ce soit parce que, outre son patronyme, elle porte un surnom : l'un aussi bien que l'autre servant à le désigner. Il est évidemment difficile de le vérifier s'il s'agit d'un acte isolé ou si la confusion ne se produit qu'une seule fois dans l'acte. Au cours de mes dépouillements, j'ai trouvé par exemple un Durant Rambert dit Callier, de Cabrières d'Avignon (84), appelé dans certains actes Durant Rambert et dans d'autres Durant Callier.

D'autres fois la confusion vient de la proximité de deux familles tellement liées que le scribe se trompe. En voici deux exemples flagrants qui ne relèvent pas du notariat mais qui peuvent expliquer ce type d'erreurs parfois difficilement décelables. Deux familles, les Serre et les Pellenc, vivaient tellement soudées que leurs bastides, sises au Plan d'Apt, non loin de la ville, communiquaient entre elles. D'ailleurs plusieurs mariages entre ces deux maisons montrent les forts liens qui les unissaient de sorte que les gens les confondaient parfois. Ainsi le greffier du Conseil de ville d'Apt, qui d'ailleurs était un notaire du lieu, à la date du 11 décembre 1540, a écrit dans la liste des habitants réunis pour le Conseil Colin Serre Pellenc, $\mathrm{feu}^{24}$. Ici le notaire a corrigé son erreur, elle n'en reste pas moins significative. Autre exemple, le premier registre paroissial d'Apt, à la date du $1^{\text {er }}$ août 1554, contient l'enregistrement d'un baptême. Le prêtre a écrit Marguerite Serre, fille de François Pellenc: erreur manifeste, puisque la fillette ne pouvait porter un autre

23. G. Audisio, Une grande migration alpine en Provence (1460-1560), Torino, Palazzo Carignano, 1989. Id., Migranti valdesi. Delfinato, Piemonte, Provenza (1460-1560). Migrants vaudois. Dauphiné, Piémont Provence, Torino, Claudiana, 2011.

24. Archives communales d'Apt, BB 21, fo 225. 
patronyme que celui de son père, ici facile à rectifier vu que les parents se retrouvent deux autres fois dans le même registre ; il est vrai que la marraine de Marguerite était Antoinette Serre ; cette fois encore il y eut confusion entre les deux familles, mais ici non corrigée.

Avec le passage obligatoire au français en 1539, un autre problème nous attend : celui de la transformation ou, pour mieux dire, de la traduction des noms. Le client a très probablement continué à énoncer ses nom et prénom comme avant, parlant d'oc. Mais cette fois le notaire le traduit parfois en français, mais conservant parfois la forme latine. Ainsi tous les patronymes qui, en latin, se terminaient souvent par ' $\mathrm{i}$ ' (forme du génitif) furent francisés: Pellenqui devint Pellenc, Anthoardi Anthoard, Cavalerii Cavalier, Arnulphi Arnoux, Ginhosi Gignoux etc. Mais pour certains noms il fut quelquefois procédé à une véritable traduction : Ruffi se transformant en Roux, Albi en Blanc, Pastor en Berger, Juvenis en Jeune ou Le Jeune, etc. Théoriquement cela ne pose pas de problème d'identification au chercheur. Pourtant voici, par exemple, Jacobi devenu Jacob, Jacques, Jaume ou Jacquême et le patronyme français Croux provient de diverses formes: Curtis, Curti, Crucis, Cros, Crux, Cruces. Dans un même acte concernant deux frères habitant Viens (84), l'un est nommé Albi et l'autre Blanqui, c'est-à-dire que la traduction française «Blanc » a été latinisée ${ }^{25}$, ce qui nous semble un évident manque de rigueur dans la nomination. Ainsi, concrètement, une dernière difficulté surgit quand tantôt le nom est traduit et tantôt non, apparemment sans logique. Je suppose que le notaire a parfois suivi l'indication et la prononciation de son client, à moins qu'il ait lui-même varié, vu que l'identification de la personne ne posait alors aucune difficulté, tout le monde connaissant la personne, même immigrée, sous un nom ou sous l'autre. Mais aujourd'hui le chercheur, lui, peut se perdre.

Le nom de lieu, de même, peut poser un problème d'identification. La localisation est toujours mentionnée dans l'acte car elle est partie de l'identité de la personne. Sont en effet habituellement mentionnés non seulement le nom, le prénom, éventuellement le surnom, la filiation surtout pour les filles, mais aussi la paroisse de résidence et son diocèse et, dans le cas d'un immigré, la paroisse d'origine et son diocèse, ce qui était le cas de tous les Alpins venus en Luberon.

Je n'aborderai pas ici la question du lieu de résidence qui, contrairement à ce que l'on peut penser, n'est pas si simple à cause des résidences multiples et de la mobilité d'une population paysanne que l'on croyait plus stable. Je me limite aux lieux d'origine. Et d'abord le diocèse. La formule habituelle est, par exemple, "Jean Brun, natif de Fressinières diocèse $\mathrm{d}^{\prime}$ Embrun, habitant Cabrières d'Aigues diocèse $\mathrm{d}^{\prime} \mathrm{Aix}$ ». La première surprise est de constater que, après vérification, le diocèse indiqué est parfois erroné. Nous pouvons trouver qualifiée de diocèse une localité qui n'est alors encore que paroisse : ainsi, pour le Piémont, Saluzzo érigé en diocèse seulement en 1511. Dans d'autres cas nous lisons, si l'on peut dire car la finale latine toujours en ensis est abrégée, le nom de diocèses qui n'existent pas ou qu'en tout cas je n'ai pas identifiés, ignorant dans quel pays ils se trouvent: est-ce une carence personnelle, une erreur du notaire ou du client?

Il en va de même pour les paroisses et, ici, la difficulté de l'identification s'accroît. D'abord parce qu'à l'époque il n'y a pas d'orthographe, pas plus pour les noms de lieu que pour les noms de personne, qu'ensuite il peut s'agir de localités minuscules parfois aujourd'hui disparues et qu'enfin la graphie peut varier. Ainsi le village aujourd'hui nommé Paesana en Piémont se trouve écrit Pessano ou Pesano. Mais il est des cas plus compliqués. Par exemple Thomas Pastor est venu de Sestrières, paroisse qui, dans un acte de 1504 est attribuée au diocèse d'Embrun tandis qu'un autre de 1516 l'affecte au diocèse de Turin ${ }^{26}$. Quand, comme ici, l'identification de la paroisse ne pose pas de problème, l'erreur est vite rectifiée : Sestrières est bien dans le diocèse de Turin. Dans d'autres cas, 
c'est plus délicat. Par exemple, Roman Ponsat, cardeur habitant La Motte d'Aigues, est natif de Las Traversas, diocèse de Gap ${ }^{27}$. Mais il n'y a pas de paroisse ainsi nommée dans ce diocèse. En revanche il existe un hameau "Traverses » dans la paroisse de Pragelato, dans le diocèse de Turin. Si nous n'avions que cet acte, nous serions embarrassés. Mais plusieurs autres le concernant nous permettent de rectifier: il est bien originaire de Pragelato. Reste l'erreur : qui en est responsable ? Sans doute le client.

Voici Jean Galéan venu del Salvage de Mentoules, paroisse de Pinerolo. Des Salvages il en existe plusieurs en Piémont, mais Mentoulles est elle-même une paroisse et ne peut donc dépendre de la paroisse de Pinerolo, d'ailleurs déjà assez loin. Il se trouve ici plusieurs confusions. De même un acte concernant deux frères, Guillaume et Jean Broc, les dit de Perosa, paroisse de Mentoulles, mais les deux localités étaient alors paroisses : cet immigré venait-il de Perosa ou de Mentoulles? Antoinette Cardon, à l'occasion de son mariage en 1526, est dite originaire de Prarostino paroisse de Roccapiata alors qu'en réalité c'est l'inverse : Roccapiata est un hameau de la paroisse de Prarostino ${ }^{28}$.

D'autres fois, le nom lu ne correspond apparemment à aucune localité connue. Voici Jean Bertin arrivé de Dengruenha et un autre de Granha, tous deux dans le diocèse de Turin ${ }^{29}$. Il faut déjà un bel effort pour reconnaître sous ces deux appellations une seule et même paroisse, aujourd'hui Angrogna, ce que permet la prononciation, car le «nh » donne le son mouillé "gn». Michel Vian est de Bernes, c'est-à-dire Bernezzo aujourd'hui, car le Piémontais dit "Bernès ». Voici encore les trois frères Doete qui s'installent à L'Isle sur Sorgue ; un acte latin de 1473 les fait venir de la paroisse de Villario Sancto Petro, dans le diocèse de Turin. Aucune localité actuelle ne porte ce nom. Dans ce diocèse se trouvent plusieurs Villars et nombre de Saint Pierre. Ici c'est la connaissance à la fois du pays et de la langue d'oc qui permet de situer la localité : en provençal saint Pierre se dit san Peyre. Il existe encore un village de ce nom, en un seul mot, Sampeyre, dans le val Varaita et, dans cette commune, un hameau appelé Villar. Ainsi nos trois frères, ou le notaire, ont inversé hameau et paroisse : ils venaient en réalité du hameau de Villar sis dans la paroisse de Sampeyre ${ }^{30}$. Dans mon travail sur l'immigration en Provence, il reste ainsi une dizaine de lieux d'origine non identifiés.

Le fait est donc là, découverte tardive : l'acte notarié peut contenir des erreurs alors que, comme pour beaucoup de chercheurs, il était jusqu'alors parole d'évangile. Reste à savoir à qui incombe l'erreur. Il n'est pas toujours aisé de trancher même si des erreurs sont certainement imputables au client, notamment en ce qui concerne l'appellation respective des diocèse, paroisse ou lieu-dit. En effet le notaire ignore tout de ces localités lointaines ; il est contraint de se fier à son client. Ce qui, du coup, nous interroge. Comment est-il possible, sachant l'emprise religieuse à cette époque, que des paysans aient pu ignorer leur paroisse ou même leur diocèse? J'ai, dans le cas précis, une hypothèse, qui serait hors de propos ici.

En revanche, certaines inexactitudes sont probablement dues au notaire. C'est en réalité la rencontre de deux cultures à laquelle nous assistons. Dans le discours de son client, le notaire entend notamment des patronymes et des toponymes qu'il ignore. Il écrit en quelque sorte sous la dictée et, comme son interlocuteur est analphabète - donc dans l'impossibilité de contrôler son texte - il transcrit et traduit phonétiquement en latin ou en français ce qui lui est dit en provençal, sans compter que le notaire peut également être mal entendant. D'où des approximations, des confusions, des erreurs.

27. Ibid., 3 E 69, 18, f $^{\circ} 495,16$ novembre 1551.

28. Ibid., respectivement : 3 E 36, 92 bis, fo 16, vente, 17 janvier 1508 (Jean Galéan) ; 3 E 38, 571, non folioté, 14 août 1476 (G. et J. Broc) ; 3 E 42, 4, f 79,3 décembre 1526 (Antoinette Cardon).

29. Arch. Dép. Var, E 925, f $317 \mathrm{v}^{\circ}$, renonciation, 25 septembre 1521.

30. A. D. 84, 3 E 38, respectivement : 435, non folioté, procuration, 4 décembre 1474 (Michel Vian) ; 3 E 38, 399 , non folioté, 20 février 1473 (Claude, Simon et Thomas Doete). 
Or une erreur dans un acte notarié peut avoir des conséquences importantes, dont son annulation pure et simple en cas de recours. Nous ne pouvons le vérifier que si plainte d'un client ou de ses successeurs est déposée en justice. J'ai cherché dans cette direction qui pourrait préciser la marge de manœuvre dont disposait le notaire, lequel se trouve dans la position d'un intermédiaire obligé entre l'individu et l'administration. Ces procès relevant du civil doivent se trouver dans les archives des sénéchaussées. Malheureusement le plus souvent, dans nos départements, elles ne sont pas classées, donc pas consultables. Depuis peu celles de la sénéchaussée de Marseille le sont. Un rapide survol, possible avec l'inventaire numérisé, montre que, dans ce fonds couvrant deux siècles et demi, seuls 42 procès impliquent un notaire, tous du XVIII ${ }^{\mathrm{e}}$ siècle, et aucun n'est poursuivi pour faute professionnelle, erreur de rédaction ou falsification d'acte. Il semble bien en effet qu'une jurisprudence ne se soit mise en place qu'à partir du $\mathrm{XVII}{ }^{\mathrm{e}}$ siècle. Un plaignant ayant porté plainte contre son notaire qui avait commis une erreur dans la rédaction d'un acte ayant entraîné son annulation se vit débouté par le parlement de Paris qui argua du fait que l'erreur est humaine ${ }^{31}$.

Notons enfin que les erreurs factuelles relevées dans les actes provençaux n'affectaient pas les dispositions mêmes de l'acte. Si elles n'entament en rien sa validité juridique elles entachent sa fiabilité. Elles peuvent gêner, troubler ou tromper le chercheur qui tente par exemple de reconstituer des familles, des terroirs ou encore la carte de l'origine migratoire d'une population. Retenons en tout cas que l'acte notarié peut receler des erreurs, décelables par la comparaison des actes mais qu'elles peuvent être résolues aussi quelquefois par la restitution de l'oralité. Gardons-nous cependant de conclure trop vite à une erreur dans l'acte: notre incompréhension provient le plus souvent soit de notre ignorance soit d'une erreur de lecture. Le chantier en tout cas reste ouvert.

\begin{abstract}
Résumé
Les actes notariés présentent, entre autres, une difficulté liée à la communication entre le notaire et son client. Les notaires provençaux pratiquaient trois langues pour la rédaction de leurs actes: le latin, langue la plus utilisée au Moyen Âge, le provençal, le français, obligatoire à partir de l'ordonnance de Villers-Cotterêts de 1539. Quant à leurs clients, tout en étant frottés de latin à l'église et de français par l'administration, ils s'exprimaient d'oc.

La traduction s'imposait donc dans les deux sens : du client parlant d'oc au tabellion qui en assurait la mise en forme, latine et plus tard française mais aussi de l'acte établi dont la lecture était obligatoire au client, qui n'y entendait goutte, ignorant à la fois ces langues officielles et le langage juridique. La confiance s'avérait ici indispensable.

La consultation de quelque 2000 registres, soit environ 500000 actes, témoignant d'une pratique notariale très courante alors dans le Midi, révèle, que ce passage de l'oral à l'écrit pouvait entraîner quelques problèmes, notamment pour l'identification des personnes et des lieux, d'où hésitation, doute et parfois erreur du notaire et donc du chercheur.
\end{abstract}

31. C. de Ferrière, La science parfaite des notaires..., Paris, Ch. Osmont, $2^{\mathrm{e}}$ éd. 1686, p. 32-34. 


\section{Bibliographie}

Aguillon E., «Dins lo present pais de Provenso... », Cahiers Critiques du Patrimoine, $\mathrm{n}^{\circ} 4$, 1989 , p. 99-100.

Audisio Gabriel (dir.), «De la masse à l'unique (Aix-en-Provence, 1532), L'historien et l'activité notariale..., Toulouse, PUM, 2005.

Audisio Gabriel, Une grande migration alpine en Provence (1460-1560), Torino, Palazzo Carignano, 1989.

AudisIo Gabriel, Migranti valdesi. Delfinato, Piemonte, Provenza (1460-1560). Migrants vaudois. Dauphiné, Piémont Provence, Torino, Claudiana, 2011.

BONNET Marie Rose, Livres de raison et de comptes en Provence, fin $d u$ XIV siècle - début du XVI siècle, Aix-en-Provence, PUP, 1995.

FERRIÈRE Claude de, La science parfaite des notaires..., Paris, Ch. Osmont, 2 éd. 1686.

HÉBERT Michel, «Latin et vernaculaire : quelles langues écrit-on en Provence à la fin du Moyen Âge? », Provence Historique, t. XLVII, fasc. 188, 1997, p. 281-299.

LEEMANS W. F., La principauté d'Orange de 1470 à 1580. Une société en mutation, Hilversum Verloren, 1986, 2 vol.

ROYER Jean-Yves, Le journal de Noé de Barras..., Les Alpes de Lumière, n 98, 1988.

VALBELLE Honoré de, Histoire journalière (1498-1539), par V.L. BOURRILLY, R. DUCHÊNE, L. Gaillard, Ch. Rostaing, Aix-en-Provence, Publications de l'Université de Provence, 1985,2 vol.

VenARD Marc, Réforme protestante, Réforme catholique..., Paris, Cerf, 1993. 


\title{
Latin ou français : la tenue des actes paroissiaux dans les États pontificaux d'Avignon et du Comtat Venaissin, entre usage canonique, pratique administrative et choix de souveraineté (1768-1792)
}

\author{
Bernard THOMAS \\ Archiviste aux Archives départementales de Vaucluse \\ (Palais des Papes - 84000 Avignon)
}

\footnotetext{
Extrait de : Guylaine BRUN-TRIGAUD (dir.), Contacts, conflits et créations linguistiques, Paris, Édition électronique du CTHS (Actes des congrès des sociétés historiques et scientifiques), 2015.

Cet article a été validé par le comité de lecture des Éditions du CTHS dans le cadre de la publication des actes du $139^{\mathrm{e}}$ Congrès national des sociétés historiques et scientifiques tenu à Nîmes en 2014.
}

Parmi les spécificités des territoires pontificaux d'Avignon et du Comtat Venaissin, possessions restées au Saint-Siège au cours des quatre siècles qui ont suivi le départ des papes des bords du Rhône, la question des langues n'est pas la moindre : voici des États où pas moins de cinq langues cohabitent entre elles: dans l'usage courant des populations, le français et le provençal, auxquels il faut ajouter le judéo-comtadin dans les communautés juives; chez les représentants de la papauté chargés du gouvernement local, l'italien parlé par les autorités de la légation ou l'italien écrit des correspondances échangées avec Rome. Enfin, la langue latine : elle a déserté les délibérations consulaires - à Avignon, en 1540, fort abruptement ${ }^{1}$, à Carpentras en 1566 - ainsi que les registres des notaires, lesquels se rallient au français pour la rédaction de leurs actes au cours de la seconde moitié du $\mathrm{XVI}^{\mathrm{e}}$ siècle; mais le latin reste encore d'usage dans les milieux judiciaires, et occupe la première place dans les documents écrits de l’Église.

Il n'y a par conséquent rien d'étonnant à retrouver la langue latine d'un emploi général dans bien des sources documentaires ecclésiastiques des $\mathrm{XVII}^{\mathrm{e}}$ et $\mathrm{XVIII}{ }^{\mathrm{e}}$ siècles ; toutefois, les autorités religieuses ont de plus en plus recours au français dans la gestion de leurs affaires temporelles. Au premier rang de ces sources, bien connus sont les registres dits paroissiaux, autrement dits d'actes de catholicité, de baptême, mariage et sépulture, tenus par les curés dans les paroisses, et dont les plus anciens exemples conservés remontent en France au $\mathrm{XV}^{\mathrm{e}}$ siècle, et à Avignon aux toutes premières années du $\mathrm{XVI}^{\mathrm{e}}$ siècle; ils se trouvent être contemporains des statuts provinciaux de 1509 qui prônent la tenue régulière de ces registres.

L'histoire de ces registres paroissiaux est bien connue. En France, la réglementation mise en place par la monarchie en fit à la fois la garantie du statut des personnes et du bon ordre des affaires familiales et successorales - ce que paracheva la loi de création de l'état civil de 1792. Ce sont aussi de véritables outils de l'administration et du contrôle des populations; de l'édit de Villers-Cotterêts (août 1539) préconisant l'enregistrement des baptêmes et des sépultures, plutôt dans une perspective de contrôle des bénéfices ecclésiastiques, jusqu'à l'ordonnance de Blois (mai 1579) qui élargit le champ des personnes aux actes des mariages, et surtout à l'ordonnance d'avril 1667 qui donne, avec l'obligation des signatures, une valeur authentique à ces actes, les registres paroissiaux

1. Arch. comm. Avignon BB 14 fol. 22 (délibération du 5 novembre 1540). 
sont de fait devenus des documents administratifs, mis au service de l'État royal, et depuis 1674, ils sont établis sur papier timbré2.

Rien de tel à Avignon et dans le Comtat Venaissin, où la réglementation française n'a pas cours. Il est volontiers admis de dire que la double originalité des registres paroissiaux avignonnais et comtadins par rapport à ceux du royaume, est qu'ils ont été écrits en latin jusqu'à la fin de l'Ancien Régime (alors que le français était imposé en France dès 1539), et qu'ils étaient établis en un seul exemplaire destiné à rester dans la paroisse ; les registres paroissiaux dans le royaume de France étaient tenus en deux exemplaires, le deuxième étant remis au greffe de justice, selon une clause également contenue dans l'édit de Villers-Cotterêts et reprise en 1667. En fait, ces affirmations méritent d'être nuancées ${ }^{3}$.

\section{Le latin contre le français, $d u$ XVI siècle à la première moitié $d u$ XVIII siècle}

Dans les États pontificaux, les registres paroissiaux sont restés des livres canoniques au service des desservants des paroisses. Leur usage a été imposé par la pratique : nécessité de reconnaître les parentés spirituelles (lors des baptêmes), tenue des obits et fondations (par les décès), comptabilité des frais casuels. C'est pourquoi parmi les registres du $\mathrm{XVI}^{\mathrm{e}}$ siècle qui ont été conservés provenant d'Avignon et de plusieurs localités comtadines, on trouve une bonne part de ces registres, tenus au propre usage des curés, « en langue vulgaire », français voire provençal. Hyacinthe Chobaut, et à sa suite Jacques de Font-Réaulx, tous deux archivistes de Vaucluse, qui se sont intéressés à l'histoire des anciens registres paroissiaux vauclusiens ${ }^{4}, \mathrm{n}^{\prime}$ ont pas abordé la question de la langue, si ce n'est pour écrire que "contrairement à l'usage français, les actes sont écrits en latin, langue d'Église » et pour regretter les inconvénients de la latinisation des noms propres, véritable piège des généalogistes.

Les synodes diocésains de la seconde moitié du $\mathrm{XVI}^{\mathrm{e}}$ siècle, de Carpentras, d'Orange, d'Avignon se firent l'écho des prescriptions du concile de Trente qui ordonnait la tenue systématique de registres pour enregistrer les baptêmes et les mariages afin de faciliter les preuves; mais alors que le latin est confirmé comme langue de la liturgie et de l'Église, la question de la langue utilisée dans les registres paroissiaux n'est évoquée ni dans les canons du concile ni dans ceux des synodes diocésains.

Les années 1590 et les premières décennies du XVII ${ }^{\mathrm{e}}$ siècle apparaissent dans les États pontificaux de France comme une période de normalisation des pratiques. Des évêques réformateurs, comme le sont ceux venus d'Italie à Avignon et à Carpentras, s'emploient à faire de leurs diocèses des laboratoires de la réforme catholique ${ }^{5}$. Le concile provincial d'Avignon de 1594, convoqué par $\mathrm{M}^{\mathrm{gr}}$ Tarugi, ordonne que chaque paroisse tienne quatre livres pour y inscrire les baptisés, les confirmés, les mariés et les morts ${ }^{6}$. Le synode tenu par son successeur l'archevêque Bordini en 1600, propose à l'attention d'un clergé sans doute encore peu formé sur ces pratiques, les formules qu'il convient d'employer:

2. Parmi les travaux les plus récents, voir à ce sujet l'article d'O. Poncet, «Inscrire les clercs dans l'État. La monarchie française, les ecclésiastiques et le gouvernement par l'écrit (XVI $-\mathrm{XVIII}^{\mathrm{e}}$ siècle) ».

3. Les recherches menées pour cette communication reposent sur un dépouillement par sondages des registres paroissiaux d'Avignon et du Comtat Venaissin pour les $\mathrm{XVI}^{\mathrm{e}}$, XVII ${ }^{\mathrm{e}}$ et $\mathrm{XVIII}{ }^{\mathrm{e}}$ siècles, et sur une consultation systématique des registres d'actes pour la période 1768-1792 pour l'ensemble des communautés, soit environ 90 paroisses. Ces registres paroissiaux sont accessibles en ligne sur le site Internet des archives départementales de Vaucluse : www.archives.vaucluse.fr

4. J . de Font-Réaulx, Les registres d'état civil antérieurs à 1792.

5. M. Venard, Réforme protestante, réforme catholique dans la province d'Avignon au XVI ${ }^{\mathrm{e}}$ siècle.

6. Constitutiones et decreta provincialis concilii Avenionensis ... anno MDXCIV. Rome, A1. Zannetti, 1597, p. 62 (Bibl. mun. Avignon $8^{\circ} 17.748 \mathrm{n}^{\circ} 1$ ): «Quilibet parochus quatuor libros conficiat, baptizatorum scilicet, confirmatorum, matrimoniorum et mortuorum; in quorum primo baptizati describantur juxta formulam per nos tradendam ». 
rédigées en latin, elles fournissent pour les quatre catégories d'actes - les excommuniés ont remplacé les confirmés - des modèles stéréotypés prêts à être recopiés ${ }^{7}$. De fait, plusieurs paroisses du diocèse d'Avignon (Vedène, Sorgues, Saint-Saturnin, Morières) passent du français au latin dans ces années (1591, 1610, 1613, 1624) ; à Avignon, les chanoines de Saint-Agricol font adopter le latin à la place du français dans les registres de la paroisse à compter du 14 septembre $1605^{8}$.

Dans le diocèse de Carpentras, cette normalisation de la tenue des registres paroissiaux avec un passage de la langue française au latin, est à porter à l'actif de l'évêque Orazio Capponi (évêque de 1596 à 1615 et par deux fois recteur du Comtat), contemporain de Bordini à Avignon: sa visite pastorale de l'église cathédrale de Carpentras le 25 septembre 1597 met un terme à 25 années de tenue des actes de baptême en français ; ici aussi, les formules latines à adopter pour les actes sont données comme des modèles prêts à l'emploi, et par voie de conséquence la langue latine s'en trouve recommandée, sans d'ailleurs que cela soit explicitement dit ${ }^{9}$. À Crillon, Flassan, Malemort, Modène, petites localités du Comtat Venaissin au pied du Ventoux, c'est aussi en ces années 1597 et 1598 que le curé se met à écrire en latin, après le passage du même évêque; à Malemort, il écrit lors de la visite du 9 novembre 1597 :

«Facta mandavit quod in posterum describi librum hujusmodi sub formula sequenti. » ${ }^{10}$

À Flassan la visite pastorale de l'évêque le 6 septembre 1598 provoque aussitôt l'abandon du français pour le latin ${ }^{11}$.

Les décennies 1610 et 1620 voient s'amplifier le mouvement consacrant l'emploi de la langue latine dans les registres, non seulement dans les diocèses d'Avignon et de Carpentras, mais aussi dans les deux autres diocèses comtadins de Cavaillon et de Vaison, également tenus par des évêques formatés selon le moule romain. Dans le diocèse de Cavaillon, au moins 12 des 14 paroisses comtadines se sont ralliées au latin avant 1625 (peut-être même la totalité, car à Lagnes et au Thor, les registres de cette époque n'ont pas été conservés).

Dans ce diocèse de frontière qu'est celui de Vaison, à cheval sur les limites du Comtat Venaissin et du Dauphiné, la situation est très variée en cette première moitié du XVII ${ }^{\mathrm{e}}$ siècle ; néanmoins, au milieu du siècle, la plupart des paroisses - de petites paroisses rurales et de montagne - ont adopté le latin dans leurs registres, parfois à une date précoce, comme à Vaison, la ville épiscopale qui donne l'exemple dès 1575. On constate aussi que l'emploi du français est resté vivace dans quelques paroisses, parfois au-delà du milieu du XVII ${ }^{\mathrm{e}}$ siècle, sans que les évêques n'aient eu à y redire lors de leurs visites : Puyméras (passage au latin seulement en 1668) ${ }^{12}$, Entrechaux (vers 1683) ${ }^{13}$, Faucon (en $1721)^{14}$. Un cas d'espèce est remarquable: à Valréas, principale localité du diocèse, enclavée dans le Dauphiné, les actes paroissiaux ont toujours été tenus en français ; sans doute doit-on mettre cette pratique sur le compte d'une influence des localités voisines du royaume.

7. Synodus Avenionensis anni 1600. Avignon, J. Bramereau, 1601. 50 p. (Bibl. mun. Avignon $8^{\circ} 24.427$ ).

De Baptismo. Nunc vero que ad sacrosancta sacramenta rite administranda pertinent brevibus expediamus, et primo de batismo, cuius describendi formulam in libro parochorum hanc observari decernimus :

"Anno ... die N. natus est Franciscus filius naturalis et legitimus Joannis et Ludovicae conjugum et baptizatus anno et die tali ; patrinus fuit N. et matrina N. ». Les mêmes formules d'actes sont reprises dans l'édition du synode de 1613 (Synodus Avenionensis anni 1613, Avignon, J. Bramereau, 1613, 27 p. (Bibl. mun. Avignon $8^{\circ}$ $\left.17.748 \mathrm{n}^{\circ} 2\right)$

8. Arch. comm. Avignon GG 9 (Saint-Agricol, baptêmes 1598-1605).

9. Arch. comm. Carpentras GG 4 (baptêmes, 1597).

10. Arch. comm. Malemort-du-Comtat GG 1.

11. Arch. comm. Flassan GG 4 (sépultures, octobre 1598-1634).

12. Arch. comm. Puyméras GG 3.

13. Arch. comm. Entrechaux GG 18

14. Arch. comm. Faucon GG 5. 
En 1625, dans le diocèse de Carpentras, cœur du Comtat pontifical, 21 des 22 paroisses comtadines tiennent désormais leurs trois livres de baptêmes, mariages et mortuaires en latin (la dernière, Méthamis, renonce au français en 1652) ${ }^{15}$. Mais dans cette partie du Comtat, rien n'est définitivement acquis ; dans la localité voisine de Saint-Didier, l'arrivée d'un nouveau vicaire desservant rompt la pratique du latin, avec une reprise de la tenue des registres en français, de 1654 à $1692^{16}$.

Force est de noter une différence en fonction des diocèses ; le Comtat Venaissin se répartit en effet sur huit diocèses, et l'origine et la personnalité des évêques ont joué un rôle certain. Chez les évêques tridentins qui occupent les sièges d'Avignon et des trois diocèses comtadins (Carpentras, Cavaillon et Vaison), l'emploi dans les registres paroissiaux de la langue latine, langue universelle de l'Église, de même que le souci d'une bonne tenue régulière de l'enregistrement des actes a été une préoccupation constante; leurs diocèses chevauchent les États du pape et le royaume de France (en Languedoc, en Provence, et en Dauphiné) ; ils connaissent les usages de France dans ce domaine, et ils sont confrontés à deux pratiques différentes selon que leur paroisse se trouve être « du royaume» ou « du pape ». Face au roi de France, il y a peu à attendre d'une influence réelle de ces évêques pour appliquer dans leurs paroisses " de France » les décisions ultramontaines de leurs synodes, surtout lorsqu'elles sont à l'encontre des mesures royales; mais ces évêques ont toute liberté d'action dans leurs paroisses du Comtat.

Inversement, les évêques français des diocèses qui empiètent sur le Comtat Venaissin ont été confrontés au statut particulier de localités de leur juridiction où ne s'applique pas la réglementation royale sur la tenue des registres paroissiaux : la géographie ecclésiastique prend le pas sur les limites des États pontificaux au nord (avancée du diocèse de SaintPaul-Trois-Châteaux dans le Comtat Venaissin), au nord-est (diocèse de Gap pour deux paroisses comtadines), à l'est (diocèse d'Apt pour l'enclave comtadine de Bonnieux) ; encore plus enchevêtré est le diocèse d'Orange qui compte douze paroisses dans le Comtat Venaissin et quatre paroisses, dont la ville épiscopale, dans la principauté, et se trouve ainsi relever d'une part du pape, et d'autre part d'un souverain étranger. La fin de l'indépendance de la principauté d'Orange en 1702 et son passage sous le contrôle du roi de France aura pour conséquence la mise en application de la réglementation royale sur les registres paroissiaux, mais pas avant $1732^{17}$.

Pour ces diocèses « de France» (Saint-Paul-Trois-Châteaux, Orange), l'influence «française » se marque parfois très tôt dans les «parties comtadines ». Au milieu du XVIII ${ }^{\mathrm{e}}$ siècle, les sept paroisses comtadines du diocèse de Saint-Paul sont toutes passées du latin au français: deux d'entre elles (Lapalud et Richerenches) l'avaient fait en 1595 et 1604 ; mais les cinq autres, dont la ville de Bollène, opèrent ce virage sous l'impulsion de l'évêque entre 1703 et 1746 ; le 10 mai 1746, le curé de Visan écrit dans son registre des mariages :

«Monseigneur l'évêque de Saint-Paul-Trois-Châteaux ayant été en visite pastorale dans cette paroisse et ayant trouvé que c'étoit la seule paroisse de son diocèse qui eut conservé l'usage d'enregistrer en latin les mariages, baptêmes et mortuaires, nous a ordonné de les écrire à l'advenir en français ; ainsi je prie Mrs les curés qui viendront après moy de n'être pas surpris de ce que j'ay commencé à me servir d'une autre langue dans ledit

15. En réalité, à Méthamis, le curé diffère selon les actes ; si les actes de baptêmes et les actes de sépultures sont tenus en français de 1589 à 1652 pour les premiers, de 1603 à 1654 pour les seconds, tandis que les catalogues sont en latin, les actes de mariage quant à eux, rédigés en français de 1593 à 1618, ont été tenus en latin après cette date.

16. Arch. comm. Saint-Didier. De 1654 à 1692, les deux vicaires perpétuels de Saint-Didier, qui se succèdent dans la paroisse, restent fidèles au français ; le retour au latin est imposé lors de la visite pastorale de l'évêque de Carpentras, Mgr Buti, le 7 octobre 1692.

17. La cession définitive de la principauté d'Orange au roi de France intervient en avril 1731 (lettres patentes de mars 1734) avec le rattachement au Dauphiné. 
enregistrement, puisque ce n'est qu'une conséquence d'un ordre de Sa Grandeur. Fait à Visan le dixième may mille sept cent quarante-six. ${ }^{18}$

Dans le diocèse d'Orange, on constate des pratiques très différentes; les actes de plusieurs localités ont alterné entre français et latin tout au long du XVII ${ }^{\mathrm{e}}$ siècle, au gré des origines géographiques des desservants ou de leur formation; là aussi, certaines paroisses finissent par pencher définitivement pour le français: Aubignan en 1673, Camaret en 1723, Vacqueyras en 1744 (ici, les actes sont d'abord tenus en latin de 1625 à 1655, puis en français de 1666 à 1713, à nouveau en latin de 1713 à 1744, et enfin définitivement en français à partir de 1744). À l'inverse, d'autres paroisses se rangent à l'usage du latin: Mornas (en 1624), Sérignan (en 1664), et tardivement - à contrecourant ? - Piolenc, prieuré de l'ordre de Cluny (en 1721), Uchaux (en 1761).

Sans surprise, la carte des paroisses du Comtat Venaissin utilisant le latin ou le français dans leurs registres paroissiaux à la veille de la $3^{e}$ occupation française $d^{\prime}$ Avignon et du Comtat en 1768 (fig. 1), révèle un usage du latin dans la quasi-totalité des paroisses des États pontificaux. Ne font exception au nord, que le bloc des paroisses du diocèse de Saint-Paul, la petite paroisse de Brantes (du diocèse de Gap) derrière le Ventoux, et quatre paroisses du diocèse d'Orange, soit seulement douze paroisses, "passées » au français. L'expérience de l'occupation française va renforcer ce courant.

\section{La « révolution institutionnelle » de 1768-1774: la troisième occupation française d'Avignon et du Comtat Venaissin}

La réunion des États pontificaux à la France, ordonnée par Louis XV en représailles contre le pape dans le conflit sur la question des jésuites, va durer six années de 1768 à 1774. Cette occupation française s'est accompagnée de bouleversements dans l'ordre des institutions : les tribunaux pontificaux furent abolis et remplacés par des sénéchaussées ; les règlements du roi de France furent appliqués ${ }^{19}$. Par un arrêt du Parlement de Provence du 30 juin 1770, il fut ordonné aux curés de toutes les paroisses d'Avignon et du Comtat Venaissin d'appliquer désormais, à compter du $1^{\mathrm{er}}$ janvier 1771, la législation française sur la tenue des registres paroissiaux selon la déclaration royale du 9 avril 1736 qui était la dernière grande compilation en la matière. Parmi les principales mesures exigées, figuraient l'abandon du latin et l'obligation de rédiger les actes en français; la clôture des registres particuliers - sauf exceptions - fut imposée au profit de cahiers cotés et paraphés par le juge des sénéchaussées (Avignon ou Carpentras) où les baptêmes, les mariages et les sépultures devaient être enregistrés pêle-mêle à la suite, à leur date ; ces cahiers, fait nouveau pour le Comtat, devaient être tenus en double exemplaire, l'un des deux étant déposé au greffe de la sénéchaussée à la clôture de l'année.

L'examen des collections des registres paroissiaux, tant pour les collections communales que pour la deuxième collection dite des greffes, nous permet de cerner les réactions du clergé comtadin face aux mesures qui lui furent imposées par le nouveau souverain: acceptation ou résistance ? Une loyauté résignée à défaut d'un réel enthousiasme semble avoir été de mise chez presque tous les curés qui respectèrent l'obligation de recourir aux registres paraphés et d'y porter, en français, les actes de baptêmes, mariages et sépultures de leurs paroissiens, clôturant leurs anciens registres d'une phrase laconique :

« Nota qu'en cette année 1771 par ordonnance du roy à commencer du premier janvier, tous les curés du Comtat Venaissin enregistrent les baptêmes, mortuaires et mariages en françois sur des cayers cottés et paraffés par Mr le lieutenant général de la sénéchaussée. $»^{20}$

18. Arch. comm. Visan GG 10 (mariages 1730-1781).

19. Sur la troisième réunion d'Avignon et du Comtat à la France, voir l'ouvrage ancien de $P$. Charpenne, Histoire des réunions temporaires d'Avignon et du Comtat à la France, et une récente mise au point d'O. Rouchon, «Entre le roi et le pape. Les réunions d'Avignon au royaume de France XVII ${ }^{\mathrm{e}}-\mathrm{XVIII}^{\mathrm{e}}$ siècle) ».

20. Arch. comm. Caromb GG 15 (baptêmes 1758-1770, 1775-1793). 
Les collections communales attestent de la présence de ces cahiers "à la française ", souvent reliés et cotés séparément pour les années 1771 à 1774, et même 1775 alors qu'Avignon et le Comtat sont rendus au pape Clément XIV le 23 avril 1774. Mais pour 17 à 18 paroisses (sur 88), les cahiers « à la française » manquent à l'appel, à la fois dans le fonds communal et dans la collection du greffe. Jacques de Font-Réaulx ${ }^{21}$ soulignait cette carence pour le ressort du greffe d'Avignon, due à une mauvaise conservation; mais il est possible de voir dans cette double absence, pour plusieurs paroisses, un refus délibéré d'appliquer des mesures civiles à des registres d'Église: Jonquerettes (au diocèse $\mathrm{d}^{\prime}$ Avignon) ${ }^{22}$, Bonnieux (au diocèse $\mathrm{d}^{\prime} \mathrm{Apt}$ ), Flassan et Loriol, petites paroisses ou succursales du diocèse de Carpentras, Mazan, ou encore Méthamis, loin à l'écart à l'entrée des gorges de la Nesque, sont ainsi dépourvues de ces cahiers «à la française » peut-être par la volonté d'un desservant récalcitrant? Des investigations seraient à poursuivre.

Mais deux exemples de résistance au français sont étonnants dans deux localités voisines du Luberon, à l'extrémité du Comtat; à Ménerbes, les deux curés qui se succèdent entre 1771 et 1774 utilisent certes le cahier paraphé par le lieutenant de la sénéchaussée d'Avignon, mais pour continuer d'y écrire les actes en latin ${ }^{23}$. Il en est de même des curés d'Oppède, chanoines d'un petit chapitre collégial, qui tiennent également à partir de 1771 et jusqu'en 1774 les cahiers paraphés par le juge de la sénéchaussée, en rédigeant les actes en latin, tandis que leurs anciens registres sont également poursuivis dans cette même langue, de façon parallèle, sans interruption de 1767 à 1775 ; ce dont se justifie le curé Beillier en ajoutant cette note :

«Les actes de cette année [1771] et des trois suivantes ont été transcrites dans les livres ordinaires de la paroisse afin qu'il n'y eut aucune interruption, et deüement attestés et signés par nous chanoine et curé. » ${ }^{24}$

Une autre attitude des curés comtadins manifeste une forme de résistance; c'est la pratique de plusieurs d'entre eux de doubler l'enregistrement des actes: pour ne pas interrompre les trois registres séparés des actes de baptêmes, mariages et sépultures, pourtant désormais proscrits, ils poursuivent ceux-ci en recopiant, en latin, les actes portés en français dans les cahiers adressés par la sénéchaussée, cette opération ayant pu se faire également a posteriori, après 1774 ; nous en avons quelques exemples ${ }^{25}$.

En bien d'autres lieux, le curé estime nécessaire, lors du retour du Comtat au pape, d'expliquer - en latin ou en français - l'absence de deux ou trois années dans ses registres par un renvoi au « registre spécial ${ }^{26} ; c^{\prime}$ est alors que certains procèdent à une véritable

21. J. de Font-Réaulx, op. cit., p. 9.

22. Le desservant, Requin, tient ses actes de baptême en latin, dans les registres d'origine, sans interruption en 1771-1774 et jusqu'en 1793. Il n'existe pas pour cette paroisse d'exemplaire du greffe. Il en est de même à Lagnes (diocèse de Cavaillon).

23. Arch. comm. Ménerbes GG 11 (baptêmes 1768-1793), 13 (mariages 1749-1792), 15 (sépultures (1737-1782).

24. Arch. comm. Oppède GG 17.

25. À Châteauneuf-de-Gadagne, le vicaire perpétuel recopie les baptêmes portés «au registre français ": "sequentes baptisati reperiantur in fine hujus libri in codice edito jussu Regis Christianorum incepto die sexta januarii anni 1771 »(arch. comm. Gadagne GG 11 - baptêmes 1755-1792). Également à Mornas : registre particulier des baptêmes, mariages et sépultures en français, 1771-1775 (arch. comm. GG 10) et registres spécifiques avec copie des actes de ces mêmes années, en latin (ibid GG 5 et 8).

26. À Beaumes-de-Venise : « Nota que les quatre années qu'on ne trouve pas icy sont de celles où étant au Roy, il fut ordonné de se conformer aux usages de France. On les trouvera pour ce registre des baptêmes dans le livre cotté XIV » (arch. comm. Beaumes-de-Venise GG 12). À Villedieu, on trouve cette mention dans le registre des baptêmes, après l'interruption des actes en 1770 et avant la reprise en 1775 : «Il faut observer que les quatre années de baptêmes qui ne sont point insérés dans le présent registre sont comprises ainsi que les baptêmes, mariages et mortuaires dans quatre cayers séparés dont le double a été envoyé à la sénéchaussée de Carpentras pour les quatre dernières années que nous avons été sous la domination du Roy très chrétien Louis quinzième du nom, roi de France et de Navarre, à scavoir depuis 1771 jusqu'à la fin de 1774 inclusivement. Je soussigné, Philippe-Néri Daruty curé perpétuel de cette paroisse de Villedieu depuis le 3e mars 1774, commence à écrire dans ces registres de cette dite paroisse » (arch. comm. Villedieu GG 3). À Morières, aux portes d'Avignon, le curé Martin reporte dans son registre des baptêmes à la date du 25 avril 1774 une simple mention, en latin, du retour d'Avignon et du Comtat Venaissin au pape, et poursuit avec le mandement de l'archevêque d'Avignon 
compilation de tous les actes passés sous le régime français «pour qu'il n'y ait pas d'interruption ", signe que pour ces prêtres, les cahiers français, purement administratifs, n'avaient aucune valeur canonique.

Après une loyauté acceptée bon gré mal gré, on pourrait penser que le retour aux pratiques anciennes interviendrait en force avec la fin du régime français et le rétablissement de la souveraineté pontificale. Quelles prescriptions furent données au clergé pour la reprise des registres paroissiaux? On l'ignore, car on ne trouve pas d'instructions générales de la part des autorités de la légation, ni de la part des évêques sous la forme de mandements particuliers, si ce n'est la mention d'une instruction donnée par l'évêque de Carpentras, $\mathrm{M}^{\mathrm{gr}}$ Vignoli, à son clergé dans les registres de Caromb ${ }^{27}$ et de Pernes:

« Je soussigné ay cru qu'il étoit a propos de donner avis a mes successeurs que le vingt trois du mois d'avril de l'année mil sept cent soixante quatorze, le Comtat fut rendu par le Roy au St Siège après avoir resté environ six ans en la puissance de Sa Majesté et qu'à cette époque il nous fut ordonné de transcrire nos registres en latin selon notre ancienne méthode et comme on le pratiquait cy-devant. En foi à Pernes $7^{\mathrm{e}}$ may 1774 . David curé. $»^{28}$

Sans doute, de façon générale, s'est-on abrité derrière l'archevêque d'Avignon, commissaire apostolique, qui recommandait dès 1774 le retour aux mesures qui régissaient les États pontificaux avant leur réunion à la France en 1768. Maintien du français, retour au latin, nous retrouvons en 1774-1775 des attitudes différentes en fonction des diocèses.

À Avignon et dans les paroisses du diocèse, la reprise du latin et des registres séparés est effective en 1774 et en 1775, à part Châteauneuf-du-Pape - pourtant un des fiefs de l'archevêque - où le curé Jean-François Clément, en place depuis 1745, poursuit de façon étonnante la pratique des registres des actes mélangés "à la française », en conservant l'usage du français, de 1775 jusqu'à sa mort en janvier 1791 ; peut-être faut-il y voir une demande du conseil de ville qui depuis le début du siècle, participe financièrement à l'achat des registres?

Dans le diocèse de Cavaillon, toutes les paroisses reprennent l'usage du latin entre mai 1774 et janvier 1775. De même dans celui de Carpentras, où les usages anciens ont repris leurs droits, dès la restitution au pape au mois d'avril 1774 ; on ne relève que deux exemples d'une reprise relativement tardive du latin, en janvier et mai 1777 au Barroux et à Mormoiron.

Il en va autrement dans le diocèse de Vaison ; la reprise du latin s'étale entre 1774 et 1777 dans la vingtaine des paroisses composant la partie du Comtat, mais quatre paroisses (outre Valréas déjà acquis de longue date) restent au français après 1774, et deux autres encore y viendront quelques années plus tard, en 1784 (Faucon) et en 1787 (Cairanne) ; le nord du Comtat se rapproche ainsi insensiblement des pratiques des paroisses voisines de France, des Baronnies et du Nyonsais, relevant de ce même diocèse de Vaison.

Le diocèse d'Orange quant à lui, illustré par son nouvel évêque Guillaume du Tillet, dont la réputation d'excellent administrateur est déjà faite ${ }^{29}$, voit dans ces années qui suivent le

annonçant un Te Deum : «Currente anno millesimo septingentesimo septuagesimo quarto die vigesima quinta aprilis, sub dato ac mandato Versaliis die decima ejusdem mensis, vir nobilissimus et universis acceptus D.D. marchio de Rochechouart, exercitibus Ludovici XV regis christianissimi subpraefectus generalis, Clementi XIV ac Sedi apostolicae civitatis Avenionensis territorii ejus et Comitatus Vindascini possessionem restituit » (arch. comm. Morières GG 7).

27. Arch. comm. Caromb GG 20 (mariages 1750-1793) : “Nota. 1774 : a restitua Illustrissimo pontifici Clementi XIV provincia Comitatus Venaissini a rege Galliorum Ludovico XV, acta matrimonorum latino idiomate jussu Illustri episcopi Carpentoractensis Josephi de Vignoli ut antea inscribantur" (mêmes mentions aux registres de baptêmes et sépultures).

28. Arch. comm. Pernes-les-Fontaines GG 15 (baptêmes-mariages-sépultures 1771-1774).

29. Mgr Guillaume-Louis du Tillet est nommé nouvel évêque d'Orange le 24 mai 1774. Voir B. Thomas, «Les paroisses du diocèse d'Orange d'après l'enquête de Mgr du Tillet (1775) », p. 53. 
retour au pape, la généralisation de l'emploi du français dans les registres paroissiaux des paroisses «de la partie du Comtat $»^{30}$; pour les quelques paroisses qui spontanément n'avaient pas conservé en 1774 le français dans la rédaction des actes et avaient rétabli l'usage du latin, l'évêque s'emploie lors de ses tournées pastorales à promouvoir l'emploi $\mathrm{du}$ français et l'abandon définitif du latin dans la tenue des actes paroissiaux : le chapitre de chanoines de Beaumes s'y range en mai $1775^{31}$, le curé de Sarrians en janvier $1776^{32}$, celui de Mornas en janvier 1784 ; à cette date, les douze paroisses comtadines du petit diocèse d'Orange ont adopté l'usage du français.

Au début des années 1780, la cause du latin dans les registres paroissiaux n'est pas encore perdue ; les diocèses d'Avignon, de Cavaillon et de Carpentras, c'est-à-dire le cœur des États pontificaux, y restent totalement acquis, juxta usum (selon l'usage), mais dans le nord du Comtat Venaissin, la carte des paroisses qui ont conservé en 1774 le français ou repris le latin, montre que dans les diocèses d'Orange et de Vaison, l'écriture des actes paroissiaux en français a gagné du terrain (fig. II).

S'ils ne touchent en général que timidement aux usages, les administrateurs ecclésiastiques du Comtat Venaissin vont chercher à retirer de l'expérience française quelques avantages. En 1774, l'assemblée du clergé du Comtat examine l'opportunité qu'il y aurait à imposer la tenue en double exemplaire des registres des paroisses afin de mieux assurer leur conservation, préconisant l'envoi dans les greffes des officialités diocésaines du second exemplaire ${ }^{33}$; cette demande est renouvelée en 1776 auprès du président de la légation, le pro-légat Durini, afin que celui-ci insiste auprès des évêques pour qu'une ordonnance soit prise à ce sujet ; le règlement de $\mathrm{M}^{\mathrm{gr}}$ Durini du $1^{\mathrm{er}}$ mai 1776 se limite à ordonner la remise aux greffiers des officialités ecclésiastiques des cahiers d'actes de catholicité déposés dans les greffes civils sous le régime français. Lors d'une nouvelle séance de l'assemblée du clergé général de la province, le 30 avril 1781, l'évêque de Carpentras fait prendre une résolution pour obliger les curés du Comtat à remettre chaque année dans les chancelleries épiscopales un double de leurs registres de baptêmes, mariages et sépultures ${ }^{34}$. Cette fois, la mesure est suivie d'effet, et les ordonnances des évêques de Carpentras et de Cavaillon, en 1781 et 1782, nous ont été conservées $^{35}$; les évêques d'Orange et de Vaison, pour leurs paroisses comtadines, répondent également de manière positive; seul l'archevêque d'Avignon n'y donne pas suite pour son diocèse. Mais si les évêques comtadins recommandent à leurs curés de procéder à cette tenue conservatoire d'un second exemplaire des registres paroissiaux, ils ne touchent en rien à l'usage de la langue latine pour l'écriture des actes. L'évêque de Vaison va jusqu'à rappeler à l'ordre l'un de ses curés - celui de Cairanne - qui s'était enhardi à adopter de lui-même le français dans ses registres; nous sommes en février 1789 lorsque ce curé s'exécute et écrit, lors de la visite pastorale de l'évêque, que ce fut

30. Les paroisses de la partie de France avaient adopté le français, pour les dernières depuis 1732 (Jonquières), 1733 (Gigondas) et 1737 (Courthézon); dans la ville épiscopale d'Orange, sous la domination des Nassau, les registres paroissiaux catholiques sont écrits en français depuis 1578.

31. Arch. comm. Beaumes-de-Venise GG 12: «Nous commençons ici d'enregistrer en français pour nous conformer aux intentions de Mgr notre évêque à nous exprimées dans sa visite pastorale faite le vingt six avril 1774. Rolery, prévôt et curé ".

32. Arch. comm. Sarrians GG 6: «Nota que le vingt quatre avril susdite année [1775], Mgr l'évêque d'Orange étant en visite pastorale permit d'écrire les actes en françois, mais comme j'avois commencé l'année en transcrivant lesdits actes en latin, je l'ai finie de même, me proposant de faire usage de ladite permission dès le premier janvier 1776 en effet ».

33. Archives départementales de Vaucluse 3 G 1.

34. Les évêques de Cavaillon et d'Apt, l'archevêque d'Avignon font observer que dans les règles de leurs diocèses respectifs, ils ne peuvent pas adopter cette ordonnance dans la façon dont elle a été proposée, si bien qu'il leur est laissé le soin de rédiger une ordonnance dans la manière qu'ils souhaitent (ibidem).

35. Mandement de Mgr Beni, évêque de Carpentras, concernant les registres des paroisses de son diocèse dans le Comtat Venaissin, 10 mai 1781 (Bibl. mun. Avignon ms. $\left.2936 \mathrm{n}^{\circ} 10\right)$; ordonnance de Mgr l'évêque de Cavaillon touchant les registres des paroisses, placard imprimé, 1er mai 1782 (arch. dép. Vaucluse 4 G 8). On trouve dans les collections des archives départementales de Vaucluse, ou dans les collections communales, des exemplaires doubles de registres paroissiaux à partir de 1781 . 
sur ordre de Monseigneur - jussu Illustrissimi domini episcopi in sua visitatione pastorali, acta latine scribentur ${ }^{36}$ - que les actes à Cairanne sont à nouveau rédigés en latin.

\section{La révolution tranquille : l'abandon du latin, à la veille de la naissance de l'état civil}

Quelques années plus tard, la question linguistique, entre latin et français dans les registres paroissiaux, s'invite dans les débats révolutionnaires, mais fort discrètement. En bien des lieux, l'affaire peut sembler entendue, y compris dans le clergé, mais il reste à trouver le moment opportun pour établir ce changement dans les usages et s'aligner définitivement sur les pratiques françaises.

La ville d'Avignon prend la tête des opérations, mais seulement dans les derniers jours de l'année 1790, après que cette même année ait vu en février l'installation d'une municipalité «à la française » en lieu et place des autorités consulaires ${ }^{37}$. En mars 1790, les districts d'Avignon décident d'adopter la Constitution française et les décrets élaborés par l'Assemblée nationale; lors des journées révolutionnaires des 10-11 juin 1790 qui renversent la souveraineté du pape, les Avignonnais se prononcent pour leur réunion à la France. Les relations de la nouvelle municipalité d'Avignon avec le clergé sont tendues : l'archevêque, qui s'est retiré de l'autre côté du Rhône, est sommé de se présenter, sous peine d'être déchu; en octobre 1790 les procédures de saisie de l'argenterie des églises sont mises en place. C'est dans ce contexte très agité, qu'une proclamation des officiers municipaux du 28 décembre 1790 instaure, à l'image de ce qui s'était passé en 1770, les usages français dans la rédaction des actes paroissiaux tenus dans toutes les églises de la ville $^{38}$. Dans la logique d'une application des règlements de la France, anticipant la réunion qu'ils appellent de leurs vœux, les patriotes avignonnais notifient aux sept curés de la ville l'emploi de cahiers paraphés par les juges nationaux nouvellement élus, pour y écrire, en français, les actes de baptêmes, mariages et sépultures conformément à la déclaration royale de $1736^{39}$. Ils anticipent en cela une réunion à la France qui à cette date est loin encore d'être admise par l'Assemblée nationale. Et dans les premiers jours de janvier 1791, les curés et pro-curés de la ville, comme celui du quartier rural de Morières, s'exécutent sans résistance, abandonnant le latin comme cela se voit dans tous les registres conservés ${ }^{40}$.

L'exemple avignonnais peine cependant à se propager dans les localités voisines qui constituent pourtant son obédience dans le pacte fédératif bientôt conclu : Châteauneufdu-Pape a déjà opté pour le français depuis 1774. Près d'Avignon, Vedène est bien la seule localité à imposer à son curé un cahier, paraphé par le juge national d'Avignon, lequel est mis en service le 15 février 1791, au moment même où les communes du BasComtat s'unissent dans leur volonté d'obtenir la réunion à la France : il y est dit que c'est

36. Arch. comm. Cairanne GG 7 (mariages 1764-1792); même mention dans les registres de baptêmes et de sépultures. Le desservant, Raymond, avait opéré le changement de langue du latin au français, sans s'expliquer, dans les premiers jours de l'année 1787.

37. Sur les événements de la Révolution avignonnaise, on se reportera à R. Moulinas, Histoire de la Révolution d'Avignon.

38. Arch. comm. Avignon C 2.

39. Ces nouveaux cahiers, tenus en double exemplaire dans les paroisses d'Avignon par des curés assermentés, ont tous été conservés : La Madeleine-Saint-Étienne (GG 113-114, 4 janvier-25 décembre 1791), Saint-Didier (GG 52, 31 décembre 1790-4 décembre 1792), Saint-Geniès (GG 86, 1er janvier 1791-1er décembre 1792), Notre-Dame la Principale (GG 138, 1er janvier 1791-27 novembre 1792), Saint-Agricol (GG 37, 2 janvier $1791-11$ décembre 1792), Saint-Pierre (GG 165, 1er janvier 1791-15 décembre 1792), Saint-Symphorien (GG 189, 1er janvier 1791-9 décembre 1792), Montfavet (GG 217, 1791-1792).

40. Arch. comm. Avignon GG 52 (Saint-Didier, baptêmes-mariages-sépultures, 1790-1792) : « cahier paraphé par le juge national d'Avignon pour servir à $\mathrm{M}$. Touzet, curé, pour inscrire à la suite les actes de baptêmes, mariages, sépultures conformément à la proclamation de la municipalité signifiée le 30 décembre dernier ». Mentions semblables dans les cahiers des autres paroisses ; à Saint-Agricol et à Notre-Dame la Principale, on fait également référence à la déclaration du roy de 1736. 
pour « inscrire les actes conformément aux lois du royaume $»^{41}$, et les actes dès lors, sont écrits en français par le nouveau curé de la localité.

À l'autre bout du Comtat Venaissin, l'exemple du village de Sainte-Cécile est éloquent, car - fait unique - le curé ${ }^{42}$ confie à son registre paroissial son ressentiment d'abandonner l'emploi du latin dans un contexte politique particulièrement troublé ; la guerre civile a éclaté dans le Comtat entre partisans de la France, menés par Avignon, et partisans du maintien au pape, réunis dans l'Union de Sainte-Cécile, et elle tourne à l'avantage des premiers provoquant au début de l'année 1791 un véritable vent de panique dans le Haut-Comtat resté fidèle au pape. Dès lors, plusieurs communautés comtadines se prononcent précipitamment pour la France : ainsi, le curé de Sainte-Cécile n'hésite pas à assimiler l'abandon du latin et le choix de la langue française qui lui furent imposés, comme un signe d'engagement politique de ses paroissiens dans le contexte aigu de la guerre civile qui divise le pays :

« Note historique. La commune de Sainte-Cécile, en vertu d'une délibération prise dans une assemblée primaire tenue avant-hier au soir, dans l'église, et à l'exemple de la majeure partie des autres villes et villages du Comté Venaissin, arbora les armes de France sur les cinq heures du soir, le dix-neuf janvier mil sept cent quatre-vingt-onze, en présence de quatre officiers de la garde nationale d'Orange qui a reçu Sainte-Cécile dans son district, jusques assez que l'Assemblée nationale, séante à Paris, ait statué sur le sort du peuple venaissin. Nous nous abstenons de décrire à nos successeurs les causes qui ont forcé le peuple venaissin à demander lui-même le changement de domination; il nous suffit d'expliquer ici celle du changement de langue qu'on va trouver dans ces registres, désiré et demandé par mes paroissiens. $\gg^{43}$

À la suite de cette note, les actes paroissiaux de Sainte-Cécile se poursuivent en français. La ville de l'Isle-sur-la-Sorgue, dans la mouvance d'Avignon, attend quant à elle en octobre 1791 la promulgation du décret de réunion d'Avignon et du Comtat Venaissin à la France, pris par l'Assemblée nationale le 14 septembre, pour exiger du curé de la collégiale l'abandon du latin et le passage au français, exprimant ainsi également son choix politique ${ }^{44}$.

Toutefois, à côté de l'exemple d'Avignon et des quelques communes citées, les premières années de la Révolution ne bouleversent guère dans toutes les autres paroisses du Comtat l'usage canonique du latin dans les registres paroissiaux. Au moins la moitié des curés respectent encore cet usage au début de 1792 (fig. III). Le changement radical aurait pu se faire avec la promulgation de la loi du 20 septembre 1792 sur la création de l'état civil, dont la mise en application prit plusieurs mois ; il n'en est rien, car le changement s'opère en fait à peine un ou deux mois plus tôt. Dans toutes les paroisses du Comtat restées fidèles au latin, soit une bonne quarantaine, $\mathrm{c}^{\prime}$ est l'obligation de prestation du serment constitutionnel imposé au clergé comtadin à l'été 1792 - soit un an après le serment en France - qui provoque massivement le passage du latin au français dans la tenue des registres paroissiaux. La grande majorité des curés du Comtat ayant refusé le serment, un renouvellement général des desservants des paroisses intervient à l'été 1792. L'arrivée dans les paroisses, de prêtres assermentés venus de tous les horizons, y compris des départements voisins, s'accompagne de décisions symboliques (ou simplement pratiques) comme l'abandon du latin dans les registres paroissiaux. Quasiment tous ces prêtres, en prenant leurs fonctions, assurent ce passage de langue dans la tenue des actes, sans le moindre commentaire. Le nouveau curé de Cheval-Blanc, petite paroisse rurale du terroir de Cavaillon, est un des rares à s'exprimer, et il donne quant à lui des raisons très pratiques pour justifier ce choix :

41. Arch. comm. Vedène 1 E 1 (baptêmes-mariage 1791-1792) : mention du 27 février 1791.

42. L'abbé Appay, curé de Sainte-Cécile, est également vicaire général de l'évêque de Vaison.

43. Passage inséré entre un acte de sépulture (en latin) du 19 janvier 1791 et un autre (en français) du 22 janvier 1791 (arch. comm. Sainte-Cécile-les-Vignes GG 10).

44. Arch. comm. L'Isle-sur-la-Sorgue GG 19, 22 et 23. 
«Pour la plus grande intelligence, j'ay trouvé plus à propos d'enregistrer les baptisés dans la langue française, qui sera intelligible au peuple de la campagne. $»^{45}$

Deux mois plus tard, en exécution de la loi, les officiers des municipalités procèdent à la clôture des registres paroissiaux et à leur dépôt dans les maisons communes, assurant ainsi le transfert vers le nouvel état civil. Lorsqu'intervient la clôture des derniers registres, au cours des premiers mois de l'année 1793, seulement huit curés de paroisses de l'ancien Comtat Venaissin tiennent encore leurs registres en latin selon l'usage traditionnel ${ }^{46}$.

L'exercice du culte dans la clandestinité, au cours des années qui suivent, sous la Terreur et après Thermidor, s'accompagne chez les prêtres réfractaires d'une résistance linguistique. Lorsque s'abattent les mesures d'interdiction du culte et que disparaissent les registres paroissiaux tenus en français par le clergé constitutionnel des paroisses, c'est en latin que les prêtres réfractaires tiennent à nouveau leurs cahiers où ils enregistrent les baptêmes et les mariages qu'ils célèbrent en cachette ${ }^{47}$. Alors, plus que jamais, l'emploi de la langue de l'Église, dans ces petits cahiers de notes, a valeur de symbole et devient même, pourrait-on dire, acte de résistance.

Français ou latin ? Les curés comtadins se sont peu exprimés sur le choix de la langue utilisée dans leurs registres paroissiaux, et nous en sommes réduits en dépouillant leurs registres, à lire entre les lignes et à scruter ces pages pour tenter de saisir de leur part ce qui peut être zèle pour une langue ecclésiastique, pure obéissance au droit canon et respect des attentes d'un épiscopat ultramontain, attirance vers le modèle français, souhait de se mettre à la portée des demandes de paroissiens qui veulent comprendre aisément le contenu des actes qui marquent les étapes de leur vie.

Mais incidemment, dans un contexte politique qui met en relation deux États, le royaume de France et les États de l'Église, cette question qui pourrait somme toute n'être $\mathrm{qu}^{\prime}$ anodine $\mathrm{du}$ choix d'une langue dans la rédaction d'actes, acquiert une tout autre dimension, en exprimant, au-delà du domaine de la pratique ecclésiastique, un choix de souveraineté, qu'il s'agisse d'une souveraineté imposée par le roi de France (1770), celle du retour à la légitimité du Saint-Siège (1775) ou celle d'une France en mouvement à laquelle on souhaite désormais unir ses destinées (1790).

45. Arch. comm. Cheval-Blanc GG 1 (baptêmes 1765-1793), à la date du 16 septembre 1792.

46. Il s'agit surtout de paroisses situées sur la frange orientale des États pontificaux, du Luberon au pied des monts de Vaucluse et du Ventoux (Robion, Saumanes, le Beaucet, Méthamis, Flassan), ainsi que des localités plus isolées comme Jonquerettes, Roaix et Loriol-du-Comtat.

47. Arch. comm. Avignon GG 114 : un second cahier d'actes pour l'année 1792 (2 janvier-10 mars) figure dans les registres de la paroisse de la Madeleine à Avignon; mais à la différence du premier, il s'agit de cahiers non paraphés, tenus en latin par le chanoine et ancien précenteur de la collégiale, Pical, qui a refusé le serment ; leur clôture le 19 décembre 1792 par l'officier municipal s'accompagne de cette mention : «M. le citoyen curé nous observant que le nommé Pical a exercé des fonctions malgré la loi ». Voir M. Maureau, Aspect du clergé réfractaire dans l'ancien diocèse d'Avignon sous la Révolution (1793-1801). 


\begin{abstract}
Résumé
Avignon et le Comtat Venaissin représentent un cas d'espèce dans la tenue des actes paroissiaux. L'usage du royaume de France où l'édit de Villers-Cotterêts d'avril 1539 imposait la tenue en français de ces registres, ne s'y est pas appliqué, de façon naturelle pour des territoires restés sous la souveraineté du Saint-Siège, et c'est l'usage canonique du latin qui prévalut dans les actes de catholicité, y compris dans les paroisses relevant de diocèses situés en France (Apt, Saint-Paul-Trois-Châteaux, Gap) ainsi que dans le diocèse d'Orange, à cheval sur la principauté de ce nom et le Comtat Venaissin. La troisième occupation française, de 1768 à 1774, bouleversa les institutions pontificales, et parmi les réformes imposées par le roi de France à ces nouveaux sujets, l'obligation fut faite aux curés, à partir du $1^{\text {er }}$ janvier 1771 , de rédiger les actes paroissiaux «à la française », selon la déclaration de 1736, c'est-à-dire en ayant recours à la langue française et en employant des cahiers paraphés au préalable par un juge de la sénéchaussée. Ce changement d'usage, accepté sauf rare exception par les curés, ne dura que quatre années. À la restitution au pape de ses États en 1774, l'usage ancien du latin ainsi que des registres séparés, fut rétabli dans la plupart des paroisses. Mais, de même que certains curés avaient observé une forme de résistance au français en tenant sous l'occupation française deux registres suivant l'un et l'autre usage, d'autres conservèrent le français dans les actes après la restitution au pape. Sur cette question de la langue dans la rédaction des actes de catholicité, c'est une situation assez diversifiée qui est perceptible à la veille de la Révolution. La réunion à la France d'Avignon et du Comtat en septembre 1791 allait encore modifier les usages de l'Église. Anticipant les mesures françaises et dans la logique de son vœu de réunion à la France, la municipalité d'Avignon impose aux paroisses avignonnaises l'abandon du latin dès janvier 1791. Quant au Comtat Venaissin, c'est le choix des nouveaux desservants des paroisses, ayant prêté le serment, qui provoque un retour en force du français, sans contrainte, quelques mois seulement avant la mise en application de la loi du 20 septembre 1792 sur la laïcisation de l'état civil.
\end{abstract}

\title{
Bibliographie
}

Charpenne Pierre, Histoire des réunions temporaires d'Avignon et du Comtat à la France, Paris, 1885, 2 vol.

FONT-RÉAUlX Jacques de, Les registres d'état civil antérieurs à 1792, d'après les notes d'H. Chobaut, Avignon, archives départementales de Vaucluse, 1958, 24 p. (extr. de Mémoires de l'Académie de Vaucluse, t. VII, 1957-1958).

Maureau Maxime, Aspect du clergé réfractaire dans l'ancien diocèse d'Avignon sous la Révolution (1793-1801), Aix-en-Provence, maîtrise d'histoire, 1985, 2 vol.

Moulinas René, Histoire de la Révolution d'Avignon, Avignon, Aubanel, 1986. 390 p.

PONCET Olivier, «Inscrire les clercs dans l'État. La monarchie française, les ecclésiastiques et le gouvernement par l'écrit (XVI ${ }^{\mathrm{e}}-\mathrm{XVIII}^{\mathrm{e}}$ siècle)», dans ARABEYRE P. et BASDEVANTGAUDEMET B. (dir.), Les clercs et les princes. Doctrines et pratiques de l'autorité ecclésiastique à l'époque moderne, Paris, École des chartes, 2013, p. 79-94.

ROUCHON Olivier, "Entre le roi et le pape. Les réunions d'Avignon au royaume de France (XVII ${ }^{\mathrm{e}}-\mathrm{XVIII}^{\mathrm{e}}$ siècle) », dans BERLIOZ J. et PONCET O., (dir.), Se donner à la France ? Les rattachements pacifiques de territoires, XIV $-X^{e} X^{\mathrm{e}}$ siècle, Paris, École des chartes, 2012, p. 5581.

THOMAS Bernard, «Les paroisses du diocèse d'Orange d'après l'enquête de $\mathrm{M}^{\mathrm{gr}} \mathrm{du}$ Tillet (1775) », dans Mémoires de l'Académie de Vaucluse, 8 e série, tome VIII, 1999, p. 47-78.

VENARD Marc, Réforme protestante, réforme catholique dans la province d'Avignon au XVI siècle, Paris, éd. du Cerf, 1993, 1280 p. 


\section{Liste des cartes}

Figure 1 : Latin et français dans les registres paroissiaux du Comtat Venaissin en 1770.

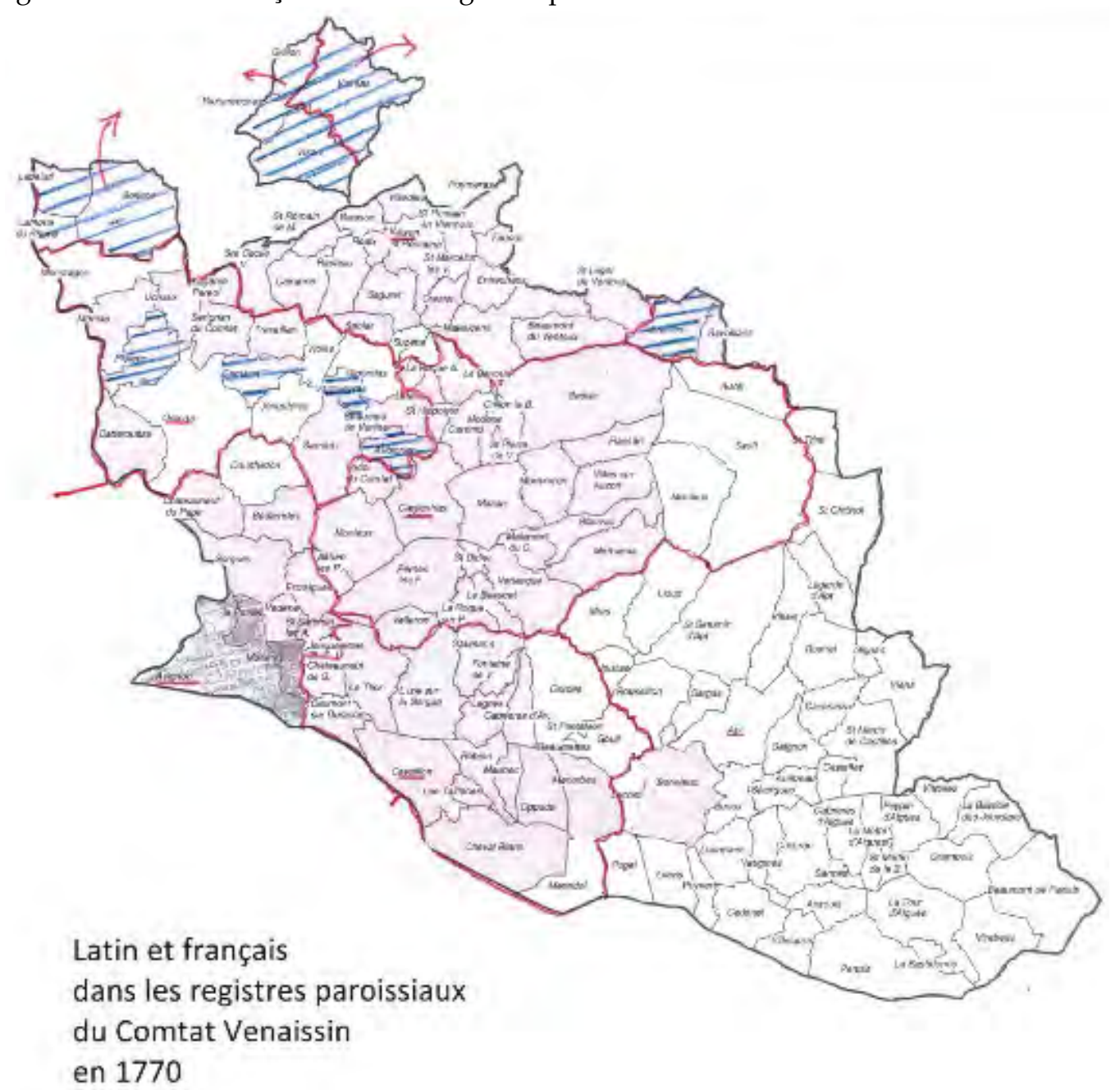

Légende :

Paroisse du Comtat Venaissin faisant usage de la langue latine

Paroisse du Comtat Venaissin faisant usage de la langue française

Limites de diocèses

Comtat Venaissin $=$ couleur rose

Avignon $=$ couleur grise

Principauté d'Orange et Provence $=$ couleur blanche 
Figure 2: Reprise du latin et maintien du français dans les registres paroissiaux $d u$ Comtat Venaissin en 1774.

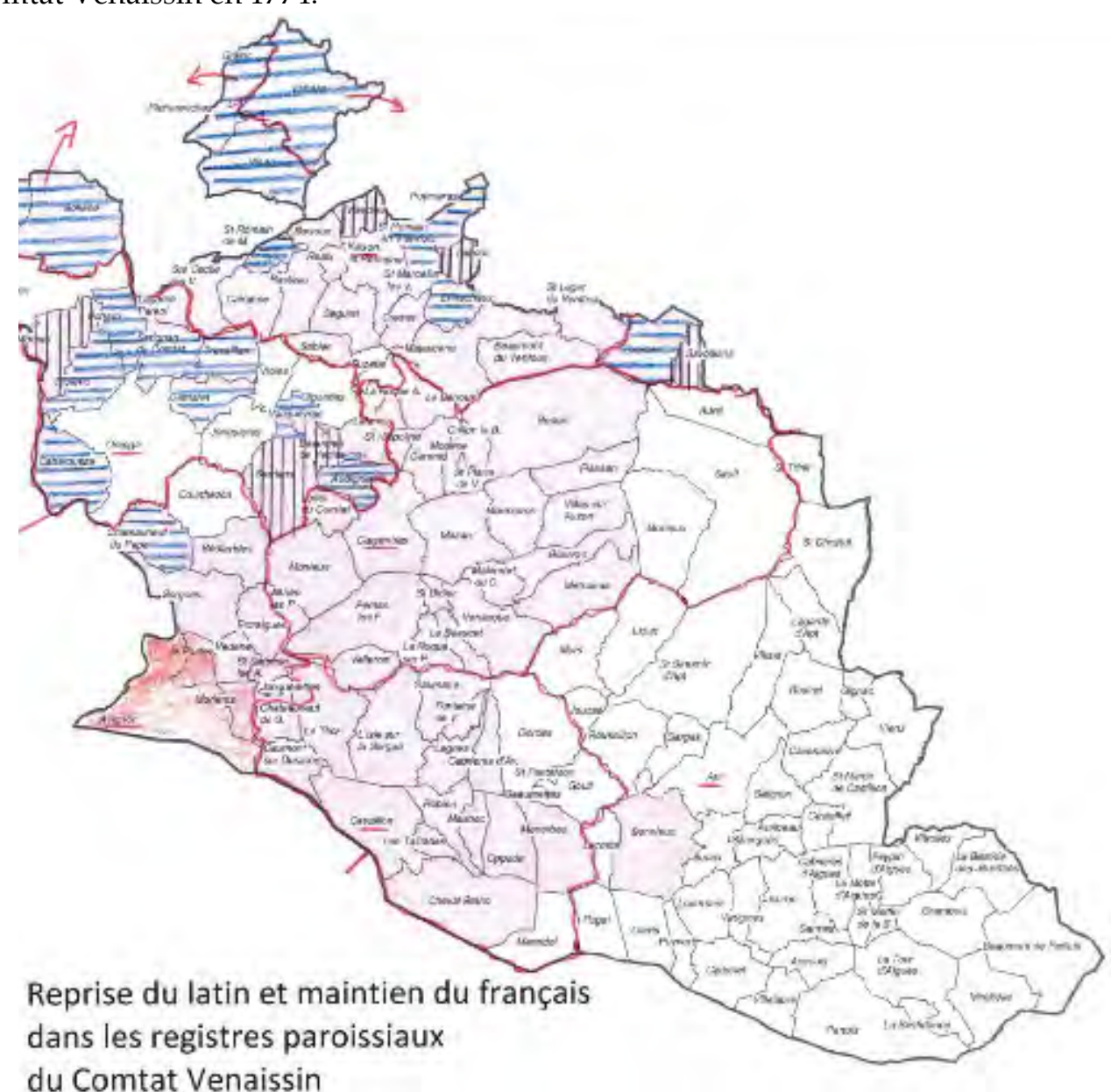

du Comtat Venaissin

en 1774

Légende:

Paroisse du Comtat Venaissin ayant repris en 1774 l'usage du latin

III! Paroisse du Comtat Venaissin ayant repris temporairement en 1774 l'usage du latin

Paroisse du Comtat Venaissin restée en 1774 à l'usage du français

Limites de diocèses

Comtat Venaissin $=$ couleur rose

Principauté d'Orange et Provence $=$ couleur blanche 
Figure 3 : La résistance du latin dans les registres paroissiaux d'Avignon et du Comtat (1774-1793).

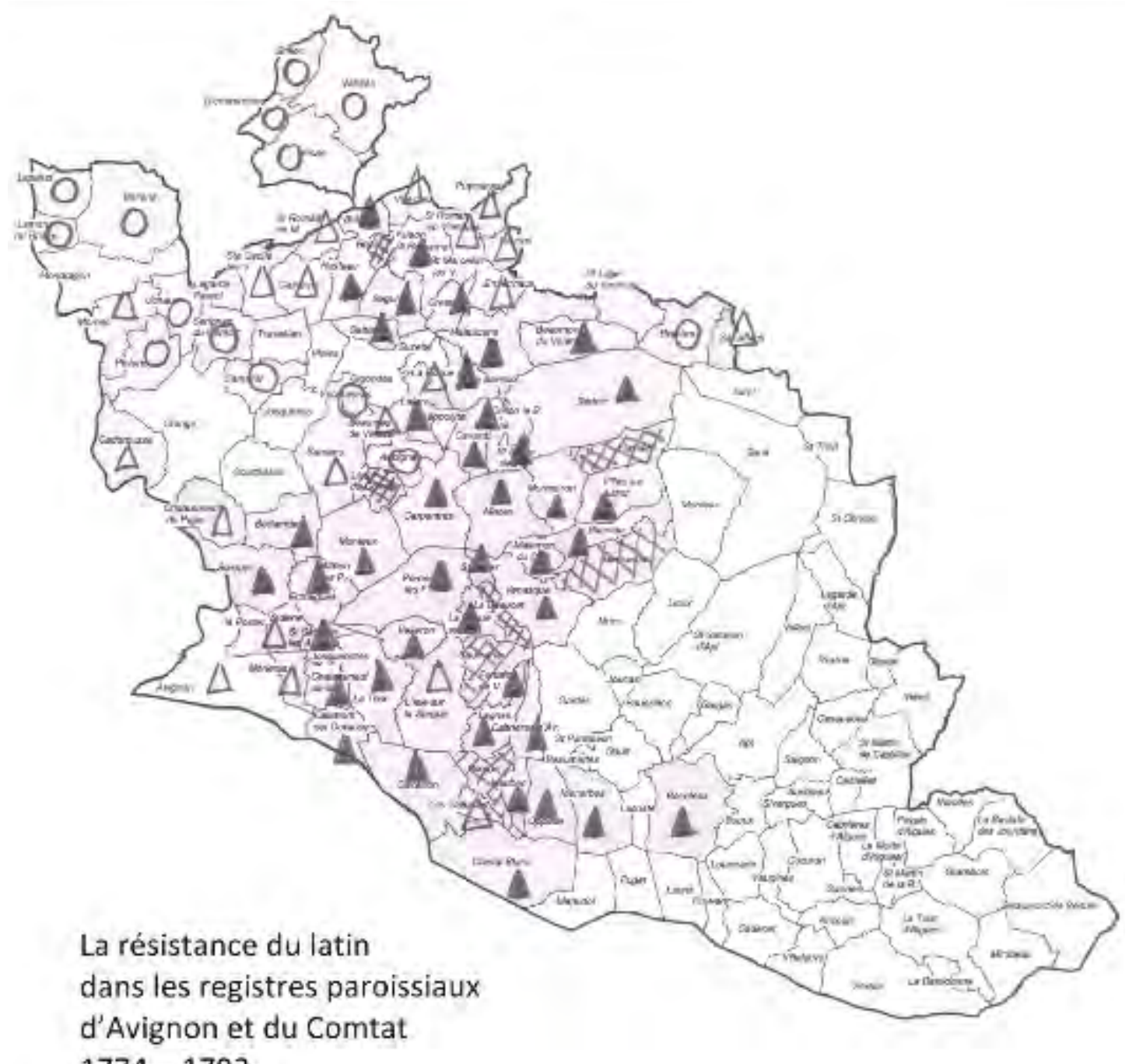

$1774-1793$

Légende :

Passage au français avant 1768

$\triangle$ Passage au français entre 1774 et 1792

Passage au français en août-septembre 1792

$18 \times$ Maintien du latin en 1793 


\title{
Aller jusqu'à user du patois? \\ Remarques sur les emplois des dialectes occitans pendant la Révolution
}

\author{
Régis BERTRAND \\ Professeur émérite d'Aix-Marseille université, \\ chercheur de l'UMR Telemme \\ (Maison Méditerranéenne des sciences de l'homme), \\ membre de la section d'histoire moderne, \\ de la Révolution et du temps des révolutions du Cths, \\ président d'honneur de la Fédération historique de Provence, \\ membre de l'Académie de Marseille.
}

\footnotetext{
Extrait de : Guylaine BRUN-TRIGAUD (dir.), Contacts, conflits et créations linguistiques, Paris, Édition électronique du CTHS (Actes des congrès des sociétés historiques et scientifiques), 2015

Cet article a été validé par le comité de lecture des Éditions du CTHS dans le cadre de la publication des actes du $139^{\circ}$ Congrès national des sociétés historiques et scientifiques tenu à Nîmes en 2014
}

Parmi les avancées du Bicentenaire de la Révolution, figurent la recherche et l'étude des traces de la langue vernaculaire dans les documents écrits de la fin du XVIII ${ }^{\mathrm{e}}$ siècle. Il m’a paru intéressant de revisiter rapidement ce dossier vingt-cinq ans plus tard, à la fois pour en proposer un court bilan, la diffusion de ses résultats ayant peut-être été assez inégale, et pour formuler quelques remarques avec le recul du temps.

Le progrès est double. Par l'importance de la collecte réalisée d'abord. Le nombre des textes en occitan, retrouvés ou mentionnés, a considérablement augmenté. Le grand inventaire publié en 1989 par François Pic atteint 225 écrits retrouvés ou mentions d'écrits attestés, imprimés ou manuscrits, ou même de chansons recueillies oralement jusqu'au début du XX $X^{\mathrm{e}}$ siècle $^{1}$. Par comparaison, le docteur Noulet dénombrait au début de la III ${ }^{\mathrm{e}}$ République environ 90 titres, pour la plupart imprimés ${ }^{2}$. Ce progrès se traduit également par un changement des attitudes à l'égard de ce corpus. L'étude de l'écrit occitan de la période révolutionnaire au cours des décennies 1980-1990 a achevé de marquer le passage de mentions longtemps négligentes à un examen attentif, voire scrupuleux, et surtout critique. Ces recherches ont aussi jalonné dans une certaine mesure le passage du militantisme occitan ou félibréen à l'érudition de type universitaire pour cette période des temps modernes.

\section{Un grand effort de collecte et d'analyse}

Quelques érudits du XIX ${ }^{e}$ siècle s'étaient intéressés aux textes produits dans les dialectes occitans pendant l'époque révolutionnaire. Les principaux sont le Toulousain JeanBaptiste Noulet (1802-1890), déjà cité, en 1877 et le Provençal Robert Reboul (1842-1905), la même année ${ }^{3}$. Ils avaient accumulé ces références manuscrites ou imprimées comme une preuve de la continuité d'usages linguistiques écrits entre le Moyen Âge et la création du Félibrige ; elles constituaient à leurs yeux quelques pointes émergées d'un gigantesque iceberg de paroles occitanes évanouies. Mais ils rejetaient en général dans l'infralittérature ce qui ne correspondait pas aux genres considérés comme nobles de la littérature française, soit la quasi-totalité des textes d'époque révolutionnaire et leurs

1. F. Pic, «Inventaire» dans H. Boyer, G. Fournier, Ph. Gardy, Ph. Martel, R. Merle, Fr. Pic, Le texte occitan de la période révolutionnaire, p. 15-216.

2. J.-B. Noulet, Essai sur l'histoire littéraire des patois du Midi de la France au XVIII siècle.

3. Id. et R. Reboul, Bibliographie des ouvrages écrits en patois du Midi de la France. 
successeurs firent souvent de même $e^{4}$. Néanmoins Auguste Brun (1881-1961), le principal romaniste de la faculté $\mathrm{d}^{\prime}$ Aix dans le second tiers du $\mathrm{XX}^{\mathrm{e}}$ siècle, avait, en étudiant l'expansion du français dans le Midi, apporté des nuances à la vision mistralienne de la substitution brutale après la Révolution d'une langue à une autre et montré qu'il s'agissait d'un phénomène bien plus complexe, progressif et de longue durée. Il avait aussi montré qu'il ne convenait pas de s'en tenir aux seuls textes rédigés en occitan : la recherche attentive dans les archives permettait de trouver aussi des allusions aux usages linguistiques en public. Il était possible d'entrevoir l'oralité disparue à travers des indices ou des traces écrites ${ }^{5}$.

La recherche collective de ces textes allait lors de la préparation du Bicentenaire prendre des aspects de chasse au trésor ou d'orpaillage. Les auteurs des générations précédentes n'avaient en général pas précisé où ils avaient vu les exemplaires qu'ils mentionnaient. On en viendrait vite à se demander s'ils les avaient vraiment consultés. Ainsi le recueil de cantiques patriotiques de l'instituteur Artaud de Draguignan était toujours mentionné et jamais cité. Lorsque René Merle parvint à en retrouver un exemplaire, l'ouvrage s'avéra entièrement en français.

Le trait le plus remarquable est que pour la première fois les textes et les mentions collectés ont fait l'objet de travaux universitaires, amorcés en particulier dès les années qui préparaient la commémoration par un colloque, une livraison de revue ${ }^{6}$ et de

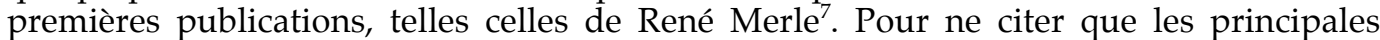
études publiées, mentionnons, outre l'ouvrage collectif de la section française de l'Association internationale d'études occitanes auquel j'ai déjà fait allusion, Le texte occitan de la période révolutionnaire, paru à Montpellier en 1989, la thèse de René Merle sur les textes occitans du Sud-Est de 1770 à 1840, publiée en 1990, qui consacre un important développement à la période révolutionnaire ${ }^{8}$, un fascicule du Dictionnaire des usages sociopolitiques 1770-1815, paru en $1991^{9}$. Et aussi des éditions critiques, en tout premier lieu, le recueil réalisé par une équipe de mouvance félibréenne sous la direction de Claude Mauron et François-Xavier Emmanuelli, dont le t. I, Textes en prose, parut dès 1986, mais le t. II, réunissant les textes en vers, ne fut pas réalisé, peut-être parce que certains avaient été republiés par ailleurs ${ }^{10}$. Plus tard viendra la thèse de Carmen Alén-Garabato sur le cas toulousain, publiée en 1999 et une intéressante tentative de synthèse dans un ouvrage collectif sur les usages de l'occitan en $2001^{11}$.

Encore doit-on ajouter des communications dans des colloques, des notices de catalogues, des passages de monographies et des articles ${ }^{12}$. Certains peuvent signaler de nouveaux textes ou des attestations inédites - parfois de façon involontaire : ainsi telle communication dont l'auteur ne s'était pas étonné de découvrir une belle chanson satirique «en patois », pour reprendre son expression ; il n'avait jugé utile de n'en citer que quelques vers, traduits par ses soins, qui suffisaient à indiquer qu'elle était inconnue jusqu'alors.

4. En témoigne le silence total au sujet de ces textes qui est commun aux deux principaux manuels de littérature occitane publiés avant le Bicentenaire, ceux de C. Camproux, Histoire de la littérature occitane et Ch. Anatole et R. Lafont, Nouvelle histoire de la littérature occitane.

5. A. Brun, La langue française en Provence de Louis XIV au Félibrige.

6. H. Boyer et Ph. Gardy éd., «La question linguistique au Sud au moment de la Révolution française »[22 communications]. «Révolution, Contre-révolution. Le texte dialectal de la période révolutionnaire " [10 contributions].

7. R. Merle, Inventaire du texte provençal de la région toulonnaise.

8. R. Merle, L'écriture du provençal de 1770 à 1840, t. I, p. 213-389. Résumé dans R. Merle, Une mort qui n'en finit pas. La totalité de l'oeuvre historique de René Merle est sur le site http:/ / www.rene-merle.com qui procure en particulier une version revue de sa thèse. Cette étude étant fondamentale pour l'aire provençale que j'étudie surtout ici, on pourra s'y reporter pour la plupart des exemples cités infra.

9. J. Guilhaumou et Ph. Gardy (dir.), Dictionnaire des usages socio-politiques (1770-1815), fasc. 5.

10. Cl. Mauron et F.-X. Emmanuelli (dir.), Textes politiques de l'époque révolutionnaire en langue provençale.

11. M. C. Alén-Garabato, Quand le patois était politiquement utile et M. C. Alén-Garabato, H. Boyer, G. Fournier,

«La Révolution française, un moment-clé dans l'évolution de la configuration sociolinguistique en domaine d'oc », dans H. Boyer et Ph. Gardy, Dix siècles d'usages et d'images de l'occitan, p. 145-176.

12. Signalons R. Merle, «Données nouvelles sur le texte provençal et les émeutes de mars-avril 1789 ». 
Les principales découvertes possibles sont surtout des manuscrits dans les archives, à l'instar de ce très court discours que m'avait signalé peu avant sa mort un érudit de Mimet (Bouches-du-Rhône) ${ }^{13}$. N'est pas négligeable cependant la découverte d'exemplaires nouveaux de pièces imprimés, dont certaines constituent pour l'heure un unicum en bibliothèque publique. Ainsi tel recueil factice toulousain entré en 2013 au Cirdoc de Béziers avec le fonds du collège d'Occitanie, qui présente l'intérêt de rassembler de façon cohérente des pièces en occitan et en français ${ }^{14}$.

\section{Caractéristiques du corpus}

L'ensemble prouve que l'occitan a bien été présent dans les écrits de la décennie révolutionnaire et même sans doute davantage écrit pendant environ quatre ans et demi, entre 1789 et la mi-1793, que dans un autre laps de temps comparable du XVIII siècle. La Convention manifeste en revanche à partir de l'an II la volonté nouvelle d'éradiquer les langues qui ne sont pas celle de la nation et l'occitan se raréfie alors de l'imprimé et de l'archive publique. Non sans exceptions, comme R. Merle l'a montré ${ }^{15}$. Ajoutons que la légende de la gravure parisienne de Descourtis d'après Swebach-Desfontaine qui fait connaître dans la capitale l'action héroïque du jeune Agricol Viala, le "martyr de la liberté " avignonnais abattu par les fédéralistes marseillais, reproduit ses dernières paroles dans leur langue originelle, sans doute pour preuve de leur authenticité :

«M'an pas manqua ; aquo es egau, moré per la liberta. » ${ }^{16}$

La répartition de ces attestations est géographiquement très inégale : la plupart des départements en fournissent une ou deux, connues parfois de seconde main. La HauteGaronne représente $40 \%$ du corpus, en partie à cause de l'affaire Sermet sur laquelle je reviendrai, suivie des Bouches-du-Rhône, de l'Hérault et du Vaucluse. Certes, dans les quatre chefs-lieux de ces départements, des collectionneurs ont tôt recueilli les occasionnels et feuilles volantes révolutionnaires mais le fait ne semble pas un argument fondamental : dans d'autres départements, des collections similaires ne contiennent que peu ou aucun texte. Philippe Martel avait observé dès 1989 que cet axe ToulouseMontpellier-Avignon-Aix-Marseille réunit les villes qui ont produit l'essentiel de l'imprimé occitan dans la décennie qui précède la Révolution. La thèse de Jean Eygun sur le texte religieux occitan, publiée en 2002, confirme qu'il s'agit de l'axe où a été édité l'essentiel des impressions occitanes entre 1650 et $1800^{17}$. On semble avoir rédigé et imprimé divers textes occitans là où l'on avait déjà, depuis longtemps, l'habitude de le faire pour des livres, en particulier religieux, composés surtout de prières et de cantiques. Les rééditions de ces recueils bilingues se poursuivent d'ailleurs dans les premières années de la Révolution. Là où l'on avait une habitude visuelle de la langue imprimée, de la part des imprimeurs et aussi des auteurs. Là aussi, ajouterai-je, où un notable a incarné dans le passé l'auteur dialectal local : Saboly à Avignon, Gros à Marseille, l'abbé Fabre à Montpellier et surtout Godolin à Toulouse. Il est dès lors possible que les catégories médianes et supérieures hésitent moins dans ces zones à utiliser si nécessaire en public la langue du peuple, ou du moins, si elles le font, qu'elles hésitent moins à en laisser des traces écrites ou imprimées.

Par ailleurs, si l'on replace ces textes occitans dans l'ensemble des écrits publiés en France méridionale pendant la décennie révolutionnaire, on doit constater qu'il s'agit de rares gouttes d'occitan dans un océan de français. Partout la langue du roi puis de la

13. R. Bertrand, «Un discours en provençal à Gardanne ».

14. Cirdoc (Centre interrégional de développement de l'occitan)-Médiathèque occitane, Béziers, cote CR A-8176. 15. R. Merle, L'écriture du provençal de 1770 à 1840 , t. I, p. 350-389.

16. Reproduite dans La Mort de Bara, Avignon, Fondation Calvet, 1989, p. 33, texte p. 138. À noter que les autres gravures contemporaines consacrées à Viala traduisent en français cette phrase.

17. Ph. Martel, «Les textes occitans de la période révolutionnaire : un peu de géographie » dans H. Boyer, G. Fournier, Ph. Gardy, Ph. Martel, R. Merle, Fr. Pic, Le texte occitan de la période révolutionnaire, p. $219-245$ et J. Eygun, Au risque de Babel. 
nation est la règle et l'occitan une exception. Cette exception semble presque toujours volontariste et ses motivations réclament d'être cernées, au moins hypothétiquement, quasiment pour chaque pièce. Les deux équipes qui de part et autre du Rhône ont fourni les deux principales publications se sont appliquées à les replacer dans les contextes politiques locaux et leurs analyses sont souvent éclairantes, ne serait-ce que parce qu'elles permettent de déterminer des textes favorables à la Révolution et d'autres hostiles ${ }^{18}$.

La nouveauté majeure de la période est évidemment la politisation du texte occitan, qui n'est cependant pas le principal trait de toutes les productions de la dernière décennie du $\mathrm{XVIII}^{\mathrm{e}}$ siècle. Celle qui a eu peut-être la plus longue postérité imprimée est la pièce d'Étienne Pelabon, Lou Groulié bel esprit (le savetier bel esprit), jouée pour la première fois en 1790 et reprise et rééditée jusqu'au début du XX $X^{\mathrm{e}}$ siècle. Elle s'inscrit dans le cadre du théâtre dialectal marseillais de la fin de l'Ancien Régime et est entièrement en provençal mais assez peu marquée par la conjoncture politique. Ses éditions de la Première République et de l'Empire vont remplacer lou rey par la lei ou la natien. La même année 1790 Pelabon a donné La réunion patriotique ou Minerve à Toulon, où le provençal a la portion congrue et dont les vers français - fort plats, mais académiques - auraient fait chuchoter que Laurent Bérenger en serait le véritable auteur ${ }^{19}$. Il est vrai qu'une autre pièce davantage politisée si l'on en juge par son titre, Lou san culotto a Niço, jouée à Marseille en janvier 1793, aurait été entièrement en provençal mais elle est perdue.

Une autre œuvre montre comment un genre traditionnel par excellence de la littérature dialectale, le cantique de Noël, peut revêtir au prix de retouches et d'ajouts un sens nouveau : le Nouhé deis san-culotos, chanté pour la Noël 1792 dans l'église des Carmes de Marseille, dont le texte figure dans les manuscrits du vicaire constitutionnel de l'église, l'abbé Bonnet, son auteur vraisemblable car il avait peu auparavant confectionné un vaste dictionnaire provençal. Je l'avais publié en 1985 d'après un de ses manuscrits. René Merle $\mathrm{m}^{\prime}$ avait signalé que l'abbé Bonnet avait transformé, pour lui donner une tonalité nettement révolutionnaire, un cantique préexistant qu'il avait copié dans un autre de ses manuscrits à la date de 1788 . Je puis indiquer aujourd'hui qu'il avait trouvé ce texte dans le recueil de l'abbé Hélion, publié en $1750^{20}$.

\section{Typologie}

\section{Discours}

Plusieurs types de textes sont propres à la Révolution : les discours d'abord. Le plus connu est celui qu'un célèbre prédicateur toulousain, le père Sermet, prononce le 14 juillet 1790 dans le petit village de Saint-Geniès près de Toulouse, où se situe la maison de sa famille. Devant les gardes nationaux, il critique l'Ancien Régime et dit ses espoirs dans la constitution. Ce discours est imprimé à Toulouse, Montauban, Béziers et Montpellier. Il suscite des libelles en français comme en occitan, d'autant que Sermet est ensuite élu évêque constitutionnel ${ }^{21}$.

18. H. Boyer, G. Fournier, Ph. Gardy, Ph. Martel, R. Merle, Fr. Pic, Le texte occitan de la période révolutionnaire et Cl. Mauron et F.-X. Emmanuelli (dir.), Textes politiques de l'époque révolutionnaire en langue provençale.

19. R. Merle, A. Tramoni, M. Vovelle, Toulon, 1789-1790. Etienne Pelabon et La réunion patriotique.

20. R. Bertrand, «Un prêtre provençaliste en Révolution, J.-J.-T. Bonnet ». H[élion H[enri], curé d'Orgon, Nouveaux cantiques spirituels provençeaux (sic) et quelques-uns françois pour les Missions, Congrégations $\mathcal{E}$ Cathechismes. Avec l'air noté au premier Couplet de chaque cantique. Par un curé du diocese d'Avignon en la partie de Provence, Missionnaire \& ancien Chanoine de St. Genies, Avignon, François-Joseph Domergue, 1750, p. $131-133$.

21. Voir C. M. Alén-Garabato, Quand le patois était politiquement utile. 


\section{Adresses et libelles}

Un deuxième ensemble caractéristique est justement constitué par la littérature polémique révolutionnaire ou contre-révolutionnaire qui se présente sous forme d'occasionnels. Parmi ces libelles, figurent les faux cahiers de doléances. La langue vernaculaire accentue encore l'aspect comique de ces satires des vrais cahiers (ainsi les Douléenços de las femnos de Toulouso). Ces parodies sont cependant plus nombreuses en français. Une partie de ces pièces de polémique est constituée par les libelles toulousains concernant l'affaire Sermet et la constitution civile du clergé, en majorité hostiles.

\section{Traductions}

C'est apparemment dans le même but que l'on a publié dans les premières années de la Révolution des traductions du français en occitan. La plus significative est la version provençale de la Constitution de 1791. Les constituants avaient décidé que son texte serait traduit dans « les différents idiomes ». Ce fut pour la Provence l'œuvre du député Charles-François Bouche, seule traduction en dialecte régional à avoir connu l'impression, qui fut faite à Paris. L'ouvrage fait 272 pages, est bilingue (français avec traduction en regard $)^{22}$.

Le célèbre Almanach du Père Gérard de Collot d'Herbois fut traduit en 1792 en provençal à Paris et diffusé dans le Vaucluse depuis Carpentras et aussi peut-être, dans les BassesAlpes. Collot d'Herbois, directeur de troupe, avait séjourné dans le Midi et même écrit une pièce bilingue en 1777. Il pourrait être l'auteur de la version occitane, qui tend à revêtir d'une apparence provençale le texte français.

\section{Textes en vers}

Il faut ajouter des chansons, parfois recueillies tardivement auprès de la mémoire orale et qui posent les problèmes spécifiques de critique de ce type de source. Outre le Nouhé deis san-culotos, déjà cité, quelques hymnes cérémoniels, pour la plantation de l'arbre de la liberté par exemple.

Et aussi une création littéraire de circonstance publiée par des auteurs qui n'appartiennent pas à une élite de la fortune et du savoir et sont même considérés en leur temps comme des représentants des catégories populaires ayant bénéficié des avancées de l'alphabétisation. Ce phénomène s'était manifesté à partir de la seconde moitié du XVIII ${ }^{\mathrm{e}}$ siècle avec les œuvres publiées du cordier Nalis d'Arles ${ }^{23}$ et du fustier (menuisier) Peirol d'Avignon. C'est le cas de ce J.-B. Rémuzat, vraisemblablement potier d'Aubagne, qui publia en 1790 à Marseille La verita desplegado per un poueto villageois, strophos prouvençalos countenen l'Histori de la nouvello revolutien, dont Philippe Gardy a dit qu'elle était «une manière de miracle stylistique et esthétique ${ }^{24}$; ou bien de Sauze, « un jardinier d'Aix» dont les écrits antirévolutionnaires paraîtront surtout sous l’Empire mais qui est bien médiocrement inspiré. Voire ce Mathieu Vayen «qui ne sait ni lire ni écrire » ou du moins est dit tel, dont R. Merle a retrouvé quelques chansons ${ }^{25}$.

22. Extraits dans $\mathrm{Cl}$. Mauron et F.-X. Emmanuelli (dir.), Textes politiques de l'époque révolutionnaire en langue provençale, p. 152-209.

23. R. Bertrand, «J.-B. Nalis ou les charmes discrets d'une littérature bilingue sous Louis XV ».

24. R. Bertrand, Ph. Gardy, R. Merle, J.-B. Remuzat, La verita desplegado per un pouèto villageois.

25. R. Merle, L'écriture du provençal de 1770 à 1840, t. I, p. 352-353. 


\section{User du patois plutôt que du français?}

Pourquoi, dans tous ces cas, employer l'occitan ? Aux yeux des érudits de naguère, la question ne se posait guère. Le principal intérêt des textes dialectaux d'époque révolutionnaire était de prouver, si besoin était, un usage public qu'ils croyaient surabondant, sinon quasi-universel, de la langue vernaculaire en France du sud, à un moment essentiel de l'histoire. Les faits sont beaucoup plus complexes. Un texte occitan recopié ou simplement mentionné dans un registre de délibération qui est par ailleurs entièrement rédigé en français suffit à mettre en doute l'idée reçue que dans les réunions publiques l'on se serait exprimé oralement en occitan pour ensuite consigner par écrit en français une trace de ces propos, puisque la presque totalité des archives publiques et même privées des $\mathrm{XVII}^{\mathrm{e}}$-XVIII ${ }^{\mathrm{e}}$ siècles est rédigée en français dans la plupart des régions occitanes.

De fait, un premier schéma est le suivant: des orateurs s'adressent à un public socialement mêlé. Apparemment ils le font d'abord en français; ils s'aperçoivent qu'ils ne sont pas compris de tous ou ils feignent de s'en apercevoir ; l'un d'eux passe alors à l'occitan. Le procès-verbal peut se borner à l'indiquer. Dans certains cas, le discours est reproduit. Un exemple désormais célèbre, le plus ancien, est celui de l'avocat Hodoul à Sisteron. Le 19 février 1789, le conseil général des chefs de famille de Sisteron est réuni. L'avocat Teissier fait un discours en français au sujet de la reconstitution des États de Provence et de la réforme de la fiscalité du pays de Provence ; il s'agit d'obtenir l'élection aux États des députés par communes et le doublement du tiers. Hodoul a dû percevoir que tout cela n'était pas compris de tous :

«Messiés, ausou sublar à mes aureillos qu'uno troupe des gens dou pople n'ausun qu'a mita ce que se di. Un moument de patiansso braves gens vous vau expliquar de ques question dins lou lengagi que vous es lou plus familier. »

Il résume en provençal le discours précédent, en l'édulcorant d'ailleurs. Suit le vote d'une motion en français. La délibération contenant les deux discours est imprimée et diffusée à 400 exemplaires (selon la décision prise alors). L'intendant de Provence La Tour a envoyé à Necker une copie du registre de délibération où elle a été transcrite en observant :

«L'affectation de traduire en langue provençale est une espèce de tocsin pour exciter et ameuter le peuple».

Le comte de Caraman, commandant en chef de la province, l'envoie également à Necker en disant son inquiétude ${ }^{26}$. C'est sans doute le but poursuivi par l'impression : montrer au pouvoir que les réformateurs peuvent atteindre toutes les couches de la population, à un moment où s'instaure un débat public inédit qui se politise rapidement.

Ce modèle sisteronais, soit un texte en occitan qui est lui-même enchâssé dans une unité de texte en français relevant en général du compte-rendu de réunion ou d'assemblée, va se retrouver au début de la Révolution dans un petit ensemble de discours marqués par le même souci d'une compréhension unanime, joint à des visées de propagande. Ainsi à la Société des Amis de la Constitution d'Aix:

«Séance publique du ${ }^{\text {er }}$ novembre $1790 \ldots$ M. Dubois a demandé la parole et il a prononcé un discours en langage provençal tendant à inviter tous les citoyens à venir se réunir dans le sein de l'assemblée pour y être instruits dans l'esprit des décrets de l'Assemblée nationale et pour y puiser le plus pur patriotisme. Ce discours a été si universellement aplaudi que l'assemblée a délibéré qu'il serait inscrit dans le registre et livré à l'impression en deux 
colonnes en français et en provençal, que des copies en seraient envoyées à toutes les sociétés en correspondance et à M. Tournel, rédacteur du Courrier d'Avignon. " $^{27}$

Henri Boyer a souligné que le fait de préciser la langue et plus encore de reproduire l'intervention, voire de l'imprimer, correspond à un "programme communicatif complexe $»^{28}$. Expliquer une décision ou un mot d'ordre à la partie la plus modeste de la population et s'efforcer de la convaincre, la gagner, en particulier en établissant à travers la langue un rapport de connivence susceptible d'atténuer quelque peu les différences sociales et culturelles avec le lettré qui parle (c'est moi qui ajoute cette remarque). Valoriser aussi aux yeux des autorités le médiateur bilingue qui se révèle avoir un contact spécifique avec le «bas peuple». Éventuellement aussi rappeler une identité sociolinguistique régionale ou locale. Mais ce dernier point relevant de l'implicite reste à démontrer.

Les papiers des clubs ou des sociétés populaires peuvent aussi renfermer des mentions et plus rarement le texte de discours en occitan qui pourraient émaner de représentants de catégories plus modestes, moins expertes dans l'usage du français. C'est le cas au club des Amis de la Constitution de Marseille le 27 février $1791 \mathrm{du}$ discours sur une feuille volante du citoyen Brouchier dont on sait seulement qu'il a 70 ans et est venu avec une délégation du quartier rural de Saint-Loup; il semble parler au nom des respectables cultivadours et met son espoir dans la constitution en cours d'élaboration pour apporter de profondes réformes, en particulier fiscales. De Pierre Julien aussi, qui semblerait être agriculteur, lequel prononce également le 6 mars 1791 un bref discours en provençal devant le club d'Apt pour mettre en garde contre le cercle des nobles de la ville. Dans les deux cas le ton est véhément. Il est possible que l'on ait transcrit ou recueilli leurs propos sans traduction pour leur en laisser la responsabilité. On peut cependant se demander s'ils étaient capables de s'exprimer facilement en français publiquement ou très éventuellement s'ils ont choisi le provençal parce qu'ils adhéraient au stéréotype qui en faisait un langage énergique et brutal ${ }^{29}$.

Dans le cas des sociétés populaires, si l'on fait la synthèse des remarques collectées autrefois par Auguste Brun et ensuite par deux étudiants de M. Vovelle ${ }^{30}$, l'impression générale est que l'on s'y exprime en français dans la mesure du possible et le plus souvent mais non toujours. Comme le note Laure Badaroux :

«Le français est considéré comme la langue à parler en priorité et le provençal n'est utilisé que pour se mettre à la portée du vulgaire.»

Mais dans plusieurs villes et bourgs du Vaucluse les motions paraissent avoir été fréquemment traduites oralement en provençal. Dans les Basses-Alpes, les difficultés de compréhension de l'assistance paraissent plus nettes. Ainsi à Castellane, un membre déclare le 3 juin 1792 que :

«La majeure partie de 1'assemblée, principalement la classe des agriculteurs, ne comprenant pas très bien la langue française il faisait la motion que dorénavant on ne parlât que la langue du pays afin que l'assemblée ne fût pas dans le cas de ce parlement qui jugea un pred à être pendu (sic). Cette motion vivement appuyée a été accueillie à l'unanimité. »

À Thorame-Haute, en mars 1793, l'on décide :

27. Id., p. $41-51$

28. H. Boyer, «Le 'patois' efficace? Une approche sociopragmatique des mises en texte de la Révolution en langue minorée » dans H. Boyer. G. Fournier, Ph. Gardy, Ph. Martel, R. Merle, Fr. Pic, Le texte occitan de la période révolutionnaire, p. 443-472, en particulier p. 450 sq.

29. Cl. Mauron et F.-X. Emmanuelli (dir., Textes politiques de l'époque révolutionnaire en langue provençale, p. 52-59 et 60-63.

30. A. Brun, La langue française en Provence de Louis XIV au Félibrige, p. 93-163. P. Alphand, «Les sociétés populaires dans les Basses-Alpes pendant la Révolution » et Laure Badaroux, "Les sociétés populaires dans le Vaucluse et les Bouches-du-Rhône de 1790 à l'an III », mémoires de maîtrise (aujourd'hui Master) sous la direction de M. Vovelle, Aix, 1983. 
«Attendu le peu d'usage qu'on a de la langue française qu'on ne peut s'énoncer dans cette assemblée qu'en langue vulgaire. »

À Riez, le règlement de la société populaire admet le bilinguisme :

«Il sera libre de parler en français ou en patois» \{mais\} «ceux qui peuvent facilement s'énoncer en patois sont invités à le faire pour que chacun puisse prendre part à ce qu'ils diront, surtout lorsque l'objet méritera quelque insistance. »

Le souci d'atteindre un public socialement diversifié, en particulier au moyen de la lecture à haute voix en un lieu public, semble sous-tendre le programme du journal du jacobin marseillais Montbrion, Le manuel du laboureur et de l'artisan, paru au printemps 1792. Montbrion annonce vouloir y donner «des pièces de poésies provençales et françaises analogues à la circonstance ». Il aura le temps de publier dans ses 12 livraisons deux fables en provençal, des vers pour un arbre de la liberté et une chanson patriotique. J. Guilhaumou a montré la fonction pédagogique des fables dans la formation du citoyen par le journal : elles introduisent et illustrent de façon expressive une question telle, par exemple, que la cruauté des grands à travers la fable en provençal du «loup et l'agneau », qui est ensuite développée en français ${ }^{31}$.

Quelle efficacité pouvait viser un certain nombre d'occasionnels en occitan dans la mesure où les occitanophones purs étaient couramment réputés analphabètes et où depuis des générations les alphabétisés étaient réputés comprendre le français ? Ainsi cette affiche, intitulée De la part doou rei, comte de Prouvenço, qui émanerait des autorités militaires, ses deux versions connues étant signées respectivement du comte de Caraman, commandant en chef en Provence, et du chevalier de Coincy, commandant la 8e division militaire à Toulon ${ }^{32}$. Elle condamne l'agitation, sans doute celle des mouvements populaires du printemps 1789 ; elle ordonne de cessar aqueleis attroupamens et assemblados sediciousos et de traduire les revendications par des mémoires écrits et non des assemblées. Ses responsables avaient sans doute une perception nuancée des pratiques linguistiques et ils ont pu connaître la catégorie que l'on a appelée depuis les peu-lettrés : ceux qui ont été alphabétisés de façon insuffisante pour parvenir à entendre convenablement le français ${ }^{33}$. On a pu espérer atteindre ainsi cette couche de la population pour qui la lecture d'un texte occitan était plus facile que celle d'un texte en français et qui surtout n'avait pas à faire l'effort d'une traduction simultanée pour en communiquer la substance aux analphabètes de leur entourage. Cette lecture directe dans la langue qu'ils pratiquaient le mieux était aussi plus sûre, le risque étant les quiproquos ou les contresens qui pouvaient naître de la compréhension approximative ou partielle d'un texte en français. Enfin, avant même de se faire comprendre, le souci de ces auteurs pourrait être de se faire d'abord admettre de leurs lecteurs potentiels en usant de leur langue ou du moins en dialectisant quelque peu leur propos. La traduction de la Constitution de 1791 semble poursuivre ces mêmes buts: dans un discours préliminaire, Bouche déclare à ses councitouyens, amis é frèros que si la Constituante a souhaité ces traductions dans touteis leis idiaoumés, lengagis é jargouns poupularis daou Rouyaoumé, c'est que soun intencién éro d'instruiré aqueleis qué coumprenién pa, vo qué sabién pas légi lou francèz, tanbén per émpâcha qué dé maou-intenciounas én l'i explican la Counstitucién, noun li diguessoun uno cavo per uno aoutro ${ }^{34}$.

31. J. Guilhaumou, «Les jacobins et la langue provençale. L'initiative linguistique des 'Missionnaires patriotes' marseillais (1792) ", dans "Révolution, Contre-révolution. Le texte dialectal de la période révolutionnaire », p. 111-123.

32. Cl. Mauron et F.-X. Emmanuelli dir., Textes politiques de l'époque révolutionnaire en langue provençale, p. 110113.

33. S. Branca-Rosoff et N. Schneider, L'écriture des citoyens.

34. Cl. Mauron et F.-X. Emmanuelli dir., Textes politiques de l'époque révolutionnaire en langue provençale, p. 156. 


\section{Un état de la diglossie à la fin du XVIII siècle}

Le corpus occitan des temps révolutionnaires fournit des informations très intéressantes sur les niveaux de la langue.

S'observe dans certains cas la très mauvaise transposition du français, où l'on se borne à donner une apparence occitane à un vocabulaire français, en maintenant parfois une syntaxe française, ce qui était déjà le cas de nombre de recueils bilingues de cantiques et vraisemblablement de la pratique orale de la traduction simultanée. La traduction de Bouche en est un exemple. Mais Bouche semble avoir tenu à serrer le plus possible le texte original de la constitution, sans doute pour éviter toute accusation d'interprétation personnelle. Il a eu aussi le très intéressant souci de tenter d'écrire dans lou lengagi lou pu généralament respéndu, aquo és-à-diré, d'aqueou qué l'o coumprén partou. Il fait en effet remarquer que lou patouas des Saintes-Maries-de-la-Mer n'aurait pas été compris à Barcelonnette et vice-versa. Cette tentative est intéressante mais cette compréhension interdialectale se fait à travers une forte francisation.

Certains discours ou des poésies révèlent un état assez francisé du vocabulaire mais beaucoup moins de la syntaxe. Ils pourraient être relativement proches de la langue parlée couramment par les bilingues qui les ont produits. Un des intérêt du corpus révolutionnaire pourrait être de proposer certains textes qui constituent l'unique tentative d'expression occitane écrite de leur auteur, à la différence des productions de ces sortes d'experts de la langue locale qu'étaient sous l'Ancien Régime les membres du clergé rédigeant des recueils bilingues de cantiques ou les notables s'adonnant à la création occitane.

Quelques pièces traduisent le sens des spécificités de la langue occitane et peut-être une recherche littéraire; une des plus intéressantes est un libelle bilingue de l'automne 1792, Eï marsillés, peut-être destiné aux membres du second bataillon des Marseillais, auxquels il conseille de défendre le roi, l'auteur se montrant hostile au procès du roi. Prétendu avoir été publié à Paris, avec une indication de libraire fantaisiste, il est signé Lou citouyen Micheou. Auguste Brun puis Claude Mauron ont fait remarquer que la langue en était savoureuse et riche. C'est un des rares cas où la traduction française s'avère nécessaire, à cause de la qualité idiomatique de la langue. Mais on ne sait rien de l'auteur ${ }^{35}$.

Enfin cet ensemble de textes peut être lu d'une autre façon. J'ai déjà souligné à quel point ces textes occitans sont autant de pépites dans le considérable ensemble imprimé ou manuscrit de textes en français produit pendant la dernière décennie du XVIII siècle. Très peu semblent indispensables à la connaissance fine d'un événement, hormis la gerbe suscitée par l'action et l'élection épiscopale du P. Sermet à Toulouse, où cependant les libelles occitans ne sauraient être séparés de ceux en français. Des épisodes essentiels ne semblent pas avoir sécrété ce type de texte - ainsi le départ du bataillon des Marseillais, qui propage à travers la France et à Paris un hymne en français dont on ne connaît pas de version occitane. Le Fédéralisme en a apparemment peu suscité. Dans le cas de la résistance clandestine à la déchristianisation, on connaît des imprimés diffusés dans les diocèses de Gap et Embrun mais ils sont en français. Il est vrai que les Hautes-Alpes n'ont quasiment pas produit alors de textes occitans. Mais cette région atteignait dès l'époque de Louis XIV le record français de l'alphabétisation masculine dans le monde rural et la francisation y semble précoce. L'étude en cours par Michèle Janin-Thivos des correspondances des marchands gavots installés dans le Nouveau monde révèle qu'ils écrivent dans un excellent français, au point que l'on ne se douterait guère qu'ils viennent d'une région occitanophone. Paraît dès lors «bien étrange » (Ph. Martel) la lettre en occitan alpin qu'aurait adressée à son frère en décembre 1796 un prêtre

35. Cl. Mauron et F.-X. Emmanuelli dir., Textes politiques de l'époque révolutionnaire en langue provençale, p. 123149. 
réfractaire, Jacques Guérin, natif de Ceillac. Publiée un siècle plus tard, son manuscrit n'est pas localisé et elle pose nombre de questions ${ }^{36}$.

Ce corpus pourrait être révélateur de la situation diglossique à la fin du XVIII ${ }^{\mathrm{e}}$ siècle, soit des modalités de coexistence de deux langues au statut inégal. Révélateur en particulier de la pénétration du français, en liaison avec l'alphabétisation, au moins au niveau urbain. À condition cependant de retenir cette conclusion de Philippe Martel :

«Le problème ne se limite pas à établir les dates auxquelles l'occitan cède devant le français : il faut aussi voir quel occitan cède devant quel français. »

L'occitan et le français sont deux langues latines marquées, selon l'expression de Philippe Gardy, par une "porosité réciproque ». Sans doute convient-il de concevoir le passage de l'une à l'autre en termes de glissements progressifs et de lente imprégnation sur une longue durée et selon les statuts socio-culturels. Et d'admettre des étapes intermédiaires d'interférence des deux langues.

Je conclurai en observant que la numérisation de l'ensemble de ce corpus sur Internet serait souhaitable, à condition cependant que chaque pièce soit accompagnée d'une notice de présentation, indispensable pour les resituer dans cette période très riche. Les travaux publiés il y un quart de siècle fournissent déjà beaucoup d'éléments, que certains de leurs auteurs pourraient d'ailleurs reprendre et enrichir. Il n'est point assuré qu'une autre langue de l'hexagone ait laissé un pareil ensemble, qui constitue un aspect particulièrement intéressant du patrimoine occitan.

\begin{abstract}
Résumé
La recherche et l'étude des attestations de la langue vernaculaire dans les écrits de la Révolution sont une des avancées du Bicentenaire. Ce corpus (225 écrits retrouvés ou mentionnés) est constitué de discours, adresses, libelles et faux cahiers de doléances, de traductions du français, de chansons - des couplets satiriques aux cantiques religieux et à l'hymne cérémoniel -, d'au moins une pièce de théâtre. La répartition spatiale est très inégale. L'essentiel se situe sur l'axe Toulouse-Montpellier-Avignon-Aix-Marseille et correspond aux sites majeurs d'impression occitane du XVII ${ }^{\mathrm{e}}$ au XIX ${ }^{\mathrm{e}}$ siècle. L'occitan a été présent dans l'écrit de la décennie révolutionnaire, sans doute davantage que dans un autre laps de temps comparable du XVIII ${ }^{\mathrm{e}}$ siècle. Mais il s'agit d'autant d'exceptions parmi les imprimés et les archives de la période. Cet ensemble révèle une situation diglossique plus avancée qu'on ne l'imagine en général. D'autre part la francisation de la langue vernaculaire elle-même paraît souvent forte.
\end{abstract}

36. Ph. Martel, «Au Nord, rien de nouveau» dans «Révolution, Contre-révolution. Le texte dialectal de la période révolutionnaire », p. 125-139 et R. Dartevelle, «La quête d'identité d'un déraciné en Révolution ». 


\section{Bibliographie}

AlÉN-GARABAto M. Carmen, Quand le patois était politiquement utile. L'usage propagandiste de l'imprimé occitan à Toulouse durant la période révolutionnaire, Paris, L'Harmattan, 1999, $192 \mathrm{p}$.

ANATOLE Christian et LAFOnT Robert, Nouvelle histoire de la littérature occitane, Paris, P. U. F., 1970, 2 vol., $847+$ III p.

BERTRAND Régis, "J.-B. Nalis ou les charmes discrets d'une littérature bilingue sous Louis XV », Lengas, revue de sociolinguistique, $\mathrm{n}^{\circ} 28$, 1990, p. 49-61.

BERTRAND Régis, «Un discours en provençal à Gardanne (Bouches-du-Rhône) pendant la période révolutionnaire », Provence Historique, t. L, fasc. 202, 2000, p. 471-474.

BERTRAND Régis, «Un prêtre provençaliste en Révolution, J.-J.-T. Bonnet. Nouvelles recherches sur l'auteur présumé du Nouhé deis San-culotos (Marseille, décembre 1792) ", Actes du colloque La Révolution vécue par la province, mentalités et expressions populaires en Occitanie, Puylaurens, 15-16 avril 1989, Béziers, C.I.D.O, 1990, p. 127-142.

BERTRAND Régis, GARDy Philippe, MERLE René, J.-B. Remuzat, La verita desplegado per un pouèto villageois (1790), La Seyne, Bulletin de la Société d'Études historiques du texte dialectal, $\mathrm{n}^{\circ} 2,1988,50$ p. [réimpression, édition critique et étude de ce récit versifié].

BOYER Henri et GARDY Philippe éd., «La question linguistique au Sud au moment de la Révolution française " (actes du colloque de Montpellier, 8-10 novembre 1984), Lengas, revue de sociolinguistique, $\mathrm{n}^{\circ} 17$ et 18, 1985, 480 p. [2 livraisons ; 22 communications].

Boyer Henri, Fournier Georges, Gardy Philippe, Martel Philippe, Merle René, PiC François, Le texte occitan de la période révolutionnaire (1788-1800). Inventaire, approches, lectures, Montpellier, Section française de l'Association Internationale d'Études Occitanes, 1989, 517 p. (Libraire du Bicentenaire de la Révolution française).

BOYER Henri et GARDY Philippe, Dix siècles d'usages et d'images de l'occitan. Des troubadours à l'Internet, Paris, 2001, L'Harmattan, 469 p.

BRANCA-ROSOFF Sonia et SCHNEIDER Nathalie, L'écriture des citoyens, une analyse linguistique de l'écriture des peu-lettrés pendant la Révolution française, Paris, Klincksieck, 1994, 306 p.

BRUn Auguste, La langue française en Provence de Louis XIV au Félibrige, Marseille, I. H. P., 1927, 167 p. (rééd. J. Laffitte, 1972).

CAMPRoux Charles, Histoire de la littérature occitane Paris, Payot, 1953, 239 p. (et réed. 1971).

DARTEVELLE Raymond, "La quête d'identité d'un déraciné en Révolution. Le prêtre Jacques Guérin de Ceillac (Hautes-Alpes), Le Monde Alpin et Rhodanien, 1993-1, p. 147-168.

Eygun Jean, Au risque de Babel. Le texte religieux occitan de 1600 à 1850, Bordeaux, Association du texte occitan, 2002, 533 p.

GuILHAUMOU Jacques et GARDY Philippe (dir.), Dictionnaire des usages socio-politiques (1770-1815), fasc. 5, Langue, occitan, usages, Paris, Klincksieck, 1991.

"L'invention du Midi. Représentations du Sud pendant la période révolutionnaire » (actes du colloque de Montpellier, 22-24 novembre 1985), Amiras/Repères occitans, $\mathrm{n}^{\circ} 15$ 16, 1987, 200 p. [13 communications]. 
MAURON Claude et EMmanuelli François-Xavier (dir.), Textes politiques de l'époque révolutionnaire en langue provençale I - Textes en prose (Discours, adresses, traductions), SaintRémy-de-Provence, Centre de recherches et d'études méridionales, 1986, 212 p. [ le t. II n'a pas paru].

MERLE René, Inventaire du texte provençal de la région toulonnaise. De la pré-révolution à la seconde République, La Seyne, G.R.A.I.C.H.S, 1986, 222 p.

MERLE René, L'écriture du provençal de 1770 à 1840. Inventaire du texte occitan publié ou manuscrit dans la zone culturelle provençale et ses franges, Béziers, Centre International de Documentation Occitane, 1990, 1027 p.

MERLE René, Une mort qui n'en finit pas. L'écriture de l'idiome natal de la fin de l'Ancien Régime à la naissance du félibrige, Nîmes, Marpoc, 1990, 215 p.

MERLE René, «Données nouvelles sur le texte provençal et les émeutes de mars-avril $1789 »$ Provence Historique, t. XL, fasc. 159, 1990, p. 111-117.

Merle René, Tramoni Antoine, Vovelle Michel, Toulon, 1789-1790. Étienne Pelabon et La réunion patriotique, La Seyne, Bulletin de la S.E.H.T.D., n 3, 1988, 64 p. [réimpression, édition critique et étude de cette pièce].

NOULET Jean-Baptiste, Essai sur l'histoire littéraire des patois du Midi de la France au XVIII ${ }^{e}$ siècle, Paris, Maisonneuve, 1877, III+233 p.

REBOUL Robert, Bibliographie des ouvrages écrits en patois du Midi de la France et des travaux sur la langue romano-provençale, Paris, Léon Téchener, 1877, III=85 p.

«Révolution, Contre-révolution. Le texte dialectal de la période révolutionnaire: Provence, Bas-Languedoc oriental, Dauphiné », Cahiers critiques du patrimoine (Obradors occitans en Provença), n² 2, 1986, 178 p. 


\title{
Antonin Perbosc à Comberouger : une expérience originale de défense de la langue d'Oc
}

\author{
Hervé TERRAL \\ Association Internationale d'études occitanes, \\ Université Toulouse II
}

\begin{abstract}
Extrait de : Guylaine BRUN-TRIGAUD (dir.), Contacts, conflits et créations linguistiques, Paris, Édition électronique du CTHS (Actes des congrès des sociétés historiques et scientifiques), 2015.

Cet article a été validé par le comité de lecture des Éditions du CTHS dans le cadre de la publication des actes du $139^{\mathrm{e}}$ Congrès national des sociétés historiques et scientifiques tenu à Nîmes en 2014.
\end{abstract} «Fondateur de l'occitanisme/Poète et réformateur de la langue d'oc/Pédagogue,
ethnographe, bibliothécaire/Majoral du félibrige (Cigale de la Liberté). »

Tel fut Antonin Perbosc selon la plaque bilingue qui lui rend hommage sur les murs de la Bibliothèque municipale de Montauban - où il acheva sa carrière administrative de 1912 à 1932 (à 71 ans, notons-le).

Né à Labarthe-en-Quercy le 25 octobre 1861 au lieu-dit «les Camps grands », d'une famille de «bordiers » (métayers), Perbosc a suivi l'enseignement de l'école publique de Vazerac, puis de la pension Gasc à Lafrançaise, avant d'entrer à l'école normale d'instituteurs de Montauban (avec 20 en français !) pour trois ans (1878 à 1881). C'est devoir souligner d'entrée qu'il appartient de facto à cette première génération de «hussards noirs de la sévérité, nourrissons de la République » dont Charles Péguy fit l'éloge dans L'Argent (1913), tout en regrettant dès cette époque leur disparition - Perbosc fut au demeurant un des rares abonnés des Cahiers de la Quinzaine d'une part et ferrailla d'autre part, comme Péguy, avec quelques figures autoritaires de l'administration scolaire.

Perbosc, mariée à sa consœur Marie Vidaillac, avec qui il aura une unique fille, Hélène, arrive à Comberouger à la rentrée 1893, à la suite d'une mutation administrative plutôt obscure : c'est déjà son $6^{\text {ème }}$ poste. Il quitte la bourgade de Laguépie dans le haut du département (il cède alors sa place à un cousin du maire) et prend pied en famille, pour quinze ans, dans ce qui lui apparaît dès son arrivée comme un "trou perdu » de la Lomagne de 441 habitants, situé à l'autre bout du petit département de Tarn-et-Garonne, si peu unifié géographiquement, créé de bric et de broc en 1808 seulement par Napoléon pour restituer à la ville de Montauban, capitale historique du Quercy, une dignité perdue en 1790 au bénéfice de Cahors ${ }^{1}$. Ce village paysan, de dialecte gascon traversé d'expressions languedociennes, est donc sur le plan linguistique un village-frontière, à mi-distance de deux bastides (Beaumont et Grenade), entre deux coteaux et sur les bords d'une petite rivière, le Lambon. Une légende, discutée, en fait la «combe rouge » à la suite d'un massacre local de moines, voleurs et violeurs, par la population (ses habitants gardent le sobriquet collectif de « canailles » plusieurs siècles après).

Perbosc va, dans ce village désormais fort paisible, cultiver ses chrysanthèmes ; membre du camp laïque, il va aussi initier son curé à... la photographie et il fera de la bicyclette -

1. Perbosc 1908. Dans sa préface, s'appuyant en partie sur la réflexion de son compatriote Jean Izoulet, professeur de philosophie sociale au Collège de France, il se montre plus attaché à l'idée de province ou de pays qu'à celle de département, bien trop artificielle à ses yeux. Selon lui, les départements auront disparu... en 2008 ! 
pour rejoindre la gare voisine de Dieupentale et partir vers Toulouse ou quelque ville organisatrice d'une Félibrée.

L'instituteur Perbosc s'est, en effet, déjà fait une petite renommée! Il n'est pas simplement un maître d'école ordinaire, formateur de cours d'adultes et secrétaire de mairie - toutes activités qui lui prennent quand même beaucoup de temps ! Dès le mois d'octobre 1886, il défend dans La Tribune des Instituteurs, journal indépendant de la hiérarchie scolaire, un «enseignement des patois »- et son article se voit cité par une petite dizaine de journaux (événement dont il se fait l'écho auprès de son ancien directeur d'école normale) $)^{2}$. Dès 1887, il est couronné par l'Académie de Montauban pour sa monographie de Lacapelle-Livron. Dès 1890, il est publié par le Bulletin de l'Instruction Primaire du Tarn-et-Garonne pour son Brinde al Carci e a sous félibres, pièce dont il dira plus tard qu'elle fut surtout didactique et applaudie à ce titre quand les auditeurs reconnaissaient le nom d'un auteur issu de leur village - lors même qu'il est sèchement rappelé à l'ordre dans la période par l'inspecteur d'Académie J. Pouillot, plus porté à l'enseignement des mathématiques, pour avoir «donné des devoirs en patois à ses élèves ». Dès 1892, il devient, soutenu par Mistral lui-même, un très jeune Majoral du Félibrige (Cigale de la liberté) : il succède alors à Auguste Fourès (1848-1891), journaliste et homme de lettres - il a assisté l'année précédente à ses obsèques civiles (maçonniques) à Castelnaudary (Aude), y rencontrant pour l'occasion l'homme, qui allait être, des décennies durant, une sorte d'alter ego, à tout le moins un frère d'armes et de cœur, l'instituteur audois Prosper Estieu (1860-1939). Dès 1889, il a fait par ailleurs la connaissance à Paris du romancier quercynois Léon Cladel (1835-1892), un « rouge » régionaliste, auteur d'un des rares romans portant sur la Commune (Inri). Dès 1890, il entre en correspondance avec un autre "pays » appelé à un grand avenir, le sculpteur Antoine Bourdelle (1861-1929), l'homme qui disait «sculpter en langue d'oc » (lettre à Perbosc du 19 juin 1914), avec qui il entretiendra un authentique dialogue artistique.

De 1893 à 1908, le modeste village de Comberouger devient le lieu où la pensée et l'œuvre de Perbosc vont s'affirmer à plusieurs titres.

\section{Au plan de la création littéraire}

Passé très tôt à la langue occitane (après avoir taquiné la Muse française, mais aussi castillane, dans sa jeunesse), Perbosc concevra dans notre village ses premières pièces majeures : Remembrança (1902), lo Gòt occitan (1903), l'Arada (1906) et, rare poème épique de notre époque, Guilhem de Tolosa (1908). Son œuvre posthume - annoncée dès 1903 et publiée... en 1970 seulement - résume dans son titre même sa perception du monde, Lo libre del Campèstre (Le Livre de la Nature). De même l'Arada, ressuscitant à partir de l'occitan le vieux mot français « l'arée » (la terre labourée) $)^{3}$, s'ouvre-t-elle par un poème au titre évocateur: Lauraires e troubaires (laboureurs et poètes) et un exergue conçu comme l'idéal d'une vie :

«A mos reires/los lauraires/qu'an virat e revirat/lo terraire,/ Que, trobaire, ai cantat e cantarai/tant que vivrai.

(À mes aïeux/les laboureurs/qui ont tourné et retourné/le terroir/que, poète,/ j'ai chanté et chanterai tant que je vivrai. »

2. Ce texte du 1-10-1886 et celui qui suivit, du 1-2-1887, ont été republiés par nos soins in Lengas, revue de sociolinguistique (Montpellier III), 2007, n62, p. 154-173. Nous y trouvons des phrases singulières pour un instituteur public: "Nous le répétons, ce n'est pas l'instituteur qui tuera la langue; mais par l'oeuvre lente de l'instruction les mots patois seront remplacés l'un après l'autre par les mots français auxquels seront adaptées la terminaison et la prononciation patoisante. »

3. Dans son pamphlet contre le ministre A. de Monzie, hostile à tout enseignement des langues régionales, Les langues de France (1926), Perbosc rappelle ainsi ce que le français doit encore... à la langue d'oc : « Un des plus nobles vocables occitans, c'est le nom du champ labouré : l'arada. La langue d'oïl avait le mot correspondant : L'arée, qu'on peut lire dans le Roman de la Rose ; il y a longtemps qu'il a disparu du dictionnaire, de même que beaucoup d'autres qu'employaient Amyot, Rabelais, Ronsard... Enfin Malherbes vint. C'est alors que les mots jugés rustiques, vulgaires, bas, disparurent... Place aux seuls mots 'nobles'. plus tard on a bien vu ce que la langue française avait ainsi perdu. » 
Il faudra attendre les années 1920 pour retrouver chez Perbosc le même souffle (Lo libre dels Auzels, 1924)... et une certaine reconnaissance en France (Prix Vignes de France 1932, partagé avec Paul Fort). Son œuvre était déjà connue ailleurs (traduction de ses Contes à Barcelone dès 1905).

\section{Au plan linguistique}

Avec l'ami Estieu, Perbosc s'efforcera de recourir à une langue d'oc à la fois proche des parlers populaires contemporains et de la tradition classique (Troubadours, auteurs du $\mathrm{XVI}^{\mathrm{e}}$ siècle), débarrassée de ses scories françaises accumulées au fil des siècles, de créer une graphie plus authentique à ses yeux que celle mise en avant par Mistral et son mentor Roumanille (ce qui lui vaudra quelques difficultés avec le Maître de Maillane). Il cherchera aussi à faire (re) vivre des mots proprement locaux, comme le mot «paragrilh» dans le conte intitulé La fille du Pellegrilleur (1900). Dans son courrier à Estieu (27-6-1900) ${ }^{4}$, Perbosc donne le mot patois dans ses variantes (parogrilh, parougrih, palagrilh), sa traduction (bêche) et précise :

«Ce mot n'existe, je crois, qu'en ce coin de Gascogne, je ne l'ai vu en aucune publication. »

Le 27 août 1900, il discute encore avec Estieu de l'origine latine et/ou ibère du «palagrilh». Mistral, qui, ne l'oublions pas était titulaire d'une licence de droit, parlera dans sa correspondance, à propos d'Estieu et Perbosc de «maîtres d'école perdus de vanité $»^{5}$. Perbosc situe alors ses travaux dans le sillage de quelques prédécesseurs locaux plus ou moins connus : le montalbanais Devais qui, dès les années 1840, entend donner à l'occitan une graphie normalisée, l'homme de lettres Mary-Lafon qui fonde "l'histoire du Midi de la France » (1845), le poète-meunier Castèla (1828-1907), un temps instituteur, le premier auteur patoisant dont il rencontra à quinze ans les Farinals (1850)... sous la forme de feuillets épars au vent, le publiciste et politique A. Fourès (1848-1891), avons-nous vu, véritable maître à penser fédéraliste de surcroît.

\section{L'expérience pédagogique proprement dite}

Dans sa monographie de Lacapelle-Livron (1886), Perbosc affirmait déjà dans la lignée des défenseurs de l'histoire locale (tel Ernest Lavisse lui-même ${ }^{6}$ ) :

«Le plus humble village a son histoire. Pour l'enfant, là commence la patrie ; là doit commencer l'enseignement historique de l'école. »

S'en suivait une étude détaillée répondant aux grandes catégories proposées par l'administration scolaire: situation, limites, physionomie générale, climat, curiosités naturelles, antiquités, population, langue, administration, culte, instruction primaire, mœurs et coutumes locales. Ce dernier point est déjà l'occasion d'un regret... qui annonce un projet :

«Mais tout cela s'en va; les naïves légendes, les vieilles chansons, les contes des bonnes veillées d'hiver. Encore quelques années et de tout cela il ne restera rien : l'originalité de ce coin du vieux Quercy aura disparu à son tour avec sa langue, ses mœurs quelque peu sauvages et la coiffure traditionnelle de ses paysannes, dernier vestige du costume local. »

\footnotetext{
4. La précieuse correspondance Perbosc-Estieu (de 1892 à 1939) a été conservée des décennies durant au Collège d'Occitanie de Toulouse (dont Espieu fut, avec l'abbé Salvat, le fondateur en 1927). Elle est désormais au CIRDOC de Béziers. Les deux hommes étaient convenus au soir de leur vie, pour des raisons non élucidées, de la faire disparaître : la descendance de Perbosc le fit, mais pas celle d'Estieu. Reste donc aujourd'hui la partie «Perbosc » essentiellement.

5. Lettre au Capoulié P. Devoluy du 3-2-1905, citée in Mauron (Claude), Frédéric Mistral, Paris, Fayard,1993, p. 327.

6. Cf. ses Discours aux enfants du Nouvion-en-Thiérache (Aisne) à la même époque.
} 
Un programme précis se fait alors jour, résumé en une simple phrase de sa correspondance avec Estieu : «Faire entrer la langue d'oc l'école » (27-8-1911). À cette fin sans aucun doute mais aussi plus encore par une sorte d'amour charnel avec le campèstre (la nature), Perbosc se lance dans l'aventure d'une authentique étude locale d'envergure. Ainsi présente-t-il son projet à Estieu, l'invitant (sans trop d'effet) à l'imiter :

«Si tu tiens à savoir ce que j'ai fait depuis octobre, apprends que j'ai folklorisé surtout. Et j'ai entrepris une œuvre originale que tu verras réalisée dans un an à peu près. En voici le plan :

Monographie d'un village

La Vie au village

Autrefois

Aujourd'hui

I - Le Folklore

1. Contes populaires

1. Aventures merveilleuses. Contes épiques.

Contes mystiques et superstitions.

Contes familiers.

Récits.

Poésies populaires

1. Romances.

2.Chansons d'amour.

Chansons de travail.

Chants spéciaux.

Chansons pour petits enfants.

Chants historiques.

Récitatifs, formules, etc.

Traditions et légendes.

Proverbes et locutions proverbiales.

Devinettes populaires.

Jeux populaires.

L'originalité, c'est que je ne suis que le directeur de ce travail d'équipe et que ce sont mes élèves, une quinzaine de garçons et de filles de dix à treize ans qui le font.

La première partie se déroulera sur une suite de petites monographies (100 environ) sur tous les sujets relatifs au terroir. Ce seront simplement des devoirs d'élèves bien coordonnés.

La deuxième partie est la plus avancée. On m'a recueilli jusqu'ici quatre-vingts contes, souvent informes, parmi lesquels (quelle surprise pour moi!) il y a des chefs-d'œuvre, certains inédits, tout cela est transcrit et traduit patiemment, et le bloc augmente tous les jours (Entre parenthèses, il y a jusqu'ici une quinzaine au moins de ces contes qui peuvent être publiés, et j'ai songé à la Revue des Pyrénées, à La Tradition...). Pour les proverbes et les devinettes, le travail est à peu près fini : il est important. Pour les poésies populaires, ça commence ; je ne compte pas trop sur ce filon ; mais j'aurais peut-être les mêmes surprises que pour les contes. »

Le 14 mai 1900, Perbosc réitère avec résolution :

«Je suis en plein dans mon folklore... et je suis de plus en plus émerveillé des contes que mes élèves recueillent, écrivent, traduisent et transcrivent avec autant de frénésie que moimême... C'est un travail formidable pour des enfants et un travail qu'un homme ne pourrait pas faire : témoin Bladé ${ }^{6}$ qui a passé sa vie à colliger des contes de Gascogne et qui n'a pas mis dans chacun de ses volumes ce que j'ai trouvé en trois mois... Je songe très sérieusement à faire imprimer un volume de Contes... Je fais noter ces contes en absolu

6. Jean-François Bladé (1827-1900), magistrat et majoral du Félibrige (1876), fut un grand collecteur de contes, légendes et chansons en Gascogne. 
patois de Comberouger. Il y a des morceaux bien plus scatologiques (que ceux cités). C'est à peine si nos terriens s'en doutent. Ils n'ont pas, eux, nos hypocrites pudeurs! »

Le 17 août, l'enthousiasme n'est toujours pas retombé :

«La première chose qu'il te faudra faire à ton nouveau poste, ce sera de fonder une société traditionniste. Celle que j'ai fondée ici, la première du monde, je suppose - fonctionne de puis janvier. Ses membres, au nombre de dix-huit, sont des enfants, garçons et filles, de huit à treize ans. Ce sont surtout les filles qui font d'excellentes folkloristes. »

En 1906 encore, Perbosc fera encore part de son enchantement :

« Je suis enfantinement heureux en leur société. »

Peut-on dire mieux?

Si le bilan proprement monographique est maigre (première partie), la collecte des «ethno-textes » est plus que conséquente: Perbosc fera paraître une partie du travail sous le titre Contes de la vallée du Lambon en 1914. L'innovation pédagogique aussi. La création de la société traditionniste dont les statuts sont déposés le 15 janvier 1900 et qui existera jusqu'au départ de Perbosc pour le bourg voisin de Lavilledieu-du-Temple (en octobre 1908) doit être considérée comme un modèle de communauté scolaire. Ainsi l'article 5 précise ainsi :

«La société fonctionne sous la direction de l'instituteur qui fait partie du bureau avec voix prépondérante $-1^{\text {er }}$ bureau comprend un président, un vice-président et un secrétaire. Ces trois derniers membres (des élèves) sont élus pour un an. ${ }^{7}$

Perbosc envisage aussi de créer une «fédération des sociétés traditionnistes scolaires du canton de Verdun-sur-Garonne» (13 septembre 1900) avec fête patronnée par le fédéraliste Jean Charles-Brun: il s'agit de "n'avoir pas l'air de faire une politique anticléricale tout en en faisant $»^{8}$, ajoute-t-il, pointant le bout de l'oreille... Mais il est vrai que c'est parfois auprès d'inspecteurs peu suspects de sympathie pour l'Église (et même en concurrence avec elle) que Perbosc et ses proches trouveront quelques échos bienveillants. Le linguiste Michel Bréal, à qui la République empruntait son point de vue vis-à-vis des patois, considérait déjà en 1872 que le maître d'école devait faire tenir son école au sol - comme les curés savaient si bien le faire avec leurs églises centenaires. Et ouvrir sa porte à des lectures de Jasmin ou Mistral... sans néanmoins enseigner leur langue $^{9}$ ! Dans sa correspondance, Perbosc semble par ailleurs indiquer le début d'une correspondance scolaire avec les élèves des écoles (d'Auvillar en Tarn-et-Garonne ?). En ce sens, s'inscrivant par son expérience de Comberouger dans l'esprit du Comte Tolstoï dont on peut penser qu'il a lu les œuvres pédagogiques diffusés en France dans les années $1900^{10}$, il annonce pleinement «l'éducation nouvelle » et, tout particulièrement, Célestin Freinet: ce dernier, informé par une jeune institutrice d'Abeilhan (Hérault), Hélène Cabane-Gracia, une des figures majeures de l'Institut d'Études Occitanes (créé en 1945) et de sa branche pédagogique (initialement dénommée de façon fort significative " groupe Antonin Perbosc »), reprendra ses options et fera publier des journaux scolaires en langue d'oc (La garba occitana, par exemple).

7. Les statuts de la Société traditionniste ont été déposés le 15 janvier 1900, in Bibliothèque d'étude et du patrimoine de Toulouse, manuscrit 1421, feuillet 66 et suivants, cités in Bru J 1987, préface.

8. Une partie de la correspondance de 1900-1901 porte sur le caractère plus ou moins "républicain », i.e anticlérical, des inspecteurs locaux, avec qui il faut composer : « Il faut affirmer, en effet, le Félibrige fédéraliste et libertaire ", disait Perbosc (lettre à Estieu, 12-9-1901).

9. Textes repris in Terral 2005, p. 129-135.

10. Tolstoï Léon, Articles pédagogiques. La revue «Iasnaïa-Poliana » 1862, (EEuvres complètes, T. XIII), Paris, Stock, 1905. 
Au-delà de son petit village d'adoption, comme ce travail mené à Comberouger n'est qu'une petite pièce dans l'activité polymorphe de l'auteur (poète, linguiste, essayiste, militant, etc.), la réflexion se poursuit sur des considérations devenues très actuelles un siècle plus tard :

«Le Félibrige me paraît tué aux trois-quarts, mais le traditionnisme gagne peut-être, et les idées de décentralisation aussi. Et encore la chance de voir se former les États-Unis d'Europe. Attention à ceci : alors refonte totale ou cataclysme. Émergeront peut-être, si des énergies le veulent, non pas la Provence, qui n'a que l'enthousiasme verbal, mais l'Aquitaine, le Languedoc, la Catalogne. C'est surtout en la Catalogne que j'ai foi. Autrefois il fallait des monts pour séparer les races, l'avenir fera peut-être des Pyrénées, au contraire, l'épine dorsale d'un État fondé sur des bases nouvelles, mais quel poids cette Espagne... Je n'achève pas l'ébauche de ce rêve. Que de choses dire là dessus! Une réalité domine : la plupart des langues mourront. Laquelle survivra? Il semble impossible que ce soit la nôtre et pourtant je vois des raisons de croire que c'est une fille du latin qui tuera l'anglais, l'allemand, le russe. Et pourquoi cette survivante ne serait-elle pas notre langue?»(A Estieu, 27-6-1900).

Le propos est, à l'évidence, utopique... et même erroné : l'école de Comberouger donne aujourd'hui des cours d'anglais aux jeunes élèves d'un village pris maintenant dans le grand orbe de Toulouse! Mais il prolonge à sa façon les toutes premières convictions de l'auteur :

«Dans notre dernière conférence pédagogique, j'ai combattu - seul contre tous - l'idée de... haine. Mais à part ça l'heure du cosmopolitisme n'est pas venue... Nous sommes une nouvelle école dans le Félibrige : non plus des séparatistes, mais des cosmopolites - ce qui en somme revient à peu près au même. Le Campèstre - 1'Humanité ! » (A Estieu, 1-6-1892).

C'est bien ce «campèstre » qu'Estieu saluait en envoyant à Perbosc une carte postale, après un séjour estival à Comberouger :

«En quitant Comba-Roger lo 12 d'Agost 1905

Val mai lo caminòl perdud demest lo bòsc/Que'l grand camin trop ufanòz, aigid e nud ;/ La floreta del prad que la roza del òrt./Una franca amistat que forse admiradors.

En quittant Comberouger, le 12 août 1905

Mieux vaut le petit chemin perdu au milieu du bois/Qu'un grand chemin orgueilleux, aisé et nu ;/ La fleurette du pré que la rose du jardin./ Une franche amitié que de nombreux admirateurs. $»^{11}$

\section{Résumé}

Antonin Perbosc (1861-1944), instituteur public, occupe parmi ses pairs une position originale. Dès 1886, il écrit dans la Tribune des Instituteurs, journal indépendant de la hiérarchie scolaire, un plaidoyer en faveur des «patois » qui le fait remarquer, tant il va audelà de la position officielle de relative tolérance portée par le professeur au Collège de France Michel Bréal (1872, 1878). Membre du Félibrige mistralien, ce maître quercynois va, de 1900 à 1908, conduire une expérience pédagogique (après la classe) de collecte de contes, chansons, proverbes, etc., avec ses élèves regroupés en une "société traditionniste " (i.e. folkloriste), donnant lieu à publication (1914), suscitant même l'admiration de l'Inspecteur général Édouard Petit, anticipant sur la démarche d'un Célestin Freinet. Ce faisant, il fonde de façon délibérée l'occitanisme culturel.

11. Poème manuscrit envoyé sur une carte postale à A. Perbosc, Bibliothèque municipale d'étude et du patrimoine de Toulouse, ms 1401, f. 19. 


\section{Bibliographie}

BRU Josiane, «Antonin Perbosc, ethnographe et poète (1861-1944)», introduction à A. Perbosc, L'anneau magique, Carcassonne, GARAE, 1987.

PERBOSC Antonin, Anthologie d'un centenaire, pages choisies des écrivains tarn-et-garonnais (1808-1908), Montauban, Masson éd., 1908.

Perbosc Antonin, Contes populaires de la vallée du Lambon, Montauban, Masson éd., 1914.

PERBOSC Antonin, Au país de la gata blanca. Contes populars, Toulouse, Letras d'òc, 2013.

TERRAL Hervé, La langue d'oc devant l'école, Puylaurens, IEO éd., 2005.

TERRAL Hervé, Antonin perbosc. Les langues de France à l'école, Canet-en-Roussillon, éd. Trabucaire, 2006. 


\title{
Une littérature en situation de diglossie: la littérature occitane vue par ceux qui l'écrivent
}

\author{
Marie-Jeanne VERNY \\ Professeur littérature occitane \\ Université Paul-Valéry-Montpellier 3, LLACS, EA 4582
}

\begin{abstract}
Extrait de : Guylaine BRUN-TRIGAUD (dir.), Contacts, conflits et créations linguistiques, Paris, Édition électronique du CTHS (Actes des congrès des sociétés historiques et scientifiques), 2015.

Cet article a été validé par le comité de lecture des Éditions du CTHS dans le cadre de la publication des actes du $139^{\mathrm{e}}$ Congrès national des sociétés historiques et scientifiques tenu à Nîmes en 2014.
\end{abstract}

Écrire en occitan en 2014 ? Ce fait peut surprendre puisque parmi les écrivains qui utilisent cette langue, aucun n'est monolingue en occitan. Pour la majorité d'entre eux, le français est la langue d'expression principale, et même parfois la langue première. La conscience du caractère paradoxal de ce choix est d'ailleurs souvent présente au cœur même des œuvres, où il n'est pas rare de lire des commentaires de type métalinguistique. D'ailleurs nos écrivains contemporains ont été précédés en cela par d'illustres personnages, depuis Pey de Garros au XVI ${ }^{\mathrm{e}}$ siècle qui évoquait sa «lenga mespresada » dont il voulait prendre la "causa damnada », expression reprise par Mistral au XIX ${ }^{\mathrm{e}}$ siècle, dès la strophe 2 de Mirèio :

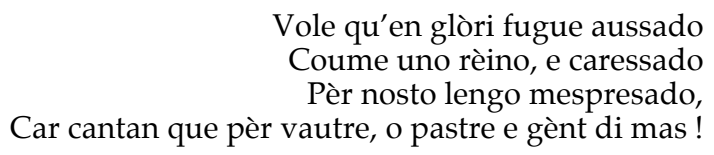

La conscience très ancienne de la situation diglossique de la langue occitane nous permet de relativiser le caractère incongru du choix que nous avons évoqué : Mistral, et encore plus Pey de Garros, écrivaient dans une langue certes intellectuellement et socialement minorée, mais parlée à leur époque par l'immense majorité de leur entourage. Et il y a là une des clefs pour comprendre le paradoxe : une population peut parler majoritairement une langue sans qu'elle juge celle-ci digne d'accéder à des usages nobles liés à l'écrit. À l'inverse, une langue peut cesser d'être majoritairement transmise et en même temps accéder à ces usages nobles par le biais de la création, littéraire ou musicale notamment. $C^{\prime}$ est globalement ce qui continue de se passer pour la littérature occitane au XXI siècle. Elle produit, annuellement, quelques dizaines de volumes de publications littéraires, de qualité inégale, dont les tirages sont bien évidemment réduits. Et parmi ces ouvrages, quelques belles réussites.

Ce sont les auteurs de ces ouvrages eux-mêmes que j'ai voulu interroger, grâce à un travail d'enquête dont j'ai commencé à traiter l'abondant matériau qu'il m'a permis de rassembler ${ }^{2}$. Ce matériau justifierait une publication intégrale ${ }^{3}$ tant sont riches les réponses fournies, et tant elles révèlent un besoin inassouvi d'échanger avec un lectorat parfois difficile à rencontrer. Ces premières analyses portent essentiellement sur le rapport de ces écrivains à la langue choisie, un choix paradoxal assumé.

1. «prener la causa damnada / de nosta lenga mespresada » : épouser la cause damnée / de notre langue méprisée, in «Epistòla au medish», transcription en graphie normalisée et traduction par Jean-François Courouau, Premiers combats pour la langue occitane. Manifestes linguistiques occitans, XVI ${ }^{\mathrm{e}}-\mathrm{XVII}^{\mathrm{e}}$ siècles, Pau / Anglet, Institut occitan / Atlantica, 2001, p. 55.

2. Un premier article «Le point de vue des auteurs. La littérature occitane vue par ceux qui l'écrivent: littérature périphérique ou littérature tout court? " a paru dans l'ouvrage Des littératures périphériques, sous la direction de Nelly Blanchard et Mannaig Thomas, Rennes, Presses Universitaires de Rennes, 2014, p. 137 - 156.

3. Cette publication devrait voir prochainement le jour sur le site du Centre Interrégional de documentation Occitane (http:/ / www.locirdoc.fr/). 


\section{Méthodologie de l'enquête}

Le questionnaire a été adressé à une cinquantaine d'écrivains, sans que soient pris en compte des critères qualitatifs. Seuls m'importaient leurs choix d'écriture dans une langue minorée. J'ai complété cette première série de données par des réponses fournies à Évelyne Faisse, une chercheuse qui a soutenu récemment une thèse sur la nouvelle d'expression occitane ${ }^{4}$.

1 - Vous avez choisi l'occitan comme langue d'écriture unique/majoritaire/non exclusive de l'emploi du français ou d'une autre langue (espagnol/catalan/italien/autre, préciser). Pourquoi ce choix ? S'est-il imposé dès que vous avez décidé d'écrire ? A-t-il été un choix raisonné, fait après le passage par l'écriture en langue majoritaire ?

2 - Qu'est-ce qui motive ce choix ? raisons militantes ? esthétiques ? affectives ?

3 - L'occitan est-il pour vous une langue apprise ? héritée ? reconquise ? par quels canaux l'avez-vous apprise ? école? démarche personnelle ? contacts avec locuteurs naturels? rencontre avec des modèles de littérature occitane ? Lesquels ?

4 - Avez-vous le sentiment de différences entre la langue héritée/apprise/entendue et votre propre choix linguistique quand vous écrivez?

5 - Le public: vous semble-t-il suffisamment existant? comment le rencontrez-vous ? à quel type de rencontres êtes-vous convié : événements «occitan (istes) »? événements artistiques ou littéraires généralistes ? rencontres avec des scolaires ou étudiants ? Quelles sont les attentes de ce(s) public(s) ? quels enseignements tirez-vous de ces échanges ? 6 - Les institutions liées à l'édition : vous est-il facile de vous faire éditer diffuser ? avezvous le sentiment que les maisons d'édition qui font le choix de l'occitan sont suffisamment aidées?

7 - Le rôle de la presse ? occitane? généraliste ? Vous semble-t-elle suffisamment ouverte à l'expression littéraire occitane?

8 - Les modèles ou influences littéraires que vous vous reconnaissez proviennent-ils exclusivement, en majeure partie ou partiellement de votre langue d'écriture choisie, du français, d'autres langues?

Les écrivains interrogés : origine et lieu de naissance

\begin{tabular}{|c|c|}
\hline Bach Xavier (1983, Castres) & Lassaque Aurélia (1983) \\
Bardou Franc (1965, Toulouse) & Laurent Sarah (1981, Nîmes) \\
Baris Miquèl (1947, Mont-de-Marsan) & Lavit Joan-Lois (1959, Hautes Pyrénées) \\
Barsotti Glaudi (1934, Marseille) & Mariot Jean François (1959, Decazeville) \\
Bonnet Albin (1980, Var) & Mathieu Guy (1949, L'Isle-sur-Sorgue) \\
Brun Jean Frédéric (1956, Montpellier) & Merle René (1936, La Seyne sur Mer) \\
Casanova Jean Yves (1958) & Miremont Brigitte (1947, Sarlat) \\
Chabaud Silvan (1980, Saint-Raphaël) & Offre Thierry (1959, Marseille) \\
Chadeuil Michel (1947, Agonac, Périgord) & Pallanca Michel (1958, Nice) \\
Courbet Jan Marc (1947, Camaret sur Aigues, & Pécout Roland (1949, Chateaurenard, \\
Vaucluse) & Bouches du Rhône) \\
Creissac Jean Paul (1955, Montpellier) & Peyras Bruno (1960, Quillan, Aude) \\
Daval Félix (1948, environs d'Aurillac) & Poitavin Matthieu (1975, Aigues-Mortes) \\
Decor Michel (1949, Bisan de Ménerbes - 11) & Privat Jacques (1953, Espalion) \\
Dupon Maëlle (1988, Montpellier) & Regourd Anna (1962, nord-Aveyron) \\
Figeac Frédéric (1958, Paris. Réside depuis & Rey-Bethveder Eric (1966) \\
l'enfance dans le Lot-et-Garonne) & Rey-Bethveder Nicolas (1972) \\
Forêt Jean Claude (1950, Lyon) & Rixte Marie Christine (1948, Valréas - 26) \\
Ganhaire Joan (1941, Agen) & Rouch Alan (Carcassonne, 1952) \\
Gayral Serge (1948, Castres) & Rouquette Yves (1936, Sète) \\
\hline
\end{tabular}

4. La nouvelle en occitan depuis 1970, entre réalisme et fantastique, Université Paul Valéry, Montpellier, 2010. Je remercie ici son auteure. 


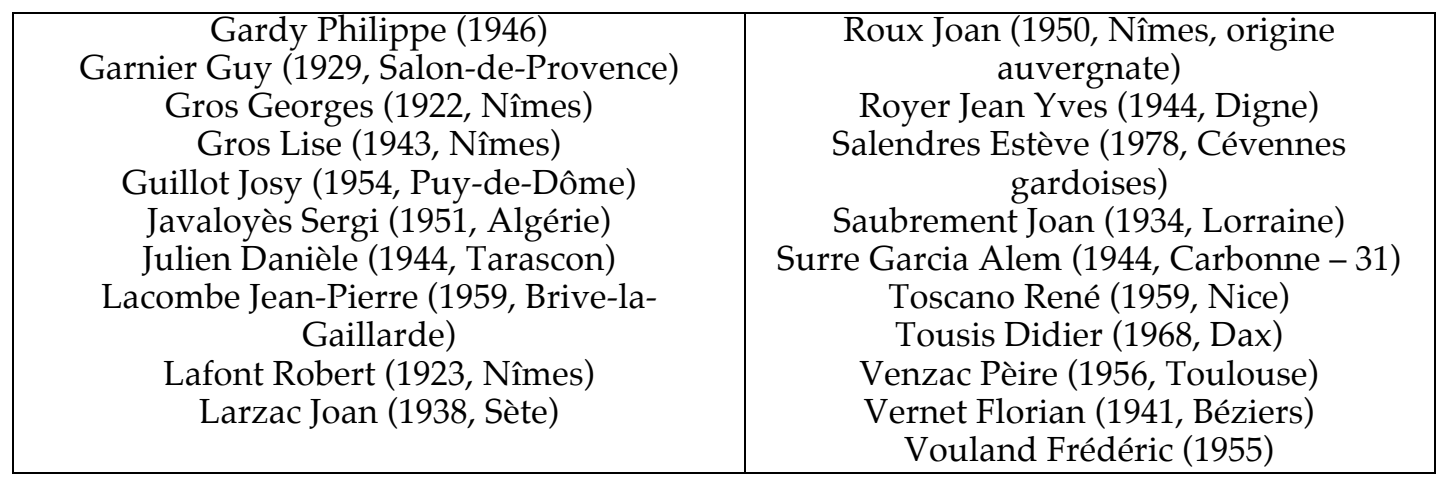

\section{Les écrivains interrogés : générations et provenances géographiques}

Six des écrivains interrogés sont nés après 1980, trois entre 1971 et 1980, six entre 1961 et 1970, seize entre 1951 et 1960, dix-sept entre 1941 et 1950, huit avant 1940. Ces données confirment la continuité du processus d'écriture en occitan. On pourrait a priori noter un renouvellement insuffisant des générations. Ce serait sans compter sur le fait que n'ont été interrogés que les écrivains ayant publié, la plupart, des ouvrages et pour une ou deux exceptions, des textes en revues. Un dépouillement systématique des revues littéraires ${ }^{5}$ révèlerait bien sûr d'autres personnalités d'écrivains en gestation.

Les réponses obtenues ne prétendent pas avoir valeur statistique. C'est la raison pour laquelle je me suis plus attardée sur le caractère qualitatif des réponses que sur le quantitatif.

Les provenances géographiques et les choix dialectaux révèlent une écrasante domination de l'espace occitan languedocien et provençal: vingt-deux écrivains écrivent en languedocien, vingt en provençal, six en gascon, ils sont deux pour l'auvergnat, le limousin et le niçois et un pour le vivaro-alpin. Certes, languedocien et provençal sont les deux dialectes démographiquement majoritaires, et le nombre d'écrivains gascons, rapporté à l'espace où cette forme dialectale est en usage, n'est pas négligeable. Cependant on notera la faible quantité d'écrivains dans les régions nord-occitanes. Si celles-ci sont moins peuplées, il n'en reste pas moins que nous avons une constante observable à travers l'histoire de notre littérature depuis l'époque moderne et que cette donnée, au $\mathrm{XXI}^{\mathrm{e}}$ siècle, recoupe la situation dramatique de la langue dans ces régions au niveau de l'enseignement, de la vie publique ou des médias, alors même qu'on y trouve le plus grand nombre de locuteurs naturels... Signe du paradoxe diglossique abordé en introduction.

Dans le cadre de cet article, je me suis limitée au regard porté par les écrivains sur l'acte de création et sur leur perception du public, éludant les questions de l'édition et du marché du livre, ainsi que de la réception critique, également présente dans le corpus. 


\section{Le choix d'une langue en situation de minoration: héritage et/ou apprentissage}

Plusieurs raisons expliquent le fait que des écrivains occitans utilisent une langue qu'ils ont dû apprendre ou réapprendre :

- écrivain d'origine non occitane : Forêt ou Javaloyès

- écrivain d'origine occitane, connaissant très peu ou pas du tout la langue : c'est le cas de la plupart des jeunes écrivains, nés après 1980

- écrivain d'origine occitane, ayant eu accès à la langue orale et apprenant l'écriture. Il s'agit du cas dominant.

Pour l'immense majorité des auteurs, l'accès à la langue est passé par les trois canaux, ce que l'on pourrait résumer ainsi :

- héritage, la plupart du temps inconscient

- reconquête, qui passe d'abord par la re-connaissance

- apprentissage de l'écriture de la langue, mais aussi imprégnation culturelle par la littérature écrite de l'occitan qui bénéficie de nombreux modèles prestigieux.

\section{Un héritage par effraction}

Si ce choix se fait, pour la plupart des écrivains, même les plus jeunes, à partir de la connaissance de la langue par héritage, l'accès à cet héritage ne va pas de soi, puisqu'il s'agit toujours de «l'autre » langue, à côté du français langue officielle. Autre langue qui souvent, d'ailleurs, ne porte pas un nom de langue, mais celui de «patois», terme employé par plusieurs écrivains, comme Matthieu Poitavin, qui évoque ainsi sa prise de conscience :

«La transmission s'est faite très tard : par l'observation et l'écoute de leur français mêlé au 'patois ', ou lorsque je les entendais rire, chanter, se disputer ou... vieillir puis mourir dans la langue. La première langue (très rude, très belle, sensible, amusante) qui revenait dans leur quotidien... Ce ' patois ' (ils ne savaient pas nommer la langue). Une langue si proche du délire du mourant, ensuite... Je regrette tellement de n'avoir pas filmé ou enregistré. Mais la pudeur m'en a empêché. »

Plusieurs témoignages évoquent ainsi un accès à la langue presque par effraction, contre la volonté des locuteurs eux-mêmes. Les années d'enfance de nos écrivains, pour les plus âgés, sont celles dans lesquelles le poids du syndrome de la répression par l'école avait conduit à l'arrêt de la transmission familiale de la langue. La situation dans les familles était celle de la coexistence de deux langues: celles des adultes entre eux et celle des adultes s'adressant aux enfants. Avec, très souvent, l'existence de grands-parents qui, n'étant pas investis de la fonction d'autorité éducative, pouvaient s'autoriser, parfois, le recours à l'occitan.

Pour tous les écrivains, il y a donc eu la nécessité de se refaire une langue à partir de lambeaux de langage. Les réponses recueillies constituent autant de récits d'émergence d'une conscience linguistique dont beaucoup mériteraient d'être ici reproduits, ainsi de ces lignes de Jean-Yves Royer :

«La reconquête a démarré au printemps 1960 (j'avais 15 ans 1/2) avec les stages du Calen de Marselha, puis avec aussi ceux de l'IEO à partir de 1963. Très vite, ils m'ont incité à me retourner vers ma grand-mère et à baragouiner en oc avec elle, avant d'en arriver à le parler normalement. Comme c'était sa langue maternelle, elle n'a eu aucune peine à me suivre. Finalement, les dix ou douze dernières années de sa vie, nous n'avons pas dû nous dire un seul mot de français. Elle avait d'ailleurs parfaitement compris ma démarche, et souvent me faisait part d'un mot, d'une expression, d'un proverbe, d'une chanson... qui venaient de lui revenir. » 
La sensation, diffuse ou clairement affirmée, d'une domination sociale d'une langue sur l'autre apparaît dans plusieurs témoignages, ainsi de Félix Daval :

«L'occitan èra la lenga dels vesins, del monde qu'èran coma mos parents. Lo francés quand ère pichon èra la lenga del monde crane, del monde plan vestits, del monde de la vila, del monde que mos parents devián anar veire dins los burèus, del curat e del mèstre d'escòla... del monde que mos parents semblavan considerar coma superiors, que per lor actitud tanben fasián veire qu'èran superiors. ${ }^{6}$

Le rapport complexe entre les langues est finement analysé par Silvan Chabaud, un des plus jeunes écrivains de notre corpus :

«Affectivement, l'occitan est une langue de ma famille mais une langue un peu 'cachée', celle du militant et du passionné et érudit qu'est mon père et celle des anciens, liée à la Provence où j'ai grandi, des lieux, des gens, des couleurs, des anecdotes, forcément ça joue beaucoup. Affectivement c'est la langue de mon 'blues ', ce folklore dans le sens de science du peuple: une musique qui m'accompagne depuis tout petit, mais en dessous de l'autre musique, celle du français. Donc une musique fascinante par sa rareté et sa capacité à passer à travers les portes et les murs de l'inconscient. »

\section{Paradoxes de la reconquête}

La langue de l'écriture, pour Alan Roch, est «la lenga de l'ostal réappropriée et reconquise ". Cette formule résume bien un processus de reconstruction qui s'exprime dans la majorité des réponses, reconstruction souvent passée, paradoxalement, par le biais de l'école :de nombreux écrivains ont su que le «patois » environnant était une langue quand l'école - ou l'université - le leur a enseigné : c'est le cas d'Yves Rouquette qui a eu Robert Lafont comme professeur de collège, mais aussi de Baris, Chadeuil, Chabaud, Courbet, Creissac, Daval, Decor, Figeac, Gardy, J. Guillot, D. Julien, Larzac, S. Laurent, Lavit, Mathieu, Offre, Poitavin, A. Regourd, Roux...

Sarah Laurent (née en 1981), raconte ainsi le rôle de l'école :

« Je dirais qu'effectivement l'occitan est une langue reconquise dans mon cas. On parlait une espèce de francitan dans la famille. L'arrière-grand-mère maternelle le parlait comme langue première. J'ai eu des rudiments en maternelle où il y avait un grand projet pédagogique sur 'Lo Drac ' qui m'avait marquée. Mon premier mot appris en primaire était 'Lo Pregadieu' (la mante religieuse). Le déclic définitif s'est fait au lycée où j'ai commencé à l'apprendre. »

Quant à la plus jeune de nos écrivains, Maëlle Dupon, ses seules références linguistiques lui viennent de sa scolarité en Calandreta ${ }^{8}$, puis de son passage à l'Université.

Autre paradoxe: c'est la plupart du temps une expérience d'exil qui a permis aux écrivains de choisir la langue méprisée. L'exil est - presque - toujours social : des écrivains d'humble origine, majoritairement paysanne, accèdent à un statut plus élevé, souvent d'ailleurs celui d'enseignant (au moins 26 enseignants dans notre corpus). Il est aussi, souvent, géographique, comme cela a été le cas pour Lafont, Pécout, Gardy, Garnier, Gayral... Et c'est le contraste avec une autre réalité qui fait surgir à la conscience l'occitanité latente, comme le formule Serge Gayral :

«Lorsque j'ai été envoyé dans l'est de la France pour enseigner l'espagnol, j'ai pris conscience peu à peu d'une anomalie dans mon parcours. J'allais enseigner une langue étrangère, l'espagnol, et la langue de ma terre, l'occitan, m'était en grande partie étrangère. »

6. «L'occitan était la langue des voisins, des gens comme mes parents. Le français quand j'étais petit était la langue des gens élégants, bien habillés, des gens de la ville, des gens que mes parents devaient aller voir dans les bureaux, du curé et du maître d'école, des gens que mes parents semblaient considérer comme supérieurs, et qui par leur attitude faisaient aussi voir qu'ils étaient supérieurs. »

7. Langue de la maison.

8. Écoles associatives occitanes de statut privé. 
La plupart du temps, les écrivains soulignent le rôle de la littérature dont la révélation a été, pour l'immense majorité, le déclic qui leur a permis de sortir de la honte. C'est ce qu'exprime Mariot :

« Il serait plus « naturel » que j'écrive en français (ma langue quotidienne) et non en occitan (langue à la fois de la grand-mère, des vieux de quand j'étais petit et d'une littérature dont la découverte a été un coup dans mon plexus...) par ce qu'elle disait de franchement différent, par ce qu'elle représentait symboliquement face à l'idéologie du «patois » dans laquelle j'étais plongé avant de la découvrir. »

Le plaisir de la lecture est souvent lié au besoin de puiser dans la littérature les leçons de langue que les écrivains ont du mal à trouver dans les résidus de pratique orale de celleci. Un manque ressenti souvent douloureusement :

«J'entends toujours, dit Gardy, mais de plus en plus lointain, au fond de ma mémoire, l'occitan hérité quand j'écris. Mais j'entends aussi celui des rencontres faites par la suite, et celui des livres, bien sûr. Tout cela a dû se mélanger au fil des années ; mais j'ai longtemps veillé à ne pas me couper de l'occitan 'naturel '. Ce n'est plus du tout le cas maintenant: je ne l'entends plus nulle part, et je ne connais plus de personnes encore capables de le parler. Il m'arrivait encore parfois il y a quelques années d'écouter des enregistrements que j'avais faits autrefois, non pas pour 'recueillir' des mots, de la langue, mais pour le seul plaisir de l'entendre « couler», et d'en conserver le souvenir. »

Ainsi, l'expérience relatée par Mariot est-elle partagée de façon presque unanime. Même si le terme de "modèle » employé dans le questionnaire est souvent réfuté, les écrivains revendiquant la recherche de leur propre voix, ils se situent cependant dans cette communauté rassurante de la littérature occitane qui a légitimé leur choix. Pour certains, comme J.F. Brun, la découverte de la littérature a même précédé le contact avec des locuteurs naturels, passionnément recherchés ensuite, et mis en scène dans l'œuvre, comme dans cette première page du recueil Lo temps clar de las encantadas ${ }^{9}$ :

«Es per aquí que me cau començar: lo Mejanèl. Sèm en 1977. Vèspre ventós d'ivèrn. Escotam. Tenèm nòstre alen. Lo vièlh pastre Edmond nos conta en occitan lo passat, las legendas... $»^{10}$

Parmi les phares qui légitiment la création contemporaine, les grands ancêtres sont souvent évoqués, à commencer par les troubadours, nommés par quatre écrivains, ou les baroques (notamment Bellaud et Zerbin), suggérés dans trois réponses. Le Félibrige est aussi une référence incontournable, avec une prédominance de Mistral (7 occurrences, mais aussi D'Arbaud (5), le gascon Camélat (4) ou encore Aubanel, évoqué par un écrivain.

Sans surprise, au $X X^{\mathrm{e}}$ siècle, apparaissent les grandes figures de Jean Boudou/Joan Bodon (34 occurrences), Max Rouquette (25), Robert Lafont (23), Bernard Manciet (15), Yves Rouquette (11), ou Marcelle Delpastre (11).

D’une manière générale, les écrivains occitans, s'ils sont rares à n'avoir eu aucun contact avec la langue orale, sont avant tout de grands lecteurs. Le nombre total d'écrivains cités est considérable et s'accompagne, ça et là, de considérations sur les œuvres, ainsi de ces propos de Frédéric Figeac :

«Les grands modèles! Le Max ${ }^{11}$, d'abord, de ceux qui te donnent des ailes et te confirment que la Grèce c'est aussi chez nous ; Manciet, au hasard d'une librairie ( « un ivèrn »), de ceux qui te coupent les bras; la Marcelle ${ }^{12}$ enfin que je regrette de ne pas avoir eu le culot d'aller

9. Puylaurens, IEO / IDECO, 2005.

10. C'est par là qu'il me faut commencer : le Méjanel [N.dT. : hameau de la vallée de la Buège, dans l'Hérault]. Nous sommes en 1977. Soirée ventée d'hiver. Nous écoutons. Nous retenons notre souffle. Le vieux berger Edmond nous raconte en occitan le passé, les légendes.

11. Il s'agit, bien sûr, de Max Rouquette.

12. Marcelle Delpastre. 
voir avec ma grand-mère! Mais le premier des passeurs, ce fut Boudou, à la fois si simple et si compliqué...»

ou de Franc Bardou :

«Parmi les Occitans modernes, [...] je suis très impressionné par les nouvelles d'Yves Rouquette, la force désespérée de Jean-Marie Pieyre, la plume raffinée de Michel Miniussi, et je reste fasciné par la puissance évocatoire, voire invocatoire, de Bernard Manciet. »

\section{Refus de l'enfermement}

\section{Un plurilinguisme revendiqué}

Nous avons souligné les chemins multiples qui mènent à l'écriture occitane. On ne le répétera jamais assez: si les écrivains sont unanimement fiers de s'inscrire dans une tradition prestigieuse, ils disent aussi le refus des enfermements identitaires ou des replis passéistes dans lesquels les préjugés voudraient enfermer les littératures en langues minoritaires, justifiant ainsi, sans vergogne, des siècles de mépris. Interrogés sur leurs lectures et leurs influences culturelles, les écrivains révèlent des curiosités multiples et refusent ce que Casanova appelle « renfermement confinant au moisi ».

On remarquera d'abord que plusieurs d'entre eux, en plus du français et de l'occitan, pratiquent une ou plusieurs langues étrangères (parfois des langues anciennes). Leur œuvre est d'ailleurs souvent marquée de cette polyphonie : La Festa ${ }^{13}$, de Lafont, contient des pages en italien, français, allemand, comme Casanova inclut du catalan dans Cap de Creus $^{14}$, ou Mariot de l'amazigh, de l'anglais, de l'espagnol, de l'italien dans Fax/Faxes ${ }^{15} . .$. Le même Mariot anime, à Decazeville, depuis plusieurs années, une fête des langues du monde, dans le sillage du Forum des langues de Toulouse, créé par le musicien Claude Sicre.

Beaucoup d'écrivains (un quart de notre corpus) connaissent des langues de la péninsule ibérique - que certains, Vernet ou Gayral, par exemple, ont enseignées - et révèlent un processus compensatoire : il n'est pas rare de voir l'interdiction des emplois « nobles » de l'occitan compensé par l'apprentissage de $\mathrm{l}^{\prime}$ espagnol ${ }^{16}$. Mais d'autres langues sont aussi connues et pratiquées, l'italien par Gros ou Toscano, le grec moderne par Forêt, l'anglais par Sarah Laurent ou Marie-Christine Rixte...

Ce n'est pas un hasard si plusieurs écrivains ont été confrontés dès l'enfance au plurilinguisme, eu sein de la famille, qui a pu se doubler d'une famille d'accueil chez Javaloyès :

«C'est une langue entendue dans une famille béarnaise conversant toute la sainte journée en "patois" comme ils disaient alors, qui m'a accueilli lorsque je suis arrivé seul d'Oran, en octobre 1961, à Nay. Je l'ai comprise très rapidement, je me suis vu dans l'obligation inconsciente de l'apprendre (comment aurais-je pu faire autrement ?) puisque je possédais le castillan et le catalan-valencien de ma grand-mère maternelle, des tantes qui échangeaient dans cette langue à Oran, en Algérie. »

Ce plurilinguisme familial - parfois conflictuel - est aussi le cas de Royer :

13. La Festa. Lyon-Paris-Montpellier, Fédérop - Le Chemin vert - Obradors, 1983-84. Libre 1 : Lo Cavalier de Març, 1983. 470 p. Libre 2 : Lo Libre de Joan, 1984 ; La Fèsta. 3 : Finisègle. Église-Neuve d'Issac, Fédérop.

14. Jorn, Montpeyroux (34), 1999.

15. Oc, coll. « Passatges », Nice, 2006.

16. Je dois confesser que cela a été mon cas. 
«Mon père était lorrain et jusque-là c'était lui qui dans la famille avait fait les plus longues études (il avait le Brevet!). Il détenait le savoir linguistique, et finalement le savoir tout court. Il reprenait ma mère quand elle faisait une faute de français (par exemple quand elle articulait le «1» final de «fusil», ce qui, paraît-il, ne se fait pas), alors que lui n'était jamais parvenu à prononcer convenablement lo Viou ou même la Fònt de Lòna... Lorsque moi, qui étais lycéen, puis étudiant, je me suis mis à l'école de ma grand-mère, c'est elle qui est devenue la référence en la matière et la détentrice du savoir. [...] Mais cela serait une longue histoire à raconter... [...] D'autant que ma famille paternelle était de la Lorraine germanophone. Autrement dit, aucun de mes quatre grands-parents n'avait eu le français pour langue maternelle. Je n'ai d'ailleurs réalisé que tout récemment que mon père, de 1915, était né Allemand... »

Apaisée, en revanche, la situation de Jean Roux :

«Enfant, je parlais français avec mes parents, mais c'est le franco-provençal savoyard qui régnait en maître chez mes grands-parents maternels, et l'occitan d'Auvergne dans ma famille paternelle. C'est probablement cette pluralité et cette mixité linguistique (ma grandmère maternelle parlait également allemand et piémontais) qui fit de moi un militant viscéral de l'occitanisme et de toutes les langues minoritaires et menacées. »

\section{Des influences esthétiques multiples}

L'influence des classiques, à côté d'écrivains contemporains, est ainsi exprimée par Xavier Bach :

«Ovidi e Vergèli, Klaus Mann e Bernat Manciet. Los ancians per la rigor plegadissa de lor tecnica, en particulièr una mesura dins l'utilisacion de la metafòra, una attencion a la musica de la lenga (mai benlèu a quò de Vergèli, que balha a las consonantas, coma o fa Manciet, una importància quasi arquitecturala). ${ }^{17}$

Matthieu Poitavin, quant à lui, revendique l'influence de langages qui dépassent la question identitaire :

«Mes modèles sont cinématographiques. Ils s'inspirent aussi de l'art contemporain. De la BD. De la chanson. Du roman populaire. Ces Arts dépassent toute problématique d'identité. Sinon on n'écrit plus... La seule question de l'identité ne peut suffire à une création. »

Entre ces deux extrêmes, que nous avons choisis précisément parce qu'ils appartiennent à la même génération, les références sont éclectiques, un éclectisme ainsi revendiqué par Silvan Chabaud :

"Comme dans la musique, il est important que la création occitane écoute le monde et essaie ensuite d'y apporter son grain de sel, j'ai d'ailleurs remarqué que beaucoup d'écrivains étrangers et de renom se sont intéressés de près ou de loin à notre langue, notre littérature, il y a donc un dialogue à établir. [...] j'essaie maintenant de ne pas trop lire de littérature occitane parce que souvent on revient sur les mêmes choses et c'est normal ! C'est dur d'oxygéner notre univers, de sortir des sentiers battus, c'est pourtant ce qu'il faut faire pour que notre création reste pertinente et originale. »

\section{E mai encara canta}

Lo paure merlhaton... ${ }^{18}$

C'est ainsi que Joan Bodon termine son Libre dels grands jorns, dans lequel beaucoup ont voulu lire une fable de la fin, de la mort du narrateur, comme de la mort de la langue. Il me plaît, quant à moi, d'y voir une fable du refus têtu de la fatalité.

17. Ovide et Virgile, Klaus Mann et Bernard Manciet. Les anciens pour la rigueur souple de leur technique, en particulier une mesure dans l'utilisation de la métaphore, une attention à la musique de la langue (plus peutêtre chez Virgile, qui donne aux consonnes, comme le fait Manciet, une importance presque architecturale). 18. Et pourtant il chante toujours, le pauvre petit merle... 
Les écrivains qui nous ont confié leur réflexion sont d'une grande lucidité par rapport à leur choix paradoxal d'une langue que l'on voudrait condamner au nom des lois du marché des langues. Que des jeunes gens prennent ou reprennent la plume, en 2014, dans une langue que 1000 ans d'ignorance n'ont pas réduite au silence, et qu'ils le fassent dans une tranquille adhésion au concert des voix du monde, n'est-ce pas le signe du refus de la fatalité ?

\begin{abstract}
Résumé
Depuis Pey de Garros au XVI ${ }^{e}$ siècle qui évoquait sa « lenga mespresada » (expression reprise par Mistral au XIX ${ }^{\mathrm{e}}$ siècle), les écrivains occitans ont manifesté, au cœur de leurs écrits, parfois dans le paratexte, la conscience douloureuse de l'état de minoration sociolinguistique où se trouvait leur langue d'expression, cette prise de conscience étant la plupart du temps associée à des discours compensatoires faisant allusion à l'expressivité sans égale de la langue employée. Le phénomène a été depuis les dernières décennies, bien analysé par les historiens de la littérature (Lafont, Gardy, Courouau...).

$\mathrm{Qu}^{\prime}$ en est-il de ceux, nombreux, qui écrivent encore au XXI ${ }^{\mathrm{e}}$ siècle ? Beaucoup d'entre eux sont aussi, parallèlement à leur pratique d'écriture, des chercheurs au fait des découvertes de la sociolinguistique et par là même, ils ne peuvent pas ne pas avoir conscience des mécanismes auxquels nous faisons allusion, alors même que la pratique "naturelle » de la langue ne cesse de baisser, mais aussi que se construisent, parallèlement, de nouveaux espaces d'expression linguistique et/ou artistique (écoles bilingues, chanson, théâtre, vidéo, blogs...).

Nous avons adressé un questionnaire à une cinquantaine d'écrivains sur leur itinéraire biographique, et c'est à partir des réponses reçues que nous essayons d'analyser le regard que portent sur eux-mêmes ces écrivains.
\end{abstract}




\section{Compléments bibliographiques}

Giovanni AGRESTI, «Parcours linguistiques et culturels en Occitanie (1996-2006). Enjeux et avatars d'une langue-culture minoritaire européenne", Quaderni di Linguistica e Linguaggi specialistici dell'Università di Teramo, 2006.

Jean-Claude FORÊT et James SACRÉ, "L'aujourd'hui vivant de la littérature occitane, Triages, éditions Tarabuste (rue du Fort, 36170 Saint-Benoît-du-Sault).

Georg KREMNITZ, "Conditions psycholinguistiques et sociolinguistiques de l'écriture occitane actuelle», in Philippe GARDY - François PIC (éds.), Vingt ans de littérature d'expression occitane. 1968-1988, Actes du Colloque International (Château de Castries, 2528 octobre 1989), S.F.A.I.E.O., Montpellier 1990, p. 17.

\section{Enquêtes antérieures}

Òc 209 - juillet-décembre 1958. Rubrique «Opinions - Accion populara»: enquête auprès de Jaume Bosc, Pèire Roqueta, Enric Pinhet.

Òc 223 - genièr març 1962 - enquête «Folklore et littérature d'òc » : Bodon, Camprós, Gouzy, JS Pons, Max Roqueta.

Letras d'òc, 4, décembre 1965: "Entrevista amb Enric Espieu e Joan Larzac», per C. Rapin, p. 1-4.

Letras d'òc, 7, julhet-agost-setembre de 1966: «Enquèsta » al prèp de Bodon, Cosem, Gardy, per C. Rapin, p. 1-4.

Viure, 7, auton de 66 : «Santat o fin dels temps », enquête auprès de Delteil, S. Brest, Max Roqueta, Sèrgi Bec, L. Còrdas, R. Allan, Camprós, Pèire Bec, Ives Roqueta, Robert Lafont, Re. Nelli, P. Fabre, B. Lesfargas, E. Gracia, E. Espieut, p. 2-32. 


\title{
Les politiques linguistiques en Alsace et la régression du dialecte
}

\author{
Marie-Noële DENIS \\ Chargée de recherche CNRS retraitée
}

\begin{abstract}
Extrait de : Guylaine BRUN-TRIGAUD (dir.), Contacts, conflits et créations linguistiques, Paris, Édition électronique du CTHS (Actes des congrès des sociétés historiques et scientifiques), 2015.

Cet article a été validé par le comité de lecture des Éditions du CTHS dans le cadre de la publication des actes du $139^{\mathrm{e}}$ Congrès national des sociétés historiques et scientifiques tenu à Nîmes en 2014.
\end{abstract}

« Le langage est aussi une patrie » Julien GREEN.

La langue majoritairement parlée en Alsace depuis les invasions barbares est un dialecte germanique $^{1}$ et la frontière linguistique avec les langues romanes n'a pas varié depuis un millénaire. Mais depuis trois siècles, les vicissitudes historiques ont imposé aux Alsaciens tantôt le français, tantôt l'allemand, comme langue officielle.

\section{Les politiques linguistiques en Alsace depuis le XVII siècle}

\section{Sous l'Ancien Régime, l'indifférence}

L'Alsace, rattachée à la France lors des traités de Westphalie (1648), se voit imposer le français dans l'administration. Mais Louis XIV, suivant le principe de «ne pas toucher aux choses d'Alsace ", n'engage pas une politique de francisation. Néanmoins le conseil d'État de 1685 ordonne l'usage de la langue française dans les actes publics «par affection pour le roi ». Le français ne devint pas pour autant la langue de l'école; il ne fut imposé que dans le système juridique.

$\mathrm{Au} \mathrm{XVIII}$ e siècle, le français demeura la langue usuelle des immigrés, officiers et fonctionnaires, suivis par l'aristocratie et la haute bourgeoisie locales. La petite bourgeoisie, les commerçants, et même les savants, y étaient hostiles et les masses populaires, surtout à la campagne, continuaient de parler le dialecte. En 1789, moins de 2000 Alsaciens s'exprimaient en français dans toute la province.

\section{L'échec de la politique linguistique de la Révolution}

Les principes révolutionnaires se devaient d'imposer l'assimilation linguistique de l'Alsace. Au nom de la liberté il était interdit de parler la langue des peuples encore asservis, et la nécessité de connaître la loi imposait la maîtrise du français. Au nom de l'égalité, il fallait apprendre la langue des privilégiés. Enfin l'unité de la nation justifiait son unité linguistique qui constituait un des éléments essentiels de la cohésion nationale. Apprendre le français aux Alsaciens fut considéré comme un devoir patriotique, l'allemand étant la langue de la contre-révolution et de l'ennemi.

Dès 1791, l'enseignement du français fut obligatoire dans les écoles primaires, injonction

1. P. Lévy, Histoire linguistique de l'Alsace. Les linguistes distinguent, au sud, le haut alémanique, au centre, le bas alémanique, et à l'extrême nord, le francique. 
sans doute peu efficace puisque renouvelée en 1793 et 1794. La loi du 2 thermidor an II (20 juillet 1794) imposa la langue nationale pour la rédaction des actes publics et privés. En 1794, Strasbourg et d'autres villes changèrent le nom des rues et adoptèrent les enseignes des magasins en français.

Cette politique échoua, mais néanmoins deux idées survécurent :

- La nécessité de la mise à contribution de toutes les ressources de l'État, en particulier de l'enseignement, pour faire triompher la langue officielle.

- La relation entre langue, politique et sentiment national.

\section{Les débuts du nationalisme linguistique}

Après la Révolution, l'usage du français ne progresse pas en Alsace. L'allemand reste la langue de la littérature, des cultes, de la presse, des ouvrages scientifiques. À l'école, le peuple, qui parle toujours le dialecte, ne veut pas apprendre le français, qualifié de «langue des riches ».

Dans un premier temps les gouvernements s'en préoccupent peu. Qu'on se rappelle à ce sujet les paroles historiques (?) de Napoléon à propos des soldats alsaciens :

«Qu'importe qu'ils parlent allemand, pourvu qu'ils sabrent en français. »

Néanmoins, à partir de 1848, l'agitation patriotique qui accompagne le réveil de l'Allemagne, assimile langue et nation. Cette instrumentalisation de la langue, devenue enjeu politique, est soutenue par l'écrivain et philosophe Johann Gottfried Herder : pour lui, la langue est l'expression de l'esprit d'un peuple. Ces idées font craindre en France, et pour l'Alsace, des revendications annexionnistes. Une politique de développement du français est donc activement menée, sous le second Empire dans le domaine scolaire : la langue française gagne effectivement du terrain dans les programmes de l'enseignement primaire jusqu'à éliminer complètement l'allemand. Néanmoins en 1864 dans le HautRhin, $17 \%$ des enfants scolarisés ne parlent pas le français et $16 \%$ le parlent mais ne savent pas l'écrire. Mais l'usage du français progresse dans la bourgeoisie locale au contact de la population immigrée, puis dans le peuple.

\section{La germanisation forcée (1870-1918)}

L'annexion à l'Empire Allemand fut justifiée en partie par des arguments linguistiques, bien que la nouvelle frontière intégrât des populations de langue française ${ }^{2}$. $\mathrm{D}^{\prime}$ où une politique d'assimilation vis-à-vis des populations francophones et dialectophones. En 1871, l'allemand devient la langue obligatoire de l'école primaire et, en 1874, les écoles des zones françaises se voient imposer un enseignement bilingue. En 1872, la langue de l'Empire devient la langue officielle de l'administration, sauf pour les communes de langue française qui bénéficient d'un sursis. En 1875, une loi impose l'état civil en allemand et l'on traduit les prénoms. La langue allemande s'impose dans tous les aspects de la vie publique : nom des localités, nom des rues, enseignes, presse, édition... Cette germanisation progresse rapidement $\mathrm{du}$ fait de la proximité linguistique du dialecte, Elsässerditch, et de l'allemand standard, ou Hochdeutsch. L'évolution lente en faveur du français, constatée entre 1830 et 1860, régresse.

\section{La politique de francisation après la Première Guerre mondiale}

Après 1918, la France impose brutalement l'usage du français dans l'administration, dans l'espace public, et surtout dans l'enseignement. Les circulaires Charléty (1920) et Pfister (1927) réintègrent le français à l'école, et les instituteurs locaux doivent aller suivre des stages dans les écoles normales de «l'intérieur».

2. La distorsion est évidente pour le nord de la Lorraine où la frontière incluait partiellement des populations francophones, mais situées sur un bassin minier fort convoité. 


\section{L'épisode nazi (1940-1944)}

Entre 1940 et 1944, l'usage du français est interdit et sévèrement réprimé. Toute une génération apprend de nouveau l'allemand sur les bancs de l'école, et le nazisme va bouleverser le rapport des Alsaciens avec leur langue.

\section{Le retour à la France}

En 1944, se met à nouveau en place une politique brutale de francisation. Le dialecte et l'allemand sont frappés d'indignité nationale et il devient "chic de parler français ${ }^{3}$ (fig. 1). Néanmoins le bilinguisme est maintenu dans les formulaires administratifs, les affiches électorales, et la presse bilingue tolérée. L'enseignement est francisé avec l'appui du très puissant syndicat des instituteurs (SNI) et la radio nationale réinstallée dès 1944, malgré des efforts pionniers pour la promotion du dialecte.

Depuis lors, la situation s'est assouplie et les lois scolaires ont donné l'exemple. En 1951, la loi Deixonne accordait un statut aux langues et dialectes locaux, mais le flamand, le corse et l'alsacien, considérés comme allogènes, en étaient exclus. En 1952 est mis en place en Alsace un enseignement facultatif de l'allemand pendant les deux dernières années de l'école primaire. Assuré par les instituteurs selon une méthode adaptée aux enfants dialectophones, il est peu efficace pour les autres. En 1975, la loi Haby institue un enseignement des «langues et cultures régionales », mis en application en Alsace par une circulaire rectorale de 1982. Le recteur Deyon déclare que :

«L'alsacien, que parle la majorité des habitants de cette région, a pour expression écrite une langue de culture et de diffusion internationales, l'allemand ».

L'allemand devient langue régionale de France. Un enseignement de langue et culture régionales est organisé à tous les niveaux d'enseignement: école élémentaire, collège, lycée, au détriment du dialecte remplacé par l'allemand. De plus, depuis 1991, l'enseignement de l'allemand est introduit dès le CE 2, à raison de $3 \mathrm{~h}$ par semaine, dans le cadre de l'apprentissage précoce des langues étrangères.

Parallèlement, l'Association pour le Bilinguisme en Classe dès la Maternelle (ABCM), fondée par un militant du cercle René Schickelé, a mis en place en 1991 un enseignement privé, bilingue, dit 13/13, moitié en français, moitié en allemand (fig.2). De son côté l'Éducation Nationale a créé en 1992 des sections bilingues, avec parité horaire des deux langues depuis la maternelle. Elles représentent en 1999, 302 classes et 6500 élèves, soit $3 \%$ des élèves, dont $7 \%$ d'entre eux seulement parlaient le dialecte. En 2012, il y avait 21000 élèves dans ces classes bilingues du primaire et de la maternelle. Mais dans le secondaire, bien que les effectifs augmentent progressivement depuis 2008, ils ne représentent qu'une infime partie des enfants scolarisés (de 1,5 à 2,1\% dans les lycées et de 3,3 à 4,1 \% dans les collèges. Tableau 1). En fait ces classes jouent surtout le rôle, comme toutes celles à enseignement spécifique, de ségrégation sociale plus que $\mathrm{d}^{\prime}$ attachement identitaire ${ }^{4}$.

\section{Le combat politique contemporain}

Mais le combat politique autour de la langue n'est pas terminé. Certains ethno-linguistes considèrent que l'allemand risque, bien plus que le français, de faire disparaître le dialecte. Bon nombre d'hommes politiques alsaciens (Robert Grossmann et d'autres avant lui) accusent un petit nombre de militants, combatifs, actifs et interchangeables dans de multiples associations, de prendre le dialecte en otage et de travailler à une regermanisation de l'Alsace. Ils intègrent dans ce mouvement le "Cercle René 
Schickelé5 ", les autonomistes du bulletin Rot un Wiss ${ }^{6}$, qui veulent une Alsace autonome de langue allemande, le groupe «Heimetsproch un Tradition ${ }^{7}$ » qui milite pour le bilinguisme et une Alsace alsacienne, et une constellation d'associations pilotées par le Cercle René Schickelé. Celui-ci possède en outre une maison d'édition, la SALDE, une revue, les Cahiers du Bilinguisme, soutenue par une fondation allemande pangermanique. Les élus régionaux auraient été abusés par ces divers mouvements jusqu'à créer un «Office régional du Bilinguisme»(ORBI), un «Office pour la Langue et la Culture d'Alsace » (OLCA), un "Haut Comité pour la Langue», et à financer l'association $\mathrm{ABCM}$. Ces groupes de pression ont été mis en cause au conseil régional car :

«Le débat sur les langues cache des enjeux plus lourds comme l'identité, le peuple, l'avenir politique, le destin même de $1^{\prime}$ Alsace ${ }^{8} »$.

La «Charte européenne des langues régionales et minoritaires » est aussi impliquée dans ce complot et serait une initiative de l'Allemagne pour étendre son influence en Europe en tentant de récupérer, par le biais de la langue, des terres et des peuples qui lui ont appartenu. Sont opposées localement à cette charte la "galaxie » laïque républicaine et une partie des élus de droite.

\section{L'évolution des pratiques linguistiques}

Ces politiques linguistiques successives et opposées ont eu des effets très négatifs sur l'usage et la pérennité du dialecte. Les statistiques générales, tant allemandes que françaises et deux enquêtes plus récentes (INSEE 1980 ; CNRS 1989) font état, d'une part, d'un usage quasi général de l'allemand (confondu avec le dialecte) au cours de l'annexion, et d'une progression lente du français, associé au dialecte, depuis 1918. Les jeunes générations, qui sont l'avenir de la langue, s'ils pratiquent encore le dialecte avec leurs parents et leurs grands-parents, parlent majoritairement le français entre eux. Mais cette évolution reste difficile à mesurer car ces statistiques ne font pas référence aux mêmes usages linguistiques. Bien qu'elles procèdent toujours d'un souci d'administration lié à l'application de la législation et à l'organisation de l'enseignement, elles se doivent de justifier les décisions politiques d'un gouvernement, et servir à des fins de propagande territoriale.

\section{Les statistiques allemandes}

Les statistiques allemandes considèrent comme langue maternelle celle qui est réputée majoritaire dans chaque commune et l'attribuent à l'ensemble de la population civile, $\mathrm{y}$ compris les enfants au berceau. La population des communes mixtes est comptée pour moitié de langue française et pour moitié de langue allemande. En outre, le dialecte est assimilé à l'allemand.

L'analyse des résultats permet de constater une légère progression de l'allemand (ou du dialecte) surtout dans le Haut-Rhin entre 1878 et 1910 (tableau 2), la langue germanique constituant la pratique largement majoritaire des habitants de la région (à $95 \%$ ).

\section{Les recensements français après la Première Guerre mondiale}

Après 1918, pour mesurer avec plus de précision les progrès du français, les recensements intègrent une série de questions sur les pratiques linguistiques, et celles-ci se font de plus en plus précises et judicieuses. En 1921 et 1926 on demande à chaque

5. Schickelé Gesellschaft. Cercle fondé en 1968 par la société «Culture et bilinguisme d'Alsace et de Moselle », du nom d'un écrivain alsacien qui désirait instituer une Alsace médiatrice entre la France et l'Allemagne.

6. Rouge et Blanc, couleurs du drapeau alsacien.

7. Langue du pays et tradition.

8. R. Grossmann, Main basse sur ma langue, p. 78 et P. Vogler, Quelle pratique linguistique pour l'Alsace. 
individu quelle est sa langue usuelle : «français... dialecte... allemand... autre ». Cette formulation ne permet pourtant pas de mesurer le bilinguisme. De 1931 à 1962 les bulletins individuels de recensement posent spécialement en Alsace les questions suivantes : «Savez-vous parler le français ?.. le dialecte ?.. l'allemand ?.. ». Cette nouvelle formule permet d'analyser les différentes formes $\mathrm{du}$ bilinguisme, ou même de trilinguisme. Elle entraîne néanmoins, faute de référence à la pratique réelle, des réponses qui surestiment les connaissances linguistiques, surtout en français. Ces questions linguistiques ont été supprimées, dans les recensements, depuis 1962.

Les résultats, pas toujours comparables, permettent néanmoins de constater que l'usage du dialecte s'est maintenu à un haut niveau, depuis la fin de la Première Guerre mondiale (86 à $87 \%$ des personnes interrogées parlent le dialecte. Tableau 3) jusqu'à la période de la deuxième annexion allemande (le taux monte alors à 90,8\%. Tableau 3). Par contre, dès 1946, le dialecte apparaît moins pratiqué, surtout dans les grandes villes : (63,8 \% des personnes le parlent dans l'agglomération de Colmar et 65,9\% à Mulhouse). À partir de 1962 les questions linguistiques sont exclues des recensements et remplacées par des enquêtes sur échantillon. Elles ne sont pas comparables entre elles faute de références démographiques et d'objectifs communs. Elles permettent néanmoins de préciser périodiquement les évolutions linguistiques.

\section{L'enquête « Mode de vie en Alsace », 1979}

Cette première enquête, diligentée par l'INSEE, comportait un certain nombre de questions concernant les pratiques linguistiques de la population. Elle portait sur un échantillon représentatif, tiré au sort, des personnes de plus de 15 ans. Au total, 3004 enquêtes ont été réalisées. Il apparaît tout d'abord que le dialecte est en régression : $75 \%$ des personnes de plus de 15 ans déclarent le parler en 1979 contre $87 \%$ en 1962. Le dialecte est plus pratiqué à la campagne que dans les villes; $88 \%$ des habitants des communes rurales le parlent contre $62 \%$ dans l'agglomération de Strasbourg, $61 \%$ dans celle de Colmar et $67 \%$ à Mulhouse. Le dialecte est aussi plus souvent parlé dans le BasRhin $(77 \%)$ que dans le Haut-Rhin $(73 \%)$, par les personnes âgées que par les jeunes : $88 \%$ des personnes de 75 ans et plus parlent le dialecte contre $66 \%$ de celles de 16 à 24 ans. Les enfants parlent moins le dialecte que leurs parents : $77 \%$ des chefs de famille parlent le dialecte, $76 \%$ de leur conjoint et seulement $63 \%$ de leurs enfants. L'alsacien est plus souvent parlé à la maison qu'à l'extérieur, et moins dans les administrations que dans tout autre lieu public (60\% à la maison; $52 \%$ pour faire les courses ; $37 \%$ dans les administrations).

\section{Une deuxième enquête de l'INSEE en 1999}

En 1999, l'enquête intitulée "Étude de l'histoire familiale » a porté, en Alsace sur un échantillon de 30000 personnes à partir de 18 ans. Elle comportait trois groupes de questions linguistiques, centrées sur la génération des parents et conforte ces résultats. $51 \%$ des personnes de plus de 18 ans, nées en Alsace, pratiquent l'alsacien, $60 \%$ parmi celles nées avant 1945 et $40 \%$ de celles nées après 1970. La pratique du dialecte reste plus forte dans le nord du Bas-Rhin. La transmission des parents aux enfants se fait de plus en plus rare : presque tous les enfants nés en Alsace parlent le français avec leurs parents, et seulement un enfant sur 4 parle le dialecte. De plus, $10 \%$ seulement des enfants nés en Alsace apprennent aujourd'hui le dialecte, contre $80 \%$ dans les années 40.

\section{L'enquête du CNRS. Laboratoire de Sociologie Régionale, $1989^{10}$}

Nous avons, pour notre part, décidé dès 1982, de mener une enquête par questionnaire auprès de 2216 lycéens appartenant à 28 établissements scolaires répartis sur l'ensemble

9. N. Seligman, Étude du mode de vie en Alsace.

10. M.N. Denis et C. Veltman, Le déclin du dialecte alsacien. C. Veltman, La régression du dialecte. M.N. Denis, Le dialecte alsacien, état des lieux. 
des deux départements alsaciens, et représentatifs des caractéristiques de l'ensemble de la population. L'orientation des questions permettait de mesurer les pratiques linguistiques des élèves (usage quasi-exclusif du français ou de l'alsacien; pratique bilingue avec priorité au français ; pratique bilingue à dominante dialectale), avec leurs parents, leurs grands-parents, leurs frères et sœurs, leurs amis, selon le lieu de résidence et la catégorie socioprofessionnelle de leurs parents. Les questions permettaient, non seulement de mesurer la régression du dialecte au cours des générations, mais d'étudier avec précision les situations de bilinguisme.

Nous ne donnerons que les résultats concernant les familles «alsaciennes », définies comme les ménages dont les deux parents sont nés en Alsace ${ }^{11}$. Dans ces familles, la grande majorité des parents savent parler le dialecte $(91 \%$. Tableau 4$)$, mais leur pratique linguistique utilise de manière complexe leurs compétences en bilinguisme (tableau 5) : les parents sont majoritairement bilingues avec leurs enfants (41,9\% des pères, $43,6 \%$ des mères) ; vient ensuite exclusivement le français (35,8\% des pères, $36,9 \%$ des mères) ; et en troisième lieu exclusivement $l^{\prime}$ alsacien ( $22,2 \%$ des pères, $19,4 \%$ des mères). Dans leurs échanges entre eux, par contre, le dialecte domine légèrement $(43,9 \%$ des pères le parlent et $43,8 \%$ des mères). Mais les situations de bilinguisme restent importantes (41,6 \% pour les pères, $43,5 \%$ pour les mères). L'usage simultané des deux langues est majoritaire avec leurs amis $(60,1 \%$ pour les pères et $58 \%$ pour les mères), comparable aux pourcentages relevés dans les usages entre époux. Mais il y a une progression du français et une perte rapide de l'usage de l'alsacien à chaque génération : plus de $20 \%$ depuis celle des grands-parents, puis des parents et des enfants. Par ailleurs, les compétences des adolescents révèlent des lacunes importantes en ce qui concerne le dialecte (tableau 6). Si 71,8\% le comprennent, 45,1\% seulement le parlent facilement. Dans ce cas, l'usage mixte de l'alsacien et du français est majoritaire, et l'usage exclusif $\mathrm{du}$ français dépasse celui du dialecte (tableau 7). Mais l'avenir de la langue dépend surtout de l'usage qu'en font les adolescents entre eux, déterminant ainsi la langue de leur futur couple et, en conséquence, celle de leurs enfants. Et l'on observe que, même chez les enfants issus de familles alsaciennes, cet usage est très faible (tableau 8) : 7,9\% des adolescents parlent généralement le dialecte entre eux et 9,8\% à mi-temps.

\section{Une enquête récente}

Enfin, une enquête de 2012, diligentée par l'Office pour la langue et la Culture Alsaciennes (OLCA), et réalisée auprès d'un échantillon de personnes de plus de 18 ans, confirme ces résultats : $43 \%$ de la population « sait bien parler l'alsacien », $33 \%$ déclarent «le parler un peu et/ou le comprendre un peu » et $25 \%$ ne le comprennent pas. Malgré les différences méthodologiques entre toutes ces enquêtes, la pente descendante est incontestable. De même, la répartition des dialectophones selon l'âge augure mal pour l'avenir : ils ne sont que $12 \%$ entre 18 et 29 ans contre $24 \%$ de 30 à 44 ans.

Les politiques linguistiques successivement imposées à la population alsacienne ont bénéficié tantôt au français, tantôt à l'allemand, aux dépens du dialecte. À l'heure actuelle, et depuis 1946, l'usage du dialecte diminue progressivement et le bilinguisme paraît être le passage obligé d'une langue à l'autre. Il se traduit par une progression du français à travers les générations. Les parents parlent alsacien aux grands-parents et les deux langues à leurs enfants. Les enfants sont bilingues avec leurs parents et parlent surtout le français avec leurs frères et sœurs et leurs amis. Les prévisions fondées sur les résultats de cette dernière enquête sont peu optimistes. On ne pourra maintenir en vie le dialecte contre l'inertie de la mentalité générale, et les mesures récentes en faveur de l'enseignement de l'allemand se heurtent au scepticisme et même à la méfiance de certains. L'indifférence de la plupart des lycéens vis-à-vis du dialecte, l'usage généralisé du français entre eux, va contraindre, à terme, la communauté jadis définie par la langue, à se distinguer par d'autres traits culturels afin de ne pas perdre son âme. 


\section{Résumé}

La langue majoritairement parlée en Alsace depuis les invasions barbares est un dialecte germanique et la frontière linguistique avec les langues romanes n'a pas varié depuis un millénaire. Mais, depuis trois siècles, les vicissitudes historiques ont imposé aux Alsaciens tantôt le français, tantôt l'allemand comme langue officielle. Cette instrumentalisation de la langue, devenue enjeu politique, date en France de la Révolution et, du côté allemand, de 1848. Sous l'Ancien Régime l'Alsace, rattachée à la France lors des traités de Westphalie (1648), se voit imposer le français dans l'administration. C'est la langue de l'armée, des fonctionnaires immigrés et de l'aristocratie. Le peuple continue de parler le dialecte, surtout en milieu rural. La Révolution, par souci d'égalité nationale et méfiance pour la «langue de l'ennemi », impose sans succès l'usage du français à l'école primaire. Notre idiome restera la «langue des riches». Il faudra attendre l'annexion à l'Empire Allemand (1870-1918) pour voir apparaître une politique linguistique plus coercitive. L'allemand est imposé dans l'administration, dans l'enseignement, et dans tous les aspects de la vie publique (état civil, nom des localités, nom des rues, enseignes, presse, édition...). Cette germanisation s'impose rapidement du fait de la proximité linguistique du dialecte (Elsässerditsch) et de l'allemand standard (Hochdeutsch).

Lors du retour de l'Alsace à la France, le gouvernement imposa l'usage du français, surtout dans l'enseignement, politique interrompue pendant la période nazie (1940-1944), où l'allemand fut de nouveau la seule langue tolérée. Après 1944 se mit en place, à nouveau, une politique brutale de francisation. Le dialecte et l'allemand furent frappés d'indignité nationale et il devint «chic de parler français ». Les enquêtes linguistiques récentes de l'INSEE (Nicole Seligman) et du CNRS (Marie- Noële Denis et Calvin Veltman) ont constaté que le français avait gagné peu à peu toutes les zones géographiques et toutes les couches sociales. Les adolescents, garants de l'avenir de la langue régionale, ne parlent plus aujourd'hui que très peu le dialecte entre eux. L'heure est maintenant venue, pour les responsables politiques, de protéger cet élément fondamental de l'identité alsacienne. 


\section{Bibliographie}

CHURIKI Eri, «Une filière sélective dès l'école maternelle : l'enseignement de la langue régionale en Alsace et ses enjeux », Regards Sociologiques, n 19, deuxième trimestre 2000, pp. 95-113.

DENIS Marie-Noële, "Le dialecte alsacien, état des lieux», Ethnologie Française, vol. XXXIII, n³, 2003, pp. 363-371.

DENIS Marie-Noële, «Bilinguisme familial en Alsace », dans DEPREZ de HÉRÉDIA Charles et CALVET Louis Jean, La communication familiale, Paris, Publications de Paris V-Sorbonne, CERPL, 1988, pp. 133-142.

DENIS Marie-Noële, "Le français en Alsace, usages socio-linguistiques, évolution et perspectives ", dans SALMON Gilbert Lucien, Bulletin de la faculté des letttres de Mulhouse, Paris-Genève, Champion-Slatkine, fascicule XIV, 1985, pp. 173-191.

Denis Marie-Noële et VelTMAN Calvin, Le déclin du dialecte alsacien, Strasbourg, Presses Universitaires, 1989, 2ème édition 1990.

GrosmanN Robert, Main basse sur ma langue, Strasbourg, La Nuée Bleue, 1999.

LÉvy Paul, Histoire linguistique d'Alsace et de Lorraine, Paris, Les Belles Lettres, 1962, 2 vol.

Seligman Nicole, Étude du mode de vie en Alsace, Strasbourg, INSEE, 1980.

VeltMan Calvin, "La transmission de l'alsacien dans le milieu familial», Revue des Sciences Sociales de la France de L'Est, n $12-12$ bis, 1983, pp. 125-133.

VeltMAn Calvin, «La régression du dialecte », Chiffres pour l'Alsace-INSEE, n 3, 1982, pp. 39-42.

VOGLER Pierre, "Quelle pratique linguistique pour l'Alsace? », Revue des Sciences Sociales de la France de l'Est, n 8, 1979, pp. 314-321. 


\section{Illustrations}

1- Cette affichette «C'est chic de parler français » apparaît sur les murs après 1945.

Le petit écolier alsacien n'a pas l'air d'apprécier cette injonction républicaine. (C) Tomi Ungerer, Illustration extraite de Elsassisch Reda. Petite anthologie de la poésie alsacienne, vol. VIII, Strasbourg, Association J-B Weckerlin, Maison de la Radio, 1978.)

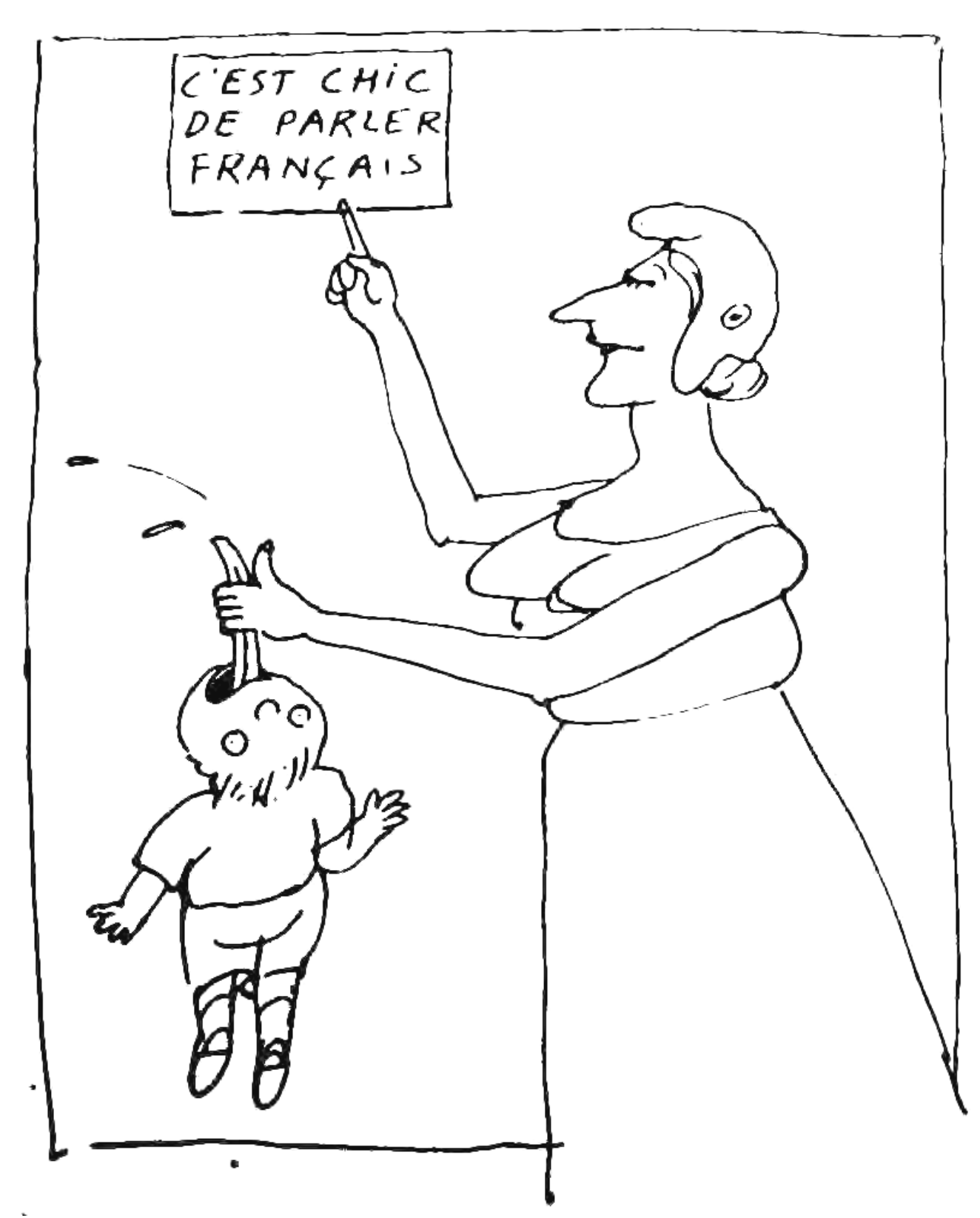


2- Avec quelle gourmandise ce chien d'Alsacien goûte aux avantages du bilinguisme. (C) Tomi Ungerer, Illustration extraite de Elsassisch Reda. Petite anthologie de la poésie alsacienne, vol. VIII, Strasbourg, Association J-B Weckerlin, Maison de la Radio, 1978.)

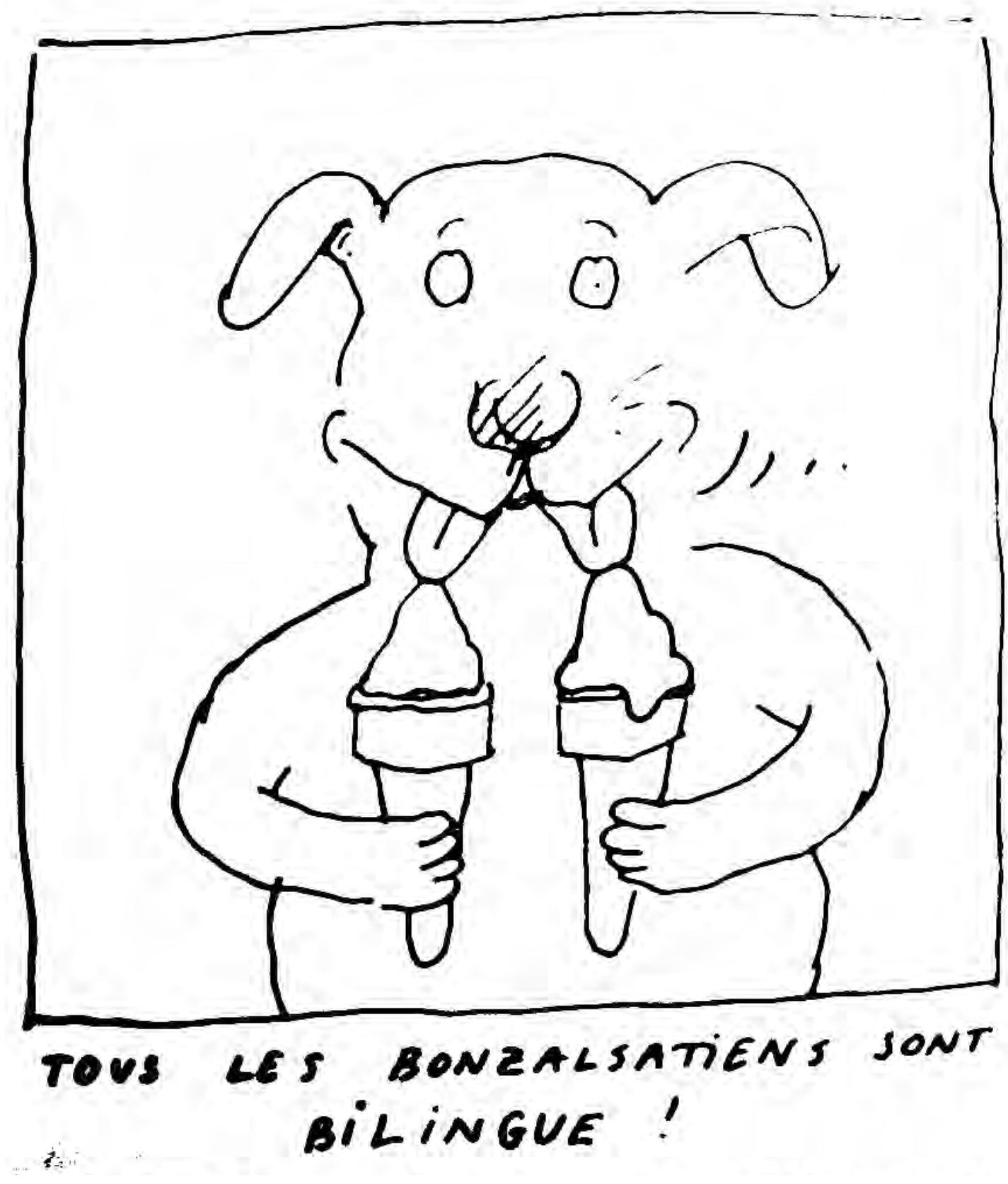


3- Manifestation contre le rectorat de Strasbourg pour la création de nouvelles classes bilingues, L'Alsace, lundi 21 octobre2013. «Bilingues nous voulons être ».

\section{Accueil Actualité Alsace \\ Éducation \\ Le recteur « remet en cause les principes du bilinguisme »}

le 03/02/2013 à 05:00 Thierry Martel

Vu 1758 fois Imprimer $\mid$ Favoris $\mid$ Facebook $\mid$ Twitter $\mid$ Envoyer à un ami $\mid \stackrel{\overline{0}}{\text { Notez cet article : }}$

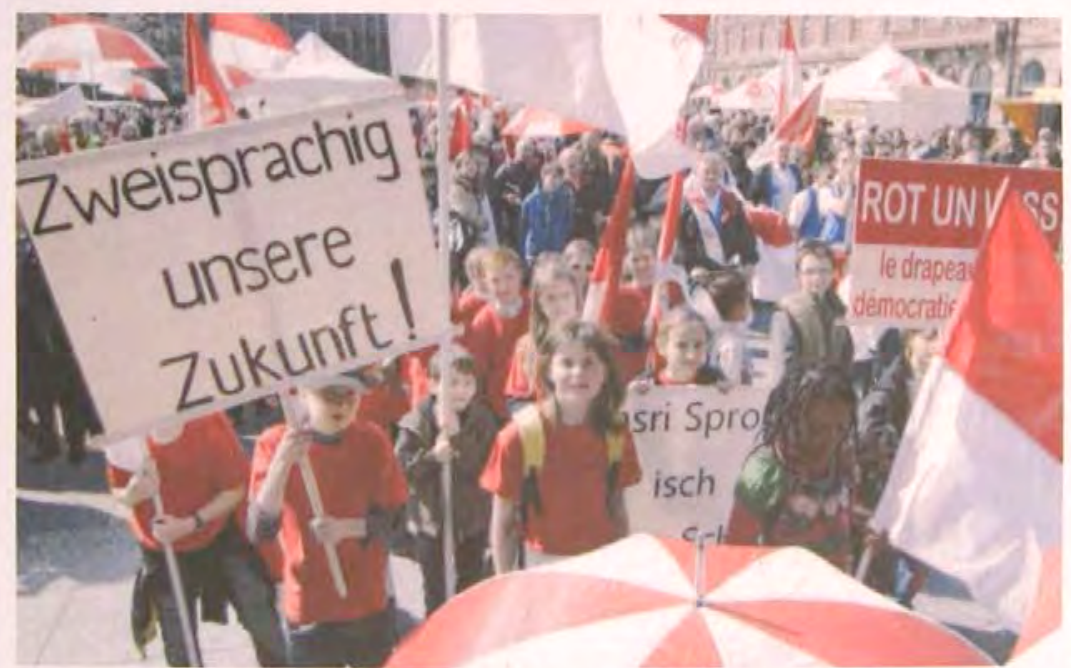

Lors d'une manif pour le bilinguisme à Strasbourg. Archives J.-M. L. 
Tableau 1 : Pourcentage des élèves des lycées et collèges en section bilingue françaisallemand. 2008-2013.

\begin{tabular}{|l|l|l|}
\hline Années & Lycées & Collèges \\
\hline 2008 & 1,5 & 3,3 \\
\hline 2009 & 1,7 & 3,5 \\
\hline 2010 & 2,0 & 3,7 \\
\hline 2011 & 2,1 & 3,9 \\
\hline 2012 & 2,2 & 4,1 \\
\hline 2013 & 2,1 & 4,4 \\
\hline
\end{tabular}

Tableau 2: Évolution des personnes parlant l'allemand ou le dialecte de 1878 à 1910 (en $\%)$.

\begin{tabular}{|l|l|l|l|}
\hline Année & Bas-Rhin & Haut-Rhin & Alsace \\
\hline 1878 & 95,5 & 78,7 & 88,2 \\
\hline 1882 & 95,8 & 88,2 & 92,5 \\
\hline 1900 & 95,7 & 93,3 & 95,0 \\
\hline 1905 & 95,8 & 93,4 & 95,0 \\
\hline 1910 & 95,8 & 93,0 & 94,8 \\
\hline
\end{tabular}

Tableau 3 : Évolution des personnes parlant le dialecte. 1926-1962. (en \%).

\begin{tabular}{|l|l|l|l|l|l|}
\hline Année & Bas-Rhin & Haut-Rhin & Alsace & Com. Urb. & Com. rurales \\
\hline 1926 & 79,6 & 80,5 & 80,0 & & \\
\hline 1931 & 86,3 & 87,2 & 86,7 & & \\
\hline 1936 & 86,6 & 87,3 & 86,9 & & \\
\hline 1941 & 90,7 & 91,0 & 90,8 & & \\
\hline 1946 & 90,7 & 91,0 & 90,8 & & \\
\hline 1962 & 86,3 & 82,5 & 84,7 & 81,4 & 90,4 \\
\hline
\end{tabular}

Tableau 4: Caractéristiques linguistiques des parents des familles alsaciennes. 1989. (en \%)

\begin{tabular}{|l|l|}
\hline Connaissance du dialecte par les parents & En \% de la population des fam. alsaciennes \\
\hline Les 2 le parlent & 91,0 \\
\hline Le père seul le parle & 3,6 \\
\hline La mère seule le parle & 2,1 \\
\hline Aucun des 2 ne le parle & 3,3 \\
\hline Ensemble & 100,0 \\
\hline
\end{tabular}


Tableau 5 : Pratiques linguistiques des parents des fam. alsaciennes avec leur entourage. (en \%).

\begin{tabular}{|l|l|l|l|l|l|l|l|l|}
\hline Langues parlées & Par le & père & & & Par la & mère & & \\
\hline & parents & conjointe & Ado. & amis & parents & conjoint & ado. & amis \\
\hline français & 10,0 & 14,2 & 35,8 & 12,2 & 8,7 & 14,6 & 36,9 & 17,3 \\
\hline Fran+als & 18,2 & 40,6 & 41,9 & 60,1 & 24,7 & 41,1 & 43,5 & 58,0 \\
\hline alsacien & 69,6 & 43,9 & 22,2 & 27,5 & 65,5 & 43,8 & 19,4 & 24,4 \\
\hline autre & 1,2 & 0,3 & 0,1 & 0,2 & 1,1 & 0,5 & 0,2 & 0,3 \\
\hline ensemble & 100,0 & 100, & 100,0 & 100,0 & 100,0 & 100,0 & 100,0 & 100,0 \\
\hline
\end{tabular}

Tableau 6 : Compétences en dialecte des adolescents des familles alsaciennes.

\begin{tabular}{|l|l|l|l|}
\hline L'adolescent parle... & $($ en \%) & L'adolescent comprend... & (en \%) \\
\hline facilement & 48,1 & facilement & 71,8 \\
\hline difficilement & 23,6 & difficilement & 14,4 \\
\hline qq. mots & 17,0 & qq. mots & 9,7 \\
\hline pas du tout & 11,3 & Pas du tout & 4,1 \\
\hline ensemble & 100,0 & ensemble & 100,0 \\
\hline
\end{tabular}

Tableau 7 : Langues parlées par les adolescents avec leurs parents. Familles alsaciennes. (en $\%)$.

\begin{tabular}{|l|l|l|}
\hline Langues parlées par les ados. & Avec leur père & Avec leur mère \\
\hline français & 35,8 & 36,9 \\
\hline Français +alsacien & 41,9 & 43,5 \\
\hline alsacien & 22,2 & 19,4 \\
\hline autre & 0,1 & 0,2 \\
\hline ensemble & 100,0 & 100,0 \\
\hline
\end{tabular}

Tableau 8 : Pratique du dialecte par les ados des familles alsaciennes avec leurs copains. (en \%).

\begin{tabular}{|l|l|}
\hline Fréquence d'emploi : & $\%$ \\
\hline généralement & 7,9 \\
\hline à mi-temps & 9,8 \\
\hline parfois & 29,2 \\
\hline jamais & 53,1 \\
\hline ensemble & 100,0 \\
\hline
\end{tabular}




\title{
Diglossie au Maroc: Inter-culturalité et Aménagement Linguistique
}

\author{
Houssine SOUSSI \\ Doctorant à l'UFR Langue, Culture et Communication \\ de la Faculté des Lettres et des Sciences Humaines, \\ Université Moulay Ismail, \\ Meknès, Maroc.
}

\footnotetext{
Extrait de : Guylaine BRUN-TRIGAUD (dir.), Contacts, conflits et créations linguistiques, Paris, Édition électronique du CTHS (Actes des congrès des sociétés historiques et scientifiques), 2015.

Cet article a été validé par le comité de lecture des Éditions du CTHS dans le cadre de la publication des actes du $139^{\circ}$ Congrès national des sociétés historiques et scientifiques tenu à Nîmes en 2014.
}

La situation linguistique au Maroc est marquée par une mosaïque multiculturelle et multilingue. Il s'agit d'un creuset de langues nationales et de langues étrangères, qui à travers l'histoire se sont enracinées dans le champ linguistique et culturel du pays. D'un côté, on trouve les langues maternelles de la majorité des Marocains que sont l'amazighe (berbère) et la darija (arabe dialectal marocain) et de l'autre, les langues d'écriture et de l'enseignement, l'arabe standard, le français et l'anglais. La diversité et l'interaction entre ces différentes langues donnent lieu, selon les usages et les usagers, à des pratiques diverses souvent qualifiées de bilinguisme, trilinguisme ou multilinguisme. Or ces qualifications ne peuvent englober toutes les situations linguistiques du Maroc, c'est pourquoi nous avons décidé d'adopter le terme diglossie. L'objectif de cet article est donc d'appliquer le concept de la diglossie sur les langues qui sont en usage au Maroc. Nous allons démontrer les différents enjeux linguistiques que nous offre le contexte spécifique de ce pays, et nous allons étudier les relations souvent conflictuelles qu'entretiennent les langues dans le marché linguistique marocain, sans toutefois les envisager sous la conception de conflit linguistique. La première partie est axée particulièrement sur le concept de diglossie, l'évolution de ce concept et son application aux diverses situations de communication. Pour nous aider à mieux discerner les différentes situations diglossiques qu'on peut étudier sur le Maroc, la deuxième partie est destinée à analyser la situation linguistique dans ce pays. Nous allons discuter plus précisément des statuts officiels des langues et des variétés linguistiques et ensuite nous allons décrire la réalité sociolinguistique du Maroc. Dans la troisième et dernière partie, nous analyserons les situations de diglossie concernant ce pays.

\section{Le concept de diglossie}

En sociolinguistique, selon la définition admise,

«La diglossie désigne l'état dans lequel se trouvent deux variétés linguistiques coexistant sur un territoire donné et ayant, pour des motifs historiques et politiques, des statuts et des fonctions sociales distinctes, l'une étant représentée comme supérieure et l'autre inférieure au sein de la société $»^{1}$.

En ce qui concerne l'étymologie du terme diglossie, le mot est emprunté au grec et est constitué de deux parties dont la préposition di- signifie deux fois et la deuxième partie, issue du mot glôssa, signifie langue. Toutefois, Il est essentiel de faire une distinction importante entre diglossie et bilinguisme même si ce n'est pas une tâche facile étant

1. Wikipédia, consultée le 19 novembre 2013. 
donné que ces termes sont très proches par leurs significations et peuvent parfois être confondus dans certains contextes.

Selon Lambert-Félix Prudent ${ }^{2}$, le premier à avoir proposé le terme diglossie fut Jean Psichari, philologue et écrivain français d'origine grecque, qui l'aurait en effet employé, dans ses Essais de grammaire néo-grecque publiée en 1885. Il y reprenait par deux fois un terme utilisé peu de temps auparavant par un certain M. Roïdis dans un article publié dans Acropolis, mais faisait simplement mention de «l'étrange diglossie dont souffre la Grèce ». Ce serait son élève Hubert Pernot qui dans sa Grammaire Grecque Moderne de 1897, aurait proposé une définition approfondie du concept dans son analyse de la situation sociolinguistique grecque en soulignant la coexistence de la katharévusa, langue scolastique, savante et langue écrite par excellence, avec le démotiki ou romaïque, grec usuel ou vulgaire, qui est la seule langue courante bien qu'elle ne soit pas enseignée ${ }^{3}$. Dans son article de 1928, Jean Psichari qualifie de diglossique toute situation où deux variantes (parlée et écrite) d'une même langue sont en usage dans un pays. Il postule que :

«La diglossie ne consiste pas seulement dans l'usage d'un double vocabulaire [...] la diglossie porte sur le système grammatical tout entier. Il y a deux façons de décliner, deux façons de conjuguer, deux façons de prononcer; en un mot, il y a deux langues, la langue parlée et la langue écrite. ${ }^{4}$

William Marçais, membre de l'Institut et professeur au Collège de France, publie en 1930 ses rapports d'inspection sur la langue arabe dans l'enseignement public qu'il intitule $\mathrm{La}$ diglossie arabe. Dans son article, Marçais reprend les mêmes termes utilisés par ses prédécesseurs pour définir la diglossie sans pourtant ne faire aucune référence directe à Psichari ou Pernot. Marçais définit ainsi la diglossie comme «la concurrence entre une langue savante écrite et une langue vulgaire, parfois exclusivement parlée $\aleph^{5}$. On peut soutenir que la définition de Marçais peut être considérée comme archaïque par le choix de ces termes mais pas dans son champ d'application. En effet, Marçais parle de la concurrence entre les langues savante et vulgaire, et au cours des étapes plus avancées du développement de la théorie de diglossie, la notion de concurrence est remplacée par distribution et les concepts de savant et vulgaire sont remplacés par variété haute et variété basse.

\section{Le concept de Diglossie chez Ferguson}

Le concept de diglossie va réapparaître aux États-Unis en 1959 dans un célèbre article de Charles Ferguson, Diglossia ${ }^{6}$, où l'auteur, tout en reconnaissant qu'il emprunte le terme, va lui donner une teneur conceptuelle sensiblement différente de celle de Psichari et de Marçais. Il définit la diglossie comme une :

«Situation linguistique relativement stable dans laquelle, en plus des dialectes premiers de la langue [...] il existe une variété superposée très différente, rigoureusement codifiée [...] qui est largement apprise par le biais de l'école, et qui est utilisée pour la plupart des textes écrits et des discours formels, mais qui n'est jamais utilisée [...] pour une conversation ordinaire. $»^{7}$

À partir de plusieurs situations sociolinguistiques comme celles des pays arabes, de la Grèce, de Haïti ou de la Suisse germanophone, Ferguson va considérer qu'il y a diglossie lorsque deux variétés de la même langue sont en usage dans une société avec des fonctions socioculturelles certes différentes mais parfaitement complémentaires. L'une de ces variétés est considérée haute (Variété H), elle est codifiée, normalisée et par

2. L. Prudent, «Diglossie et Interlecte», pp. 13-38.

3. Ibid.,p. 15.

4. Ibid.,p. 66.

5. W. Marçais, «La diglossie arabe, dans l'Enseignement public», p 402.

6. C. Ferguson, «Diglossia», pp.325-340.

7. L. Prudent, « Diglossie et Interlecte », p. 22. 
conséquent, elle est valorisée, investie de prestige par la communauté : elle est essentiellement utilisée à l'écrit dans la littérature ou dans des situations d'oralité formelle, et dans le système éducatif. L'autre, considérée comme basse (Variété B), est celle de communications ordinaires, de la vie quotidienne, elle est réservée à l'oral et considérée comme inférieure par rapport à la variété $H$, avec laquelle elle partage quelques ressemblances dans le système grammatical, lexical et phonologique.

\section{Diglossie selon Fishman}

La conception que donne Ferguson au mot diglossie serait élargie par Joshua Fishman, qui propose une extension du modèle diglossique à des situations sociolinguistiques où deux langues (et non plus seulement deux variétés de la même langue) sont en distribution fonctionnelle complémentaire. Fishman insiste sur la différence fonctionnelle entre ces systèmes linguistiques et sur la présence de plus de deux langues sans avoir, forcément, la parenté génétique. Il oppose le bilinguisme, qu'il définit par «la capacité d'un individu à utiliser plusieurs langues » et qu'il considère comme fait individuel et par conséquent relève de la psycholinguistique, à la diglossie qu'il considère comme fait social et par conséquent relève de la sociolinguistique.

\section{Description de la situation sociolinguistique au Maroc}

La situation linguistique au Maroc est assez complexe et est caractérisée par une pluralité qui est marquée par la coexistence de langues et de variétés différentes qui se distinguent par leur histoire, leur distribution géographique, leur typologie langagière et leur fonction sociolinguistique. L'explication de cette pluralité de langues, qui se présente comme un signe de richesse, réside dans le côté social et historique du pays. En effet, le Maroc, de par son emplacement géographique, était un lieu propice pour l'émergence de différentes langues et cultures, un lieu qui a connu plusieurs invasions étrangères: Phénicienne, Carthaginoise, Vandale, Romaine, Byzantine, Arabe, Portugaise, Espagnole et Française, qui ont profondément marqué le côté linguistique et culturel du peuple autochtone Amazighe.

Nous pouvons classer les langues en présence au Maroc en trois catégories :

- les langues maternelles, l'amazighe et l'arabe marocain,

- la langue des institutions, l'arabe standard/classique,

- les langues étrangères, le français, l'espagnol et l'anglais.

Ces langues qui cohabitent dans le marché linguistique marocain peuvent être hiérarchisées selon le modèle gravitationnel proposé par Calvet $^{8}$ dans son approche écolinguistique. L'anglais, langue dominante au niveau mondial ou langue impériale représente ainsi la strate hyper-centrale, le français ou langue coloniale représente la strate super-centrale, l'arabe, langue régionale représente la strate centrale et au niveau inferieur on trouve l'amazighe qui est à la périphérie du modèle langue locale.

\section{Les langues maternelles}

L'arabe marocain et l'amazighe, dans des variations plus ou moins grandes, sont les deux seules langues maternelles des Marocains, elles sont aussi considérées comme les langues les plus utilisées en tant que moyen de communication orale?

L'amazighe

La langue amazighe (berbère) appartient à la famille chamito-sémitique. Elle constitue la langue la plus anciennement attestée dans l'Afrique du nord et elle peut être considérée comme la langue autochtone dans toute cette région. Des documents archéologiques de

8. L. J., Calvet, Pour une écologie des langues du monde, p. 16

9. A. Boukous, «Le champ langagier, diversité et stratification », p. 18. 
l'Égypte ancienne font remonter l'histoire écrite de l'amazighe au moins au second millénaire avant Jésus $\mathrm{Christ}^{10}$. L'amazighe, est présent à l'heure actuelle dans une dizaine de pays de l'ensemble Maghreb-Sahara-Sahel : Maroc, Algérie, Tunisie, Libye, Égypte, Niger, Mali, Burkina-Faso et Mauritanie. Mais l'Algérie et le Maroc sont, de loin, les deux pays qui comptent les populations amazighophones les plus importantes. L'évaluation du nombre d'amazighophones au Maroc est une question difficile et controversée car il n'existe pas dans ce pays de recensements linguistiques systématiques et fiables ${ }^{11}$. Toutefois, selon Chaker l'amazighe est parlé par environ $40 \%$ de la population marocaine ${ }^{12}$.

Au Maroc, l'amazighophonie est répartie en trois grandes zones géolectales qui couvrent l'ensemble du pays : au nord et dans le Rif avec le dialecte tarifit; au centre, le Moyen Atlas et une partie du Haut Atlas avec le dialecte tamazighte; au sud, sud-ouest, Haut Atlas, Anti-Atlas et la vallée du Souss, le domaine chleuh avec le dialecte tachelhite. Chaker constate qu'il est important de souligner que les ensembles géolinguistiques que forment les dialectes amazighs actuels sont le résultat d'un processus historique de fragmentation d'une amazighophonie qui formait autrefois un continuum sur toute l'Afrique du Nord et le Sahara ${ }^{13}$.

Au Maroc, l'amazighe a toujours possédé un statut minoré malgré un nombre élevé de locuteurs. Cette situation bien spécifique est considérée par Louis-Jean Calvet, comme étant un cas de diglossie enchâssée ${ }^{14}$. Ses variétés étaient exclusivement réservées au domaine familial ou informel entre pairs du même groupe. Actuellement, et après la reconnaissance de l'amazighe par la nouvelle constitution promulguée dans le contexte du Printemps Arabe en juillet 2011, de nouvelles fonctions ont été attribuées à la langue amazighe en tant que langue nationale, officielle et enseignée. Toutefois, la concrétisation du statut officiel est renvoyée à une éventuelle loi organique qui devrait définir le processus de mise en œuvre du caractère officiel de cette langue et préciser les modalités de son intégration. En outre, les travaux de standardisation de l'amazighe en vue de son intégration dans les systèmes éducatif, socioculturel et médiatique nationaux, ont commencé il y a plus d'une décennie avec la création de l'IRCAM (l'Institut Royal de la Culture Amazighe) en 2001. Durant cette même année, l'amazighe fait son introduction dans le système éducatif marocain au niveau du primaire. Actuellement, elle est progressivement généralisée à l'ensemble du territoire national et aux différents niveaux du système éducatif. Depuis quelques années, les études amazighes ont fait leur entrée à l'université au niveau de la licence et du master dans plusieurs facultés des lettres et des sciences humaines.

\section{L'arabe dialectal marocain}

On peut désigner par l'arabe dialectal cette variété parlée par la grande partie du peuple marocain non amazighophones. Elle est parlée selon Youssi ${ }^{15}$ par $90 \%$ de la population. Ainsi, on lui attribue l'appellation darija (langue courante). Bien qu'elle constitue la langue maternelle de cette masse populaire, elle est marginalisée car elle n'a jamais eu ni de reconnaissance ni de statut. Outre sa présence dans le milieu familial et dans la rue, l'arabe dialectal est utilisé dans la littérature populaire, dans les pièces de théâtre et dans le cinéma, à la radio et lors de certains débats parlementaires. À l'école, l'emploi de l'arabe marocain est courant en dehors de la classe, mais la plupart des enseignants utilisent cette variété dans les classes, même si les directives du ministère de l'éducation interdisent cette pratique. L'arabe marocain dérive d'une altération de l'Arabe classique qui, à travers la succession des générations, a subi des déperditions et a fait l'objet de nouvelles substitutions. Les chercheurs distinguent, en général, trois types d'arabe parlé, selon les régions géographiques :

10. A. Boukous, Revitalisation de la langue amazighe. Défis, enjeux et stratégies, p 20.

11. Ibid., p. 15.

12. S. Chaker, «Le berbère / Tamazight en France », p. 20

13. S. Chaker, «Le berbère», p. 215.

14. L.J., Calvet, La guerre des langues et les politiques linguistiques, p. 47.

15. Youssi «The Moroccan triglossia: facts and implications», p. 29. 
- le parler citadin ou urbain (mdini) comporte des traits andalous dominants et est utilisé dans les grandes villes comme Fès, Tétouane, Rabat, Salé, Tanger,

- le parler montagnard (jebli) est utilisé dans la région nord-ouest,

- le parler bédouin qui est lui-même subdivisé en trois catégories:

- le parlé bédouin (3rubi) employé dans les plaines atlantiques, notamment le Gharb, la Chaouia, les Doukkala et les Abda, il est utilisé aussi dans les plaines intérieures comme le Haouz de Marrakech et le Tadla.

- le parler bédouin (bedwi) des tribus d'origine hilalienne installées sur les plateaux du Maroc oriental.

- et enfin le parler bédouin hassani (3ribi) des tribus d'origine maâquilienne des régions sahariennes du sud du Maroc.

À ce propos, Boukous fait remarquer que quiconque intériorise les structures morphosyntaxiques de l'un de ces idiomes, ne trouve aucune difficulté à communiquer avec les locuteurs des autres parlers. L'intercompréhension est donc assurée entre ces différents parlers qui ne constituent en fait qu'un seul idiome.

\section{L'arabe classique/standard}

Historiquement, l'arabe est une langue qui appartient à la branche sémitique, c'est-à-dire à la même famille que l'akkadien, l'hébreu, l'amazighe et l'araméen. L'arabe classique ou littéraire n'est la langue maternelle d'aucun Marocain et n'est pas utilisé comme véhicule spontané de communication. C'est la langue dans laquelle fut révélé le Coran, et dans laquelle s'est exprimée toute la culture arabe. L'arabe classique demeure pour tout arabophone la langue de la prédication islamique et de l'enseignement religieux, puis celle de la langue écrite en concurrence surtout avec le français. Mais c'est également la référence et l'outil symbolique de l'identité arabo-musulmane, une langue supranationale réservée à des usages formels et limités à certaines situations particulières. Aux yeux des nationalistes, l'arabe classique représente le moyen de lutte contre l'oppression linguistique exercée par l'Occident à travers ses langues, que ce soit le français, l'espagnol ou l'anglais.

L'arabe moderne standard, correspond à la variante moderne de la langue arabe classique. Au Maroc, l'arabe standard sert de véhicule dans l'enseignement à tous les niveaux du système, sauf dans l'enseignement supérieur scientifique. Il est également la langue des productions littéraires, de la presse écrite, de la presse électronique, et de toute sorte de brochures et de documents administratifs et judiciaires. Surtout, c'est la langue qui est utilisée dans les manifestations officielles et institutionnelles.

\section{Les langues étrangères}

Le français

Le français a été la langue officielle du régime du protectorat et de ses institutions depuis la signature du traité de Fès, le 30 mars 1912 jusqu'à la proclamation de l'indépendance le 2 mars 1956. Après cette date, le français a conservé un rôle privilégié en tant que première langue étrangère du Maroc. Le français est présent dans le système éducatif, dans l'administration, dans les secteurs politique et économique, dans les médias audiovisuels et dans la presse. Même si le français n'a aucun statut officiel de droit au Maroc, le français est la seule langue au Maroc, qui puisse prétendre d'être à la fois lue, écrite et parlée, tout en étant la langue de toutes les promotions sociales et économiques. Boukous, postule que la dominance de la langue française sur le marché linguistique marocain résulte de "la force logistique dont bénéficie le français sur les plans économique, financier et politique ${ }^{16}$. Sans oublier :

«Que la France constitue un partenaire principal dans les échanges économiques avec les pays du Maghreb, c'est la plupart du temps le premier fournisseur, le premier client et le 
premier investisseur étranger ; c'est aussi le premier pays formateur de cadres maghrébins à l'étranger. ${ }^{17}$

Le français a donc acquis un statut de fait au Maroc. Dans le système éducatif, le français est considéré comme une langue fonctionnelle, c'est-à-dire que c'est par l'intermédiaire de cette langue que l'on accède aux connaissances techniques et technologiques et au savoir scientifique d'une manière générale, c'est la langue de l'ouverture sur le monde moderne, langue de culture, elle continue d'être le lien d'une création littéraire.

L'anglais

La position de l'anglais sur le marché linguistique marocain reste encore faible, mais sa force augmente lentement et sûrement en raison de son statut au plan international. En effet, avec la mondialisation, les relations économiques internationales du Maroc se diversifient progressivement avec les États-Unis, l'Union Européenne, la Turquie, la Chine et l'Inde.

\section{Situations de diglossies dans le contexte marocain}

Nous estimons que l'on peut établir trois situations principales de diglossie au Maroc, arabe dialectal/arabe standard, amazighe/arabe, et en dernier arabe/français.

\section{Diglossie arabe dialectal/arabe classique}

Comme nous l'avons déjà indiqué, Marçais fut le premier à avoir étudié la dualité de la pratique langagière des locuteurs arabophones qu'il qualifia de situation diglossique et qu'il résuma comme suit :

«La langue arabe se présente à nous sous deux aspects sensiblement différents; $1^{\circ}$ une langue littéraire dite arabe écrit ou régulier, ou littéral, ou classique, qui seule a été partout et toujours écrite dans le passé, dans laquelle seule aujourd'hui encore sont rédigés les ouvrages littéraires ou scientifiques, les articles de presse, les actes judiciaires, les lettres privées, bref tout ce qui est écrit mais qui, exactement telle qu'elle se présente à nous, n'a peut-être jamais été parlée nulle part, et qui dans tous les cas ne se parle aujourd'hui nulle part ; $2^{\circ}$ des idiomes parlés, des patois tantôt assez proches, tantôt sensiblement éloignés les uns des autres, dont aucun n'a jamais été écrit, dont la fixation scripturale a valu parfois aux orientalistes qui l'ont tentée les sarcasmes indignés du monde arabe, dont les gens peu cultivés eux-mêmes s'efforcent de s'éloigner dans leurs correspondances, mais qui partout et peut-être depuis longtemps, constituent la seule langue de la conversation dans tous les milieux, populaires ou cultivés. » ${ }^{18}$

Un peu plus loin dans son texte, Marçais tente de décrire les caractéristiques linguistiques et sociolinguistiques des deux variétés de l'arabe, qu'il considère comme complémentaires, en précisant que c'est bien là le point faible de cette langue pour laquelle deux variétés sont nécessaires afin de répondre à tous les besoins de la communication :

«Tel à mes yeux l'arabe. Une langue? Deux langues? Pour qui a lu les Antinomies linguistiques de Victor Henry, la question est oiseuse. Disons deux états d'une même langue, assez différents pour que la connaissance de l'un n'implique pas, absolument pas, la connaissance de l'autre; assez semblables pour que la connaissance de l'un facilite considérablement l'acquisition de l'autre. En tout état, un instrument pour l'expression de la pensée qui choque étrangement les habitudes d'esprit occidentales; une sorte d'animal à deux têtes, et quelles têtes! Que les programmes scolaires ne savent trop comment traiter, car ils ne sont pas faits pour héberger les monstres. $\gg^{19}$

17. Ibid., p. 32.

18. W. Marçais, «La diglossie arabe, dans l’Enseignement public», p. 401.

19. W. Marçais, «La diglossie arabe, dans l'Enseignement public», p. 409. 
Après plus de huit décennies, cette description reste valable dans ses grands traits et les situations décrites résument bien les relations conflictuelles entre l'arabe dialectal et l'arabe classique. La distinction majeure qu' on peut faire en ce qui concerne l'usage des deux variantes est celle entre l'écrit et l'oral. Compte tenu que l'arabe dialectal est une langue maternelle acquise naturellement dans le milieu familial, les locuteurs s'en servent spontanément à l'oral comme outil d'expression et de communication intracommunautaire et intercommunautaire, entre la communauté arabophone et la communauté amazighophone, et dans certains cas entre amazighophones. Elle est, par conséquent, limitée à des domaines informels. En outre, l'arabe classique, qui ne peut être acquis qu'en milieu scolaire, se présente le plus souvent sous la forme écrite. Son utilisation sous sa forme écrite dans tout le monde arabe et sa diffusion à travers les médias et les technologies modernes lui confèrent une dimension internationale et lui permettent de prendre en charge la communication écrite dans tous les domaines: philosophique, littéraire, scientifique...

Toutefois, il est intéressant d'analyser les conditions extralinguistiques (historique et politique) qui ont donné à l'arabe classique sa position privilégiée ou supérieure par rapport à l'arabe dialectal. Pour mieux situer le contexte qui a gouverné la destinée des langues au Maroc, il est nécessaire de rappeler le projet nationaliste et réformiste élaboré par le parti de l'Istiqlal pour le Maroc de l'après-indépendance et le choix de l'arabe comme langue nationale et officielle. En effet, après l'indépendance, l'état a instauré une politique culturelle et linguistique qui visait à la restauration rapide du caractère arabomusulman de la civilisation du pays, et c'est dans cette perspective que la langue arabe a été considérée comme une constante de la nation marocaine. En matière d'enseignement, la doctrine officielle est définie selon quatre points: l'unification, l'arabisation, la généralisation et la marocanisation. La valorisation de l'arabe classique prend donc ses origines de cette politique linguistique homogénéisante dite d'arabisation. Abou Abdou postule que :

«L'arabisation consiste à rendre à la langue arabe la place qu'elle avait perdue durant la période coloniale, c'est-à-dire lui permettre de remplir à nouveau pleinement son rôle de langue nationale assurant les fonctions de communication, de formation et de gestion à tous les niveaux et dans tous les secteurs de la vie collective. L'objectif ultime de l'arabisation au Maroc vise à faire de la langue arabe la langue de la science et de la technologie. En définitive, la langue qui appartient à une société moderne, donc une langue complète, dans laquelle on exprime aussi bien les sentiments, que les anciennes traditions, comme on peut suivre une conférence en chimie ou en mécanique. ${ }^{20}$

Après l'indépendance du pays, l'arabe officiel avait donc deux missions principales, la première était de réinvestir les champs institutionnels jadis occupés par le français et de réinstaurer les référents identitaires précédemment occultés par la politique coloniale française et la deuxième était la modernisation de cette langue en vue de son utilisation dans tous les domaines de la vie et plus spécialement dans la science et la technologie.

La diglossie arabe classique/arabe dialectale que nous avons étudiée manque d'aspect conflictuel. Par conséquent, nous pouvons avancer que la promotion et la valorisation de l'usage de l'arabe classique dans les domaines officiels ne menacent pas le statut de l'arabe dialectal comme langue vivante de communication quotidienne.

\section{Diglossie amazighe/arabe dialectal}

Il est important de rappeler qu'en dépit de la compétition entre l'amazighe et l'arabe dialectal dans le marché linguistique marocain, ces deux langues partagent les mêmes propriétés sociolinguistiques. En effet, ce sont les seules langues maternelles marocaines, elles ont toutes les deux un statut défavorable et dominé et elles ont les mêmes usages quotidiens limités aux situations informelles et les mêmes fonctions expressives. 
Toutefois, ce qui caractérise la situation diglossique entre l'amazighe et l'arabe dialectal, c'est la différence de leurs fonctions sociologiques, puisque d'une part, l'amazighe est considéré comme une langue vernaculaire limitée à la communication tribale et intracommunautaire, et d'autre part, l'arabe dialectal est considéré comme une langue véhiculaire, utilisée pour les communications intercommunautaires et joue donc le rôle de Lingua Franca ${ }^{21}$. De ce fait, la langue amazighe a un statut de marqueur linguistique d'appartenance communautaire et sert de vecteur de l'identité culturelle amazighe.

Il convient de noter ici que face à la marginalisation de l'amazighe après l'indépendance du pays, les intellectuels amazighes ont décidé de lutter pour la promotion de leur langue et culture et se sont organisés dans un mouvement de la société civile baptisé le Mouvement Culturel Amazighe (MCA). Les débuts de la revendication amazighe remontent à la fin des années 1960 et au début des années 1970.

En mars 2000, plusieurs associations signent le Manifeste berbère qui souligne la nécessité d'une reconnaissance officielle de l'amazighité au Maroc. Suite à ces revendications, une nouvelle politique culturelle et linguistique est annoncée dans les discours du roi de l'année 2001, notamment le discours d'Ajdir prononcé le 17 octobre 2001 dans lequel la langue et la culture amazighes sont reconnues en tant que patrimoine national à promouvoir. Ce discours constitue un tournant dans la lutte amazighe, puisque le roi se montre partisan de la promotion de la culture amazighe dans l'espace éducatif, socioculturel et médiatique.

À la suite de ce discours est créé, par décret royal, l'Institut Royal de la Culture Amazighe qui vise à sauvegarder et à promouvoir la culture amazighe dans toutes ses expressions. Ils revendiquent l'introduction de l'amazighe dans le système éducatif et en termes plus généraux, son rayonnement dans l'espace social, culturel et médiatique, national, régional et local. Le chantier de la standardisation et de la normalisation de l'amazighe fut lancé.

Par conséquent, on peut constater une dynamique de revitalisation de l'amazighe dans le contexte de la nouvelle politique linguistique et culturelle au Maroc. Ces développements dans les années à venir nous permettront de considérer si le cadre diglossique a évolué en faveur d'un vrai rééquilibrage de l'amazighe et sa promotion sociale dans différentes sphères de la vie publique et de la communication collective.

\section{Diglossie Français/Arabe}

Le français, langue coloniale implantée au Maroc au début du $\mathrm{XX}^{\mathrm{e}}$ siècle connaît encore une grande vitalité au sein de la société marocaine, ce qui lui confère son prestige et plus particulièrement dans les milieux intellectuels. Malgré les politiques d'arabisation de l'espace linguistique et du système éducatif qui ont succédé à l'indépendance du pays, le français a su garder sa place de langue d'ouverture à la modernité occidentale et d'accès aux nouvelles technologies. On peut constater que le français jouit au Maroc d'un statut spécial qui reste ambigu, puisque, comme nous l'avons déjà indiqué, il n'a aucun statut officiel. Selon Benzakour:

« [cette] Perception ambiguë du français lui vient principalement de son statut qui n'a été et $n^{\prime}$ est encore jamais clairement défini. Tout se passe comme si toute tentative de politique d'aménagement linguistique transparente est vouée d'avance à l'échec dans cette terre du Maghreb, sans cesse confrontée aux démons de ses (re) constructions identitaires. ${ }^{22}$

Ce constat peut aussi être fait dans le secteur de l'éducation où le français joue un rôle très important comme langue d'enseignement. Benzakour remarque :

21. J. Hooglang, «L'arabe marocain langue écrite», p. 177.

22. F. Benzakour, "Le français au Maroc. De la blessure identitaire à la langue du multiple et de la "copropriation", [en ligne]. 
«Au Maroc, même la Charte nationale d'éducation et de formation, promulguée en 1999, et donc plus de quarante après l'indépendance, ne dit pas explicitement mais sous-entend seulement que le français est la première langue étrangère. Il s'agit là plus d'un statut de fait que de jure. On peut penser que ce statut qui ne se dit pas, ne peut, en toute logique, que fragiliser la position du français dans une région sous l'emprise du multilinguisme et du pluralisme culturel. $\gg^{23}$

Aujourd'hui, la langue française coexiste avec les langues maternelles comme l'arabe dialectal et toutes les variétés linguistiques de l'amazighe, ainsi que les langues de prestige ou institutionnelles comme l'arabe classique.

Toutefois, il est important de signaler que dans le contexte marocain, c'est le français élitaire qui est en position de diglossie avec l'arabe. Benzakour précise que cet idiome :

«Représente des enjeux symboliques fondamentaux. C'est une variété haute qui rivalise avec les variétés de l'arabe moderne; il détient la clef du marché de l'emploi moderne et est le véhicule des sciences et de la technique. Il est associé dans l'imaginaire du locuteur marocain à la culture et au mode de vie de la société occidentale. Langue de prestige social, de valorisation de soi, d'affirmation du statut socioculturel, il est une langue de classe, le bien de l'élite sociale dirigeante. $»^{24}$

La diglossie exolingue arabe/français se manifeste aussi dans le fait que le français est considéré comme une langue de liberté et de la libération de l'expression, alors que l'arabe reste la langue du respect, du Coran et une langue chargée d'une valeur religieuse. Frank Jablonka considère que dans le contexte marocain,

«La compétence en français permet de contourner les impératifs traditionnels, notamment moraux, en vigueur au sein de la communauté d'appartenance. Ainsi, le français est apte à verbaliser des sujets tabous, ce qui ne serait pas ou difficilement possible en arabe sans perdre la face (...) le français se révèle être la langue de la liberté, en vertu de sa force subversive qui permet de créer un espace communicatif libéré où les répressions de la communauté sont annulées. $»^{25}$

Ce même constat peut être fait dans les médias en général, et plus spécialement dans la presse. En effet, au Maroc, la question du récepteur joue un rôle important dans le choix des langues à utiliser pour évoquer les questions taboues. Selon un journaliste marocain,

«Il n'y a qu'à regarder la télévision et lire la presse pour comprendre que, selon la langue $\mathrm{d}^{\prime}$ expression, arabe/français, on ne montre ni on ne dit la même chose puisqu'en tant que journaliste, la première préoccupation que nous avons est le public auquel nous nous adressons. ${ }^{26}$

Dans cette perspective, Anouk Cohen distingue deux types de lectorats qui appartiennent selon lui à des milieux sociaux distincts: lecteurs arabophones et francophones. Le lectorat francophone :

«Se compose de personnes issues de classes aisées ayant réalisé leurs études à la Mission Française et à l'étranger. C'est pourquoi la langue française constitue le signe d'une ouverture vers l'extérieur qui véhicule une autre culture que celle strictement arabomusulmane (...) La langue française est associée à des valeurs, des idéaux et des attentes différents de la langue arabe. Éloignée de la religion et de la Révélation, elle est plus proche des valeurs du siècle des Lumières : liberté, tolérance, laïcité. $»^{27}$

Le lectorat arabophone quant à lui se compose :

23. F. Benzakour, «Le français au Maroc. De la blessure identitaire à la langue du multiple et de la 'copropriation' ». [en ligne].

24. Ibid.

25. F. Jablonka: Un cas de francophonie nord-africaine - à quoi sert le français au Maroc ? [en ligne].

26. A. Cohen, Langue du silence, p. 255.

27. Ibid., p 256. 
«De Marocains issus de milieux populaires et bourgeois, qui présentent un attachement plus grand à l'Islam et au roi, sujets par rapport auxquels ils ont une position moins critique que le lectorat francophone. ${ }^{28}$

Pour démontrer la situation diglossique arabe/français dans la presse, Cohen cite l'exemple de l'affaire Nichane ${ }^{29}$. En 2006, l'hebdomadaire marocain Nichane (écrit en arabe classique et dialectal) est interdit par décision du Premier ministre pour avoir publié un dossier intitulé en traduction française Blagues : comment les Marocains rient de la religion, du sexe et de la politique. L'article publié en français et portant sur le même sujet dans le magazine Tel Quel, l'alter ego arabophone de Nichane, n'entraîne aucune sanction, alors que le rédacteur en chef de Nichane est poursuivi pour atteinte aux valeurs sacrées et la publication et distribution d'écrits contraires à la morale et aux mœurs. Comment expliquer donc cette situation où un article soit condamné pour la seule raison qu'il soit écrit en arabe? L'affaire Nichane montre bien que dans certains contextes, l'arabe semble imposer le silence et rendre certains sujets tabous. Par conséquent on peut postuler que tant à l'écrit qu'à l'oral, la langue arabe est soumise à des contraintes vis-à-vis certains sujets tels que la religion, la sexualité, et de ce fait les locuteurs préfèrent l'usage du français pour exprimer en toute liberté leurs sentiments, leur intimité et leurs idées.

Au terme de cette étude, nous pouvons dire que de la situation linguistique qui prévaut au Maroc indique qu'elle est marquée par sa diversité et par une dynamique frappante. Celle-ci se traduit par l'interaction des idiomes, souvent à travers l'emboitement de leurs usages, et par leur complémentarité dans le champ linguistique, à travers leur métissage et brassage au niveau phonologique, syntaxique et morphologique. Cette dynamique constante fait de la société marocaine une société multilingue, voire multiculturelle. Par conséquent, les différents cas de diglossie qu'on a étudiés dans ce travail doivent être considérés comme des formes de diglossie instable dans lesquelles les positions acquises par chacune des langues ne sont pas irrévocables, puisqu'elles évoluent en fonction des équilibres de pouvoirs entre leurs usagers respectifs, leurs motivations et leurs représentations dans le champ symbolique. On a vu par exemple, comment le cadre diglossique commence à évoluer en faveur d'un rééquilibrage et d'une normalisation de l'amazighe après la création de l'IRCAM et après la reconnaissance de cette langue comme langue officielle. On a vu également le cas du français, langue qui ne bénéficie d'aucun statut de droit mais d'un statut de fait et qui est parfois encouragée et parfois marginalisée selon la conjoncture et en fonction des rapports de forces entre les tenants de l'arabisation et les tenants de la francophonie.

\footnotetext{
Résumé

La situation linguistique au Maroc est marquée par une mosaïque multiculturelle et multilingue. Il s'agit d'un creuset de langues nationales et de langues étrangères, qui, à travers l'histoire se sont enracinées dans le champ linguistique et culturel du pays. D'un côté, on trouve les langues maternelles de la majorité des Marocains que sont l'amazighe (berbère) et la darija (arabe dialectal marocain) et, de l'autre, les langues d'écriture et de l'enseignement, l'arabe standard, le français et l'anglais. La diversité et l'interaction entre ces différentes langues donnent lieu, selon les usages et les usagers, à des pratiques diverses souvent qualifiées de bilinguisme ou multilinguisme. Or ces qualifications ne peuvent englober toutes les situations linguistiques du Maroc; c'est pourquoi nous avons décidé d'adopter le terme diglossie. L'objectif de cet article est donc d'appliquer le concept de diglossie aux langues qui sont en usage au Maroc.
} 


\section{Bibliographie}

ABOU ABDOu Mohammed, L'Arabisation et ses problèmes, IERA, Rabat, 1989.

BENZAKOUR Fouzia, "Le français au Maroc. De la blessure identitaire à la langue du multiple et de la 'copropriation'», Repères DoRiF, $n^{\circ} 2$ Voix/voies excentriques : la langue française face à l'altérité - volet n.1, novembre 2012,

Disponible sur: http://www.dorif.it/ezine/ezine_articles.php?id=47 (consulté le 28.10.2013).

BouKous Ahmed, «Le champ langagier, diversité et stratification », Asinag, no 1, 2008, pp. 15-37.

CALVET Louis-Jean, La guerre des langues et les politiques linguistiques, Payot, 1987.

CALVEt Louis-Jean, Pour une écologie des langues du monde, Paris, Éditions Plon, 1999.

CHAKER Salem, "Le berbère », dans Bernard CERQUIGLINI (dir.), Les langues de France, Paris, PUF, 2003, pp. 215-227.

COHEN Anouk, "La langue du silence dans le Maroc urbain contemporain », Revue de l'histoire des religions, $\mathrm{n}^{\circ}$ 2, 2011, pp. 245-263.

FERGUSON Charles, «Diglossia », Word, n¹5, 1959, p. 325-340.

HoOGLANG Jan, «L'arabe Marocain Langue Écrite», dans FERNANDEZ MONTSERRAT Benitez, Miller Catherine, de RUITER Jan Jaap, TAMER Youssef (dir.), Évolution des pratiques et représentations langagières dans le Maroc du XXI siècle, (volume 1), Paris, L'Harmattan, coll. « Espaces discursifs », 2013, pp. 175-185.

JABLONKA Frank, Un cas de francophonie nord-africaine - à quoi sert le français au Maroc? Disponible sur :

http: / / www.upicardie.fr/Lesclap/IMG/pdf/jablonka_zurichMAR_cle8ade4b.pdf (consulté le 13.11.2013).

PRUDENT Lambert-Félix, "Diglossie et Interlecte». Langages, $15^{\mathrm{e}}$ année, n 61, 1981, pp. 13-38.

MARCAIS William, «La diglossie arabe, dans l'Enseignement public ». Revue pédagogique, tome $104, \mathrm{n}^{\circ} 12,1930$, pp. 401-409.

YOUSSI Abderrahim, «The Moroccan triglossia : facts and implications », International Journal of the Sociology of Language, 1995, pp. 29-44. 


\title{
Un dictionnaire savant de la langue occitane au XVIII siècle
}

\author{
Claire TORREILLES \\ Université Paul Valéry, Montpellier III, \\ LLACS, (EA 3020), membre associé.
}

\footnotetext{
Extrait de : Guylaine BRUN-TRIGAUD (dir. ), Contacts, conflits et créations linguistiques, Paris, Édition électronique du CTHS (Actes des congrès des sociétés historiques et scientifiques), 2015.

Cet article a été validé par le comité de lecture des Éditions du CTHS dans le cadre de la publication des actes du $139^{\circ}$ Congrès national des sociétés historiques et scientifiques tenu à Nîmes en 2014.
}

Les temps sont fastes pour la lexicographie occitane! En 2013 Jean Thomas présentait dans la revue Lengas ${ }^{1}$ un dictionnaire provençal inédit du XVIII ${ }^{\mathrm{e}}$ siècle ${ }^{2}$, d'auteur inconnu. Un an après, un autre dictionnaire est sorti de l'oubli, à Nîmes. Non pas dans un grenier, mais tout prosaïquement là où on pouvait s'attendre à le trouver, dans les archives et bibliothèques. Il a pour titre : Dictionnaire Languedocien.

\section{Une découverte}

En septembre 2013, François Pugnière ${ }^{3}$ a découvert aux Archives départementales du Gard le manuscrit coté ms 1F12, relié portant sur le dos la mention : «DICTION / NAIRE / LANGUE / DOCIEN / anony / me et / inachevé ». Cet ouvrage comprend 272 fo, format $24 / 19,5$. Il s'arrête à " pagadou». Ce manuscrit est une copie soignée pour l'édition (fig. 1) On ne sait pas ce qui l'a interrompu.

François Pugnière pense qu'il vient de la bibliothèque du grand séminaire dont la cote se trouve encore au dos du volume : M 9-43. Quelques jours plus tard, c'est Didier Travier, consulté sur l'ouvrage, qui retrouve la suite dans le fonds de la bibliothèque municipale du Carré d'Art. Il s'agit du manuscrit $804^{4}$ : « Dictionnaire occitan, incomplet, lettres $\mathrm{P}$ à U. ». L'écriture est identique, même si la présentation est celle d'un brouillon, non paginé, un ensemble de cahiers de format $23 \times 18$. Il comprend 11 cahiers. Il en manque un pour que le dictionnaire soit vraiment complet : il y a une lacune de Rao à Ras, une quarantaine de pages.

\section{Description}

En l'état, les deux parties forment un ensemble de 1037 pages. Le nombre d'entrées est approximativement estimé à 15000, ce qui situe notre dictionnaire entre la première (1756) et la deuxième édition (1785) du Dictionnaire languedocien-français de l'abbé de Sauvages, loin derrière le Dictionnaire Provençal dont Jean Thomas évalue le nombre d'entrées à 34000 .

Actuellement, nous ne pouvons nous avancer ni sur l'histoire de ces manuscrits, ni sur le nom de l'auteur. Nous pouvons toutefois proposer comme lieu d'écriture Montpellier et

1. Lengas.revues.org/

2. Disponible sur le site de l'université de Toulouse : http:/ / tolosana.univ-toulouse.fr/ notice/165803770

3. Tous mes remerciements vont à François Pugnière qui a non seulement découvert le dictionnaire mais l'a photographié pour le mettre tout de suite à portée des chercheurs en domaine occitan.

4. Bibl. mun. de Nîmes. Ce manuscrit avait été répertorié par Brigitte Schlieben-Lange (Fabié 2015). 
comme date une période qui va de 1760 à 1780. Les deux références les plus tardives sont 1764 (busquieiro [p. 142]) et $1765^{5}$ (estimo [ $\left.\left.\mathrm{f}^{\circ} 161 \mathrm{r}^{\circ}\right]\right)^{6}$.

Le titre, Dictionnaire languedocien, ne signale pas le caractère bilingue du dictionnaire, mais désigne comme langue source le languedocien ou plus exactement la variété languedocienne, au singulier, de la langue d'oc. De fait, l'espace couvert est le Languedoc, dans son acception la plus large, de Toulouse à Nîmes et la langue est traitée comme l'ensemble des "parlers languedociens». Mais en l'absence de toute forme de métatexte, préface, note, explication ou commentaire, nous devons expliciter nous-mêmes le codage du dictionnaire, ses représentations linguistiques et ses intentions.

Par exemple, l'entrée suivante :

[f106 $\mathrm{r}^{\circ}$ ] courdurié. s. m. [pen. br.] h. b. couturier.

fait apparaître trois ensembles d'abréviations désignant la caractérisation grammaticale du mot, son accentuation et sa localisation.

- La caractérisation grammaticale distingue classiquement: substantifs (s. ), adjectifs (adj.), au féminin (f. ) ou au masculin (m); adverbes (adv. ), verbes (v. ) «actifs» ou «neutres » (intransitif) pour lesquels l'accentuation n'est pas indiquée.

courdura : v. actif. h. b. coudre. [ $\left.\mathrm{f}^{\circ} 106 \mathrm{r}^{\circ}\right]$

courrê, v. neut. h. b. courir. [ $\left.\mathrm{f}^{\circ} 106 \mathrm{v}^{\circ}\right]$

- L'accentuation est notée entre crochets. On trouve les notations suivantes: [pr. long.], [pen. long.], [pr. br.], [pen. br.]. L'auteur utilise un système unique qui adapte à l'occitan, pour indiquer l'accent du mot, les principes de l'accentuation latine fondée sur la longueur et non sur la quantité de la voyelle.

Ainsi, ce n'est pas l'accent qui indique la voyelle tonique. L'accent sert seulement à indiquer l'ouverture de la voyelle:/é/ $[\varepsilon]$ ou sa fermeture: /ê/ [e]. Au reste, l'auteur dispose d'un système graphique propre, sans originalité mais cohérent, dans lequel il transpose toutes les citations d'auteurs.

u fermé [u] est noté / ou / : frêscou, faissou, fangous, gous, houro

les diphtongues [ay], [au], [èw], [ow], [iw] sont notées comme dans les mots: airê, houstaou, fourréou, poou, ioou, adiêou, liêoure, iêou, viêourê...

pour les consonnes :

[j] est noté / lh / : Cêndrilhou, Mounpêlhé, acounsêlha, batalha...

[n] est noté /gn/: mountagno, vêrgougno, gagnairê...

[d]] est noté / ge/ : mestregea, moungê, moustegea, gourgeado

- La localisation du mot est indiquée par les abréviations : h. b. ou h. ou b.

L'auteur distingue Haut et Bas-Languedoc. On déduit de la localisation des œuvres citées que le Haut-Languedoc va de Toulouse à Narbonne, le Bas-Languedoc de Béziers à Nîmes. L'auteur enregistre les différences. Il y a par exemple une entrée escoubo, b. (du latin 'skopa', précise-t-il) $\left[\mathrm{f}^{\circ} 150 \mathrm{v}^{\circ}\right]$ et une entrée engraniéro, $h$. [ $\left.\mathrm{f}^{\circ} 142 \mathrm{v}^{\circ}\right]$, une entrée luchet, b. $\left[\mathrm{f}^{\circ} 230 \mathrm{v}^{\circ}\right]$ (qu'il traduit louchet, bêche) et une entrée becat, $h$. [ $\left.\mathrm{f}^{\circ} 47 \mathrm{v}^{\circ}\right]$.

Il se place plus facilement du point de vue du Bas-Languedoc, renvoyant bendemia à vendemia, belha à velha, luto à lucho, loc à lioc. Il lui arrive aussi de donner le choix des deux mots à la même entrée : counêissê ou counouissê, empêdaou ou empêraou, ou encore de mettre

5. La citation est ainsi annoncée : « On lit dans un Noël imprimé à Narbonne, 1765 ».

6. À partir de maintenant, les références au ms 1F12 des Archives de Nîmes sont indiquées par le numéro du foliotage d'archive, mais celles du ms.804 de la Bibl. mun. sont indiquées par le numéro d'origine de la page, à défaut d'autre foliotage. 
séparément les deux entrées: gabach et gavach, balê et valê, les deux mots, dans les deux cas, sont également localisés : $\mathrm{h}$. b.

On note que le scrupule dialectologique, s'il est réel, se manifeste avec une certaine souplesse. Si l'on trouve, en début d'ouvrage, quelques considérations systématiques sur la variation comme dans l'article suivant :

Abéy, adv. de temps [pr. br] h. aujourd'hui. À Toulouse, on dit houéy. À Lavaur, à Castres, à Saint Pons on dit béy ou abéy. Â Montpellier et aux environs on dit hioi. Et à Nîmes, à Alais, à Uzès, on dit hiuéi. [f $\left.{ }^{\circ} 3 \mathrm{r}^{\circ}\right]$

Ce traitement de la variation n'est pas la règle dans l'ensemble de l'ouvrage. Le plus souvent, l'auteur se contente de noter la différence d'emploi «en quelques lieux du Languedoc » :

Piboul. s. m. [pr. br] h. peuplier [...] En quelques lieux on fait longue la première syllabe de piboul. [p. 78].

\section{Sources}

Deux sources importantes dans le domaine occitan sont aisément identifiables. La première est le Dictiounari moundi de Doujat qui accompagne les œuvres de Godolin à partir de l'édition de 1638 (Toulouse). La seconde n'est autre que la première édition du Dictionnaire languedocien-français (1756) de l'abbé de Sauvages. Avec ces deux ouvrages, l'auteur assure une bonne couverture de l'espace haut et bas languedocien. Certes, il intègre avec méthode le matériau lexical emprunté (l'entrée et une partie de la définition) : il transpose le mot dans son propre code graphique et procède à des ajouts, des coupures, des reformulations ou à des redistributions grammaticales et sémantiques en fonction de son propre sentiment de la langue et de l'ordonnance interne de son ouvrage. Ainsi on peut suivre la filiation dans les deux exemples suivants pour les entrées Majoural et Péirado:

Doujat [p. 377]

Majouraüt, l'aîné de la maison, le coq de la paroisse, un gros garçon.

Dictionnaire Languedocien $\left[\mathrm{f}^{\circ} 234 \mathrm{v}^{\circ}\right] \mathrm{ms} .1 \mathrm{~F} 12$

Majoural ou Majouraou. s. m. [pen. br. ] h. b. le berger principal, le maitre berger du latin 'major'.

Aqui vênién lous majouraous ên sas claouzissos e barraous... Le Sage

Alounguat dêssus un toural pêr rêjouhi lou majoural... L'E. de Besièrs, liv. 1 de l'Enéide.

Majoural dans le Haut-Languedoc se prend pour le coq de la paroisse et pour l'aîné de la maison.

Sauvages [p. 348]

Pêirâdo, buvée, s. f. ce qu'on fait cuire dans un chauderon pour le repas des cochons, pr. chodron.

Dictionnaire Languedocien [p. 48] ms. 804

Péirado. s. f. [pen. long. ] h. un chemin pierreux. En certains lieux du Bas-Languedoc, péirado signifie buvée, ce qu'on fait cuire dans un chaudron pour le repas des cochons.

L'auteur du dictionnaire établit le sens le plus général, se fondant sur l'étymologie, puis donne le sens local particulier. Il ajoute une ou plusieurs citations littéraires et laisse de côté systématiquement ce qui, chez Sauvages par exemple, soit indique la bonne 
prononciation du mot français (ici: chaudron) soit relève de la botanique ou de la médecine populaire ${ }^{7}$ (badâfo, marsîourë, pebrié, rouzêlo...).

D'autres sources existent dans la lexicographie occitane, comme le petit lexique d'Amilha, mis en annexe au Tableu de la bido del parfet crestia...(1673), ou, très certainement, le dictionnaire actuellement perdu ${ }^{8} \mathrm{du}$ montpelliérain Jacques Roudil dont notre auteur possédait une ou plusieurs copies manuscrites.

Alors qu'il est pour le moins discret sur ses sources occitanes (il ne cite qu'une fois Sauvages à l'article Raiol [ $\mathrm{f}^{\circ} 167 \mathrm{r}^{\circ}$ ], l'auteur du Dictionnaire languedocien a toujours soin de donner le plus précisément possible les références de ses sources françaises ou européennes.

Les dictionnaires français les plus fréquemment cités sont ceux de Nicot (1606), Guichard (1618), Pasquier (1643), Ménage (1650), Borel (1655), Du Cange (1678), Furetière (1690), le Dictionnaire de l'Académie (1694), le Dictionnaire de Trévoux (1721), comme on le voit à l'entrée Êscarrabilhat [fำ $\left.149 \mathrm{r}^{\circ}\right]$ :

Êscarrabilhat. adj. m. [pen. br. ] escarrabilhado. f. [pen. long. ] h. b. éveillé, réjoui, gai, de bonne humeur ; gaillard, enjoué, joyeux. Les femmes, pour consoler Augier Gaillard sur la mort de son épouse lui disent:

Aco cal dêbrêmba, nous bou'n sabén uno aoutro qu'ês escarrabilhado, é n'a sounquê vingt ans... Augier Gaillard

Pasquier liv. 7 de ses Recherches chap. I parlant des Gascons les appelle « êscarrabilhats » [...] Montagne liv. 2 chap. 35 dit «scarbillat ». [...] Furetière a dit « escarbillat » et M. M. de l'Académie « escarbillard».

Alors que la définition reprend terme à terme celle de Sauvages et à peu près celle Doujat, sans le dire, la présence du mot occitan chez Pasquier, Montaigne, Furetière et dans le dictionnaire de l'Académie est mise en évidence comme un brevet de francité. D'ailleurs Sauvages donnait en première définition pour ëscarabilia : escarbillat, faisant remarquer ensuite que les deux mots « ont trop de ressemblance pour que certaines personnes eussent osé l'employer », évoquant l'insécurité linguistique dans laquelle se trouvent les Languedociens cultivés. Mais l'aspect normatif intéresse moins notre auteur que la démonstration de la vitalité de la langue d'oc, en soi et en osmose avec la langue française. Il s'appuie sur de nombreuses citations empruntées à Rabelais et Montaigne et inspirées par les éditions critiques du début du XVIII ${ }^{\mathrm{e}}$ de ces deux auteurs (Le Duchat 1741 ; Pierre Coste 1724).

L'influence des lexicographes français $\mathrm{du} \mathrm{XVII}^{\mathrm{e}}$ est surtout sensible sur deux points: l'interrogation sur les origines et l'intention encyclopédique.

\section{Recherches des origines et tentation encyclopédique}

Comme chez Pasquier, Nicot, Ménage, Borel, le dictionnaire tend à rassembler le plus grand nombre d'explications sur "l'antiquité » d'un mot, l'origine d'une expression lexicalisée. On trouve encore plusieurs références explicites ou non à la dissertation de

7. Claire Torreilles (2013): Les trois éditions du Dictionnaire Languedocien-Français de l'abbé Boissier de Sauvages, occitanica.eu/

8. Roudil, dans un poème dédicatoire de son «Dictiounari vulgari » adressé à Henry de Bourbon, duc de Verneuil (Barral, 1982, 149-152) fait l'éloge de ce dictionnaire et dit son utilité pour les «francimans». Vous y apprendrez, dit-il, ce que veut dire "gibré, / embalausit, eglach, embrounquat, espeillat, / embut, escafarnel embe escarabillat / fanabreguo, faufrach, faudo, falourd, fringairo, / garcegea, galavar, goullamas, gavelairo... ». Si petit soit-il, cet échantillon de son dictionnaire se trouve sans exception dans le Dictionnaire languedocien. 
Caseneuve ${ }^{9}$ sur les origines « de la langue d'oc ou provençale » qui accompagne, comme le dictionnaire de Doujat, l'édition de 1678 de Godolin.

L'auteur anonyme est attentif à rechercher et proposer diverses hypothèses de racines celtes, grecques, latines, arabes ou hébraïques des mots occitans, comme le fait à la même époque le linguiste Court de Gebelin ${ }^{10}$ dont on ne sait s'il l'a consulté. Ainsi il fait dériver cêzê $\left[\mathrm{f}^{\circ} 93 \mathrm{r}^{\circ}\right] \mathrm{du}$ latin 'cicer'noro $\left[265 \mathrm{v}^{\circ}\right]$ du latin 'nurus'counil $\left[\mathrm{f}^{\circ} 104 \mathrm{r}^{\circ}\right] \mathrm{du}$ grec 'kunillos'coumbo $\left[\mathrm{f}^{\circ} 103 \mathrm{r}^{\circ}\right]$ du grec 'kumbos'meno [ $\left.{ }^{\circ} 247 \mathrm{r}^{\circ}\right]$ de l'hébreu 'min'. Il confronte au besoin plusieurs théories, comme dans l'exemple suivant :

$\left[\mathrm{f}^{\circ} 92 \mathrm{v}^{\circ}\right]$ Cérs : s. m. b. vent de bise. Ce mot se trouve souvent dans les anciens actes qui parlent de la position d'un champ, d'un pré etc. Ce vent est particulier au bas Languedoc ; il est appelé en latin Cercius ou Circius.

Basile Faber ${ }^{11}$ dans son Trésor (litt. C) dit que ce vent «est nulli reliquorum vehementia inferior in narbonensi praesertim provincia... huic, ne galliam rapidus infestaret, Augustus aliquando votum solvit » et l'on voit dit-on, encore à Narbonne, l'autel que cet Empereur lui consacra.

Rabelais, liv. 4. chap. 43 : «Ô qui pourrait avoir une vessie de ce bon vent de Languedoc que l'on nomme Cercie qui renverse les charrettes chargées ». Borel dit que, selon Aulu-Gelle, en le Grand Atlas, Cers est un mot d'ancien gaulois.

L'accumulation de références érudites tend à prouver que le mot est non seulement attesté dans un espace précis mais qu'il a une incontestable ancienneté juridique, linguistique, historique, littéraire laquelle renvoie in fine à l'hypothèse celte. On trouve le même procédé d'étagement, parfois complexe, des références pour des noms propres dont l'étymologie a déjà fait couler beaucoup d'encre : Mountpêlhé $\left[\mathrm{f}^{\circ} 255 \mathrm{v}^{\circ}\right]$, Huganaout $\left[\mathrm{f}^{\circ} 209 \mathrm{r}^{\circ}\right]$, Catarinot $\left[\mathrm{f}^{\circ} 91 \mathrm{r}^{\circ}\right]$ Languedoc $\left[\mathrm{f}^{\circ} 225 \mathrm{r}^{\circ}\right]$.

Le Castrais Pierre Borel (1655) est pour notre auteur bien plus qu'une source, un modèle. Abondamment cité, il représente d'une part une ressource en matière d'étymologie et de linguistique comparée en domaine roman puisqu'il intègre dans son dictionnaire de nombreux mots occitans médiévaux ou modernes ${ }^{12}$ et d'autre part il est porteur, comme le montre Jean-Pierre Cavaillé (1982), d'une «curiosité encyclopédique héritée de la Renaissance » qui ouvre le dictionnaire à de nombreux champs du savoir de son temps.

L'auteur du dictionnaire cède sans réserve cette tentation encyclopédique qui fut celle de Furetière, non qu'il ait la prétention d'être « universel » mais, semble-t-il, avec l'intention de ne laisser de côté aucun des aspects du champ culturel et de la vie sociale qui correspondent aux usages de la langue, aux $\mathrm{XVII}^{\mathrm{e}}$ et $\mathrm{XVIII}^{\mathrm{e}}$ siècles. En cela il produit, consciemment, méthodiquement, un dictionnaire savant. Savant, moins par la profusion des connaissances et des domaines abordés que par la capacité de les mettre en relation et de leur donner du sens.

On voit par exemple au fil des articles se constituer un véritable tableau de la vie montpelliéraine au XVIII ${ }^{\mathrm{e}}$ siècle qui, certes, doit beaucoup aux historiens, aux érudits et aux écrivains des siècles précédents ${ }^{13}$, Pierre Gariel, Laurent Joubert, Pierre Magnol, Guillaume Rondelet, Isaac Despuech et Jacques Roudil, mais qui fait aussi appel à une connaissance personnelle: façons de parler de cuisiner, de jouer ${ }^{14}$, de se distraire ${ }^{15}$,

9. Pierre Caseneuve a mené une double réflexion sur les "origines françaises", dissertation publiée dans le dictionnaire de Ménage à partir de 1694, et sur les origines de la langue d'oc.

10. Nîmes, Bibl. mun. Ms 141, $\mathrm{f}^{\circ}$ 93-107. Essai sur l'origine de la langue gasconne.

11. Basil Faber (1571, rééd. 1735).

12. Fabienne Gégou $(1983,30)$.

13. À notre connaissance, il ne cite pas l'ouvrage de Charles d'Aigrefeuille, Histoire de la ville de Montpellier, paru pourtant en 1739, Montpellier, Rigaud.

14. Les nombreuses descriptions de jeux d'enfants constituent un véritable trésor des jeux anciens en Languedoc: cambaleto $\left[\mathrm{f}^{\circ} 79 \mathrm{r}^{\circ}\right]$; castelet $\left[\mathrm{f}^{\circ} 90 \mathrm{v}^{\circ}\right]$; coucoumet $\left[\mathrm{f}^{\circ} 100 \mathrm{r}^{\circ}\right]$; courcasselo $\left[\mathrm{f}^{\circ} 106 \mathrm{v}^{\circ}\right]$; coutelou $\left[\mathrm{f}^{\circ} 108 \mathrm{r}^{\circ}\right]$; coucut $\left[\mathrm{f}^{\circ} 100 \mathrm{v}^{\circ}\right]$; cabro ses tu cabro $\left[\mathrm{f}^{\circ} 73 \mathrm{v}^{\circ}\right]$; jusso $\left[\mathrm{f}^{\circ} 216 \mathrm{v}^{\circ}\right]$; pipot $[\mathrm{p} .94]$; pateto un $[\mathrm{p} .41] \ldots$

15. Le jeu de mail (jòc de palamar) avec son vocabulaire spécifique, le jeu de paume (paoumo), ou encore l'ouleto $\left[\mathrm{f}^{\circ} 269 \mathrm{v}^{\circ}\right]$, «jeu fort en vogue parmi le bas peuple à Montpellier » dont parle Rabelais. 
mémoire des lieux ${ }^{16}$ et des personnes, monnaies et mesures... De nombreuses définitions commencent par "à Montpellier ou dans les environs ». Le dictionnaire nous paraît à l'évidence écrit à Montpellier par quelqu'un qui en connaît bien l'économie locale ${ }^{17}$, la vie municipale ${ }^{18}$, les structures administratives et les institutions académiques.

Les autres villes languedociennes sont également présentes, mais l'approche en semble plus livresque. L'auteur s'appuie sur des historiens du Languedoc dont le plus récent semble être Jean Astruc (1737), sur les Toulousains Lafaille (1687) et Odde de Triors ${ }^{19}$ (1578) à qui il emprunte quantité d'anecdotes pittoresques dont quelques-unes ont déjà été évoquées par Borel et Furetière mais dont il se délecte encore, comme le moinebourru ${ }^{20}$, la « Malobestio », ou les « Réveilleurs ».

Dans un registre plus grave, l'auteur du Dictionnaire, comme tous les intellectuels de son temps, s'intéresse aux relations nombreuses, témoignages, récits historiques et monographies sur les troubles religieux anciens et récents en Languedoc. Mais les auteurs qu'il cite : Guillaume de Reboul (1600), Jean Léger (1669), le père Bonnefoy (1667) et quelques commentaires qu'il en fait ne laissent aucun doute sur sa foi catholique, sa connaissance de la doctrine et de la liturgie... et ses positions radicales.

\section{Curiosité ethnographique}

L'auteur éprouve à l'égard des croyances et des superstitions une fascination/répulsion non déguisée. Elles sont aussi vivement décrites que décriées et toujours assimilées à la sorcellerie, condamnées au nom de la foi chrétienne plus que du rationalisme, renvoyées à l'ignorance populaire. Ce sont pratiques du "peuple», de "paysans mal instruits ${ }^{21}$ », de "gens de la campagne ${ }^{22}$ ", «en certains lieux du Haut Languedoc». Ses sources ethnographiques sont nombreuses. Outre les chroniqueurs et historiens déjà mentionnés, comme Laurent Joubert, professeur de médecine à Montpellier, auteur des Erreurs populaires (1578) citons son continuateur Gaspard Bachot (1626), Jean Bodin auteur De la démonomanie des sorciers, (1580), Jean-Baptiste Thiers, auteur du Traité des superstitions (1697) sans oublier "L'examen de las supersticius ${ }^{23}$ » dans Le Tableu de la bido del parfet crestia... (1673) qui est l'ouvrage littéraire le plus fréquemment cité dans le dictionnaire.

Les feux de la saint Jean sont particulièrement dénoncés comme des survivances du paganisme combattu par les Pères de l'Église. Le renvoi aux entrées qui traitent des « herbes de la saint Jean » arsenizo $\left[\mathrm{f}^{\circ} 33 \mathrm{v}^{\circ}\right.$, faougièro $\left[\mathrm{f}^{\circ} 167 \mathrm{r}^{\circ}\right.$ ]et trescalan [p. 415] poursuit l'attaque en règle où voisinent citations érudites et répugnance personnelle. Il y a bien d'autres «superstitions abominables» décrites sous les entrées : mandrigoulo [ $\left.\mathrm{f}^{\circ} 238 \mathrm{v}^{\circ}\right]$, masco $\left[\mathrm{f}^{\circ} 243 \mathrm{r}^{\circ}\right]$, fado $\left[\mathrm{f}^{\circ} 165 \mathrm{v}^{\circ}\right]$, fachilié $\left[\mathrm{f}^{\circ} 165 \mathrm{r}^{\circ}\right]$, souco [p. 292], garles [fำ $\left.190 \mathrm{v}^{\circ}\right]$.

Tous ces articles de contenu ethnographique, Sauvages, dans sa deuxième édition de 1785, puis Mistral s'en inspireront, mais leur regard sur la société et le peuple se chargera

16. agulho [ $\left.\mathrm{f}^{\circ} 15 \mathrm{v}^{\circ}\right]$, Salicato [p. 239], Baboto [ $\left.\mathrm{f}^{\circ} 38 \mathrm{r}^{\circ}\right]$, dougo [129 $\left.\mathrm{v}^{\circ}\right]$, ourgearié (II 723$) \ldots$

17. à l'entrée verdet [p.469] par exemple, il détaille les techniques de la production particulière du vert de gris, à Montpellier.

18. baile $\left[\mathrm{f}^{\circ} 40 \mathrm{v}^{\circ}\right]$ évoque par exemple $\mathrm{l}^{\prime}$ ancienne «cour daou baile» devenue «cour des ordinaires »; rullé $\left[\mathrm{f}^{\circ} 217 \mathrm{r}^{\circ}\right]$ décrit en détail le système d'élection des consuls de Montpellier. Il cite souvent le code Reboul (livre municipal), les règlements de police sur les moulins à huile (menado $\left.\left[\mathrm{f}^{\circ} 246 \mathrm{v}^{\circ}\right]\right)$, la vente des abats pendant le Carême (frechan $\left.\left[\mathrm{f}^{\circ} 181 \mathrm{v}^{\circ}\right]\right) \ldots$

19. Odde de Triors dont l'auteur recopie de nombreux développements a toute sa place dans la liste des lexicographes / ethnographes inspirateurs de l'auteur du dictionnaire : il a lui-même, remarque Gaston Brunet qui l'édite en 1847 , « beaucoup lu et relu Rabelais».

20. Furetière cité par H. Meschonnic (1991), p. 141.

21. arsenizo $\left[\mathrm{f}^{\circ} 33 \mathrm{v}^{\circ}\right]$

22. [p. 415].

23. p. 223-286. Cette partie qui traite de «La bido del fals crestia descuberto é coundamnado» constitue une revue très informée des faits, gestes, paroles et croyances populaires que les « Rittous, Missiounaris, Coufessous é autres que tribailhon al salut de las armos » auront à cœur de dénoncer et combattre. 
de plus d'indulgence et même d'une réelle connivence. Avec le Félibrige héritier du romantisme, en un siècle, les valeurs se seront inversées : les sorcières, le feu de la saint Jean, le souc de Nadal - que notre auteur trouve parfaitement ridicule - ainsi que les créatures fantastiques: la farramaouco $\left[\mathrm{f}^{\circ} 108 \mathrm{r}^{\circ}\right]$, lou babaou $\left[\mathrm{f}^{\circ} 38 \mathrm{r}^{\circ}\right]$, lou fantasti, lou drac $\left[\mathrm{f}^{\circ} 167 \mathrm{r}^{\circ}\right]$ seront considérées comme les manifestations originales d'une culture et d'une langue.

\section{Conscience et culture littéraires}

C'est très souvent la littérature, on l'a déjà vu avec certains exemples, qui sert de lien entre les savoirs mis en œuvre dans le Dictionnaire languedocien. On peut difficilement parler d'arrière-plan littéraire tant la littérature occitane (languedocienne) des XVII ${ }^{\mathrm{e}}$ et XVIII ${ }^{\mathrm{e}}$ siècles s'impose au premier plan dans cet ouvrage. Elle est montrée, valorisée, mise en scène. Nulle part ailleurs au XVIII ${ }^{\mathrm{e}}$ siècle, on ne trouve un tel rassemblement $\mathrm{d}^{\prime} œ u$ res constituant véritablement un corpus littéraire cohérent et ouvert, une sorte d'anthologie personnelle dans une graphie commune.

À la lecture de ce dictionnaire, on ne peut s'empêcher de rêver à la bibliothèque que l'auteur avait à sa disposition. La profusion des œuvres citées, imprimées ou manuscrites est telle que très vite, quand on feuillette le dictionnaire, c'est cela qui frappe : le plaisir du texte partagé. Il donne l'impression, pour citer Robert Lafont, " qu'un nœud de conscience occitane existe dans les lectures érudites ».

Deux Toulousains, un Bénédictin le père Grimaud (1669) et un Augustin, le père Amilha (1673), déjà cité, sont les auteurs de loin les plus présents, dans toutes les parties du dictionnaire, avec une régularité remarquable. Ils sont accordés à la culture ecclésiastique de notre auteur, qui est probablement un clerc.

La première moitié $\mathrm{du} \mathrm{XVII}^{\mathrm{e}}$ siècle toulousain est dominée par la figure du poète Godolin qui est aussi abondamment cité, sans doute d'après l'édition déjà mentionnée de 1678 qui comprend, outre le Doujat et la dissertation de Caseneuve, nombre de pièces dédicatoires citées : Le trimfle del moundi $\left[\mathrm{f}^{\circ} 85 \mathrm{r}^{\circ}\right.$ ], L'oumbro del grand Goudelin, Épigramme de D. Rouguié $\left[\mathrm{f}^{\circ} 244 \mathrm{v}^{\circ}\right]$, Odo en fabou del bi costo l'aigo de Gautier [ $\left.\mathrm{f}^{\circ} 55 \mathrm{v}^{\circ}\right]$. Notre auteur cite avec finesse et commente non seulement les différentes Flouretos (environ 260 occurrences) mais aussi une trentaine de pièces en prose, prologues et cartels.

Parmi les Toulousains, plus près de lui, il n'ignore ni la Pastorale de Daphnis et Alcimaduro de Cassanea de Mondonville (soulel [p. 298]), ni Lou sourcié de la lando de Coussé de Latomy (1755), adaptation du Devin de village de Rousseau. Augier Gaillard (1584), le " rodier » de Rabastens, lui plaît particulièrement pour sa verve et la richesse d'une langue en prise sur les usages populaires.

Les pastorales du "Théâtre de Béziers » occupent dans cet ensemble de références littéraires une place très importante : treize pièces citées, 258 occurrences, couvrant toute la période de production (1628 à 1660) et tous les auteurs, dont l'avocat Bonnet qu'il cite aussi (environ vingt occurrences de longs passages) pour les Desordres dêl pahis bas. Nous ne savons pas de quelles éditions il disposait parmi les livres édités par Martel de 1628 à 1660 .

Dans la seconde moitié du XVII ${ }^{\mathrm{e}}$ sont publiées au moins deux traductions de l'Enéïde, d'un burlesque tempéré, celle de Bergoing (1652) à Narbonne et celle de L'Estagniol, avocat à Béziers (1682), toutes deux fort présentes dans le dictionnaire, ainsi que les poèmes du père Martin, jésuite, $d$ 'inspiration goudelinienne mais marqués par une sensibilité nouvelle au paysage, aux mœurs, aux saisons. Les citations faites de ce Bouquet de cauquos flouretos cuillidos sul Parnasso biterrois pour l'année 1723, 1726, 1729 et 1738 nous laissent penser que l'auteur du dictionnaire avait pu consulter ces ouvrages imprimés (chez 
Barbut à Béziers) mentionnés comme rares dans les bibliographies du XIXe siècle et aujourd'hui perdus ${ }^{24}$.

De Béziers viennent encore des pièces inconnues jusqu'à aujourd'hui comme $L a$ bancarouto de la Matriculo de Besiérs dont il dit qu'elle a été jouée en $1710^{25}$ (12 occurrences) ou comme le long poème cité in extenso, à la fin de la première partie, Las Justos de Beziers, daté du 29 août $1712\left[\mathrm{f}^{\circ} 217 \mathrm{r}^{\circ}\right.$ à $\left.218 \mathrm{v}^{\circ}\right]$, écrit par « un poète biterrois » à $\mathrm{l}^{\prime}$ occasion de la victoire remportée en Flandres sur les ennemis de la France.

Dans le paysage littéraire du Dictionnaire languedocien, Montpellier occupe une place centrale. C'est le Montpellier du XVII siècle qui se dessine, celui d'Isaac Despuech, de Jacques Roudil et de Nicolas Fizes. L'abbé Fabre est tout juste connu de l'auteur qui le désigne comme « M. F. prieur dans le diocèse de Montpellier » auteur de la traduction de la $8^{\mathrm{e}}$ satire $\mathrm{d}^{\prime}$ Horace (cabraou $\left[\mathrm{f}^{\circ} 73 \mathrm{v}^{\circ}\right]$ ) dont il cite les quatre premiers vers.

Les références qu'il donne des Fouliés daou Sage (Despuech) attestent que l'auteur a utilisé l'édition de 1650, composée par Roudil. Il cite en effet toutes les grandes pièces de ce recueil (160 occurrences) mais aussi la fameuse «Cansoun de la maoumaridado » à la page 201 de l'édition 1650 ainsi que « divers poèmes » érotiques censurés dans l'édition Pain (1700) comme elles le seront dans l'édition du XIX ${ }^{\mathrm{e} 26}$. Mais il a aussi d'autres sources, comme en témoignent quatre vers d'un «Dialogo daou Sabat » dont il précise qu'il est « non imprimé » (plegadis [p. 105]).

L'œuvre de Roudil est toujours citée en référence à un manuscrit, ce qui est normal puisque la première édition de l'œuvre de Roudil est celle de Marcel Barral (1982 et 1983). Mais le fait qu'une trentaine de titres de poèmes cités ${ }^{27}$ ne se trouvent pas dans cette édition laisse penser, à juste titre, que l'auteur possédait une autre copie manuscrite que celle que Barral a suivie ${ }^{28}$.

On est plus étonné de trouver mention de L'opéra de Frontignan de Nicolas Fizes dont l'édition de 1679 est depuis longtemps signalée comme fort rare, mais notre auteur devait en avoir un exemplaire ${ }^{29}$ parce que les références qu'il fait (15) ne comportent pas la mention « $\mathrm{ms}$ ». Il cite en outre neuf vers d'une idylle «L'apotheozo de l'oulo » de Fizes (jerlé [ $\left.\left.\mathrm{f}^{\circ} 212 \mathrm{r}^{\circ}\right]\right)$, et huit vers d'une chanson inédite (ussos [p. 489]).

L'espace languedocien de notre auteur s'étend jusqu'à Nîmes, avec l'œuvre imprimée de Jean Michel publiée en 1700 dans l'édition Pain, avec Despuech, abondamment citée (et quelque peu infléchie linguistiquement vers le languedocien) dans le Dictionnaire (plus de 150 occurrences). Mais c'est moins L'embarras de la fieiro de Beucaire... ${ }^{30}$ qui est mise en avant que les pièces suivantes, moins connues ${ }^{31}$, comme Emblemo de la vido de l'homme (159-173).

Enfin, nous trouvons de très nombreuses et très plaisantes références à des chansons (99 occurrences) placées surtout au début de la première partie de l'ouvrage. Les citations

24. Léon Gaudin a publié quelques pièces dans la Revue des Langues Romanes de 1884 et Frédéric Donnadieu a donné une édition complète d'après une copie manuscrite, dans les bulletins de la Société Archéologique de Béziers en 1899.

25. ailleurs il dit : 1701 .

26. édition de la Sté des bibliophiles languedociens (A. Des Mesnils) Montpellier, Coulet, 1874.

27. («Satyro»; aco sieou $\left[\mathrm{f}^{\circ} 7 \mathrm{v}^{\circ}\right]$; gouma $\left[\mathrm{f}^{\circ} 196 \mathrm{r}^{\circ}\right]$; pengea [p.57] ; pieouzelo [p.85] putarro [p.140], sicap [p.282],

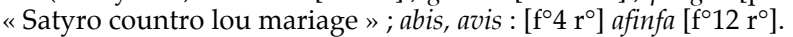

28. Barral avait édité le ms du fonds Lunaret de la Société Archéologique de Montpellier. Notre auteur avait en sa possession le manuscrit actuellement répertorié au Cirdoc sous la cote: Ms 296, portant l'ex-libris de Sauvadet. cf.Occitanica.eu/

29. qui est peut-être celui que Léon Gaudin décrit ainsi « un exemplaire dont le titre manque, petit in B de 64 p. entièrement imprimé en italiques sortant des presses de Daniel Pech de Montpellier », il le voit dans la vente de Villiers en 1837.

30. À l'entrée fieiro $\left[\mathrm{f}^{\circ} 172 \mathrm{r}^{\circ}\right]$ : il dit: Michel de Nîmes a fait un poème qu'il a intitulé L'êmbarras dê la fiéiro dê Bêoucairê ». En quelque lieu on dit «fiéro » cite Goudelin « a la fiéro dês trucs... ».

31. 140-186 de l'édition Pain. 
sont souvent longues, jamais moins d'une strophe - et pas nécessairement la première souvent deux ou trois, et quelquefois la chanson est donnée dans son intégralité : «Menudo » (amistat $\left.\left[\mathrm{f}^{\circ} 23 \mathrm{r}^{\circ}\right]\right)$, «Soi a Bacus » (bebeire $\left.\left[\mathrm{f}^{\circ} 47 \mathrm{r}^{\circ}\right]\right)$, « La noiriço endormido » (Margarido [ $\left.\left.\mathrm{f}^{\circ} 241 \mathrm{r}^{\circ}\right]\right)$. Selon, Pierre-Joan Bernard, elles proviennent de plusieurs répertoires différents toulousains, narbonnais, montpelliérains ou provençaux de la seconde moitié du XVIII ${ }^{\mathrm{e}}$ siècle. Mais les airs ne sont pas donnés, un grand nombre de chansons ne sont pas encore identifiées. La chanson, même libertine, ne paraît pas choquer notre auteur; bien au contraire, il en apprécie la facilité, la langue juste. On pressent la vogue montpelliéraine d'un genre qui va porter le renouveau de l'écriture en occitan, une transparence de registre qui plaît à la bonne société et que Philippe Gardy (1985) a appelé l'oraliture.

\section{Le roman du langage}

Chaque mot de la langue ou presque, on l'a vu, entraîne un discours savant dans différents domaines, en différentes langues : l'occitan et le français, mais aussi le latin et ponctuellement l'espagnol ou l'italien. Parfois ce discours est plaqué, parfois il est bien enchaîné avec la définition qu'il éclaire et agrémente, comme dans Estats :

Estats $\left[\mathrm{f}^{\circ} 160 \mathrm{v}^{\circ}\right]$ s. m. pl. [pr. br. ] h. b. Les États. En cette province, c'est l'assemblée du Clergé, de la Noblesse et du Tiers État qui une fois l'an s'assemble par ordre du Roi, pour pourvoir aux impositions des tailles, don gratuit et autres affaires de la province. La tenue de ces États est à présent fixée à Montpellier ${ }^{32}$. On les tenait autrefois tantôt dans une ville tantôt dans une autre, comme le donnent à entendre ces vers du Prologue de Las Amours de la Guimbardo :
E vous dirai, mêssieus, per fini moun prêludo
quê s'oun foussên êstats dedins l'incertitudo
d'avê ou d'oun avê dins Bêziérs lous Estats
Aourian bê fach milhou rêluzi Caritats
més un cop on dizio ; noun vous tourmêntês gairê
Moussur vol fa têni lous Êstats a Bêoucairê
d'aoutrês en Pêzênas d'aoutrês al Sant Esprit...

La citation littéraire a ici valeur documentaire. Elle s'articule souvent, comme dans tous les dictionnaires, sur les exemples d'emploi d'un mot ou d'une expression, à titre d'illustration sémantique ou syntaxique.

Ainsi, ce dictionnaire arrive-t-il à nous étonner, à sa réapparition, par ce foisonnement de références savantes et par une finesse littéraire qui n'a pas d'équivalent. Longtemps enseveli, il n'a pas été cependant sans effet sur les ouvrages postérieurs comme nous l'avons déjà suggéré. L'abbé de Sauvages dont la première édition (1756) avait été largement mise à contribution a utilisé à son tour ce dictionnaire dans la seconde édition (1785) de son Dictionnaire languedocien-français. Il l'a évidemment eu entre les mains et a copié de nombreux articles contenant des références culturelles. Mais l'esprit des deux dictionnaires restant très différent, les emprunts sont patents. Par exemple, toutes les citations de Godolin que fait Sauvages ${ }^{33}$ viennent du dictionnaire anonyme, quelques bévues de recopiage et des erreurs d'attribution en fournissent la preuve.

32. À dater de 1737.

33. Jean-François Courouau (2014, 724 note 7) relève 12 entrées du dictionnaire de Sauvages (1785) qui comportent une citation de Godolin, à savoir : amaga, apazima, lugar, caüs, foulzë, jhipo, perlic, pipot, ramelet, tremoula, tripou, ufer. Tous ces mots et citations plus pëssamën (citation de Godolin sans nom d'auteur) viennent du Dictionnaire languedocien. 
Quelles ont été les motivations et les intentions de l'auteur, pour l'instant anonyme, de ce dictionnaire interrompu après le mot "pagadou $»^{34}$ dans la phase de mise au propre du brouillon ? On décèle sans difficulté un attachement à la langue moderne (le Moyen Âge est passé sous silence) telle qu'elle est parlée de son temps et telle qu'elle a été écrite aux siècles précédents, on devine une intention de valorisation de cette langue à qui sont appliquées les « recherches » qui ont fabriqué la langue française mais aucun « éloge de la langue " ne vient le dire explicitement. L'appellation reste le patois (patés [p. 38]), la langue vulgaire, voire, avec beaucoup de réticences, la langue $d^{\prime} o c\left(o c\left[f^{\circ} 267 r^{\circ}\right]\right)$. Ce monument anonyme garde sa part de mystère ; son exploration ne fait que commencer, d'un mot à l'autre, entre les mots ${ }^{35}$. Car, comme dit Henri Meschonnic (1991) :

«On cherche des mots, on trouve le discours. On cherche le discours, on trouve des mots. [...] Ainsi toutes les recherches, et les plus savantes, ne racontent jamais que le roman du langage, celui du continu à travers le discontinu, celui des demeures rêvées en errant à travers des ruines. »

\begin{abstract}
Résumé
Le manuscrit du Dictionnaire languedocien découvert à Nîmes par François Pugnière en septembre 2013 représente une somme d'érudition linguistique, scientifique et littéraire qui ne peut manquer de modifier le paysage de la lexicographie occitane du XVIII ${ }^{\mathrm{e}}$ siècle. Alors que l'abbé de Sauvages rendait compte avant tout dans son Dictionnaire languedocien-français (1756 et 1785) de l'évolution des usages de la langue dans la société de son temps, l'auteur anonyme du Dictionnaire languedocien applique à la langue occitane, dans le vaste domaine géographique du Languedoc, de Toulouse à Nîmes, le savoir encyclopédique qui est le sien. Il témoigne en particulier d'une connaissance remarquable du texte écrit occitan (publié ou manuscrit) des XVII et XVIII ${ }^{e}$ siècles. Par l'abondance des citations qu'il fournit dans tous les genres (chanson, théâtre, poésie lyrique, burlesque, religieuse...), cet ouvrage important (1037 pages) constitue un des premiers monuments littéraires de la langue moderne. Nous nous proposons de décrire ce manuscrit dont nous ne faisons qu'entrevoir la richesse et d'indiquer quelques pistes de recherches préliminaires.
\end{abstract}

\title{
Bibliographie
}

\section{Dictionnaires}

VENUTI DA CORONA, 1578, Dittionaro vulgare è latino, Bolonia, G. Pietro.

NICOT Jean, [1606] Trésor de la langue française tant ancienne que moderne, Paris, rééd. Le Temps, 1979.

GUICHARD Étienne, 1618, L'harmonie étymologique des langues, Paris, V. Le Roy.

PASQUIER Étienne, 1643, Recherches de la France, Paris, Ménard.

MENAGE Gilles, 1650, Dictionnaire étymologique ou origines de la langue française, Paris, A. Courbe.

BOREL Pierre, 1655, Dictionnaire des termes du vieux français ou trésor des recherches et antiquités gauloises et françaises, Paris, Briasson.

DU CANGE (Charles du Fresne, sieur du Cange), 1678, Glossarium mediae et infimae latinitatis, Paris.

34. L'article est conservé dans le ms 804 de la Bibl. mun. de Nîmes : il y a un chevauchement de quelques pages entre le brouillon et la copie.

35. En cours de numérisation, il sera mis en ligne sur le site du CIRDOC : occitanica.eu/ 
FURETIERE Antoine, Dictionnaire universel contenant généralement tous les mots français tant vieux que modernes et les termes de toutes les sciences et des arts, La Haye et Rotterdam, Arnout et Reiner Leers, 1690.

Dictionnaire universel français et latin, vulgairement appelé Dictionnaire de Trévoux, Paris, Cie des Libraires associés. 1704, 1721, 1742.

CASENEUVE Pierre, 1694, Les origines françoises de Mr de Caseneuve in Ménage, Dictionnaire étymologique..., Fragments de M. de Cazeneuve, in Las obros de Pierre Goudelin, Jean Pech, 1678. p. XXVIII-XL.

WACHTER George, Glossarium germanicum continens origines et antiquitates linguae germanicae, Leipzig, 1736.

SAUVAGES M. l'Abbé de $S^{* * *}$, 1756, Dictionnaire languedocien-français, Nîmes, Michel Gaude.

SAUVAGES M. l'Abbé de $\mathrm{S}^{* * *}$, 1785, Dictionnaire languedocien-français, nouvelle édition, Nîmes, Michel Gaude.

\section{Ouvrages historiques et scientifiques}

RONDELET Guillaume, 1554, De piscibus marinis, Mathiam Bonhomme, Lyon.

ETIENNE Charles, 1565, Agriculture et Maison Rustique, Paris (traduction du Praedium rusticum de 1554).

FABER Basil, 1571, Thesaurus eruditionis scholasticae, Leipzig 1571( souvent rééd. en particulier en 1735).

JOUBERT Laurent, 1578, Erreurs populaires et propos vulgaires touchant la médecine et le régime de santé, Paris.

ODDE DE TRIORS Claude [1578], Joyeuses recherches de la langue toulousaine, éditées par Gaston Brunet, Paris, Jannet et Techener, 1847.

BODIN Jean, 1580, De la démonomanie des sorciers, Paris, Du Puis.

REBOUL Guillaume de, 1600, Actes du synode universel de la sainte réformation tenu à Montpellier le 15 mai 1598, Montpellier.

BACHOT Gaspard, 1626, Erreurs populaires touchant la médecine et le régime de santé, à la suite de celles de M. Joubert, Lyon, Vve T. Soubron.

OLIVE Simon d', 1638, Les CEuvres de Me Simon d'Olive Sieur du Mesnil, conseiller du Roy en la cour de parlement de Tolose. Toulouse, P. Bosc et A. Colomiès.

GARIEL Pierre, 1657, Epitome rerum inferiore Occitania pro religione gestarum ab excessu Henrici IV regis sive anno 1610 ad annum 1657, Monspellii, in 4.

GARIEL Pierre, 1665, Idée de la ville de Montpellier, Daniel Pech, Montpellier.

BONNEFOY P. Jésuite, 1667, Historia heresis in Gallia ortae et oppugnatae, Toulouse, Boude.

LÉGER Jean, 1669, Histoire des Vaudois, Leyde.

MAGNOL Pierre, 1676, Botanicum Monspeliense sive plantarum circa Monspelium nascentium index, Lyon. 
LAFAILle Germain de, 1687, Annales de la ville de Toulouse depuis la réunion du comté de Toulouse à la couronne, Toulouse, J-L Colomiès et J. Posuël.

THIERS Jean-Baptiste, 1697, Traité des superstitions qui regardent les sacrements selon l'Écriture sainte, les Conciles et les sentiments des saints Pères et des Théologiens, Paris.

Essais de montaigne, 1724, avec les notes de Pierre Coste, Londres, Jean Nourse et Vaillant.

ASTRUC Jean, 1737, Mémoire pour l'histoire naturelle de la Province de Languedoc, Paris, Cavelier.

CEuvres de rabelais 1741, avec des remarques historiques et critiques de M. Le Duchat, Amsterdam, J-F Bernard.

ANDOQUE Pierre, 1748, Histoire du Languedoc, avec l'estat des Provinces voisines, Béziers, Jean et Henri Martel.

\section{Ouvrages littéraires}

Lou banquet d'augier gaillard, 1584, Paris, François Audebert, in 12, 483 p.

[DESPUECH, Isaac], 1650, Las fouliés dau Sage de Mounpelié, revistos e augmentados de diversos piessos de l'Auteur, embé son Testamen, obro tant desirado, 208 p.

GRIMAUD P. Bernard, 1659, Le dret cami del cel dins le pais moundi o la bido del gran Patriarcho sant Benoist, Toulouso, Frances Bordo, imprimur, daban le couletge des Payres de la Coumpagno de Jesus. 386 p.

GRIMAUD P. Bernard, 1664, Granoulratomachio, o la Furioso é descarado bataillo des rats é de las granouillos, jouts le règne de Rodilard é Croacus, à l'imitaciu del gréc d'Homéro, poémo burlesco, Toulouse, B. Bosc. 156 p.

AMILHA P. Barthélémy, 1673, Le Tableu de la bido del parfet crestia que represento l'exercici de la fe... per le P. A. N. C. regisseur de l'ordre de St Augustin. Toulouse, J-J. Bondo, in 8 en vers languedociens. 345 pages. Autre édition : Toulouse 1703 avec un dictionnaire gascon.

LE THÉÂTRE DE BÉZIERS, ou Recueil des plus belles pastorales et autres pièces historiées qui ont ésté représentées au jour de l'Ascension en la dite ville, composées par divers auteurs en langue vulgaire, 1657, édition Martel Béziers, (BM recueil factice C 367 (4) 1 vol in 12, 168 p.

[BERGOING], 1652, L'Eneido de Virgile, livre quatrièsme, reuestit de naou, et habilhat à la brullesco. / Sieur de Bergoing, Narbonne, Dominge Le Cuirot, 69 p.

FIZES Nicolas, 1679, L'opéra de Frontignan, obra galoya accoumpagnada de decouratieous de théâtre e de symphonias escarabilladas, Montpellier, Étienne et Paul Marret. Rééd. de Léon Gaudin, Montpellier, Seguin, 1873.

[l'estagniol] 1682, Traductieou del premié, second, quatrieme et sixieme livre de l'Eneido de Virgilo, per L. E avocat de Besiés, A Besiés, Henric Martel ou imprimavo, 279 p.

Las obros de pierre goudelin, 1678, augmentados de forço péssos, é le dictiounari sus la lengo moundino ount és més per ajustié sa bido, remarquos de l'antiquitat de la lengo de Toulouso, le Trinfle moundi é soun oumbro Toulouse, Jean Pech.

Las obros de pierre goudelin, 1700, augmentados de forço péssos, é le dictiounari sus la lengo moundino ount és més per ajustié sa bido, remarquos de l'antiquitat de la lengo de Toulouso [de Cazeneuve], le Trinfle moundi é soun oumbro, d'amb'un manadet de 
bérses de Gautié é d'autres pouétos de Toulouso, (Recueil des poètes gascons. $1^{\text {re }}$ partie), Amsterdam, Daniel Pain, 363 p.

[DESPUECH Isaac], Les folies du sieur Le Sage de Montpellier, 1700, (Recueil de poètes gascons, $2^{\mathrm{e}}$ partie), Amsterdam, Daniel Pain, $196 \mathrm{p}$.

MICHEL Jean, 1700, L'embarras de la fieiro de Beaucaire, en vers burlesques vulgaris, per Jean Michel de Nismes, revist, courijat et aumentat embé plusieurs autres piessos tant seriouzes que burlesques, (Recueil de poètes gascons, $2^{\mathrm{e}}$ partie), Amsterdam, Daniel Pain, $191 \mathrm{p}$.

MARTIN P. Jean, Bouquet de cauquos flouretos cueillidos sul Parnasso biterrois pour l'année 1723, 1726, 1729 et 1738, Béziers, Étienne Barbut.

\section{Éditions de textes}

DONNADIEU Frédéric, 1899, "Poésies biterroises du P. Jean Martin », Bulletin de la Société archéologique scientifique et littéraire de Béziers, troisième série, tome III, Béziers, Sapte. $136 \mathrm{p}$.

BARRAL Marcel, 1982, Jacques Roudil, poète montpelliérain du XVII siècle, CEuvres poétique languedociennes et françaises, publiées pour la première fois sur un manuscrit retrouvé avec introduction, notes et glossaire, par Marcel Barral, Montpellier, Publications de l'Entente bibliophile, $226 \mathrm{p}$.

BARRAL Marcel, 1983, Suite des cuvres poétiques languedociennes et françaises, Montpellier, Publications de l'Entente bibliophile, $238 \mathrm{p}$.

\section{Études}

CAVAILlé Jean-Pierre, 1982, «Pierre Borel (1620 ?-1671), médecin et polygraphe castrais, un curieux et ses mondes », Revue du Tarn n`146, p. 264.

GÉGOU Fabienne, 1983, «Un dictionnaire d'ancien français au XVII ${ }^{\mathrm{e}}$ siècle, le Trésor des recherches de Pierre Borel ». In Cahiers de l'Association Internationale des études françaises, n³5, p. 30.

GARDY Philippe, 1985, « Montpellier-Clapas, ou les plaisirs partagés de l'oraliture », Revue des Langues Romanes, T. LXXXIX, p. 53-75.

MESCHONNIC Henri, 1991, Des mots et des mondes. Dictionnaires, encyclopédies, grammaires, nomenclatures. Paris, Hatier, 311 p.

THOMAS Jean, 2013, « À propos de la découverte d'un dictionnaire inédit du XVIII ${ }^{\mathrm{e}}$ siècle », Lengas [En ligne], 73 | 2013, Montpellier, PULM.

COUROUAU Jean-François, 2014, «L'ombre de Godolin (1649-1790) » p. 716-738, in Los que fan viure e treslusir l'occitan, Actes $d u X^{e}$ Congrès de l'AIEO, (dir.) C. Alén Garabato, C. TORREILlES, M-J VERNY, Limoges, Lambert-Lucas, 2014, 971 p.

FABIÉ David, 2015, «l'essor des études lexicographiques et grammaticographiques » in J.F. COUROUAU (dir.), La langue partagée. Écrits et paroles d'oc. 1700-1789. Genève, Droz 


\section{Illustration}

Figure 1 : Légende

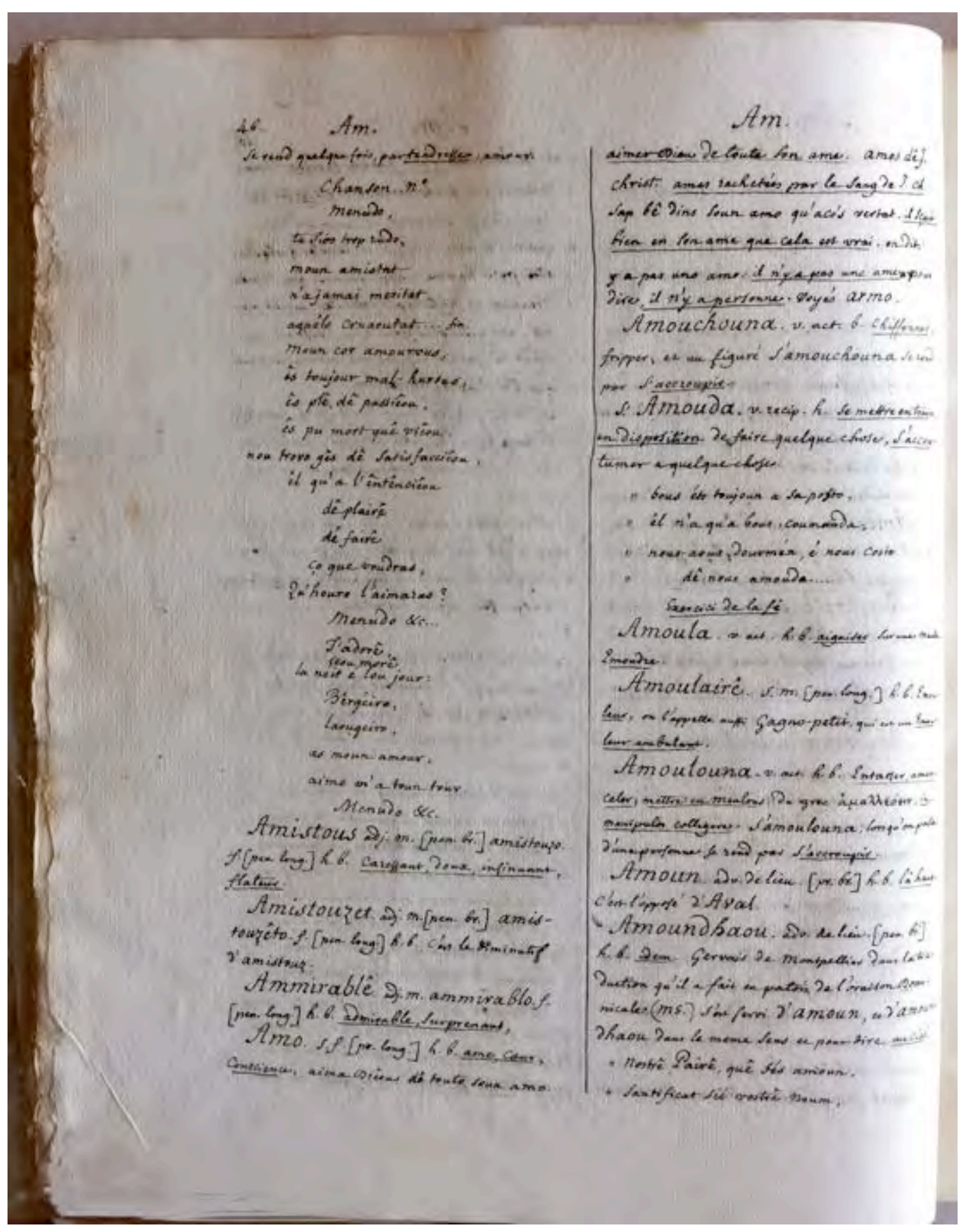




\title{
Quelques aspects du vocabulaire en usage dans une région se situant sur les confins de l'Artois et de la Picardie
}

\author{
Jean-Roger WATTEZ \\ Professeur honoraire de l'Université de Picardie Jules-Verne
}

Extrait de : Guylaine BRUN-TRIGAUD (dir.), Contacts, conflits et créations linguistiques, Paris, Édition électronique du CTHS (Actes des congrès des sociétés historiques et scientifiques), 2015.

Cet article a été validé par le comité de lecture des Éditions du CTHS dans le cadre de la publication des actes du $139^{\mathrm{e}}$ Congrès national des sociétés historiques et scientifiques tenu à Nîmes en 2014.

\section{La Picardie et la nation picarde}

Ce préambule nécessaire à la présentation des termes qui seront cités doit beaucoup à l'article de N. Gorochov :

« La nation picarde de l’Université de Paris à la fin du Moyen Âge » (1998).

Apparu au XII ${ }^{\mathrm{e}}$ siècle, le mot de Picardie n'est usité qu'à partir du milieu du XIII ${ }^{\mathrm{e}}$ siècle. N. Gorochov indique qu'en 1249, «la division entre quatre nations est explicitement mentionnée », mais son " recrutement géographique (est) assez vague ». Il s'agit de la nation de France (c'est-à-dire l'île de France, la France méridionale, l'Italie et l'Espagne), la nation anglaise (rassemblant les étudiants anglais et ceux de l'Empire), la nation normande (qui regroupe les Normands et les Bretons) et la nation picarde.

Mais que faut-il entendre par nation? Selon N. Gorochov, ce terme désigne " un groupe humain qui a une origine commune tandis que le peuple est un groupe humain politiquement organisé ». Cet auteur précise que «le terme de nation reste bien vague et trouve sa cohésion tantôt dans un pays, tantôt dans une langue ou un dialecte, tantôt dans le culte d'un saint local, tantôt dans la conjonction de toutes ces caractéristiques ».

Il s'avère que l'appellation nation picarde :

- n'a pas de cohérence politique car elle est traversée par la frontière entre le royaume de France et l'empire germanique, matérialisée localement par les cours de l'Escaut et de la Meuse,

- regroupait des clercs et des étudiants originaires de neuf diocèses : Amiens, Beauvais, Noyon, Arras, Thérouanne, Laon, Cambrai, Tournai et Liège.

En revanche, elle offre par contre une certaine cohérence linguistique, car le dialecte picard est essentiellement parlé dans les territoires situés au nord et à l'ouest de l'Oise. N. Gorochov rappelle qu'au XIII ${ }^{\mathrm{e}}$ siècle, la langue française est « assez nettement teintée de picard »; cette particularité résulte de l'activité des trouvères picards ; certes, «entre ceux-ci, des différences dialectales existent mais elles n'empêchent pas la compréhension ».

Toutefois, à l'Université de Paris, dès la fin du XIV siècle, la nation de Picardie devient anachronique. Les multiples péripéties de la trop longue guerre de Cent Ans et les déchirures territoriales qui en résultèrent font « fuir ses membres potentiels vers la nation de France ou vers les universités des terres germaniques ». L'effacement du picard date de cette époque ; un siècle plus tard, l'édit de Villers-Cotterêts (1539), signé par François 
$1^{\text {er }}$ marginalisera progressivement le picard qui ne sera plus désormais qu'un parler régional, aux maintes variantes, essentiellement transmis par la voie orale.

La phrase suivante figurant dans le «Manuel de l'Instruction primaire» (1905) est significative de la mentalité qui prévalait chez les instituteurs de la III ${ }^{e}$ République :

«Il faut se garder de tout ce qui peut valoir aux patois de la considération, mais on ne devrait rien négliger pour les discréditer et les extirper de l'usage. »

Toutefois, le parler picard n'a pas pour autant disparu; mon propos est de révéler sa persistance dans une petite région se situant sur les confins de l'Artois et de la Picardie localisée dans le sud de l'actuel département du Pas-de-Calais. Deux petites agglomérations, l'une artésienne, Hesdin et l'autre picarde puisque faisant partie du Ponthieu, Montreuil-sur-mer et que l'histoire a longtemps séparées en sont les centres les plus importants sur le plan culturel.

Concluons ce long préambule en soulignant que l'expression parler picard, largement usitée dans le département de la Somme ne l'est pas, ou à peine, dans le Pas-de-Calais où les populations (surtout les ruraux) s'expriment volontiers en patois (Dewaste, 1995).

Les termes utilisés dans le langage courant ont été répartis comme suit :

. les verbes et les adjectifs correspondants,

. les substantifs,

. les modifications subies par certains mots courants de la langue française,

. quelques particularités grammaticales seront envisagées,

. un certain nombre de « tournures de phrase » originales seront rapportées.

Il manquera la prononciation des mots mais comment la transcrire?

Je rappelle que seuls seront cités les termes et les expressions que j'ai personnellement entendus utiliser et qu'il m'arrive encore parfois d'employer...

Précisons que cette compilation de termes en usage dans le Montreuillois ne saurait être comparée avec les travaux scientifiques autrement importants des spécialistes de la linguistique picarde ; toutefois, j'ai tiré parti des informations précieuses rassemblées par Dubois (1981) et Dickes (1984) ainsi que dans le « Que sais-je ?» de Guiraud (1978).

N.B. : une abréviation a été utilisée.

- s.l. signifie au sens large.

\section{Les verbes}

. acouveter : dissimuler sous des couvertures ; s.l. être entièrement dominé par quelqu'un

. appateler : donner de la nourriture aux enfants par petites bouchées

. berluronner : loucher

. bunner : réfléchir silencieusement dans son coin, comme les vaches qui ruminent

. buquer : frapper ou être frappé ; par ex. buquer à une porte

. déligoter : se dégourdir les jambes

. dénorter : sortir du droit chemin

. dueller : passer la serpillière (qu'on appelle un duel)

.échouir : assourdir ; adjectif échoui

. galter : tomber et rouler sur le sol ; s.l. se débarrasser de quelqu'un

. godailler : trainasser

- garotter : jeter des cailloux, des mottes de terre

.houigner : grincer (une roue par ex.) ; s.l. geindre

. mahonner : bagarrer (gentiment lorsqu'il s'agit d'enfants)

. maloter : parler entre ses dents, ne pas bien articuler

. mangonner : bougonner, grogner

.moudre : traire les bestiaux (proche du latin mulgere : traire)

. mucher: cacher, dissimuler

.muter : former un amas de terre; on mute les pommes de terre 
. pluquer : manger peu, sans appétit, par petits morceaux

- quer: chercher

. radiner (se) : arriver à l'improviste en dérangeant

. rapurer (se) : reprendre son souffle après un effort

. ratrucher: nettoyer soigneusement le fond d'une assiette ou d'un plat

- ravauder : trainer, fouiller un peu partout

. raviser : regarder attentivement

. reluquer : faire le curieux; observer avec insistance

. requinquer : retrouver une bonne santé ; adjectif requinqué

. souglouter : avoir le hoquet

. traiter : insulter ; les enfants disent « untel, il m’a traité ».

\section{Les adjectifs}

. aigrelette : se dit d'une voix pointue

. bellot, bellotte : mignon, mignonne

. bitaclé : multicolore, bigarré

. empiété, être mal empiété : marcher difficilement

. enchepé : maladroit; terme dérivant du vieux français encepé : entravé

.étombi : hébété comme celui qui sortirait d'une tombe

- flapi : exténué a près un effort

- fraiqui : être mouillé et avoir froid

. ragrioté : recroquevillé sur soi-même lorsque l'on a froid

. répilleux : rugueux au toucher; des mains gercées, répilleuses

. rétu: en bonne santé ; un vieillard encore bien rétu

. soilé s'emploie pour parler de la peau irritée par un contact avec un tissu trop rude

. tillache : coriace ; s.l. de caractère difficile

. vertillant se dit d'un enfant éveillé et vif.

\section{Les adverbes}

toudis : toujours

. gramint ou granmint : beaucoup ; «il n'y a pont granmint de fruits cette année ».

\section{Un article}

. chole remplace l'article féminin la ; par exemple « chole femme à Pierre, elle est partie »

\section{Les substantifs}

- agache: pie

. baluchon : affaires personnelles, bagages (faire son baluchon)

. blot : galoche à semelles de bois

. bousat: bouse de vache

. boutinette : nombril

.brayou : enfant qui grogne et pleurniche

. brin : m... (gros mot)

. buée : lessive

. buanderie : lieu où se fait la lessive, débarras

. buise : gros tuyau

. cayelle: chaise (le terme le plus emblématique du picard !)

. calimuchon : escargot

. carmène : agité, indocile

. censier : paysan (terme usité avec une connotation plutôt ironique)

. chuque : bonbon

. codin : dindon

. créquier : buisson épineux ; terme repris en héraldique

. cuvelle : grand seau

. dache : clou plat enfoncé dans les semelles

. dallot: caniveau

. découpette : silhouette

. ducasse : fête locale (provient de dédicace, celle de l'église du village) 
.enlevée : se disait de quelqu'un qui ne se mariait pas comme sa famille l'aurait souhaité ( «il ou elle a fait une drôle d'enlevée »)

.étrons : excrément des poules

. fouffes : morceaux de tissus mis au rebut, chiffons

fourdraines: prunelles; il s'agit du fruit du prunellier. Guiraud (1978) commente l'origine de ce terme et la localisation précise de son usage dans le nord de la France

- frusquin : bagages divers, mal ordonnancés

- glène : poule (du vieux français géline)

. hourlon: gros insecte, hanneton

. loupiot: petit enfant

. malot : bourdon; s l. personne qui articule mal en parlant

. minteries : petits mensonges

. miroulle : fortune («ne pas faire miroulle»)

. muches : cachettes

. nochère: gouttière

. nonnes : l'heure de midi; après nonnes : après midi

- passant : grande scie de bûcheron

- péquelle : énorme louche

- plu : chandail de laine épais et chaud

- pluquart ; enfant sans appétit, mangeant par petits morceaux

. rimée : gelée blanche matinale

. souglou: hoquet

. tine : très grand récipient, cuve importante

. tiot : enfant jeune

. toubaquier: paysan qui cultivait le tabac

. viéseries : vieilles choses devenues inutiles

. vinque : nom de la pervenche (du latin vinca)

Citons également deux surnoms ironiques :

- fend l'air : désigne une personne pressée, marchant très vite

. tristavir : attribué à un homme qui n'est pas très beau

Les modifications subies par certains mots usuels du français

Il est possible de mentionner plusieurs «altérations» qu'ont subies des mots couramment utilisés dans la langue française.

acheter devient aquater

beau devient biau

bien devient bin

bois devient bos

chapeau devient capiau

charbon devient carbon

charron devient caron

champ devient camp

chanter devient canter

chasseur devient cacheux

chien devient tien ou quien

chat devient cat

coq devient co

Dieu devient Diu

encore devient cor

échelle devient équelle

feu devient $f u$

grenouille devient garnoulle

jambe devient gambe

jardin devient gardin

jouer devient juter

loup devient leu

moisi devient musi

œil, yeux deviennent un oel, des yus 
peau devient piau

pêche devient pèque

poisson devient pichon

prunes devient prones

trou devient treu

vache devient vaque

veau devient viau

vieux devient viu

voir devient vir

Quelques tournures de phrases originales

à s t'heure : maintenant, en ce moment

à t'a l'heure : à plus tard

à l'hurlure : n'importe comment

après mi tu passeras d'vint : écartes toi

avec sin nez qui pleut $n^{\prime}$ dans : personne ayant le nez en trompette

avec s'n'oel qui dit zut à l'autre: personne qui louche

canchon dormoire : berceuse

$c^{\prime}$ est s'n'affaire: c'est son problème

$c^{\prime} e s t$ cor émieux : c'est un peu fort

$c^{\prime}$ est tout l'bout : rien de plus

faire son baluchon: déguerpir en vitesse

$j^{\prime}$ vous dirai quoi : je vous tiens au courant

il est loin dans chez camps : il est attardé, il traîne (expression particulièrement utilisée en période électorale !)

l'fu n'y est pont : rien ne presse

$m^{\prime} e s t$ avis : il me semble

on f'ra d'assez: on s'en satisfera (à propos de la nourriture)

un tien d'cache pour aller à l'pèque : un mauvais chien de chasse

une fois à m'sure: petit à petit

une trotte à chien : aller et venir sans but précis

un tiot qu'min: un petit chemin, un sentier

un tape à travers : personne maladroite dans ses interventions orales

vla ti pas : ne voilà t-il pas, $\mathrm{c}^{\prime}$ est alors que...

vas y vir : va voir ailleurs

va moudre tes glènes : va traire tes poules! (expression moqueuse).

\section{Un peu de grammaire}

La grammaire du picard a particulièrement retenu l'attention des linguistes régionaux ; je me limiterai à quelques exemples.

Le verbe avoir remplace le verbe être comme dans les expressions suivantes : il $a$ tombé, il $s^{\prime} a$ disputé, il $a$ marié une collègue.

La négation peut s'exprimer de manière différente :

. ne pont remplace ne point, par exemple : il ne reviendra pont

.rien que est usité, par exemple : il fait rien que m'embêter

- ne mie, en usage dans le vieux français subsiste en picard, par exemple dans les expressions suivantes : il ne pleuvra mie, on n'en parle mie, je ne sais mie, il n'est mie si riche qu'il ne le dit, il n'est mie si malade qu'il ne le prétend, on n'a mie jamais vu cela.

Le vocabulaire en usage dans les années 1950-1970 dans la région prise en considération est-il encore compris et utilisé par les adolescents en 2014 ? Il est important cependant de le leur faire connaître de façon à ce qu'ils se l'approprie (au moins partiellement) afin de le transmettre à leur tour. Formons le vœu qu'il en soit ainsi car, comme l'écrit J.P. Dickès (1984) (5), « ceux qui aiment le patois aiment la vie». 


\begin{abstract}
Résumé
Bien que faisant partie de l'ensemble des langues romanes, le picard a été supplanté par le français «académique » et il n'est plus désormais qu'une langue régionale. Son aire de répartition s'étend depuis le nord de l'île-de-France et les confins de la Haute-Normandie jusqu'à l'actuelle frontière de la Belgique qu'elle franchit cependant dans la région de Tournai. Sur ce territoire au relief peu marqué, le picard s'est diversifié comme l'ont révélé les observations antérieures des linguistes régionaux mais, par rapport à leurs amples recherches, ce travail ne représente qu'une modeste contribution. Ne seront mentionnés en effet que les termes, les expressions, les tournures de phrase que j'ai personnellement entendus (et parfois usités) dans une région située sur les confins de l'Artois et de la Picardie; les petites villes de Hesdin et de Montreuil-sur-mer en sont les plus importantes sur les plans historique et culturel. Ce territoire demeuré essentiellement rural recèle des richesses linguistiques qui se rattachent pro parte à des termes oubliés du vieux français. Mentionnons par exemple :

- des verbes: berluronner, galter, moudre, mahonner, mucher, pluquer, souglouter...

. des substantifs : cayelle, découpette, duel, fourdraine, malot, miroulle, rimée...

. des adjectifs : échoui, enchepé, musi, répilleux, rétu, tillache...

Les jeunes générations devraient les connaître, en faire usage opportunément afin de le préserver et de les transmettre à leur tour.
\end{abstract}

\title{
Quelques références bibliographiques
}

DeWASTE A. 1995, "Ces patois si précieux; le retour aux sources », in La Voix du Nord, $12 / 03 / 1995$

DICKES J. P. 1984, Le patois pour tous; les parlers du Boulonnais, Montreuillois, Calaisis, 149 p. Collection Eklitra, LIV.

DuBoIs G. 1981, 2000 mots du patois de chez nous, Imprimerie S.C.I.E., Bully les Mines, $247 \mathrm{p}$.

GOROCHOv N. 1998, «La nation picarde de l'Université de Paris à la fin du Moyen Âge (XIII-XIV ${ }^{\mathrm{e}}$ siècles) ", in Picardie, terre de frontière, Ouvrage collectif DUMÉNIL A. et NIVET P. (dir.), Colloque d'Amiens 1997, Collection Hier, dirigée par A. Trogneux.

GUIRAud P. 1978, Patois et dialectes français, « Que sais-je ? », P.U.F., 126 p.

Manuel général de l'Instruction primaire, 1905, in Exposition «P. comme Patrie ». 19881989, Musée national de l'Éducation, Rouen. 


\title{
Langues du roi et langues des sujets en France et en Angleterre : identité et communication
}

\author{
Serge LUSIGNAN \\ Professeur émérite, \\ Université de Montréal \\ Extrait de : Guylaine BRUN-TRIGAUD (dir.), Contacts, conflits et créations linguistiques, Paris, \\ Édition électronique du CTHS (Actes des congrès des sociétés historiques et scientifiques), 2015. \\ Cet article a été validé par le comité de lecture des Éditions du CTHS dans le cadre de la publication \\ des actes du $139^{\circ}$ Congrès national des sociétés historiques et scientifiques tenu à Nîmes en 2014.
}

L'historien qui se penche sur les pratiques linguistiques du passé peut croire à première vue qu'il se donne un objet simple et facile à circonscrire. Nous croyons tous savoir ce qu'est une langue. Mais, vue de plus près, la réalité linguistique s'avère souvent mouvante et toujours complexe. En guise de préliminaire à mon étude comparative des usages linguistiques des rois de France et d'Angleterre, je voudrais revenir sur certaines notions linguistiques qui devraient garnir le coffre d'outils de tout historien qui aborde un tel sujet. Je soulignerai à l'occasion que certaines de ces idées ont trouvé leur première formulation dans la pensée linguistique médiévale.

Spécialiste de la sociolinguistique historique, Anthony Lodge, rappelle à propos de la langue :

«Un des grands paradoxes de la linguistique générale c'est que la notion de " langue ", comme celle de "dialecte", n'est pas au fond un concept linguistique. Il s'agit dans les deux cas de " représentations " socioculturelles, idéologiques, même politiques. »"1

Effectivement, on appelle «langue » des systèmes linguistiques très éloignés l'un de l'autre tels le chinois ou le français, ou beaucoup plus proches, comme le français ou l'italien. L'intercompréhension entre deux locuteurs n'offre même pas un critère sûr pour établir qu'ils partagent une même langue; pensons aux Danois et aux Norvégiens qui peuvent se comprendre tout en estimant parler deux langues différentes. Inversement, l'intercompréhension n'est pas toujours facile entre un touriste français et certains locuteurs québécois, alors que tous deux ont la certitude de parler français. C'est que la singularité d'une langue tient à la fois à des critères linguistiques - phonétique, grammaire et lexique et à la conscience des locuteurs que le système linguistique avec lequel ils s'expriment constitue une langue.

Au Québec, le débat quant à savoir si on parle québécois ou français a été tranché par l'Assemblée nationale, en 1977, dans l'article un de la Charte de la langue française :

«Le français est la langue officielle du Québec. »²

1. R. A. Lodge, « Le clivage oc-oïl au Moyen Âge, fiction méthodologique », p. 602.

2. Voir http: // www. olf. gouv. qc. ca/charte/charte/index. html. 
C'est un mouvement inverse qui, dans la longue histoire de l'émergence de la langue française, conduit à son détachement du latin. Ce fut le résultat d'un lent processus évolutif amorcé en Gaule à la fin de l'Antiquité, qui connut son aboutissement au IX ${ }^{\mathrm{e}}$ siècle, lorsque les locuteurs prirent conscience d'utiliser un diasystème linguistique qu'ils ne reconnaissaient plus comme du latin et qu'ils commencèrent à nommer le roman ${ }^{3}$. De dialecte du latin, le français devenait une langue, pour paraphraser A. Lodge 4 .

Chaque langue est susceptible de variations qui tiennent à plusieurs facteurs. Le premier est géographique; il s'agit des dialectes. Cette réalité était déjà reconnue par les penseurs médiévaux. Au milieu du XIII ${ }^{\mathrm{e}}$ siècle, Roger Bacon relevait pour la France :

« Le picard et le normand, le bourguignon, le parisien et le français : c'est une même langue pour tous, c'est-à-dire la française, mais qui se diversifie accidentellement selon les lieux; cette diversification produit des dialectes (idiomata), mais non des langues différentes. »

La distinction entre les dialectes se fonde sur les différences phonétiques et lexicales que l'on peut relever entre les locuteurs de différentes régions. Elle comporte également une part d'arbitraire qui, au même titre que pour la langue, tient aux représentations que l'on s'en fait.

Ainsi, le linguiste Jean-Michel Éloy a pu écrire à propos du rapport du dialecte picard au français :

«Dans sa dynamique, 'le picard' se définit comme un idiome dont l'autonomie par rapport à un autre est demeurée partielle, et qui reste marqué par rapport à cette autre variété. Sa construction comme idiome distinct est inachevée, dans la mesure où il n'est pas pleinement reconnu comme tel, et légitimé, par des pouvoirs politiques au plan national. » ${ }^{6}$

Lorsqu'on reporte sur une carte de la France la localisation de l'emploi du verbe " chanter » utilisé dans une bonne partie du pays d'oïl, "canter», en région picarde, "tchanter», en Wallonie, et en pays d'oc "tsanta/tchanta " et "canta», il se dégage des frontières bien nettes ${ }^{7}$. Mais, plus on multiplie les tracés de telles frontières, que les linguistes appellent des isoglosses, plus les contrastes s'estompent. C'est pour cette raison que les grands romanistes de la fin du XIX ${ }^{\mathrm{e}}$ siècle, comme Paul Meyer et Gaston Paris, mettaient en doute la notion même de frontières linguistiques à l'intérieur de la France. Ils estimaient que les variations des parlers régionaux de leur époque se compénétraient à un point tel que, de proche en proche, il y avait toujours intercompréhension dans la variance. Ils en venaient à conclure à l'unicité linguistique de la France et à refuser en particulier la démarcation entre l'oïl et l'oc. La thèse confortait leurs convictions politiques républicaines et centralisatrices.

En réalité, s'il n'existe pas de frontières dialectales très nettes, on peut identifier des faisceaux de traits linguistiques qui peuvent singulariser plus ou moins fortement une région par rapport à ses voisines. La meilleure représentation de cette réalité nous est fournie par Hans Goebl. Cartographiée sur la base des départements actuels, elle fournit une représentation des lignes de démarcation plus ou moins nettes qui se dégagent des variations régionales du français médiéval telles qu'on les trouve dans les chartes du XIII ${ }^{\mathrm{e}}$ siècle. Cette carte est disponible sur internet ${ }^{8}$. L'étanchéité plus ou moins grande des frontières dialectales est

3. M. Banniard, Viva voce. Communication écrite et communication orale du IV au IX siècle en Occident latin.

4. R. A. Lodge, Le français. Histoire d'un dialecte devenu langue.

5. Roger Bacon, Compendium studii philosophiae, edit. J. S. Brewer, p. 438-439. La traduction est de nous.

6. J-M. Éloy, La constitution du picard: une approche de la notion de langue, p. 209-210. Voir également: R. Wardhaugh, An Introduction to Sociolinguistics, p. 27-47, qui montre que les critères pour distinguer l'un et l'autre relèvent tout autant de facteurs sociaux et linguistiques que des représentations.

7. J. Chaurand, Nouvelle histoire de la langue française, p. 37.

8. H. Goebl, "Sur le changement macrolinguistique survenu entre 1300 et 1900 dans le domaine d'Oill. Une étude diachronique d'inspiration dialectométrique ", p. 37, http:/ / www. publicacions. ub. edu/ revistes/dialectologia1/ 
représentée par l'arc-en-ciel des couleurs froides aux couleurs chaudes et par l'épaisseur des traits. Les frontières les plus nettes sont marquées par un trait épais bleu marine et les plus faibles par un léger trait rouge. On remarque que les régions qui se distinguent davantage sont situées au sud-ouest et au nord-ouest du domaine d'oïl.

La sociolinguistique identifie d'autres variations dans les usages d'une langue telles les variations selon les groupes sociaux (diastratique) ou selon les niveaux discursifs (diaphasique); elles restent secondaires pour mon propos. En revanche, la distinction entre l'usage écrit et oral de la langue est fondamentale pour l'historien des temps anciens. Les seules sources dont il dispose sont écrites et c'est à travers elles qu'il tente de saisir l'oralité. Certes, la phonétique historique nous assure que les traits régionaux distinctifs d'une charte tirent leur origine de la langue parlée. En même temps, ce serait une grande naïveté de considérer une charte en picard, par exemple, comme une transcription phonétique de la langue parlée à Amiens ou à Douai. La description des pratiques linguistiques du passé demeure un subtil jeu d'ombres et de lumières.

L'historien doit également prendre en compte la variation des compétences linguistiques des personnes, selon qu'elles ont l'habitude ou non des déplacements sur de longues distances, qui les familiarisent d'avec la variation linguistique, ou qu'elles sont carrément bilingues ou multilingues. Par exemple, A. Lodge constate que les consuls de la ville de Montferrand en pays d'oc qui se rendaient à Paris au XIV ${ }^{\mathrm{e}}$ siècle ne semblaient éprouver aucun problème de communication. À ses yeux, l'explication tient au fait que :

«L'intercompréhension au sein des différents diasystèmes et entre les deux diasystèmes [oc et oill] se faisait non pas au moyen de koinès orales stables, mais à l'aide de milliers d'actes d'accommodation individuels et ad hoc. »"

En ce qui concerne mon propre propos, il faut souligner que ceux qui écrivaient en français au nom du roi maîtrisaient également le latin. Dans leur conscience linguistique, la frontière entre les deux langues était très poreuse et l'influence de l'une sur l'autre, incessante ${ }^{10}$.

Finalement, il faut rappeler qu'outre sa fonction de médium de la communication, la langue est porteuse de valeurs. Elle est un marqueur fort de l'identité de la personne. Ainsi, une lettre de rémission de 1388 atteste qu'un Parisien pouvait identifier sur le champ un Picard à sa façon de parler :

"Le dit de Chastillon cognut au parler que ycellui Thomas estoit picart et pour ce, par esbatement, se prist a parler le langage de Picardie. ${ }^{11}$

Dans le cas où deux langues cohabitent sur un même territoire, il n'est pas rare que l'une soit perçue comme plus prestigieuse que l'autre. C'était le cas du français en Angleterre par rapport à l'anglais. Les linguistes qualifieront alors le français de langue haute, et l'anglais, de langue basse.

Dans le système de valeurs des langues au Moyen Âge, le latin occupait une place à part. Il était une langue haute par rapport à tous les vernaculaires. Il tenait cette position du caractère sacré qu'on lui reconnaissait. Parmi les arguments élaborés par les penseurs médiévaux à cet effet, le plus important est sans doute celui inspiré du passage de l'Évangile de saint Jean (XIX, 20) à l'effet que sur la croix, l'inscription « Jésus de Nazareth roi des Juifs »

9. R. A. Lodge, « Le clivage oc-oïl au Moyen Âge », p. 612.

10. S. Lusignan, «Écrire en français ou en latin au pays d'oï : le cas de la chancellerie royale au début du $X V^{e}$ siècle »; S. Lusignan, "Chartes et traduction, Les actes latins et français de la chancellerie royale et le paradigme de la traduction».

11. S. Lusignan, «Une affaire de mots et de couteaux : la mauvaise fortune d'un Picard à Paris », p. 125. 
était apposée en hébreu, en grec et en latin. Il permettait aux exégètes de conclure au caractère sacré de ces trois langues, qui les opposait aux langues vernaculaires ${ }^{12}$. Le latin était également la langue du pouvoir impérial et du droit romain. Tout contribuait à le survaloriser par rapport aux autres langues.

\section{Les langues de l'autorité royale en France (XIII - XV siècles)}

Dans son commentaire de la Politique d'Aristote rédigé à la demande de Charles V, Nicole Oresme pose que :

« Nature a donné a homme parole pour entendre l'un et l'autre afin de communication civile. ${ }^{13}$

Les échanges et les relations entre les hommes constituaient à ses yeux le fondement de la société politique. Mais encore fallait-il qu'ils partageassent une même langue, car, poursuit Oresme :

«La division et diversité des langages repugne a conversation civile et a vivre de policie. » ${ }^{14}$

La situation linguistique de la France du XIV ${ }^{e}$ siècle était loin d'offrir les conditions souhaitées pour la constitution d'une communauté politique. En effet, on y parlait pas moins de quatre langues, le flamand, le français, l'occitan et le gascon, qui elles-mêmes étaient fragmentées en dialectes ${ }^{15}$. Dès le XIII ${ }^{\mathrm{e}}$ siècle, toutes ces langues avaient accédé au registre de l'écrit littéraire et administratif. Pourtant, le roi de France n'utilisa jamais que le latin et le français pour communiquer avec ses sujets. Quelles ont pu être les considérations relatives à la qualité de la communication et aux valeurs attachées à ces deux langues, qui expliquent ce choix ? C'est ce que je vais examiner en abordant successivement le cas du latin, puis du français.

\section{L'usage du latin par l'administration royale}

Le latin fut la langue exclusive des rois de France depuis les Mérovingiens jusqu'à Louis IX, et $c^{\prime}$ est bien timidement que les derniers capétiens commencèrent à utiliser la langue vernaculaire. Paul Videsott a complété l'édition de tous les actes royaux originaux en français jusqu'à l'année 1301. Son enquête dans un grand nombre de dépôts d'archives lui a permis d'identifier 4 actes en français pour le règne de Louis IX (1226-1270), 16, pour celui de Philippe III (1270-1285) et 104 pour la partie du règne de Philippe le Bel allant de 1285 à 1301. Ce travail complète en amont ma propre enquête faite à partir des seuls registres de l'enregistrement de la chancellerie ${ }^{16}$. J'ai pu établir qu'entre 1305 et 1314, seulement $5 \%$ des actes de Philippe le Bel furent écrits en français. Pour ses fils, ce pourcentage s'établit à $19 \%$ pour les 20 mois du court règne de Louis $X$, et à $10 \%$ pour celui de Philippe V (1316-1321). Sous Charles IV, on passe de $10 \%$ d'actes français au début du règne, en 1322 , à $25 \%$ à la fin, en 1328. Il faut mettre ces données en contraste avec les usages linguistiques des grands princes du Nord et de la plus petite noblesse qui adoptèrent majoritairement le français entre 1240 et 1270, et des villes de la même région dont les écritures en vernaculaire débutèrent avec le XIII ${ }^{\mathrm{e}}$ siècle.

12. Sur la sacralité du latin : S. Lusignan, Parler vulgairement. Les intellectuels et la langue française aux XIII et XIVe siècles. 13. S. Lusignan, "'De communité appellee cité'. Les lectures de Gilles de Rome et de Nicole Oresme de la Politique I, 2 d'Aristote », p. 653-674 (249d).

14. Ibid., (250a).

15. J'omets le breton car à la période que j'étudie la Bretagne échappait pour une grande part à l'emprise des institutions royales.

16. P. Videsott, Les plus anciens documents en français de la chancellerie royale capétienne (1241-1300); S. Lusignan, La langue des rois au Moyen Âge. Le français en France et en Angleterre, p. 80-94. 
Un premier tournant se produisit au cours du règne Philippe VI. Au début, en 1328 et 1329, ce sont seulement $21 \%$ et $22 \%$ des actes qui sont en français, mais tout change à compter d'octobre 1330. Sans que la décision n'ait laissé de trace écrite, le roi semble avoir ordonné à la chancellerie d'utiliser principalement le français ; à partir de cette date et jusqu'à la fin de son règne, en 1350, ce sont les trois quarts des actes royaux qui empruntent le français et un quart seulement, le latin. Lorsqu'on examine les données plus finement, il se dégage que le régime juridique du lieu de résidence des bénéficiaires fut le facteur principal qui justifia le choix de la langue. On constate en effet que $91 \%$ des actes destinés à des sujets habitant la moitié nord de la France qui vivaient sous le régime du droit coutumier sont en français, alors que seulement $27 \%$ des actes au bénéfice de gens du Sud soumis au droit romain sont en français. On sait qu'entre les deux régions, les juristes identifient maintenant un couloir de mixité du droit qui traverse la France d'ouest en est: les actes à l'intention de cette région sont dans une proportion de $46 \%$ en français. Avec l'avènement du roi Jean II, en 1350, le latin s'imposa à nouveau et devint la langue exclusive de la chancellerie royale. Le français ne reprit progressivement son importance qu'à partir du règne de Charles V. Dès lors, le choix du français ou du latin semble plutôt déterminé par la nature de l'acte ; ainsi les lettres de rémission sont de plus en plus souvent écrites en français, alors que les légitimations ou les anoblissements demeurent toujours en latin. $\mathrm{Au} \mathrm{XV}{ }^{\mathrm{e}}$ siècle, le latin conservait encore une importance certaine, comme l'illustre le formulaire de chancellerie compilé par Odart Morchesne, en 1427. Le recueil compte 268 formules différentes, dont les deux tiers sont en français et un tiers en latin Un sondage dans les registres du milieu $d u X V^{e}$ siècle révèle que $10 \%$ des lettres enregistrées sont en latin ${ }^{17}$.

Si l'on ajoute qu'au Parlement de Paris, la plus haute juridiction du royaume, tous les arrêts et jugés furent rédigés en latin jusqu'à l'ordonnance de Villers-Cotterêts de 1539, force est de conclure que celui-ci resta avec le français l'une des deux langues d'expression de la volonté royale jusqu'à l'aube des Temps modernes. Il n'y eut jamais d'adéquation entre les langues du roi et celles de leurs sujets puisque selon les époques Flamands, Français ou Occitans étaient susceptibles de se voir adresser des documents en latin, et que par ailleurs, l'autorité royale pouvait écrire en français aux régions de langue néerlandaise ou occitane. On était loin de l'idéal de la communication civile souhaitée par Oresme.

Le latin pouvait présenter un avantage du point de vue fonctionnel de la communication. Il était la seule langue maîtrisée par un nombre significatif de personnes partout dans le royaume. Savoir lire le latin s'imposait à tous les clercs pour jouir de leur statut ${ }^{18}$. De même, tous ceux qui avaient poursuivi un certain niveau d'études avaient été initiés au latin. Le latin était d'un usage courant dans l'Église. Dans les régions de droit romain du sud de la France, il était la langue d'usage des juristes. Tous ces facteurs assuraient au latin une solide implantation sociale à la grandeur du royaume. Partout, il était maîtrisé par une certaine élite lettrée qui pouvait se faire le relais de la parole royale.

Les valeurs qui connotaient le latin ajoutaient un surcroît de prestige à la parole royale. N'était-il pas la langue de la Bible et de la parole sacramentelle ? On ne peut manquer de noter qu'à la fin du Moyen Âge, les dernières chartes royales systématiquement écrites en latin, les légitimations et les anoblissements, étaient précisément celles qui transformaient le statut de la personne du bénéficiaire à la manière d'une parole sacramentelle. N'oublions pas non plus que de façon générale le développement des institutions royales s'inspirait des structures administratives de l'Église ${ }^{19}$.

17. O. Guyotjeannin et S. Lusignan, Le formulaire d'Odart Morchesne dans la version du ms BnF fr. 5024, p. 26.

18. R. Génestal, Le procès sur l'état de clerc aux XIII' et XIV siècles, p. 1-39.

19. Voir les actes du colloque édités par J-P. Genet (dir.), État et Église dans la genèse de l'État moderne. 
L'usage du latin contribuait également à rehausser certaines facettes de l'image du roi. On pense en particulier à la définition juridico politique du pouvoir royal qui isolait le roi du reste de la hiérarchie féodale, en insistant sur sa nature impériale, ainsi que le résume l'adage « le roi est empereur en son royaume». L'idée prit naissance au temps de Louis IX sous la plume de Jean de Blanot qui s'appuyait lui-même sur les Institutes de Justinien ${ }^{20}$. Elle fut reprise par la suite par d'innombrables auteurs français. Or, le latin était la langue emblématique du pouvoir impérial qui y resta attaché jusqu'aux dernières années du $\mathrm{XV}^{\mathrm{e}}$ siècle. Au XIII ${ }^{\mathrm{e}}$ siècle, à la cour de Frédéric II, il connut un éclat particulier grâce à Pierre de La Vigne dont le recueil de modèles de lettres influença les grandes chancelleries laïques $\mathrm{d}^{\prime}$ Occident durant les deux siècles qui suivirent ${ }^{21}$. C'est seulement sous Maximilien $\mathrm{I}^{\text {er }}$ que $l^{\prime}$ empereur commença à s'adresser à ses sujets en allemand ${ }^{22}$. En restant attachés au latin, les rois de France s'inscrivaient dans cette prestigieuse tradition.

L'usage du latin renforçait une autre composante de l'image du roi qui découlait de son sacre et du modèle de formation proposé par les miroirs des princes, tel le célèbre De regimine principum de Gilles de Rome ${ }^{23}$. Alors qu'on recommandait aux jeunes nobles les exercices physiques, la chasse et le maniement des armes, on encourageait le futur roi à acquérir la sagesse d'un clerc par la lecture d'ouvrages de morale, d'instruction religieuse, d'histoire et d'autres sujets de ce genre. Car selon l'adage de Jean de Salisbury répété inlassablement: «un roi illettré est comme un âne couronné » (Policraticus IV, 6) ${ }^{24}$. On encourageait d'ailleurs l'apprentissage du latin par le futur roi que le sacre allait investir d'un caractère surnature ${ }^{25}$. J'ai discuté ailleurs de la difficile question de déterminer quels furent les rois de France qui connaissaient effectivement le latin. Je crois pouvoir conclure que Louis IX, Philippe le Bel et Jean II le maîtrisaient, alors que Philippe VI l'ignorait sans doute, et que Charles V le connaissait moins bien que les hommes de lettres de son entourage voulaient bien le faire croire $^{26}$. Ce n'est pas un hasard si ces deux rois favorisèrent l'usage de la langue française. Mais, alors que Philippe VI avait vraisemblablement adopté le français pour se mettre au diapason du monde féodal dont il était issu et qui l'avait porté au pouvoir, Charles $\mathrm{V}$ cherchait à promouvoir par sa politique de traduction l'émergence d'une véritable culture lettrée savante en français, ainsi qu'en témoigne Nicole Oresme :

«Donques puis je bien encore conclurre que la consideracion et le propos de nostre bon roy Charles est a recommender, qui fait les bons livres et excellens translater en françois. » ${ }^{27}$

L'objectif de Charles V fut de faire du français une langue de culture lettrée comparable au latin.

De Philippe VI à Charles V, le français devint la langue du roi au prix de certaines transformations. La première a touché son orthographe. Lorsqu'on examine les chartes françaises de Philippe VI, on remarque une tendance à l'accroissement du nombre de consonnes quiescentes dans l'orthographe des mots. Il s'agit de consonnes qui souvent étaient peu ou pas présentes jusque-là en ancien français et qui rappelaient l'étymologie

20. J. Krynen, L'empire du roi. Idées et croyances politiques en France, XIII - XV siècles, p. 79.

21. B. Grévin, Rhétorique du pouvoir médiéval. Les Lettres de Pierre de la Vigne et la formation du langage politique européen (XIII - XV siècle), p. 271-300.

22. A. Marineau-Pelletier, "'Je ne say s'ilz m'entendront en tioche, ou si je parlerai latin': Metz, l'Empire et les langues à la fin du Moyen Âge ». Les plus anciens documents en allemand adressés à la ville de Metz datent de 1495.

23. S. Lusignan, «Université, savoir et langue française : l'exercice du pouvoir sous Charles V » ; N. L. Perret, Les traductions françaises du De Regimine Principum de Gilles de Rome ; J-J. Vincensini, " Des valeurs qui légitiment de 'translater en françois' des textes latins ".

24. J. Krynen, Idéal du prince et pouvoir royal en France à la fin du Moyen Âge (1380-1440), p. 97-106.

25. M. Bloch, Les rois thaumaturges: étude sur le caractère surnaturel attribué à la puissance royale en France et en Angleterre.

26. S. Lusignan, La langue des rois, p. 112 et ss.

27. Nicole Oresme, Le livre de Ethiques d'Aristote, éd. A. D. Menut, p. 101. 
latine des mots. Citons à titre d'exemple la terminaison plurielle des substantifs et des adjectifs en - aus, qui commence à s'écrire - aulx ou - aulz pour rappeler son étymologie latine - ales. Mon étude de l'apparition des consonnes quiescentes dans les chartes de Philippe VI montre qu'elles sont présentes dans 30,5\% des cas, en 1329-1330, et que ce taux atteint les $90 \%$ à compter de $1339-1340^{28}$. L'orthographe du français de la chancellerie s'est fortement latinisée à partir du moment où le roi a imposé son usage. Je n'hésite pas à conclure avec B. Cerquiglini qu'une telle évolution orthographique du français, visait à l'investir de :

« La dignité inhérente au maître de l'écrit, le latin. ${ }^{29}$

La latinisation $d u$ français s'est poursuivie au temps de Charles $V$, particulièrement sous l'influence des traducteurs royaux qui créèrent des milliers de néologismes, le plus souvent des calques du latin, pour doter le français d'un lexique abstrait et savant dont il ne disposait pas jusqu'à cette date ${ }^{30}$.

\section{L'usage du français par l'administration royale}

Il est rarissime de trouver une justification de l'usage du français par la chancellerie royale. Je peux en citer deux qui datent de l'époque où son emploi restait marginal ${ }^{31}$. En 1307, les articles d'une ordonnance de nature économique furent rédigés en français, ut facilius intelligantur, pour qu'ils soient mieux compris et respectés. En 1321, un échange de terres entre Philippe $V$ et l'évêque de Tournai est en français pour ses points cruciaux, ut per hoc clarius et certius videantur. Ces rares expressions d'une volonté d'être mieux compris n'ont provoqué aucun mouvement de fond en faveur de la langue vernaculaire sous les derniers capétiens. Par ailleurs, je n'ai trouvé aucun argument justifiant l'adoption du français par Philippe VI. Le moins que l'on puisse dire est que la réflexion sur la qualité de la communication ne fut pas une préoccupation dominante du pouvoir royal français.

À défaut de témoignages explicites des sources, l'historien peut tenter d'évaluer dans quelle mesure l'usage du français pouvait améliorer la qualité de la communication. On peut supposer que l'expédition d'actes royaux en français dans le pays d'oïl leur assurait un potentiel de lecteurs plus large qu'en latin. À la période où ils se multiplient, puis deviennent la règle, soit entre le règne de Philippe le Bel et octobre 1330, le français était la langue d'usage des administrations locales princières et municipales depuis plusieurs décennies, voire un siècle dans certains cas. Mais qu'en était-il en pays néerlandophone et occitan?

Avant d'aborder la question, je propose un petit détour afin de préciser la langue utilisée par les sujets pour s'adresser à l'administration royale. Il va nous révéler en creux ce que pouvaient être les attentes des sujets à l'égard des usages linguistiques du pouvoir royal. Il existe un type de sources riche et éclairant sur le sujet : ce sont les procurations par lesquelles des sujets ou des institutions déléguaient une personne pour agir en leur nom auprès de l'autorité royale. Les procurations étaient très souvent écrites au lieu même de résidence de celui qui déléguait ses pouvoirs. On les trouve écrites en latin ou en français par une grande variété de clercs et de notaires. Le premier corpus est formé des procurations confiées aux délégués des villes qui, en 1308, avaient été convoquées par Philippe le Bel à une assemblée à Tours pour discuter de la question des Templiers. Il nous reste 232 procurations urbaines,

28. S. Brazeau et S. Lusignan, «Jalon pour une histoire de l'orthographe française au XIV siècle : l'usage des consonnes quiescentes à la chancellerie royale ».

29. B. Cerquiglini, Le Roman de l'orthographe: au paradis des mots, avant la faute 1150-1694, p. 44.

30. J. Chaurand, Introduction à l'histoire du vocabulaire français ; O. Bertrand, Histoire du vocabulaire français.

31. S. Lusignan, « Le choix de la langue d'écriture des actes administratifs en France : communiquer et affirmer son identité ». 
dont 115 en français et 117 en latin ${ }^{32}$. Le second corpus date des années 1371-1382. Il s'agit de procurations données à leurs représentants par des plaideurs au Parlement de Paris pour qu'il puisse négocier en leur nom un accord avec la partie adverse afin d'éviter que leur procès traîne en longueur. J'en ai analysé 292 dans le fonds des accords du Parlement de Paris $^{33}$.

On reconnaît dans les deux corpus l'opposition entre le nord de la France où l'on utilise le français pour s'adresser au roi, et le sud, le latin. L'analogie est évidente avec la répartition des actes royaux sous Philippe VI, après 1330. D'un corpus à l'autre, on note toutefois que l'aire du français s'étire davantage vers le sud. Parmi les actes français du début du $\mathrm{XIV}^{\mathrm{e}}$ siècle, on n'en trouve aucun provenant des actuels départements de la CharenteMaritime, des Deux-Sèvres, de la Vienne ou de l'Indre, tous situés dans le sud du pays d'oïl. En revanche, les actes de la fin du XIV siècle viennent de l'ensemble du pays d'oïl et même du nord du pays d'oc, comme du Bourbonnais ou de la Basse-Auvergne. Cette pénétration $\mathrm{du}$ français dans le nord du pays d'oc à la fin du XIV ${ }^{\mathrm{e}}$ siècle est connue depuis longtemps ${ }^{34}$. Les différences entre les deux corpus se remarquent également au niveau des traits régionaux du français. Au début du XIV ${ }^{\mathrm{e}}$ siècle, ils sont perceptibles dans les actes écrits en domaine picard, en Normandie, dans l'Aube, la Côte d'Or, la Haute-Marne et les Ardennes. En revanche, l'ensemble des actes de la fin du XIV ${ }^{\mathrm{e}}$ siècle est dans un français qui s'apparente à celui de Paris et à la langue du roi. Les seules procurations à s'en écarter sont celles de la Charente-Maritime, dans un français encore légèrement marqué, et celles du domaine picard qui portent les traits distinctifs de la région. Enfin, le corpus nous livre un acte écrit à Bruges en français picard. Par d'autres sources, on sait qu'il était habituel pour les Flamands d'emprunter le picard pour leurs communications avec l'extérieur de leur comté pour des motifs politiques ou commerciaux. Nombreux étaient les Flamands qui maîtrisaient le français, surtout parmi les élites urbaines ${ }^{35}$.

Toutes les sources que je connais attestent des nombreuses inadéquations entre les langues parlées par les habitants de la France et celles utilisées pour la communication entre le roi et ses sujets. Pour s'adresser au pouvoir royal, les néerlandophones utilisaient le français picard et jamais leur propre langue. En pays d'oïl, les français écrits régionaux se sont effacés au cours du XIV siècle au profit de la langue du roi, sauf dans l'aire picarde et sur la façade atlantique méridionale. En pays occitans, seul le latin avait cours et jamais la langue locale. Quant à l'administration royale, si elle semble s'être un peu rapprochée des usages linguistiques des régions au temps de Philippe VI, elle s'en est distancée complètement par la suite, par le recours exclusif au latin sous Jean II, et par l'usage grandissant du français pour tout le royaume à partir de Charles V. Les sources nous renvoient une image de la communication entre le roi et ses sujets plus proche de la tour de Babel que de l'idéal du partage d'une même langue souhaité par Nicole Oresme. Pourtant, tout suggère que la communication entre le roi et ses sujets fonctionnait plutôt bien.

Pour expliquer ce paradoxe, il faut revenir sur le fonctionnement de la communication langagière dans la société française médiévale, beaucoup mieux acclimatée que la nôtre à la mouvance des langues et à leur multiplicité. Comme dans le reste de l'Occident chrétien, l'Église avait propagé un modèle bilingue de la communication depuis le haut Moyen Âge. Á l'intérieur de l'Église, le latin était la langue du dogme et de la liturgie. En revanche, l'encadrement des fidèles et leur instruction chrétienne passaient par la prédication dans le vernaculaire local; c'était déjà le vœu du concile de Tours de 813 qui recommandait de

32. G. Picot, Documents relatifs aux États généraux et assemblées réunis sous Philippe le Bel, p. 588 à 719 ; Sur l'assemblée de Tours : F. Lot et R. Fawtier, Histoire des institutions françaises au Moyen Âge, t. II, Institutions royales, p. 553-554. 33. Archives nationales de France, $\mathrm{X}^{1 \mathrm{c}} 26$ à 43.

34. A. Brun, Recherches historiques sur l'introduction du français dans les provinces du Midi.

35. S. Lusignan, Essai d'histoire sociolinguistique : le français picard au Moyen Âge, p. 199-213. 
prêcher aux fidèles dans la langue romane rustique ou dans la langue germanique ${ }^{36}$. La confession annuelle devenue obligatoire à partir $\mathrm{du} \mathrm{XIII}{ }^{\mathrm{e}}$ siècle se faisait également en vernaculaire. Tout au long du Moyen Âge, les membres du clergé avaient développé l'aptitude d'enseigner aux fidèles dans leur langue des vérités qu'ils avaient apprises en latin. La communication au sein de la société chrétienne était en quelque sorte fondée sur la traduction.

Les rois de France s'inspiraient de ce même modèle lorsqu'ils mettaient par écrit leurs volontés dans une langue inconnue de leurs sujets. Il faut ajouter à ce propos que les actes royaux étaient destinés autant à la lecture privée silencieuse qu'à la lecture à haute voix à l'intention d'une personne ou d'un groupe selon les circonstances. Il faut donner son sens premier à la formule «à tous ceux qui verront ou orront » que l'on retrouve inlassablement répétée en tête des actes. Examinons d'abord le cas du latin. Le processus de réception pouvait se dérouler suivant différents cas de figure, selon qu'un acte était destiné à une seule personne qui connaissait le latin, ou à la même personne qui devait le lire à d'autres qui l'ignoraient, ou à un bénéficiaire qui ne pouvait le lire. Dans ces deux derniers cas, l'acte devait être traduit dans l'idiome local, soit pour le lire en public, soit pour en permettre la compréhension à ceux qui ignoraient la langue savante. Celui qui avait accès à la parole latine du roi s'en faisait son médiateur en vernaculaire à la manière des prédicateurs dans leurs sermons.

Les archives conservent de nombreuses traces de la traduction d'actes royaux latins dans la langue locale. Malheureusement, il s'agit d'un sujet très peu étudié. Voici quelques exemples. Lorsqu' on dépouille les cartulaires des villes du Nord, on ne compte pas les transcriptions d'actes royaux latins suivies de leur traduction en français local. Par exemple, on lit en tête du cartulaire de Douai :

«Che sont les chartres et li previlege de le ville de Douay tant en latin comme en rommans, et cheles en latin transcriptes en rommans, tant de roys, de contes, de contesses, de evesques, de abbes, de chevaliers, comme de autres segneurs quels que il soient. » ${ }^{37}$

Un problème semblable se posait avec les arrêts et jugés du Parlement qui étaient consignés en latin, mais qui devaient être obligatoirement lus sur les lieux du litige pour que tous en prennent connaissance. Voici comment une charte de l'abbaye de Dunes, en Flandre, décrit la publication d'une telle sentence, en 1427. Le bailli du lieu rapporte que devant un groupe :

«jusques au nombre de cinquante personnes ou environ, je lierech et exposay mot après l'autre la tenue du dit arrest et si leur exposay en langage flameng comment par la dicte court de Parlement $[\ldots] »^{38}$

Enfin, citons cette ordonnance de 1403 (n. st.), confirmant les statuts des cordonniers de Carcassonne rédigés en latin. On stipule à la fin qu'elle soit lue et expliquée chaque année in romancio sive romana lingua, c'est-à-dire en langue occitane ${ }^{39}$.

Les actes royaux écrits en français parisien pouvaient poser des problèmes analogues. J'ai trouvé très peu de chose concernant le besoin de les traduire en néerlandais. Cela s'explique sans doute par la familiarité de nombreux Flamands avec le français. À l'exception de Louis de Male qui recourra abondamment au néerlandais entre les années 1349 et 1358, les comtes de Flandre utilisèrent exclusivement le français dans leurs écrits à partir des années $1270^{40}$. La

36. Monumenta Germaniae Historica, Concilia, II/1, p. 288

37. S. Lusignan, Essai d'histoire sociolinguistique, p. 90.

38. S. Lusignan, La langue des rois, p. 146.

39. S. Lusignan, « Le choix de la langue d'écriture des actes administratifs en France », p. 194.

40. S. Lusignan, Essai d'histoire sociolinguistique. p. 189. 
réception d'actes royaux en français devait également poser problème en pays occitan. Paul Videsott a trouvé la trace d'une traduction médiévale en occitan du traité de Paris de 1259 entre Louis IX et Henri III d'Angleterre dont l'original était en français. Un très beau dossier à ce propos concerne le conflit entre la ville d'Aurillac et son seigneur, l'abbaye de SaintGéraud, à la fin du XIII ${ }^{\mathrm{e}}$ siècle. On voit les consuls de la ville faire traduire en occitan certains documents latins émanés de l'abbaye, et eux-mêmes rédiger en occitan les brouillons d'actes ensuite mis en latin pour être expédiés à Saint-Géraud ${ }^{41}$. En pays d'oïl, on peut soupçonner que les actes écrits en français pouvaient donner lieu lors de leur lecture publique à certaines adaptations en fonction des variations phonétiques locales de la langue. On en trouve une certaine confirmation en domaine picard. On constate en effet que dans les cartulaires urbains du Nord, les actes royaux émis en français parisien se voyaient souvent ajouter des traits picards au moment de leur transcription ${ }^{42}$. Pour ce qui concerne leur lecture silencieuse, tout me prouve qu'un acte écrit dans une forme régionale était compréhensible par quiconque savait lire le français.

L'étude du choix des langues dans la communication entre l'autorité royale et ses sujets révèle qu'au Moyen Âge, le français n'élimina jamais le latin. Langue exclusive des Mérovingiens à Louis IX, le latin possédait encore de bonnes chasses gardées à la fin du $\mathrm{XV}^{\mathrm{e}}$ siècle, qu'on pense aux chartes de légitimation ou d'anoblissement et aux arrêts et jugés du Parlement. Il fallut attendre l'ordonnance de Villers-Cotterêts de 1539 pour que le latin cessât d'être une langue du roi. Le latin bénéficiait de son riche capital symbolique à titre de langue sacrée de l'Église et de langue du droit romain et de la fonction impériale. Il s'avérait être également une langue véhiculaire efficace puisque la parole royale pouvait trouver partout en France des médiateurs capables de la relayer dans le vernaculaire local.

Quant au français, après une suite d'avancées et de reculs, son utilisation commença à surpasser celle du latin à partir du règne de Charles $\mathrm{V}$, Mais, pour qu'il accédât à la dignité de langue du roi, les clercs de la chancellerie n'eurent de cesse de lui ajouter un vernis latin. L'adoption rapide du français royal comme modèle de la langue écrite, un peu partout en pays d'oïl, au cours du XIV ${ }^{\mathrm{e}}$ siècle, témoigne bien de son prestige aux yeux des sujets du roi. Le français du roi pouvait être lu par tous les lettrés francophones et entendu par l'ensemble des sujets de langue d'oïl, au seul prix d'accommodements phonétiques selon les régions. Mais, tout comme le latin, il devait être traduit partout ailleurs. Cela soulève la question de l'apprentissage du français langue seconde dans la France médiévale. J'ai suggéré ailleurs que les écoles urbaines ont pu y contribuer en pays néerlandophones ${ }^{43}$. Quant aux pays d'oc, on en sait trop peu et cette question mériterait d'être étudiée en profondeur.

Force est de conclure que le modèle de la communication entre l'autorité politique et les sujets dans la France médiévale différait profondément de celui qui fut progressivement implanté beaucoup plus tard, entre la Révolution et les premières décennies du $\mathrm{XX}^{\mathrm{e}}$ siècle, qui visait à instaurer une communication directe et immédiate de l'État avec chaque citoyen en imposant à tous une même langue, le français. À l'opposé, l'autorité royale médiévale a pu privilégier deux langues qui manifestaient la grandeur du roi sans être comprises par tous, loin de là. Le bon fonctionnement de ce modèle dépendait de la présence d'innombrables relais régionaux qui savaient lire d'abord, et qui fussent en mesure d'adapter ou de traduire les deux langues royales dans le vernaculaire local.

41. R. Grand, Les «Paix» d'Aurillac. Étude et documents sur l'histoire des institutions municipales d'une ville à consulat. 42. S. Lusignan, La langue des rois au Moyen Âge. p. 225-231.

43. S. Lusignan, Essai d'histoire sociolinguistique, p. 207-209. 


\section{Les langues de l'autorité royale en Angleterre (XIII - XV siècles)}

Je vais maintenant aborder brièvement le cas de l'Angleterre en me concentrant sur ce qui est susceptible de compléter notre compréhension du modèle de communication entre l'autorité royale et ses sujets, qui prévalait au Moyen Âge.

L'écart entre les langues de l'autorité royale et celles de ses sujets est encore plus flagrant dans l'Angleterre des derniers siècles du Moyen Âge. Le roi régnait sur d'immenses territoires aux langues les plus variées. L'Angleterre elle-même était de langue anglaise, encore qu'il restait des populations celtes en Cornouaille et dans certaines communautés aux frontières du pays de Galles. Le pouvoir du roi s'étendait également sur deux autres contrées où dominaient les populations celtes, soit le pays de Galles, conquis définitivement en 1282, et l'Irlande dont la lente conquête amorcée au XII ${ }^{\mathrm{e}}$ siècle y introduisit très tôt l'anglo-normand et l'anglais. Le roi d'Angleterre avait également des possessions continentales. On pense au premier chef à l'Aquitaine où l'on parlait occitan et gascon, dont l'étendue du territoire sous autorité anglaise varia tout au long de la période, jusqu'à sa conquête finale par la France en 1453. Plus au nord, le Ponthieu fut sous la coupe du roi anglais entre 1279 et 1369, avec trois interruptions, soit de 1294 à juillet 1299, de 1324 à 1325, puis de 1339 à 1360. Charles V reprit définitivement le Ponthieu, en $1369^{44}$. Ce comté appartenait à l'aire linguistique picarde. Quant à la ville de Calais, qui devint anglaise en 1347, elle était de langue néerlandaise. Enfin, il ne faut pas négliger que les rois anglais régnèrent sur des espaces variables selon les aléas de la guerre, en Normandie et dans le nord de la France, depuis 1415 et jusqu'en 1450 en certains endroits. Pour communiquer avec ses sujets, le roi n'utilisa jamais que deux langues : le latin et le français. Le premier n'était la langue maternelle de personne, alors que le français fut celle de ses sujets uniquement lorsque le roi exerça son autorité sur le Ponthieu, la Normandie et le nord de la France!

Le choix du latin ou du français par l'autorité royale obéissait à des règles bien différentes de celles qui prévalaient en France; il dépendait en fait du mode de scellement de l'acte ${ }^{45}$. Il importe de rappeler au départ que la chancellerie royale anglaise n'avait pas le monopole des écritures royales. Sa compétence se limitait aux chartes scellées du grand sceau. Celui-ci resta l'unique garant de la parole royale jusqu'à ce que soit introduit l'usage du sceau privé sous Édouard I ${ }^{\text {er }}$ (1272-1307). La rédaction d'actes sous ce sceau fut confiée à des clercs de la garde-robe, proches du roi, mais à partir de 1311, le bureau responsable de ce sceau gagna son autonomie et devint l'une des trois grandes institutions administratives du royaume au côté de la chancellerie et de l'échiquier. Deux autres modes de validation firent leur apparition par la suite, soit le sceau du secret, à partir des années 1312-1313, puis le signet, en 1355, qui l'un et l'autre étaient apposés à des actes écrits par les clercs d'une sorte de secrétariat personnel du roi.

La chancellerie royale anglaise utilisa presque exclusivement le latin durant tout le Moyen Âge. Le français n'apparaît que sporadiquement, principalement dans les actes à l'intention de la France et de quelques principautés continentales francophones ${ }^{46}$. Le grand sceau servait à authentifier tous les actes importants des rois d'Angleterre. Les actes les plus solennels

44. H. Johnstone, «Le comté de Ponthieu (1279-1307)»; S. B. Storey-Chalenger, L'administration anglaise du Ponthieu après le traité de Brétigny 1361-1369; H. E. Shealy, « The English Administration of Ponthieu, 1279-1369 ».

45. Pour ce qui suit: E. Déprez, Études de diplomatique anglaise. De l'avènement d'Édouard Ier à celui d'Henri VII (12721485). Le sceau privé, le sceau secret, le signet, p. 10-11, 73-74, 88 ; H. C. Maxwell-Lyte, Historical Notes on the Use of the Great Seal of England, p. 101-103 ; T. F. Tout, Chapters in the Administrative History of Medieval England, vol. 5, p. 54-112, 116, 135, 161-81 ; H. Sugget, " The Use of French in England in Later Middle Ages ».

46. H. C. Maxwell-Lyte, Historical Notes on the Use of the Great Seal of England, p. 238-239. 
empruntaient même une rhétorique très recherchée; l'œuvre de Pierre de la Vigne avait exercé très tôt son influence sur le latin de la chancellerie ${ }^{47}$. En revanche, la langue française domina largement dans les actes authentifiés par le sceau privé, le sceau du secret et le signet. Quant à la langue anglaise, on la retrouve utilisée par le roi une première fois en 1415 et à partir de 1417, elle devint la langue exclusive des actes sous le signet.

Les premiers documents royaux écrits en anglo-normand apparurent sous le sceau privé au cours des dernières années $\mathrm{du}$ règne $\mathrm{d}^{\prime}$ Édouard $\mathrm{I}^{\mathrm{er}}$ (1272-1307). Sous son successeur, Édouard II (1307 à 1327), on compte autant d'actes latins que vernaculaires scellés de ce sceau, et finalement l'anglo-normand domina sous Édouard III (1327-1377), pour demeurer la langue la plus utilisée jusqu'en $1440^{48}$. Le sceau privé était apposé aux actes par lesquels le roi faisait connaître ses décisions ou ses intentions aux différentes instances de l'administration centrale, à ses officiers en région ou à toute autre personne concernée. Ainsi nous reste-t-il d'innombrables documents scellés de ce sceau, par lesquels le roi commandait à la chancellerie la rédaction de ses chartes. On les appelle writs, ce que l'on pourrait traduire par « mandats » en français. Les plus anciens writs datent de 1282. D'abord écrits en latin, ils passèrent progressivement à l'anglo-normand qui devint la langue dominante jusqu'à la fin des années 1430. Pour les seules dix premières années du règne d'Édouard III, soit de 1327 à 1336, il en reste un peu moins de 10000 dans les fonds des National Archives à Kew ${ }^{49}$. Un rapide sondage me laisse croire qu'environ $90 \%$ sont en anglo-normand. Chaque writ écrit en français donnait lieu à la rédaction par la chancellerie d'une charte latine scellée du grand sceau. Le roi communiquait sa volonté personnelle en anglo-normand, mais sa décision acquérait sa valeur légale et perpétuelle lorsqu'elle était exprimée par écrit en latin.

Que l'anglo-normand puisse être considéré comme la langue personnelle du roi, par opposition au latin, sa langue publique et officielle, se confirme à mes yeux par l'étude de la langue empruntée par les sujets pour communiquer avec le roi. Comme on l'a bien mis en évidence ces dernières décennies, le gouvernement par la grâce constituait un volet central de l'exercice du pouvoir, qu'il s'agisse du pape ou des rois ${ }^{50}$. En aval des décisions royales communiquées à la chancellerie par un writ, il pouvait y avoir eu une pétition adressée au roi par des sujets ou par des institutions. Les archives anglaises conservent des milliers de pétitions pour la période qui nous intéresse. Elles proviennent pour l'essentiel des domaines soumis à l'autorité du roi, qu'ils se trouvent dans les îles Britanniques ou sur le continent. Des étrangers pouvaient également adresser de telles pétitions en fonction de leurs intérêts en Angleterre: par exemple, on en trouve plusieurs venant de marchands flamands ou italiens. Une seule règle s'imposait aux requérants, c'était que leurs pétitions fussent rédigées en français; les pétitions en latin sont rarissimes. Les pétitions en français restèrent majoritaires jusqu'en 1436, alors que l'anglais qui se manifestait timidement depuis 1422 finit par dominer ${ }^{51}$.

On pourrait supposer que les pétitions ont contribué à diffuser l'usage de l'anglo-normand partout où s'exerçait l'autorité du roi d'Angleterre. Mais les choses ne sont pas aussi simples. Précisons d'abord que les pétitions ne comportent habituellement aucune datation précise, ni mention de lieu d'écriture, ni de nom du rédacteur ; seule l'analyse de leur contenu permet

47. B. Grévin, Rhétorique du pouvoir médiéval, p. 629-662.

48. E. Déprez, Études de diplomatique anglaise, p. 10-11; T. F. Tout, Chapters in the Administrative History of Medieval England, vol. 5, p. 116 et 135 ; H. Suggett, "The Use of French in England in Later Middle Ages »; G. Dodd, « Trilingualism in the Medieval English Bureaucracy : The Use - and Disuse - of Languages in the Fifteenth Century Privy Seal Office ».

49. The National Archives, Kew, C81 136 à 23.

50. H. Millet (dir.), Suppliques et requêtes : le gouvernement par la grâce en Occident, XII - XVe siècle ; G. Dodd, Justice and Grace: Private Petitioning and the English Parliament in the Late Middle Ages ; M. Ormrod et G. Dodd (dir.), Medieval Petitions : Grace and Grievance.

51. G. Dodd, « The Rise of English, the Decline of French; Supplications to the English Crown c. 1420-1450 ». 
de les situer dans le temps et l'espace. G. Dodd a beaucoup discuté de la question de leurs lieux d'écriture. Si bon nombre ont pu être écrites au lieu même de résidence du requérant par des scriveners locaux ${ }^{52}$, il estime que dans d'autres cas, celui-ci avait pu faire rédiger sa demande à Londres même ou dans la ville où se tenait le Parlement et où il était facile de trouver des clercs familiers avec la procédure pétitionnaire. Sans s'étendre davantage sur ce point, il faut tout de même retenir que l'usage répandu des pétitions eut pour conséquence que tout sujet du roi, peu importe où il habitait, savait qu'il devait utiliser le français, et de préférence l'anglo-normand, pour communiquer avec le roi.

La nécessité de communiquer en français avec le roi s'imposait tout autant à ses sujets du sud-ouest de la France de langue gasconne ou occitane. Guilhem Pépin a réalisé de très beaux travaux sur les pétitions provenant de la Gascogne anglaise. Il en a retrouvé près de 1600 dans les archives à Kew, la plus ancienne datant de 1280. Elles sont habituellement en anglonormand. Quelques-unes furent de toute évidence écrites au lieu même de résidence du requérant, car l'anglo-normand du texte porte des traits orthographiques gascons. Il reste que les pétitions gasconnes écrites en «bon anglo-normand» pouvaient avoir été également rédigées sur place, soit par des clercs anglais en poste en Gascogne, soit par des notaires gascons qui maîtrisaient le français du roi aussi bien qu'un clerc londonien, comme le rapporte Guilhem Pépin. Bien entendu, d'autres Gascons présents en Angleterre ou représentés là-bas par un procureur pouvaient avoir eu recours à un clerc anglais. La présence en Gascogne de clercs autochtones maîtrisant l'anglo-normand ne doit pas surprendre. J'en ai fourni des exemples dans La langue des rois et David Trotter a également attiré l'attention sur ce fait ${ }^{53}$.

Le gouvernement par la grâce trouvait sa justification dans la fiction politique d'un rapport individualisé entre le roi et chacun de ses sujets. Pour adresser une pétition au roi, le requérant se devait d'emprunter la langue personnelle du roi, l'anglo-normand. S'il acquiesçait à la requête, le roi faisait part par écrit de sa décision en anglo-normand dans un writ. Mais, la volonté royale n'acquérait sa valeur de droit qu'une fois transposée en latin par la chancellerie dans une charte scellée du grand sceau. Ces usages linguistiques furent la règle des années 1280 à 1430-1440. À la grandeur des possessions du roi, il fallait qu'un nombre suffisant de personnes apprennent les deux langues royales à titre de langue seconde. Le latin ne soulevait pas de difficulté étant donné la place qu'il occupait dans la société médiévale. Mais que l'anglo-normand s'impose de la même manière ne peut s'expliquer que par un impératif politique absolument contraignant.

La dichotomie entre l'expression de la volonté personnelle du roi en anglo-normand et l'énoncé du droit en latin rejoint la distinction faite par les théoriciens du pouvoir, comme Bracton ou Fortescue, entre le roi et la Couronne, entre la personne physique détentrice transitoire du pouvoir et l'État intemporel, garant du droit et du bien commun ${ }^{54}$. C'était la base de la théorie des deux corps du roi dont Kantorowicz a démontré toute l'importance pour la monarchie anglaise ${ }^{55}$. Le roi privilégiait l'anglo-normand, la langue identifiée au lignage dont il tirait sa légitimité, alors que l'État s'exprimait en latin, la langue universelle du sacré, du droit et de la majesté. Les deux langues reflétaient le double système de désignation du roi d'Angleterre qui comme roi, était dit roi par la grâce de Dieu, mais qui comme individu, portait un nom, Édouard ou Richard par exemple, accompagné d'un nombre précisant son rang dans la succession des rois ayant porté ce nom depuis la conquête

52. N. Ramsay, «Les notaires en Angleterre (XIII - XV siècle)».

53. S. Lusignan, La langue des rois au Moyen Âge, p 182-184; D. Trotter, "'Mossenhor, fet metre aquesta letra en bon francés' : Anglo-French in Gascony ».

54. J. Dubabin, « Government », p. 498-501 ; S. Lockwood, Sir John Fortescue. On the Laws and Government of England, p. xxi-xxii.

55. E. Kantorowicz, Les deux corps du roi. Essai sur la théologie politique au Moyen Âge. 
normande. Ainsi, trouve-t-on Richard II régulièrement désigné dans les sources comme : «le Roy Richard second apres le conquest » ce qui rappelait bien le lignage normand du roi. Ce sont des valeurs de légitimation politique associées aux deux idiomes qui expliquerait que les rois d'Angleterre ont pu imposer pendant plus d'un siècle et demi deux langues de communication qui n'étaient les langues maternelles d'aucun de leurs sujets, mais qu'un grand nombre ont pu trouver opportun d'apprendre pour bien le servir depuis le nord de l'Angleterre jusqu'aux Pyrénées et pour agir comme intermédiaires de la transmission de la parole royale dans les vernaculaires locaux.

Dans une ultime et brève conclusion, je soulignerai que les modèles de la communication que nous avons étudiés n'ont pu être mis en œuvre que dans des conditions sociolinguistiques très différentes de celles de nos sociétés modernes. La France et l'Angleterre médiévales se caractérisaient comme des sociétés où la valeur symbolique d'une langue pouvait justifier son emploi pour la communication entre le roi et ses sujets, même aux dépens des impératifs pragmatiques de la communication. Le latin disposait dans les deux royaumes d'un riche capital symbolique à titre de langue sacrée et de langue du droit et de la majesté impériale. En France, le français devint la seconde langue du roi grâce une nouvelle dignité acquise au prix de sa latinisation. Enfin, l'anglo-normand tenait sa valeur d'être la langue identitaire du lignage des rois d'Angleterre. Dans les deux royaumes, l'efficacité de la communication reposait sur la présence un peu partout de médiateurs capables de traduire la parole du roi dans les vernaculaires locaux à l'image des prédicateurs dans l'Église.

\begin{abstract}
Résumé
Le présent article examine les enjeux du choix de la langue de communication du pouvoir royal en France et en Angleterre du XIII ${ }^{\mathrm{e}}$ au $\mathrm{XV}^{\mathrm{e}}$ siècle. Les populations des deux royaumes parlaient une variété d'idiomes romans, germaniques et celtes. Malgré le développement d'institutions de nature étatique, on était loin de l'État Nation fondé sur le partage d'une langue commune.

Les différentes langues utilisées en France et en Angleterre se distinguaient par la valeur symbolique qu'on leur attribuait. Le latin dominait toutes les autres par son prestige à titre de langue du sacré et du droit. À l'opposé, les langues vernaculaires restaient déconsidérées par les lettrés. Il reste qu'au cours de la période, chacune a pu accéder de façon plus ou moins achevée au registre de l'écrit. Le français devint même une langue usuelle du pouvoir royal français et anglais. Le présent article tente d'expliquer comment se sont conciliées les valeurs symboliques de la langue et les exigences de communication avec des populations multilingues durant la période où le latin et le français furent les langues exclusives des rois de France et d'Angleterre.
\end{abstract}




\section{Bibliographie}

\section{Sources}

Roger BACON, Compendium studii philosophiae, éd. John Sherren Brewer, London, Longman, Green, Longman and Roberts, 1859.

Nicole Oresme, Le livre de Ethiques d'Aristote, éd. Albert D. Menut, New York, G. E. Stechert, 1940.

\section{Études}

BANNIARD Michel, Viva voce. Communication écrite et communication orale $d u I V^{e}$ au IX siècle en Occident latin, Paris, Institut des Études augustiniennes, 1992.

BERTRAND Olivier, Histoire du vocabulaire français, Paris, Éditions du Temps, 2008.

BLOCH Marc, Les rois thaumaturges : étude sur le caractère surnaturel attribué à la puissance royale en France et en Angleterre, Paris, Gallimard, 1983.

BRAZEAU Stéphanie et LUSIGNAN Serge, «Jalon pour une histoire de l'orthographe française au XIV ${ }^{\text {e }}$ siècle : l'usage des consonnes quiescentes à la chancellerie royale ", Romania, vol. CXXII, 2004, p. 444-467.

BRUN Auguste, Recherches historiques sur l'introduction du français dans les provinces $d u$ Midi, Paris, Champion, 1923.

CERQUIGLINI Bernard, Le Roman de l'orthographe : au paradis des mots, avant la faute 1150-1694, Paris, Hatier, 1996.

CHAURAND Jacques, Nouvelle histoire de la langue française, Paris, Seuil, 1999.

CHAURAND Jacques, Introduction à l'histoire du vocabulaire français, Paris, Bordas, 1977.

DÉPREZ Eugène, Études de diplomatique anglaise, de l'avènement d'Édouard Ir à celui d'Henri VII (1272-1485). Le sceau privé, le sceau secret, le signet, Paris, Champion, 1908.

DodD Gwillym, Justice and Grace: Private Petitioning and the English Parliament in the Late Middle Ages, Oxford, Oxford University Press, 2007.

DODD Gwillym et ORMROD Mark (dir.), Medieval Petitions : Grace and Grievance, Woodbridge, York University Press, 2009.

DODD Gwilym, "The Rise of English, the Decline of French; Supplications to the English Crown c. 1420-1450», Speculum, vol. LXXXVI, 2011, p. 117-150.

DODD Gwilym, « Trilingualism in the Medieval English Bureaucracy : The Use - and Disuse of Languages in the Fifteenth Century Privy Seal Office», Journal of British Studies, vol. LI, 2012, p. 253-283. 
DUBABIN Jean, "Government ", dans BURNS J. H. (dir.), The Cambridge History of Medieval Political Thought c. 350-1450, Cambridge, Cambridge University Press, p. 477-519.

ÉLOY Jean-Michel, La constitution du picard: une approche de la notion de langue, Louvain-laNeuve, Peeters, 1997.

GENET Jean-Philippe et VINCENT Bernard (dir.), État et Église dans la genèse de l'État moderne. Actes du colloque organisé par le Centre national de la recherche scientifique et la Casa de Velázquez, Madrid, 30 novembre et $1^{\text {er }}$ décembre 1984, Madrid, Casa de Velásquez, 1986.

GÉNESTAL Robert, Le procès sur l'état de clerc aux XIII et XIV siècles, École pratique des Hautes Études, section sciences religieuses, Paris, Imprimerie nationale, 1909.

GoEbl Hans, "Sur le changement macrolinguistique survenu entre 1300 et 1900 dans le domaine d'Oỉl. Une étude diachronique d'inspiration dialectométrique », Dialectologia, vol. I, 2008, p. 3-43.

GRAND Roger, Les "Paix» d'Aurillac. Étude et documents sur l'histoire des institutions municipales d'une ville à consulat, Paris, Recueil Sirey, 1945.

GRÉVIN Benoît, Rhétorique du pouvoir médiéval. Les Lettres de Pierre de la Vigne et la formation du langage politique européen (XIII $-X V^{e}$ siècle), Rome, École française de Rome, 2008.

GRÉVIN Benoît. «Les mystères rhétoriques de l'État médiéval », Annales. Histoire, Sciences Sociales, vol. LXIII, 2008, p. 271-300.

GUYOTJEANNIN Olivier et LUSIGNAN Serge, avec le concours des étudiants de l'École nationale des chartes et la collaboration de FRUNZEANU Eduard, Le formulaire d'Odart Morchesne dans la version du ms BnF fr. 5024, Paris, École des chartes, 2005.

JOHNSTONE Hilda, "Le comté de Ponthieu (1279-1307)», dans JORON Adrien et PETIT Raymond (dir.) Le Ponthieu et la dynastie anglaise au XIII siècle, Abbeville, Société d'émulation historique et littéraire, 1969, p. 13-44

KANTOROWICZ Ernst, Les deux corps du roi. Essai sur la théologie politique au Moyen Âge, Paris, Gallimard, 1989.

KRYNEN Jacques, Idéal du prince et pouvoir royal en France à la fin du Moyen Âge (1380-1440), Paris, Picard, 1982.

KRYNEN Jacques. L'empire du roi. Idées et croyances politiques en France, XIII - XV siècles, Paris, Gallimard, 1993.

LOCKWOOD Shelley, Sir John Fortescue. On the Laws and Government of England, Cambridge, Cambridge University Press, 1997.

LODGE R. Anthony, Le français. Histoire d'un dialecte devenu langue, Paris, Fayard, 1997.

LODGE R. Anthony, «Le clivage oc-oïl au Moyen Âge, fiction méthodologique », Mélanges de l'École française de Rome. Moyen Âge, vol. CXVII, 2005, p. 595-613.

LOT Ferdinand et FAWTIER Robert, Histoire des institutions françaises au Moyen Âge, t. II, Institutions royales, Paris, Presses universitaires de France, 1958. 
LuSIGNAN Serge, Parler vulgairement. Les intellectuels et la langue française aux XIII ${ }^{e}$ et XIV siècles, Paris-Montréal, Vrin-Presses de l'Université de Montréal, 1986.

LUSIGNAN Serge, "Écrire en français ou en latin au pays d'oïl : le cas de la chancellerie royale au début du $\mathrm{XV}^{\mathrm{e}}$ siècle", dans TAMINE Michel (dir.) Ces mots qui sont nos mots. Mélanges d'Histoire de la Langue française, de Dialectologie et d'Onomastique offerts au Professeur Jacques Chaurand, Charleville-Mézières, Institut Charles Bruneau (Parlure, 7-10), 1995, p. 19-30.

LuSIGNAN Serge, " "De communité appellee cité ". Les lectures de Gilles de Rome et de Nicole Oresme de la Politique I, 2 d'Aristote", dans BAKKER Paul J. J. M. (dir.), Chemins de la pensée médiévale. Études offertes à Zénon Kaluza, Brepols, Turnhout, 2002, p. 653-674.

LUSIGNAN Serge, "Chartes et traduction. Les actes latins et français de la chancellerie royale et le paradigme de la traduction", dans Di STEFANO Giuseppe et BIDLER Rose (dir.), Traduction, dérimation, compilation. La phraséologie: Actes du colloque international, Université McGill, Montréal, 2-3-4 octobre 2000, Montréal, Ëd. CERES (Le Moyen français, 51-53), 20022003, p. 395-420.

LuSIGNAN Serge, La langue des rois au Moyen Âge. Le français en France et en Angleterre, Paris, Presses Universitaires de France, 2004, p. 80-94.

LUSIGNAN Serge, "Le choix de la langue d'écriture des actes administratifs en France: communiquer et affirmer son identité", dans BOUDREAU Claire, FIANU Kouky, GAUVARD Claude et HÉBERT Michel (dir.), Information et société en Occident à la fin du Moyen Âge, Paris, Publications de la Sorbonne, 2004, p. 187-201.

LUSIGNAN Serge, «Une affaire de mots et de couteaux: la mauvaise fortune d'un Picard à Paris », dans Claustre Julie, MATTÉONI Olivier et OfFENSTADT Nicolas (dir.), Un Moyen Âge pour aujourd'hui. Mélanges offerts à Claude Gauvard, Paris, Presses universitaires de France, 2010, p. 119-127.

LusIGnAN Serge, Essai d'histoire sociolinguistique: le français picard au Moyen Âge, Paris, Classiques Garnier, 2012.

LUSIGNAN Serge, "Université, savoir et langue française: l'exercice du pouvoir sous Charles V », dans Actes du colloque Évrart de Conty et la vie intellectuelle à la cour de Charles V, organisé par l'Université Paris IV-Sorbonne en collaboration avec la Katholieke Universiteit Leuven, 14-16 mai 2009, à paraître.

MARINEAU-PELletIER Amélie, "Je ne say s'ilz m'entendront en tioche, ou si je parlerai latin". Metz, l'Empire et les langues à la fin du Moyen Âge ", mémoire de maîtrise en histoire, Ottawa, Université d'Ottawa, 2013.

MAXWELL-Lyte Henry C., Historical Notes on the Use of the Great Seal of England, London, Harrison and Sons, 1926.

MiLlET Hélène (dir.), Suppliques et requêtes: le gouvernement par la grâce en Occident, XII ${ }^{e}$ $X V^{e}$ siècle, Rome, École Française de Rome (Coll. de l'École française de Rome, 310), 2003.

PERRET Noëlle Laetitia, Les traductions françaises $d u$ De Regimine Principum de Gilles de Rome, Leiden, Brill, 2011. 
PICOT Georges, Documents relatifs aux États généraux et assemblées réunis sous Philippe le Bel, Paris, Imprimerie nationale, 1901.

RAMSAY Nigel, "Les notaires en Angleterre (XIII $-\mathrm{XV}^{\mathrm{e}}$ siècle) », dans ARNOUX Mathieu et GUYOTJEANNIN Olivier, Tabellions et tabellionages de la France médiévale et moderne, Paris, École des chartes (Mémoires et documents de l'École des Chartes, 90), 2011, p. 109-120.

SHEAly Howard E., « The English Administration of Ponthieu, 1279-1369 », Thèse de doctorat en histoire, Atlanta, Emory University, 1978.

StOReY-CHALENGer Sheila B., L'administration anglaise du Ponthieu après le traité de Brétigny 1361-1369, Abbeville, Société d'émulation historique et littéraire d'Abbeville, 1975.

SUGGET Helen, "The Use of French in England in the Later Middle Ages », Transactions of the Royal Historical Society, Fourth Series, vol. XXVIII, 1946, p. 61-83.

TouT Thomas Frederick, Chapters in the Administrative History of Medieval England: The Wardrobe, the Chamber and the Small Seals, Londres, Longmans, Green \& Co., 1920-1933, 6 vol.

TROTTER David A., " "Mossenhor, fet metre aquesta letra en bon francés": Anglo-French in Gascony ", GREGORY Stewart et TROTTER David A. (dir.), De mot en mot. Aspects of Medieval Linguistics. Essays in Honour of William Rothwell, Cardiff, University of Wales Press, 1997, p. 199-222.

VIDESOTT Paul, Les plus anciens documents en français de la chancellerie royale capétienne (12411300). Présentation et édition, Strasbourg, Éditions de Linguistique et de Philologie, 2015.

VINCENSINI Jean-Jacques, «Des valeurs qui legitiment de "translater en françois" des textes latins », dans GALDERISI Claudio et PignATELli Cinzia (dir.), La traduction vers le moyen français, Turnhout, Brepols, 2007, p. 421-452.

WARDHAUGH Ronald, An Introduction to Sociolinguistics, Oxford, Blackwell, 2006. 


\title{
Assurer la communication politique à l'étranger : enjeux et stratégies linguistiques au début du XVII siècle
}

\author{
Camille DESENCLOS \\ Docteur en histoire \\ ATER à l'Université de Haute Alsace \\ CRESAT (EA 3436)

\begin{abstract}
Extrait de : Guylaine BRUN-TRIGAUD (dir.), Contacts, conflits et créations linguistiques, Paris, Édition électronique du CTHS (Actes des congrès des sociétés historiques et scientifiques), 2015.
\end{abstract} \\ Cet article a été validé par le comité de lecture des Éditions du CTHS dans le cadre de la publication des actes du \\ $139^{\mathrm{e}}$ Congrès national des sociétés historiques et scientifiques tenu à Nîmes en 2014.
}

Qu'elle soit ou non politique, la communication repose sur un postulat de base : la mise en relation avec autrui, l'échange. Plus encore, pour prendre tout son sens, elle requiert une compréhension mutuelle entre l'énonciateur et le destinataire. Sans elle, l'établissement d'une relation verbale ou scripturale est voué à l'échec. Mais si l'on s'intéresse communément à la compréhension du sens du discours, on oublie souvent un élément pourtant essentiel au processus de compréhension: la présence d'un dénominateur linguistique commun. Aucune communication, et a fortiori aucune compréhension du discours, n'est possible si les interlocuteurs parlent une langue différente et que nul ne maîtrise la langue de l'autre. La maîtrise, même imparfaite d'une langue, permet d'assurer la communication, mais cette imperfection peut également la mettre en danger et conduire à des incompréhensions voire à des contresens qui ne pourront être identifiés. À l'impossibilité de communiquer s'ajoute alors une perversion éventuelle du discours.

Au sein du royaume de France, l'ordonnance de Villers-Cotterêts a imposé en 1539 le français comme langue officielle et a, de fait, créé un dénominateur commun à l'ensemble des sujets. Cependant, à l'échelle de l'Europe, un dénominateur commun peine à s'imposer et ce d'autant plus que peu d'États, à l'image du Saint Empire, font coïncider unité politique et linguistique. Charles Quint impose par une capitulation en 1519 l'allemand et le latin comme langues officielles mais à celles-ci s'ajoutent d'autres langues, couramment parlées au sein de certaines cours de l'Empire. L'empereur lui-même, depuis Ferdinand $\mathrm{I}^{\mathrm{er}}$, préfère s'exprimer en italien1, tandis que la partie occidentale de l'Empire, majoritairement les territoires situés autour de l'axe rhénan (Palatinat du Rhin, électorats de Cologne et de Trêves, landgraviat de Hesse, etc.) utilisent fréquemment le français, y compris dans des correspondances ne sortant pas du cadre géo-linguistique de l'Empire. À Bruxelles enfin, on parle généralement le flamand et le français auxquels s'ajoutent le latin, l'italien ou l'espagnol à la Cour².

Face à cette mosaïque linguistique, la compréhension des discours entre souverains, et à plus forte raison entre ministres et agents étrangers, semble difficile à assurer. Elle est pourtant indispensable à l'établissement de relations diplomatiques et plus largement d'une communication politique efficace. Sans compréhension, les actions de collecte, de transmission et de diffusion de l'information, à l'origine même du processus de communication politique, ne peuvent avoir lieu. Se pose alors la question suivante: comment faire pour assurer la communication politique et lui rendre son efficacité face à ces nombreux obstacles linguistiques?

1. M. Schnettger, «Auf dem Weg in die Bedeutungslosigkeit? Die Rolle der Italiener und des Italienischen in der frühneuzeitlichen Diplomatie », p. 25-60.

2. Mantoue, Archives Guidi di Bagno, Cc, 2, «Instructions de Lucio San Severino à Giovanni Francesco Guidi di Bagno ». 
L'enjeu dépasse cependant la simple compréhension réciproque. Mis à part quelques rares cas, celle-ci peut toujours être assurée mais fait face à d'autres écueils, plus politiques : comment s'assurer de la bonne compréhension d'un discours pour éviter sa perversion par un usage approximatif de la langue ou pire encore par la traduction ? À quelle langue recourir et dans quel contexte? Autant de questions auxquelles les diplomaties européennes ont tenté de répondre, dès le début du XVII ${ }^{\mathrm{e}}$ siècle, en mettant en place diverses stratégies à la fois pragmatiques et théoriques, au gré des besoins.

La majorité des exemples est prise dans les premières années de la guerre de Trente Ans ; cependant ils témoignent de pratiques déjà éprouvées par la majorité des diplomaties européennes. Encore balbutiantes au $\mathrm{XVI}^{\mathrm{e}}$ siècle, les pratiques diplomatiques sont, au début $\mathrm{du} \mathrm{XVII}^{\mathrm{e}}$ siècle, parfaitement établies et rompues aux habitudes quotidiennes comme cérémonielles. Aussi ne s'étonnera-t-on pas de les retrouver, sous une forme similaire, tout au long de la première moitié du XVII ${ }^{e}$ siècle. Pourtant, cette étude ne cherche nullement à dépasser l'année 1643 et la mise en place des congrès de Westphalie où, par la réunion de l'ensemble de la diplomatie européenne en un même lieu, les problématiques linguistiques s'exacerbent et se révèlent confrontées à d'autres enjeux ${ }^{3}$.

\section{La langue, part du cérémonial diplomatique}

Selon le cadre d'exercice de la diplomatie, le rapport à la question linguistique est bien différent. Deux cadres généraux doivent être distingués : la diplomatie ordinaire où des agents résident en permanence auprès de Cours étrangères pour y représenter leur souverain, et la diplomatie extraordinaire, constituée d'ambassades ponctuelles envoyées pour tenir un discours donné (négociation d'un traité de paix ou de mariage, félicitations pour une naissance, etc.). Or, si pour la diplomatie ordinaire, la langue est un simple outil de compréhension - elle permet le bon déroulement du travail diplomatique -, pour la diplomatie extraordinaire, elle prend une tournure plus politique et sert à la représentation du souverain, à la défense de son prestige à l'étranger.

La notion de compréhension passe donc, dans le cadre d'une ambassade extraordinaire, au second plan, au profit d'un cérémonial fortement codifié qui n'a d'autre but que de représenter, par les gestes, par la parole, par l'attitude, toute la puissance et l'autorité du souverain. Langue et prestige deviennent alors indissociables. En défendant sa propre langue, la langue de son souverain, l'agent diplomatique défend le prestige de celui-ci. Aucun compromis ne peut être toléré sous peine de voir la puissance royale ainsi projetée diminuée. Prolongement d'une suite pléthorique, d'une entrée majestueuse ou de costumes chatoyants, la langue sert aussi à représenter, dès le premier contact avec le souverain étranger, l'autorité royale. Lors de la première audience, avec l'empereur, de l'ambassade extraordinaire française menée par le duc d'Angoulême en juillet $1620^{4}$, le premier discours est tenu, non en allemand ou en latin, mais en français, qui plus est par le membre le plus prestigieux de l'ambassade, Charles de Valois, duc d'Angoulême et fils naturel de Charles IX. Recourir au français revêt plusieurs avantages pour le duc. Elle lui permet d'exprimer dans leur globalité les instructions telles qu'énoncées par le roi mais surtout de manifester, grâce à une volubilité et une emphase que seule une parfaite maîtrise de la langue permet, toute la puissance qui doit émaner de l'ambassade et tenter d'obtenir le respect qui lui est dû. Le choix de la langue participe alors des éléments de représentation politique de la puissance d'un souverain.

3. La question des langues lors des congrès de Westphalie a été davantage étudiée, et bénéficie d'une documentation plus abondante sur le sujet. Étant l'un des sujets même de négociation, avant les questions politiques, elle est amplement discutée dans les dépêches diplomatiques. Sur le sujet, cf. G. Braun, La connaissance du Saint-Empire en France du baroque aux Lumières 1643-1756, p. 204-237.

4. L'ambassade est envoyée en mai 1620 dans l'Empire, d'abord auprès des princes catholiques et protestants, puis auprès de l'empereur, pour proposer une médiation, et ainsi mettre fin aux troubles qui agitent l'Empire depuis la Défenestration de Prague en mai 1618 (cf. C. Desenclos (éd.), L'ambassade extraordinaire des duc d'Angoulême, comte de Béthune et abbé de Préaux, Paris, 2010). 
De l'aveu même des ambassadeurs, le discours du duc d'Angoulême ne fut pas compris par l'empereur et fut immédiatement traduit en italien, langue de prédilection de celui-ci, par Philippe de Béthune ${ }^{5}$. Aucune communication n'a en effet de valeur si le contenu ne peut être compris. Bien que secondaire, la compréhension reste nécessaire à l'établissement d'une négociation ou plus simplement à la délivrance d'un message, d'où la traduction immédiate dans une langue commune. Quant à savoir si le choix de l'italien fut discuté en amont, les correspondances diplomatiques ne nous le disent pas. L'hypothèse la plus probable reste cependant un accord tacite reposant sur les pratiques de la diplomatie permanente. Nicolas de Baugy, résident permanent auprès de l'empereur, conversant avec ce dernier en italien, la pratique linguistique s'étend aux ambassades extraordinaires ${ }^{6}$. Le choix de l'italien dépasse cependant le seul cadre de la Cour impériale. Il s'agit certes de la langue favorite de Ferdinand II, et plus largement de nombreux membres de la maison de Habsbourg, mais également de la langue de la diplomatie pour l'ensemble des communications informelles ${ }^{7}$. Dans le cadre d'échanges bilatéraux, l'italien est toujours préféré au latin, plus formel, lorsque les deux parties le maîtrisent.

Pour autant, on ne retrouve pas l'italien dans les correspondances entre souverains, pour la partie impériale du moins. Seules les correspondances particulières ou internes sont rédigées dans cette langue à l'image de la correspondance entre l'empereur et Laurent Malcot, son agent à Paris ${ }^{8}$. Les correspondances officielles, comme celles entre le roi et l'empereur, sont toujours rédigées en latin. Langues des chancelleries, mais surtout langue d'Église, le latin reste commun à l'ensemble du monde chrétien. Même dans des provinces plus reculées comme la Transylvanie, il est compris et s'impose de ce fait comme outil par excellence de la diplomatie. Pour autant, il ne s'agit pas de la langue dominante, toutes les correspondances officielles n'étant pas rédigées en latin. Cette dernière langue n'est utilisée que lorsqu'aucun dénominateur linguistique n'a été trouvé, soit parce que les deux souverains ne partagent aucune langue soit parce qu'ils ne le veulent pas. À ces critères politico-linguistiques s'ajoute également le caractère moins prestigieux de langues vernaculaires telles que l'italien ou l'allemand. Alors que l'empereur converse en italien, il écrit en latin au roi de France. Ce dernier cependant lui écrit toujours en français, bien qu'il soit de notoriété publique que l'empereur n'en maîtrise mot. Des secrétaires sont certes chargés de la lecture et $a$ fortiori de la traduction, comme pour le latin par ailleurs; cependant la compréhension immédiate n'est pas l'objectif principal de ces dépêches, souvent suppléées par un discours oral de l'agent diplomatique en poste. Comme pour les ambassades extraordinaires, l'usage du français sert à imposer la majesté du roi jusque dans sa correspondance pour en faire une véritable langue cérémonielle. En refusant de discourir dans une langue qui n'est pas la sienne, le roi cherche à imposer le respect et à conserver la pleine mesure de son autorité.

Cette insertion dans le complexe cérémonial diplomatique n'est pas fortuite, encore moins inconsciente, mais sciemment élaborée par les pouvoirs européens. Si le Cérémonial françois de Théodore Godefroy, détaillant davantage le cérémonial physique (visites, habits, sièges, etc.), ne mentionne pas les questions linguistiques, celles-ci n'en sont pas moins prégnantes lors de l'envoi d'ambassades. Le prince de Ligne, envoyé en France par les Archiducs en 1616 pour féliciter le roi de son récent mariage avec l'infante d'Espagne, s'interroge ainsi sur le cérémonial à adopter lors de son séjour : quel titre accorder à la nouvelle reine («Madame» ou «Señora»), dans quelle langue s'adresser à elle (français

5. «Ce que le sieur de Bethune reprints en langue italiene, l'empereur n'entendant quasy un mot de la françoise » (Bibliothèque nationale de France, ms fr. 15930, « Lettre de Charles de Valois, Philippe de Béthune et Charles de Préaux-Châteauneuf à Pierre Brûlart, vicomte de Puisieux », fol. 269-278).

6 . Il est délicat de prétendre généraliser cette pratique à l'ensemble de la diplomatie extraordinaire en raison du silence des sources sur ces questions linguistiques. Si le cérémonial diplomatique est amplement décrit, parfois jusqu'au port du couvre-chef, l'usage de la langue n'est que très rarement renseigné, témoignant de son caractère établi au sein des diverses Cours européennes et donc de sa stabilité au cours des années.

7. M. Schnettger, «Auf dem Weg in die Bedeutungslosigkeit? Die Rolle der Italiener und des Italienischen in der frühneuzeitlichen Diplomatie », p. 25-60.

8. Österreichische Nationalarchiv - Haus-, Hof- und Staatsarchiv, Frankreich, Berichte 23. 
ou espagnol ? $)^{9}$. La question de langue est d'autant plus cruciale que le statut de la reine est complexe au regard de sa parenté avec les Archiducs : nouvellement reine de France, elle est la fille du roi d'Espagne Philippe III, et donc la nièce des Archiducs. S'adresser à elle en espagnol ferait ressortir ces liens familiaux, tandis que l'usage du français constituerait une reconnaissance témoignage de son nouveau statut. Les Archiducs exigeront l'usage du français en première intention ${ }^{10}$ et placent clairement la visite dans le registre diplomatique et officiel. Une fois encore, le choix de la langue du premier discours, quel que soit l'usage linguistique par la suite, est crucial au sein du processus diplomatique. Si l'exemple peut paraître anecdotique - les documents préparatoires aux envois diplomatiques sont trop rares pour que l'on puisse estimer avec justesse la fréquence de ces questionnements -, il n'en reflète pas moins une réalité effective des relations diplomatiques : le choix d'une langue révèle l'importance que prête le souverain à l'ambassade ainsi envoyée.

L'enjeu peut être la reconnaissance d'un statut international comme lors de l'ambassade du prince de Ligne ou plus simplement la volonté d'exprimer sa déférence. Le choix de s'adresser à un prince dans la langue de ce dernier reflète une certaine soumission, amitié ou proximité. Cette dernière intention politique de la langue s'observe plus spécifiquement dans la correspondance entre souverains. Certains princes de l'Empire rédigent ainsi en français les dépêches adressées au roi ou à son secrétaire des Affaires étrangères, alors que leurs correspondances quotidiennes sont rédigées dans une autre langue, majoritairement l'allemand ou le latin. Cet usage suppose, naturellement, en amont la maîtrise de la langue et seuls les princes dont les terres sont situées sur l'axe rhénan y recourent. Mais de surcroît, l'usage du français coïncide avec une certaine proximité entre les correspondants. Les principales correspondances rédigées en français, à savoir celles de l'électeur palatin, du landgrave de Hesse et de l'électeur de Cologne, correspondent aux potentats allemands avec lesquels la France entretient les meilleures relations. En s'exprimant dans la langue du roi, ceux-ci cherchent à montrer leur déférence à son égard et ainsi à s'attirer ses bonnes grâces, que ce soit par l'établissement d'une alliance, d'une protection ou même d'une pension. Le choix de la langue devient un outil communicationnel, au même titre que les mots eux-mêmes, pour témoigner de son affection envers le souverain destinataire de la correspondance.

\section{Maîtriser les principales langues européennes}

Contrairement à la diplomatie extraordinaire ou à la correspondance officielle, l'agent permanent ne se situe pas dans la seule représentation mais dans la négociation et le recueil quotidien d'informations. L'établissement d'une langue commune, si possible la langue de la Cour de résidence, est nécessaire à la bonne exécution de ses diverses missions. Aussi ne s'agit-il pas d'imposer une langue, comme précédemment, mais de s'adapter aux pratiques linguistiques locales. La défense du prestige du souverain, si sensible pour les ambassades extraordinaires, passe désormais par le seul vecteur du contenu du discours et non plus de son contenant. La langue n'est plus qu'un simple outil de travail, pour l'agent diplomatique.

L'enjeu devient alors tout autre et passe du domaine politique au champ strictement linguistique. Les agents diplomatiques doivent maîtriser les diverses langues parlées au sein des Cours européennes pour s'acquitter au mieux de leur mission : latin, italien, français, espagnol, allemand, anglais. La maîtrise du latin, langue des chancelleries et langue commune en dernière instance, est indispensable à tout diplomate à la fois pour avoir accès à l'ensemble de documents officiels, mais également pour mener des

9. Archives de l'État en Belgique - Archives générales du Royaume, Audience 419, « Instruction pour le prince de Ligne, ambassadeur extraordinaire en France », fol. 237.

10. «Il parlera du commencement en françois si apres entrant en discours avecq la royne il se veult servir de la langue espagnole il le pourra faire » (ibid.). 
négociations dans des territoires plus reculés comme la Hongrie ${ }^{11}$. De ce fait, aucun des agents diplomatiques français en poste au début du XVII ${ }^{\mathrm{e}}$ siècle ne semble ignorer le latin. L'italien est également nécessaire pour dialoguer avec les Cours de Vienne et de Bruxelles. Il semblerait toutefois que sa connaissance ne soit pas indispensable pour des résidences au sein même de l'Empire, notamment auprès de l'électeur palatin. La maîtrise de l'allemand surtout semble délaissée, quel que soit le poste dans l'Empire. Sa faible importance dans la diplomatie française tient principalement à sa mauvaise réputation au début $\mathrm{du} \mathrm{XVII}$ siècle. L'allemand est encore considéré comme une langue barbare, réservée aux soldats et autres gens de peu d'éducation ${ }^{12}$ et demeure fort peu parlée par la noblesse française, ce qui contraint donc à recruter, pour la résidence auprès des princes protestants, au sein de la petite noblesse protestante française, qui a souvent accompli une partie de sa formation dans les principales universités protestantes allemandes. Son absence de maîtrise n'empêche pas le bon exercice de la charge diplomatique, l'allemand étant peu parlé au sein des diverses Cours, mais peut s'avérer être un frein dans la collecte d'information en dehors du seul cercle ministériel et courtisan.

L'enjeu est ici plus important que la seule maîtrise d'une langue. Les Cours, à l'image de l'Empire, sont multilingues. À la Cour de Vienne, bien que l'italien soit préféré par l'empereur, l'allemand n'en est pas exclu et demeure utilisé par des potentats de moindre importance. Plus encore, à la Cour de Bruxelles, le français et l'italien le disputent à l'espagnol, et à un échelon plus local au flamand. Méconnaître l'allemand ou l'espagnol dans ces deux contextes oblige l'agent diplomatique à se limiter aux seules informations que la Cour veut bien lui laisser entendre dans sa langue de prédilection. La mission d'information est alors incomplète : c'est auprès de l'ensemble des acteurs politiques, voire socio-économiques, que les informations doivent être collectées puis rediffusées. De la même manière, seule une maîtrise des langues plus locales peut permettre l'établissement d'un réseau large d'informateurs dans l'ensemble des couches de la société.

S'il est aisé de connaître les langues parlées dans les Cours impériales, il est difficile d'estimer les connaissances linguistiques des agents diplomatiques, et donc leur efficacité. Ces informations sont rarement mentionnées dans leurs correspondances, hormis dans le cas de nouveaux interlocuteurs. Jamais les instructions fournies aux agents diplomatiques français n'évoquent les langues dans lesquelles ils devront discourir et auprès de qui ${ }^{13}$. La langue de la Cour de résidence ainsi que les diverses langues utilisées dans leurs papiers - lorsque les documents conservés sont écrits de leur main -, constituent un point de départ, insuffisant cependant pas pour dresser un tableau complet de leurs connaissances linguistiques. En l'absence de mentions claires dans leurs dépêches ou a fortiori d'autres documents attestant de ces connaissances, seules des suppositions peuvent être réalisées sur l'usage exact des langues au sein de la diplomatie française. Rien ne permet de connaître l'ampleur des connaissances linguistiques des agents. L'absence de toute mention d'obstacles linguistiques laisse cependant supposer une certaine étendue de ces connaissances, même s'il est peu probable qu'un agent diplomatique déclare ouvertement ne pas avoir pu mener à bien sa mission, car il ne connaissait pas la langue utilisée et n'a pu mettre en place des stratégies de contournement.

11. J. Bérenger, « Latin et langues vernaculaires dans la Hongrie du XVII siècle », p. 5-28.

12. P. Lévy, La langue allemande en France : pénétration et diffusion des origines à nos jours, p. 87-88.

13. Il faudrait se confronter à l'ensemble des instructions européennes pour l'époque moderne pour s'en faire un jugement définitif, mais il est plus probable que de tels conseils aient été transmis oralement lors du départ de l'agent diplomatique. Seule une instruction, donnée au futur nonce apostolique à Bruxelles, Giovanni Francesco Guidi di Bagno, par son prédécesseur Lucio Sansverino, évoque les langues qui ont cours à Bruxelles et les langues que le nonce devra maîtriser pour dialoguer avec les souverains et principaux ministres des Pays-Bas (Mantoue, Archives Guidi di Bagno, Cc, 2, «Instructions de Lucio San Severino à Giovanni Francesco Guidi di Bagno "; B. de Meester (éd.), Correspondance du nonce Giovanni Francesco Guidi di Bagno (1621-1627), t. 1, p. 9). L'instruction donnée à Guidi di Bagno se justifie cependant par le laps de temps entre le départ de Sanseverino et l'arrivée de Guidi di Bagno, empêchant le nonce de dispenser oralement ces recommandations, et constitue, à notre sens, une exception dans les pratiques diplomatiques courantes. 
L'absence de maîtrise, ou du moins une apparence de non-maîtrise, peut, par ailleurs, participer d'une véritable stratégie diplomatique. Le recours à une langue commune peut être utilisé pour cacher sa maîtrise de la langue vernaculaire et ainsi s'ériger en stratégie d'espionnage. L'agent devient le témoin de propos tenus librement et sans méfiance, sur la supposition de son absence de maîtrise de ladite langue ${ }^{14}$ Cela demeure cependant purement théorique. Pour le début du XVII ${ }^{\mathrm{e}}$ siècle, il n'y a aucune mention d'une telle attitude, assumée ou découverte, chez les diplomates. Sans aller jusqu'à une pareille dissimulation, une utilisation politique de la maîtrise des langues se remarque chez quelques diplomates. Juan de Mendoza y Velasco, ambassadeur espagnol à la Cour de Bruxelles au début des années 1620, profite de sa mauvaise maîtrise du latin pour éviter les discussions trop longues ou trop précises. En recourant au prétexte linguistique, il évite les négociations qu'il ne souhaite pas mener en gardant un masque de bonne volonté. Malgré une utilité certaine, cette pratique fait naître la méfiance chez d'autres diplomates, pas toujours dupes de la manœuvre, à l'image de Jean de Péricard, qui relate en décembre 1623 le procédé dans une de ses dépêches adressées à Pierre Brulart, vicomte de Puisieux et secrétaire d'État des Affaires étrangères ${ }^{15}$. La pratique peut donc permettre de mener à bien une politique étrangère comme de la retarder par l'isolement que le procédé, une fois révélé, peut créer au sein de la classe diplomatique.

\section{L'enjeu de l'interprétariat}

Dans certains cas cependant, la communication demeure impossible. Les ambassadeurs ne peuvent pas maîtriser toutes les langues employées en Europe, notamment dans l'Empire ottoman où le sultan refuse de communiquer dans une autre langue que le Turc, non maîtrisée par une grande majorité des Européens. Dans ces cas, le recours à un interprète devient indispensable ${ }^{16}$.

Si la Sublime Porte demeure un cas particulier, le recours aux interprètes en Europe n'en existe pas moins, de manière plus ponctuelle. Ceux-ci sont utilisés uniquement lorsque le besoin s'en fait sentir et ce pour le laps de temps le plus court possible. Cet emploi parcimonieux d'interprètes qui pourraient pourtant faciliter la communication dans bien des cas, tient à la crainte, fortement ancrée chez les diplomates, de l'infidélité ou de l'ignorance de l'interprète. Le diplomate n'a aucun moyen pour s'assurer de la validité de la traduction de l'interprète, encore moins de son adéquation avec la pensée initialement exprimée. Rien ne lui permet non plus de s'assurer que l'interprète ne joue pas un double jeu en tenant un discours bien différent. Cette impossibilité de contrôle met en valeur un élément clé de la pratique diplomatique : la confiance dans ses exécutants et dans leur capacité à conserver le secret de la politique étrangère. Dès qu'il est dépositaire d'une partie du discours diplomatique, à des fins de traduction, l'interprète devient l'un de ces exécutants et peut être soumis à la tentation de divulguer certains secrets contre rétribution ou pour servir les intérêts d'un autre souverain.

De ce fait, certains théoriciens comme François de Callières ${ }^{17}$ recommandent de les exclure du secret diplomatique et de réserver leur usage aux seuls cas où la communication est menacée par l'impossibilité de dialoguer. Cette recommandation, émise au début du XVIII ${ }^{\mathrm{e}}$ siècle, s'inspire d'une pratique adoptée de longue date par les agents diplomatiques. L'ambassade menée par le duc d'Angoulême dans l'Empire en 1620-1621 a ainsi recours à ses propres membres pour l'interprétariat - Charles de l'Aubespine, abbé de Préaux pour le latin et Philippe de Béthune pour l'italien. En se

14. B. Barbiche, «L'ambassadeur (1603) de Jean Hotman de Villiers », p. 39

15. Bibliothèque nationale de France, ms. fr. 16134, «Lettre de Jean de Péricard à Pierre Brulart, vicomte de Puisieux », fol. 447 .

16. Nommés drogmans, ces interprètes ont fait l'objet d'études plus abondantes que leurs homologues européens, voir notamment M. de Testa et A. Gautier, "Les drogmans au service de la France au Levant », p. 738.

17. F. de Callières, De la manière de négocier avec les souverains, p. 105. 
passant d'un intermédiaire, l'adéquation entre la pensée de l'ambassade et le discours tenu est garantie. Pourtant, un interprète - Bernard, puis Desprez - suit l'ambassade à ses débuts. Aucun membre de l'ambassade ne parlant allemand, celui-ci a pour charge de faire le lien avec les gentilshommes envoyés par les différents princes allemands aux trois ambassadeurs pour les saluer et témoigner de leur affection envers le roi. Mais, dès l'arrivée d'Étienne de Sainte-Catherine, ancien résident français auprès de l'électeur palatin, auprès de l'ambassade, Desprez est congédié. Ce remplacement révèle l'enjeu réel de l'interprétariat: le recours, non à une traduction, mais à une personne n'appartenant pas au corps diplomatique.

Le recrutement d'un interprète doit donc répondre à des critères draconiens de confiance, et de confession. L'ambassade menée par le duc d'Angoulême refuse l'interprète proposé par Jean de Flavigny, chargé par le secrétaire d'État des Affaires étrangères de leur en fournir un, en raison de sa confession protestante ${ }^{18}$. L'ambassade étant composée exclusivement de membres de confession catholique, il est fort probable que la confession protestante ait été jugée comme incompatible avec la confiance requise, les huguenots étant supposés vouloir assister leurs coreligionnaires de l'Empire. Face à la difficulté de trouver pareil interprète, l'ambassade doit se résoudre à employer un protestant nommé Bernard. Elle se sépare cependant rapidement de lui, dès que l'occasion d'employer un interprète catholique, Desprez, se présente à Strasbourg à peine quelques semaines plus $\operatorname{tard}^{19}$

Cette réticence à employer des interprètes provient surtout de l'absence d'interprètes accrédités par le pouvoir royal. Ceux-ci sont parfois extérieurs à la diplomatie française ou d'un rang suffisamment inférieur pour que les diplomates en poste les estiment corruptibles par un parti adverse. Au début du XVII ${ }^{\mathrm{e}}$ siècle, il n'existe pas d'école pour former les interprètes, pas plus qu'il n'en existe pour les diplomates. Il faut attendre 1753 pour qu'un bureau des interprètes soit créé pour traduire les documents envoyés par l'ensemble des agents en poste et pour former en même temps les futurs interprètes ${ }^{20}$. Interprète semble être une charge royale, mais celle-ci ne coïncide nullement avec la maîtrise des langues nécessaires à son exercice. Praillon, titulaire de la charge en 1620, aurait été maintenu uniquement en récompense des services rendus par son père mais sans connaissance de l'allemand, pourtant nécessaire à son emploi ${ }^{21}$. Pour suppléer d'éventuelles lacunes, des interprètes sont donc utilisés de manière ponctuelle mais sans que l'on connaisse leur origine, encore moins les raisons exactes de leur choix, hormis leurs compétences linguistiques.

Si parfois la question de la langue est un obstacle à la communication, les stratégies mises en place par le pouvoir royal semblent porter leur fruit au début du XVII ${ }^{\mathrm{e}}$ siècle. La communication est toujours assurée par le biais d'une langue commune ou du recours à des interprètes, malgré les problèmes inhérents en termes de confiance ou de préservation du secret de l'information. Surtout, le choix de la langue ne vise pas seulement la seule compréhension mais est vecteur d'une véritable valeur politique. Il permet de défendre la réputation du souverain à l'étranger, s'attirer les bonnes grâces d'un autre ou tout simplement de témoigner d'une proximité politique ou familiale entre les deux correspondants. Pourtant, jamais ce cérémonial linguistique n'est formalisé, précisé ou théorisé, preuve du caractère profondément ancré de ces pratiques linguistiques dans l'exercice de la diplomatie.

18. Bibliothèque nationale de France, ms. fr. 4118, « Lettre de Jean de Flavigny à Étienne de Sainte-Catherine », fol. 57.

19. Bibliothèque nationale de France, ms. fr. 3972, « Lettre de Charles de Valois, Philippe de Béthune et Charles de Préaux-Châteauneuf à Pierre Brûlart, vicomte de Puisieux », fol. 89r.

20. J. Baillou, Les affaires étrangères et le corps diplomatique français, t. 1, p. 117-119.

21. Bibliothèque nationale de France, ms fr. 15930, «Lettre de Charles de Valois, Philippe de Béthune et Charles de Préaux-Châteauneuf à Pierre Brulart, vicomte de Puisieux », fol. 146. 


\begin{abstract}
Résumé
Une langue commune est la condition sine qua non de tout dialogue, plus encore lorsque la communication politique se tourne vers l'extérieur. Mais, outre la dissension fréquente entre unités politiques et zones linguistiques, la recherche d'une langue commune doit intégrer des pré-requis diplomatiques comme la défense du prestige du souverain ou l'expression d'une certaine déférence. Si une langue commune est l'outil indispensable du travail diplomatique quotidien, la communication politique ne peut se faire sans la maitrise de l'ensemble des langues de la zone concernée et nécessite alors un recours à des interprètes ou à des traductions avec leurs problèmes inhérents de transposition et de possible perversion de l'information originale. La question de l'usage des langues avant 1648 étant souvent ignorée des études diplomatiques, il s'agit de s'interroger sur les difficultés et les atouts des usages linguistiques dans la communication politique d'un État à l'étranger au début du XVII ${ }^{\mathrm{e}}$ siècle.
\end{abstract}

\title{
Bibliographie
}

BAILlOU Jean, Les affaires étrangères et le corps diplomatique français, t. 1: «De l'Ancien Régime au Second Empire », Paris, CNRS Éditions, 1984.

BARBICHE Bernard, "L'ambassadeur (1603) de Jean Hotman de Villiers », dans PEKAR LEMPEREUR Alain et COLSON Aurélien, Négociations européennes d'Henri IV à l'Europe des 27, Paris, A2C Medias, 2008, p. 31-41.

BÉRENGER Jean, «Latin et langues vernaculaires dans la Hongrie du XVII ${ }^{\mathrm{e}}$ siècle », Revue historique, vol. 242 (1969), p. 5-28.

BRAUN Guido, La connaissance du Saint Empire en France du baroque aux Lumières 1643-1756, Munich, R. Oldenbourg (Pariser Historische Studien, 91), 2010.

CALLIÈRES François de, De la manière de négocier avec les souverains, Amsterdam, pour la Compagnie, 1716.

DESENCLOS Camille (éd.), L'ambassade extraordinaire des duc d'Angoulême, comte de Béthune et abbé de Préaux, Paris, École nationale des chartes (Éditions en ligne de l'École des chartes, 23), 2010 [http: / / corpus.enc.sorbonne.fr/ angouleme].

LÉVY Paul, La langue allemande en France: pénétration et diffusion des origines à nos jours, Paris, IAC (Bibliothèque de la Société des études germaniques, 4), 1950-1952, 2 vol.

MEESTER Bernard de (éd.), Correspondance de Giovanni Francesco Guidi di Bagno (1621-1627), Bruxelles/Rome, Institut historique belge à Rome (Analecta Vaticano-Belgica, $2^{\mathrm{e}}$ série : Nonciature de Flandre, V), 1938, 2 vol.

SCHNETTGER Matthias, "Auf dem Weg in die Bedeutungslosigkeit? Die Rolle der Italiener und des Italienischen in der frühneuzeitlichen Diplomatie », dans ESPENHORST Martin (dir.), Frieden durch Sprache? Studien zum kommunikativen Umgang mit Konflikten und Konflitlösungen, Göttingen, Vandenhoeck \& Ruprecht (Veröffentlichungen des Instituts für Europäische Geschichte Mainz, 91), 2012, p. 25-60.

TESTA Marie de et GAUTIER Antoine, "Les drogmans au service de la France au Levant », Revue d'histoire diplomatique, vol. 105, 1991, p. 7-38. 


\title{
Récits de voyages : barrières et passerelles linguistiques L'exemple de l'Autrichienne Ida Pfeiffer (1797-1858)
}

\author{
Annie LAGARDE FOUQUET \\ Ingénieur en retraite, \\ Membre de la Société de géographie et de Centrale Histoire
}

Extrait de : Guylaine BRUN-TRIGAUD (dir.), Contacts, conflits et créations linguistiques, Paris, Édition électronique du CTHS (Actes des congrès des sociétés historiques et scientifiques), 2015.

Cet article a été validé par le comité de lecture des Éditions du CTHS dans le cadre de la publication des actes du $139^{\mathrm{e}}$ Congrès national des sociétés historiques et scientifiques tenu à Nîmes en 2014.

La voyageuse Ida Pfeiffer, née Reyer (1797-1858) appartient à une famille aisée de la bourgeoisie d'affaires autrichienne. Elle a d'abord partagé les jeux de ses frères avant de recevoir les enseignements d'un précepteur. Le jeune homme, Émile Trimmel ${ }^{1}$, l'initie à la géographie et lui fait découvrir la littérature de voyage. Il doit quitter le service de la famille Reyer pour avoir osé demander la main de son élève. Après ce départ, la jeune fille refuse plusieurs partis avant d'épouser Anton Pfeiffer. Elle s'installe avec son mari à Lemberg (L'viv en Ukraine), où il exerce la profession d'avocat. Des revers de fortune l'incitent à revenir, dans sa famille à Vienne. Ce n'est qu'après avoir assumé seule l'éducation de ses deux fils, qu'elle entreprend à quarante-cinq ans, et pendant les seize dernières années de sa vie, une carrière d'écrivain voyageur.

\section{Langues et voyages}

Commentant le récit de voyage autour du monde de l'Allemand Meyen, un publiciste anglais remarquait en 1835, que le voyage d'un Allemand était différent de celui d'un Anglais, précisant que leurs regards et leurs critères de comparaison n'étaient pas identiques $^{2}$. Ces différences, qui s'expliquent par des particularités culturelles, ont quelquefois été soulignées, mais au-delà des origines nationales, l'incidence de la langue sur le déroulement du voyage, sur les rencontres et sur la narration mériterait, comme le souligne Michael Cronin, d'être prise en compte :

«L'indifférence à la question de la langue dans la plupart des textes clés sur la littérature de voyage publiés depuis deux décennies a conduit à des interprétations sérieusement erronées à la fois sur l'expérience du voyage et sur la construction du récit narratif de ces expériences. $»^{3}$

L'œuvre d'Ida Pfeiffer constitue un champ d'investigation particulièrement intéressant pour les raisons suivantes :

- Amplitude géographique et diversité des voyages :

Ida Pfeiffer, qui voyage seule, sans disposer de moyens financiers importants, a enchaîné cinq grands voyages entre 1842 et 1858, dont deux tours du monde (cf. carte 1). Ils l'ont tenue éloignée de Vienne pendant plus de dix années cumulées. Nous ne retenons pour

1. Joseph Franz Emil Trimmel (1786-1867) poète et écrivain, membre correspondant de la Société de géographie de Paris.

2. «[...] a voyage round the world by a German differs materially from a voyage round the world by an Englishman: they see with different eyes, and refer to different standards of comparison. ", Dr Meyen's voyage around the world, p. 167. 3. "Indifference to the question of language in many of the key texts on writing and travel that have been published over the past decades had led to a serious misrepresentation of both the experience of travel and the construction of narrative accounts of these experiences.», M. Cronin, Across the lines, travel, language, translation, p. 2. 
cette étude que les voyages hors d'Europe avec un regroupement en cinq zones géographiques visitées à l'occasion d'un ou deux voyages: Moyen-Orient, Asie, Amérique du Nord, Amérique du Sud, Océan indien-Tahiti.

- Publications :

Elle a pris des notes, depuis le premier jour de son premier départ de Vienne en 1842 jusqu'à son retour à l'île Maurice, en 1857, après un séjour éprouvant à Madagascar. Tous ses récits ont été publiés, soit environ deux mille pages en allemand, totalement traduites en anglais et partiellement en français. Ce travail s'appuie sur les textes des éditions originales allemandes. Toutes les citations en français (dont le texte allemand figure en note de bas de page) sont des traductions libres ou des traductions revues de la première édition française.

- $\quad$ Rencontres :

$\mathrm{Au}$ fil du récit, Mme Pfeiffer qui voyage de place en place, munie de lettres de recommandation comme on le fait au XIX ${ }^{\mathrm{e}}$ siècle, dévoile l'identité des personnes qu'elle rencontre et nous parle des groupes humains qu' elle côtoie (caravane, harem, tribus...). À la diversité des régions visitées s'ajoute celle de ces rencontres, organisées ou fortuites. De la qualité de la communication dépendent : le déroulement du voyage, la collecte et la transmission d'informations; passerelle ou barrière, la langue a nécessairement une incidence sur le récit.

L'étude systématique des personnes rencontrées permet d'établir la répartition des langues parlées par les interlocuteurs de Mme Pfeiffer (cf. carte 2). Ces statistiques font apparaître, sauf dans la zone Océan Indien-Tahiti, une prédominance des germanophones. La part du français pourrait être majorée, mais sauf information sur l'usage de cette langue, ses interlocuteurs anglais en Inde, ou néerlandais dans l'Archipel indonésien sont répertoriés dans leur langue maternelle.

\section{L'allemand, langue maternelle, langue " nation»}

L'allemand, sa langue maternelle, contrairement à d'autres langues européennes, ne s'est pas répandue hors de l'Europe. Les États allemands sont des foyers d'expatriation et tous les germanophones qu'ils soient Autrichiens, Bavarois, Prussiens ou citoyens de la République d'Hambourg se reconnaissent dans leur identité linguistique, ils sont Allemands. Le premier consul accrédité par la Prusse à Guangzhou (Canton), le négociant von Carlowitz, originaire de Dresde, évoque dans sa correspondance de 1847 la visite d'une «dame allemande ${ }^{4}$ », et elle-même, dans l'avant-propos de son second tour du monde, remercie ses « compatriotes allemands $s^{5} »$.

Lors de son voyage à Jérusalem, elle a été introduite par un prêtre autrichien auprès d'un groupe d'aristocrates tchèques, hongrois et bavarois ${ }^{6}$, qui ont accepté qu'elle les accompagne dans leur voyage vers le Jourdain et la Mer Morte, puis à Baalbek et Damas. Cette rencontre joue un rôle majeur, non seulement dans le déroulement de son voyage, car elle profite d'une escorte qu'elle n'aurait pas pu se procurer, mais aussi dans le lancement de sa carrière d'écrivain. De retour à Vienne, ses compatriotes parlent de cette femme qui rédige chaque jour son journal de voyage, attirant l'attention de l'éditeur Dirnböck qui la publiera.

Mme Pfeiffer est heureuse de rencontrer des femmes qui parlent sa langue. Quand elle arrive à Singapour en septembre 1847, elle éprouve beaucoup de plaisir à converser avec Mme Behn, qui est la première Allemande rencontrée depuis son départ de Hambourg en mai 1846. Les femmes allemandes apprécient sa présence qui rompt la monotonie de leur vie. À Indore, la femme d'un homme d'église tyrolien qui n'a pas eu l'occasion de parler allemand avec une compatriote depuis quinze ans, fond en larmes en l'accueillant. Les

4. R. von Carlowitz, Briefe Richards v. Carlowitz aus Ostindien und China von 1844 an, Lettre à Fedor von Köppen, datée du 20 juillet 1847, p. 108.

5. «Deutschen Landsleute », I. Pfeiffer, Meine zweite Weltreise, n.p. dédicace et avant-propos (Widmung und vorrede). 6. Les Comtes Salm Reifferscheitet, Wratislaw, Von Berchtold, Zichy, et le Baron Von Wrede. 
Allemands présents dans les régions visitées, qu'ils soient marchands, médecins, botanistes ou, comme nous le verrons (§ 2-1), exilés politiques aux États-Unis, constituent des réseaux utiles au bon déroulement de ses voyages et à la collecte d'informations qu'elle transmet à ses lecteurs.

\section{Le français, langue universelle}

Mme Pfeiffer parle bien le français. Sur le bateau qui la conduit à Jaffa, voyage un autre Européen. Les voyageurs sont heureux de se comprendre mutuellement dans la « langue universelle des Français ${ }^{7}$ ». Le lendemain, elle découvre que son compagnon de voyage est Anglais. En 1849, William Henry Bartlett, écrivain et illustrateur, apprend par la presse les exploits de son ancienne compagne de voyage; il publie un récit de leur rencontre en Palestine ${ }^{8}$. Plus tard, à Londres, leur entretien se déroule en français, l'anglais de Mme Pfeiffer n'étant pas parfait'.

Partout, la promesse d'une conversation en français la ravit, mais sa déception est grande quand l'interlocuteur ne maîtrise pas bien la langue ou est absent. M. Damiani, (D. dans le texte), le vice-consul de France à Jaffa, est une figure bien connue des voyageurs. C'est un homme affable toujours prêt à ouvrir sa maison aux visiteurs étrangers. Mme Pfeiffer fait l'objet des mêmes attentions, mais la conversation n'est pas à la hauteur de ses attentes. Elle décrit avec humour la soirée passée dans cette famille chrétienne de Palestine avant de conclure :

«On parlât beaucoup, on comprit peu. Une chose qui se produit dit-on souvent dans les cercles savants ; ce qui pour nous ne portait pas à conséquence. ${ }^{10}$

Lamartine ne semble pas avoir rencontré de difficultés de compréhension chez M. Damiani, mais il était accompagné $\mathrm{d}^{\prime}$ un interprète ${ }^{11}$. Séjournant à Bagdad, elle visite Ctésiphon. Un Prince persan ${ }^{12}$ a installé son campement à proximité des ruines. Il invite Mme Pfeiffer à partager son repas. Ce " beau jeune homme prétendait savoir le français ", mais «il n'en savait pas long; car toute sa science se bornait à ces mots: Vous parlez français ? ». Heureusement, un des hommes de sa suite parlait un peu mieux l'anglais, de sorte qu'ils purent « causer ensemble tant bien que mal ${ }^{13}$.

En Équateur, en 1854, elle s'est jointe à une caravane de mulets pour rejoindre Quito depuis Guayaquil, ce qui représente environ 450 kilomètres parcourus en partie à pied, en partie à dos de mulet, avec pour seule compagnie le muletier et son aide Indien. $\mathrm{Ne}$ parlant pas l'espagnol, elle vit une situation d'isolement linguistique un peu analogue à celle qu'elle a vécu pendant son premier tour du monde, dans les caravanes en Turquie et en Perse (Irak et Iran). Elle dort dans des refuges sans confort. Près de Quito, elle séjourne dans l'hacienda du général Algierro. Le fils aîné a fait ses études à Paris, la belle-fille du général a résisté pour ne pas être enfermée au couvent. Mme Pfeiffer trouve dans la bibliothèque de cette maison « les meilleurs ouvrages de la littérature française ${ }^{14}$ ». Il n'en faut pas plus, avec la présence de cette jeune femme courageuse, et le spectacle des volcans, pour atténuer sa première impression assez négative de ce pays.

7. «In der überall herrschenden Spräche der Franzosen unterhielten wir uns und waren zufrieden, uns gegenseitig verstehen zu können. ", I. Pfeiffer, Reise einer Wienerin in das Heilige Land, p. 67.

8. W.H. Bartlett, «A lady who has seen the world », p. 52.

9. W.H. Bartlett, « A Morning with Madame Ida Pfeiffer», p. 382.

10. «Gesprochen wurde viel, verstanden wenig. Eine Sache, die oft in gelehrten Zirkel ereignen erringen soll, wie man sagt; desto weniger hatte es also bei uns bedeuten.», I. Pfeiffer, Reise einer Wienerin in das Heilige Land, vol. 1, p. 91.

11. A. de Lamartine, Voyage en Orient 1832-1833, p. 300.

12. Hany-Aly-Culy-Mirza : Il pourrait s'agir d'Ali Quli Mirza né en 1819, plusieurs fois ministre, francophile ; il aurait eu 28 ans au moment de cette rencontre.

13. "Der Prinz, ein schöner junger Mann, und gab vor, französisch zu können. Allein damit waren wir halb zu Ende, da seine Kenntnis nicht weiter reichte als: Vous parlez français? Glücklicherweise war einer seiner Leute besser in englischen unterrichtet, und so ging unser Gespräch doch einigermaßen von statten. ", I. Pfeiffer, Eine Frauenfahrt um die Welt, vol. 3 , p. 131

14. «Der ältesteSohn des Generals, Herr Carlos Algierre, hat ein Teil seiner Erziehung in Paris genossen; [...] Ich fand bei ihm die auserlesensten Werke der französischen Literatur. ", I. Pfeiffer, Meine zweite Weltreise, vol. 2, p. 194. 
Mais, c'est à Tahiti dont les Français viennent de prendre le contrôle et surtout à Madagascar, comme nous le verrons, que sa bonne connaissance du français oriente son récit.

\section{L'anglais, même imparfait...}

Ida Pfeiffer parle l'anglais moins bien que le français, comme en témoigne Bartlett. Ellemême le regrette : à Boston, le maire de la ville, le docteur Van Croninsfield Smith l'invite au banquet de la Société des Mécaniciens du Massachussetts ; il introduit la voyageuse en termes élogieux et la prie de se lever pour se présenter à l'assistance. Ida regrette de ne pas parler assez bien l'anglais pour répondre à ce discours :

«Quand je me levai, conformément au désir de M. Smith, aussitôt un tonnerre d'applaudissements m'accueillit, et même si je n'avais jamais regretté jusqu'à présent de ne pas posséder parfaitement l'anglais, j'en aurais été bien contrariée à cet instant; aussi à défaut de mots je ne pus que témoigner en silence par des gestes mes remerciements pour leur aimable bienveillance. ${ }^{15}$

En Inde, entre Dehli et Mumbai (Bombay), elle voyage d'un lieu à l'autre, munie de lettres de recommandation pour les autorités anglaises. Elle est parfois escortée par des serviteurs, mandatés par les Anglais. Il ne semble pas qu'elle ait connu de difficultés particulières à se faire comprendre. Son anglais est-il suffisant, ou bien, est-ce parce que, comme Bartlett, ils parlent français?

À Ctésiphon, elle doit se satisfaire de converser avec le Prince persan grâce à l'entremise d'un membre de sa suite qui parle l'anglais. À Mumbai, elle est curieuse de connaître les rites funéraires des Pârsi dont on lui avait dit à Kolkata qu'ils abandonnaient leurs cadavres sur les toits des maisons :

«Je ne pouvais me figurer que le gouvernement anglais autorise une coutume aussi barbare et aussi contraire à la salubrité publique ; mais jusqu'à la preuve du contraire il fallut bien ajouter foi à ce récit : aussi, quand j'eus fait la connaissance de M. Manuckjee, la première question que je lui adressai fut pour lui demander comment les Pârsi enterraient leurs morts. » 16

M. Manuckjee-Cursetjee est une personnalité pârsi importante, cultivé et riche, il a été le premier non-européen admis à la Société royale asiatique, en raison de sa connaissance approfondie de la langue anglaise. Il ne fait aucune difficulté à répondre aux interrogations de la voyageuse. Il lui fait visiter une tour des morts et l'invite chez lui. Ida nous restitue en détail tout ce qu'elle a noté sur les Zoroastriens. Bien qu'elle avoue ellemême ne pas parler assez bien l'anglais pour s'exprimer en public, elle peut juger des capacités des autres. Quand elle rencontre les souverains d'Indore, le Prince, âgé de quatorze ans, parle un mauvais anglais mais elle apprécie ses connaissances quand il lui pose des questions pertinentes sur la géographie ${ }^{17}$.

\section{Autres langues européennes}

En Égypte, elle a l'occasion de parler l'italien. En Équateur, elle passe par le truchement d'intermédiaires italiens pour l'achat d'une selle, puis pour obtenir les services d'un domestique muletier, mais elle a les deux fois le sentiment de s'être fait berner. Elle tente

15. "Als ich seinem Wunsche zufolge aufstand, empfing mich sogleich ein lautes Beifallklatschen, und wenn ich ein bisher nie bedauert hätte, der englischer Sprache nicht vollkommen mächtig zu sein, so wäre es in diesem Augenblick der Fall gewesen sein; ich konnte der Gesellschaft meinen Danke für freundliches Wohlwollen nur durch stumme Verbeugungen bezeugen. ", I. Pfeiffer, Meine zweite Weltreise, vol. 4, p. 160-161.

16. "Ich konnte mir nicht denken, dass die englische Regierung eine solche barbarische, der Gesundheit schädliche Verfahrungsweise erlauben sollte; allein ich musste es vor der Hand glauben. Meine erste Frage, als ich Herrn Manuckjee kennen lernte, war, auf welche Art die Parsi ihre Toten begraben. ", I. Pfeiffer, Eine Frauenfahrt um die Welt, vol. 3, p. 77.

17. «Der junge Prinz sprach gebrochen englisch, und die Fragen, die er an mich stellte, bewiesen, dass er in der Geographie gut bewandert war. ", I. Pfeiffer, Eine Frauenfahrt um die Welt, vol. 3, p. 45. 
de parler le danois pendant son voyage en Islande (hors du champ de cette étude). Elle acquiert quelques notions de portugais, d'espagnol et de néerlandais, qui ne lui permettent pas de soutenir une conversation.

Au Brésil, où règne un Habsbourg, l'influence allemande est grande, mais la langue est celle du premier colonisateur, le portugais. Si on met de côté certaines remarques sur la société brésilienne, fruit d'observations qui ne nécessitent pas le dialogue avec la population, et sa visite chez les Indiens Puri, elle a surtout connu le pays par l'intermédiaire de relais germanophones (allemands et suisses). Son séjour au Chili, à Valparaiso, est beaucoup plus difficile et moins fructueux. Elle ne reçoit l'assistance d'un marchand allemand que quelques jours avant son départ. Au cours de son second voyage en Amérique latine, l'aide du consul de Hambourg, Hermann Georg Rodewald, natif de Brême, facilite son séjour à Lima :

« Le 19 janvier, je me rendis à Lima, où le consul de Hambourg, M. Rodewald, eut la bonté de m'inviter à venir demeurer chez lui. J'appréciai d'autant plus cette complaisance que l'on ne parle, pour ainsi dire, dans le pays, que l'espagnol, langue avec laquelle je ne m'étais pas encore familiarisée. $»^{18}$

Aux Indes néerlandaises (Indonésie, Malaisie), Ida Pfeiffer bénéficie du soutien des représentants du gouvernement néerlandais. Elle ne parle pas leur langue, mais elle semble n'avoir eu aucun problème de compréhension. Certains, par exemple le Résident Willer, ou le Contrôleur Schoggers, lui donnent, nous dit-elle, des renseignements sur les mœurs des Dayaks et des Bataks avec lesquels elle n'a pu avoir que des échanges superficiels. On peut postuler, comme pour les Anglais en Inde, qu'ils appartiennent à une catégorie sociale lettrée où l'on parle le français et peut-être pour certains, l'allemand.

\section{Langues non européennes}

Pendant son long séjour en Malaisie - Indonésie, elle acquiert assez vite quelques notions de malais, puisqu'elle nous dit comprendre cette langue chez le Sultan de Sintang (Sulawesi) :

« Il [Ministre du sultan] revint bien tard dans la soirée pour m'annoncer que le sultan était de retour et qu'il m'attendrait le lendemain au divan. Par bonheur je possédais déjà assez la langue malaise pour pouvoir comprendre ce que l'on me disait. $»^{19}$

Aux Célèbes, Mme Pfeiffer s'entretient directement en malais avec le souverain de ParéParé $^{20}$. Elle lui raconte ses voyages. Le roi $s^{\prime} y$ intéresse, et se dit prêt à acheter son prochain livre $^{21}$. Mais il y a d'autres langues locales et des variantes qu'elle ne comprend pas. À la fin d'une réception chez le Susuhunan de Solo (Surakarta), le souverain prononce un long discours en tirant un anneau de son doigt pour le passer à celui de la voyageuse. Ida est bien incapable de comprendre ni le discours, ni la signification de ce geste, et le missionnaire allemand qui aurait pu traduire est trop loin pour l'entendre ${ }^{22}$.

À Bagdad, elle se constitue, un lexique de mots arabes. Elle le complète à Mossoul avec de nouveaux mots arabes et persans. Cette précaution lui permet, du 17 juin au 7 août 1848 , de poursuivre son voyage en se joignant à des caravanes où elle est la seule Européenne. Elle ne parle pas dans son récit du lexique d'hindi, trouvé dans les carnets

18. "Am 19 Januar fuhr ich nach Lima, wo der Hamburger Konsul, Herr Rodewald, so gütig war, mich in sein Haus einzuladen, eine Gefälligkeit, die für mich von umso größerem Wert war, als man in diesem Lande ausschließlich die spanische Sprache spricht, mit welcher ich mich noch nicht vertraut gemacht hatte. ", I. Pfeiffer, Meine zweite Weltreise, vol. 3, p. 107.

19. «Spät abends kam er wieder, um mir zu sagen dass der Sultan zurückgekehrt sei und mich am folgenden Morgen im Divan erwarte. Ich hatte glücklich weise schon so viel von der Malaiischen Sprache inne, um die Leute verstehen zu können. » I. Pfeiffer, Meine zweite Weltreise, vol. 1, p. 121.

20. «Ich verstand von der Malaiischen Sprache schon so viel, um mich mit dem Könige unterhalten können. » I. Pfeiffer, Meine zweite Weltreise, vol. 2, p. 238.

21. Traduit en malais en 1877 et réédité jusqu'en 1912.

22. I. Pfeiffer, Meine zweite Weltreise, vol. 2, p. 139. 
de son premier tour du monde ${ }^{23}$. On peut rapprocher ce document assez élaboré puisqu'il comportait quelques notions de conjugaison et de grammaire, de la rencontre à Dehli avec son compatriote autrichien Aloys Sprenger; orientaliste, il a été chargé par le gouvernement anglais de faire l'inventaire des recueils de poèmes persans de la bibliothèque du Rajah de Lucknaw. Il a préparé la suite du voyage d'Ida Pfeiffer, en direction de Kota, et fait signer à son voiturier (char à bœufs) un contrat en hindi ${ }^{24}$.

\section{Communiquer sans parler}

À New York, Ida Pfeiffer rencontre le poète et écrivain voyageur américain Bayard Taylor. Il témoigne :

«J'ai demandé à Ida Pfeiffer comment elle arrivait à communiquer avec les populations à Tahiti, en Perse, en Circassie et dans tous les autres pays dont elle ignorait la langue. Elle me répondit 'uniquement par signes jusqu'à ce que je connaisse quelques mots nécessaires à l'expression de mes besoins, et je n'ai connu aucune difficulté à me faire comprendre'. $»^{25}$

Ses passages chez les Dayaks de Bornéo, les Bataks de Sumatra, les Alfores de Ceram, les Indiens Puri du Brésil et ceux de Roque Vallée à l'ouest des États-Unis sont tous caractérisés par des conversations gestuelles.

«J'eus plus tard souvent l'occasion de remarquer avec quelle admirable justesse et quelle promptitude les sauvages entendent les signes. Moi-même je m'habituai tellement à ce langage qu'à mon retour parmi les blancs il me fallait bien faire attention pour ne pas expliquer plus amplement mes paroles à l'aide des mains et des yeux. $»^{26}$

Si Mme Pfeiffer assume de bon gré cette absence de dialogue avec certains peuples, et les crédite d'une bonne compréhension du langage gestuel, il arrive que cette situation lui pèse et influence le ton du récit comme nous le verrons avec les femmes en Orient. Car, autant elle lui paraît naturelle avec des populations éloignées de sa civilisation de référence, autant elle la trouve paradoxale et la supporte mal avec des peuples plus proches.

\section{Passerelles et barrières linguistiques}

\section{Les exilés politiques allemands aux États-Unis}

La réussite des voyages de Mme Pfeiffer doit beaucoup à la présence de ses « compatriotes allemands » qui l'accueillent, l'aident et parfois l'instruisent. À côté de réseaux marchands ou savants, il y a un petit réseau d'exilés politiques installés aux États-Unis après les révolutions de 1848.

Quittant Saint-Louis pour Highland, elle y est accueillie par M. Bernays, dont elle nous dit qu'il est un «ancien attaché de l'ambassade de France à Vienne». Charles Louis Bernays, ami de Heine, Marx et Engels, a été le directeur du journal marxiste Vorwärts,

23. H. Jehle, Ida Pfeiffer Weltreisende im 19.Jahrhundert, p. 194.

24. "Da ich die Reise allein machte, war Dr. Sprenger so gefüllig, Alles für mich zu besorgen; er Schloss mit dem Tschaudrie (Fuhrmann) einen schriftlichen Kontrakt in hindustanischer Sprache ab, dem zu folge ich ihm die Hälfte des Fuhrlohnes, fünfzehn Rupien, gleich bezahlte, die andere Hälfte sollte er in Kottah bekommen...», I. Pfeiffer, Eine Frauenfahrt um die Welt, vol. 3, p. 3 .

25. "Once asked Ida Pfeiffer how she managed to communicate with the people in Tahiti, in Persia, Circassia and other countries where she was acquainted with the language "Entirely by signs" she answered "until I have acquired the few words which are necessary to express my wants" and I have never experienced any difficultymaking myself understood.", B. Taylor, At Home and Abroad, p. 44.

26. "Ich hatte späterhin häufig Gelegenheit zu bemerken, wie wunderbar richtig und schnell die Wilden die Zeichen verstehen. Ich selbst wurde so an die Zeichensprache gewöhnt, dass ich, als ich wieder unter die Weißen kam, sehr Acht geben musste, meine Worte nicht mit den Händen und Augen näher zu erörtern. » I. Pfeiffer, Meine zweite Weltreise, vol. 1, p. 142 . 
publié à Paris. Il a fait partie, sur recommandation de Lamartine, de la mission diplomatique envoyée à Vienne par les Républicains au pouvoir en 1848. Il a quitté la France pour les États-Unis, peu de temps avant l'élection de Louis Napoléon Bonaparte.

Bien qu'elle ne nous donne aucune information sur le passé politique de ses interlocuteurs, la comparaison des noms cités avec des listes d'exilés politiques permet d'identifier quatre autres personnalités importantes : Vojtěch Náprstek à Milwaukee au bord du lac Michigan, Francis Wutschel, Godfrey Aigner et Ernst Krackowizer à New York.

L'accueil qu'elle reçoit s'explique par la langue commune ; elle peut aussi se justifier par l'intérêt de ces German forty eighters pour une femme exceptionnelle. On a souligné l'importance politique de ces exilés pour leur pays d'accueil, et étudié leurs relations avec les abolitionnistes américains ${ }^{27}$. Grâce à eux, Ida est introduite dans les milieux philanthropiques et antiesclavagistes. À Milwaukee, on lui présente Mme Mary H. C. Booth dont le mari, avocat, a été emprisonné pour avoir organisé le passage d'esclaves échappés des États esclavagistes vers le Canada. Elle rapporte les évènements avant de porter ce jugement :

«Combien les lois sont contradictoires dans ce pays, ou plutôt avec quelle facilité on sait les éluder! Quand quelqu'un allume un incendie, ou fait une banqueroute frauduleuse, commet un meurtre ou quelque autre grand crime, il peut toujours espérer s'en tirer plus facilement que s'il assiste un esclave échappé et l'aide à fuir. Si l'on pouvait donner à un crime le nom de moral, ce serait à celui-ci, et c'est justement celui pour lequel les juges se montrent inexorables; combien une telle loi n'est-elle pas révoltante dans un jeune État républicain qui devrait servir de modèle au monde entier $!{ }^{28}$

De Highland, où elle réside chez Bernays, Ida Pfeiffer se rend spécialement à Lebanon (Illinois) sans autre but que de rencontrer l'exilé badois Friedrich Hecker, grande figure républicaine, le Garibaldi allemand. Cette démarche n'est pas surprenante car, dès octobre 1848, elle avait livré ses sentiments favorables aux changements politiques. C'était juste après des émeutes qui venaient de ruiner définitivement tout espoir de révolution pacifique en Autriche :

«J'avais été informée, à Bombay, de la révolution de Paris du 24 février ; à Bagdad, de celle du mois de mars dans ma patrie ; à Tauris [Tabriz], à Tiflis [Tbilissi] et dans d'autres villes, j'eus connaissance des autres événements politiques. De toute ma vie, aucune nouvelle ne me surprit autant que celle de Vienne. Mes bons, mes paisibles autrichiens... Renverser le gouvernement! Quel réveil après une si longue léthargie ! [...] Les événements du mois de mars m'avaient enchantée et enthousiasmée au point que j'étais fière d'être Autrichienne. Mais le mois de mai me désenchanta ; quant au 6 octobre, il me remplit de douleur et de tristesse ! Aucune révolution politique n'avait si bien commencé. Elle aurait été sans pareille dans l'histoire, si l'on avait continué à suivre les idées qui avaient triomphé au mois de mars! Et il fallait que tout cela eût une si triste fin! [...] La catastrophe du 6 octobre m'affligea tellement, que je n'eus plus d'intérêt pour rien. ${ }^{29}$

27. M. Honeck, We are the Revolutionists. German-speaking immigrants and American abolitionists after 1848.

28. "Wie wiedersprechend sind doch die Gesetze oder vielmehr wie leicht umgangen in diesem Lande! Wenn jemand einen Brand anlegt, ein betrügerisches Falliment macht, ja einen Mord oder was immer für ein großes Verbrechen begeht, kann er leichter durchzukommen hoffen, als wenn er sich eines entlaufenen Sklaven annimmt, demselben zur Flucht behilflich ist. Könnte man ein Verbrechen sittlich nennen, so würde es dieses sein, und gerade da sind di Richter unerbittlich. Wir empörend ist nicht ein solches Gesetz in einem republikanischen jungen Staate, welcher der ganzen Welt als Muster aufgestellt werden sollte. ", I. Pfeiffer, Meine zweite Weltreise, vol. 4, p. 88.

29. "Die Revolution vom 24. Februar in Paris hatte ich in Bombay vernommen, jene in den Märztagen meines Vaterlandes zu Bagdad, die ferneren politischen Ereignisse zu Tebis, Tiflis und in andern Städten.In meinem ganzen Leben hatten mich keine Nachrichten so sehr überrascht als jene aus Wien.Meine gemütlichen, friedliebenden Österreicher - und ein Umsturz der Regierung! -Ein Erwachen aus langer Lethargie! [...]Die Ereignisse der Märztage hatten mich so entzückt und begeistert, dass ich mich mit Stolz eine Österreicherin nannte.Die späteren Begebenheiten aber vom Mai u. s. w. stimmten mich wieder herab, und vollends die des 6. Oktober erfüllten mich mit Wehmut und Trauer.Kein Umsturz eines Staates hatte so schön begonnen.Einzig würde er in der Geschichte da gestanden haben, wäre man im Sinne der Märztage fortgefahren; - und nun musste es so kommen! - Ach, ich war über den 6 . Oktober so bestürzt und ergriffen, dass ich für alles die Teilnahme verloren hatte. ", I. Pfeiffer, Eine Frauenfahrt um die Welt, vol. 3, p. 313. 
Nous ne savons pas si elle a évoqué la situation politique en Europe avec cet homme "érudit et talentueux ${ }^{30}$ ", ou avec d'autres exilés politiques, mais ceux-ci ont été d'intéressants passeurs d'informations, qu'elle a relayées, sur l'état de la société américaine quelques années avant la guerre civile.

\section{Le français, la langue du complot, à Madagascar}

Le livre connu sous le titre Voyage à Madagascar comporte dans son édition originale en allemand deux volumes dont seul le deuxième concerne Madagascar. L'essentiel du récit est consacré aux six semaines passées en juin et juillet 1857 dans la capitale Antanarivo, où elle a été témoin d'un complot, contre la Reine Ranavalona. Joseph Lambert qui vit à Maurice et Jean Laborde installé à Antananarivo ont projeté de remplacer la Reine par son fils, plus favorable aux Européens. Ils sont désireux d'asseoir la main mise de la France sur Madagascar ou plus prosaïquement d'y développer en toute liberté leurs propres activités commerciales.

Lambert est présent au Cap à l'arrivée de Mme Pfeiffer. Il la rencontre immédiatement et lui propose de l'accompagner à Madagascar. Il entretient, dit-il, de bonnes relations avec la souveraine et projette de lui rendre visite. Une aubaine pour Ida, qui avait renoncé à cette destination jugée trop dangereuse. Tout étranger se rendant dans la capitale doit passer par des intermédiaires et obtenir des patronages pour monter une véritable expédition $^{31}$, et sans cette aide, elle n'aurait pas pu s'aventurer sur l'île. Après un séjour de plusieurs mois à Maurice, elle profite de la colonne de porteurs de Joseph Lambert et arrive à Antananarivo, où commence son court mais mouvementé séjour chez l'industrieux Jean Laborde.

Ida découvre le complot à l'occasion d'un dîner en son honneur chez Laborde le 6 juin 1857. Elle y adhère et en note chaque jour toutes les péripéties. Après l'échec de la conjuration, elle subit le même châtiment que Lambert... Chassés par la Reine, ils rejoignent le port de Toamasina, sous escorte, en 58 jours au lieu de 8 ou 10, en passant par les lieux les plus malsains de l'île. Ce châtiment, substitut à une peine de mort que Ranavalona n'a pas osé prononcer, car l'exécution des Européens aurait certainement entraîné une action militaire, ruine définitivement la santé d'Ida Pfeiffer qui doit attendre de longs mois, soignée par la famille Moon, avant de rentrer en Europe. De retour à Vienne après une absence de deux ans et demi, elle y décède le 28 octobre 1858.

Elle avait transmis son manuscrit à son fils cadet, installé à Rio de Janeiro, par l'intermédiaire d'un botaniste allemand, venu se procurer à Maurice des plants de canne à sucre. Oskar Pfeiffer ne l'a apporté aux éditeurs européens qu'en janvier 1860, plus d'un an après le décès de sa mère. Le témoignage de Mme Pfeiffer sur cet épisode de l'histoire de Madagascar n'a été publié qu'à partir de 1861.

Ida Pfeiffer a vu la Reine à trois reprises, elle a joué pour elle de l'harmonium (instrument offert par Lambert), elle a rencontré le Prince, ami des Français. Elle a assisté à diverses cérémonies (funérailles d'un maréchal, cérémonie du bain de la Reine, lecture des oracles). On lui a parfois reproché une approche superficielle et erronée de la société malgache, de ses rites et des rapports à la religion, mais elle n'en connaît que ce que son entourage français lui en a appris, comme l'a noté Dominique Bois :

« Ainsi c'est Lambert qui fait remarquer à Ida Pfeiffer que le chef des chœurs de Radama II est un homme habillé en femme. Bien plus ce qu'elle sait de Laborde et qui fait l'objet d'un début de chapitre de son récit lui a été raconté par Marius Arnaud. Tout comme sans doute sa notice ethnographique et historique doit beaucoup à Laborde. $»^{32}$

30. "Mit Erstaunen sah ich diesen talentvollen, hochgebildeten Mann...», I. Pfeiffer, Meine zweite Weltreise, vol. 4, p. 60 .

31. D. Bois 2009, « Les Vazaha en route vers Tananarive : récits de voyage et appréhension de l'altérité au milieu du XIXe siècle », p. 91.

32. Ibid., p. 85. 
Il faudrait ajouter une autre source: les deux missionnaires français, présents chez Laborde sous une fausse identité. Elle approuve les conjurés, elle assiste aux réunions et se range aux avis et jugements des Français contre Ranavalona et contre les missionnaires anglais qui soutiennent une Reine qu'elle tient pour sanguinaire. Elle apprécie le Prince pour ses bonnes dispositions vis-à-vis des Européens, mais surtout envers ses sujets. Elle relate les démarches de Lambert à Paris et à Londres, et le rôle joué par les services anglais contre le projet de destitution, toutes informations qu'elle ne peut détenir que de l'intéressé.

La première traduction partielle en français paraît en 1861, dans la revue Le Tour $d u$ Monde $^{33}$. La situation à Madagascar a évolué, la Reine est morte, son fils l'a remplacée, ce qui justifie ce commentaire :

«Les derniers vœux de Mme Pfeiffer en faveur de Madagascar semblent sur le point de se réaliser. Les plus récentes nouvelles venues de cette île nous ont appris que le 18 août dernier, la reine Ranavalo avait enfin trouvé le terme de son odieuse existence, et que le prince Rakoto, sorti vainqueur, grâce au dévouement de ses fidèles, d'une lutte armée avec le prince Ramboasalama, représentant de la vieille barbarie malgache, avait été proclamé roi sous le nom de Rakotond-Radama. Il peut donc dès aujourd'hui et sans obstacle, donner suite à ses projets de réforme, et ouvrir sa belle patrie au souffle vivifiant de la civilisation européenne. $»^{34}$

Le commentateur ${ }^{35}$ aurait pu se contenter de signaler le changement de souverain, mais il a tenu à souligner l'opinion d'Ida Pfeiffer, évidemment au-dessus de tout soupçon. Le commentaire a été abandonné dans le livre, mais l'éditeur a ajouté une longue introduction sur Madagascar dont le but est de rappeler l'antériorité de la présence des Français sur les côtes malgaches et de souligner, en se gardant bien d'en citer la source, les jugements d'Ida sur la Reine et sur le missionnaire anglais Ellis. Le livre, publié en 1861, est réédité en 1881 au moment où la France entreprend une expédition militaire.

La rencontre au Cap avec Lambert n'était pas fortuite ; il avait appris à Paris, où il était venu solliciter en vain un soutien du gouvernement, que Mme Pfeiffer rêvait de visiter Madagascar. Lambert a-t-il pressenti la publicité que l'écrivain voyageur pouvait faire à son entreprise, ou bien voulait-il simplement impressionner la Reine en lui présentant cette femme exceptionnelle ? Les conjurés n'ont eu aucun mal à la rallier à leur cause, et sa bonne maîtrise de la langue française lui a permis de relayer efficacement leur réquisitoire contre la souveraine. Instrumentalisation volontaire ou non, après l'échec du complot, le témoignage de Mme Pfeiffer a été largement utilisé, sous l’Empire, mais surtout sous la troisième République, en faveur de la politique de la France à Madagascar.

\section{La communication impossible avec les femmes, au Moyen-Orient}

En Orient, le harem est un lieu incontournable pour les voyageuses, qui seules peuvent parler de cet endroit où les hommes ne sont pas admis. Mme Pfeiffer ne déroge pas à cette règle, mais elle a aussi côtoyé des épouses de notables chrétiens et vécu avec des femmes du peuple. Que ce soit dans un palais luxueux ou dans la plus humble des demeures, faute de langue commune, et en l'absence d'interprète, la communication ne peut pas s'établir. Ida ne peut nous décrire que ce qu'elle voit, et bien sûr juger sur les apparences.

Pour Ida Pfeiffer, les femmes du harem du Pacha d'Acre, rencontrées en 1842, sont « ignorantes et curieuses au plus haut degré ; elles ne savent ni lire ni écrire, et il n'est pas

33. Ida Pfeiffer, "Madagascar », Le Tour du Monde, vol. 4, second semestre, p. 321-351

34. «Madagascar » Le Tour du Monde, vol.4, deuxième semestre, 1861, p. 351.

35. Vraisemblablement le Directeur de publication : Édouard Charton. 
question de connaître une langue étrangère ${ }^{36} »$. Ida Pfeiffer s'ennuie en leur compagnie, elle est heureuse du retour de ses compagnons qui lui permet de partir.

Son jugement est à peine plus nuancé, pour les femmes de notables chrétiens invitées chez le Résident anglais à Bagdad en 1848. Ce groupe, "agréable à regarder », finit par ennuyer Ida Pfeiffer,

«Car dans ce pays, on n'apprend rien aux femmes »; " elles passent pour très instruites quand elles savent lire la langue de leur pays, l'arménien ou l'arabe, et, en ce cas, on ne leur met entre les mains que des livres religieux. " ${ }^{37}$

Elle attend, silencieuse, au milieu du groupe de femmes, la fin de la réception.

Chez le Pacha de Bagdad, dont les quinze femmes sont gaies et bruyantes, elle est étourdie par le bruit mais profite des mets raffinés. Mme Pfeiffer rencontre une des femmes du Prince persan qui l'a invitée sous sa tente à Ctésiphon; faute d'interprète, il faut se contenter du langage des signes. À Tabriz, la première femme du Vice-roi (futur Shah) la reçoit, en compagnie de ses servantes. La jeune épouse, âgée de quinze ans, a mis ses plus beaux vêtements car elle sait que Mme Pfeiffer est écrivain. Pendant cette «muette conversation », Mme Pfeiffer a tout le temps d'observer les jeunes femmes, leurs vêtements, leur maquillage, leur maintien et même de découvrir, par la fenêtre, l'étendue de la ville de Tabriz ${ }^{38}$.

Chez Mme Haggi-Chefa-Hanoum, à Tabriz, le fils de la maîtresse de maison parle le français ; il est encore assez jeune pour rester avec les femmes, et servir d'interprète, ce qui change radicalement la situation, et le point de vue de la voyageuse :

«Ce cercle de dames était le plus agréable et le plus distingué que j'avais rencontré jusqu'à présent dans les maisons orientales; je pus m'entretenir en français avec la maîtresse de la maison par l'intermédiaire de son fils, âgé de dix-huit ans, qui avait reçu une excellente éducation à Constantinople. Non seulement ce jeune homme, mais aussi sa mère et les autres dames étaient instruits et cultivés. »39

De Bagdad à Tabriz, via Mossoul, Ida Pfeiffer parcourt plus de 800 kilomètres. Entre ces trois grandes villes où elle est reçue chez des notables, elle se joint aux caravanes pour voyager « comme le plus pauvre des Arabes ${ }^{40} »$. Elle se nourrit d'eau, de pain et de dattes, se repose dans les Caravansérails ou à la belle étoile. Son trajet est marqué de quelques étapes chez l'habitant où le plus souvent elle est confinée dans la pièce commune de la maison. Elle observe, ne ménage pas ses critiques et parfois ne peut s'empêcher d'intervenir...

Un peu avant Kirkouk, Ida fait étape pendant deux jours chez le caravanier, elle n'a pas d'autre occupation que de poser un œil critique sur la vie de cette famille. À Rawanduz, le marchand pour lequel elle a une lettre de recommandation lui a fait comprendre par signes qu'étant célibataire il ne peut pas l'accueillir chez lui ; il l'accompagne dans une

36. «Unwissend und neugierig sind die Orientalinnen im höchsten Grade; sie können weder lesen noch schreibe, von der Kenntnis einer fremden Sprache ist schon gar keine Rede.», I. Pfeiffer, Reise einer Wienerin in das Heilige Land, vol. 2, p. 24.

37. «Die eingeboren Mädchen lernen nichts; ihre Kenntnisse sind ausgebildet, wenn sie in ihrer Muttersprache (armenisch oder arabisch) lesen können, und dann bekommen sie außer einigen religiösen Büchern keine andere Lektüre in die Hand.», I. Pfeiffer, Eine Frauenfahrt um die Welt, vol. 3, p. 123.

38. «Ich fand während dieses stummen Gespräches Muse genug, die Fernsicht aus den Fernstern und die Lage der Stadt zu betrachten.», I. Pfeiffer, Eine Frauenfahrt um die Welt, vol. 3, p. 229.

39. "Dieser Frauenkreis war der angenehmste und feinste von allen, die ich bis jetzt in orientalischen Häusern gefunden hatte. Mit der Frau vom Hause konnte ich mich mit Hülfe ihres achtzehnjährigen Sohnes, der eine ausgezeichnete Erziehung in Constantinopel genossen hatte, in französischer Sprache unterhalten. Nicht nur der Sohn, sondern auch die Mutter und die andern Frauen waren belesen und unterrichtet.», I. Pfeiffer, Eine Frauenfahrt um die Welt, vol. 3, p. 235. 40. «Ich reiste wie der ärmste Araber und musste, wie er, gefasst sein, die glühendste Sonne auszuhalten, nichts als Brod und Wasser, höchstens eine Handvoll Datteln oder einige Gurken zu genießen, und den heißen Erdboden zur Schlafstätte zu haben.» I. Pfeiffer, Eine Frauenfahrt um die Welt, vol. 3, p. 148. 
famille où il pourvoit à sa nourriture. La maison est mal tenue, les femmes sont oisives et se laissent malmener par les enfants. C'est là que se situe un des épisodes les plus commentés de ses voyages $^{41}$ : ne pouvant faire comprendre aux femmes qui lui ont préparé un bain qu'elle ne veut pas être observée pendant sa toilette, elle renonce au bain. Elle tente, surmontant la barrière de la langue, de se rendre utile. Après avoir enseigné quelques principes de comportement et propreté à une fillette, elle organise un cours de raccommodage :

«Après leur avoir montré leurs robes déchirées, j'allai chercher une aiguille et du fil ${ }^{42}$, et je leur appris à être convenable et à raccommoder. Cela leur plu, et bientôt il y eut une petite école de couture organisée autour de moi. Que de bien on pourrait faire dans ce pays si on en savait la langue, et si on avait la volonté ! Il ne faudrait pas seulement s'occuper des enfants, mais aussi en même temps des parents! $»^{43}$

À Mahabad ${ }^{44}$, il y a vingt familles chrétiennes, un missionnaire français et une jolie petite église. Ida se réjouit à l'idée de parler français, mais le missionnaire est absent et le séjour dans cette famille chrétienne où personne ne se respecte est d'autant plus décevant que faute de parler leur langue elle ne peut pas intervenir.

"J'essayais bien de rétablir la paix; je ne réussissais que très rarement car je ne possédais malheureusement pas assez leur langue pour leur faire prendre conscience de leur comportement coupable. $»^{45}$

Elle ne s'attarde pas et préfère prendre un guide particulier plutôt que d'attendre le départ d'une caravane, mais avant de partir elle écrit une lettre au missionnaire français pour dénoncer le comportement peu chrétien de cette famille.

Ida Pfeiffer a traversé pendant l'été 1848, un véritable "désert langagier ", une situation qu'elle supporte assez mal et qui stimule son esprit critique. À de rares exceptions près, la compagnie des femmes de notables, au harem ou ailleurs, l'ennuie. Quand elle peut enfin communiquer par le truchement du français avec des femmes persanes, elle découvre avec satisfaction qu'elles sont instruites. Son critère d'appréciation pour les femmes de notables, est la culture, mais pour les femmes du peuple, ce sont les qualités ménagères. Dans les deux cas, elle se montre assez sévère, tout en attribuant les carences observées au défaut d'instruction.

Ces trois exemples, illustrent l'importance de la langue. Au-delà de la simple question pratique : " passerelle ou barrière ? ", ils montrent qu'il convient aussi de s'interroger sur la qualité des interlocuteurs. Qui sont-ils (marchands, missionnaires, savants...), quelles sont leurs compétences, leurs intentions, leur fiabilité ? Quels sont les réseaux formels ou informels dont a bénéficié la voyageuse? Quelle incidence sur les sujets d'étude classiques de la littérature viatique (ethnocentrisme, altérité, intertextualité, genre...) ? Ces questions ouvrent le champ pour un travail plus approfondi sur les "relations de voyage d'Ida Pfeiffer", englobant l'étude de toutes les personnes rencontrées, la narration et les liens existant entre récit et rencontres.

41. Pudeur glorifiée au XIX siècle, pudibonderie moquée un siècle plus tard.

42. Ida Pfeiffer ne part jamais un nécessaire de couture.

43. "Ich wies auf ihre ergriffenen Kleider, holte Nadel und Zwirn herbei und lehrte sie, selbe zu schicken und auszubessern. Die Sache gefiel ihnen, und bald hatte ich um mich eine kleine Nähschule eingerichtet. Was könnte man hier erst Gutes wirken, wenn man der Sprache mächtig wäre und den Willen dazu hätte; nur müsste man sich nicht mit den Kindern allein befassen, sondern gleichzeitig auch mit den Eltern. ", I. Pfeiffer, Eine Frauenfahrt um die Welt, vol. 3, p. 187-188. 44. Sauh Bulak dans le texte, ancien nom parfois orthographié Sovuj-Bulâq, Sawdj-Boulaq ou Saoudj-Boulaq. 45. "Ich versuchte zwar immer Frieden zu stiften; dies gelang mir aber höchst selten, denn ich war leider der Sprache nicht mächtig genug, um ihnen das Sündhafte ihres Benehmens vorzustellen. ", I. Pfeiffer, Eine Frauenfahrt um die Welt, vol. 3 , p. 197. 


\section{Résumé}

La langue est un élément important du bagage culturel du voyageur : barrière ou passerelle, elle conditionne l'origine et la qualité des informations recueillies puis retranscrites dans le récit de voyage. Cette problématique, mise en évidence par Michael Cronin pour la littérature du XX ${ }^{\mathrm{e}}$ siècle est-elle pertinente pour l'œuvre de l'Autrichienne Ida Pfeiffer (17971858). Aventurière, parfois exploratrice, elle a effectué cinq voyages de 1842 à 1858, dont deux tours du monde, qui ont tous fait l'objet de récits publiés. Voyageant seule, sans moyens financiers, elle profite d'un réseau germanophone mondial (commerçants, savants, ...). Comment Ida Pfeiffer s'approprie-t-elle et nous transmet-elle des informations collectées dans sa langue maternelle ? Comment la pratique du français, langue universelle, lui ouvre-t-elle des portes et oriente-t-elle son récit et même son destin ? Quid de l'anglais, et d'autres langues européennes ? Que se passe-t-il quand elle ne peut communiquer que par gestes et ne comprendre qu'en regardant? Voici quelques questions auxquelles nous tenterons de répondre, en nous appuyant sur trois exemples: Les exilés politiques allemands aux États-Unis, des conjurés français à Madagascar, et les femmes en Orient.

\section{Bibliographie}

« Dr Meyen's voyage around the world », The London quarterly review, vol LIII, (53) $\mathrm{N}^{\circ} \mathrm{CVI}$ (106), avril 1835, p. 167-177.

BARTLETT William Henry (signé WHB, attribué à), "A lady who has seen the world", Sharpe's London Journal, vol. X, 1849, p 52-54.

BARTLETT William Henry (signé WHB, attribué à) «A Morning with Mme Ida Pfeiffer » Sharpe's London Journal, vol. XII-XIV, 1856, p 382-384.

BoIs Dominique, 2009, "Les Vazaha en route vers Tananarive: récits de voyage et appréhension de l'altérité au milieu du XIX siècle» dans NATIVEL Didier et RAJAONAH Fanarinira V. (dir.), Madagascar revisitée : en voyage avec Françoise Raison-Jourde, Paris, Khartala, p. 79-93.

CARLOWITZ Richard von, Briefe Richards v. Carlowitz aus Ostindien und China von 1844 an, BSB Bayerisch Staats Bibliotek digital,

Permalink : http: / / www.mdz-nbn resolving.de/urn/ resolver.pl?urn=urn:nbn:de:bvb:12bsb10930396-7

CRONIN Michael, Across the lines, travel, language, translation, Cork, Cork University College, 2000, reprint 2013.

HONECK Mischa, We are the Revolutionists. German-speaking immigrants and American abolitionists after 1848, Athens, University of Georgia Press, 2011.

JeHLE Hiltgund, Ida Pfeiffer Weltreisende im 19.Jahrhundert, Münster, New York, Waxmann, 1989.

LAMARTINE Alphonse de, Voyage en Orient 1832-1833, Euvres complètes, tome 5, Paris, Gosselin, Furne et Cie, 1850.

PFEIFFER Ida, Reise einer Wienerin in das Heilige Land; unternommen im März bis Dezember $1842,3^{\text {ème }}$ éd., Wien, J. Dimböck, 2 vol., 1849.

PfeIfFer Ida, Eine Frauenfahrt um die Welt, Wien, Carl Gerold, 3 vol., 1850. 
PfEIFFER Ida, Meine zweite Weltreise, Wien, Carl Gerold's Sohn, 4 vol., 1856.

PFEIFFER Ida, Reise nach Madagaskar : nebst einer Biographie der Verfasserin nach ihren eigenen Aufzeichnungen, Wien, Carl Gerold, 2 vol., 1861.

PFEIFFER Ida « Madagascar », Le Tour du Monde, vol. 4, deuxième semestre, p.321-351.

TAYLOR Bayard, At Home and Abroad, New York, GP Putnam 1860. 


\section{Illustrations}

Carte 1 : Les voyages 1842-1858

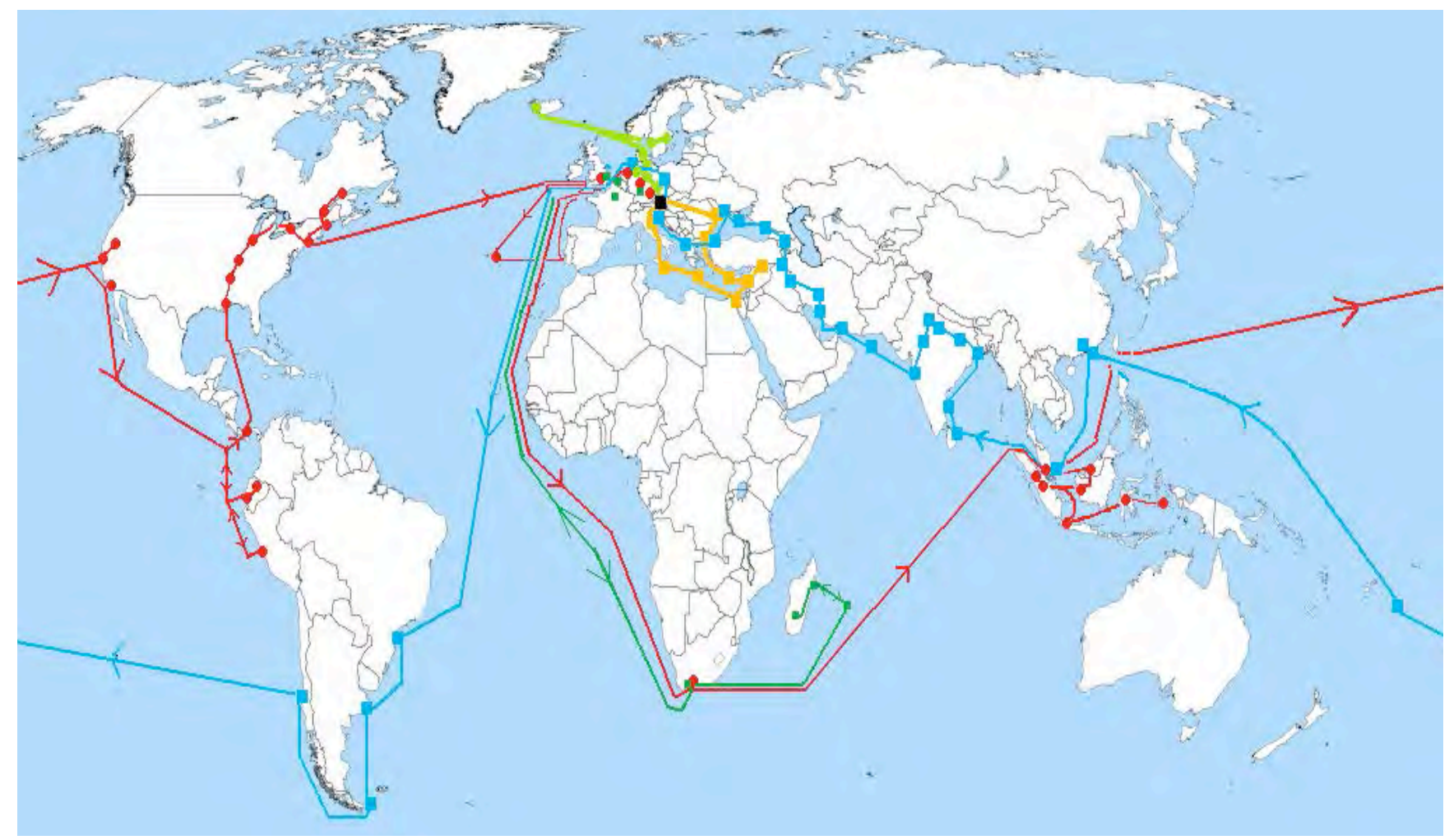

Palestine-Égypte - 1842

Islande-Scandinavie - 1845

Tour du Monde 1 - 1846/ 48

Tour du Monde 2 - 1851/55

Maurice-Madagascar - 1856/58

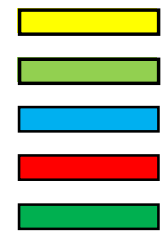

(C) A Lagarde Fouquet 
Carte 2 : Répartition des langues

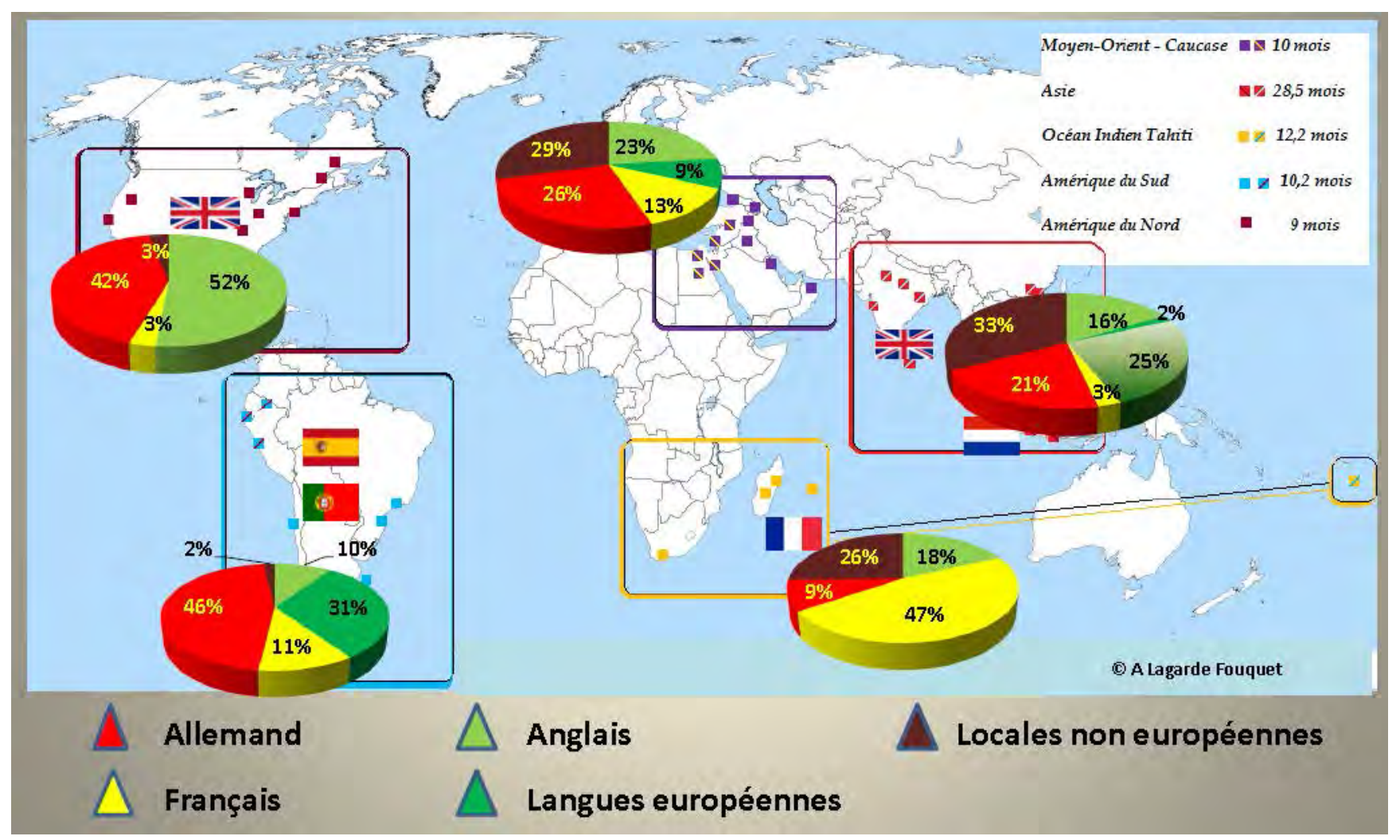




\title{
Les écrivains allemands et autrichiens dans l'exil (1933-1945)
}

\author{
Annette NOGARÈDE \\ Professeur agrégée d'histoire-géographie, \\ Lycée A. Daudet Nîmes
}

\footnotetext{
Extrait de : Guylaine BRUN-TRIGAUD (dir.), Contacts, conflits et créations linguistiques, Paris, Édition électronique du CTHS (Actes des congrès des sociétés historiques et scientifiques), 2015.

Cet article a été validé par le comité de lecture des Éditions du CTHS dans le cadre de la publication des actes du $139^{\mathrm{e}}$ Congrès national des sociétés historiques et scientifiques tenu à Nîmes en 2014 .
}

La prise de pouvoir de Hitler en 1933 ainsi que l'Anschluss de l'Autriche en 1938 ont conduit à une émigration de masse des élites intellectuelles et économiques de ces deux pays : environ 500000 personnes s'expatrient, dont plus d'un quart (130 000) aux ÉtatsUnis ${ }^{1}$. Dans cet exode, les écrivains ne représentent qu'une petite minorité, environ 1500 personnes, mais parmi eux on trouve les esprits les plus brillants de la République de Weimar' ${ }^{2}$. Ce mouvement d'émigration représente un transfert de savoir sans précédent, surtout en direction des États-Unis, mais aussi des autres pays de l'émigration comme l'Union soviétique ou le futur État d'Israël. L'historien Peter Gay le formula ainsi :

«Les exilés qu'Hitler produisit représentaient le transfert le plus important d'intelligence, de talent et d'érudition que le monde ait jamais connu. » ${ }^{3}$

Nous proposons d'étudier la situation des écrivains allemands et autrichiens dans l'exil, sous l'angle de la "perte » de la langue maternelle et de l'adaptation à la langue et à la culture du pays d'accueil.

\section{Le chemin vers l'exil}

\section{La perte de l'existence sociale}

En 1932, l'Allemagne était encore un État démocratique, avec d'énormes difficultés, générées par la crise économique et les affrontements violents entre forces de droite et de gauche. Néanmoins, comme le suggère Bertolt Brecht par le titre de sa pièce La Résistible Ascension d'Arturo Ui, la marche au pouvoir d'Adolf Hitler ne fut, jusqu'à la fin 1932, ni linéaire ni irrésistible. Il y eut certes une polarisation de la politique et les intellectuels, surtout ceux de gauche ou les pacifistes avérés, ressentirent un risque de marginalisation ${ }^{4}$, mais ils étaient toujours entendus, comme Heinrich Mann, président de la section poésie de l'Académie prussienne des arts jusqu'en 1933. Lors des élections législatives en novembre 1932, les résultats du NSDAP marquèrent même un net recul ${ }^{5}$, et Kurt von Schleicher fut nommé chancelier.

Le retournement de situation avec le remplacement de Schleicher par Hitler le 30 janvier 1933 et surtout la rapidité avec laquelle il liquida la démocratie de Weimar prit donc beaucoup de personnes au dépourvu (le premier camp de concentration pour les opposants politiques fut ouvert le 20 mars 1933 !). En Autriche, l'Anschluss de 1938,

1. C.D. Krohn, «Emigration 1933-1945/50», p. 1.

2. C.L. Lang, «L'Allemagne et son émigration», p. 453-466.

3. P. Gay, Weimar Culture, p. 12.

4. J. R. Becher, «Exil», Deutsche Literatur im Exil, p.427/428.

5. Voir les statistiques sur: www.dhm.de 
même s'il avait été redouté, se fit également plus vite que prévu. Alors qu'un référendum devait se tenir sur l'indépendance de l'Autriche, le parti nazi organisa un coup d'État le 11 mars 1938. Les troupes de la Wehrmacht entrèrent en Autriche le 12 mars pour soutenir l'annexion.

L'Anschluss poussa à l'exode des écrivains autrichiens d'origine juive ou opposés au parti nazi, ainsi que des écrivains allemands qui avaient trouvé refuge en Autriche. Il en fut de même en France et dans d'autres pays européens dès que les troupes allemandes envahirent le pays et cette fuite perpétuelle contribua au sentiment de déracinement des exilés ${ }^{6}$. Stefan Zweig résuma cette déchéance rapide dans ses mémoires publiées en 1944 sous le nom « Le monde d'hier » :

«Né en 1881 dans un grand et puissant empire [...], il m'a fallu le quitter comme un criminel. Mon œuvre littéraire, dans sa langue originale, a été réduite en cendres. Étranger partout, l'Europe est perdue pour moi... J'ai été le témoin de la plus effroyable défaite de la raison [...]. Cette pestilence des pestilences, le nationalisme, a empoisonné la fleur de notre culture européenne. ${ }^{7}$

\section{L'anéantissement des œuvres littéraires}

L'expérience la plus déchirante pour les écrivains fut sans doute l'interdiction de leurs œuvres et leur anéantissement symbolique par les autodafés de livres, dont le plus connu est celui de Berlin du 10 mai 1933. L'écrivain Erich Kästner nous livre son témoignage :

«Et en l'an 1933 mes livres furent brûlés en grande pompe funèbre sur la place de Berlin, près de l'opéra [...]. Le nom de vingt-quatre écrivains allemands, qui devaient être à jamais symboliquement effacés, furent triomphalement proclamés. J'étais le seul des vingt-quatre qui me fus personnellement déplacé pour assister à cette mise en scène éhontée. Je me trouvais près de l'université, coincé entre des étudiants en uniforme de SA, la fleur de la nation, et là je vis nos ouvrages s'envoler vers les flammes étincelantes [...] Au cours des années suivantes, je ne vis plus mes livres en public que les rares fois où je me trouvai à l'étranger. À Copenhague, à Zurich, à Londres. C'est un sentiment extraordinaire que d'être un auteur interdit et de ne plus voir ses livres sur les étagères des bibliothèques et dans les vitrines des librairies. Dans aucune ville de mon pays natal. Pas même dans la ville où j'étais né. Pas même à Noël, lorsque les Allemands courent les rues enneigées à la recherche de cadeaux. $»^{8}$

Kurt Tucholsky, l'un des esprits les plus brillants de la scène intellectuelle berlinoise, écrit à son ami Walter Hasenclever le 11 avril 1933 de son séjour à Göteborg dont il ne reviendra pas :

«Je n'ai pas besoin de vous apprendre que notre monde n'existe plus en Allemagne. Et donc: Je vais maintenant la fermer. On n'engueule pas un océan. » ${ }^{9}$

Tucholsky se suicida par ailleurs dans son exil en Suède en 1935. Le PEN club (association internationale d'écrivains) refusa cependant de prendre une position claire contre les autodafés. En mai 1933, Ernst Toller prit la parole lors du congrès à Raguse (Italie) pour dénoncer cette attitude :

«Qu'est-ce que vous avez fait quand des écrivains allemands et des dizaines de milliers d'ouvriers ont été emprisonnés? Qu'est-ce que vous avez fait contre les autodafés ? Contre l'expulsion des universitaires les plus éminents? Rien. Des millions d'hommes n'osent ni parler ni écrire librement dans l'Allemagne actuelle, et quand je prends la parole ici, c'est au nom de ces millions qui sont désormais privés de voix. ${ }^{10}$

6. B. Brecht, «1940», Deutsche Literatur im Exil, p. 96-98.

7. S. Zweig, Die Welt von Gestern, p. 8-10.

8. E. Kästner, Kennst du das Land, in dem die Kanonen blühn ?, p. 7-9.

9. K. Tucholsky, Politische Briefe, p. 16.

10. E. Toller, «Vortrag auf dem PEN-Club in Ragusa », Deutsche Literatur im Exil, p. 159-163. 
Bientôt les écrivains qui avaient fui l'Allemagne se retrouvèrent dans une nouvelle structure : la section du PEN club des auteurs allemands à l'étranger.

\section{L'installation dans l'exil}

L'accueil des exilés fut plus ou moins facile selon les pays. Ils arrivaient épuisés et appauvris, surtout ceux partis précipitamment. Certains virent leurs avoirs bancaires gelés dans des pays pourtant considérés comme sûrs, tels que la Suède, la Hollande ou le Canada $^{11}$. Ils maîtrisaient souvent mal la langue du pays d'accueil. Des pays, comme la Suisse, décidèrent en 1939 de fermer complètement leurs frontières aux réfugiés. D'autres, comme la Grande-Bretagne ou les États-Unis, ne donnèrent des permis de séjour qu'aux personnes jugées intéressantes pour la vie scientifique et culturelle du pays. En France, des écrivains furent confrontés, dès 1938-1939, au refus de permis de séjour $^{12}$ ou furent internés au début de la guerre dans des camps comme Aix-Les Milles, sous prétexte $q u^{\prime} i l s$ étaient ressortissants $d^{\prime} u n$ pays ennemi ${ }^{13}$. On parlait d'ailleurs à l'origine $\mathrm{d}^{\prime}$ " émigrés » et non pas $\mathrm{d}^{\prime}$ « exilés ». Bertolt Brecht critique cette terminologie dans son poème De la notion $\mathrm{d}^{\prime}$ «émigré » :

«J'ai toujours trouvé que ce nom sonnait faux : émigrés.

Cela veut bien dire celui qui émigre de son plein gré.

Mais nous, nous ne sommes pas partis de nous-mêmes, en choisissant un autre pays.

Nous ne sommes pas non plus immigrés dans un pays pour y rester, si possible pour toujours.

Nous avons fui. Nous sommes des expulsés, des bannis.

Et le pays qui nous accueillit ne sera jamais un chez-nous, il sera un exil. $»^{14}$

Les écrivains de gauche, comme Bertolt Brecht, Heinrich Mann et Lion Feuchtwanger qui avaient émigré aux États-Unis, furent confrontés à la défiance des autorités à leur égard. Heinrich Mann, qui se définissait comme «Européen dans l'âme », s'intégra parfaitement pendant son exil en France de 1933 à 1940, ce qu'il ne parvint pas à faire aux États-Unis ${ }^{15}$. Ces écrivains furent convoqués après la guerre, comme Albert Einstein, au bureau pour des activités anti-américaines ${ }^{16}$. Bertolt Brecht s'installa, par ailleurs, lors de son retour, non pas en Allemagne de l'Ouest, mais en RDA. Heinrich Mann voulut le suivre, mais il mourut avant son départ pour la RDA, en 1950 (enterré à Berlin-Est).

La situation ne fut guère mieux dans l'autre grand pays de la future coalition antihitlérienne : l'Union soviétique. On demandait aux écrivains accueillis de suivre la ligne officielle du parti. Leurs enfants étaient envoyés dans l'école du Komintern à Ufa (Ural), tandis que les adultes étaient logés dans des hôtels, comme le célèbre Hôtel Lux à Moscou où ils étaient surveillés et séparés de leur environnement ${ }^{17}$. 3000 Allemands exilés en Union soviétique furent d'ailleurs emprisonnés ou envoyés dans les Goulag. Les pays d'accueil pouvaient ainsi faire preuve d'un certain rejet de ces étrangers, qui étaient pourtant leurs alliés. Ils devinrent des réfugiés, soumis au bon vouloir des autorités.

Certains auteurs sont néanmoins parvenus à gagner une influence importante dans le pays d'accueil, comme Thomas Mann aux Etats-Unis. Ce dernier réussit en effet à monter, avec l'aide de sa fidèle amie américaine Agnès E. Meyer, un réseau d'aide aux écrivains émigrés. En contact permanent avec le monde de l'exil sous toutes ses facettes, notamment avec Albert Einstein ou le sociologue marxiste Theodor W. Adorno, il

11. L. Feuchtwanger, Le Diable en France, p. 31.

12. T. Balk, «Das verlorene Manuskript», Deutsche Literatur im Exil, p. 71-80.

13. L. Feuchtwanger, Le Diable en France, p. 61-63.

14. B. Brecht, "Von des Bezeichnung "Emigranten" ", Deutsche Literatur im Exil, p. 39.

15. H. Mann, «Abschied von Europa», Deutsche Literatur im Exil, p. 114-131.

16. C.L. Lang, «L'Allemagne et son émigration», p. 460.

17. H. Plivier, «Flucht nach Taschkent», Deutsche Literatur im Exil, p. 138-149. 
mobilisa des Américains fortunés, comme Siegfried Guggenheim ou Louis B. Mayer ${ }^{18}$, pour assurer des contrats aux écrivains.

\section{La lutte pour le maintien de la langue allemande}

\section{Les obstacles à la publication en allemand}

Un certain nombre d'écrivains purent bénéficier d'une publication de leurs œuvres grâce à des maisons d'édition installées à l'étranger. Querido à Amsterdam par exemple, maison fondée en 1933 par le Néerlandais Emanuel Querido et l'Allemand Fritz Helmut Landshoff, est alors la plus importante pour la littérature de l'exil jusqu'à l'occupation des Pays-Bas par l'armée allemande. Mais Emanuel Querido fut déporté à Sobibor où il meurt en 1943.

Gottfried Bermann, était quant à lui co-propriétaire d'une maison d'édition très connue en Allemagne, le S. Fischer Verlag. Il décida en 1933 de la partager entre Berlin, sous le nom de S. Fischer Verlag avec Peter Suhrkamp comme nouveau directeur, et l'Autriche, avec Gottfried Bermann à sa tête, pour suivre les écrivains exilés. La partie allemande pouvait ainsi transférer des fonds afin de soutenir l'édition en exil. Après l'Anschluss, Gottfried Bermann fit déménager la partie « exil » à Stockholm et à New York.

Ces maisons, indispensables pour les écrivains allemands et autrichiens en exil, ne furent en aucun cas suffisantes pour sauvegarder leur notoriété et assurer leur survie. Le nombre de lecteurs potentiels se rétrécissait au fur et à mesure de l'avancée allemande en Europe et les pays d'accueil n'étaient pas forcément intéressés par des publications en allemand, même aux États-Unis ou en Amérique du Sud où une forte minorité germanophone était présente, issue de l'immigration de travail du début du XX $x^{\mathrm{e}}$ siècle.

Cette dernière considérait en effet avec méfiance ces exilés, qui lui semblait dénigrer une Allemagne enfin forte et redressée. Une partie était même acquise au régime nazi ${ }^{19}$, qui jouissait aux Amériques, comme en Angleterre ou aux pays scandinaves, de certaines sympathies : l'industriel Henry Ford, par exemple, était l'un des plus célèbres bailleurs de fonds étrangers d'Adolf Hitler, et il fut récompensé en 1938 pour ce soutien durable avec la Grand-Croix de l'Aigle allemand ${ }^{20}$.

Les écrivains exilés rencontrèrent une difficulté inverse auprès des élites intellectuelles " éclairées » des pays d'accueil, car la langue allemande fut progressivement assimilée au régime nazi. Le philosophe Ernst Bloch l'illustre par cette formule :

«La langue allemande est devenue la langue du diable ; le diable est le père du mensonge, et elle ne sert plus qu'à cela : les cris, le brouillard et la démagogie. $»^{21}$

L'expérience la plus douloureuse de la perversion de la langue fut certainement celle de Lion Feuchtwanger. Dans son œuvre Le Juif Süss paru en 1925, qui connut un succès mondial, l'auteur dénonçait l'antisémitisme à travers l'histoire de Joseph SüssOppenheimer, conseiller financier du duché de Wurtemberg au début du XVIII ${ }^{\mathrm{e}}$ siècle. Cela n'empêcha pas le régime nazi, sous l'impulsion de Goebbels, de s'emparer du roman et d'en pervertir le sens pour l'adapter au cinéma en 1940 à des fins de propagande antisémite.

18. T. Mann, Briefe 1937-1947, p. 160, 203, 210-212, 284-286, 469-472.

19. Préface de M. Winkler, Deutsche Literatur im Exil, p. 21.

20. G. Sager, «Der Diktator von Detroit», in: spiegel.de, 29 juillet 2008.

21. E. Bloch, «Zerstörte Sprache - zerstörte Kultur», ibid., p. 362. 


\section{Le problème de la « dégénération » de la langue}

La langue littéraire de $l^{\prime}$ «autre Allemagne» fut désormais obligée d'évoluer dans un vase clos. Ernst Bloch présente ce dilemme de la façon suivante :

"Comment pouvons-nous nous en sortir, comment pouvons-nous remplir notre mission politique et culturelle? Nous ne pouvons pas renier notre langue sans détruire la culture que nous portons en nous. Et nous ne pouvons pas sauvegarder la culture et la faire évoluer sans parler la langue qui fut le vecteur principal de notre apprentissage culturel. $»^{22}$

Le risque de voir mourir la langue à défaut de pouvoir l'utiliser fut également évoqué par Hans Natonek :

«J'aime ma langue maternelle, mais je ressens avec grand chagrin qu'elle est condamnée à s'étioler dès que l'on arrache du sol où elle avait pris racine. La langue maternelle ne peut pas être emportée sous d'autres cieux, elle ne peut pas y pousser et fleurir. $»^{23}$

Coupés de leur pays d'origine, les exilés ne pouvaient plus suivre au jour le jour les évolutions politiques ou les mouvements de la langue parlée, ce qui pouvait être néfaste, surtout pour les auteurs engagés qui travaillaient des sujets de la vie quotidienne.

Bien qu'on pût craindre un lent appauvrissement de la langue et de la syntaxe, cela ne fut pas vraiment le cas. On décèle chez certains écrivains, plus conservateurs ou arrivés à une plus grande maturité avant le départ en exil, l'emploi d'une langue plus traditionnelle reprenant les canons classiques. Cette langue devint même parfois extrêmement riche et soignée, au point d'être comparable à celle des grands auteurs de la littérature allemande. En outre, elle fut enrichie des expressions anglaises ou françaises, là où elles étaient plus pertinentes que les expressions allemandes, ce qui apporta une densité de l'expression et des sentiments très moderne. La trilogie de Joseph et Charlotte à Weimar, de Thomas Mann, en est la parfaite illustration. Cette langue n'a pas connu de suite dans la littérature allemande d'après-guerre, mais elle reste aujourd'hui encore exemplaire pour sa richesse et son originalité, au point d'avoir donné de nouveaux « classiques » entrés aujourd'hui au panthéon de la littérature allemande.

Pour explorer cette langue dans tout son raffinement et pour traduire toute la complexité de leurs personnages, le monologue devint un des moyens d'expression favori des écrivains. Les auteurs expriment bien souvent leurs réflexions personnelles à travers leurs personnages, comme dans Charlotte à Weimar ${ }^{24}$ de Thomas Mann et La mort de Virgile de Hermann Broch ${ }^{25}$. On peut également citer les réflexions du narrateur dans l'œuvre de Thomas Mann, Docteur Faustus, ou le dialogue du héros du roman, Adrian Leverkühn, le «Faust » moderne, avec le diable, qui, tout en s'écartant de la forme du monologue, s'insèrent dans la même démarche intellectuelle ${ }^{26}$.

En ce qui concerne les écrivains dits « de gauche ", l'exil a conduit à un renforcement des idées qu'ils défendaient, à un langage plus politique et plus dur, quitte à caricaturer la réalité sociale et à noircir la nature humaine, comme on peut le remarquer chez les écrivains exilés en URSS, mais aussi Bertolt Brecht et Heinrich Mann (collection d'essais publiés en 1933 sous le titre « La haine » par Querido à Amsterdam ${ }^{27}$ ). Pour certains, leur écriture se prêtait à la glorification de la société communiste, comme ce fut le cas pour les poèmes de Johannes R. Becher publiés en URSS ${ }^{28}$. Mais est-il possible de parler d'un «appauvrissement»? Un appauvrissement en nuances par rapport à leur

22. E. Bloch, op. cit., p. 347

23. H. Natonek, «In search of myself», Deutsche Literatur im Exil, p. 155.

24. T. Mann, Lotte in Weimar, p. 351-353.

25. H. Broch, Der Tod des Vergil, p. 380-399.

26. T. Mann, Doktor Faustus, p. 300-339, 400-402.

27. H. Mann, Der Hass, p. 61-85.

28. J.R. Becher, «Moskau», Deutsche Literatur im Exil, p. 150-151. 
positionnement politique, peut-être, une certaine «radicalisation » - ce qui n'est pas étonnant, d'ailleurs, compte tenu du contexte historique - mais certaines de ces œuvres développèrent une perspicacité et une force de persuasion impressionnantes. Ils acquièrent également une valeur historique car ces écrivains établirent de précieux témoignages pour la période de l'exil $^{29}$.

La peur de la dégénérescence ou même de la mort de la langue littéraire, exprimée par Bloch et Natonek, n'était donc pas complètement justifiée. La littérature de l'exil est au contraire arrivée à créer un univers nouveau, dans le contexte particulier de sa conception, qui garde une grande valeur jusqu'à nos jours.

\section{Le choix des sujets}

Les sujets étaient soumis au même problème que la langue elle-même : compte tenu de l'éloignement de leurs pays d'origine, les écrivains en exil avaient du mal à trouver des sujets contemporains, surtout dans la période de 1933 à 1939. Certains l'essayèrent, à l'exemple de Brecht et de son œuvre Grand-Peur et misère du III ${ }^{\mathrm{e}}$ Reich. Cette pièce témoigne d'ailleurs, malgré l'exil, d'une bonne analyse de la société et d'une bonne connaissance de la nature humaine.

Mais ces œuvres sont restées minoritaires. On pouvait remarquer, en revanche, une renaissance du roman historique, comme Henri IV de Heinrich Mann, Joseph et ses frères de Thomas Mann, les biographies de Stefan Zweig (Marie-Antoinette, Erasme, Marie Stuart, Magellan) ou Le faux Néron de Lion Feuchtwanger (critique déguisée de Hitler). Cette concentration sur le roman historique a provoqué des critiques amères, de la part de Kurt Hiller par exemple, écrivain exilé à Paris, en 1938 :

«La production littéraire des Allemands émigrés dans sa totalité, c'est un scandale! Ils écrivent sur Machiavel, sur Ignace de Loyola, sur Cervantès... si cela est absolument nécessaire et si vous avez réellement la tranquillité intérieure pour faire cela, faites-le ; les questionnements philosophiques et artistiques sont valables pour toutes les périodes, semblent éternels... Mais si ces écervelés des belles-lettres échafaudent une science à partir de ce qui est inintéressant et inutile, avec des livres sur Catherine de Russie, Christine de Suède, Joséphine de France, Fernand I ${ }^{\mathrm{er}}$, Philippe II, Napoléon III, le faux Néron ou le vrai Pierre, qu'ils soient maudits, cette bande d'arriérés! Hitler va être empereur de l'Europe demain, si vous vous enfuyez aujourd'hui devant les exigences du jour, dans votre cupidité et votre lâcheté ! » 30

Toutes les recensions littéraires ont par la suite réagi à ce reproche de futilité et ont pris parti dans la discussion. Alfred Döblin, par exemple, défendit les sujets historiques par rapport à la situation spécifique de l'exil, où il n'était plus possible de s'immiscer dans la politique quotidienne. Il souligna qu'il ne s'agissait pas d'une fuite devant la réalité, mais de tentatives d'explication de la situation actuelle qui permettaient de faire des propositions d'actions concrètes ${ }^{31}$.

Pendant la guerre, on remarque cependant un retour vers l'actualité. Les exilés trouvaient leurs sujets dans les articles de journaux ou les récits de rescapés européens. On peut citer ici le roman d'Anna Seghers, La septième croix, ou La hache de Wandsbek d'Arnold Zweig, publié d'abord en hébreu et en allemand en 1947.

La découverte de l'existence des camps de concentration, qui était devenue une évidence à partir de 1943, transformait, en même temps que les sujets, le regard que portaient surtout les écrivains d'origine juive sur l'Allemagne. Pour Hannah Arendt, la découverte des camps de concentration représente la vraie césure entre la vie des écrivains " avant» et "après", davantage même que l'exil lui-même ${ }^{32}$. Ils se détachèrent de tout lien

29. Voir, p.ex.: B. Brecht, Arbeitsjournal, p. 113, 256, 378, 428.

30. K. Hiller, Profile. Prosa aus einem Jahrzehnt, Paris 1938, p. 236-238.

31. A. Döblin, «Der historische Roman und wir», Deutsche Literatur im Exil, p. 296-321.

32. Interview von G. Gaus mit H. Arendt, 28.10.1964. 
sentimental avec leur pays d'origine. Pour certains, l'épreuve fut terrible, comme pour le sociologue Theodor W. Adorno qui disait :

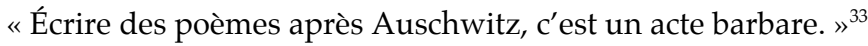

L'identité juive, l'antisémitisme et l'anéantissement des juifs d'Europe formaient désormais un nouveau champ de travail inépuisable pour la littérature de l'exil.

\section{L'adaptation aux pays d'accueil et l'après-guerre}

\section{L'apprentissage d'une nouvelle langue et ses limites}

Les écrivains apprirent tous la langue du pays d'accueil, ce qui les aidait à intervenir dans leur vie intellectuelle pendant et après l'exil. Nombre d'exilés (environ 600 aux États-Unis) réussirent à obtenir des chaires universitaires et décidèrent de ne pas retourner en Allemagne.

Mais la majorité d'entre eux continuait à écrire en allemand. Ils n'arrivaient pas à atteindre le même niveau d'expression en langue étrangère, comme le décrit Hannah Arendt dans une interview de 1964 : à la question "Qu'est-ce qui vous reste de vos origines? », elle répond :

« Il reste la langue maternelle. En Allemand, j'ose dire des choses que je ne pourrais pas exprimer en anglais. Ce sont les rêves, les souvenirs d'enfant. $»^{34}$

Hannah Arendt faisait cependant partie de la jeune génération d'exilés, ceux qui avaient entre 20 et 30 ans au moment de partir ou qui avaient suivi leurs parents, et qui ont eu moins de difficultés à s'approprier une langue étrangère.

Raoul-Othmar Auernheimer décrit ce problème quand il se rappelle son arrivée aux États-Unis :

«"Leurs pertes sont nos gains", me disait l'épouse affable de mon mécène américain, en montrant $l^{\prime}$ Europe de son menton, quand elle m'accueillit avec son mari à New York. Cette phrase encourageante n'est cependant pas valable dans la même mesure pour l'écrivain que pour les autres professions libérales, les universitaires ou les musiciens [...]. Pour maîtriser réellement une langue, une vie d'homme est guère suffisante, pour une deuxième, elle n'est pas assez longue. Ce qui n'exclut pas de parler ou même d'écrire couramment une autre langue. Mais l'écriture créative ne se borne pas à l'écriture proprement dite, elle nécessite cette source originaire de représentations et d'expériences, qui porte les mots inconsciemment vers celui qui écrit et qui le relie à ses lecteurs. ${ }^{35}$

Max Brod décrit ses efforts pour s'approprier l'hébreu dans son exil en Palestine. Il était arrivé à une maîtrise parfaite de la langue, à l'exemple du Hifil : un groupe de verbes difficile à conjuguer, mais couramment utilisé. Il l'employait, comme il disait, « inconsciemment». Il arriva néanmoins à une limite de l'apprentissage, comme le montre l'anecdote suivante : après une conférence commune avec la « reine du théâtre », Chana Rowina, sur l'œuvre de Stefan Zweig, qu'il avait tenu dans un hébreu parfait, mais écrit avec de lettres latines, $\mathrm{M}^{\mathrm{me}}$ Rowina lui dit :

«Votre conférence fut parfaite, votre hébreu est magnifique. Il n’y a qu'une seule chose qui me dérange : on s'aperçoit que vos yeux vont de gauche à droite quand vous regardez vos notes. $»^{36}$

33. T. W. Adorno, «Kulturkritik und Gesellschaft», in: Adorno: Gesammelte Schriften, Bd. 10, p. 11-30.

34. Interview von G. Gaus mit H. Arendt, 28.10.1964.

35. R.-O. Auernheimer, «Das Wirtshaus zur verlorenen Zeit», Deutsche Literatur im Exil, p. $372 / 373$.

36. M. Brod, «Ein neues Dasein», ibid., p. 95. 
Pour citer d'autres exemples de la jeune génération, et pour cerner de plus près ce problème, on peut évoquer les enfants de Thomas Mann, Klaus et Erika. Klaus Mann fut un écrivain engagé, sa sœur et lui faisaient des allers-retours entre les États-Unis et l'Europe, souvent dans des conditions dangereuses, pour garder le contact avec des écrivains qui y étaient restés ou dans le cadre de reportages sur la guerre civile espagnole. Après la guerre, ils travaillaient comme correspondants pour des journaux américains en Allemagne, dans le cadre des procès de Nuremberg, entre autres.

Klaus Mann s'intégra parfaitement aux États-Unis, il mit en garde les écrivains, dans le journal Die Sammlung qu'ils ne devaient pas tomber dans le piège du repli sur soi :

«L'esprit allemand qui, autrefois, voulait conquérir l'Europe - non pas une Europe impérialiste, mais une Europe gouvernée par la raison - et qui fut soumis, justement à cause de cela, à la persécution dans la nouvelle Allemagne, qui fut méprisé et banni, jusqu'à ce qu'il ne puisse plus y respirer, cet esprit ne doit pas se manifester uniquement, dans les pays où on lui offre l'hospitalité, par l'analyse incessante de son objet de haine, par sa plainte, ses querelles et ses revendications. Il doit faire ses preuves en tant que cet élément infiniment précieux qui continue d'être productif pendant qu'il lutte, qui fleurit, pendant que ses ennemis essaient de l'étouffer, et, tout en jouant et en luttant en même temps, dégage une lumière qui va survivre à l'obscurité. $~^{37}$

Il continuait cependant à écrire ses œuvres littéraires en allemand, en espérant sauvegarder la langue et pouvoir un jour renouer avec le public allemand, comme le roman Mephisto qui dénonce la soumission d'une certaine partie de l'élite artistique au régime nazi.

L'adaptation aux pays d'accueil et à sa langue restait donc dans la plupart des cas limitée à la langue d'usage, même si les exilés maîtrisaient parfaitement bien celle-ci. Il leur fut cependant difficile ou même impossible de l'utiliser comme ils le faisaient avec leur langue maternelle.

\section{La traduction}

Comme les exilés n'arrivaient pas, pour la plupart, à écrire directement dans la langue des pays d'accueil, ils devaient passer par la traduction. Pour certains, comme Thomas Mann ou Lion Feuchtwanger, cette démarche fut une réussite. Ils écrivaient tous leurs livres en allemand, mais le succès était toujours là, malgré le passage obligé par la traduction.

L'impact de l'œuvre de Thomas Mann dans les pays anglophones peut être mesuré grâce à l'anecdote suivante. Pendant les procès de Nuremberg, le procureur britannique Shawcross, qui coordonnait l'ensemble de l'accusation, cita à deux reprises dans son réquisitoire des extraits du monologue de Gœthe de Charlotte à Weimar, en prétendant qu'il s'agissait de citations authentiques :

« Il y a très longtemps, Gœthe disait du peuple allemand qu'il sera un jour rattrapé par son sort : le sort va s'abattre sur eux car ils se sont trahis eux-mêmes et ne voulaient pas assumer ce qu'ils étaient réellement. Qu'ils ne connaissent pas le charme de la vérité, c'est à déplorer, que les paroles dans le vent, les écrans de fumée et la barbarie démesurée leur soient aussi chers, c'est répugnant. $\mathrm{Qu}$ 'ils s'offrent à chaque criminel fou, qui appelle à leurs instincts les plus bas et les renforce dans leurs vices... c'est misérable. $»^{38}$

Les maisons d'édition de l'exil décidaient, elles aussi, de publier des traductions de romans, pour s'assurer, ainsi qu'à leurs auteurs, une plus grande visibilité. Le succès fut inégal selon les pays. L'éditeur Gottfried Bermann Fischer, installé à Stockholm depuis

37. K. Mann, «Die Sammlung», Deutsche Literatur im Exil, p. 278.

38. Der Prozess gegen die Hauptkriegsverbrecher vor dem internationalen Militärgerichtshof. Nürnberg 14. November 1945 - 1. Oktober 1946. Bd. 19, Nürnberg 1948, S. 592. 
1938 après avoir quitté l'Autriche pour éditer la littérature de l'exil, décrit ce combat de tous les jours dans ses mémoires:

«Pour l'année 1939, 17 livres étaient en préparation, une production importante pour la petite maison d'édition qui travaillait dans des conditions extrêmement difficiles. La coopération avec les éditeurs néerlandais avait été très harmonieuse [...]. Mais la correction des œuvres imprimées en Suède fut une torture. Il n'y avait aucun imprimeur qui maîtrisait la langue allemande, et le résultat fut un nombre effarant d'erreurs [...]. À chaque erreur, il fallait changer la ligne entière car le matériel ne permettait pas de changer une seule lettre. Cela a pris des années - jusqu'à longtemps après la guerre - pour éliminer complètement les erreurs des éditions suédoises de nos œuvres. » ${ }^{39}$

Il restait que les traductions n'arrivaient pas toujours à restituer toute la finesse et les nuances du manuscrit original, si elles n'étaient pas pleines de fautes. Comme le disait Raoul-Othmar Auernheimer :

«La meilleure traduction ne reste cependant qu'une main dans un gant. ${ }^{40}$

\section{L'exil comme catalyseur de l'écriture}

Malgré toutes les difficultés rencontrées dans l'exil, certaines des œuvres les plus importantes de la littérature allemande furent accomplies pendant cette période: Le joueur d'échecs de Stefan Zweig, Le Docteur Faustus et les deux derniers volumes du Joseph de Thomas Mann, Henri IV de Heinrich Mann, La vie de Galilée de Bertolt Brecht, Exil de Lion Feuchtwanger, Le principe espérance d'Ernst Bloch, esquissé en grande partie pendant l'exil aux Etats-Unis, pour n'en citer que quelques exemples.

On peut en déduire que l'exil pouvait également avoir un effet enrichissant sur l'œuvre des écrivains. Je me permets de citer encore Ernst Bloch, qui tente de donner une explication, par rapport à son pays d'accueil, les États-Unis :

« Nous sommes ici dans un pays ouvert et hospitalier. Les États-Unis ne sont pas un ÉtatNation. Depuis sa fondation, c'est un pays d'immigration ou, comme on dit habituellement, un melting-pot. Les métaux à l'origine de ce mélange sont encore reconnaissables, et ils n'ont pas encore complètement fondu. [...] L'Amérique laisse la liberté personnelle à tout un chacun qui ne remet pas en cause les fondements sociaux de cet État. [...] Le contenu du melting-pot reste malléable et prêt à s'allier à des nouveaux apports. Chaque immigré doit apporter quelque chose qui vaut le coup d'y être fondu et qui est prêt à s'unir au reste. Notre relation avec ce pays ne doit donc pas être une adaptation aveugle et soumise, surtout pas vis-à-vis de la classe régnante, ni l'indifférence et le repli sur soi. Il faut garder une sorte de distance originale. En Amérique, il y a plus de rêves d'une vie meilleure que dans tout autre État bourgeois; il ne manque qu'un contenu à cet optimisme. Il faut que nous prenions parti à l'Amérique, comme si elle était - aussi - un morceau de l'Allemagne. Nous devons stabiliser la cause pour laquelle nous fûmes obligés de quitter notre pays natal. Cette cause sont les Droits de l'homme qu'il faut réaliser entièrement. ${ }^{41}$

Hajo Holborn, un historien de renommée qui est, parmi d'autres, à l'origine d'une nouvelle école d'historiographie en Allemagne après la guerre, cite un autre aspect positif de l'exil :

«Ma transformation en Américain m'a donné une perspective beaucoup plus large sur tout ce qui est allemand. ${ }^{42}$

Fritz Stern, qui a dû s'enfuir avec ses parents en 1938 à l'âge de 12 ans, fait part du même enrichissement personnel :

39. G. Bermann-Fischer, «Bedroht - Bewahrt», Deutsche Literatur im Exil, p. 344/345.

40. Ibid., p. 374.

41. E. Bloch, op. cit., p. 346-372.

42. H. Holborn, History of modern Germany, p. 12. 
«J'adoptais une double vie : le passé allemand d'un côté, toujours présent, toujours funeste ; le présent américain de l'autre, direct, insécurisant, mais toujours prometteur. Je vivais par la force des choses et par ma propre volonté, dans ces deux mondes. » ${ }^{43}$

L'exil a donc représenté pour certains une source d'inspiration. Il semblerait que la clé de l'énigme réside ici : la volonté de s'intégrer dans le pays d'accueil et la capacité de vivre dans deux mondes : deux sociétés, deux histoires, deux univers linguistiques différents. Les écrivains qui ont accepté les nouvelles expériences et influences résultant de l'exil, tout en gardant leur distance originale, ceux qui avaient conscience de la valeur de leur œuvre et de ce qu'ils pouvaient apporter à l'édifice social de leur pays d'accueil et, dans certains cas, à l'Allemagne de l'après-guerre, pouvaient puiser une nouvelle inspiration de l'exil.

Les écrivains de l'exil ne furent cependant pas tous les bienvenus dans l'Allemagne de l'après-guerre. On les traitait de "lâches », de "traîtres", car ils n'avaient pas vécu les mêmes choses que leurs compatriotes restés dans le pays ${ }^{44}$. L'influence des anciens nazis restait, à certains égards, importante. On peut encore citer l'exemple de Klaus Mann. Après la guerre, il tenta de faire publier ses romans en Allemagne, mais les maisons d'édition se montraient très réticentes car il attaquait des personnes qui avaient regagné une certaine influence en Allemagne de l'Ouest, comme l'acteur Gustaf Gründgens, dans son roman Mephisto ${ }^{45}$. Le sentiment de n'appartenir à aucun pays, des problèmes financiers et une dépression l'ont conduit au suicide en 1949 à Cannes.

Sa sœur Erika réagit de manière différente. Après le suicide de Klaus, elle écrit :

« Je ne sais pas encore comment vivre, je sais seulement que je n'ai pas d'autre choix. ${ }^{46}$

Elle retourne en Europe, s'installe en Suisse et s'investit jusqu'à sa mort, en 1969, dans la sauvegarde et la promotion des œuvres de son père et de son frère. Elle a largement contribué à leur popularité posthume.

La plupart des exilés sont restés dans leurs pays d'accueil, à quelques exceptions près. Ils ne sont plus arrivés à reprendre pied dans l'Allemagne de l'après-guerre. Leur évolution personnelle avait été trop différente de celle des Allemands ou Autrichiens restés sur place.

Une nouvelle génération d'écrivains s'affirmait après la guerre, autour du Groupe 47. Ils n'étaient pas partis en exil et voulaient contribuer au renouveau de l'Allemagne grâce aux expériences qu'ils y avaient vécues pendant la guerre. On assiste donc, après l'exil, a un changement profond du paysage littéraire en Allemagne et en Autriche. Les œuvres de l'exil restent cependant parmi les plus abouties au niveau du langage littéraire, et on peut dire que c'est justement la situation particulière de leur conception qui leur a conféré une valeur durable.

43. F. Stern, Fünf Deutschland und ein Leben, p. 172.

44. Préface de M. Winkler, Deutsche Literatur im Exil, p. 16.

45. Le roman fut publié en Allemagne (en RDA !) en 1956. En Allemagne de l'Ouest, où M. Gründgens avait continué sa carrière après la guerre, la première édition eut lieu en 1963, mais la famille de l'acteur entama une procédure qui conduisit à son interdiction de 1968 à 1975. Voir préface de l'éditeur, Klaus Mann, Mephisto, p. IV.

46. Erika Mann, The Last Year of Thomas Mann, p. 41. 


\section{Résumé}

Les écrivains allemands et autrichiens contraints à l'exil sous Hitler furent confrontés au problème déchirant de la perte de leur langue maternelle, à l'image du philosophe Ernst Bloch : "Comment pouvons-nous nous en sortir, comment pouvons-nous remplir notre mission politique et culturelle ? Nous ne pouvons pas renier notre langue sans détruire la culture que nous portons en nous. Et nous ne pouvons pas sauvegarder la culture et la faire évoluer sans parler la langue qui fut le vecteur principal de notre apprentissage culturel. » Nous proposons d'analyser la situation de l'exil, sous l'angle de la «perte » de la langue maternelle et de l'adaptation à la langue et à la culture du pays d'accueil. Dans quelle mesure ces difficultés ont-elles freiné la productivité littéraire des écrivains, ou au contraire représenté un vecteur d'évolution personnelle et de créativité, car nombre d'œuvres majeures ont été écrites pendant la période d'exil ?

\section{BIBLIOGRAPHIE}

ADORNO Theodor W., Gesammelte Schriften, Frankfurt/M., Suhrkamp, 1980.

BRECHT Bertolt, Arbeitsjournal, Frankfurt/M., Suhrkamp, 1973.

BRECHT Bertolt, Der aufhaltsame Aufstieg des Arturo Ui, Berlin, Suhrkamp, 1965.

BRECHT Bertolt, Furcht und Elend des Dritten Reiches, Frankfurt/M., Suhrkamp, 1998.

HERMANN Broch, Der Tod des Vergil, Bonn, Rheinische Verlagsanstalt, 1958.

Feuchtwanger Lion, Le Diable en France, Paris, Belfond, 2010.

GAY Peter, Weimar Culture : The Outsider as Insider, New York, Norton, 1969.

HILler Kurt, Profile. Prosa aus einem Jahrzehnt, Paris, Édition du Carrefour, 1938.

Holborn Hajo, History of modern Germany, Princeton, Princeton University Press, 1982.

KÄSTNER Erich, PÜSCHEL Walter, Kennst Du das Land, in dem die Kanonen blühn ? Berlin, Eulenspiegel, 1967.

MANN Erika, The Last Year of Thomas Mann, New York, Farrar, Straus and Cudahy, 1958.

MANN Heinrich, Ein Zeitalter wird besichtigt, Claassen, Düsseldorf 1974.

MANN Heinrich, Der Hass, Berlin, Aufbauverlag, 1983.

MANN Klaus, Mephisto, Hamburg, Rowohlt, 1981.

MANN Thomas, Briefe 1937-1947, Frankfurt/M., Fischer, 1963.

MANN Thomas, Deutsche Hörer ! Frankfurt/M., Fischer, 1987.

MANN Thomas, Doktor Faustus, Frankfurt/M., Fischer, 2003.

MANN THOMAS, Lotte in Weimar, Frankfurt/M., Fischer, 2012.

WINKLER Michael (ed.), Deutsche Literatur im Exil, Stuttgart, Reclam, 2003.

STERN Fritz, Fünf Deutschland und ein Leben. Erinnerungen, München, C.H. Beck, 2007. 
TUCHOlsky Kurt, POLITISCHE BRIEFe, Rowohlt, Reinbek, 1969.

ZWEIG Stefan, Die Welt VON GeSTERN, Fischer, Frankfurt/M., 1997.

\section{Articles et émissions}

KROHN Claus-Dieter, «Emigration 1933-1945/50 », 31.5.2011, in : EGO-Europäische Geschichte online.

LANG C. L, « L'Allemagne et son émigration », in : Politique étrangère $N^{\circ} 4,1955$.

SAGER Gesche, « Der Diktator von Detroit », 29 juillet 2008, in : spiegel.de

GAUS Günter, Interview mit Hannah Arendt, 28.10.1964, in : rbb.de

\section{Recueils documentaires}

Der Prozess gegen die Hauptkriegsverbrecher vor dem internationalen Militärgerichtshof. Nürnberg 14. November 1945 - 1. Oktober 1946, Nürnberg 1948

Sites :

www.dhm.de 


\title{
Tocqueville et le problème de la "langue démocratique » Le cas de l'anglais américain
}

\author{
Regina POZZI \\ Professeur d'histoire contemporaine, \\ Université de Pisa, Italie
}

\begin{abstract}
Extrait de : Guylaine BRUN-TRIGAUD (dir.), Contacts, conflits et créations linguistiques, Paris, Édition électronique du CTHS (Actes des congrès des sociétés historiques et scientifiques), 2015.

Cet article a été validé par le comité de lecture des Éditions du CTHS dans le cadre de la publication des actes du $139^{\mathrm{e}}$ Congrès national des sociétés historiques et scientifiques tenu à Nîmes en 2014.
\end{abstract}

On lit dans la seconde Démocratie en Amérique (c'est ainsi qu'on appelle communément le volume paru en 1840, après que le premier volet de l'ouvrage avait paru en 1835) :

«Si ce que j'ai dit précédemment, à propos des lettres en général, a été bien compris du lecteur, il concevra sans peine quelle espèce d'influence l'état social et les institutions démocratiques peuvent exercer sur la langue elle-même, qui est le premier instrument de la pensée. ${ }^{1}$

Il s'agit du chapitre XVI de la Première Partie, qui a pour titre Comment la démocratie américaine a modifié la langue anglaise, et c'est de ces pages que je vais analyser ici. En les lisant, on ne peut que partager ce qu'écrivait en 1995 un tocquevilliste tel que Daniel Jacques, qui s'étonnait de :

«La rareté des études concernant cet aspect de la réflexion de Tocqueville, notamment disait-il - en raison de la précision de ses remarques sur l'évolution de la langue anglaise en Amérique et sur la disparition progressive des dialectes en Europe. » ${ }^{2}$

La raison est sans doute due aux cloisons qui, à notre époque de spécialisation très poussée, se dressent entre des disciples ayant pourtant tout à faire avec les humanités. Les linguistes ne considèrent pas l'œuvre de Tocqueville et, si jamais ils le faisaient, trouveraient son langage tout à fait inadéquat. Par ailleurs, les historiens et les philosophes ne connaissent pas les problèmes et les méthodes avec lesquels les premiers se mesurent. J'ajoute que, si la lacune dont se plaignait Jacques a été récemment au moins en partie comblée, on le doit à une tocquevilliste, dont la particularité est d'avoir une formation littéraire : il s'agit de Laurence Guellec, qui en 2004 a consacré des pages très denses $^{3}$ - auxquelles je suis redevable de plusieurs des observations que je présenterai par la suite - à la notion tocquevillienne de langue démocratique, à partir justement de ce chapitre, qui est en effet capital, comme j'essaierai de le montrer. Quant à moi, si j'ose proposer mes réflexions à des auditeurs qui ont une familiarité avec les problèmes linguistiques qui est bien loin d'être la mienne, c'est dans l'espoir de contribuer à jeter un pont - pour étroit et chancelant qu'il puisse être - entre deux domaines des sciences de l'homme qui, dans le passé, ont tiré beaucoup de profit à marcher ensemble. Un seul exemple suffirait : c'est celui d'Ernest Renan, historien, philologue, linguiste.

1. Tocqueville 1951, 2, p. 69.

2. Jacques 1995, p. 20.

3. Guellec 2004. Voir notamment le chap. II, Le langage de la démocratie : langue démocratique et parole politique démocratique. 


\section{De la nécessité de quelques prémisses}

Pour saisir dans sa juste portée le discours de Tocqueville, il faut éclaircir tout d'abord quelques points concernant sa méthode aussi bien que son argumentation. En premier lieu, au point de vue de la méthode, son analyse appartient au domaine de la sociolinguistique, même s'il ne connaissait pas ce terme, qui, bien sûr, est beaucoup plus récent (et qu'il y aurait partant de l'anachronisme à le lui appliquer) ${ }^{4}$. Car elle se base sur le principe qu'il avait énoncé dans la première Démocratie, c'est-à-dire que «l'état social », en l'espèce l'égalité des conditions, est :

«La cause première de la plupart des lois, des coutumes et des idées qui règlent la conduite des nations »; et «ce qu'il ne produit pas, - avait-il ajouté - il le modifie. » ${ }^{5}$

Et, après avoir illustré dans ce premier volume le travail de l'égalité dans les institutions et dans la vie politique américaines, dans la seconde Démocratie, il s'applique à analyser son influence sur les idées (première partie), sur les sentiments (deuxième partie) et sur les mœurs (troisième partie).

Or - c'est ma deuxième prémisse - dans cette analyse, Tocqueville suit une démarche de type hypothético-déductive (qui ne manque pas, à nos yeux de lecteurs, de paraître parfois quelque peu "mécaniste $\left.»^{6}\right)$. Car à partir de l'observation empirique, il construit un modèle au sens wéberien de "langue démocratique », par opposition à un modèle de «langue aristocratique ». On a là un cas spécifique de sa démarche générale : les ÉtatsUnis, avec leur égalité des conditions (qu'il ne faut pas entendre comme une égalité réelle, mais comme une égale possibilité donnée à tout le monde de s'élever dans l'échelle sociale) et avec leur mobilité et confusion des rangs, lui fournissent le modèle d'une société démocratique, qu'il "pense», plus encore qu'il ne la voit sous ses yeux, en la comparant à son opposé, une société aristocratique où les rangs sont établis par la naissance et juridiquement fixés ${ }^{7}$. C'est le cas de l'Angleterre (même si lors de ses deux voyages dans ce pays en 1833 et 1835, l'écrivain s'était bien aperçu des transformations en acte), mais aussi de la France d'avant la Révolution et de toutes les sociétés qui ont précédé l'actuelle, y compris (c'est à remarquer) les républiques anciennes. Dans le cas qui nous intéresse, les modifications connues par l'anglais au-delà de l'Atlantique représentent pour lui une expérience in corpore vivo pour en déduire les lois qui président à l'influence des causes sociales sur le fait linguistique. Preuve en est que lorsqu'il parle, par la suite, de la tendance de la langue démocratique à faire grand usage des termes génériques et abstraits, il abandonne la langue des Américains, et les exemples que nous trouverons sous sa plume ce sont des mots français, "capacités", au lieu d'hommes capables, «actualités » pour indiquer tout ce qui se passe dans le présent ou bien «éventualités » pour dire tout ce qui peut arriver à partir du moment où l'on parle.

Il y a une troisième remarque à faire, peut-être la plus intéressante au point de vue linguistique. À propos de l'importance reconnue au milieu social sur la vie intellectuelle, on avait le précédent illustre de Mme de Staël et de son essai de 1800, De la littérature considérée dans ses rapports avec les institutions sociales. Et il est vrai que dans le chapitre XIII de cette Partie de la Démocratie, Tocqueville avait traité de la littérature chez les

4. Toujours attentif au fait linguistique, ailleurs Tocqueville avait adopté une autre approche, descriptive et quelque peu pittoresque. Dans une note très longue de la première Démocratie, il s'était étendu sur la complexité des langues parlées par les Indiens d'Amérique, en se montrant très au courant des études sur la matière (Tocqueville 1951,1, p. 436-437, note C). Dans les Carnets de Voyage, il avait pris note, non sans une petite nuance de sentiment de supériorité, de la particularité du français des Canadiens: «Singulier effet que cause sur nous cette langue française entendue à la fin du monde et avec ses vielles tournures et son accent provincial: laridondaine, laridondon. De temps en temps : hou ! ou : marche» (Tocqueville 1957, p. 174).

5. Tocqueville 1951, 1, p. 45.

6. Je dois cette remarque à Simone Mazauric, que je remercie.

7. Voir sur ce point Aron 1967, pp. 221-272 et Poggi 1972, pp. 15-128. Pour les remarques ci-dessus je me permets de renvoyer aussi à Pozzi 2006. 
Américains (toujours avec le souci, il faut le répéter, de généraliser ce qu'il avait empiriquement constaté) ; mais ce n'était que pour remarquer qu'il n'existait pas encore une véritable littérature en Amérique et que les seuls écrivains autochtones dont on pût parler étaient les journalistes ${ }^{8}$. C'est pourquoi, contrairement à Mme de Staël qui n'avait pris en considération que la langue littéraire des différents peuples, il s'empresse de déclarer, juste au début du chapitre XVI, que l'objet de son analyse sera la langue parlée (c'est-à-dire la langue commune) :

«Les auteurs américains vivent plus, à vrai dire, en Angleterre que dans leur propre pays, puisqu'ils étudient sans cesse les écrivains anglais et les prennent chaque jour pour modèle. Il n'est est pas ainsi de la population elle-même : celle-ci est soumise plus immédiatement aux causes particulières qui peuvent agir sur les États-Unis. Ce n'est donc pas au langage écrit, mais au langage parlé, qu'il faut faire attention, si l'on veut apercevoir les modifications que l'idiome d'un peuple aristocratique peut subir en devenant la langue d'une démocratie. $»^{9}$

La langue commune contre la langue littéraire : c'est un choix de Tocqueville à propos duquel Laurence Guellec a parlé de « la désacralisation de l'écrivain » ${ }^{10}$. S'il fallait citer un précédent de ce que j'ai nommé le caractère sociolinguistique de son analyse, c'est plutôt François Guizot qu'on devrait nommer, lorsque celui-ci avait soutenu en 1809 que « pour déterminer avec justesse le sens propre des termes, il faut connaître l'histoire des mœurs, des usages de la nation qui les emploie, et de celle à qui ils ont été empruntés ».

La langue - avait-il écrit ${ }^{11}$ - est intimement liée avec les habitudes, les principes de ceux qui la parlent; elle en dépend comme l'image dépend de l'objet, comme le signe dépend du signifié : celle liaison, moins sensible lorsque la grammaire formée et perfectionnée s'est mise en quelque sorte à l'abri de la variation des opinions, ne laisse pas d'avoir toujours une influence réelle.

\section{La langue démocratique}

On trouve les observations condensées de Tocqueville sur l'anglais américain dans un assez long passage, que je demande de pouvoir reproduire en entier, en me réservant de le commenter par la suite dans toutes ses implications.

«Des Anglais instruits, et appréciateurs plus compétents de ces nuances délicates que je ne puis l'être moi-même, m'ont souvent assuré que les classes éclairées des États-Unis différaient notablement, par leur langage, des classes éclairées de la Grande Bretagne. Ils ne se plaignaient pas seulement de ce que les Américains avaient mis en usage beaucoup de mots nouveaux, la différence ou l'éloignement des pays eût suffi pour l'expliquer ; mais de ce que ces mots nouveaux étaient particulièrement empruntés, soit au jargon des partis, soit aux arts mécaniques, ou à la langue des affaires. Ils ajoutaient que les anciens mots anglais étaient souvent pris par les Américains dans une acception nouvelle. Ils disaient enfin que les habitants des États-Unis entremêlaient fréquemment les styles d'une manière singulière, et qu'ils plaçaient quelquefois ensemble des mots qui, dans le langage de la mère patrie, avaient coutume de s'éviter. $»^{12}$

8. «Ceux-ci - avait-il écrit (Tocqueville 1951, 2, p. 61) - ne sont pas de grands écrivains, mais ils parlent la langue du pays et s'en font entendre. Je ne vois dans les autres que des étrangers. Ils sont pour les Américains ce que furent pour nous les imitateurs des Grecs et des Romains à l'époque de la renaissance des lettres, un objet de curiosité, non de générale sympathie».

9. Ibid., p. 69.

10. Cf. Guellec 2004, p. 130.

11. Cf. Guizot 1848 [1809], p. VIII.

12. Tocqueville, 2, p. 69. Le chapitre XVI occupe les pages 69-75, auxquelles je renvoie, sans donner dans la suite la référence des passages cités. 


\section{Le lexique}

Lorsqu'il parle de la langue, a-t-on remarqué, «Tocqueville parle essentiellement des mots et de leurs procédés de fabrication, c'est-à-dire de la néologie démocratique ». S'il parle aussi du style, c'est dans le sens restrictif du mélange que les hommes démocratiques emploient entre des niveaux d'expression que normalement on ne devrait pas retrouver ensemble. Par contre, il ne s'intéresse ni à la syntaxe ni à la phonétique ou à l'orthographe. Serait-ce, se demande Laurence Guellec à laquelle on doit cette remarque, parce que "c'est en sémantique que l'action des causes sociales apparaît avec le plus d'évidence? ». Et de rappeler ce qu'avait écrit Antoine Meillet dans un article de 19051906 :

«Le groupe des faits linguistiques où l'action des causes sociales est dès maintenant reconnue de la manière la plus certaine et la plus exactement déterminée est celui des innovations apportées au sens des mots. $»^{13}$

Tocqueville, évidemment, n'est pas autant explicite sur ses fondements théoriques. On pourrait même soutenir qu'il accueille à ce propos deux théories différentes, car si la langue est pour lui $l^{\prime}$ «instrument de la pensée », c'est-à-dire qu'elle a une fonction cognitive, elle est aussi par excellence le moyen de la communication sociale. Et s'il donne sa préférence à l'analyse sémantique, c'est surtout parce que la communication connaît dans les sociétés démocratiques sa forme apicale. Ici « les hommes, n'étant plus tenus à leur place, se voient et se communiquent sans cesse $»^{14}$.

Or, le phénomène qui, dans la langue démocratique, frappe davantage notre spectateur, c'est qu'elle crée sans cesse de nouveaux mots. On a là un exemple très clair du procédé comparatif et déductif de Tocqueville.

Dans les aristocraties, - observe-t-il - la langue doit naturellement participer au repos où se tiennent toutes choses. On fait peu de mots nouveaux, parce qu'il se fait peu de chose nouvelles; et, fît-on des choses nouvelles, on s'efforcerait de les peindre avec les mots connus et dont la tradition a fixé le sens.

C'est le phénomène opposé qui arrive dans les démocraties, car le mouvement perpétuel qui règne dans leur sein «tend, au contraire, à y renouveler la face de la langue, comme celle des affaires », et d'ailleurs ces sociétés aiment le mouvement pour lui-même. "Cela se voit dans la langue aussi bien dans la politique. Alors qu'elles n'ont pas le besoin de changer les mots, elles en sentent quelquefois le désir». Et quelle est la nature de ces néologismes ? À la déterminer ce sont les modalités de la vie sociale.

Chez ces peuples, c'est la majorité qui fait la loi en matière de langue, ainsi qu'en tout le reste. [...] Or, la majorité est plus occupée d'affaires que d'études, d'intérêts politiques et commerciaux que de spéculations philosophiques ou de belles lettres. La plupart des mots créés ou admis par elle porteront l'empreinte de ces habitudes ; ils serviront principalement à exprimer les besoins de l'industrie, les passions des partis ou les détails de l'administration publique. C'est de ce côté-là que la langue s'étendra sans cesse, tandis qu'au contraire elle abandonnera peu à peu le terrain de la métaphysique et de la théologie.

13. Cf. Guellec 2004, pp. 125-126. Il s'agit de l'article Comment les mots changent de sens, maintenant repris dans Meillet 1965, p. 233.

14. Tocqueville, 2, p. 72. Plus loin Tocqueville compare la différente conduite de deux Anglais ou bien de deux Américains qui par hasard, sans se connaître, se rencontrent à l'étranger: les premiers se tiennent à distance, tandis que les Américains sont «sur le champ amis, par cela même qu'ils sont Américains». On attribue ce différent trait au caractère insociable des Anglais et à la sociabilité américaine, mais, selon l'auteur, c'est à l'état social de leur pays qu'il faut revenir pour le comprendre. En Angleterre, l'orgueil aristocratique est encore très grand, mais les limites de l'aristocratie sont devenues douteuses: $c^{\prime}$ est pourquoi «ne pouvant juger du premier coup d'oeil quelle est la situation sociale de ceux qu'on rencontre, l'on évite prudemment d'entrer en contact avec eux». En Amérique, où les privilèges de naissance n'ont jamais existé et où la richesse ne donne aucun droit particulier, les gens «ne trouvent ni avantage ni péril à se communiquer librement leurs pensées» (ibid., p. 176-177). 
Quant à la source de ces néologismes, ce n'est pas dans les langues mortes, qu'ils ne connaissent pas, que les peuples démocratiques vont les puiser ${ }^{15}$, mais plutôt dans les autres langues vivantes, «car ils communiquent sans cesse entre eux, et les hommes des différents pays s'imitent volontiers, parce qu'ils se ressemblent chaque jour davantage ». On pourrait soutenir que Tocqueville conçoive par là l'idée qu'à l'avenir, à la suite de ce rapprochement, il pourrait y avoir une langue universelle, dans le sens qu'avait décrit Sébastien Mercier dans sa Néologie, c'est-à-dire "celle qui emprunterait des mots à toutes les langues connues, et les assujettirait ensuite à sa syntaxe». C'est au moins ce que semble suggérer Laurence Guellec ${ }^{16}$. Quant à moi, je ne pousserais pas si loin cette hypothèse, pour remarquer plutôt que l'auteur ne montre aucune prévention à l'égard des emprunts aux langues étrangères. On le voit plus loin, même si dans le registre de l'ironie, lorsque, en déplorant un autre caractère de la langue démocratique, le manque de clarté, il n'hésite pas à déclarer :

«J'aimerais mieux qu'on hérissât la langue de mots chinois, tartares ou hurons, que de rendre incertain le sens des mots français. L'harmonie et l'homogénéité ne sont que des beautés secondaires du langage. [...] Mais il n'y a pas de bonne langue sans termes clairs. »

Mais c'est surtout dans leur propre langue que les peuples démocratiques cherchent les moyens pour innover. Ils le font en suivant plusieurs voies : ou bien ils reprennent « des expressions oubliées qu'ils remettent en lumière ${ }^{17}$, ou bien - on l'a déjà vu - ils font entrer dans la circulation générale « une multitude d'expressions qui n'avaient d'abord appartenu qu'à la langue spéciale d'un parti ou d'une profession». Toutefois, le moyen le plus ordinaire qu'ils emploient " consiste à donner à une expression déjà en usage un sens inusité ». Moyen bien simple et très commode - observe Tocqueville - mais qui fait courir de grands périls à la langue. Car « les peuples démocratiques, en doublant ainsi le sens d'un mot, rendent quelquefois douteux celui qu'ils lui laissent et celui qu'ils lui donnent ». Si la langue démocratique est créative, elle est donc aussi une langue confuse.

Un auteur commence par détourner quelque peu une expression connue de son sens primitif, et, après l'avoir ainsi modifiée, il l'adapte de son mieux à son sujet. Un autre survient qui attire la signification d'un autre côté ; un troisième l'entraîne avec lui dans une nouvelle route; et, comme il n'y a point d'arbitre commun, point de tribunal permanent qui puisse fixer définitivement le sens du mot, celui-ci reste dans une situation ambulatoire. Cela fait que les écrivains n'ont presque jamais l'air de s'attacher à une seule pensée, mais qu'ils semblent toujours viser au milieu d'un groupe d'idées, laissant au lecteur le soin de juger celle qui est atteinte.

On remarquera que Tocqueville abandonne ici son premier propos de ne traiter que de la langue commune, tout comme il abandonne au cours du chapitre l'objet qu'il avait énoncé dans le titre, c'est-à-dire l'anglais américain, et qu'il pense plutôt en général aux écrivains de son temps, surtout aux écrivains de son pays. Mais ce qui est plus remarquable - et quelque peu drôle - c'est le fait que lui-même pourrait être la cible de cette critique. Les spécialistes ont souvent parlé de la polysémie de son langage. Un seul exemple, mais de poids : son mot-clé, "démocratie », est employé tour à tour par lui, et parfois au cours de la même page, pour indiquer soit l'égalité des conditions (c'est le sens

15. «S'ils ont quelquefois recours aux savantes étymologies, - dit-il - c'est d'ordinaire la vanité qui les leur fait chercher au fond des langues mortes, et non l'érudition qui les offre naturellement à leur esprit. Il arrive même quelquefois que ce sont les plus ignorants d'entre eux qui en font le plus d'usage. Le désir tout démocratique de sortir de sa sphère les porte souvent à vouloir rehausser une profession très grossière par un nom grec ou latin. Plus le métier est bas et éloigné de la science, plus le nom est pompeux et érudit. C'est ainsi que nos danseurs de corde se sont transformés en acrobates et en funamboles».

16. Cf. Guellec 2004, p. 122 : c'est à elle que je dois la citation de Mercier (an IX [1801], p. XXI-XXII).

17. Peut-être - c'est encore Guellec à le soutenir (ibid., p. 147) - ne fait-il ici que s'approprier sans le nommer le thème de l'archaïsme en vogue dans la première moitié du siècle». En effet les écrivains romantiques ont eu la passion des noms désuets, ce qui était une façon de faire revivre le passé, comme le montre parmi tant d'autres le cas d'Augustin Thierry. Et, lorsqu'il parle de la littérature démocratique, Tocqueville - on le verra - envisage surtout les écrivains français de son temps, en leur prêtant tous les caractères du romantisme. 
prédominant), soit la souveraineté populaire soit les régimes politiques ayant des institutions libres.

Créative, mais confuse, la langue démocratique est aussi une langue abstraite. Précédemment Tocqueville avait montré - c'est le titre du chapitre III - «pourquoi les Américains montrent plus d'aptitude et de goût pour les idées générales que leurs pères les Anglais ». Son procédé avait été, comme toujours, celui que j'ai défini hypothéticodéductif, car son explication était la suivante : tandis que, lorsque les conditions sont très inégales, les individus deviennent si dissemblables qu'il y a «autant d'humanités distinctes qu'il y a de classes » et que, «perdant de vue le lien général qui les rassemble toutes dans le vaste sein du genre humain, on n'envisage jamais que certains hommes et non pas l'homme », l'homme des sociétés démocratiques ne voit près de lui que des êtres qui lui ressemblent :

«Il ne peut donc songer à une partie quelconque de l'espèce humaine, que sa pensée ne s'agrandisse et ne se dilate jusqu'à embrasser l'ensemble. » ${ }^{18}$

Cette tournure de l'esprit ne peut donc que se refléter dans la langue.

«Cet amour des idées générales - dit-il - se manifeste, dans la langue démocratique, par le continuel usage des termes génériques et des mots abstraits, et par les manières dont on les emploie. C'est là le grand mérite et la grande faiblesse de ces langues ».

Et cette fois-ci l'observateur se fait lui-même l'objet de son observation, car il remarque qu'il a souvent employé le mot « égalité » dans un sens absolu, qu'il l'a même plusieurs fois personnifié en disant que «l'égalité faisait certaines choses, ou s'abstenait de certaines autres ». Sa conclusion est, comme toujours dans cette analyse, à double face :

«Ces mots abstraits qui remplissent les langues démocratiques, et dont on fait usage à tous propos sans les rattacher à aucun fait particulier, agrandissent et voilent la pensée; ils rendent l'expression plus rapide et l'idée moins nette. Mais, en fait de langage, les peuples démocratiques aiment mieux l'obscurité que le travail. [...] Les hommes qui habitent les pays démocratiques ont [...] souvent des pensées vacillantes : il leur faut des expressions très larges pour les renfermer. Comme ils ne savent jamais si l'idée qu'ils expriment aujourd'hui conviendra à la situation nouvelle qu'ils auront demain, ils conçoivent naturellement le goût des termes abstraits. Un mot abstrait est comme une boîte à double fond : on y met les idées que l'on désire, et on les en retire sans que personne le voie. »

Il y a une dernière remarque à faire, qui est peut-être la plus importante. Dans les siècles aristocratiques - de même que chaque nation tend à se tenir à l'écart des autres et qu'il n'y a donc pas d'échange entre les langues - au sein de la même nation il n'y a pas d'échange entre les différentes classes. "On rencontre alors dans le même idiome une langue de pauvres et une langue de nobles, une langue savante et une langue vulgaire $»^{19}$. C'est le contraire qui arrive dans les siècles démocratiques, lorsque tous les rangs sont confondus et, par conséquent, « tous les mots de la langue se mêlent ».

Ceux qui ne peuvent pas convenir au plus grand nombre périssent; le reste forme une masse commune où chacun prend peu à peu au hasard. Presque tous les différents dialectes qui divisaient les idiomes de l'Europe tendent visiblement à s'effacer; il n'y a pas de patois dans le nouveau monde, et ils disparaissent chaque jour de l'ancien.

18. Il ajoutait que, dans les siècles d'égalité, tous les hommes étant également isolés et faibles, on n'en voit point «dont la volonté dirige d'une façon permanente les mouvements de la foule». C'est pourquoi, «pour expliquer ce qui se passe dans le monde, on en est [...] réduit à rechercher quelques grandes causes qui, agissant de la même manière sur chacun de nos semblables, les porte ainsi à suivre tous volontairement une même route» (Tocqueville 1951, 2, p. 22-23). Cette réflexion connaîtra de plus longs développements dans les chapitre XX de cette Première Partie, où l'auteur traitera «de quelques tendances particulières aux historiens dans les siècles démocratiques».

19. «Je parierais volontiers - ajoute-t-il - que, parmi les castes de l'Inde, le langage varie prodigieusement et qu'il se trouve presque autant de différence entre la langue d'un paria et celle d'un brame qu'entre leurs habits». 


\section{... et le style}

Cette dernière remarque nous introduit à la question du style. Car «non seulement tout le monde se sert des mêmes mots, mais on s'habitue à employer indifféremment chacun d'eux ». Les règles que le style classique avait créées disparaissent, et il n'y a plus de registre linguistique qui, par sa nature, puisse paraître vulgaire ou distingué.

Je sais - dit Tocqueville - que dans la classification des mots, il se rencontre des règles qui ne tiennent pas à une forme de société plutôt qu'à une autre, mais qui dérivent de la nature même des choses. Il y a des expressions et des tours qui sont vulgaires parce que les sentiments qu'ils doivent exprimer sont réellement bas, et d'autres qui sont relevés parce que les objets qu'ils veulent peindre sont naturellement fort hauts. Les rangs se mêlant ne feront jamais disparaître ces différences. Mais l'égalité ne peut manquer de détruire ce qui est purement conventionnel et arbitraire dans les formes de la pensée. Je ne sais même pas - ajoute-t-il - si la classification nécessaire, que j'indiquais plus haut, ne sera pas toujours moins respectée chez un peuple démocratique que chez un autre ; parce que, chez un pareil peuple, il ne se trouve point d'hommes que leur éducation, leurs lumières et leurs loisirs disposent d'une manière permanente à étudier les lois naturelles du langage et qui les fassent respecter en les observant eux-mêmes.

En somme, constate Tocqueville, dans les démocraties il se fait « une confusion dans le langage comme dans la société ».

\section{Quelle littérature pour la démocratie?}

Ma communication pourrait se conclure ici. Je ne voudrais toutefois terminer sans donner au moins un aperçu de ce que Tocqueville dit de la littérature démocratique. On a déjà vu qu'il n'a pas trouvé aux États-Unis une véritable littérature autochtone. Cependant dans le chapitre XIII - ayant pour titre Physionomie littéraire des siècles démocratiques - d'un côté il s'aventure à imaginer quels seront ses caractères lorsque les Américains finiront par en avoir une ; et de l'autre, comme il lui arrive bien souvent, il parle en même temps de celle qu'il a déjà sous les yeux dans son propre pays. Son procédé est encore une fois comparatif, le terme de sa comparaison étant la littérature des siècles aristocratiques : c'est-à-dire d'une société où "un petit nombre d'hommes, toujours les mêmes, s'occupent en même temps des mêmes objets, ils s'entendent aisément et arrêtent en commun certaines règles principales qui doivent diriger chacun d'eux ${ }^{20}$; des hommes, en plus, qui, occupant une position héréditaire, seront naturellement portés "non seulement à adopter pour eux un certain nombre de règles fixes, mais à suivre celles que s'étaient imposées leurs aïeux »; qui, ayant toujours vécu dans l'aisance, ont conçu «le goût des jouissances recherchées et l'amour des plaisirs fins et délicats ", et qui, ayant contracté dans ces loisirs une certaine mollesse d'esprit et de cœur, sont portés à écarter « de leurs plaisirs mêmes ce qui pourrait s'y rencontrer de trop inattendu et de très vif ».

Imaginez maintenant un grand nombre de travaux littéraires exécutés par les hommes que je viens de peindre, ou pour eux, et vous concevrez sans peine une littérature où tout sera régulier et coordonné à l'avance. Le moindre ouvrage y sera soigné dans ses plus petits détails ; l'art et le travail s'y montreront en toutes choses; chaque genre y aura ses règles particulières dont il ne sera point loisible de s'écarter et qui l'isoleront de tous les autres.

20. Pour ce passage et les suivants cf. Tocqueville 1951, 2, pp. 60-65. 
Il est aisé de deviner que Tocqueville parle là de la littérature du Grand Siècle, de son élégance, mais aussi des périls que les auteurs y courent quelquefois, de tomber, comme il le dit, dans "une sorte de jargon littéraire, qui n'est guère moins éloigné du beau langage que le patois du peuple ».

Les sociétés démocratiques ne sont que le revers de ce tableau. Voilà une foule confuse, où tous les rangs sont mêlés et confondus; où les connaissances, comme les pouvoirs, sont "divisés à l'infini »; où tous n'ont pas reçu la même éducation ni ne possèdent les mêmes lumières; où les hommes «ne ressemblent point à leurs pères, et à chaque instant ils diffèrent d'eux-mêmes, car ils changent sans cesse de place, de sentiments et de fortune ». Quelle sera donc la littérature propre à satisfaire aux besoins intellectuels d'une société pareille?

Prise dans son ensemble, la littérature des siècles démocratiques ne saurait présenter, ainsi que dans les temps d'aristocratie, l'image de l'ordre, de la régularité, de la science et de l'art; la forme s'y trouvera, d'ordinaire, négligée et parfois méprisée. Le style s'y montrera souvent bizarre, incorrect, surchargé et mou, et presque toujours hardi et véhément. Les auteurs y viseront à la rapidité de l'exécution plus qu'à la perfection des détails. Les petits écrits y seront plus fréquents que les gros livres, l'esprit que l'érudition, l'imagination que la profondeur, il y régnera une force inculte et presque sauvage de la pensée, et souvent une variété très grande et une fécondité singulière dans ces produits. On tâchera d'étonner plutôt que de plaire, et l'on s'efforcera d'entraîner les passions plus que de charmer le goût.

Sans le dire, l'auteur trace ici une esquisse de ce qu'on appelle la littérature romantique. Romantique par tempérament, si je peux le dire, Tocqueville n'a pas toutefois trop de goût pour cette production littéraire. C'est ailleurs que vont ses préférences : c'est à la littérature des époques de transition, lorsqu'on passe d'un état social à l'autre.

Dans le passage qui conduit un peuple lettré de l'un à l'autre, il survient presque toujours un moment où, le génie littéraire des nations démocratiques se rencontrant avec celui des aristocraties, tous deux semblent vouloir régner d'accord sur l'esprit humain. Ce sont là des époques passagères, mais très brillantes: on a alors la fécondité sans exubérance, et le mouvement sans confusion. Telle - conclut-il - fut la littérature française du XVIII ${ }^{\mathrm{e}}$ siècle.

Voilà une preuve de plus, s'il le fallait, que, lorsqu'il parle de l'Amérique et qu'il esquisse, à partir de ce qu'il y a vu, les traits des sociétés démocratiques présentes et à venir, au cœur de la réflexion de Tocqueville il y a toujours son propre pays, la France.

\footnotetext{
Résumé

La communication analyse un chapitre de la Démocratie en Amérique où Tocqueville décrit «comment la démocratie américaine a modifié la langue anglaise », posant par là un problème linguistique capital, car les contacts et les conflits ne concernent pas, dans ce cas, deux langues différentes, mais les contextes sociaux opposés où la même langue a évolué et les effets qui en dérivent. En résumant les plus importants: l'anglais américain non seulement produit beaucoup de nouveaux mots (souvent tirés du jargon des partis, des arts mécaniques, des affaires), mais donne un sens nouveau aux mots anciens; ce que la langue acquiert en richesse lexicale, elle le perd en précision, car le sens des mots se trouve constamment «dans une situation ambulatoire»; les règles gouvernant l'emploi des différents styles linguistiques disparaissent, car " non seulement tout le monde emploie les mêmes mots, mais on s'habitue à employer indifféremment chacun d'eux ». On montre aussi comment, à partir de l'observation empirique de la langue américaine et par un procédé hypothético-déductif, Tocqueville dessine les traits généraux de la langue démocratique, c'est-à-dire des modifications que les langues subissent dans les sociétés démocratiques.
} 


\section{Bibliographie}

ARON R. 1967, Les étapes de la pensée sociologique, Paris, Gallimard.

GuELLEC L. 2004, Tocqueville et les langages de la démocratie, Paris, Honoré Champion.

GUIZOT F. 1848, Introduction [1809] au Nouveau dictionnaire universel des synonimes de la langue française, $4^{\mathrm{e}}$ éd., Paris, A. Payen

JACQUES D. 1995, Tocqueville et la modernité. La question de l'individualité dans la « Démocratie en Amérique », Montréal, Boréal.

MeILlET A. 1965, Linguistique historique et linguistique générale, Paris, Honoré Champion.

MERCIER S. an IX [1801], Néologie, ou Vocabulaire des mots nouveaux, à renouveler ou pris dans des acceptions nouvelles, Paris, Moussard.

POGGI G. 1972, Immagini della società. Saggi sulle teorie sociologiche di Tocqueville, Marx et Durkheim, Bologna, Il Mulino.

PozzI R. 2006, Tocqueville e i dilemmi della democrazia, Pisa, Edizioni Plus-Pisa University Press.

Tocqueville A. de 1951, CEuvres complètes. I. De la démocratie en Amérique, Paris, Gallimard, 2 vol.

TOCQUEVILlE A. de 1957, CEuvres complètes. V.Voyages en Sicile et aux États-Unis, Paris, Gallimard. 


\section{Horlor gorom ${ }^{1}$ !}

Isabelle-Rachel CASTA

Professeur de Littérature,

Université d'Artois

\footnotetext{
Extrait de : Guylaine BRUN-TRIGAUD (dir.), Contacts, conflits et créations linguistiques, Paris, Édition électronique du CTHS (Actes des congrès des sociétés historiques et scientifiques), 2015.

Cet article a été validé par le comité de lecture des Éditions du CTHS dans le cadre de la publication des actes du $139^{\mathrm{e}}$ Congrès national des sociétés historiques et scientifiques tenu à Nîmes en 2014.
}

«Pour s'initier à la magie, rien de mieux que les hauteurs...

-... Et le souffle du vent ! reprennent les deux femmes.

- Car tout est dans le souffle, vois-tu, Cham ! Sans le souffle...

$-\ldots$ les mots ne sont rien. $»^{2}$

Riche en «fictions linguistiques » de toute nature, le «médiéval fantastique », abrégé en «medfan », est souvent désigné par ses deux composantes les plus spécifiques : donjons et dragons ${ }^{3}$. La complexité et la sophistication des productions inspirées de cette thématique dépassent bien entendu ce binôme réducteur, et s'affirment pleinement dans un traitement symboligène $\mathrm{du}$ langage, qui fera proprement l'objet de cette communication.

Prenons quelques instants pour remonter à l'origine : J. R. R. Tolkien, dans Le Seigneur des Anneaux (1955; en fait dès Bilbo the Hobbitt en 1937), induit une fantasy haut de gamme, assez élitiste, très cultivée : c'est le courant anglais - où s'illustrent déjà Lewis Carroll, Lord Dunsany (La Fille du Roi des Elfes)... le Peter Pan de James Barrie, ou bien encore, contemporain de Tolkien (c'est son meilleur ami) Clive Stapple Lewis et Le Monde de Narnia (1950-1956); quelques traits communs se retrouvent, dans tous les cas :

- un sacré immanent,

- un cadre pré-technologique,

- un monde alternatif.

Au nom même de cet «autre monde », s'autorise une langue plus ou moins construite, cohérente et articulée, chargée de véhiculer un rapport plus essentiel aux choses et aux êtres, dans un esprit souvent très proche du cratylisme - qui, on s'en souvient refuse l'arbitraire du signe pour privilégier une motivation plus profonde entre ce qui est désigné et l'outil linguistique.

Souvent lié à la magie - les sorts lancés par le Harry Potter de J. K. Rowling rempliraient un volume entier - ce «nouveau» langage (en fait connoté comme " ancien, originel, atavique ") emprunte à tous les systèmes phonétiques et syntaxiques déjà existants, pour créer un hybride qui parle suffisamment à chacun, tout en restant opaque à tout le monde. Il va de soi que cette prétendue «pureté » (ou «impureté ») d'une langue est ellemême une fiction, ou plus exactement la métaphorisation d'un ressenti expérientiel idéologiquement reconstruit.

Nous évoquerons donc, dans un premier temps, l'exemple des Harry Potter, et de MarieHélène Delval, comme discret mais efficace recyclage des diglossies en tension dans la fantasy, réévaluée en allégorie de l'apprentissage enfantin des puissances et des impuissances du langage; puis nous élargirons notre questionnement en comparant

1. En langue dragon : "arrière, démon!", prononcé pour la première fois dans Delval, Les Dragons de Nalsara, vol. 3 : Complot au palais, p. 75 . À lire dès 8 ans, ce roman illustré est conforme à la loi $49-956$ du 16 juillet 49 sur les publications destinées à la jeunesse.

2. Delval, Les Dragons de Nalsara, vol. 8, Sortilèges sur Nalsara, p. 26.

3. On lira par exemple A. Ruaud, Panorama illustré de la fantasy et du merveilleux. 
quelques traits linguistiques marquants - et même discriminants - entre les fantasies anglaise, américaine et française; pour enfin conclure en nous demandant si le merveilleux ne tient pas précisément à cette «confiance fictionnelle » qui s'affirme explicitement comme telle - contrairement au fantastique qui, lui, simule encore un « réel » dont l'artificialité jure avec la factualité revendiquée.

\section{Dire le Cosmos ou dire l'Anthropos: quelle place pour la langue des Dragons de Nalsara?}

Les fictions linguistiques - entendons par là un récit où le langage inventé va jouer un rôle déterminant dans le déroulement de l'intrigue - sont souvent rassemblées en deux grandes catégories du logos: exprimer essentiellement un autre monde, ou construire principalement un autre être. Pour exemplifier, prenons deux romans d'H. G. Wells : $L a$ Machine à remonter le temps interroge plutôt le statut des humains, alors que La Guerre des Mondes se préoccupe davantage du sort de notre univers... et l'on pourrait étendre à d'autres auteurs ces remarques (en particulier Lovecraft et Ursula le Guin ${ }^{4}$ ). Nous savons par ailleurs qu'une acception plus restreinte et plus critériée ramène les fictions linguistiques à un plus étroit compendium: pour des chercheurs comme Marina Yaguello ${ }^{5}$, Umberto Eco ou Noam Chomsky, seuls les récits qui mettent réellement les langues inventées comme sujet de leur discours ont si je puis dire droit à cette dénomination... qu'il s'agisse de The coming race (La race à venir $\left.{ }^{6}\right)$, d'Edward BulverLytton (1871), de Babel 17 de Samuel R. Delany (1966)... ou de l'appendice en novlang (sorte de «basic English») dont Orwell fait suivre son roman 1984... et qu'on ne lit guère! La question linguistique est bien au centre de l'intrigue, alors que le latin de Potter n'est qu'un adjuvant. Nous utiliserons donc la formule « fiction linguistique » avec précaution et guillemets!

Venue d'une généricité grande pourvoyeuse de scénarios de dark fantasy - nous voulons parler de la matière de Bretagne et des légendes arthuriennes, l'épopée des Dragons de Nalsara, de Marie-Hélène Delval, forme l'adaptation à la fois juvénile et didactique du legendarium de Tolkien ; l'auteur s'est fait accompagner par les superbes dessins d'Alban Morilleau qui dit explicitement s'inspirer du monde de l'illustrateur et peintre John Howe (tons sépia, bruns, pourpres, vert sombre, or bruni pour les couvertures). Précisons encore un point: notre réflexion portera sur la "première époque» (les 12 premiers épisodes).

Les intrigues se déroulent principalement sur «l'île aux dragons », ainsi nommée parce que les dragonnes viennent y pondre leurs œufs; Antos, le père de Cham et Nyne (les petits héros), est l'éleveur des jeunes dragons, jusqu'à ce qu'on puisse les emmener à la capitale, où ils font alors partie de l'armada royale. Les sous-titres (chaque épisode pose et résout une mini-énigme, et peut donc être lu pour lui seul) restent majoritairement «localistes »: La Citadelle noire, Les maléfices du marécage, Dans le ventre de la montagne, Complot au palais, etc. Ce qui permet de répondre à la question « où ? ».

Nous le disions il y a un instant : encore une histoire de famille ! Comme dans Star Wars! Ici, le méchant c'est Darkat (Dark... Vador ?), demi-frère de Dhydra, épouse d'Antos, et donc oncle de Nyne et Cham ; Dhydra est la fille d'un puissant sorcier, mais elle a choisi la Lumière en épousant Antos ; enlevée par maléfice à sa famille, elle se morfond dans une prison «addrake», car elle refuse d'appeler les Dragons qui permettraient aux

4. Dans The Left hand of Darkness (1969), par exemple... ajoutons qu'entrent alors dans cette catégorie des œuvres aussi diverses entre elles que La machine à parler de Marcel Schwob, Les langages de Pao de Jack Vance (1958) ou Le Samouraï virtuel de Neal Stephenson (1992)... Même La Tour sombre de S. King, par le nombre de ses néologismes, pourrait à la limite entrer dans le cadre définitoire.

5. Opus essentiels : Les langues imaginaires : mythes, utopies, fantasmes, chimères et fictions linguistiques (2006) et Les Fous du langage : des langues imaginaires et leurs inventeurs (1984).

6. Un peuple souterrain, les Vril-ya, y parle le vril. 
sorciers de vaincre le royaume d'Ombrune et son roi. Plus l'histoire s'avance, plus on plonge dans le passé : Solveig, la mère de Dhydra, fut séduite par Eddhor, le seigneur noir des Addraks ; elle mourut d'épuisement en fuyant, et remit son enfant à sa fidèle servante et nourrice, Viriana; celle-ci sert de lien et de mémoire entre les trois générations : Solveig/Dhydra/Nyne... Eddhor fut tué par sa propre Strige, animal fait de noirceur qu'il avait inventé ; son fils, Darkat, a hérité de la Strige, qui s'efforce de comprendre ses désirs...

Le titre ne fait d'ailleurs pas mention de personnages humains, mais d'animaux fabuleux (dragons) et d'un lieu proprement u-topique: NALSARA. On apprendra que c'est la ville-capitale $\mathrm{du}$ royaume $\mathrm{d}^{\prime} \mathrm{Ombrune}$ (« une ombre »... ?). L'accent est mis non sur les deux jeunes héros que l'on va découvrir, mais sur leurs amis légendaires, ces dragons qui font la force et la fierté du royaume... les $4 \mathrm{~A}$ du titre : DRA/NAL/SA/RA connotent une promesse épique (assonance) et annoncent aussi les prénoms d'un certain nombre de héros: Cham, Antos, Dhydra, les Addraks, Darkat, Nastrad, Sappi, Saddi, Hadal, Damian, tous porteurs de la lettre A. Il est permis de songer à la ville de "Samsara », qui procède de la même répartition syllabique, ou tout simplement au Monde de Narnia. Pour rester dans l'ordre phonétique, ou syllabique, peut-on aller jusqu'à constater que les « enfants » ont des noms monosyllabiques (Cham, Nyne, Nour...) et les adultes des noms plus longs?

On le voit: épée, magie, héroïne déchirée, cruelle Strige contre vaillant Dragon, frère fourbe contre mari dévoué... Chacun des clans a ses adjuvants et ses opposants : le petit garçon Cham sera bientôt capable de parler «en dragon » comme sa mère (exactement comme Potter en fourchlangue), et deux magiciennes l'aident à déjouer les pièges ourdis par les sorciers; nommées Mélisande et Isendrine (ce qui est à peu près l'anagramme d'un nom par l'autre...), elles peuvent à la rigueur rappeler le duo de sorcières WillowTara de la série Buffy contre les vampires ${ }^{7}$.

C'est une constante, dans le monde de la fantasy, qu'une langue énigmatique et sacrée s'ajoute à la langue usuelle ; le dialogue avec les animaux (cela s'appelle artiser) est un autre grand classique de la magie: Nour, le dragonneau, et Cham, l'adolescent, se comprennent et se parlent. Nyne, la petite sœur, est liée aux éléments aquatiques, elle peut appeler le serpent de mer Vag à son secours, et il la transporte sur son dos comme Nour transporte Cham : là encore, on se souvient de Harry voyageant sur l'hypogriffe de Hagrid, Buck. Donc ce qui frappe le plus, c'est la présence constante non pas d'une « langue magique », mais de deux ou trois langages cryptés... celui des Dragons et celui des magiciennes, qui calque évidemment l'inventivité des sortilèges de Harry Potter, ou le cherokee de la saga La maison de la Nuit (K. et P.C. Cast). Mais vient s'y ajouter, nous le disions, un troisième genre de communication - entre Nyne et des poissons fabuleux, les Élusims, à ceci près que si l'on entend textuellement se parler Nour et Cham, on sait seulement qu'il y a un langage propre aux bêtes des eaux et à l'enfant, mais tout ce qui est retranscrit est un murmure ou un chantonnement : Hruummmm ${ }^{8} .$. le reste relevant du discours narrativisé, de type : "La gamine, elle... elle parle avec cet animal ! [...] La petite fille pose des questions, et l'élusim lui répond ${ }^{9} »$, etc.

Si nous procédons à un regroupement des "massifs exolinguistiques », quelques séquences majeures apparaissent. D'abord, le sort d'ouverture :

«Messire Damian prononce :

- Effractet! Le couvercle s'ouvre, laissant apparaître une simple boule de verre [...] ${ }^{10}$

7. Dans la série Buffy contre les vampires, les sorcières Willow et Tara lancent aussi des sorts en «latin de cuisine ». Sur l'utilisation des mythologies orientales et antiques dans les séries télévisées, lire Wenskus, «Die Serie erzieht ihre Zuschauer, Zur Intellektualisierung erfolgreicher Fehrnsehserien ».

8. Delval, Les Dragons de Nalsara, vol. 4 : La nuit des Élusim, 2010, p. 32.

9. Op. cit., p. 33.

10. Delval, Les Dragons de Nalsara, t. II, Le plus vieux des Dragonniers, p. 51. Notons tout de suite qu'il s'agit indéniablement d'un «latin macaronique » reconstruit à partir du subjonctif d'ordre des verbes en 0 , as are, avi, atum... et du sème effraction. Très en vogue aux XVI ${ }^{\mathrm{e}}$ et XVII ${ }^{\mathrm{e}}$ siècles, cette latinisation burlesque de termes 
«Agenouillé sur le plancher, le garçon murmure le mot qui provoque l'ouverture :

- Effractet $!^{11} »$

«Cham [...] prononce la formule d'ouverture :

- Effractet ! ${ }^{12} »$.

«Effractet! Le couvercle se soulève. Cham prend la boule de verre dans ses mains. ${ }^{13}$

Puis le commandement des dragons, leitmotiv essentiel :

«Il lui semble alors que sa gorge forme des mots étranges, qu'il ne connaît pas: Horlor gorom ! ${ }^{14}$

La même incantation revient au moins trois fois dans l'épisode 6 (p. 78, 79, 81)

Ensuite, l'apprentissage lexique, fondé sur la mémorisation et sur la virtu, dirait Vico :

"Sans même réfléchir, il lance rageusement: Brilill'iol! ${ }^{15}$ »; "Cham découvre que Brilill'iol est une contraction de brilillié orinioli, qui signifie "brillez, lucioles". [...] Pluie se dit lochti, et mer c'est slimane.[...] Aile, c'est fenn, et au pluriel, fennas ; épée, c'est swor... ${ }^{16}$

Quelques pages plus loin, l'apprentissage est immédiatement testé :

«Il clame :

- Swor! Il a réussi ! Une épée s'est matérialisée devant lui. » ${ }^{17}$

Dans l'épisode suivant, il surprend sa mère, elle-même magicienne, en créant de la lumière avec le fameux Brilill'iol!; mais c'est pour avouer tout de go qu'une autre tentative a échoué :

« Mais quand j'ai lancé «Fennas! » pour avoir des ailes, ça n'a pas marché. » ${ }^{18}$

Plus tard encore (épisode 10), il convoque les lucioles avec une énergie quasi maléfique :

«Brilill'iol ! Les lucioles lui obéissent à une vitesse surprenante ${ }^{19} »$.

«Cham se concentre. [...] Et il lance d'un coup :

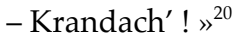

Enfin, Cham et Nyne apprennent ensemble la formule d'appel aux dragons :

«Virnié nouri stragi ! [...] c'est drôle : Nouri ça ressemble à Nour... » ${ }^{21}$

C'est même Nour, un bébé dragon, qui explique à Cham le sens de ces mots... avec un petit cours de grammaire en plus :

souvent triviaux nous a laissé le célèbre «pedibus cum jambis » que Molière invente à la fin de son Malade Imaginaire..

11. Delval, Les Dragons de Nalsara, vol. 3, Complot au palais, p. 17.

12. Delval, Les Dragons de Nalsara, vol. 7, Le secret des magiciennes, p. 33. La scène se reproduit à d'innombrables reprises...

13. Delval, Les Dragons de Nalsara, vol. 8, Sortilèges sur Nalsara, p. 30.

14. Cf. note 1. Précisons quand même qu'il faut attendre le 12e épisode pour connaître le sens précis de ces mots inconnus : "- Les dragons ne te l'ont pas appris, Cham ? Ça signifie : Arrière, Démon! ", Delval, Les Dragons de Nalsara, vol. 12 , Dans le ventre de la montagne, p. 59).

15. Delval, Les Dragons de Nalsara, vol. 8, Sortilèges sur Nalsara, p. 36.

16. Op. cit., p. 63.

17. Op. cit., p. 77.

18. Delval, Les Dragons de Nalsara, vol. 9, La Citadelle noire, p. 23.

19. Delval, Les Dragons de Nalsara, vol. 10, Aux mains des sorciers, p. 28.

20. Delval, Les Dragons de Nalsara, vol. 8, Sortilèges sur Nalsara, p. 27.

21. Delval, Les Dragons de Nalsara, vol. 6, La colère de la strige, p. 30-31. 
"Straji, ça veut pas dire dragon, par hasard? "Dragon se dit «straj », précise Nour. Au pluriel, straji » «Et virnié nouri straji ? « «enez, vaillants dragons ? »22

La formule revient de façon obsessionnelle tout au long du cycle, puisqu'elle est au cœur de la guerre que se livrent le roi Bertram et les sorciers Addraks; mais au-delà des enjeux de pouvoir et de suprématie, se distingue un pur instant de grâce lorsque dans La Citadelle noire, la mère de Cham le berce « en dragon » :

« Néoc varna slimane, karug er nos dûrim, Sorna lami, mnelek, sorok vanyl... » ${ }^{23}$

Elle domine également les sorts de métamorphose :

«Slimane, murmure-t-elle. Vanya slimane... La mer, le vent de la mer... » ${ }^{24}$

«Néoc Niévidim ${ }^{25}$ » permet de se rendre invisible, mais l'énergie que ce sort nécessite excède les forces de Dhydra... Heureusement qu’ «Ispélénia » guérit les blessures :

«Il a appris un mot très utile pour soigner les petites plaies : ispélénia ! ${ }^{26}$

Entre le Monde et le Moi, le logos agit donc comme un pharmakon réparateur ; pour reprendre des termes freudiens, il rétablit le heimlich au sein de l'Unheimlichkeit - faire de la lumière quand tout est noir, soigner, bercer pour que l'on s'endorme, ou encore dévoiler des secrets qui vont aider au triomphe du bien. On comprend pourquoi, pour Giovanni Berjola, « la fantasy est l'aboutissement cosmogonique du fantastique ${ }^{27}$ ».

\section{Une incommensurabilité paradigmatique?}

Ce relevé rudimentaire nous amène néanmoins à une constatation : nous sommes très loin encore du déploiement de fictions comme celle de Frédéric Werst ${ }^{28}$, qui dans son épopée WARD se sert de 10000 mots complètement inventés... avec même une anthologie des œuvres censées avoir été écrites en wardwesân; fleuron des conlangs (pour constructed languages) et idole des conlangers, cette monumentale saga ${ }^{29}$ (le tome II vient de paraître au Seuil, sous le titre : WARD : III $^{\mathrm{e}}$ siècle) se revendique digne héritière du klingon, le langage inventé pour Star Trek; la Bible et même Shakespeare sont d'ailleurs traduits en klingon - qui peut aussi s'enorgueillir d'un opéra! Un autre «contre-exemple» pourrait être donné par le curieux roman de l'américain Russel Hoban, Enig Marcheur, écrit en parlénigm dans un monde post-apocalyptique où les langues se sont effondrées sur elles-mêmes... les 304 pages de ce roman ont pris 6 ans de la vie de l'auteur (disparu en 2011), et un an et demi pour son traducteur ${ }^{30}$; rien de tel ici, cœur de cible oblige!

22. Delval, Les Dragons de Nalsara, vol. 7, Le secret des magiciennes, p. 54-55.

23. Delval, Les Dragons de Nalsara, vol. 9, La Citadelle noire, p. 81. La même scène se reproduit dans l'épisode suivant, Aux mains des sorciers, p. 36.

24. Delval, Les Dragons de Nalsara, vol. 10, Aux mains des sorciers, p. 84.

25. Delval, Les Dragons de Nalsara, vol. 11, Les maléfices du marécage, p. 31-36.

26. Delval, Les Dragons de Nalsara, vol. 12, Dans le ventre de la montagne, p. 75.

27. Tritter, Encyclopédie du fantastique, p. 540. La cosmogonie est la théorie (scientifique ou mythique) expliquant la formation de l'univers, ou de certains objets célestes.

28. Ce pseudonyme - car c'en est un - vient du Château des Carpates de Jules Verne...

29. Un excellent article est consacré à cette idéolangue : "Le monde selon WARD », Edouard Launet, Libération, 3 mars 2014, p. 31-33. On nous recommande d'ailleurs d'aller consulter le site Conlang.org, pour faire connaissance avec la Language Creation Society.

30. Hoban, Enig Marcheur, « riddleyspeak » traduit en français par Nicolas Richard. Dans le passionnant article qui lui est consacré dans Libération (Thomas Stélandre, "A s'en tordre la langue »), on découvre qu'il n'existe que deux versions traduites: la française et l'espagnole, l'auteur s'étant farouchement opposé à toute transposition. 
Nalsara consiste plutôt en une appropriation progressive des puissances du Verbe, un apprivoisement aux forces indomptées de la nature et des éléments, à la fois écologique et féministe ; nous sommes certes dans une «royauté » hors du temps ; mais lors de leur fuite éperdue loin des Addraks, Dhydra et son fils rencontrent un «Libre Peuple », caché dans les replis du marécage et des Mornes Monts. Ils sont les survivants du Norland, pays décimé par les sorciers noirs, et ils attendent des jours meilleurs pour retrouver toute leur place. Il y a donc, même au sein d'une royauté féodale (roi bienveillant, peuple heureux, magiciennes puissantes, dragons protecteurs...) tous les signes d'une "démocratie " (Les maléfices des marécages), qui n'attend qu'un signal pour se soulever et retrouver ses prérogatives. Guidé par un chaman aveugle (mais la vraie vision est celle du cœur), ce peuple parvient à repousser la magie de Darkat, qui traque sa sœur et son neveu...

Les jeunes lecteurs suivent deux enfants qui ont l'âge des élèves en fin de primaire : 9 ans et 11 ans : l'identification est puissamment facilitée ; à la fois hors-temps et hors-lieu, le monde de Nalsara, répétons-le, a le charme d'une chronique médiévale fabuleuse, mais les rapports y sont modernes: enfants entreprenants, initiation réussie, premiers émois amoureux, retrouvailles avec la mère absente... Nous croisons donc Philia, Eros et Agapé; les dragons, comme dans la populaire série Merlin, délèguent à leurs amis humains une "sagesse » venue du fond des âges obscurs, et que seuls un patient apprentissage et une initiation exigeante permettront de comprendre.

Soulignons d'ailleurs le récent changement de paradigme du dragon: jadis gardien redoutable et dangereux des trésors et des princesses, il devient peu à peu un animal positif, généreux, résistant... même si les dragons de La Coupe de feu (Harry Potter) restent, eux, assez peu sympathiques. On peut cependant penser au mouvement général de dédiabolisation des anciennes figures horrifiques ; chimérique, dangereux, tout-puissant... le dragon cracheur de feu porte l'un des statuts les plus ambigus de la "xénoencyclopédie » animale propre à la fantasy. Implacable comme Smaug (le dragon ennemi des Nains d'Erebor, chez Tolkien), cabochard et caractériel comme Norbert, le bébé dragon insupportable qu'aime Hagrid dans Harry Potter, sensible comme la dragonne de Schreck ou mystérieux et séduisant comme les bêtes d'Eragon... Le seul personnage entièrement positif de Game of Thrones est une jeune princesse déchue, Daenerys Targaryen, qui est toujours accompagnée de trois jeunes dragons qu'elle a littéralement " couvés » et qui l'aiment comme leur mère ; convoités par tous, ces dragons la protègent et la défendent en «carbonisant» les ennemis imprudents qui croisent près de leurs naseaux; le titre original de la saga est d'ailleurs A Song of Ice and Fire: le «feu » en question est bien celui que crachent les « enfants » de Daenerys.

Mais le grand modèle reste et demeure Harry Potter - insurpassable horizon de tous les blockbusters adolescents.

J. K. Rowling a fait de sa saga un compendium des cultures et des références, où $l^{\prime}$ « Ignotus » Harry - car c'est évidemment lui qu'allégorise le $3^{\mathrm{e}}$ frère Peverell du conte du barde Beedle $-\mathrm{s}^{\prime}$ ouvre à la profondeur du savoir et de la souffrance en même temps qu'il s'initie à la chaleur de l'amitié et de la fraternité (ces Contes transposent d'ailleurs les Contes de Canterburry de Chaucer). On comprend dès lors pourquoi le latin, qui était déjà l'esperanto de l'Europe médiévo-renaissante, va servir de langue véhiculaire à tous les sorciers ${ }^{31}$, en tant que commun dénominateur des élites lettrées. Dans la topique de Jakobson, le latin pourrait emblématiser la fonction «conative» du langage, puisque les incantations sont généralement suivies d'effets... parfois irrévocables.

Il ne sera pas question ici de passer en revue l'étendue du registre des sorts - de nombreux sites ${ }^{32}$ le font à la perfection, mais d'interroger les latinismes ou hellénismes dominants comme référence souterraine constante à une culture résolument «classique »,

31. Les noms «latinisés» des sorciers de Poudlard attestent la permanence de cette imprégnation : Severus, Albus, Sirius, Lucius, Rubeus, Remus, Dédalus...

32. Sites: http://fr.vikidia.org/wiki/Sortil\%C3\%A8ges_de_Harry_Potter ; on peut aussi consulter l'encyclopédie des sorts, sur http://www.encyclopedie-hp.org/spells/spells.php. 
permanente ré-affirmation d'un trésor à préserver et à diffuser. Nous allons fonder essentiellement nos propos sur la traduction de Jean-François Ménard ${ }^{33}$, en précisant cependant qu'il y a, même dans la transposition des formules latines ${ }^{34}$, des différences entre la version originale et la version française...

La plupart des commentateurs saluent en Harry Potter une union réussie entre le phénomène mass-médiatique que nous connaissons, et la revendication d'un nouveau " moment élisabéthain », comme si l'auteur faisait siennes les théories qui voient dans la culture classique une science occulte, à protéger inconditionnellement. La renaissance anglaise a lié le latin, le grec et la magie blanche: Albus (le Blanc) Dumbledore serait le nouveau John Dee (d'où le « $\mathrm{D}$ » répété deux fois), savant, alchimiste et philosophe, qui voyait dans l'occultisme un bien à mettre au service de tous. Mais contrairement peutêtre à l'époque élisabéthaine, dans Harry Potter la magie est plus exhibée que cachée c'est même la première chose que l'on retient... Or ce qui est réellement occulté, en revanche, c'est le rapport au latin, au français - archi-présent à Poudlard ${ }^{35}$, que ce soit dans les noms de Gryffindor, de la famille Malefoy ou de Voldemort, mais aussi par le personnage de Fleur Delacour ou l'école de BeauxBâtons...

Dès le premier épisode, Dumbledore est montré comme ami du français Nicolas Flamel et de son épouse ${ }^{36}$ - ce que masque malencontreusement le titre français, qui anodinise la «pierre philosophale » originale en « école des sorciers » infiniment plus passe-partout. Dans un article retentissant ${ }^{37}$, le linguiste Jean-Claude Milner va jusqu'à voir dans les Moldus les Anglais "thatchéro-blairistes », et dans les Sorciers l'aristocratie libre de préjugés, unie au peuple souffrant, contre la petite bourgeoisie bornée et matérialiste que représentent les Dursley. Le latin et le grec sont alors des voies de résistance, contre un système libéral qui présente une apparence d'hédonisme, fait en réalité de multiples mini-oppressions. Wingardium leviosa $!^{38}$

Or, dans Les Dragons..., il n'y a que très peu de sorts à consonance purement latine... à part le déjà signalé effractet; faudrait-il y voir une «timidité » de l'auteur, devant une langue ancienne réputée complexe, donc potentiellement élitiste ? Faut-il - de la même façon - y lire un reflet des "connaissances et compétences » du socle commun qui n'impliquent pas le latin? Les consonances mélangent plutôt idiomes nordiques ou même slaves (straj fait son pluriel en « $\mathbf{i}$ », comme en russe et en... latin, tandis que le Néoc niévidim peut s'inspirer aussi bien du verbe vidietjs (voir) que du latin video, vidi, visum... à condition que ne hoc veuille dire " pas cela », ce qui est assez cohérent) ; on croise aussi quelques orientalismes (slimane, élusim, durim avec le pluriel en - im de l'hébreu, même si le singulier le comporte déjà !). La mélodie générale des propos réfère bien davantage aux langues de Tolkien, dont le critique Stéphane Jarno rappelle la variété et les origines indo-européennes, essentiellement finnoises d'ailleurs :

33. Lui-même a reconnu avoir «allégé » certaines descriptions ou gags dans Le prisonnier d'Azkaban... Il n'est pas le seul à avoir craint une "surcharge cognitive» des jeunes lecteurs : la version américaine du premier Harry Potter stipule « and the Sorcerer's stone », plus simple croyait-on que l'original «Philosopher's stone ».

34. La formule "exspecto patronum » a été rendue dans le version française par "spero patronum » : à l'attente, on ajoute l'espérance... "Patronus », c'est le défenseur, le protecteur (Cf.: en anglais "exspecto patronum» in Rowling, Harry Potter et le Prisonnier d'Azkaban, p. 179), tandis que la traduction française préfère: «spero patronum » (p. 197 du même volume). «Endoloris ", c'est le cri que l'on pousse en français (Rowling, Harry Potter et les Reliques de la mort, p. 673). Le nom du sort se dit en version originale «Cruciatus curse »... d'où en anglais : Crucio (par exemple, Rowling, Harry Potter et les Reliques de la mort, p. 506, quand Crabble essaie de tuer Harry). Le néologisme horcruxe garde bien son lien sémantique avec l'idée de souffrance « crucifiante » du Crucio.

35. Poudlard est une public school sur le modèle d'Eton (Hogwarts School of Witchcraft and Wizardry), donc d'un système qui voit en effet le jour sous Henri VIII puis sous Elisabeth $1^{\text {ére }}$, lorsque Cambridge et Oxford échappent à la tutelle de 1'Eglise.

36. "Je parie que c'est Flamel en personne qui a demandé à Dumbledore de la mettre en lieu sûr. Ils sont amis [...] (Rowling, Harry Potter à l'école des sorciers, p. 218).

37. Milner, « Pourquoi Harry Potter est de gauche », p. 8-9.

38. Rowling, Harry Potter et les Reliques de la mort, p. 695. 
«L'auguste philologue d'Oxford [...] forge même [...] plusieurs langues. Les plus abouties, le "quenya" et le "sidarin" comptent chacune plus de deux mille mots de vocabulaire, une vraie structure grammaticale et même une calligraphie ! ${ }^{39}$

Il en reste quelque chose chez M. H. Delval : le guttural horlor gorom est censé rappeler le mugissement des dragons, dont il garde en effet le " $\mathrm{g}$ », le « $\mathrm{r}$ », appuyés par la liquide « 1 » et la labiale « $\mathrm{m} » \ldots$ avec le fond vocalique sombre $\mathrm{du}$ « $\mathrm{o} » \operatorname{montant} \mathrm{du}$ fond $\mathrm{du}$ gosier en feu des dragons royaux. Entre l'onomatopée et le rugissement, cette formule particulièrement réussie symbolise également le lien inconscient et involontaire qui unit Cham aux dragons: il sait d'instinct crier les mots qui leur donneront énergie et direction, et n'en découvrira le sens - assez stéréotypé, d'ailleurs - qu'au terme de son initiation...

En revanche, le Brilill'iol! rappelle davantage les mots-valises et les télescopages qui occupent également une grande place dans le langage des petits sorciers : on se souvient du choixpeau magique, ou des lashlabask et autres mutinlutin malimpesti ! Swor (l'épée) est d'ailleurs un hommage direct au sword anglais (le glaive). Extrêmement composite dans ses emprunts, ses allégeances et ses effets, l'idéo-langue de Nalsara reste bien en deçà de son modèle implicite; en effet dans Harry... la mythologie, ou tout simplement les consonances, latines ou grecques se mêlent à d'autres langues, sous-langues, allusions... dont la plus brillante est l'identité du grand professeur féminin de Poudlard, « MINERVA » McGonagall!

Minerve-Athéna, la plus intellectuelle des déesses antiques, associée à un nom de clan écossais haut en couleur... donne la mesure du métissage et des courts-circuits culturels et civilisationnels dont Poudlard est le cadre bienveillant. C'est pour la défendre que Harry jettera le sort d'Endoloris, (VO : Crucio !), lorsque le Mangemort Amycus Carrow ${ }^{40}$ lui crache à la figure ; c'est assez rare pour être noté :

«Vous n'auriez pas dû faire ça. [...] Harry s'écria :

- Endoloris! Le Mangemort fut arraché au sol. Il se tortilla dans les airs [...] se débattant,

hurlant de douleur [...] et s'effondra par terre, inconscient. $»^{41}$

Très proche, par son charisme et sa bienveillance, des magiciennes de Nalsara, Minerva verra cependant mourir trois des hommes qu'elle aura le plus aimés: Remus Lupin, Severus Rogue et Albus Dumbledore. La perte et le deuil sanctionnent-ils toujours l'exception?

\section{Valar Morghulis $!^{42}$}

Apparue à l'incipit de la septologie sous la forme d'un chat ${ }^{43}$, Minerva incarne pourtant l'esprit de résistance au point d'animer l'inanimé, pendant la bataille de Poudlard : elle lance le fameux «Piertotum locomotor», qui précipite toutes les statues et les armures

39. Jarno, «Dans un trou vivait un hobbit... », p. 27.

40. Sa sœur s'appelle Alecto, comme l'une des trois Parques ; quelle famille! Ajoutons que la tribu des Black est riche en noms gréco-latins, aux accents de constellations ou de demi-dieux : Andromeda, Cygnus, Cassiopeia, Pollux, Orion, Narcissa... Vrai snobisme ou légère parodie ? Les deux, n'en doutons pas.

41. Rowling, Les Reliques de la Mort, p. 633.

42. Cette formule signifie : «tout homme doit mourir!» Elle illustre dans Game of Thrones (saison II), la difficile condition d'Aria Stark, fille d'un chef déchu, bientôt orpheline et en fuite perpétuelle... (G.R.R Martin pour la saga littéraire, Benioff et Weiss pour la série télévisée).

43. «Il s'assit sur le muret, à côté du chat. [...] C'est amusant de vous voir ici, professeur McGonagall, dit-il. Il tourna la tête pour adresser un sourire au chat tigré » (Rowling J.K., Harry Potter à l'école des sorciers, p. 14). Quand on sait que "Miss Teigne », la compagne féline d" "Argus » Rusard, se nomme en version originale «Mrs Norris », on mesure mieux encore l'attention prêtée aux références culturelles ; "Mrs Norris », c'est la commère fouineuse typique des personnages de Jane Austen; clin d'œil et coup de griffe d'un même tenant! 
dans le conflit; "Poudlard est menacé ! hurla le professeur McGonagall. Faites votre devoir envers notre école $!^{44}{ }^{»}$.

Elle est ainsi l'intime d'Albus, qui représente aux yeux de beaucoup la quintessence de l'enseignement aristotélicien; ce sous-texte grec ${ }^{45}$ est attesté également par les exergues choisis pour le dernier volume: l'un provient d'un auteur grec, Eschyle, l'autre d'un penseur chrétien, William Penn. Comme l'évoque fortement la critique Suzanne Bray ${ }^{46}$, les commentateurs William Bates et Steven Patterson insistent sur l'ancrage aristotélicien de la saga. Elle rappelle également l'apport de Andrew Goddard, pour qui la vision du monde de J.K. Rowling «est enraciné(e) dans le monde classique et met l'accent sur l'amitié, les vertus et la formation du caractère $»^{47}$.

Marie-Hélène Delval ne peut avoir tout à fait la même motivation, mais elle est aussi rejointe, dans son choix d'idiomes slavisants ou saxons par la saga de G.R.R. Martin Game of Thrones («Le trône de fer»); en plus de la réhabilitation des dragons, dont nous parlions plus haut, cette série fait exister une langue, le dothraki, qui mixe habilement le swahili et l'estonien, et comporte plus de 3400 mots (il existe d'ailleurs déjà un dictionnaire anglais-dothraki). Ce n'est pas Martin l'inventeur de l'exo-langue, mais David J. Peterson, pour les besoins de la série télévisée ; la collaboration entre l'auteur « littéraire » et son développeur " télévisuel » a bel et bien accouché d'un langage dont les amateurs se répètent déjà les plus frappantes formules : « hajas » (sois fort) ; "addrivat » (tuer); "san athchomari yeraan» (merci). Le numéro du Courrier international récemment consacré à la série affirme d'ailleurs que pour le New York Times : "Game of Thrones offre sans doute la plus grande vitrine télévisée pour une langue inventée ${ }^{48}$ "; ajoutons en guise de péroraison qu'un million de téléchargements illégaux ont " salué » la diffusion du premier épisode de la $4^{\mathrm{e}}$ saison, en une demi-journée seulement (6 avril 2014) : ispélénia !

Longtemps notre conception du fantastique a été dépendante des cadres donnés par T. Todorov, différenciant fantastique "pur » et merveilleux; aujourd'hui... on oppose plutôt deux fantastiques entre eux: le fantastique de l'hésitation au fantastique de la présence. La "peur» qui était liée aux lectures fantastiques a déserté l'ordre du surnaturel pour réintégrer les littératures mimétiques (thriller et «policier » en général), avec des figures du Mal très repérables : le serial killer, le pédophile.

Mais la dark fantasy garde le «sense of wonder »... comme dans Star Wars, le space opera ou "planetary romances » (voir le succès d'Avatar, vaste "space » militaire), qui a fait rêver le monde entier depuis trente ans ; des genres novateurs ont vu le jour dans les années 1990-2000, ainsi Alan Moore dans The Watchmen ou La ligue des gentlemen extraordinaires, le steampunk ${ }^{49}$ fantasy (ou gaslight romance), les fantasy historiques de Pierre Pevel, les uchronies... Face aux romans noirs et aux techno-thrillers, l'œuvre colossale de l'Américaine Robin Hobb (alias Megan Lindholm) est elle aussi unanimement appréciée: Cycle de l'assassin royal, cycle des Aventuriers de la mer, cycle du soldat chamane... Il en va exactement de même pour Nalsara, Potter ou bien encore Game of Thrones.

Il s'agit en fait de ré-enchanter le monde par une parole d'affect et d'énergie, de puissance et de bonté, après le triple choc de la fin des religions et des idéologies, et le

44. Rowling, Les Reliques de la mort, pp. 643-644.

45. Pour apprécier l'étendue du sous-texte grec, on lira Wenskus, «Die dunkle Seite des Fachs. Latein und andere magische Sprachen ", p. 429-442.

46. Voir l'évocation d'un Dumbledore aristotélicien dans Bray, «La septologie de Harry Potter : un monde où se rencontrent la morale traditionnelle et le politiquement correct...», p. 175-176.

47. Propos rapportés dans William Bates, "Magic, Christianity and Harry Potter", http:/ / www.christaquarian.net/papers/ bates_potter.pdf., le 7 janvier 2001, p. 1.

48. « Parlez-vous le dothraki? », p. XI.

49. Futur à vapeur: tout se passe comme si la vapeur avait continué à régner depuis la fin du XIXe siècle, qu'il n'y avait ni électricité, ni matières plastiques, ni pétrole... Avant 1979, on parle de « proto-steampunk ». 
triomphe corrélé de la révolution numérique; c'est pourquoi la philosophe Sandra Laugier souligne que :

«Cette temporalité à la fois étrange, décalée et proche de la vie donne [...] sa texture sensible, en constitue l'expérience, la nôtre, celle aussi de personnages voués à la mort [...]. Mais en attendant, il faut vivre. $»^{50}$

\begin{abstract}
Résumé
Une langue hybride qui parle suffisamment à chacun, tout en restant opaque à tous : c'est le sort des paroles magiques qui, du Seigneur des Anneaux aux Dragons de Nalsara, nervurent notre imaginaire de leur aporie. Leur prétendue " pureté » (ou « impureté ») est elle-même une fiction, ou plus exactement la métaphorisation d'un ressenti expérientiel

idéologiquement reconstruit : mais leur charme, au sens profond de «carmen », n'en agit pas moins, porté et subsumé par l'apprentissage enfantin des puissances et des impuissances du langage.

On comprend dès lors pourquoi le latin macaronique, qui était déjà l'esperanto de l'Europe médiévo-renaissante, va servir de langue véhiculaire aux univers de la fantasy, puisqu'il s'agit en fait de ré-enchanter le monde par une parole d'affect et d'énergie, de puissance et de bonté, après le triple choc de la fin des religions et des idéologies, et le triomphe corrélé de la révolution numérique.

Le klingon, la fourchelang, le dothraki ou le parlénigm : ces littératures nous disent qu'il y a sans doute encore, dans la lumière du Logos, une Pentecôte poétique pour toucher le cœur des choses : « Néoc varna slimane, karug er nos dûrim, Sorna lami, mnelek, sorok vanyl... $»^{51}$
\end{abstract}

\title{
Bibliographie
}

«Parlez-vous le dothraki ?», Game of Thrones, supplément du Courrier international $\mathrm{n}^{\circ} 1221,27$ mars 2014, p. 9.

BRAY Suzanne, «La septologie de Harry Potter : un monde où se rencontrent la morale traditionnelle et le politiquement correct... », dans CASTA Isabelle (dir.), Si d'aventure... La littérature aventureuse a-t-elle vécu ? Paris, Le Manuscrit, 2009, p. 157-180.

Delval Marie-Hélène, Les Dragons de Nalsara, vol. 2, Le plus vieux des Dragonniers, Paris, Bayard Éditions Jeunesse, 2008.

Delval Marie-Hélène, Les Dragons de Nalsara, vol. 3, Complot au palais, Paris, Bayard Éditions Jeunesse, 2008.

Delval Marie-Hélène, Les Dragons de Nalsara, vol. 4 : La nuit des Elusims, Paris, Bayard Éditions Jeunesse, 2009.

Delval Marie-Hélène, Les Dragons de Nalsara, vol. 6, La colère de la strige, Paris, Bayard Éditions Jeunesse, 2009.

50. Laugier, « Absolutisme sériephile », p. 35

51. Delval, Les Dragons de Nalsara, vol. 9, La Citadelle noire, p. 81. 
Delval Marie-Hélène, Les Dragons de Nalsara, vol. 7, Le secret des magiciennes, Paris, Bayard Éditions Jeunesse, 2009.

Delval Marie-Hélène, Les Dragons de Nalsara, vol. 8, Sortilèges sur Nalsara, Paris, Bayard Éditions Jeunesse, 2010.

Delval Marie-Hélène, Les Dragons de Nalsara, vol. 9, La Citadelle noire, Paris, Bayard Éditions Jeunesse, 2010.

Delval Marie-Hélène, Les Dragons de Nalsara, vol. 10, Aux mains des sorciers, Paris, Bayard Éditions Jeunesse, 2010.

Delval Marie-Hélène, Les Dragons de Nalsara, vol. 11, Les maléfices du marécage, Paris, Bayard Éditions Jeunesse, 2011.

Delval Marie-Hélène, Les Dragons de Nalsara, vol. 12, Dans le ventre de la montagne, Paris, Bayard Éditions Jeunesse, 2011.

Hoban Russel, Enig Marcheur, 1980, trad. De Nicolas Richard, Monsieur Toussaint Louverture éditions, 2012.

JARNO Stéphane, «Dans un trou vivait un hobbit... », Télérama n²971-2972, 20 décembre 2006.

LAUGIER Sandra, « Absolutisme sériephile », Libération, 26-27 avril 2014.

LAUNET Édouard, «Le monde selon WARD», Libération, 3 mars 2014, p. 31-33.

LEWIS Clive Stapple, Le Monde de Narnia, 1950-1956.

MiLNeR Jean-Claude, «Pourquoi Harry Potter est de gauche », Libération, 26 octobre 2007, p. 8-9.

RowLING J.K., Harry Potter à l'école des sorciers, trad. Jean-François Ménard, Gallimard Jeunesse, $1998^{52}$.

ROWLING J.K., Harry Potter et la Chambre des secrets, trad. Jean-François Ménard, Gallimard Jeunesse, 1999.

RoWLING J.K., Harry Potter et le Prisonnier d'Azkaban, trad. Jean-François Ménard, Gallimard Jeunesse, 2000.

RowLING J.K., Harry Potter et la Coupe de Feu, trad. Jean-François Ménard, Gallimard Jeunesse, 2001.

Rowling J.K., Harry Potter et l'Ordre du Phénix, trad. Jean-François Ménard, Gallimard Jeunesse, 2003.

RoWLING J.K., Harry Potter et le Prince de sang-mêlé, trad. Jean-François Ménard, Gallimard Jeunesse, 2005.

RowLING J.K., Harry Potter et les Reliques de la mort, trad. Jean-François Ménard, Gallimard Jeunesse, 2007.

RuAud A., Panorama illustré de la fantasy et du merveilleux, éd. Les moutons électriques, 2004.

52. Volumes originaux parus chez Bloomsbury Publishing, London, 1997-2007. 
STÉLANDRE Thomas, "À s'en tordre la langue », Libération, 6 décembre 2012.

STEPHENSON Neal, Le Samouraï virtuel, 1992.

TOLKIEN J. R. R., Le Seigneur des Anneaux, 1955.

TOLKIEN J. R. R., Bilbo the Hobbitt, 1937.

TRITTER Valérie (dir.), Encyclopédie du fantastique, éditions Ellipses, 2011.

VANCE Jack, Les langages de Pao, 1958.

WENSKUS Otta, «Die Serie erzieht ihre Zuschauer, Zur Intellektualisierung erfolgreicher Fehrnsehserien ", in Gegenwart und Altertum, s/d Robert Rollinger et Gundula Schwinghammer, Innsbrück, 2011, p. 167-186.

YAGUELLO Marina, Les Fous du langage : des langues imaginaires et leurs inventeurs, 1984.

YAGUELLO Marina, Les langues imaginaires: mythes, utopies, fantasmes, chimères et fictions linguistiques, 2006. 


\title{
L'homme préhistorique, Janus linguistique La représentation du langage préhistorique dans la seconde moitié $d u X X^{e}$ siècle français
}

\author{
Pascal SEMONSUT
}

Docteur en Histoire (Paris IV-Sorbonne)

\author{
Extrait de : Guylaine BRUN-TRIGAUD (dir.), Contacts, conflits et créations linguistiques, Paris, \\ Édition électronique du CTHS (Actes des congrès des sociétés historiques et scientifiques), 2015. \\ Cet article a été validé par le comité de lecture des Éditions du CTHS dans le cadre de la publication \\ des actes du $139^{\mathrm{e}}$ Congrès national des sociétés historiques et scientifiques tenu à Nîmes en 2014.
}

Pour Jean-Marie Hombert, directeur scientifique des Origines des langues et du langage, le langage, parce qu'il est «miroir de l'âme, moyen de communication avec autrui, élément de sociabilité, signe de reconnaissance et d'appartenance à une communauté », parce qu'on le dit « spécifique à notre espèce », « fascine et intrigue » ${ }^{1}$.

Cette fascination, les préhistoriens la partagent-ils ? La réponse est loin d'être univoque. En effet, si l'on peut affirmer, comme le paléoanthropologue Jean-Jacques Hublin que la question du langage «a commencé à se poser [...] dès les débuts de la paléoanthropologie, dans la seconde moitié du XIX ${ }^{\mathrm{e}}$ siècle $»^{2}$, bien rares pourtant sont les livres de préhistoire à évoquer cette question. Si Louis Figuier, auteur d'un des livres de vulgarisation sur la Préhistoire les plus connus du XIX siècle, déclare en 1870 que "l'instinct sociable de l'homme, qui le pousse à entrer en communication avec ses semblables, s'était déjà manifesté " dès $l^{\prime}$ « époque du renne " ${ }^{3}$, il ne va pas jusqu'à en déduire l'existence d'un langage préhistorique, puisqu'il ne consacre aucune ligne aux paroles de nos ancêtres, donnant l'impression de vouloir éviter le sujet. Un demi-siècle après, on retrouve la même prudence, ou le même mutisme, dans L'Humanité préhistorique de Jacques de Morgan paru en 1921. Louis-René Nougier avec sa Géographie humaine préhistorique, en 1959, et Marie-Henriette Alimen dans son Atlas de Préhistoire, en 1969, ne sont pas plus loquaces. Catherine Perlès, dans le Dictionnaire de la Préhistoire dirigé par Leroi-Gourhan, se plaint encore, à la fin des années 1980, que « le langage est le grand absent de la préhistoire $»^{4}$.

Ce regret pourtant sonne comme un programme. Et c'est ainsi qu'il semble avoir été compris car on constate, dans les deux dernières décennies du XX siècle, qu'il n'est pratiquement plus d'ouvrages de préhistoire à ne pas consacrer plusieurs lignes à cette épineuse question ${ }^{5}$. Sujet longtemps contourné par les linguistes, comme par les préhistoriens, le langage originel semble avoir retrouvé la faveur des uns et des autres dans les dernières décennies $\mathrm{du} \mathrm{XX}^{\mathrm{e}}$ siècle. Confrontées à la même question, comment l'école et la fiction réagissent-elles?

1. J.-M. Hombert, «Introduction », p. 10 et p. 11.

2. J.-J. Hublin, «La langue des premiers hommes », p. 102.

3. L. Figuier, L'Homme primitif, p. 113. C'est nous qui soulignons.

4. A. Leroi-Gourhan, Dictionnaire de la Préhistoire, p. 628.

5. P. Semonsut, Le passé du fantasme, p. 297. 


\section{Muet à l'école, bavard dans la fiction}

Pour ce qui concerne l'école, la réponse est sans ambiguïté : les programmes et les livres de classe ignorent volontairement ce sujet (voir le tableau ${ }^{\circ} 1$ ).

Tableau $\mathrm{n}^{\circ} 1$ : Le langage préhistorique dans les manuels scolaires de l'enseignement primaire et secondaire (en $\%$ ).

\begin{tabular}{|c|c|c|c|}
\hline Décennies & Enseignement primaire & Enseignement secondaire & Total \\
\hline 1940 & 0 & 0 & 0 \\
\hline 1950 & 4 & 17,6 & 9,5 \\
\hline 1960 & 0 & 13,6 & 8,1 \\
\hline 1970 & & 11,1 & 11,1 \\
\hline 1980 & 14,3 & 0 & 9,7 \\
\hline 1990 & 0 & 14,3 & 8,7 \\
\hline Total & 4,9 & 11,1 & 8,1 \\
\hline
\end{tabular}

Exemple de lecture : $4 \%$ des manuels scolaires de l'enseignement primaire que nous avons recensés pour les années 1950 évoquent le langage à l'époque de la Préhistoire.

Même si l'enseignement secondaire accorde deux fois plus de place au langage préhistorique que dans le primaire, la proportion de manuels évoquant cette question est extrêmement faible: aucun au Cours Moyen dans trois décennies sur cinq et, au total, moins d'un sur dix tous niveaux confondus. De plus, ce pourcentage ne cesse de diminuer dans les trois dernières décennies du siècle. Pourtant, c'est à cette période que linguistes et préhistoriens commencent à vaincre leurs réticences et consacrent lignes, chapitres, voire ouvrages entiers à ce sujet. La prudence scientifique s'impose aux concepteurs des programmes, comme aux auteurs des manuels, même lorsque celle-ci n'est plus de mise. Dans la transposition didactique, dans ce processus subtil qui mène du savoir savant au savoir enseigné, tant l'obéissance du second au premier que la force d'inertie de l'institution scolaire sont considérables, le préhistorique est donc, par défaut, un être muet pour les écoliers et les collégiens de la seconde moitié du $\mathrm{XX}^{\mathrm{e}}$ siècle. La désincarnation scolaire est à l'œuvre.

Il en est tout autrement de la fiction (voir le tableau $\mathrm{n}^{\circ} 2$ ).

Tableau $\mathrm{n}^{\circ} 2$ : La littérature, la bande dessinée, le cinéma et le langage préhistorique (en $\%)$.

\begin{tabular}{|c|c|c|c|}
\hline \multicolumn{2}{|c|}{ Décennies } & Avec langage & Sans langage \\
\hline 1940 & Littérature & 80 & 20 \\
\hline 1950 & Littérature & 25 & 75 \\
\hline 1960 & Littérature & 80 & 20 \\
\cline { 2 - 4 } & Bande Dessinée & 100 & 0 \\
\cline { 2 - 4 } & Cinéma & 75 & 25 \\
\cline { 2 - 4 } & Total & 88,5 & 11,5 \\
\hline \multirow{10}{*}{1970} & Littérature & 100 & 0 \\
\cline { 2 - 4 } & Bande Dessinée & 100 & 0 \\
\cline { 2 - 4 } & Cinéma & 100 & 0 \\
\cline { 2 - 4 } & Total & 100 & 0 \\
\cline { 2 - 4 } & Littérature & 100 & 0 \\
\cline { 2 - 4 } & Bande Dessinée & 100 & 0 \\
\cline { 2 - 4 } & Cinéma & 100 & 0 \\
\hline \multirow{nyyy}{*}{ Total } & Total & 100 & 4,8 \\
\cline { 2 - 4 } & Littérature & 95,2 & 33,3 \\
\cline { 2 - 4 } & Cinéma & 66,7 & 8,3 \\
\cline { 2 - 4 } & Total & 91,7 & 13,7 \\
\cline { 2 - 4 } & Littérature & 86,3 & 0 \\
\cline { 2 - 4 } & Cande Dessinée & 100 & 15,4 \\
\hline
\end{tabular}


Pour la Bande Dessinée, il s'agit de Rahan et de Tounga, les deux productions phares de cette période. Le nombre d'aventures de Rahan et Tounga n'est pas assez important dans les années 1990 pour établir des statistiques significatives.

Exemple de lecture : $80 \%$ des romans des années 1940 que nous avons recensés dotent leurs personnages d'un langage.

Muet sur les bancs de l'école, l'homme premier devient bavard à l'écran, dans les livres et dans les bulles. Si l'on considère, comme tout un chacun, que le langage fait l'Homme, alors le préhistorique ne deviendrait-il pas pleinement humain qu'après avoir franchi la frontière séparant le savoir de l'imaginaire ? Cette hypothèse peut sembler exagérée ; elle n'en est pas moins légitime tant la différence de traitement est grande entre l'enseignement et la fiction. Aucune aventure de Rahan et de Tounga n'est exempte de dialogues. Très rares sont les films dans lesquels les acteurs ne parlent pas. Même Les trois âges, un film muet réalisé par Buster Keaton en 1923, met en scène des préhistoriques dotés de la parole. À la seule exception des années 1950, il n'est pratiquement pas, non plus, de roman sans parole: la Préhistoire, qui voit la naissance de l'Homme, assiste aussi, en littérature, à celle des mots. Rien d'étonnant à cela. Comment rédiger un roman d'aventure - car le roman préhistorique appartient sans conteste à ce genre - sans dialogue? ou, pour le moins, sans supposer l'existence d'une langue? Comment prétendre s'adresser à de jeunes lecteurs sans faire parler les personnages? Comment leur permettre de s'identifier à eux ? L'affirmation de la contemporanéité du langage et de la Préhistoire est donc une constante littéraire, mais la raison en est le plus souvent implicite. Pour plusieurs romans à partir des années 1970, elle se fait explicite. Pour Cavanna :

«Tout à fait au début, l'Homme ne parlait pas. D'abord, il ne savait pas. Et puis, il n'avait pas besoin. Les relations humaines encore rudimentaires ne nécessitaient que des échanges d'idées très simples auxquels pourvoyaient aisément quelques gestes [...] Mais bientôt la vie devint plus compliquée. Les progrès foudroyants de la technique exigeaient un tel vocabulaire que parler par gestes était une fatigue et une perte de temps. ${ }^{6}$

Suivant en cela l'un des lieux communs de l'imagination conditionnée que relève Wiktor Stoczkowski ${ }^{7}$, le langage serait ainsi fils de l'outil. Il le serait tout autant du couple, couple qui accouche de la parole pour Edmond Haraucourt :

«Étant deux, ils parlèrent. Le besoin de communiquer suscita l'exercice normal d'une fonction qui était possible [...]. Le cri qui sortait de la bête, à force de se répéter identiquement, gagna un sens précis et devint un mot; quatre ou cinq de ces cris divers, et le couple avait, à son insu, inventé le langage. » ${ }^{8}$

Les étudiants cobayes du voyage temporel intérieur décrit dans Les origines de l'Homme en font l'expérience :

«Des sons aux résonances de cavernes profondes sortaient [de leur] corps [...]. Ils communiquaient entre eux d'une voix brute et rauque [...] La parole naissait [...]. La parole de l'homme, la parole de la femme, mélange de cri, de mélodie, d'amour. »"

Le couple et la technologie seraient ainsi, à lire les romanciers, les maïeuticiens du verbe : tendre et pragmatique patronage pour une activité partagée tant par les poètes que les industriels. Mais si les hommes parlent, quels mots leur fait-on prononcer?

6. Et le singe devint con, 1972, Livre de poche, 1988, p 22-23.

7. W. Stoczkowski, Anthropologie naïve, anthropologie savante, p. 106.

8. E. Haraucourt, Daâh, le premier homme, p. 59.

9. A. Germain, Les origines de l'Homme ou les aventures du professeur Coppensius, p. 66-67. 


\section{Une langue étonnamment moderne}

Le « romancier d'Histoire » est, comme l'explique Zoé Oldenbourg, « un chercheur d'une langue nouvelle au moyen d'un appauvrissement, ou d'une orientation particulière, $\mathrm{du}$ vocabulaire ${ }^{10}$. Car, et c'est la thèse défendue par Krzysztof Pomian,

«On ne fait jamais parler les personnages dans la langue qu'ils sont supposés avoir pratiquée quotidiennement, si seulement cela risque de rendre le roman incompréhensible. ${ }^{11}$

La recherche du romancier des temps premiers est beaucoup plus ardue que celle de ses collègues « d'Histoire » : il ignore tout de la langue que ses personnages sont «supposés avoir pratiquée quotidiennement». Une langue dont on ne sait même pas, encore au début du XXI $\mathrm{e}^{\mathrm{e}}$ siècle, si elle a toujours existé puisque, à en croire Jean-Jacques Hublin :

«Peu d'indices suggèrent une apparition très ancienne du langage articulé. En fait, il n'y a guère que pour les Homo sapiens récents que l'on dispose de tout un faisceau d'arguments démontrant des capacités linguistiques similaires à celles des populations actuelles. [...] Après 40000 ans BP en Europe, [...], les Homo sapiens possèdent donc un langage moderne. $\gg^{12}$

Mais, même pour eux, même pour Cro-Magnon, les mots sortis de leur bouche semblent inaccessibles à la science. Les propos de Christophe Coupé, linguiste au Laboratoire de Dynamique du Langage du CNRS, résument bien le consensus existant au sein de sa discipline en ce début du XXI ${ }^{\mathrm{e}}$ siècle :

«Il n'est pas possible d'obtenir des reconstructions [du langage] raisonnablement fiables audelà d'une limite d'environ 8000 ans dans le passé »; "il paraît donc illusoire d'imaginer retrouver la trace des premiers mots ou sons produits par les premières langues, ou de prouver l'existence d'une unique langue initiale. $»^{13}$

Le romancier de la Préhistoire se trouve donc d'emblée placé face à un obstacle méthodologique autant que poétique : quelle langue donner à ses personnages alors qu'il ignore tout d'elle, et qu'il l'ignorera vraisemblablement toujours? Comme le relève Roberta de Félici :

«On dirait qu'il est tout à fait libre de créer n'importe quel genre de langage pour ses personnages. En revanche, l'exigence de la vraisemblance devient ici encore plus contraignante. En effet, on risque soit d'atteindre facilement au ridicule ou à l'anachronisme si l'on opte pour un langage trop élaboré ou très cultivé, soit de devenir inintelligible si l'on opte pour un langage trop différent de celui du lecteur. » ${ }^{14}$

Comment naviguent les auteurs de fiction entre ces deux écueils que sont l'anachronisme et l'inintelligibilité?

La réponse des auteurs de romans et de bande dessinée est simple : leurs personnages s'expriment comme leurs lecteurs. Peu de romanciers s'expriment sur ce choix, mais, lorsqu'ils le font, ils expliquent toujours qu'il faut voir dans la langue utilisée une traduction de l'originale. Dans une note en bas de page de La horde de Gor, paru en 1967, et dont la présence illustre bien la gêne du romancier, Jean-Claude Froelich explique qu'il «transcri[t] en français courant le langage rudimentaire, concret et imagé de Gor ${ }^{15}$. En

10. Z. Oldenbourg, « Le roman et l'histoire », p. 140.

11. K. Pomian, « Histoire et fiction », p. 116.

12. J.-J. Hublin, « La langue des premiers hommes », p 116-117.

13. C. Coupé, «L'impossible quête de la langue mère », p. 174 et p. 186

14. R. de Félici, «Émotions et langages dans le roman préhistorique de J.-H. Rosny Aîné », p. 253.

15. J.-C. Froelich, La horde de Gor, p. 72. C'est nous qui soulignons. 
1977, Louis Mirman reconnaît, en incipit au Silex noir, qu' « il y a douze mille ans [...] les gens parlaient», qu' «ils avaient un mot clair pour désigner chaque objet, des phrases pour communiquer [...]. Bref, une langue... que personne ne connaît». Dans ces conditions, "l'histoire de Finn et de Lia [les héros du livre], de leurs amis et de leurs ennemis, en est, en quelque sorte, traduite. Aussi fidèlement que possible ${ }^{16}$. Enfin, dans son avant-propos à La déesse mère, sorti en librairie en 1997, Cavanna estime qu'il n'a "pas cru devoir faire s'exprimer [ses] "primitifs" par des grognements plus ou moins articulés ou en un "petit-nègre" pittoresque ». Ainsi, ses "personnages parlent donc comme vous et moi : c'est une traduction fidèle $!{ }^{17}$. Pourquoi cette traduction?

Pour Roy Lewis, dans Pourquoi j'ai mangé mon père, la réponse est simple : il s'agit de faire rire. C'est Théodore Monod qui fait découvrir ce roman anglais à son ami Vercors, à la fin des années 1980. D'après le témoignage de l'auteur des Animaux dénaturés, le célèbre biologiste "voulant [lui] en citer des passages, ne put y parvenir tant il s'étranglait de rire ${ }^{18}$. Il est vrai que le langage utilisé par Lewis est si proche du nôtre que, face à l'anachronisme qui en résulte, tout lecteur ne peut faire autrement que s'étrangler de rire. Tout comme s'étrangla, mais pas de rire, le mari de tante Barbe :

«Tante Aglaé avait perdu son mâle du fait d'un lion, tante Amélie d'un rhinocéros velu et tante Barbe d'un boa constrictor. "Il a voulu l'avaler à tout prix, pleurnichait-elle. "Ça va te faire du mal", je lui disais; mais est-ce qu'il m'écoutait? Pensez-vous: "C'est comme manger des orvets", qu'il disait. Et moi : “Au moins coupe-le en morceaux! Mais non, il suffisait que je lui dise une chose pour qu'il fasse le contraire. "Et lui, qu'il disait, est-ce qu'il découpe les choses qu'il mange? Alors pourquoi pas moi, qu'il disait, ce qu'il fait je peux bien le faire aussi". Malheur, bien sûr qu'il n'a pas pu ! Même pas la moitié. Mais quand cette tête de mule a dû convenir que j'avais raison comme d'habitude, hélas, c'était trop tard. Que cela te serve de leçon, mon garçon! concluait-elle, car elle racontait toujours cette histoire à un enfant en train de s'étrangler par paresse de mâcher avant d'avaler. ${ }^{19}$

Il n'empêche : malgré le succès de son livre, Roy Lewis constitue un cas très à part en littérature et il faut chercher hors du territoire du rire les raisons à l'utilisation d'un langage proche du nôtre. On peut en citer deux. La première se veut pragmatique. Cela facilite la tâche de l'écrivain et du lecteur : plus simple à écrire, le roman est plus simple à lire. La seconde raison tient du symbole, du principe : l'homme préhistorique s'exprime comme son lecteur, car entre eux point de différence. Ce Cro-Magnon de papier parle comme nous, car il est nous. Abolissant le temps, réunifiant notre espèce, le langage sert alors de trait d'union entre le passé et le présent. Plus qu'un parti pris stylistique, placer des mots contemporains dans la bouche des préhistoriques est la manifestation d'une philosophie, celle qui enseigne qu'au-delà des différences, et cela depuis ses premiers balbutiements, l'humanité est une.

Mais à toute règle il faut des exceptions. La plus courante est à chercher dans les salles obscures. À toutes les décennies, à l'exception de la dernière du siècle, le cinéma recourt à un langage différent du nôtre. Il est vrai que l'image lui facilite grandement la tâche : le geste, l'attitude, la mimique suppléant le mot, le spectateur peut comprendre en voyant, ce qui, bien évidemment, est impossible pour le lecteur. Ce sont deux réalisateurs, JeanJacques Annaud avec La guerre du feu en 1981 et Jacques Malaterre dans Ao le dernier Néandertal sorti en 2010, qui, à l'écran, poussent l'expérience le plus loin. Annaud demande à Anthony Burgess «d'inventer quelques mots qui se passent de sous-titres parce que les gestes sont suffisamment éloquents ${ }^{20}$. Pourquoi inventer une langue? Parce que c'est, selon le réalisateur, le seul moyen pour rendre le film crédible :

«On ne peut pas faire parler les acteurs avec un langage contemporain car, d'une part, on appuie alors sur le dialogue qui, encore aujourd'hui dans nos campagnes, est un mode

16. L. Mirman, Le silex noir, p. 4. C'est nous qui soulignons.

17. Cavanna, La déesse mère, p. 11. C'est nous qui soulignons.

18. R. Lewis, Pourquoi j'ai mangé mon père, p. 9.

19. Ibid, p. 35

20. Le Figaro, 7 décembre 1981. 
d'expression minoritaire et, d'autre part, cela donne toutes les facilités au détriment du comportement, ce qui a le défaut majeur de véhiculer des pensées toutes contemporaines. En minorant le dialogue et donc en donnant la primauté au comportement et à l'action, on fait un film plus crédible que si l'on passait par l'usage de la langue. $»^{21}$

Dans le lexique donné aux acteurs du film, Annaud affirme que :

«The audience is not going to understand right away the whole dialogue : it is not what we are looking for, and it would not be appropriate for a film which must be understood through the images. $»^{22}$

Pour Annaud, le geste l'emporte sur le mot. Le préhistorique est davantage un être agissant que pensant : tel est le postulat de son film, discutable et discuté dès sa sortie.

Trente ans plus tard, ce ne sont pas du tout les mêmes raisons qui poussent Malaterre à doter ses préhistoriques d'un véritable langage. À la question « pourquoi avoir inventé un langage précis », le réalisateur répond :

«Parce qu'aujourd'hui, tout le monde s'accorde à dire que nos ancêtres parlaient. J'ai écrit des dialogues en français adaptés au contexte préhistorique, avec des pensées simples et uniques. Je me suis inspiré du langage nomade, notamment mongol, qui, réduit au strict minimum, est un langage utile. [...] Faire des dialogues en français permet aux acteurs de donner du sens aux scènes qu'ils vont devoir dire. Je voulais également qu'ils aient un véritable lexique pour qu'ils puissent improviser. Le langage libère le corps. Si on n'a pas de mot, on commence à faire du mime, ce que je ne voulais pas. Le mot permet d'accéder à l'émotion. Pour créer ce "langage préhistorique", nous [Pierre Pelot et Malaterre] nous sommes appuyés sur les similitudes existant entre les différentes langues actuelles (maman se dit ainsi presque de la même façon dans le monde entier) et les correspondances ethniques. [...] Les mots que nous prêtons ainsi à nos personnages ont été inventés, mais avec une imagination rigoureuse au service de l'émotion, de la dramaturgie. $»^{23}$

Le langage est, ici, une sorte d'hommage aux Néandertaliens. Le mot l'emporte sur le geste. L'Homme des temps premiers est un être pensant à part entière. On le voit, la philosophie des deux films est radicalement contraire. À la différence d'Annaud pour qui le langage choisi est une façon de montrer ce qui nous éloigne des préhistoriques, un outil pour en faire des êtres très proches de l'animal, Malaterre leur donne la parole afin de nous convaincre du contraire, c'est-à-dire de leur proximité. Impression renforcée par le fait que, pour constituer ce lexique, le réalisateur et le romancier Pierre Pelot vont aller chercher dans les langues actuelles et «ethniques » (celles des peuples que l'on qualifiait il n'y a pas si longtemps de «primitifs»). Même la voix off, utilisée de façon systématique, a le même objectif :

«J'ai écrit et tourné le film en me disant qu'il y aurait une voix off, [...]. Le spectateur comprend le film sans elle, mais sans elle peut-être ne peut-il aller aussi loin dans l'intimité du personnage, dans la compréhension de l'histoire. Elle est là pour lui tenir la main. Avec la voix off, je voulais également qu'il comprenne que Néandertal avait une pensée élaborée, des sentiments, des émotions, une philosophie. $»^{24}$

Chez Annaud le mot animalise et sépare, chez Malaterre il humanise et réunit. En littérature, les romanciers inventant une langue sont très rares. On peut même affirmer, sans crainte d'exagérer, qu'il n'en existe qu'un. Certes, dans les années 1960, Jean-Claude Froelich s'aventure sur cette voie, mais timidement, se contentant, sur un ton très didactique, de présenter quelques mots prétendument préhistoriques :

21. Notre entretien d'avril 1998.

22. Quest for fire (working title). English-Ulam vocabulary. «Le public n'a pas à comprendre tout de suite tout le dialogue: ce n'est pas ce que nous recherchons et cela ne serait pas approprié pour un film qui doit être compris par les images $»$ (notre traduction).

23. Notre entretien de novembre et décembre 2010.

24. Ibid. 
«Briant profita des bonnes dispositions du chef de famille pour apprendre quelques mots tels que emaste, femme ; emaste tipi, petite fille ; aoura, enfant ; askor, hache ; rala, grattoir ; ralana, racloir ; etc. $\gg^{25}$

Cependant, dans le cours de l'aventure, les personnages finissent par parler une langue en tous points semblable à la nôtre. Le seul romancier à avoir inventé de toutes pièces une langue est Pierre Pelot pour sa série Sous le vent du monde publiée en cinq tomes dans la seconde moitié des années 1990 et au début du XXI ${ }^{\mathrm{e}}$ siècle :

«Oorh interrompit le geste. Désignant Aaknah de sa main tendue et ouverte paume vers le ciel, il dit :

- Aaknah vâ ata'ata iwah. Aaknah ouô'iwa-biak'ata'ata iwah.

[...] La gorge de Aaknah, au fond de sa bouche, se serrait comme sous la douleur d'un coup porté. Un tremblement picotant montait dans sa peau, chauffait tous ses cheveux. D'une voix rauque, déchirée, il dit qu'il n'avait pas attrapé ata'ata iwah, qu'il ne l'avait pas tué. ${ }^{26}$

Cette langue est si différente que, pour la comprendre, il faut consulter le glossaire placé en fin de volume. Entre la recherche de l'exotisme et la facilité de compréhension, Pelot a fait son choix, appliquant à la lettre ces mots d'Antonin Artaud :

« Tout vrai langage est incompréhensible. »

Froelich, Annaud et Malaterre partagent cet avis (voir le tableau n ${ }^{\circ}$ ).

Tableau $n^{\circ} 3$ : Quelques exemples de noms communs préhistoriques dans la littérature et au cinéma.

\begin{tabular}{|c|c|c|c|c|c|}
\hline Noms & $\begin{array}{l}\text { J.-C. Froelich, Voyage } \\
\text { au pays de la pierre } \\
\text { ancienne, } 1962, \\
\text { Magnard jeunesse, } \\
1996\end{array}$ & $\begin{array}{l}\text { J.-C. Froelich, } \\
\text { La horde de } \\
\text { Gor, 1967, } \\
\text { Magnard } \\
\text { jeunesse, } 1996\end{array}$ & $\begin{array}{l}\text { J.-J. Annaud, } \\
\text { La guerre du } \\
\text { feu, 1981 } \\
\text { Lexique } \\
\text { d'Anthony } \\
\text { Burgess }\end{array}$ & $\begin{array}{l}\text { P. Pelot, Avant } \\
\text { la fin du ciel, } \\
\text { Denoël, } 2000\end{array}$ & $\begin{array}{l}\text { J. Malaterre, } \\
\text { Homo sapiens, } \\
2004 \\
\text { Lexique de } \\
\text { Pierre Pelot }\end{array}$ \\
\hline Cerf & Lama & & & Edroü & Uog-moraghi \\
\hline Eau & Our & Nyoum & Wodh & Nik & $\begin{array}{l}\text { Iroah } \\
\text { Nakitr'a }\end{array}$ \\
\hline Enfant & Aoura & & & $\begin{array}{l}\text { U'urehwêh } \\
\text { U'urehwêtoh }\end{array}$ & $\begin{array}{l}\text { H'nan } \\
\text { Nîn } \\
\text { Oo-ough-te }\end{array}$ \\
\hline Feu & Ard & Fii & $\begin{array}{l}\text { Na-kahm } \\
\text { Pa-i-rrhe }\end{array}$ & Ohr & $\begin{array}{l}\text { O'hadoour } \\
\text { O'hr } \\
\text { Oourh } \\
\text { Rran-o'h }\end{array}$ \\
\hline Femme & Emaste & & Gin & Urehwêtoh & $\begin{array}{l}\text { Doaban } \\
\text { X'loh }\end{array}$ \\
\hline Fort & & Makou & Mag & Ot'ênik & Nar \\
\hline Homme & Kisonak & & Ulam & Urehwêtwêh & $\begin{array}{l}\text { Doahan } \\
\text { N'loh } \\
\text { Xuah }\end{array}$ \\
\hline
\end{tabular}

Bien évidemment, la langue choisie diffère selon les auteurs : les mots du Voyage au pays de la pierre ancienne n'ont rien en commun avec ceux d'Homo sapiens, et le Naoh de JeanJacques Annaud s'exprime dans des termes radicalement différents de ceux de Gor. Plus encore, si la langue préhistorique varie selon les auteurs, elle change également chez un même auteur : pour des mots identiques, Froelich et Pelot proposent ainsi, à quelques années d'écart, des traductions fort différentes.

25. J.-C. Froelich, Voyage au pays de la pierre ancienne, p. 78.

26. P. Pelot, Le nom perdu du soleil, p. 104-105. 
Mais, au-delà de ces différences, il est un point commun à toutes ces œuvres. Avec de tels vocabulaires, le lecteur et le spectateur se retrouvent en terre inconnue. Le dépaysement est total : rien ne rattache ce qu'ils lisent, ni ce qu'ils écoutent, à ce qu'ils disent. On chercherait en vain des similitudes entre le français contemporain et les mots de ces préhistoriques. Sans vouloir tirer de conclusions trop générales d'un corpus aussi mince, il semblerait même que le dépaysement croisse avec les décennies. Pour étranger qu'il soit, le langage que Froelich donne à ses personnages est néanmoins d'une prononciation plus simple que celui d'Annaud et, surtout, de Pelot. Pour ce dernier, on ne peut qu'être frappé par la complexité de la traduction de mots pourtant aussi simples que ceux cités en exemple: l'utilisation très répandue de l'apostrophe, du $\mathrm{h}$ muet ou aspiré et de l'accent circonflexe, la multiplication des consonnes, la répétition des voyelles rendent leur prononciation et donc leur compréhension extrêmement difficiles.

Annaud donne même pour consigne à ses acteurs :

«All the words must be said with DIFFICULTY, AWKWARNESS, and very SLOWLY. ${ }^{27}$

Les mots doivent sortir difficilement de la bouche des préhistoriques pour entrer difficilement dans l'oreille des spectateurs et lecteurs. Pourquoi cette recherche de la difficulté ? Pourquoi demander tant aux uns et aux autres? Jean-Jacques Annaud apporte lui-même la réponse :

"This is very important for the direction of the film and must be kept in mind while reading the script : this indicates the effort of man to escape animality. $»^{28}$

Les mots viennent difficilement parce que la Préhistoire accouche de l'humanité difficilement. L'hominisation est un effort de l'Homme sur lui-même. Comment le représenter mieux qu'en contraignant lecteurs et spectateurs, en leur compliquant la tâche? Ils doivent faire l'effort de comprendre afin de se faire une idée des difficultés que l'homme préhistorique dut surmonter.

Le préhistorique parle donc, soit, mais dans une ou plusieurs langues? Aucun scientifique ne peut le dire, cependant l'histoire biblique de la tour de Babel est dans toutes les mémoires, y compris dans celle, semble-t-il, des auteurs de fiction. Avant le châtiment divin sur les hommes de Babel, il n'existe qu'une seule langue, celle d'Adam. Puis, c'est parce qu'ils commettent le péché d'orgueil que Dieu jette la discorde entre eux : désormais, ils ne pourront plus se comprendre. À la langue originelle, pure, sacrée, succèdent des langues marquées du sceau de la faute. Il est frappant de constater que tout au long de la seconde moitié $d u X X^{e}$ siècle, les auteurs de fiction situent la très grande majorité de leurs aventures avant cet épisode dramatique. La main de Dieu ne s'abattra donc pas sur les préhistoriques de papier. Leur langue est unique. Pourquoi ? Est-ce pour montrer qu'en ces temps, rien ne sépare les hommes, que la concorde règne ? Non, car on constate, par ailleurs, que c'est l'agressivité qui dicte les rapports des préhistoriques de fiction. Dans les romans, comme dans les films, posséder un langage unique ne protège en rien contre la guerre. Ne donner qu'une seule langue à leurs personnages, ne serait-ce pas la solution de facilité pour les auteurs qui, de cette façon, ne seraient pas contraints de déployer des trésors d'imagination afin de concevoir différents vocabulaires, grammaires, etc. ? Ne serait-ce pas également un gage de lisibilité plus aisée pour lecteurs et spectateurs? Vraisemblablement. Un langage unique leur permettrait ainsi de suivre plus facilement les aventures qui leur sont contées, tout simplement. Il existe une troisième hypothèse, plus philosophique. S'il n'existe qu'une seule langue, c'est parce qu'il n'existe qu'un seul homme. Si les préhistoriques ne parlent que d'une seule voix,

27. Quest for fire (working title). English-Ulam vocabulary. «tous les mots doivent être dits avec DIFFICULTÉ, $M A L A D R E S S E$, et très LENTEMENT». En majuscules dans le texte. (notre traduction).

28. Ibid. " cela est très important pour la réalisation du film et doit être présent à l'esprit pendant la lecture du script : cela montre l'effort de l'homme pour sortir de l'animalité ». (notre traduction). 
n'est-ce pas parce qu'ils ne forment qu'une seule et même humanité ? Certes une humanité percluse de violence, mais une humanité embarquée sur un même navire, destinée à un même sort. Le but de la Préhistoire de fiction serait ainsi de faire la démonstration de ce qui fait l'unité de l'espèce, au-delà des inévitables contingences.

La question de la langue de ces Cro-Magnon de fantaisie n'est pas qu'un simple problème de création artistique. Elle est lourde de sens. Elle véhicule une image très nette de nos ancêtres, une conception très précise du printemps de l'humanité: celle d'un temps de germination. Nous sommes ce que nous fûmes. Nous étions déjà ce nous sommes.

\section{Des noms barbares}

Quel que soit le romancier, et plus largement l'auteur de fiction, le choix du nom pour un personnage n'est jamais anodin. Il est « une des armes narratives de l'écrivain », d'après Jean-Louis Vaxelaire, et Philippe Hamon souligne :

«Le souci quasi maniaque de la plupart des romanciers pour choisir le nom ou le prénom de leurs personnages. $»^{29}$

Alors que rien ne prouve, ni même ne laisse supposer, que les hommes préhistoriques avaient des noms, les auteurs de Préhistoire n'échappent pas à ce qui semble être la règle. Reste à savoir quel est leur choix. La complexité et la modernité du langage préhistorique se retrouvent-elles dans l'onomastique? Oui et non.

Qu'il s'agisse de la littérature, de la bande dessinée ou du cinéma, les noms des personnages, comme ceux des tribus, ne ressemblent en rien aux noms propres en usage dans la seconde moitié du XX $x^{\mathrm{e}}$ siècle (voir le tableau $\mathrm{n}^{\circ} 4$ ).

Tableau $\mathrm{n}^{\circ} 4$ : Quelques exemples de noms de personnages et de tribus préhistoriques dans la littérature, la bande dessinée et au cinéma.

\begin{tabular}{|c|c|c|c|c|c|c|c|c|c|}
\hline \multirow[t]{2}{*}{ Décennies } & \multicolumn{3}{|c|}{ Littérature } & \multicolumn{3}{|c|}{ Bande dessinée } & \multicolumn{3}{|c|}{ Cinéma } \\
\hline & Hommes & Femmes & Tribus & Hommes & Femmes & Tribus & Hommes & Femmes & Tribus \\
\hline 1940 & Naoh, Yug & Djêha, Ouchr & $\begin{array}{l}\text { Kzamm, } \\
\text { Oulhamr }\end{array}$ & & & & & & \\
\hline 1950 & Akroûn, Urm & Amhao, Glâva & Gwah, Tzoh & & & & & & \\
\hline 1960 & Deïwo, Magh & Muta, Tibirane & $\begin{array}{l}\text { Guerse, } \\
\text { Kisonak }\end{array}$ & $\begin{array}{l}\text { Rahan, } \\
\text { Tounga }\end{array}$ & Maraha & $\begin{array}{l}\text { Swurg, } \\
\text { Oak-ro }\end{array}$ & $\begin{array}{l}\text { Ahot, } \\
\text { Sakana }\end{array}$ & $\begin{array}{l}\text { Khaku, } \\
\text { Loana }\end{array}$ & Rock \\
\hline 1970 & Finn, Rob-Sen & Eï-Mor, Grite & $\begin{array}{l}\text { Ariès, Ou- } \\
\text { loâ }\end{array}$ & $\begin{array}{l}\text { Granook, } \\
\text { Nyoko }\end{array}$ & $\begin{array}{l}\text { Ohama, } \\
\text { Inoo }\end{array}$ & $\begin{array}{l}\text { Tholk, } \\
\text { Uru }\end{array}$ & $\begin{array}{l}\text { Bolum, } \\
\text { Sabbala }\end{array}$ & Ajor & $\begin{array}{l}\text { Bolou, } \\
\text { Galou }\end{array}$ \\
\hline 1980 & $\begin{array}{l}\text { Broud, } \\
\text { Jondalar }\end{array}$ & Ayal, Shram & Hudi, Siour & $\begin{array}{l}\text { Maok, } \\
\text { Freuk }\end{array}$ & $\begin{array}{l}\text { Houkaï, } \\
\text { Ulcha }\end{array}$ & $\begin{array}{l}\text { Orka, } \\
\text { Wronk }\end{array}$ & $\begin{array}{l}\text { Faum, } \\
\text { Norg }\end{array}$ & Ebra, Uka & $\begin{array}{l}\text { Ivaka, } \\
\text { Ulam }\end{array}$ \\
\hline 1990 & $\begin{array}{l}\text { Ika, Ué-ll'ô- } \\
\text { veh }\end{array}$ & Iawaho, Outu & Boah, Xuah & & & & & & \\
\hline 2000 & $\begin{array}{l}\text { Abar, Aô, } \\
\text { Marah, Tûd }\end{array}$ & $\begin{array}{l}\text { Âki-naâ, } \\
\text { Aweïda, Chaân, } \\
\text { Gia }\end{array}$ & * & $\begin{array}{l}\text { Faudraug } \\
\text { Kozamh } \\
\text { Laghou } \\
\text { Thuriaq }\end{array}$ & $\begin{array}{l}\text { Mana } \\
\text { Vo' } \\
\text { Hounâ }\end{array}$ & * & $\begin{array}{l}\text { Ao } \\
\text { D'leth }\end{array}$ & $\begin{array}{l}\text { Aki } \\
\text { Evolet }\end{array}$ & \\
\hline
\end{tabular}

* les noms de tribus empruntent au vocabulaire courant

Afin de ne pas encombrer au-delà du raisonnable notre tableau, nous n'indiquons pas les références des œuvres dans lesquelles nous avons puisé ces exemples.

Ce qui est la norme en matière de vocabulaire devient l'exception lorsque les auteurs abordent l'anthroponymie: si la langue qu'utilisent les préhistoriques de fiction est

29. Respectivement : J.-L. Vaxelaire, Les noms propres. Une analyse lexicologique et historique, p. 667. P. Hamon, "Pour un statut sémiologique du personnage », p. 147. 
familière aux lecteurs et spectateurs, leurs noms doivent délibérément leur paraître étranges. Rien ne les raccroche à quelque chose de connu. Ainsi, romanciers et cinéastes organisent la coexistence, des années 1940 à nos jours, de deux effets contraires : par la langue utilisée, ils permettent l'identification avec les personnages; avec les noms propres, ils la rendent difficile, voire impossible. Comment un Français de la seconde moitié $\mathrm{du} X \mathrm{XX}^{\mathrm{e}}$ siècle pourrait-il en effet s'identifier avec un individu se nommant Ouchr, Tholk ou Iawaho ? Le nom commun se veut un trait d'union alors que le nom propre fait barrage. Cette dichotomie linguistique est tout à fait révélatrice du socle sur lequel est construite la représentation de la Préhistoire. L'homme préhistorique est notre semblable, il parle donc comme nous. Il est différent, il ne répond pas au même état civil. Il est pareil et autre à la fois.

Autre paradoxe : si les noms propres frappent par leur étrangeté, ils surprennent par la simplicité de leur structure. Étrange, dans cette Préhistoire fantasmatique, ne signifie pas complexe. Sur l'ensemble de notre période, pour les personnages masculins et féminins, comme pour les tribus, la majorité des patronymes sont composés de deux syllabes uniquement, et cela dans tous les médias, à l'exception des femmes dans Rahan et Tounga. Si l'alchimie aboutissant au baptême des préhistoriques de papier demeure mystérieuse, il est un fait très clair : au moment de donner un nom à son personnage, dans les années d'après-guerre comme à la fin du millénaire, c'est la recherche de la simplicité qui conduit l'auteur. Pourquoi ? Le doterait-il d'un nom simple pensant, à tort ou à raison, que son auditoire le considère comme un être simple ? Pour ne pas le dérouter, pour ne pas le décevoir, il lui apporterait ce qu'il attend. La simplicité attribuée à la pensée en ces temps premiers aurait-elle pour corollaire la simplicité des noms? Il est troublant de constater qu'il en est de même pour les préhistoriens eux-mêmes. Si, dans le cadre du laboratoire ou de la monographie scientifique, il n'est question que de fossiles nommés Afar Locality 288, Homme du Similaum ou Sahelanthropus tchadensis, ces mêmes fossiles deviennent Lucy, Otzi ou Toumaï quand il s'agit de les présenter au public. Le passage du nom savant au nom vulgaire se fait au prix d'un indéniable appauvrissement, appauvrissement jugé indispensable pour la lisibilité de l'information. La simplicité des noms préhistoriques de fantaisie, surtout féminins, est d'autant plus frappante quand on les compare aux prénoms les plus usités en France. Si un peu plus de $52 \%$ et $48 \%$ des patronymes de fiction, respectivement masculins et féminins, ne possèdent que deux syllabes, ces pourcentages changent nettement quand ils concernent les Français de la seconde moitié du XX ${ }^{\mathrm{e}}$ siècle. Un rapide recensement des vingt prénoms les plus donnés depuis $1940^{30}$ montre qu'à $65 \%$ pour les hommes et $25 \%$ pour les femmes, ils sont composés de deux syllabes. Il semblerait donc que les hommes préhistoriques sortent de l'imagination des auteurs avec des noms plus compliqués que ceux des lecteurs et spectateurs. En revanche, la situation s'inverserait quand elle s'applique aux femmes, les personnages féminins portant des noms beaucoup plus simples que les Françaises. Même dans cette onomastique de fantaisie le machisme ferait sa loi.

Sans vouloir trop solliciter nos sources, ni couper les cheveux en quatre, ce machisme semble bien être en œuvre jusque dans les initiales choisies. Est-ce un hasard si l'on observe que sur les quinze initiales dominantes de prénoms masculins, neuf se trouvent dans le premier tiers de l'alphabet, dont le A présent dans quatre décennies ? Est-ce encore le hasard qui veut que, pour le même tiers, on ne trouve que trois initiales féminines sur les dix initiales dominantes ? Si cette constatation était isolée, si elle ne répondait à aucune autre observation, alors on se garderait de toute conclusion, ne pouvant faire la part entre le hasard et l'acte délibéré. Mais ce qu'elle met en valeur se rajoute à bien d'autres remarques du même genre. La représentation du langage à la Préhistoire apporte la démonstration de la soumission de la femme à l'homme. À l'homme préhistorique le début du classement, à la femme préhistorique la fin : même par son nom, le mâle précède encore une fois sa compagne.

30. Voir http: / www.linternaute.com/femmes / prenoms/1940-2004/index.shtml 
Enfin, dernière distinction entre Monsieur et Madame Cro-Magnon : la sonorité du nom (voir le tableau ${ }^{\circ} 5$ ).

Tableau $n^{\circ} 5$ : La sonorité dominante dans les noms des personnages préhistoriques dans la littérature, la bande dessinée et au cinéma.

\begin{tabular}{|c|c|c|c|c|c|}
\hline \multirow{2}{*}{\multicolumn{2}{|c|}{ Décennies }} & \multicolumn{2}{|c|}{ Personnages masculins } & \multicolumn{2}{|c|}{ Personnages féminins } \\
\hline & & \multirow{2}{*}{$\begin{array}{c}\text { Sonorité } \\
-\end{array}$} & \multirow[t]{2}{*}{$\%$} & \multirow{2}{*}{$\begin{array}{c}\text { Sonorité } \\
\text { Consonne }\end{array}$} & \multirow{2}{*}{$\begin{array}{l}\% \\
75\end{array}$} \\
\hline 1940 & Littérature & & & & \\
\hline 1950 & Littérature & Consonne & 57,2 & - & \\
\hline \multirow[t]{4}{*}{1960} & Littérature & Consonne & 60,6 & Voyelle & 52,9 \\
\hline & $\begin{array}{l}\text { Bande } \\
\text { Dessinée }\end{array}$ & Consonne & 81,2 & - & \\
\hline & Cinéma & Voyelle & 60 & Voyelle & 60 \\
\hline & Total & Consonne & 62,5 & Voyelle & 55,6 \\
\hline \multirow[t]{4}{*}{1970} & Littérature & Consonne & 58,7 & Voyelle & 85,7 \\
\hline & $\begin{array}{l}\text { Bande } \\
\text { Dessinée }\end{array}$ & Consonne & 69,5 & Voyelle & 100 \\
\hline & Cinéma & Consonne & 100 & Voyelle & 100 \\
\hline & Total & Consonne & 73,3 & Voyelle & 94,7 \\
\hline \multirow[t]{4}{*}{1980} & Littérature & Voyelle & 52,4 & Voyelle & 70 \\
\hline & $\begin{array}{l}\text { Bande } \\
\text { Dessinée }\end{array}$ & Consonne & 83,3 & Voyelle & 75 \\
\hline & Cinéma & Consonne & 62,8 & Voyelle & 100 \\
\hline & Total & Consonne & 65,9 & Voyelle & 84,8 \\
\hline \multirow[t]{3}{*}{1990} & Littérature & Voyelle & 55 & Voyelle & 62,5 \\
\hline & Cinéma & - & & Consonne & 66,7 \\
\hline & Total & Voyelle & 54,8 & Voyelle & 60,7 \\
\hline \multirow[t]{4}{*}{ Total } & Littérature & Consonne & 52,5 & Voyelle & 61,4 \\
\hline & $\begin{array}{l}\text { Bande } \\
\text { Dessinée }\end{array}$ & Consonne & 74,2 & Voyelle & 89,5 \\
\hline & Cinéma & Consonne & 61,3 & Voyelle & 85,2 \\
\hline & Total & Consonne & 61,5 & Voyelle & 69,1 \\
\hline
\end{tabular}

Le nombre d'aventures de Rahan et de Tounga n'est pas assez important dans les années 1990 pour établir des statistiques significatives.

Exemple de lecture : dans les romans des années 1950 que nous avons recensés, une majorité de noms de personnages masculins $(57,2 \%)$ comptent plus de consonnes que de voyelles. Le tiret signifie que les deux sonorités sont à égalité

Des années 1940 à nos jours, avec une assez remarquable constance, le sexe du personnage est très clairement indiqué par la sonorité de son nom. Cette règle ne souffre guère de dérogations. Le patronyme est déjà une description. Il ne peut, il ne doit, exister aucune ambiguité. Incontestablement, la consonne est masculine, à la seule exception des années 1990, et la voyelle féminine. Les romanciers, comme les auteurs de Bande Dessinée et les cinéastes, choisissent tel prénom plutôt qu'un autre pour le héros ou l'héroïne, car ils ont en tête, qu'ils le veuillent ou non, qu'ils en soient conscients ou pas, des stéréotypes immémoriaux sur l'homme et la femme. L'homme est le chasseur, le guerrier, celui qui nourrit et protège ; il lui faut donc un nom à la hauteur de sa tâche. La consonne, dure, agressive, ferait ainsi viril. À l'inverse, la femme est la mère, l'épouse, celle qui élève, nourrit et aime ; son nom doit avoir toute la douceur qui sied à une si tendre tâche. La voyelle, plus ronde en bouche, plus douce à l'oreille, serait la marque du beau sexe. Bel exemple d'imagination conditionnée, le choix de la sonorité véhicule donc un message sexiste, octroyant à chaque moitié de l'humanité un rôle, une posture particuliers. Mais, il n'y a là rien de préhistorique, même en fiction. Encore une fois, la représentation de la Préhistoire ne fait que reprendre à son compte de vieux préjugés ancrés dans les imaginations. 


\section{Janus biologique, Janus linguistique}

Postuler l'existence d'un langage à la Préhistoire est scientifiquement fondé. La représentation de la Préhistoire ne peut donc être taxée d'anachronisme. Mais, savoir quel est ce langage est inaccessible à la science, peut-être même pour toujours. Cela n'empêche pas la fiction préhistorique, ignorant cet obstacle épistémologique, de doter ses personnages non seulement d'une langue, mais également de noms. Nonobstant la jeunesse de son espèce, le préhistorique parle, il ne babille pas. La fantaisie comble ainsi les vides de la science, mais d'une bien curieuse manière. Assurément, il est étonnant de constater que, pour toute la seconde moitié $\mathrm{du} X \mathrm{X}^{\mathrm{e}}$ siècle, vocabulaire et onomastique s'opposent. Autant le premier est familier aux lecteurs et spectateurs, élaboré et unique, autant la seconde est étrange, simple et sexiste. Mélange de barbarie et de modernité, le langage que la fiction prête à l'homme préhistorique renvoie de lui une image double, à la limite de la schizophrénie. Il n'y a là rien d'étonnant. L'un des a priori les plus prégnants sur la Préhistoire est celui qui en fait une période pendant laquelle l'Homme s'extirpe, non sans mal, de son animalité pour atteindre à l'humanité. Mais, s'il devient humain, il n'a pas encore totalement tué l'animal qui est en lui, l'animal d'où il vient, l'animal qui lui colle toujours à la peau. Doter le préhistorique d'un langage intrinsèquement ambigu ne ferait que renforcer cette proximité épidermique. Nous sommes ce que nous disons. Janus biologique, le préhistorique se doit d'être Janus linguistique.

\section{Résumé}

Les préhistoriens s'accordent sur l'existence du langage dès la Préhistoire. Si l'école se tait sur ce sujet, l'évacuant de ses manuels, la fiction en revanche s'en empare. Passé au travers de son prisme, que devient alors ce postulat dans la France du second $\mathrm{XX}$ e siècle ? Comment imagine-t-on le langage des temps premiers? C'est à ces questions que désire répondre cet article en convoquant littérature, bande dessinée et cinéma. Pour tous ces médias, Homo sapiens est également loquens et la langue qu'ils lui prêtent est étonnamment moderne, alors que les noms dont ils l'affublent nous sont, à l'inverse, totalement étrangers. La raison profonde d'une telle dichotomie se trouve dans la volonté, de la part des auteurs, de démontrer l'alliage d'humanité et d'animalité dont nos ancêtres sont pétris. 


\section{Bibliographie}

CAVANNA, Et le singe devint con, Livre de poche, 1988.

CAVANNA, La déesse mère, Livre de poche, 1999.

COUPÉ Christophe, "L'impossible quête de la langue mère », dans HOMBERT Jean-Marie (dir.), Aux origines des langues et du langage, Paris, Fayard, 2005, p. 162-195.

De FÉLICI Roberta, «Émotions et langages dans le roman préhistorique de J.-H. Rosny Aîné », dans Albert et Jacqueline DUCROS (dir.), L'homme préhistorique. Images et imaginaire, L'Harmattan, 2000, p. 243-271.

FIGUIER Louis, L'Homme primitif, Hachette, 1870.

FrOELICH Jean-Claude, Voyage au pays de la pierre ancienne, Paris, Magnard jeunesse, 1996.

FROELICH Jean-Claude, La horde de Gor, Paris, Magnard jeunesse, 1996.

GERMAIN Alain, Les origines de l'Homme ou les aventures du professeur Coppensius, Hachette, 1997.

HAMON Philippe, "Pour un statut sémiologique du personnage » dans Poétique du récit, Points Seuil, 1977, p. 141-153.

HARAuCOURT Edmond, Daâh, le premier homme, Paris, Arléa, 1988.

HOMBERT Jean-Marie, "Introduction » dans HOMBERT Jean-Marie (dir.), Aux origines des langues et du langage, Paris, Fayard, 2005, p. 10-13.

Hublin Jean-Jacques, «La langue des premiers hommes » HOMBERT Jean-Marie (dir.), Aux origines des langues et du langage, Paris, Fayard, 2005, p. 102-117.

Leroi-Gourhan André, Dictionnaire de la Préhistoire, Paris, PUF, 1994.

LEWIS Roy, Pourquoi j'ai mangé mon père, Arles, Actes Sud, 1990.

MIRMAN Louis, Le silex noir, Folio junior, 1990.

OlDENBOURG Zoé, «Le roman et l'histoire», NRF, octobre 1972, n 238, Le roman historique, p. 130-155.

PELOT Pierre, Le nom perdu du soleil, Paris, Denoël, 1997.

POMIAN Krzysztof « Histoire et fiction », Le Débat, mars-avril 1989, n 54, p. 114-137.

SEMONSUT Pascal, Le passé du fantasme, Arles, Éditions Errance, 2013.

STOCZKOWSKI Wiktor, Anthropologie naïve, anthropologie savante, CNRS Éditions, Coll. Empreintes de l'Homme, 1994.

VAXELAIRE Jean-Louis, Les noms propres. Une analyse lexicologique et historique, Honoré Champion, 2005. 


\title{
Extension de l'emploi de quelques lexèmes français à l'étranger : le cas des créations onomastiques commerciales porteuses de prestige linguistique et culturel
}

\author{
Université du Temps Libre (UTL), Onomastique, Bergerac ; Name Society of Southern Africa \\ (NSA), Pietermaritzburg, Afrique du Sud ; Société Française d'Onomastique (SFO), Paris.
}

\footnotetext{
Extrait de : Guylaine BRUN-TRIGAUD (dir.), Contacts, conflits et créations linguistiques, Paris, Édition électronique du CTHS (Actes des congrès des sociétés historiques et scientifiques), 2015.

Cet article a été validé par le comité de lecture des Éditions du CTHS dans le cadre de la publication des actes du $139^{\mathrm{e}}$ Congrès national des sociétés historiques et scientifiques tenu à Nîmes en 2014
}

L'objet de cette présentation est de démontrer qu'il existe, par suite d'emprunts linguistiques d'une langue à une autre, une sorte de :

«Lexique onomastique d'éléments empruntés, composant ou pouvant composer les noms de lieux commerciaux (NLC), international, non conventionnel mais implicitement, oralement conventionnel mais non officiel, ici, plus spécifiquement d'origine française et / ou francophone, et reflet d'un certain prestige linguistique et / ou culturel, lui-même international ou internationalisé, dans lequel toute créatrice ou tout créateur de société commerciale et, en conséquence, de nom commercial (NC), puise très librement, afin de nommer son magasin, sa boutique, son salon, son café, son restaurant, son hôtel... »

Pour ce faire, sera expliqué ce que nous entendons par un tel «lexique», dans quels domaines «prestigieux » et dans quels buts commerciaux ou financiers ce dit lexique est préféré (notions de typologie) à d'autres pratiques sociolinguistiques, de quelles unités de communication il peut être constitué, qui en sont les utilisatrices et les utilisateurs, les "nommeurs" (en anglais, les name-givers), comprendre: "celles et ceux qui dénomment », «qui créent des noms de lieux commerciaux » et quels usages elles / ils en font...

Enfin, nous terminerons cet article à l'aide de quelques premières remarques conclusives.

\section{Le lexique}

\section{Pourquoi appeler lexique ce «contenant d'éléments onomastiques de communication »?}

En général, il est consensuellement admis qu'une fois la capacité d'élocution acquise par l'être humain, les langues elles-mêmes se sont développées, sans doute par besoin, nécessité, envie ou fantaisie, de façon plutôt naturelle, ce qui a également été le cas de ce genre de lexique. Par langue, nous entendons, ici, n'importe quel système de signes linguistiques, "écrivables », lisibles, interprétables, vocaux, sonores, gestuels et / ou représentés (peints, gravés, sculptés...), imaginables ou inimaginables même, qui permettent la communication entre divers individus et ce, plus précisément, dans un grand nombre de contextes donnés, inhérents au domaine de l'onomastique. Notre définition s'appuie ici, pour sa partie fondamentale, sur celle que propose le site Wikipedia/langue (12 février 2014) que nous avons volontairement augmentée de cas de figure inhérents à notre sujet. Les contenus des langues se sont formés et construits au fur et à mesure de l'émergence d'idées nouvelles, de notions, de concepts ou de constats, émotionnels ou non, ainsi que de rencontres et d'échanges entre les êtres humains... Ainsi, les mots ont été créés et le sont encore, de cœur ou de raison, de façon spontanée ou réfléchie. 
Afin de choisir quel pourrait être le terme le plus approprié pour nommer un tel ensemble, nous avons consulté un très grand nombre de dictionnaires imprimés et électroniques, et nous avons comparé les nombreuses définitions, ainsi que les exemples donnés et les synonymes proposés pour les mots suivants : dictionnaire, glossaire, index, nomenclature, phraséologie, répertoire, terminologie, thésaurus, vocabulaire... et, naturellement, le terme lexique $(\langle\lambda \varepsilon \xi$ iкóv, lexikon $=$ "livre de mots »). Un lexique (qui est également assez couramment appelé "vocabulaire ») d'une langue constitue l'ensemble de ses lemmes ou, d'une manière plus courante mais moins précise, «l'ensemble de ses mots». "Notre» lexique onomastique se situe au sein du lexique général d'une langue donnée ou / voire des langues en général, avec, cependant, des variations souvent issues d'une éventuelle fantaisie (onomatopées, jeux de mots ou d'esprit, erreurs volontaires d'orthographe, associations d'idées, jeux de sonorités...). Le lexique onomastique, contrairement à quelque répertoire que ce soit, n'est pas un inventaire méthodique (énumération, liste, table...).

Dans son cas et sans entrer ici dans l'observation typologique détaillée du phénomène socio-onomastique de l'emprunt de «mots» ou de "groupes de mots » (expressions complexes), ce qui sera fait plus après, il faut observer :

- qu'un NC est un «nom propre »;

- qu'il peut être composé d'un seul ou de plusieurs éléments empruntés ;

- que dans le cas de l'emploi de plusieurs éléments (ici, une polylexicalité onomastique), ces derniers forment obligatoirement un tout dans leurs fonctions officielles (impôts, adresses...) et que ce tout n'est pas sécable, qu'il est donc insécable, sauf dans l'emploi (en général) oral que peuvent volontairement en faire les passants, les clients, les habitués, les usagers, dans un but d'économie linguistique ;

- qu'il est donc irréfutablement unique, tant dans l'esprit de sa créatrice ou de son / ses créateur(s) que dans le cadre des lois nationales du commerce ;

- qu'il est, commercialement, officiellement, topographiquement et toponymiquement, « propre au lieu commercial créé » et qu'il ne l'est et ne peut l'être qu'à celui-là ;

- que pour deux NC, aux mêmes contenus linguistiques (ex. Le Café de Paris, à Biarritz, Calais, Périgueux, Paris...) et créés sans plagiat (question de légalisation et d'annulation des NLC), on parle d'homonymie. On les qualifie d'homographes lorsque leurs graphies sont les mêmes, voire $d^{\prime}$ « homographes complets », lorsqu'ils sont tous deux (ou plus...) correctement accentués (accents diacritiques). Ils peuvent être homophones, à condition que les locuteurs éventuellement mis en scène leur donnent une forme vocale (ici, éventuellement celles de l'anglo-américain et de l'anglo-sud-africain) suffisamment proche l'une de l'autre (accents phonétiques, accents toniques). Cette dernière remarque tient compte du fait que ces deux régions du monde sont les lieux d'immigration.

- que ce dernier exemple ne présente pas de cas de polysémie mais de convergence, de même dénotation. Ex.: Café de Paris, à Johannesbourg (RAS) et à Santa Monica (Californie, EUA).

- qu'il existe, pour chaque création onomastique commerciale, une «explicationdéfinition verbale », une sémantisation (ici, le signifié réel, effectif, profond) personnelle, personnalisée ou individualisée du lemme ou du groupe de lemmes utilisés, et, en principe, non ou jamais publiée : celle de la créatrice ou du créateur. Dans le cas de ce lexique, ce sont les créatrices et les créateurs qui confirment le sens donné par les dictionnaires ou bien qui l'altèrent et, ainsi, produisent leurs propres définitions ou "explications approximatives ou apparentées », lorsqu'elles leur sont demandées, par exemple, à l'occasion des enquêtes que nous avons pu mener sur le terrain. Ex.: un " café » n'est pas le même genre d'établissement et n'est pas porteur du même sens social à Paris, à Tokyo, à Greenwich Village, New York, dans la banlieue minière de Johannesbourg, à Buenos-Aires... Il peut alors exister une sorte d'opacité sémantique, flottant au sein d'un sens plus global, des variations sémantiques lors du passage d'une langue ou d'une culture à l'autre. Ces explications peuvent correspondre à de «nouvelles définitions », parfois plutôt inattendues ou insoupçonnées. Elles ne correspondent pas obligatoirement aux définitions «conventionnelles» des dictionnaires imprimés ou électroniques. Il s'agit alors du fruit d'une simple connotation (sens personnel, individuel et particulier) qui peut s'ajouter à la dénotation habituelle. 


\section{Quel « corpus » lexical ?}

Ce «corpus» ne correspond pas à une liste alphabétique spécifique, que d'ailleurs personne ne pourra probablement jamais constituer ni terminer, faute de temps, au moins (plusieurs vies n'y suffiraient sans doute pas), de moyens (techniques ou financiers), de connaissances linguistiques et d'accessibilité documentaire. Ce n'est pas non plus un recueil ou une collection de mots ou de termes, ni un relevé, un état, un dénombrement lexical, un catalogue, une énumération ou un inventaire. Il ne peut être qu'un ensemble inachevé, non exhaustif, mais aussi possible ou pas impossible, potentiellement réalisable, virtuel...

Ce corpus est constitué d' "unités de communication" (de celles qui peuvent aider à constituer ou qui aideront peut-être à constituer les "noms des lieux commerciaux»), existantes, réemployées ou inventées (jeux de mots, d'esprit, rébus, charades, onomatopées...). En outre, ces unités incluent également des expressions idiomatiques, des unités lexicales ou phrasèmes, des polylexicalités, des locutions diverses, des tropes majeurs ou mineurs, des tropes de fonction ou tropes grammaticaux, appartenant à une ou à plusieurs langues (ayant existé, reconstituées, existantes, inventées, mélangées...), correctement orthographiées ou non, grammaticalement utilisées ou non, ou de suites de mots-éléments, parfois copiées, recopiées, imitées, plagiées par d'autres prétendus créateurs de NC...

Elles correspondent à toutes les catégories d'unités linguistiques, sociologiques et culturelles qui sont employées dans la création de NLC. On peut véritablement parler ici d'un ensemble de signes non plus seulement linguistiques vocaux, animés, gestuels, mais aussi écrits, lus ou déchiffrés, prononcés, entendus, reproduits, réinventés, avec plus ou moins de précision, d'inventivité, de chance, de bonheur, aussi! Ces éléments peuvent aussi être accompagnés ou illustrés, soulignés ou renforcés à l'aide ou par des textes (accompagnateurs, aidant à comprendre le jeu de mots, etc. ; ils ne font pas partie du $\mathrm{NC}$ ), des couleurs (n'importe la/lesquelles, toutes s'il le faut), des logotypes des plus simplifiés aux plus étranges, des dessins représentatifs (la Tour Eiffel), des objets symboliques (le drapeau français), des formes, suggestives ou non, des sons (musique, onomatopées, etc.), des animations lumineuses, clignotantes ou autres, des projecteurs, des spots... lesquels deviennent des «compléments» ou «supports sémantiques" servant d'accroches publicitaires, voire, eux-mêmes, d'autres éléments constituant, à part entière, des NLC...

Leur(s) usage(s) onomastique(s) dépend(ent) des langues elles-mêmes, des langues d'emprunts, des cultures, des contextes, des modes en tous genres, des motivations ainsi que des êtres humains, de leurs propres cultures, de leurs statuts sociaux, de leurs religions, de leurs niveaux d'éducation ou financier, du fait qu'une langue soit leur langue maternelle ou non, de leur fantaisie, de leur sens de l'humour ou de celui de leurs besoins ou envies de provocation individuels.

Enfin, dans un tel lexique, se trouvent mêlés ou peuvent se trouver mêlés, sans distinction spécifique, des éléments linguistiques appartenant à une ou à plusieurs langues du monde entier. Leur nombre est illimité car il ne peut être fixé. Il n'est pas quantifiable.

\section{Quels lieux ? Quels acteurs ? Quels domaines, quel prestige et dans quel but?}

Les lieux commerciaux, leurs noms, la législation

De façon générale, les professionnel(le)s concerné(e)s doivent prendre en compte le monde des méthodes de distribution et de vente à distance, plus récentes, (télé-achat ou vente sur écran, télévente par commercialisation téléphonique, commerce électronique, sur internet, e-commerce, par correspondance...), des marchés à l'ancienne et du démarchage au porte-à-porte. 
En conséquence, elles et ils sont logiquement amené(e)s à ouvrir un établissement de commerce ou fonds de commerce, magasin, épicerie fine, boutique, salon, atelier, échoppe, bordelaise ou non, kiosques divers et étals couverts et fermés, ou tout autre lieu correspondant à l'activité légale exercée), dans l'un des nombreux domaines du commerce traditionnel (vente directe et / ou de revente), des services aux personnes (salons divers: coiffure, beauté, cosmétiques...) ou aux animaux (vente, garderie, toilettage, soins divers...), des productions artisanales (mode, bijoux, boulangerie, pâtisserie, confiserie...), du tourisme (hôtels, restaurants, bars, brasseries, cafés...).

On le sait, d'une part, les propriétaires de ces lieux sont alors légalement contraint(e)s par les lois nationales (en France, par exemple : chambres des métiers, de commerce, centres des impôts, ...) de leur donner un nom $\mathrm{d}^{\prime}$ " enseigne commerciale » (EC), laquelle identifie officiellement le local d'exploitation (boutique, salon, magasin, ...) et non la "dénomination ou raison sociale »(DS ou RS), qui est l'entreprise qui gère le fonds de commerce, ni celui du « nom commercial » (NC). D'autre part, commercialement, elles et ils sont obligé(e)s, une seconde fois, de nommer leurs lieux de travail, afin qu'ils puissent être connus et / ou reconnus par la clientèle, éventuelle ou effective, qu'elles et qu'ils procèdent à des actes publicitaires, que leurs fournisseurs les trouvent facilement... Bien entendu, si tel est son choix, rien empêche un(e) propriétaire de nommer / dénommer un tel endroit d'un nom constitué de la DS / RS, du NC. L'EC peut être constitué du mélange ou de l'adition des trois.

Notons ici et maintenant, et afin d'éviter toute confusion, qu'en onomastique, la formule " enseigne commerciale » (EC) n'est guère utilisée, mais que, en revanche, c'est celle de « nom commercial » qui est la plus couramment employée. Et c'est donc l'abréviation NC qui prend ici le relais. On note aussi que, dans ce domaine, le NC est un microtoponyme et qu'il connaît la fonction de repère toponymique à l'aide duquel les passants peuvent se repérer ou bien qu'utilisent d'autres individus pour orienter des visiteurs étrangers aux lieux.

Les actrices et les acteurs concerné(e)s : les créateurs-emprunteurs

De façon générale, les créatrices et les créateurs des NC sont celles et ceux qui créent l'entreprise, à moins qu'il y ait eu vente / rachat, cession, transfert par héritage... de cette dernière. Dans ces derniers cas de figure, il y aura peut-être eu maintien ou bien changement officiel du NC suivi d'une nouvelle création onomastique.

On comprend alors quelles sont les personnes qui vont, intellectuellement et / ou affectivement, désirer créer un NC, y réfléchir, en parler avec leur entourage le plus proche ou avec des (conseillers) professionnels, proposer un nom ou une formule de leur cru, et finir par s'engager dans la rédaction légale et, en général, définitive d'un NC, un acte de communication en faveur du but qu'elles se sont donné. Par principe commercial, la création d'un NC est motivée par l'envie que la lecture dudit NC permette à la / au propriétaire qui sera peut-être aussi la / le gérant(e), d'obtenir totale satisfaction en augmentant avantageusement son chiffre d'affaires.

Dans le cadre du sujet de cette intervention, les locutrices et locuteurs concerné(e)s habitent en Afrique du Sud: ce sont des Sud-Africain(e)s ou des étrangers / -ères, et $c^{\prime}$ est, en conséquence, dans un pays multilingue, où se pratiquent onze langues officielles (afrikaans, anglais + neuf autres langues appartenant à la famille bantoue), ainsi que d'autres langues, non officielles, également rattachées à la famille bantoue. D'autres langues, autochtones (khoïkhoï, hottentot) ou d'origine asiatique (hindi tamoul, chinois, ...) sont quotidiennement parlées bien que (toujours) pas reconnues. Enfin, il existe de nombreux regroupements communautaires d'origine migratoire européenne (allemandes, grecques, italiennes, juives «yiddishisantes », norvégiennes, portugaises, russes, ...) dont ceux pouvant être rassemblés sous le terme de "francophonie » (belge, congolaise, française, mauricienne, réunionnaise, ...). À ce stade de cet éclairage, il apparaît nécessaire de préciser que l'ensemble de cette mozaïque hétérogène, à l'exception des anglophones de langue maternelle, a pour seconde langue, l'anglais. 
Les domaines, le prestige et le but

La liste de ces domaines est interminable. Elle peut inclure des notions empruntées à toutes les langues et à toutes les cultures. Ainsi, il est des langues qui font plus aisément penser à certains pays, à diverses cultures voire aux meilleures de leurs productions régionales ou nationales, quel(s) que soi(en)t le(s) domaines, "prestigieux ", auxquels on se réfère alors : l'allemand, au lyrisme wagnérien ou à la bière, l'italien, au bel canto, aux pâtes de grande qualité, à ses chaussures de luxe, l'anglo-américain aux affaires, l'Écosse $\mathrm{au}(\mathrm{x})$ whiskys et l'Irlande $\mathrm{au}(\mathrm{x})$ whiskeys... Le français, à l'histoire intellectuelle et mouvementée de ce pays, à sa cuisine, à sa mode, à ses parfums, à la qualité de ses produits, etc. Et de par le monde entier, créatrices et créateurs, chacune et chacun dans son domaine professionnel, puisent dans ces langues et ces cultures, au moment de nommer son magasin, sa boutique, son café, son restaurant, son hôtel...

Afin de tenter d'attirer le plus grand nombre de chalands possibles dans leurs locaux commerciaux, et d'augmenter ainsi le nombre de leurs clients ainsi que leurs chiffres d'affaires, les créatrices et les créateurs de NC font souvent appel à des noms, propres ou communs, porteurs d'un prestige culturel, si possible universellement reconnu. Ces références sont censées opérer une influence favorable au succès commercial. Dans ce but, elles et (ils) font grande preuve d'imagination, d'ingéniosité, de fantaisie, quelquefois les plus savoureuses.

L'acte de dénomination est un acte de communication. Il est destiné à dire à celle ou à celui qui le lit :

«Mon magasin, ma boutique... s'appelle ; mémorisez-le (bien) ; parlez-en à la ronde, faîte $\mathrm{du}$ bouche-à-oreille, (renseignez tout le monde); son nom rappelle ce que je vends (Aux Bonbons d'autrefois), mais aussi qui je suis (Chez Lorette), où se trouve ce lieu commercial (Boutique de l'Église, Bar de la Gare...) et, enfin: Mais, entrez donc! Soyez la / le bienvenu(e)!»

\section{Quelle typologie}

Le phénomène socio-onomastique d'emprunt à une langue étrangère vers celle du locuteur, pour cause de valorisation commerciale, par le biais de l'expression d'un certain prestige, dans le cadre de la création de NLC, est mondial.

Entreprendre, à cette échelle, une typologie générale de ces noms propres (un essai fait actuellement l'objet d'un travail collectif), par exemple pour les $\mathrm{XX}^{\mathrm{e}}$ et $\mathrm{XXI}^{\mathrm{e}}$ siècles, afin de pouvoir en observer l'évolution, exigerait la collaboration de fort nombreux chercheurs, recrutés par pays, possédant des connaissances linguistiques (plurilinguisme ou polyglottie) quelquefois fort peu courantes et / ou des acquis multilingues considérables à l'intérieur de la plupart des pays. En outre, la constitution d'un tel corpus impliquerait des recherches en archives diverses, irréalisables dans l'espace et dans le temps ainsi que des coûts prohibitifs. Enfin, la fabrication d'un logiciel multilingue polyvalent (langues et écritures) et d'une base de données de très grande performance, au sens français (réalisation optimale) comme à celui de l'anglicisme (comportement), ne paraît guère réalisable. Une typologie des NC sud-africains d'origine française est en cours de réalisation.

La longueur maximale de cet article étant ce qu'elle est, il ne sera présenté, ici, qu'une sélection d'observations typologiques : des cas de grammaire, de langue, d'emplois... En outre, pour la même raison, il ne sera rien dit du questionnaire utilisé sur le terrain lors des diverses phases de l'enquête menée, laquelle, de toutes les façons, ne peut être exhaustive. 


\section{Un exemple de cas grammatical glorifiant}

Une construction grammaticale française pour un rappel historique français prestigieux

La Villa Prince Imperial est une sorte de gîte (guesthouse) sud-africain de qualité, situé à Vryheid, Province du KwaZulu-Natal (RAS). Ce nom se réfère à Napoléon Eugène Louis Bonaparte (1856-1879), dit Louis-Napoléon, fils de Napoléon III (président de la République, 1848-1851; empereur, 1852-1870) et d'Eugénie de Montijo, mort au champ d'honneur, frappé de dix-sept coups de sagaies zouloues, à Itelezi, non loin d'Ulundi, Province du KwaZulu-Natal. Les témoignages d'époque rapportent que le jeune prince impérial mourut héroïquement, sous l'admiration et le respect de ses ennemis. Ce NLC s'adresse très directement au monde du tourisme qu'il tente d'attirer. On note ici que les propriétaires sont franco-sud-africains et que la construction grammaticale française a été privilégiée à *Prince Imperial Villa, alors que l'accentuation n'a pas été respectée. La propriétaire, une Française, m'a expliqué, en 2002, que c'était par soucis de simplification de la lecture et de la mémorisation du nom qu'elle avait fait ce choix. Une réappropriation sémantique de prestige est ici mise en scène : Villa prend alors le sens de "lieu prestigieux ", au sens français d' « hôtel particulier ", tel l'Hôtel de Soubise, à Paris, et, bien entendu, à celui véhiculé par la Villa Médicis, à Rome.

\section{Quelques cas de langue}

\section{De quelques sémantismes}

Les éléments linguistiques empruntés, à un moment plus ou moins ancien ou récent de l'histoire lexicale d'une langue, donnent aux clients l'impression de quelque ouverture d'esprit linguistiquement "internationalisante». Certains mots empruntés peuvent être culturellement réducteurs voir destructeurs, même s'ils leur arrivent de paraître novateurs... Ainsi, les formes hôtel (en principe, accentué en pays francophone) / hotel (hors de la francophonie) ont évincé tout un vocabulaire culturel quelquefois devenu (presque) obsolète. Autrefois, dans un très grand nombre de langues, la notion de base $\mathrm{d}^{\prime}$ «(lieu $\mathrm{d}^{\prime}$ ) hébergement de voyageurs » se traduisait par des mots tels que auberge. Pour cause de modernisation de ce concept d'hébergement (national ou international), on a progressivement pu voir ce terme remplacer de nombreux sémantismes étrangers. Quelques exemples : afrikaans, hotel vs gastehuis ; allemand, Hotel vs Gasthaus ; anglais, hotel vs inn / guesthouse; catalan, hotel vs fonda ; espagnol, hotel vs albergo / fonda ; italien, hôtel et hotel vs albergo ; japonais, ホテル (graphie Hepburn, hoteru, prononcé [«otelu], < de l'anglais hotel, < français) vs 旅館 (graphie Hepburn, ryokan = « établissement pour voyageurs»); néerlandais, hotel vs gasthuis; portugais, hotel vs hospederia ; roumain, hotel vs han (vieilli); russe, оmesb ([otel] ou [atel»], < français) vs гостинийа ([gas't'initsə] ; équivalent de guesthouse en anglais) qui n'est pas obsolète mais qui ne réfère pas à un établissement situé à l'étranger ni à un hôtel local à prétention européenne ou internationale (Gorajev)... Il arrive que le manque de connaissances lexicales conduise à quelque confusion, à moins qu'il ne s'agisse d'une trompeuse prétention...

Le mélange des langues, parfois méconnues, produit des résultats curieux. Ainsi, une créatrice ou un créateur de NC peut emprunter un mot ou une formule dans l'une des autres langues de son propre pays, dans une autre langue qu'elle / il parle ou ne parle pas. Ex. : Posada inka Manco Capac (célèbre empereur inca légendaire), à Cuzco, Pérou. Le terme générique posada (= auberge) et les anthroponymes Manco Capac sont en espagnol. Ces derniers, en langue quetchua, s'écrivent Manqu Qhapaq et «inka » est également en écriture quetchua, pour inca en espagnol. « Posada» fait partie du lexique onomastique international lorsqu'il est employé pour nommer un lieu de culture hispanique ou hispano-américaine, hors d'un pays hispanophone, à l'exemple de La Posada Hotel, à Winslow, Arizona. Bien que «posada » et «hotel » soient synonymes, Posada, un terme emprunté à l'espagnol, est le nom de l'hôtel et « hotel », sans accent, est emprunté au lexique international, existant également en anglais et issu du français, comme élément générique. 
Les expressions toutes faites ou expressions figées

Pour la Vie / PLV: Les créatrices et les créateurs de NLC empruntent également à d'autres langues, des "groupes de mots", des «expressions toute faites", des «expressions figées", des «expressions nominales». L'exemple suivant est très révélateur du phénomène alliant l'emprunt à une culture réputée, à tort ou à raison, pour son romantisme amoureux, et la langue du pays représenté. Son origine remonte à l'anecdote suivante : deux étudiants en commerce de l'Université de Stellenbosch (SBH, RAS) avaient décidé de se marier, une fois leurs diplômes obtenus. Et ils s'étaient promis de partir en voyage de noces à l'île Maurice. Un jour, sur la plage, la jeune fille ayant soif, son tout jeune époux alla lui chercher quelque rafraîchissement. Au magasin, le jeune homme ayant vu une chaînette avec une plaque sur laquelle était gravé un petit texte, demanda: "What does that mean?». La vendeuse lui répondit: «Pour la Vie, Monsieur », lui expliquant le sous-entendu «l'amour... toujours... ». Il en acheta une et l'offrit à son épouse. De retour au pays, ils ouvrirent une boutique de vêtements pour jeunes qu'ils appelèrent Pour La Vie. En ce pays particulièrement multilingue, la prononciation de la clientèle fut rapidement agrémentée de tous les sons produits par les Sud-africain(e)s aux onze langues officielles comme par les locutrices et les locuteurs de celles qui ne le sont pas encore... sans oublier celles parlées par les migrant(e)s venu(e)s des cinq continents. En outre, ils firent peindre sur le store et sur les vitrines le sigle français et commercial PLV, qui dans ce cas ne signifie évidemment pas «Publicité sur le Lieu de Vente ». Ce dit sigle, prononcé à l'anglaise / pi-el-vi / et à la française / pé-el-vé /, selon les client(e)s, devint le nouveau nom de cette boutique (Rateau, 2013, 188). L'emploi de la langue française comme langue de prestige de production commerciale n'est pas ici l'idée de référence. Mais celui de la réputation des Français(e)s et de l'amour a joué tout son rôle auprès de celles et de ceux qui découvrirent l'histoire-conte de fée romantique de ces deux jouvenceaux.

Un cas de fautes d'orthographe lié à une écriture empruntée

Madam de Pompadur, est l'un des magasins de mode féminine de la ville d'Ekatarinbourg (ou Iekaterinburg, en russe : Екамеринбүрг). Le [e] final du mot français "Madame » étant muet, il n'est pas marqué lors de la translittération ; le son français [ou] (graphé «y», en alphabet cyrillique) de «Pompadour» est romanisé (latinisé) et translittéré en De Pompadur, après majusculisation de la lettre initiale de la particule nobiliaire «de». En 1756, Jeanne-Antoinette Poisson (1721-1764), favorite du roi Louis XV (1715-1774) et marquise de Pompadour, a également été rendue célèbre par le peintre François Boucher, pour son élégante façon de s'habiller «à la française » (entre autres choses, ses escarpins!). On note que la posture publicitaire du mannequin de la devanture reprend tout à fait celle du fameux tableau. Ce nom de célébrité, certes du passé et bien tombé dans le domaine public, est alors en passe de devenir une sorte de «marque déposée » pour ce magasin.

\section{Une symbolique prestigieuse à l'origine confuse}

Vie de France Café est un NC composé de «Vie de France» + «Café ». Vie de France était, à l'origine, une société de boulangerie fondée (1988) par des Américains, anglophones, donc! Après une importante étude de marché incluant une recherche linguistique. En 1991, la société nipponne Yamazaki Baking en fit l'acquisition et souhaita transformer le NC américain d'origine française, Vie de France, en NC japonais... de même origine, mais en lui ajoutant un élément générique (1991), Café, et en augmentant ses activités : faire de la boulangerie et de la viennoiserie (+ gâteaux) à emporter ou à consommer sur place (fonction de café), ouvert à Tokyo, la même année. Ici, se présentent plusieurs cas de figure réunis en un seul. D'abord, la première partie de ce NC, grammaticalement correcte, Vie de France (en rouge dans le texte), indiquant le nom de ce magasin spécialisé en produits de boulangerie et de viennoiserie à réputation française, véhicule l'idée de vie "qualité à la française». Sémantiquement, ce nom privilégie une authenticité d'origine : la France (et son savoir-faire culinaire). On note, cependant, que la construction grammaticale du NC est anglaise. En outre, une illustration, très lumineuse la nuit, un drapeau tricolore bleu - blanc - rouge, précédant le NC, augmente et renforce l'identification visuelle du pays d'origine des produits proposés à la vente, consommés sur place ou emportés. Ensuite, le terme 
générique, Café (en bleu, le tout sur fond blanc), correctement accentué, est un emprunt à une langue qu'il reste à déterminer. Il est en voie d'adoption sociolinguistique et d'intégration sociale à la langue japonaise, accélérées depuis les années 1980 et ce plus spécialement dans les grandes agglomérations, dans le langage des plus jeunes, de nombre d'animateurs et de commentateurs télévisuels ainsi que dans celui du domaine publicitaire. Explications rétrospectives: le produit a d'abord timidement été officieusement importé, à Nagasaki, par les Hollandais, entre 1781 et 1788 ; localement, quelques Japonais découvrent ce nouveau breuvage. Dans son livre paru en 1804, Keihoyutetsu, le fonctionnaire gouvernemental Shokusanjin (Ota Nambo) publie le résultat de sa propre expérience, nommant le produit カウヒイ(kauhii ; une graphie nipponne approximativement sonorisée de l'époque et transcrite en caractères katakana ; ici, avec la transcription en alphabet Hepburn). Cependant, il est alors utilisé comme remède contre l'hydropisie. À part de rares exceptions, cela durera jusqu'à l'ouverture du Japon au monde, à Yokohama, en 1853. Cinq ans plus tard, le gouvernement autorise l'importation du produit, mais ce n'est qu'en 1872 que l'on commencera à infuser le café au même titre que le thé. On le nomme alors カフヒー (kafuhi-, le tiret final représente un /i/ long mais pas un double /i/). Dès 1888, on appelle le lieu de consommation du café et du thé 可否茶館 (kahiichakan, c'est-à-dire " café (kahii-) thé (cha) établissement (ken) », l'équivalent de notre «salon de thé'... où l'on boit tout également du café).

Aujourd'hui, le produit s'appelle コーヒー (kohi). Pour le lieu où l'on consommait le thé, on disait 喫茶店 (kissaten), mais aujourd'hui, c'est également un lieu où l'on peut prendre n'importe quelle autre boisson (ou presque), dont le café et où l'on peut se restaurer. Bien entendu, il existe aussi des bars spécialisés dans la consommation de ce produit et qui s'appellent コーヒー専門店 (kohisenmonten). Notons ici que kohi est une adaptation phonétique de la forme moyenne-néerlandaise koffie (< possiblement du moyen-anglais coffee ou peut-être plus directement du turk kahve) et non un dérivé direct de l'anglais. Ce n'est qu'en 1911, qu'apparaissent des cafés (le lieu), avec, par exemple, le カフェープランタン (Kafe- Purantan, comprendre ${ }^{*}$ Café Printemps). On observe ici qu'il s'agit bien d'un emprunt direct au français, lequel est en train de se japoniser lexicalement.

Respect de l'orthographe dans l'emploi d'un terme emprunté accentué

Comme il vient d'être montré, il est des créatrices et des créateurs, ici anglophones, qui se font un devoir de respecter l'accentuation, comme gage d'identification. Lors de l'enquête menée sur place, ils s'en expliquent en précisant que les accents «font plus French »... Exemple: Bon Appétit Coffee-Shop, à Franschhoek (RAS). Coffee-Shop correspond à café et, plus anciennement, à maison du café, à l'origine magasin où l'on achète le café.

Un autre exemple, plus curieux, est celui de The Café, à Hanoï, en République Socialiste du Viêt Nam (depuis 1976), une ancienne colonie française et francophone (1902-1953). On observe ici, un «mélange de prestiges»: linguistique et culturo-commercial anglophone (The) et culturel français (Café), sachant qu'aujourd'hui, en vietnamien, on écrit cà phê... et que café en est son internationalisation.

Une activité culturelle prestigieuse (la mode) rapportée à la qualité d'un service (en horlogerie) Watch Couture : le nom de ce magasin réunit ici deux mots avec subtilité et un certain sens de l'humour. Tout d'abord, la lecture de ce NC / NLC est complétée par la vision très parlante que l'éventuel futur client a de l'intérieur de la vitrine, empli de montres, goussets et horloges. Ici, le mot couture (aujourd'hui français, anglais et intégré à tant d'autres langues de part le monde entier) remplace le terme anglais repairs (réparations) et, à cette occasion, en devient le synonyme approprié. Après tout, la couture ne permetelle pas, aussi, de "réparer des vêtements »? Bien entendu, couture est emprunté au vocabulaire international de la mode, rappelant prestige et qualité français. Il laisse entendre que la réparation sera tout également de ce niveau d'exécution et de raffinement. La construction n'en reste pas moins fidèle à la grammaire anglaise. Enfin, le fait de remplacer le « $\mathrm{O}$ » de couture par un « ${ }^{\circ}{ }$ souligné est destiné à attirer l'œil du 
passant. On pourrait même y voir une action de «subliminal advertising » : en effet, ce " ${ }^{\circ}$ » souligné, placé après un " $\mathrm{C}$ " plus grand que lui, rappelle considérablement l'abréviation du mot commercial anglais company (compagnie, société), une façon de faire équipe avec l'humour et/ou la subtilité, le clin d'œil de prestige français véhiculée par couture, mis en parallèle à ce $" \mathrm{C}^{\circ}$ » dénotant de l'efficacité commerciale angloaméricaine.

Des mélanges d'emprunts qualifiables de "tous azimuths "

Le NLC The French Connection Bistro mélange les langues et les cultures. Le nom du lieu se réfère au monde des films américains les plus prestigieux (cinq Oscars). Le titre anglais (The French Connection) est préféré à celui qui est considéré comme étant « titre français» (French Connection) officiel; l'intrigue est franco-américaine et le titre américain inclut le mot French (= français) ; cependant, l'élément générique (Bistro) est devenu très international, sous ses deux formes, bistro et bistrot, quand bien même il se réfère toujours à quelque atmosphère «à la française ". Enfin, la construction grammaticale est anglaise. En outre, il est intéressant de voir combien ce NC cadre thématiquement bien avec son environnement. Ce café se trouve dans Huguenot Street (rue des Huguenots, des Français calvinistes), à Franschhoek (= le coin des Français).

L'expression d'une certaine poésie campagnarde "à la française »

Belle Fleur Cottages est le nom d'un ensemble de gîtes de la province du Cap. Il parle de lui-même. À côté de la flore, se compte la faune, avec Alouette Country House, à Franschhoek (FHK), ou bien avec L'Auberge Chanteclair, dans son voisinage. Auberge, élément générique, synonyme de Cottages et de Country House, est particulièrement prisé des nommeurs : Auberge Clermont (FHK), Auberge La Dauphine (FHK). La Petite Ferme rivalise des autres lieux par sa qualité et son standing peu ruraux! De façon générale, l'envie de servir, de satisfaire le client est à la hauteur du prodigieux sens de l'hospitalité des Sud-Africains qui adorent recevoir. Chez les Jourdan, à Bloemfontein, en est un exemple typique. Le propriétaire, descendant de huguenot, bien que non francophone, a souhaité « honorer le souvenir de ses courageux ancêtres ».

Des clins d'œil à leurs compatriotes en même temps qu'aux touristes francophones

Le monde hôtelier ne manque pas d'intérêt pour les toponymes hexagonaux: Basse Provence (un gîte), Grande Provence (un gîte de grand luxe), La Petite Dauphine (plus modeste mais non moins magnifique), tous à Franschhoek. Tous ces NLC rappellent aux descendants des réfugiés calvinistes réfugiés au Cap aux $\mathrm{XVI}^{\mathrm{e}}$ et $\mathrm{XVII}$ e siècles les noms des provinces d'origine de leurs ancêtres et ne lassent de surprendre les touristes francophones qui s'y précipitent pleins d'émotion.

L'hôtel Mont Rochelle connaît la même fonction, quand bien même l'association de Mont et de Rochelle est totalement anachronique. Mont a été choisi parce qu'un autre NLC de Franschhoek s'appelle Mont Blanc... Cependant, s'il n'y a pas de «mont » à La Rochelle, ce lieu hôtelier se trouve au flanc d'une belle élévation dans cette ville huguenote d'Afrique du Sud. Et Rochelle est une connotation historique portant sur le port français de cette ville, longtemps cité aux mains desdits calvinistes et ayant par deux fois fait l'objet de sièges destructeurs (1573, puis 1627-1628). Toujours de l'émotion et de la fierté mises en scène et autant d'étonnement pour les visiteurs.

\section{Le prestige gastronomique français}

En Afrique du Sud, ce sont des milliers de NLC qui incluent des termes français ou d'origine française. En voici quelques exemples à l'honneur du fin palais des Français: Café Antoinette, Cotage Fromage Shop (sic), Le Bon Vivant, Maison Chablis Guest House, Mange Tout (nom du restaurant de l'hôtel Mont Rochelle), Bon Appétit CoffeeShop. 
Nous l'avons vu, les éléments linguistiques empruntés peuvent appartenir à n'importe quelle langue, à n'importe quelle culture et à n'importe quel domaine. Ils sont employés selon les connaissances (variables et souvent approximatives) des propriétaires des lieux commerciaux, sans restrictions grammaticales et selon leur bon plaisir. Au cours des temps, ces propriétaires ont été, sont et seront toujours des créatrices / créateurs de NC / NLC mais également celles et ceux dudit lexique.

Enfin, ce lexique ne constitue pas et ne constituera jamais un corpus exhaustif, faute de temps, au moins, et / ou de documentation. Il ne peut être qu'un ensemble inachevé et demeurer non quantifiable. On ne peut ni le recenser ni le publier. Il n'a pas de limites, sauf celles de la bienséance universelle, mais il existe virtuellement, dans la tête, dans l'esprit, peut-être même, tout également, dans le cœur et les émotions de ces créatrices et de ces créateurs « onomastico-commerciaux». Au total, nous constatons :

* d'abord, que tous les noms de lieux commerciaux créés sont de nouveaux noms propres, d'où leur appartenance au domaine de l'onomastique ;

* qu'en conséquence, d'une certaine façon, ils n'ont pas d'orthographe officielle, sinon plutôt tacitement « recommandée» ;

${ }^{*}$ que chaque nom créé est irréfutablement unique, au moins dans l'esprit de sa créatrice ou de son créateur:

* qu'existe, à chaque fois, s'il en est une, une définition personnelle ou individualisée des lemmes utilisés, et donc, la plupart du temps, non publiée ;

* que, enfin, les « explications " avancées par les auteurs correspondent généralement, à des définitions « très personnellement conceptualisées » par ces dernières et ces derniers, et qui ne correspondent pas obligatoirement aux définitions " conventionnelles » des dictionnaires imprimés ou électroniques. Note: dans le cas de ce lexique, ce sont les créatrices et les créateurs qui confirment le sens donné par un / les dictionnaires, ou bien qui produisent leurs propres définitions ou «explications apparentées », lorsqu'elles leur sont demandées, par exemple, à l'occasion de l'enquête que nous avons menée sur le terrain.

\section{Résumé}

L'objet de cette présentation est de démontrer combien il existe une sorte de "langage international », incluant l'ébauche d'un « lexique commercial conventionnel mais qui est ni écrit ni officiel », ici, d'origine française et / ou francophone, et reflet d'un certain prestige international, dans lequel toute créatrice ou tout créateur de société commerciale puise très librement, afin de nommer son magasin, sa boutique, son salon, son café / cafe, son restaurant, son hôtel / hotel... Ces lexèmes / unités lexicales / morphèmes lexicaux participent alors à la formation de noms propres (d'où leur appartenance au domaine de l'onomastique) tels que les noms de lieux commerciaux qui peuvent également connaître la fonction de repères toponymiques urbains ou ruraux. Dans le cadre de cette étude, nous puiserons nos exemples dans les annuaires téléphoniques de plusieurs pays ainsi que dans nos relevés personnels et nous verrons alors que, au gré des langues pratiquées et / ou des cultures existantes, chacun de ces «mots empruntés / réinterprétés ou traduits» peut véhiculer une valeur commerciale et / ou culturelle universelle, même si, dans chaque pays, dans les usages nationaux, régionaux ou locaux, ils n'en représentent pas moins d'indiscutables variantes.
Abréviations
$\mathrm{NC}=$ nom(s) commercial / commerciaux
$\mathrm{NLC}=$ nom(s) de lieu $(\mathrm{x})$ commercial / commerciaux
RAS $=$ République d'Afrique du Sud 


\section{Bibliographie}

GORYAEV Sergey. 2010. "Company names as an imitation of personal names. Models with a borrowed etiquette word ". Étude présentée en 2010, lors du $16^{\mathrm{e}}$ Congrès International de la NSA, à Langebaan, Afrique du Sud. Note: il s'agit d'une étude présentée par S. Goryaev et produite conjointement avec Olga Olshvang, tous deux membres de l'Ural State Medicine Academy, Ural Federal University. Elle n'a pas (encore ?) été publiée par la NSA. Contact : gorayev@yandex.ru.

RATEAU Michel A. 2013. «De la notion de grammaire dans l'acte de dénomination : le cas des Sud-Africains donnant des noms d'origine française à des lieux commerciaux », in Name and Naming, Proceedings of the Second international Conference on Onomastics, pp. 170-189; intervention présentée lors du congrès "Onomastics in Contemporary Public Space », à Baia Mare, Roumanie, 9-11 mai 2013, Edited by Oliviu Felecan. ClujNapoca : Editura Maga - Editura Argonaut. 